UNIVERSIDADE DE SÃO PAULO

FACULDADE DE ECONOMIA, ADMINISTRAÇÃO E CONTABILIDADE DEPARTAMENTO DE CONTABILIDADE E ATUÁRIA

PROGRAMA DE PÓS-GRADUAÇÃO EM CONTROLADORIA E CONTABILIDADE

DIGA-ME QUANTOS TE CITAM, E EU TE DIREI QUEM ÉS ESTUDO SOBRE AS CITAÇÕES NO ÂMBITO DA PESQUISA CONTÁBIL BRASILEIRA

Sandro Vieira Soares

Orientadora: Profa. Dra. Silvia Pereira de Castro Casa Nova

SÃO PAULO 
Prof. Dr. Marco Antonio Zago

Reitor da Universidade de São Paulo

Prof. Dr. Adalberto Américo Fischmann

Diretor da Faculdade de Economia, Administração e Contabilidade

Prof. Dr. Ariovaldo dos Santos

Chefe do Departamento de Contabilidade e Atuária

Prof. Dr. Luiz Paulo Lopes Fávero

Coordenador do Programa de Pós-Graduação em Controladoria e Contabilidade 
Sandro Vieira Soares

\section{DIGA-ME QUANTOS TE CITAM, E EU TE DIREI QUEM ÉS - ESTUDO SOBRE AS CITAÇÕES NO ÂMBITO DA PESQUISA CONTÁBIL BRASILEIRA}

Tese apresentada ao Programa de PósGraduação em Controladoria e Contabilidade do Departamento de Contabilidade da Faculdade de Economia, Administração e Contabilidade da Universidade de São Paulo, como requisito parcial para a obtenção do título de Doutor em Ciências.

Área de Concentração: Controladoria e Contabilidade

Orientadora: Profa. Dra. Silvia Pereira de Castro Casa Nova

\section{Versão Corrigida}

(versão original disponível na Biblioteca da Faculdade de Economia, Administração e Contabilidade)

São Paulo 
Autorizo a reprodução e divulgação total ou parcial deste trabalho, por qualquer meio convencional ou eletrônico, para fins de estudo e pesquisa, desde que citada a fonte.

Soares, Sandro Vieira.

Diga-me quantos te citam, e eu te direi quem és: estudo sobre as citações no âmbito da pesquisa contábil brasileira / Sandro Vieira Soares -- São Paulo, 2017.

$277 \mathrm{p}$.

Tese (Doutorado) - Universidade de São Paulo, 2017.

Orientador: Silvia Pereira de Castro Casa Nova.

1. Contabilidade - Pesquisa. 2. Citação bibliográfica. 3. Periódicos científicos. 4. Pesquisa científica. I. Universidade de São Paulo. Faculdade de Economia, Administração e Contabilidade. II. Título.

$$
\text { CDD }-657.07
$$


Dedico este trabalho à minha família 



\section{AGRADECIMENTOS}

Agradeço a Deus pela oportunidade de entrar na USP e por me conceder saúde e força necessárias para concluir o doutorado.

Agradeço a minha família que me apoiou pacientemente, principalmente minha mãe, minha irmã, meu irmão, minha cunhada e meu sobrinho. $O$ apoio de vocês foi fundamental.

Agradeço a minha orientadora, professora Silvia, por aceitar me orientar, por me guiar ao longo do doutorado e me ensinar a ser resiliente.

Agradeço aos professores do EAC/FEA/USP, na figura dos professores Afonso, Bruno, Edgard, Gustavo, Fernando, Gilberto, Isabel e Valmor, por todo o aprendizado que me possibilitaram.

Agradeço aos professores Fábio, Henrique e Maria Thereza pelas contribuições na banca de qualificação e aos professores Raimundo e Amélia na banca de defesa.

Agradeço aos colegas de PPGCC/USP, que compartilharam toda a trajetória desta caminhada de doutorado, principalmente ao Ademir, Alan, Anderson, André, a Bárbara, Bruna, ao Carlos, a Cida, Cintia, Chris, Diane, ao Eduardo, a Iracema, ao João, José Renato, a Paula, Raquel, ao Ricardo, a Sandra, Sara, ao Sérgio e a Verônica.

Agradeço aos meus amigos, a compreensão e palavras de apoio, principalmente ao Anderson, a Célia, ao Diogo, ao Donizete, Emerson, a Fernanda, Francimar, ao Juan, Leonardo, Philipe, Rafael, Richardson, a Silvia, ao Tiago.

Agradeço aos professores Fávero, Barbetta e Roberto, pelas lições de estatística.

Agradeço aos professores do CCN/CSE/UFSC, na figura dos professores Maria Denize, Elisete, Fabrícia, Rogério, Valdirene, Aghata, Harley, Denize, Erves e Sérgio, pelo apoio na minha passagem pela UFSC, como docente, e pelos materiais emprestados.

Agradeço a Francielle, Luana, Luiza, Maíra, Maura, ao Matheus, a Sandra, Suliani e ao Vittor, pelo convívio no CCN.

Agradeço às professoras Nelise, Juciney, Mariluci e Dinéia, por todo o aprendizado que me permitiram.

Agradeço o apoio da Fipecafi e da Capes, que financiaram, parcialmente, minha permanência no doutorado.

Agradeço aos responsáveis pelas editoras Atlas, Bookman e Cengage pelo apoio às minhas atividades docentes.

Agradeço a oportunidade única, proporcionada pela USP, de conhecer pessoas fantásticas e estudar num programa de qualidade excepcional.

Agradeço, ainda, àqueles e àquelas que não nomeei aqui mas que, de alguma maneira, me ajudaram a conquistar este objetivo. 



\section{RESUMO}

Soares, S. V. (2017). Diga-me quantos te citam, e eu te direi quem és - Estudo sobre as citações no âmbito da pesquisa contábil brasileira. Tese de Doutorado, Faculdade de Economia, Administração e Contabilidade, Universidade de São Paulo, São Paulo.

Existe uma perspectiva teórica que afirma que os diversos motivos para que artigos sejam citados transitam entre dois polos chamados universalista e socialconstrutivista. Características como originalidade dos resultados e rigor metodológico são classificados como fatores universalistas; enquanto características como fama do autor e prestígio do periódico são classificados como social-construtivistas. Diante dessa perspectiva teórica, se coloca a questão de pesquisa desta tese: quais fatores do polo social-construtivista influenciam as citações que um artigo sobre contabilidade recebe no âmbito da pesquisa contábil brasileira? Para responder essa questão, fezse uma coleta de dados de 2.540 artigos, publicados por revistas brasileiras de contabilidade, entre os anos de 2007 e 2012. Para a análise desses dados, utilizaramse estatísticas descritivas, correlação de Pearson e teste de qui-quadrado, análise de correspondência e regressão binomial negativa. Foram criadas 16 hipóteses de fatores que influenciam a quantidade de citações dos artigos, sendo, totalmente, aceitas as hipóteses sobre a influência dos fatores afiliação institucional do primeiro autor, revista em que o artigo foi publicado, linha de pesquisa e número de referências no artigo. Mostraram-se estatisticamente significantes, em apenas determinadas circunstâncias, as hipóteses sobre a influência da quantidade de autores, do gênero do primeiro autor, da titulação do primeiro autor, do estrato do Qualis da revista e da idade da revista, assim, portanto, foram apenas parcialmente aceitas. Foram rejeitadas as hipóteses sobre a influência do número de termos no título do artigo e nas palavras-chave, do número de páginas, da posição do artigo e do tipo de edição, da proporção de autoras e da abordagem de análise dos dados. A aceitação das hipóteses sobre afiliação, revista, linha de pesquisa e número de páginas indica que há influência do polo teórico social-construtivista no padrão de citações na pesquisa contábil brasileira. Contudo, a rejeição das demais doze hipóteses mostram que essa influência é menor que no âmbito internacional, no qual mais hipóteses desse polo são aceitas. Assim, no Brasil, o padrão de citações de pesquisas é influenciado por características construídas socialmente e valorizadas pela comunidade científica.

Palavras-chave: Citação, Periódicos científicos, Pesquisa científica, Contabilidade, Pesquisa contábil, Fator de impacto. 


\begin{abstract}
Soares, S. V. (2017). Tell me how many quote you, and I'll tell who you are - Study about citations in the context of Brazilian accounting research. Ph.D. Thesis, Faculty of Economics, Administration and Accounting, University of São Paulo, São Paulo.

There is a theoretical perspective that maintains that the various reasons that lead to articles being cited fall between two poles called universalist and social-constructivist. Characteristics such as originality of results and rigorous methodology are classified as universalist factors, and characteristics such as author's prestige and journal's prestige are classified as social-constructivist. With this perspective in mind, the research question of this dissertation is posed: what are factors that influence the citations received by a paper within the scenario of Brazilian accounting research? To answer this question, we collected data from 2,540 papers published in Brazilian accounting academic journals between 2007 and 2012. The data analysis is based on descriptive statistics, Pearson's correlation and chi-square test, correspondence analysis, and negative binomial regression. We created 16 hypotheses of factors that influenced the number of times articles were quoted. The rejected hypotheses were the ones about the influence of the number of terms in the title or in the keywords of the paper, the number of pages, the position of the article and the type of edition, the proportion of female authors, and the data analysis approach (qualitative or quantitative). The following hypotheses were only statistically significant in certain circumstances, and thus, were only partially accepted: the influence of the number of authors, the gender of the first author, the academic degree of the first author, the Qualis grade of the journal, and the age of the journal. The totally accepted hypotheses were the ones about the influence of the factors such as the institutional affiliation of the first author, the journal in which the paper was published, the research line, and the number of references in the article. From these results, we can state that, in Brazil, the citation pattern of a paper is influenced by social-constructivist criteria, but to a lesser degree than that of the international context, in which more social-constructivist hypotheses are accepted. Therefore, in Brazil, the citation pattern is influenced by characteristics that are socially constructed and valued by the scientific community.
\end{abstract}

Keywords: Citation, Scientific journals, Scientific research, Accounting, Accounting research, Impact factor. 


\section{Lista de Tabelas}

Tabela 1 - Estatística descritiva da variável citação

Tabela 2 - Frequência absoluta, relativa e acumuladas das citações dos artigos 59

Tabela 3 - Estatística descritiva do número de termos no título do artigo 62

Tabela 4 - Estatística descritiva do número de termos usados nas palavras-chave $\quad 65$

Tabela 5 - Estatística descritiva do número de páginas dos artigos $\quad 68$

Tabela 6 - Estatística descritiva do número de referências dos artigos $\quad 70$

Tabela 7 - Estatística descritiva do número de autores por artigo 73

Tabela 8 - Estatística descritiva do número de autores por artigo, por ano 74

Tabela 9 - Estatística descritiva da proporção de autoria feminina $\quad 78$

Tabela 10 - Estatística descritiva da idade das revistas quando os artigos foram publicados 80

Tabela 11 - Estatísticas descritivas resumidas das citações das revistas e número de observações 81

Tabela 12 - Participação de cada Revista entre os 10\% e 1\% de artigos mais citados 83

Tabela 13 - Estatística descritiva das citações por tipo de edição $\quad 84$

Tabela 14 Participação de cada Tipo de edição entre os 10\% e 1\% de artigos mais citados 85

Tabela 15 - Estatística descritiva das citações dos artigos pela posição na edição 85

Tabela 16 - Participação de cada posição na edição entre os 10\% e 1\% de artigos mais citados 87

Tabela 17 - Estatística descritiva das citações dos artigos pelo gênero do primeiro autor 88

Tabela 18 - Participação de cada Gênero do 10 autor entre os 10\% e 1\% de artigos mais citados 89

Tabela 19 - Estatística descritiva das citações dos artigos pela titulação do 10 autor 90

Tabela 20 - Participação de cada Titulação do 10 autor entre os 10\% e 1\% de artigos mais citados 92

Tabela 21 - Estatística descritiva das citações dos artigos de acordo com a IES do 10 autor 94

Tabela 22 - Participação de cada IES do 10 autor entre os 10\% e 1\% de artigos mais citados 96

Tabela 23 - Estatística descritiva das citações dos artigos de acordo com a linha de pesquisa 97

Tabela 24 - Participação de cada Linha de pesquisa entre os 10\% e 1\% de artigos mais citados 99

Tabela 25 - Estatística descritiva das citações dos artigos de acordo com o estrato Qualis da revista 100

Tabela 26 - Participação de cada estrato do Qualis entre os 10\% e 1\% de artigos mais citados 102

Tabela 27 - Estatística descritiva das citações dos artigos de acordo com a abordagem da análise de dados 103

Tabela 28 - Participação de cada Abordagem de dados entre os 10\% e 1\% de artigos mais citados 105

Tabela 29 - Estatística descritiva das citações dos artigos, por ano $\quad 105$

Tabela 30 - Coeficientes de correlação linear de Pearson entre as variáveis explicativas quantitativas 106

Tabela 31 - Coeficientes de correlação linear de Pearson das variáveis explicativas quantitativas com a variável dependente

Tabela 32 - Resultados do teste de qui-quadrado de associação entre as variáveis explicativas qualitativas 108

Tabela 33 - Proporção dos artigos de cada revista, por gênero do primeiro autor $\quad 110$

Tabela 34 - Proporção dos artigos de cada revista, pela titulação do primeiro autor 112

Tabela 35 - Proporção dos artigos de cada revista, de acordo com a IES do primeiro autor $\quad 116$

Tabela 36 - Proporção dos artigos de cada revista por Linha de pesquisa $\quad 121$

Tabela 37 - Proporção dos artigos de cada revista, de acordo com a abordagem dos dados 125

Tabela 38 - Relação entre Gênero do primeiro autor e Titulação do primeiro autor $\quad 126$

Tabela 39 - Relação entre gênero do primeiro autor e IES do primeiro autor $\quad 127$

Tabela 40 - Relação entre Gênero do primeiro autor e Linha de pesquisa $\quad 128$

Tabela 41 - Relação entre Gênero do primeiro autor e Abordagem da análise $\quad 129$

Tabela 42 - Relação entre Abordagem da análise e Gênero do primeiro autor $\quad 129$

Tabela 43 - Relação entre Titulação do primeiro autor e IES do primeiro autor $\quad 130$

Tabela 44 - Relação entre Titulação do primeiro autor e Linha de pesquisa 132

Tabela 45 - Relação entre Titulação do primeiro autor e Qualis da revista 134

Tabela 46 - Relação entre Titulação do primeiro autor e Abordagem da análise 136

Tabela 47 - Relação entre Abordagem da análise e Titulação do primeiro autor 136

Tabela 48 - Relação entre IES do primeiro autor e Área de pesquisa $\quad 138$

Tabela 49 - Relação entre IES do primeiro autor e Qualis da revista $\quad 140$

Tabela 50 - Relação entre IES do primeiro autor e Abordagem da análise 142

Tabela 51 - Relação entre Linha de pesquisa e Qualis da revista 143

Tabela 52 - Relação entre Linha de pesquisa e Abordagem da análise 146 
Tabela 53 - Relação entre Qualis da revista e Abordagem da análise

Tabela 54 - Modelo 1, inclui todas as variáveis

Tabela 55 - Modelo 2, sem a variável Revista

Tabela 56 - Modelo 3, sem a variável Idade da revista

Tabela 57 - Variação da taxa estimada de incidência entre os Modelos

Tabela 58 - Modelo 4, sem as variáveis idade da revista e estrato Qualis 157

Tabela 59 - Modelo 5, com a variável Idade do artigo 158

Tabela 60 - Modelo 6, sem a USP como categoria de IES do primeiro autor $\quad 161$

Tabela 61 - Variação da taxa estimada de incidência das revistas, entre os modelos 162

Tabela 62 - Modelo 7, sem a RC\&F como categoria de Revista $\quad 163$

Tabela 63 - Modelo 8, sem a USP como categoria de IES do primeiro autor e sem a RC\&F como categoria de Revista

Tabela 64 - Comparação entre os modelos elaborados 


\section{Lista de Figuras}

Figura 1 - Fatores relacionados ao periódico $\quad 31$

Figura 2 - Fatores relacionados ao autor $\quad 33$

Figura 3 - Fatores relacionados ao artigo $\quad 35$

Figura 4 - Pesquisas sobre fatores que impactam a quantidade de citações 38

Figura 5 - Revistas da Amostra por Instituição, Ano e Sigla $\quad 51$

Figura 6 - Instituição de ensino superior do primeiro autor e sigla $\quad 54$

Figura 7 - Distribuição da variável citação $\quad 61$

Figura 8 - Distribuição do número de termos no título do artigo 63

Figura 9 - Média de termos no título dos artigos por linha de pesquisa, por ano 64

Figura 10 - Distribuição no número de termos usados nas palavras-chave 66

Figura 11 - Média de termos nas palavras-chave por linha de pesquisa, por ano 67

Figura 12 - Distribuição do número de páginas dos artigos $\quad 68$

Figura 13 - Média do número de páginas por artigo por linha de pesquisa, por ano 69

Figura 14 - Distribuição do número de referências $\quad 70$

Figura 15 - Média do número de referências de cada artigo, por linha de pesquisa, por ano 72

Figura 16 - Média do número de autores por artigo, por ano $\quad 74$

Figura 17 - Distribuição do número de autores por artigo $\quad 75$

Figura 18 - Média do número de autores por artigo por linha de pesquisa, por ano 76

Figura 19 - Proporção de autoria do gênero feminino $\quad 77$

Figura 20 - Média da proporção de autoria do gênero feminino, por linha de pesquisa, por ano 79

Figura 21 - Distribuição da idade da revista quando o artigo foi publicado $\quad 80$

Figura 22 - Média de citações dos artigos de acordo com a posição na edição, por ano 87

Figura 23 - Média de citações do artigo, por gênero do primeiro autor, por ano 89

Figura 24 - Média de citações do artigo por grau acadêmico do primeiro autor, por ano 92

Figura 25 - Média de citações do artigo por linha de pesquisa, por ano 98

Figura 26 - Média de citações do artigo, por estrato do Qualis, por ano 101

Figura 27 - Média de citações do artigo, de acordo com a abordagem dos dados, por ano 104

Figura 28 - Média de citações por artigo, por ano 106

Figura 29 - Associações estatisticamente significantes segundo o teste qui-quadrado 109

Figura 30 - Mapa perceptual da relação entre Revista e Titulação do 1o autor $\quad 114$

Figura 31 - Mapa perceptual da relação entre IES do primeiro autor e Revista $\quad 119$

Figura 32 - Mapa perceptual da relação entre Linha de pesquisa e Revista $\quad 124$

Figura 33 - Mapa perceptual da relação entre IES do 10 autor e Titulação do 1 autor 131

Figura 34 - Mapa perceptual da relação entre Linha de pesquisa e Titulação do 10 autor 133

Figura 35 - Mapa perceptual da relação entre Qualis vigente e Titulação do primeiro autor 135

Figura 36 - Mapa perceptual da relação entre Linha de pesquisa e IES do 10 autor 139

Figura 37 - Mapa perceptual da relação entre IES do 10 autor e Qualis vigente 142

Figura 38 - Mapa perceptual da relação entre Linha de pesquisa e Qualis vigente $\quad 145$

$\begin{array}{lr}\text { Figura } 39 \text { - Mapa perceptual da Anacor Múltipla } & 148\end{array}$

Figura 39 - Relação entre citações e idade da revista $\quad 153$

Figura 40 - Pesquisas sobre o uso do Google Acadêmico $\quad 189$

Figura 41 - Relação entre número de citações e número de termos no título do artigo 190

Figura 42 - Relação entre número de citações e número de termos nas palavras-chave 191

Figura 43 - Relação entre número de citações e número de páginas 192

Figura 44 - Relação entre número de citações e número de referências 193

Figura 45 - Relação entre número de citações e número de autores $\quad 194$

Figura 46 - Relação entre número de citações e proporção de autoras $\quad 195$

Figura 47 - Relação entre número de citações e idade da revista 196

Figura 48 - Média de citações dos artigos por revista, por ano 197

Figura 49 - Média de citações dos artigos por IES do 1ํ autor, por ano 198 



\section{Sumário}

1. INTRODUÇÃO

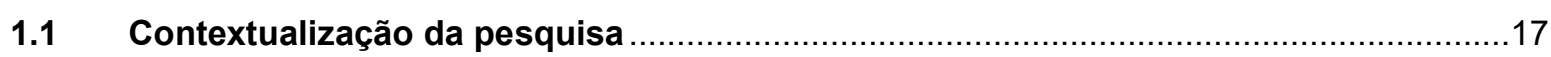

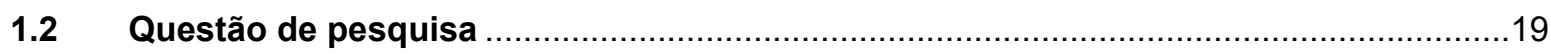

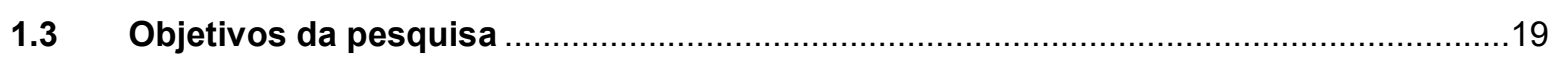

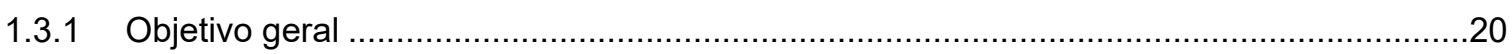

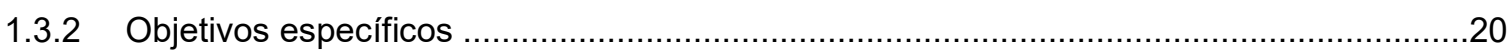

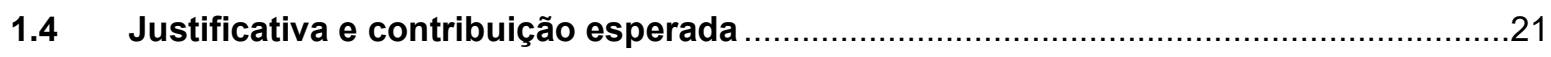

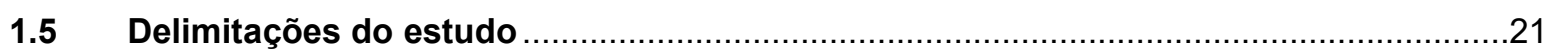

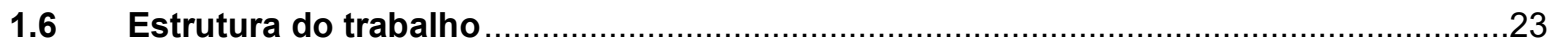

2. REVISÃO DA LITERATURA

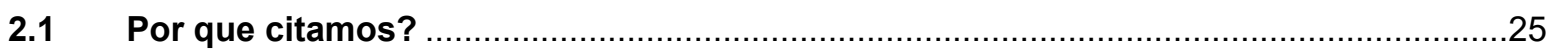

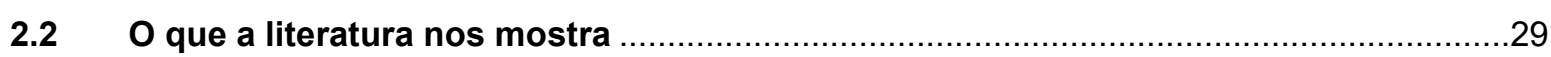

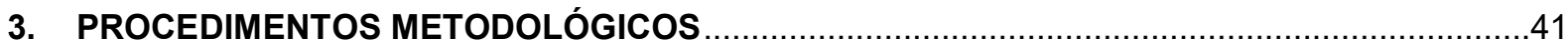

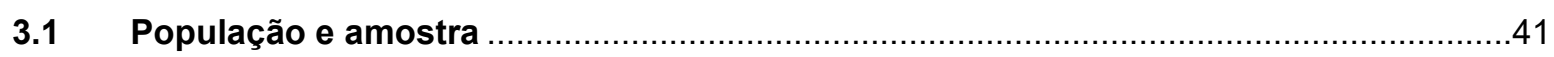

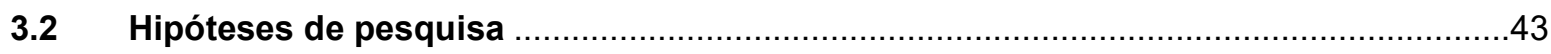

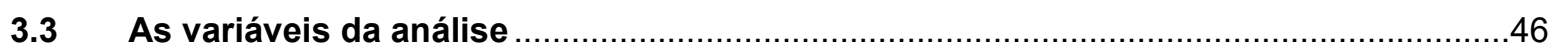

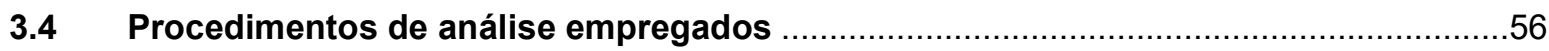

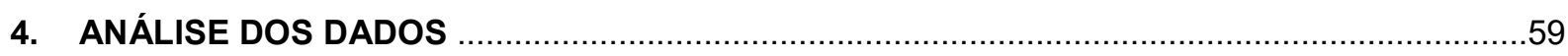

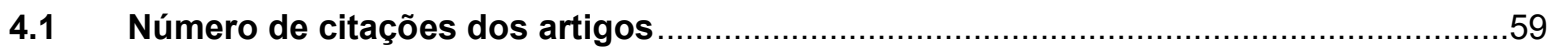

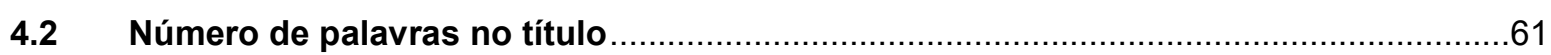

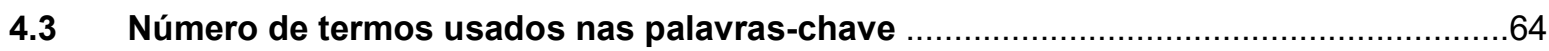

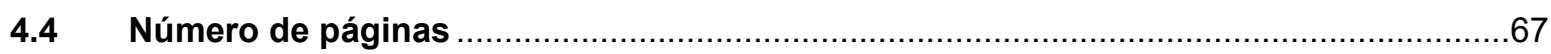

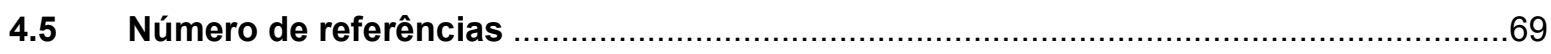

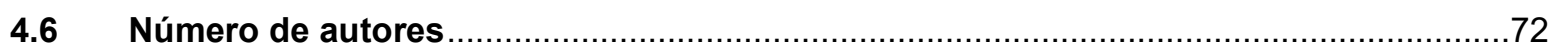

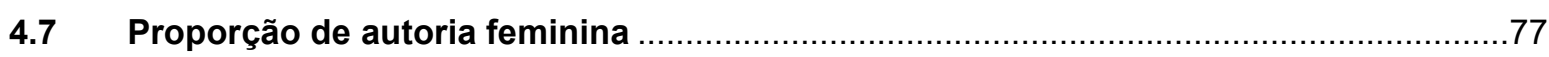

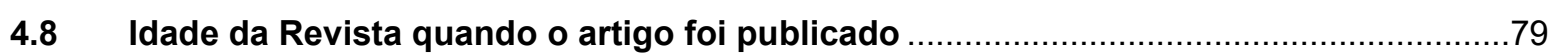

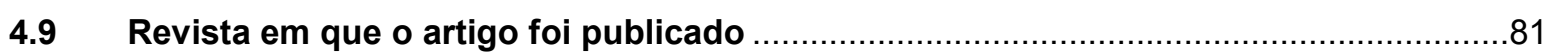

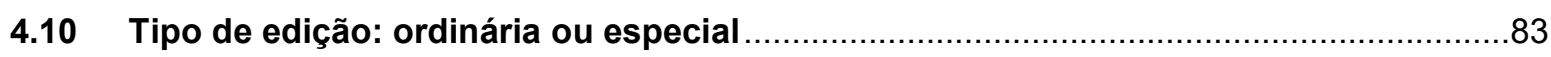

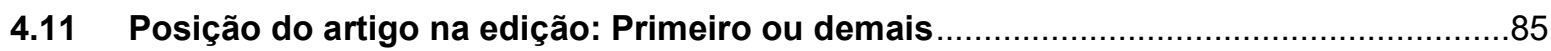

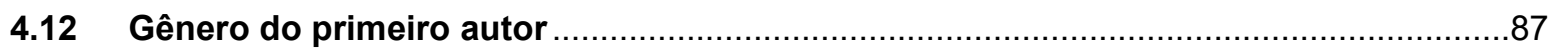

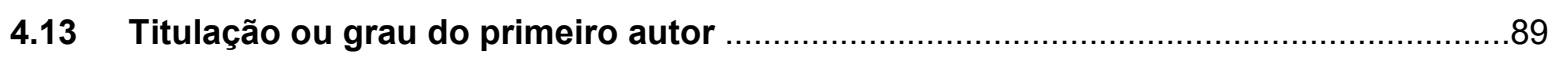

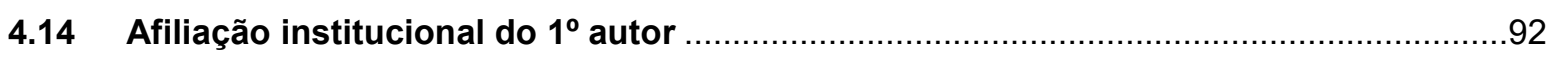

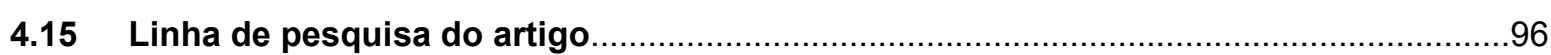

4.16 Estrato do Qualis da revista, vigente no ano que o artigo foi publicado .....................99

4.17 Abordagem da análise de dados: Quantitativa ou não ...........................................102

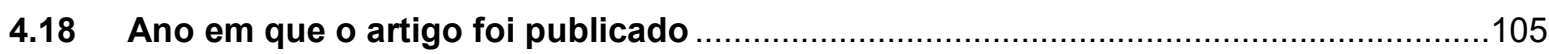

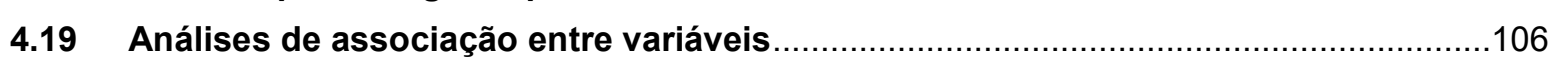

4.20 Relação entre Revista e Gênero do primeiro autor .................................................110 
4.21 Relação entre Revista e Titulação do primeiro autor .............................................111

4.22 Relação entre Revista e IES do primeiro autor .........................................................115

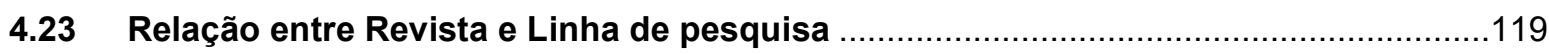

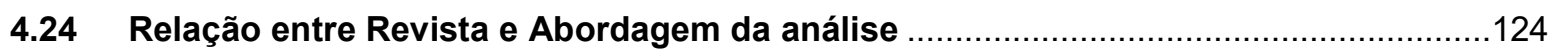

4.25 Relação entre Gênero do primeiro autor e Titulação do primeiro autor ......................126

4.26 Relação entre Gênero do primeiro autor e IES do primeiro autor ...............................127

4.27 Relação entre Gênero do primeiro autor e Linha de pesquisa ...................................128

4.28 Relação entre Gênero do primeiro autor e Abordagem da análise .............................128

4.29 Relação entre Titulação do primeiro autor e IES do primeiro autor .............................129

4.30 Relação entre Titulação do primeiro autor e Linha de pesquisa .................................131

4.31 Relação entre Titulação do primeiro autor e Qualis da revista ....................................133

4.32 Relação entre Titulação do primeiro autor e Abordagem da análise ...........................136

4.33 Relação entre IES do primeiro autor e Área de pesquisa ..........................................137

4.34 Relação entre IES do primeiro autor e Qualis da revista .............................................140

4.35 Relação entre IES do primeiro autor e Abordagem da análise ....................................142

4.36 Relação entre Linha de pesquisa e Qualis da revista ................................................143

4.37 Relação entre Linha de pesquisa e Abordagem da análise ..........................................145

4.38 Relação entre Qualis da revista e Abordagem da análise .........................................146

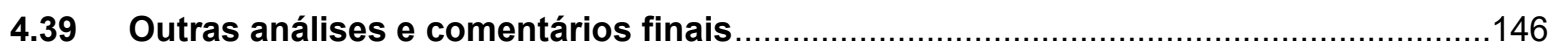

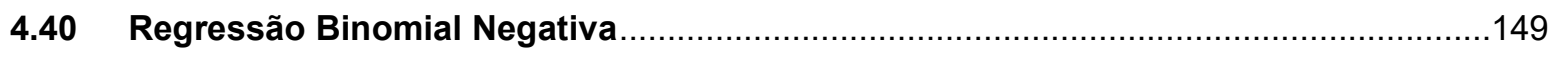

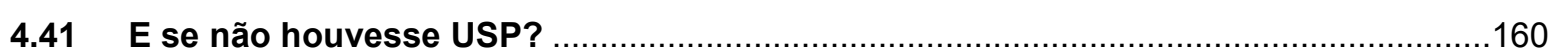

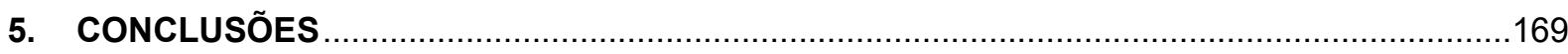

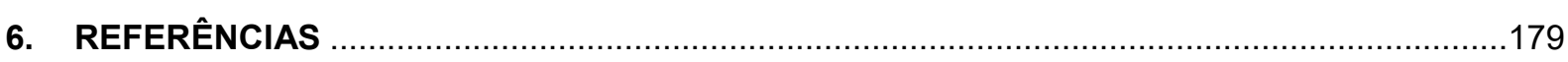




\section{INTRODUÇÃO}

The times they are a-changin'

Bob Dylan

\subsection{Contextualização da pesquisa}

O avanço da ciência depende de dois processos: o desenvolvimento de pesquisas e a comunicação científica. Pesquisar e comunicar as descobertas são dois processos que interagem de forma tão intensa, atualmente, que podem parecer serem um só processo. Contudo, nem sempre foi assim: o cientista inglês Henry Cavendish e o matemático alemão Carl F. Gauss desenvolveram um grande volume de pesquisas que tiveram divulgação póstuma, indicando ausência de preocupação com a rapidez em se comunicar suas descobertas (Meadows, 1999; Judge, Cable, Colbert, \& Rynes, 2007).

Entretanto, tanto o cientista quanto o matemático já atuavam no período em que a revista científica estava alvorecendo: os dois primeiros periódicos científicos, o Journal des Sçavans e o Philosophical Transactions, começaram a ser publicados em 1665 (Banks, 2009).

A comunicação científica diz respeito às formas pelas quais esse conhecimento é divulgado entre a comunidade científica. Hoje não se concebe mais que ocorram casos como os de Cavendish e Gauss, principalmente, pelo fato de que a comunicação científica se tornou a grande proxy de valor do pesquisador. Para Meadows (1999, p. 85), "em termos de comunicação científica, as duas mais importantes características do pesquisador são a quantidade de informações que comunica e sua qualidade". Nesse sentido, a demanda por publicação se tornou tão grande que na década de 1930, a academia já começava a apresentar críticas à máxima "Publish or perish".

A forma de se fazer comunicação científica, em função do desenvolvimento das tecnologias de informação e da internet, a partir da metade do século XX, sofreu alterações dramáticas. Os avanços tecnológicos permitiram que a velocidade da 
comunicação aumentasse consideravelmente e que a distribuição de informação se tornasse quase ilimitada em torno do globo. Rossi $(1998$, p.1) relata um caso ilustrativo desse aumento:

A notícia do assassinato do presidente norte-americano Abraham Lincoln, em 1865, levou 13 dias para cruzar o Atlântico e chegar à Europa. A queda da bolsa de valores de Hong Kong, na semana passada, levou 13 segundos para cair como um raio sobre São Paulo e Tóquio, Nova York e Tel Aviv, Buenos Aires e Frankfurt.

Em julho de 2014, um grupo de pesquisadores da Technical University of Denmark noticiou ter conseguido transferir dados a uma velocidade de $43 \mathrm{Tbps}$, batendo o recorde anterior que era do Karlsruhe Institute of Technology, da Alemanha, com 26 Tbps. A essa velocidade seria possível transmitir, aproximadamente, 215 filmes em alta definição por segundo e toda a Biblioteca do Congresso Americano em apenas 3 segundos (Anthony, 2014).

A ciência da informação tem estudado os fenômenos relacionados à comunicação científica, observando que um dos fenômenos mais interessantes é que pesquisas de cientistas famosos, naturalmente, atraem mais atenção do que pesquisas de cientistas não famosos.

O efeito Mateus, como esse fenômeno foi batizado, foi descrito, primeiramente, por Merton (1968) e foi assim chamado por causa de um versículo do evangelho de São Mateus: "Porque àquele que tem, se dará, e terá em abundância; mas àquele que não tem, até aquilo que tem Ihe será tirado" (MATEUS, 13:12).

Esse fenômeno, ainda, caracteriza a atribuição de citações a um artigo pela fama de seu autor e não pelo mérito da pesquisa. llustração desse fenômeno é o caso de uma pesquisa que chama a atenção da academia poder ser indicada ao prêmio Nobel e ser premiada, e, ao ser premiada acarretar em mais atenção ainda para a pesquisa.

No entanto, sabe-se que a fama do autor da pesquisa é apenas uma das características de um artigo, que pode impactar no quão citado ele é. Nesse caso, existem outras características que merecem ser estudadas. Assim, identificar essas características, que explicam as citações a um artigo sobre Contabilidade na 
comunidade científica brasileira, constitui o problema central sobre o qual se debruça esta Tese.

Segundo a literatura científica (Judge et al., 2007; Stremersch, Verniers, \& Verhoef, 2007), os artigos são citados por uma variada gama de razões, que podem ser classificadas em: razões universalistas, como inovação dos resultados, rigor metodológico, capacidade de explicação de um fenômeno; ou como status dos autores, fama do periódico ou renome da instituição em que a pesquisa foi desenvolvida, razões essas denominadas de social-construtivistas. No entanto, fatores relacionados ao polo universalista são difíceis de serem operacionalizados em variáveis que possam ser relacionadas ao número de citações. Afinal, como "medir" o rigor, a inovação ou capacidade de explicação de uma pesquisa?

Law, Ye, Chen e Leung (2009) afirmam que o crescimento da importância da análise de citações sugere, fortemente, que o desempenho de pesquisa acadêmica está mudando lentamente o cenário de "Publish or Perish" para "Be cited or Vanish".

\subsection{Questão de pesquisa}

Diante do exposto, apresenta-se a questão de pesquisa desta Tese: Quais fatores do polo social-construtivista influenciam o número de citações que um artigo sobre Contabilidade recebe no âmbito da pesquisa contábil brasileira?

A tese, subjacente a questão de pesquisa, é: existem fatores social-construtivistas que influenciam o quanto um artigo é citado no âmbito da pesquisa contábil brasileira.

\subsection{Objetivos da pesquisa}

Embora haja relativa concordância entre acadêmicos de que características qualitativas, como originalidade, contribuição para a ciência e rigor metodológico no desenvolvimento da pesquisa, sejam variáveis que se associam positivamente ao número de vezes que o artigo é citado, essas características não explicam todos os padrões de citação, que podem incluir as altas taxas de citação de artigos com conclusões absurdas, controversas ou pouco ortodoxas, bem como os artigos que são 
citados pela inovação apresentada no método utilizado e não nos resultados propriamente ditos. Posto isso, apresenta-se o objetivo geral e os objetivos específicos desta pesquisa.

\subsubsection{Objetivo geral}

Considerando a relevância que as citações alcançaram no meio acadêmico, o objetivo desta pesquisa é estudar e avaliar a influência de fatores do polo social-construtivista nas citações que artigos sobre Contabilidade recebem na comunidade científica brasileira. Entende-se que esses fatores revelam, igualmente, o estágio da pesquisa em dada área e contexto. Especificamente, no caso desta Tese, entende-se que o estudo desses fatores têm o potencial de revelar algo em relação ao estágio da pesquisa contábil no Brasil.

\subsubsection{Objetivos específicos}

Ao objetivo geral alinham-se alguns objetivos específicos que auxiliam em sua consecução. Assim, tendo em vista o objetivo geral colocado anteriormente, para essa Tese, é necessário o alcance de três objetivos específicos:

a) identificar quais são as características dos artigos publicados em revistas brasileiras nas dimensões de autoria, revista e artigo. Para cada dimensão, estão relacionadas variáveis que permitem compreender como se estrutura a pesquisa contábil no Brasil, considerando as publicações em revistas da área;

b) mensurar como essas características se relacionam com a quantidade de citações que os artigos recebem. Dessa forma, buscar-se-á entender como as variáveis, em suas dimensões, se relacionam com uma medida de impacto de pesquisa, apesar de, como medida, o número de citações ter suas limitações, que serão discutidas no decorrer deste trabalho;

c) verificar o impacto desses resultados para a comunidade científica brasileira. 
Desse modo, pretende-se, também, refletir, como dito anteriormente, sobre o estágio de desenvolimento da pesquisa contábil brasileira e sobre o quadro que resulta, tendo em vista o estudo das características, em suas dimensões, tanto para esse estágio de pesquisa, como para os pesquisadores e pesquisadoras da área, bem como para os órgãos encarregados de incentivar, avaliar e direcionar a pesquisa no país.

\subsection{Justificativa e contribuição esperada}

A justificativa para esta Tese se sustenta na necessidade de se apurar os cuidados a serem tomados quando se analisam as citações de artigos sem considerar o papel das características dos pesquisadores, periódicos e das instituições, que viabilizaram a execução da pesquisa. Espera-se, portanto, que esta pesquisa contribua com evidências empíricas sobre o entendimento da avaliação do impacto das pesquisas contábeis brasileiras com base em citações.

Se os indícios encontrados no estudo mostrarem que as citações não constituem uma proxy de mensuração do impacto, esta Tese poderá influenciar todos os processos que utilizam os índices de citações como critério de avaliação, impactando eventos, como a concessão de financiamento de pesquisas, contratação e promoção de docentes, composição de comitês editoriais, bem como diretrizes por eles utilizadas, por exemplo. Se, por outro lado, os achados mostrarem consistência no uso deste critério, a pesquisa poderá impactar até mesmo a classificação dos periódicos nos estratos Qualis.

Esta Tese, na medida que identifica aquilo que gera impacto na comunidade científica nacional, ainda pode fornecer um dignóstico a ser utilizado no debate sobre a perspectiva de longo prazo da ciência contábil brasileira, que, atualmente, transita entre adoção de uma agenda de pesquisa com temas globais, que possui inserção em periódicos internacionais de alto impacto, como aqueles indexados pelo Web of Science e Scopus; e, na outra extremidade, uma agenda de pesquisa de problemas locais, que se veicula em revistas brasileiras.

\subsection{Delimitações do estudo}


Costuma-se diferenciar as delimitações do estudo das limitações encontradas, separando-se aquelas que ocorreram por opção metodológica do pesquisador daquelas que ocorreram contra a sua vontade.

A primeira escolha do pesquisador nesta Tese diz respeito ao limite geográfico do escopo da análise. O autor optou por estudar as revistas brasileiras, a despeito do fato de apenas três revistas brasileiras de Contabilidade estarem indexadas nas grandes bases de dados internacionais (Revista Contabilidade \& Finanças, Revista Brasileira de Gestão de Negócios e Custos e @agronegócio online) e a despeito de que nenhum estudo anterior focou o Brasil em sua análise.

A segunda delimitação da pesquisa diz respeito ao período analisado. $\mathrm{Na}$ verdade, não existe regra formalmente estabelecida que defina o espaço de tempo mais adequado para a amostra de uma pesquisa. Em teoria, o mais adequado a se fazer é não limitar períodos de tempo, em uma tentativa de eliminar o viés do recorte da análise. No entanto, essa recomendação esbarra na consecução, ao se adequar a análise dos dados pela comparabilidade deles. A importância dessa delimitação fica mais caraterística quando se pergunta, por exemplo, sobre quão adequada é a comparação das taxas de citação de artigos veiculados no ano de 2000 , quando havia apenas cinco revistas brasileiras de Contabilidade, com artigos veiculados no ano 2010, quando o número de revistas já era de 36 .

Para equilibrar a representatividade com a comparabilidade, neste estudo, escolheuse analisar artigos de revistas de acordo com triênios da avaliação da Capes, sendo escolhidos os triênios de 2007-2009 e 2010-2012.

O quadriênio de 2013-2016 não foi incluído por duas razões: por compreender um período muito recente, sendo assim os artigos recém começaram a ressoar em citações; e por limitação da capacidade física do autor para coletar dados. O trabalho de coleta de dados foi particularmente árduo e intensivo, principalmente por não haver bases disponíveis com as informações necessárias. A base foi construída especificamente para esta Tese. 
O triênio 2004-2006 foi excluído devido a sistemática de classificação de periódicos, vigente no referido período, que agrupava os periódicos como Internacionais, Nacionais, Regionais e Locais, subdividindo-os em A, B e C, diferente da sistemática vigente entre 2007 e 2012, de estratos A1 e A2, B1 a B5 e C.

Esse sistema de classificação de periódicos é considerado importante, visto que autores, quando escolhem a revista em que submetem seus artigos, são, potencialmente, influenciados pelo estrato em que um periódico está classificado. Este trabalho também deverá revelar algo sobre esse ponto.

\subsection{Estrutura do trabalho}

Este trabalho está estruturado em cinco capítulos. No primeiro, se apresenta o contexto e a questão de pesquisa. No segundo, é apresentada a literatura revisada, dividida entre literatura acerca de fator de impacto e literatura sobre fatores que explicam as quantidades de citações. No terceiro capítulo, descreve-se a trajetória metodológica da pesquisa, incluindo a população e a amostra, as hipóteses, o processo de coleta de dados, e as técnicas estatísticas empregadas na análise. No quarto capítulo, é discutida a análise dos dados em níveis de estatística descritiva, correlação e associação, e regressão binomial negativa. No último capítulo, relacionam-se as conclusões desta Tese e as recomendações para trabalhos futuros. 


\section{REVISÃO DA LITERATURA}

Open up my eager eyes

'Cause I'm Mr. Brightside

The Killers

\subsection{Por que citamos?}

A citação, ao fazer parte da comunicação científica, é um fenômeno inerente à construção do conhecimento. Um pesquisador que deseja fazer uma contribuição inovadora para o avanço da ciência necessita, inicialmente, identificar até que ponto a ciência já avançou. O matemático francês Henri Poincaré (1905, p. 157) afirma que a "[...] ciência é construída com fatos, como uma casa é construída com pedras, mas um acumulado de fatos não é mais ciência que uma pilha de pedras é uma casa." A citação, dentro desse processo, documenta a origem e evolução das pesquisas (Cronin, 1984; Judge et al., 2007).

Para Cronin (1984), a literatura publicada sobre um campo é um inventário seletivo, editado e aprovado, de conhecimento que, se for corretamente esquematizado, pode evidenciar toda a trajetória de sua genealogia. Essa esquematização é possível devido as citações, que, para o autor, são a constatação da relação inequívoca entre dois documentos: o citado e o citante.

O rigor na sistematização da revisão da literatura científica permite ao pesquisador identificar quais novas questões pode e deve propor. Glass (1955) afirma que "nenhum problema enfrentado por um pesquisador é tão desafiador quanto o esforço para lidar com a inundação de pesquisas científicas publicadas mesmo dentro de uma única especialidade".

Sobre esse esforço de seleção de leitura de pesquisas, o químico britânico Michel Faraday se queixava, já em 1826:

É com certeza impossível para qualquer pessoa ansiosa por devotar uma parcela de seu tempo a experiências químicas ler todos os livros e artigos que se publicam acerca de seu mister; seu número é imenso, e é tal o esforço para joeirar as poucas verdades experimentais e teóricas 
que em muitos deles são estorvadas por uma proporção muito grande de matéria desinteressante, de fantasias e erros que a maioria das pessoas que fazem experiências são logo induzidas a fazer uma seleção de sua leitura, e assim, inadvertidamente, às vezes, deixam escapar o que realmente presta (CROWTER, 1940, p. 96 in Meadows, 1999, p. 20).

Antes do desabafo de Faraday e antes mesmo da existência dos primeiros periódicos científicos, tem-se relato similar de Barnaby Rich, do ano de 1613, transcrito por Price (1963): "Um dos males destes tempos é a multiplicidade de livros; eles, de fato, sobrecarregam de tal modo a gente que não conseguimos digerir a abundância de matéria inútil, que todos os dias, é gerada e despejada no mundo." Essa queixa foi feita passados pouco mais de 170 anos da invenção da prensa de tipos móveis, por Johannes Gutenberg.

Para Cronin (1984), o sistema de comunicação científica tem três objetivos: disseminar conhecimento; assegurar a manutenção de padrões científicos; e distribuir créditos e reconhecimento àqueles cujo trabalho tem contribuído para o desenvolvimento de ideias em diferentes campos.

Usualmente os pesquisadores tentam delinear e reportar o estado da arte de determinada área, citando as pesquisas mais recentes e mais importantes para que o leitor consiga enxergar de que ponto partir e qual será a importância da sua contribuição. A citação é usada, ainda, como o meio mais comum de conceder crédito e reconhecimento em ciência (Cronin, 1984).

Merton (1957) acredita que, quando a ciência opera de forma eficaz, o enriquecimento do conhecimento e o enriquecimento da fama pessoal do cientista andam de mãos dadas, de modo que o objetivo maior da ciência, que é a produção de conhecimento, está intrinsecamente amarrado à recompensa pessoal dos indivíduos que atuam na área.

Kaplan (1965) afirma que a citação é, provavelmente, o principal recurso institucional, que permite a comunicação livre das descobertas de alguém e, ao mesmo tempo, protege os direitos de propriedade individuais, no que diz respeito ao reconhecimento e às reivindicações de originalidade. 
E alerta, ainda, Kaplan (1965) para a influência que os índices de citação têm sobre a forma como os cientistas fazem citações. Cronin (1984), por sua vez, ressalva que a relação entre dois documentos, dos quais a citação constitui indício, não pode ser identificada nem em sentido, nem em intensidade, somente com o uso de índices de citação.

A despeito disso, Cronin (1984) afirma que, embora haja um considerável corpo de evidências, que sugerem que a quantidade de citação está correlacionada com uma variedade de medidas subjetivas e objetivas de desempenho, há um volume igualmente amplo de pesquisas que se constituem críticas às análises de citação e, portanto, são um alerta de que o uso de medidas de citação requer cuidados.

O mesmo autor ainda enfatiza que a ausência de uma satisfatória "teoria das citações", em parte, explica porque pesquisadores do assunto, muitas vezes, recorrem a uma metáfora, em uma tentativa de esclarecer o que não é inteiramente autoevidente (Cronin, 1984).

Para Cronin (1984), o uso de citações como base para julgamentos de valor deve implicar que existe uma convenção, universalmente reconhecida, entre os pesquisadores, acerca da capacidade de citações serem uma medida de interesse e repercussão de artigos. No entanto, essa convenção, na medida em que se pode dizer que existe, exibe uma notável resistência à normalização. Nesse sentido, parece haver uma inclinação da comunidade científica em aceitar que citação reflete impacto, mas não há um único indicador baseado em citações que chegue perto de algo que possa ser chamado de consensual, como dispositivo de mensuração.

Cronin (1984) afirma que há muitas razões por que os autores citam as obras dos outros, sendo bem possível que, se questionados, eles apresentem o motivo. Mas esse é um exercício atributivo e que pode não constituir as reais intenções do autor. Sendo assim, sempre haverá uma lacuna entre a razão pela qual o autor é citado e a razão pela qual o autor supõe ser citado.

Ravetz (1971) interpreta as citações como uma forma de recompensa ou de renda, enquanto Gilbert (1977) prefere vê-las como ferramentas de persuasão. 
Weinstock (1971) divide as razões para uso de citações em sérias e frívolas e identificou quinze funções específicas de citações, que poderiam ser classificadas como sérias (apud Cronin, 1984):

1. Homenagear os pioneiros;

2. Dar crédito para trabalhos relacionados;

3. Identificar metodologia, equipamentos etc.;

4. Fornecer a literatura revisada;

5. Corrigir o próprio trabalho;

6. Corrigir o trabalho dos outros;

7. Criticar trabalhos anteriores;

8. Fundamentar reivindicações;

9. Alertar investigadores para próximos trabalhos;

10. Apresentar trabalhos pouco disseminados, mal indexados ou não publicados;

11. Autenticar dados e classificações - constantes físicas;

12. Identificar publicações originais em que uma ideia ou conceito foi discutido;

13. Identificar publicação original, descrevendo um conceito epônimo ou termos como, por exemplo, doença de Hodgkin;

14. Negar trabalhos ou ideias dos outros;

15. Debater a prioridade de trabalhos dos outros.

No entanto, vale registrar que uma pesquisa não é necessariamente citada tão somente porque é importante ou recente. Existe um conjunto de fatores que podem fazer um artigo ser mais ou menos citado, incluindo entre eles a comunicação de resultados controversos ou mesmo equivocados.

Cronin (1984) ressalva que as ligações interdocumentais, representadas pela citação, não possuem a mesma função e elenca inúmeros estudos que propuseram taxonomias para categorização das funções das citações: Lipetz (1965), Duncan et al. (1981), Frost (1979), Hodges (1978), Moravcsik e Murugesan (1975, 1979), Murugesan e Moravcsik (1978), Chubin e Moitra (1975), Oppenheim e Renn (1978) e Finney (1979).

E ainda, critica Cronin (1984) o fato de que todos esses estudos criaram taxonomias próprias, não havendo um esforço visível para a consolidação de um sistema de classificação mais amplo. No entanto, alerta ele que determinadas funções tiveram ocorrência em mais de um sistema de taxonomia, o que pode indicar certa consistência de algumas funções. 
Numa visão mais recente, Stremersch et al. (2015) adotam uma perspectiva em que as citações se dividem em 5 tipos: Aplicação - os autores citam um artigo por causa dos seus achados, métodos ou conceitos; Afirmação - um artigo é citado porque confirma os resultados do outro artigo; Negação - autores citam um artigo para criticar, atacar ou desconfirmar os resultados do outro artigo; Revisão - os autores citam artigos para ilustrar o que a literatura anterior pesquisou; e Menções superficiais - a citação ocorre sem o uso real do conteúdo citado. Os mesmos autores constaram, ainda, que os três primeiros tipos, que são os que apresentam níveis maiores de relação entre os trabalhos, representam apenas $15 \%$ do total de citações na área de Marketing.

\subsection{O que a literatura nos mostra}

Judge, Cable, Colbert, e Rynes (2007) afirmam que as publicações podem ser analisadas do ponto de vista universalista ou particularista da ciência. Na visão universalista, um artigo deve ser aceito para publicação quando: (1) oferece contribuições originais para a ciência; e (2) foi concebido e executado com elevado padrão de qualidade, independentemente da reputação ou colocação do autor no sistema de estratificação acadêmica.

Já os céticos quanto a esse sistema acreditam numa visão particularista/socialconstrutivista, sugerindo que as citações podem basear-se na fonte da contribuição científica, como, por exemplo, a formação ou o status de um cientista, ao invés de seu conteúdo ou mérito.

Judge et al. (2007) desenvolveram um trabalho no qual analisaram quatro categorias de fatores que podem influenciar as citações: i. características exclusivamente universalistas do artigo; ii. características exclusivamente particularistas dos autores; iii. variáveis mistas que combinam ambas as visões; e iv. variáveis de controle.

Dentro do grupo i., os autores indicam como principal variável a originalidade da ideia. Apoiados nos estudos de Gottfredson (1978) e Beyer, Chanove e Fox (1995), os autores apontam que artigos com parcelas de exploração de novos paradigmas ou 
que levam paradigmas a novos territórios são mais provavelmente citados que os que testam ou refinam teorias existentes.

A metodologia foi o outro aspecto universalista apontado pelos autores, os quais se apoiam nos trabalhos de Gottfredson (1978) e Shadish, Tolliver, Gray e Sengupta (1995) para afirmar que, independente da qualidade da ideia, métodos pobres impactam negativamente a contribuição da pesquisa e suas posteriores citações. Os autores indicam que pesquisas empíricas têm mais probabilidade de serem citadas se possuem: (1) altas taxas de resposta; (2) fontes de dados independentes; (3) desenhos longitudinais; (4) confiabilidade das escalas aceitáveis; (5) amostras nãoestudantis; e (6) estudos múltiplos. Por fim, os autores citam a redação como uma característica que influencia as taxas de citações. A clareza e legibilidade do texto, a apresentação clara das limitações e das implicações do estudo e o número grande de páginas são fatores que podem influenciar as taxas de citação de artigos.

Dentro do grupo ii., são apontadas três características particularistas dos autores, em que os leitores podem basear suas decisões de citações: (1) histórico de publicações dos autores; (2) o prestígio da afiliação dos autores; e (3) gênero dos autores. Sobre a primeira característica, Merton (1968, pp. 597) afirma que "[a] sobrecarga do sistema de comunicação científica leva os cientistas a escolher o seu material de leitura com base na reputação anterior de um autor, muitas vezes, aumentando ainda mais essa reputação". Cientistas também podem escolher citar artigos de cientistas mais renomados, numa tentativa de conferir maior legitimidade aos seus próprios achados.

Sobre a segunda característica, Judge et al. (2007) afirmam que o prestígio da universidade de um cientista envia sinais para os pares sobre sua posição social, pois, numericamente, há menos escolas de elite do que cientistas de elite. $\mathrm{E}$, sobre a última característica, os autores afirmam que as pesquisas empíricas mostram que pesquisas de autores do gênero feminino tendem a ser menos citadas do que do gênero masculino.

Dentro do grupo iii., de variáveis mistas, Judge et al. (2007) elencam que, possivelmente, o melhor indicador de qualidade de um artigo é a revista em que foi publicado. O sistema de avaliação por pares serve como uma proxy de qualidade, que 
é mais rigorosa em revistas de melhor qualidade, de modo que essas revistas recebem melhores artigos e podem recusar um número maior de artigos do que revistas de menor qualidade. Os autores elencam que outro indício de qualidade é se o artigo é o principal da edição da revista, sendo colocado em primeiro lugar. A justificativa para isso é que essa seria uma forma de se filtrar os artigos analisados. Ao consultarem 16 editores, apenas quatro disseram que a qualidade percebida no artigo não influenciou em suas decisões de ordenação dentro da edição em que foram publicados.

Como variáveis de controle, os autores utilizaram: o tempo, dado que os artigos mais velhos têm mais oportunidade de serem citados; os artigos de revisão, dado que artigos de revisão tendem a ser mais citados que artigos empíricos isolados; a grande área de pesquisa, dado que determinadas áreas angariam mais pesquisadores que outras; e o número de artigos citados, dado que, quando há mais autores referenciados, há mais autores que podem "retribuir o favor" no futuro, aumentando a contagem de citações.

Mingers e Xu (2010) trazem uma categorização bem organizada dos fatores que acarretam citações, dividindo-a em três níveis: revista, autor e artigo. A Figura 1, a seguir, explora a categorização de fatores relacionados ao periódico.

\begin{tabular}{|c|c|}
\hline Fatores testados & Pesquisa \\
\hline \multirow{3}{*}{$\begin{array}{l}\text { Qualidade } \\
\text { (Prestígio) }\end{array}$} & Judge et al. (2007) \\
\hline & Seglen (1989) \\
\hline & Peters e van Raan (1994) \\
\hline Taxa de citação & Judge et al. (2007) \\
\hline Acessibilidade & Lawrence (2001) \\
\hline Circulação & Leimu e Koricheva (2005) \\
\hline \multirow[t]{3}{*}{ Visibilidade } & Baldi (1998) \\
\hline & Hoffmann e Holbrook \\
\hline & Peters e van Raan (1994) \\
\hline
\end{tabular}

Figura 1 - Fatores relacionados ao periódico Fonte: Mingers e Xu (2010)

O acesso livre e gratuito aos periódicos é uma das variáveis interessantes, que podem ter seu impacto estudado no âmbito internacional; no entanto, fazer essa análise, no Brasil, incorre em um risco grande de desproporcionalidade. A única revista brasileira de Contabilidade que cobra pelo acesso ao acervo é a Revista Brasileira de Contabilidade, do Conselho Federal de Contabilidade, que mantém, ainda, versão 
impressa além da versão digital. Outra revista que mantém a versão impressa é a Revista Catarinense de Ciências Contábeis, além de manter seu acervo digital e com acesso livre e gratuito, tendo descontinuado as edições impressas em 2016.

Outra variável interessante é a adoção do regime de revisão por pares, que pode ser aberto, single blind, double blind ou triple blind. Na modalidade single blind o autor desconhece o revisor. Na modalidade double blind, o autor desconhece o revisor e o revisor desconhece o autor. Na modadelidade triple blind, o autor desconhece o revisor, e o revisor e o editor-assistente desconhecem o autor.

No entanto, testar a influência dessa variável no impacto dos artigos das revistas não é viável no Brasil, uma vez que todas as revistas brasileiras afirmam adotar o modelo double blind review.

A circulação também é uma variável controversa para os periódicos no Brasil, dado que todos os periódicos possuem sítios eletrônicos e, teoricamente, isso cria um acesso global a eles. Mesmo os periódicos que surgiram quando se faziam apenas as versões impressas, o acesso às edições mais antigas se tornou viável pela disponibilização dos artigos escaneados em formato Portable Document Format (.pdf).

No tocante à dimensão autor, indentificam-se, na Figura 2, alguns fatores já estudados, segundo a literatura.

\begin{tabular}{|c|c|}
\hline Fatores testados & Pesquisa \\
\hline \multirow{2}{*}{ Número de autores } & Leimu and Koricheva (2005) \\
\cline { 2 - 2 } & Ayres and Vars (1999) \\
\cline { 2 - 2 } & Baldi (1998) \\
\cline { 2 - 2 } & Peters and van Raan (1994) \\
\hline Nacionalidade & Leimu and Koricheva (2005) \\
\hline Gênero & Leimu and Koricheva (2005) \\
\cline { 2 - 2 } & Ayres and Vars (1999) \\
\cline { 2 - 2 } & Baldi (1998) \\
\hline Idade & Ayres and Vars (1999) \\
\hline Afiliação institucional & Leimu and Koricheva (2005) \\
\hline Rankings de institutos & Stremersch et al. (2007) \\
\cline { 2 - 2 } & Judge et al. (2007) \\
\cline { 2 - 2 } & Leimu and Koricheva (2005) \\
\cline { 2 - 2 } & Bergh et al. (2006) \\
\cline { 2 - 2 } & Baldi (1998) \\
\hline & Leimu and Koricheva (2005) \\
\hline
\end{tabular}




\begin{tabular}{|c|c|}
\hline \multirow{2}{*}{ Reputação } & Judge et al. (2007) \\
\cline { 2 - 2 } & Peters and van Raan (1994) \\
\cline { 2 - 2 } & Baldi (1998) \\
\hline Taxa de autocitação & Stremersch et al. (2007) \\
\hline Status social & Hoffman and Holbrook (1993) \\
\hline Registro de publicações anteriores & Stremersch et al. (2007) \\
\hline Registro de citações anteriores & Leimu and Koricheva (2005) \\
\cline { 2 - 2 } & Bergh et al. (2006) \\
\hline Membros do corpo editorial & Stremersch et al. (2007) \\
\hline
\end{tabular}

Figura 2 - Fatores relacionados ao autor

Fonte: Mingers e Xu (2010)

O número de autores é uma variável bastante fácil de ser operacionalizada no Brasil, visto que a maioria das revistas elenca os autores na primeira página do artigo. $\mathrm{O}$ gênero dos autores se mostra quase tão operacionalizável quanto o número, embora haja uma série de nomes andrógenos (como, por exemplo, Sidney, Darci, Joisse), que pode reduzir em uma pequena proporção a amostra para testes estatísticos com a variável gênero, se não houver um esforço adicional pela classificação destes nomes.

A nacionalidade dos autores é uma variável que só pode ser testada com coleta de dados em campo. Nenhuma revista brasileira de Contabilidade identifica a nacionalidade de seus autores, e utilizar o idioma ou a instituição de afiliação mencionada no artigo como sinalizador da nacionalidade não é uma alternativa segura, pois muitos brasileiros submetem artigos em inglês, bem como muitos estrangeiros, principalmente portugueses e nativos de outros países lusófonos, submetem artigos aos periódicos brasileiros em português.

A idade dos autores é igualmente difícil de ser testada estatisticamente sem uma coleta de dados em campo. As revistas brasileiras de Contabilidade não expõem a idade dos autores.

Por outro lado, o grau acadêmico é uma variável que pode ser testada. Um número significativo de revistas apresenta o autor juntamente com seu grau acadêmico e curso de formação.

A afiliação institucional também pode ser testada, visto que as revistas costumam apresentar a afiliação acadêmica dos autores. No entanto, há uma dificuldade que é separar a afiliação de formação da afiliação de atuação. Há autores que utilizam a 
instituição em que se formaram, há autores que utilizam a instituição na qual atuam profissionalmente, e há autores que utilizam ambas.

O ranking e a reputação dos cursos também podem ser testados, desde que assumidos alguns pressupostos. O primeiro deriva do fato de que não existe um ranking formal de instituições de ensino superior brasileiras, mas algumas proxies podem ser adotadas. Uma delas é o conceito do programa de pós-graduação, segundo a Capes, embora esse conceito estabeleça uma ordenação entre instituições, restringindo-se a instituições que possuem programas de pós-graduação. No caso da graduação, uma alternativa é usar a nota do curso no Exame Nacional de Desempenho dos Estudantes (Enade), ressalvando que esse é um denominador comum a praticamente todos os cursos, e abrange muitos cursos que não possuem vocação para a produção científica por serem ofertados por faculdades, que não têm a obrigação institucional de realizar pesquisa científica, como ocorre com as universidades. Outro limitador do uso do Enade é que ele é desenvolvido principalmente em função do desempenho do curso em nível de graduação, do qual se espera uma fração pequena do total de produção científica de uma instituição de ensino superior.

Outra via, ainda, é a utilização das notas do curso, atribuídas pelo Guia do Estudante. Essa opção, no entanto, sofre dos mesmos problemas que a opção anterior, isto é, o conceito da Capes ou a nota do ENADE. Um caminho possível também é assumir a posição da instituição em um ranking ao invés da posição do curso. No entanto, além de se saber que há um gap entre a qualidade dos cursos de Contabilidade e a qualidade das instituições, nenhum dos rankings internacionais abrangeria todas as instituições brasileiras.

A taxa de autocitação pode ser encontrada apenas nas revistas da base Spell ou contadas manualmente, com o uso do Google Acadêmico. A participação de autor em corpo editorial também pode ser testada. Mais da metade das revistas brasileiras de Contabilidade divulga a composição do corpo editorial e a lista dos avaliadores ad hoc, pelo menos, anualmente. 
Por último, apresentam-se os fatores relacionados às características do artigo, segundo a literatura, sintetizadas da Figura 3 , conforme segue.

\begin{tabular}{|c|c|}
\hline Fatores testados & Pesquisa \\
\hline \multirow[t]{2}{*}{ Ano de publicação } & Hoffman and Holbrook (1993) \\
\hline & Bergh et al. (2006) \\
\hline \multirow[t]{5}{*}{ Posição na revista } & Stremersch et al. (2007) \\
\hline & Judge et al. (2007) \\
\hline & Laband and Piette (1994) \\
\hline & Leimu and Koricheva (2005) \\
\hline & Ayres and Vars (1999) \\
\hline Edição especial & Bergh et al. (2006) \\
\hline \multirow[t]{3}{*}{ Área } & Hoffman and Holbrook (1993) \\
\hline & Judge et al. (2007) \\
\hline & Bettencourt and Houston (2001) \\
\hline Tamanho da área & King (1987) \\
\hline Método & Judge et al. (2007b) \\
\hline \multirow[t]{2}{*}{ Comprimento do título } & Stremersch et al. (2007) \\
\hline & Ayres and Vars (1999) \\
\hline Número de palavras-chave & Stremersch et al. (2007) \\
\hline \multirow[t]{2}{*}{ Idioma } & Leimu and Koricheva (2005) \\
\hline & Peters and van Raan (1994) \\
\hline \multirow[t]{3}{*}{ Número de páginas } & Leimu and Koricheva (2005) \\
\hline & Ayres and Vars (1999) \\
\hline & Peters and van Raan (1994) \\
\hline \multirow[t]{2}{*}{ Número de referências } & Judge et al. (2007b) \\
\hline & Peters and van Raan (1994) \\
\hline \multirow[t]{5}{*}{ Comprimento do artigo } & Stremersch et al. (2007) \\
\hline & Judge et al. (2007b) \\
\hline & Leimu and Koricheva (2005) \\
\hline & Baldi (1998) \\
\hline & Bergh et al. (2006) \\
\hline Artigo premiado ou não & Stremersch et al. (2007) \\
\hline
\end{tabular}

O ano de publicação do artigo foi testado na pesquisa de Soares e Casa Nova (2016) e se mostrou estatisticamente significante. A posição do artigo dentro da edição, o comprimento do título, o número de palavras-chave, o idioma, o número de páginas, o número de referências e o comprimento do artigo podem ser identificados objetivamente e testados.

A metodologia e a linha de pesquisa também podem ser testadas de forma indireta. Há pelo menos dois caminhos que podem ser traçados para desenvolver esses testes. O primeiro consiste em verificar como o autor classifica a pesquisa, buscando identificar, por meio de análise de conteúdo, essa classificação dentro do corpo do texto. O problema dessa metodologia é que ela depende do julgamento do autor, e autores diferentes podem possuir conceitos distintos sobre a metodologia de 
pesquisa. Um pesquisador pode classificar uma pesquisa como exploratória enquanto outro pode classificar como descritiva, ou mesmo explicativa. Ou seja, há o viés da atribuição individual de rótulos aos artigos. Embora a classificação de pesquisa em exploratória, descritiva e explicativa proposta por Gil (2002) seja uma taxonomia popular no Brasil, há outras taxonomias de que os autores se utilizam e que inviabilizam a uniformidade da classificação, baseada na atribuição dada pelo autor.

Uma segunda forma que pode uniformizar a classificação é utilizá-la por pares, às cegas. Essa metodologia consiste em apresentar a lista de problemas de pesquisa a esquisadores que devem classificar essas pesquisas segundo uma taxonomia prédeterminada. Pode-se aumentar a credibilidade da classificação, tornando as classificações independentes, ou seja, cada classificador desconhece a classificação realizada pelo seu colega. Os casos contraditórios devem ser analisados pelo pesquisador e desempatados por ele ou, ainda, serem reenviados para os mesmos classificadores para que eles tornem a reclassificar até que haja um consenso. Essa classificação foi usada na pesquisa de Antonakis, Bastardoz, Liu e Schriesheim (2014) e é utilizada na técnica Delphi.

Tais considerações são igualmente atribuídas à classificação quanto à linha de pesquisa. A divisão interna do Programa de Pós-graduação em Controladoria e Contabilidade da Universidade de São Paulo, nas linhas de pesquisa de Controladoria e Contabilidade Gerencial, Contabilidade para Usuários Externos, Mercado Financeiro, de Créditos e de Capitais, e Educação e Pesquisa em Contabilidade, influenciou fortemente as taxonomias de classificação de pesquisas contábeis no Brasil, até meados da década de 2000. Mais recentemente, as linhas de Contabilidade aplicada ao Setor Público, Contabilidade aplicada ao Terceiro Setor, Atuária, e Auditoria e Perícia começaram a ganhar força, aparecendo como áreas de interesse de eventos científicos, como, por exemplo, o Congresso USP de Controladoria e Contabilidade.

Faz-se necessário mencionar que a análise de periódicos contábeis, no Brasil, não é fato novo, embora possa ser tratada como uma área jovem. Possivelmente, iniciou-se com a pesquisa de Frezatti e Borba (2000) acerca dos periódicos internacionais de Contabilidade. Todavia, o foco pelas revistas brasileiras de Contabilidade teve seu 
início com a pesquisa de Oliveira (2002). Muitas análises foram realizadas e, nos anos mais recentes, as bibliometrias de periódicos brasileiros de Contabilidade, como objeto de análise, se multiplicaram. No entanto, somente a pesquisa de Aragão et al. (2014) foi localizada ao se procurar por pesquisa tratando de fatores explicativos das citações das pesquisas contábeis, publicadas no Brasil.

A comunidade científica internacional, no entanto, apresenta uma tradicional linha de análise sobre fatores que impactam as taxas de citação. A Figura 4 mostra algumas das pesquisas mais citadas nas áreas de Negócios, Direito e Sustentabilidade/ecologia, publicadas a partir de 2000, sobre essa temática. Na Figura 4, são listadas as variáveis testadas em cada pesquisa e sublinhadas as variáveis que se mostravam estatisticamente significantes dentro dos modelos gerados pelos autores.

\begin{tabular}{|c|c|}
\hline Autor & Pesquisa \\
\hline $\begin{array}{l}\text { Ayres e Vars } \\
\qquad(2000)\end{array}$ & $\begin{array}{l}\text { Os autores investigaram o comportamento das citações de } 979 \text { artigos e outros } \\
\text { documentos publicados em } 3 \text { revistas de Direito, entre os anos de } 1980 \text { e } 1995.0 \\
\text { estudo foi feito por meio de análise de dados em painel. A pesquisa analisou a } \\
\text { Posição do artigo na edição, Linha de pesquisa, Número de autores, Presença de } \\
\text { figuras, Presença de apêndice, Taxa de notas de rodapé por página, Gênero, Idade } \\
\text { do autor, Emprego do autor e Nepotismo dos artigos. Quando se incluem os outros } \\
\text { documentos, a Instituição, Número de páginas e Número de palavras no título } \\
\text { (curtos) se tornam relevantes. }\end{array}$ \\
\hline $\begin{array}{l}\text { Leimu e } \\
\text { Koricheva } \\
(2005)\end{array}$ & $\begin{array}{l}\text { Os autores investigaram o comportamento das citações de } 228 \text { artigos publicados } \\
\text { em } 53 \text { revistas de ecologia, entre os anos de } 1975 \text { e } 2001 \text {. A coleta do número de } \\
\text { citações foi realizada em janeiro de } 2004 \text {. A análise foi feita por meio de correlações } \\
\text { e testes de diferença de média. No artigo, foi analisado o impacto das variáveis: } \\
\text { Hipótese testada (confirmação ou rejeição), Número de páginas, Número de autores, } \\
\text { País e Ranking da instituição no Academic Ranking of World Universities, Gênero do } \\
\text { primeiro autor, Revista. }\end{array}$ \\
\hline $\begin{array}{l}\text { Judge et al. } \\
\qquad(2007)\end{array}$ & $\begin{array}{l}\text { Os autores investigaram o comportamento das citações de } 614 \text { artigos publicados } \\
\text { em } 21 \text { revistas de negócios, entre os anos de } 1990 \text { e } 1994 \text {. A análise foi realizada } \\
\text { por meio de equações estruturais e englobou as variáveis: Idade do artigo, Tipo de } \\
\text { artigo, Número de referências, Fração amostral, Independência das fontes de dados, } \\
\text { Amostras não-estudantis, Método de pesquisa, Número de páginas, Revista, } \\
\text { Posição do artigo na edição, Afiliação dos autores, Gênero do primeiro autor, } \\
\text { Confiabilidade, Facilidade de leitura, }\end{array}$ \\
\hline $\begin{array}{l}\text { Stremersch } \\
\text { et al. (2007) }\end{array}$ & $\begin{array}{l}\text { Os autores investigaram o comportamento das citações de } 1.825 \text { artigos publicados } \\
\text { em cinco revistas de marketing, entre os anos de } 1990 \text { e } 2002 \text {. A coleta do número } \\
\text { de citações foi realizada em dezembro de } 2004 \text {. A análise foi feita por meio de uma } \\
\text { regressão binomial negativa e englobou as variáveis: Posição do artigo na edição, } \\
\text { Premiação, Número de páginas, Tipo do artigo, Linha de pesquisa, Número de } \\
\text { publicações que os autores tinham nas cinco revistas, Participação no corpo editorial, } \\
\text { Ranking da instituição, Afiliação norte-americana, Número de referências, Número } \\
\text { de autocitação, Número de palavras no título, Presença das palavras "Marketing", } \\
\text { "Market", "New" no título, Número de palavras-chave, Número de equações, Número } \\
\text { de figuras, Número de tabelas, Número de notas de rodapé, Número de apêndices, } \\
\text { Facilidade de leitura, Revista. }\end{array}$ \\
\hline
\end{tabular}




\begin{tabular}{|c|c|}
\hline Autor & $\begin{array}{r}\text { Pesquisa } \\
\end{array}$ \\
\hline $\begin{array}{l}\text { Mingers e Xu } \\
\quad(2010)\end{array}$ & $\begin{array}{l}\text { Os autores investigaram o comportamento das citações de } 696 \text { artigos publicados } \\
\text { em seis revistas de gestão, no ano de } 1990 \text {. A coleta do número de citações foi } \\
\text { realizada em julho de } 2008 \text { no Web of Science. A análise foi feita por meio de } \\
\text { regressão binomial negativa. Os percentuais de não-citação foram de } 4,5 \% \text { a } 22,7 \% \text {. } \\
\text { O artigo registrou o impacto das variáveis Número de autores, Número de } \\
\text { publicações do primeiro autor no WoS, Ranking da instituicão na The Times Higher } \\
\text { Education, Nacionalidade do primeiro autor, Número de palavras no título, Número } \\
\text { de referências, Número de páginas, Número de palavras-chave, Linha de pesquisa, } \\
\text { Tipo de artigo e } \\
\end{array}$ \\
\hline $\begin{array}{c}\text { Vanclay } \\
(2013)\end{array}$ & $\begin{array}{l}\text { O autor investigou o comportamento das citações de } 131 \text { artigos publicados por uma } \\
\text { faculdade de negócios, sobre ciências ambientais, durante } 2006 \text { e } 2007 \text {. A análise } \\
\text { foi feita por meio de correlações de Pearson e de análise de regressão linear. O } \\
\text { artigo relatou o impacto das variáveis Revista, H-índex, Número de autocitações, } \\
\text { Artigo de revisão, Número de páginas, Acesso aberto ao periódico, Ano de } \\
\text { publicação, Primeira letra do sobrenome do primeiro autor. }\end{array}$ \\
\hline $\begin{array}{l}\text { Antonakis et } \\
\text { al. (2014) }\end{array}$ & $\begin{array}{l}\text { Os autores investigaram o comportamento das citações de } 776 \text { artigos sobre } \\
\text { ciências sociais publicados na The Leadership Quarterly, entre } 1990 \text { e } 2012 \text {. A coleta } \\
\text { do número de citações se deu na base Scopus. A análise foi realizada por meio de } \\
\text { uma regressão binomial negativa inflada de zeros e incluiu as variáveis: Tipo do } \\
\text { artigo, Idade do artigo, Número de referências, Senioridade do editor, Número de } \\
\text { autores, Média do número de citações anteriores recebidas pelos autores, Média do } \\
\text { número de artigos prévios dos autores, Média do ranking da afiliação institucional } \\
\text { dos autores, Número de artigos publicados pela revista por ano, Número da edição, } \\
\text { Linha de pesquisa, Abordagem dos dados, Localização da amostra, Desenho da } \\
\text { pesquisa, Número de fonte de dados, Contexto temporal do estudo, Tipo de escala } \\
\text { utilizada. }\end{array}$ \\
\hline $\begin{array}{l}\text { Aragão et al. } \\
\qquad(2014)\end{array}$ & $\begin{array}{l}\text { Os autores analisaram o comportamento das citações de } 577 \text { artigos sobre } \\
\text { contabilidade publicados em quatro revistas, entre os anos de } 2006 \text { e } 2011 \text {. A análise } \\
\text { foi realizada por meio de teste de qui-quadrado e Anacor. Os autores analisaram o } \\
\text { impacto da Revista, Idade do artigo e Idioma. }\end{array}$ \\
\hline $\begin{array}{l}\text { Martinez- } \\
\text { Blasco et al. } \\
(2016)\end{array}$ & $\begin{array}{l}\text { Os autores analisaram o comportamento das citações dos } 134 \text { artigos publicados no } \\
\text { Spanish Journal of Finance and Accounting, entre os anos de } 2008 \text { e } 2013 \text {. A coleta } \\
\text { do número de citações ocorreu em dezembro de } 2014 \text {. A análise foi realizada por } \\
\text { meio de regressão de Poisson. As variáveis utilizadas foram: Número de páginas, } \\
\text { Posição na edição, Tipo de edição, Número de autores, Número de referências, } \\
\text { Número de publicações anteriores dos autores, Participação no conselho editorial, } \\
\text { Idade do artigo, Idioma, Método de pesquisa, Tamanho da amostra, Localização da } \\
\text { amostra, Participação no mainstream. }\end{array}$ \\
\hline $\begin{array}{l}\text { Stremersch, } \\
\text { Camacho, } \\
\text { Vanneste, e } \\
\text { Verniers } \\
(2015)\end{array}$ & $\begin{array}{l}\text { Os autores investigaram o comportamento das citações de } 659 \text { artigos de cinco } \\
\text { revistas de marketing, entre os anos de } 1990 \text { e } 2007 \text {. A coleta do número de citações } \\
\text { foi realizada no final de } 2009 \text { e início de } 2010 \text {. A análise foi feita por meio de } \\
\text { regressão binomial negativa. O artigo descreveu o impacto da Posição do artigo na } \\
\text { edição, Premiação, Número de páginas, Tipo do artigo, Linha de pesquisa, Número } \\
\text { de publicações que os autores tinham nas cinco revistas, Participação no corpo } \\
\text { editorial, Ranking da instituição na Financial Times, Centralidade, País e Número de } \\
\text { autores, Número de referências, Número de autocitação, Número de palavras no } \\
\text { título, Presença de "Marketing", "Market" e "New" no título, Número de palavras- } \\
\text { chave, Número de equações, Número de figuras, Número de tabelas, Número de } \\
\text { notas de rodapé, Número de apêndices, Facilidade de leitura. }\end{array}$ \\
\hline $\begin{array}{c}\text { Fox et al. } \\
(2016)\end{array}$ & $\begin{array}{l}\text { Os autores analisaram o comportamento das citações de } 26.088 \text { artigos publicados } \\
\text { por } 32 \text { revistas de ecologia, entre } 2009 \text { e } 2012 \text {. A coleta das citações ocorreu em } \\
\text { outubro de } 2014 \text { por meio da Web of Science. Os autores analisaram o impacto das } \\
\text { variáveis: Número de referências, Número de páginas, Número de autores. }\end{array}$ \\
\hline
\end{tabular}

Figura 4 - Pesquisas sobre fatores que impactam a quantidade de citações 
número de páginas e número de referências, a linha de pesquisa e o fator de impacto da revista.

Outras variáveis mostraram desempenho contraintuitivo em determinados casos. $\mathrm{Na}$ pesquisa de Ayres e Vars (2000), por exemplo, num estudo de três periódicos da área do Direito, o tamanho do título mostrou-se negativamente relacionado com a quantidade de citações, e nas demais pesquisas, se mostrou positivamente correlacionado com a quantidade de citações.

Nesta Tese, tentou-se englobar o máximo de variáveis possíveis para proporcionar uma análise mais ampla das quantidades de citação, embora determinadas variáveis tiveram de passar por adaptações para o contexto brasileiro. Nesse sentido, no próximo capítulo, mostra-se como a pesquisa foi desenvolvida e como as variáveis foram operacionalizadas. 


\section{PROCEDIMENTOS METODOLÓGICOS}

Nobody said it was easy

No one ever said it would be this hard

Coldplay

A seção de metodologia desta Tese aborda a população e amostra, as hipóteses de pesquisa, as variáveis da análise e as técnicas de análise empregadas.

\subsection{População e amostra}

A população observada para análise, nesta Tese, é composta pelos artigos sobre Contabilidade publicados em revistas científicas brasileiras de Contabilidade, entre os anos de 2007 e 2012. Nesse período foram publicados, pelas 36 revistas brasileiras de Contabilidade, listadas no site da Associação Nacional de Programas de PósGraduação em Contabilidade (ANPCONT) e no Blog do Nemac, no início de 2013, um total de 3.375 artigos, que foram coletados em consulta ao site de cada revista e baixados em formato Portable Document Format (.pdf).

Com base em cada edição das revistas, criou-se uma planilha eletrônica em Microsoft Excel ${ }^{\circledR}$, contendo o nome da revista, o ano, a edição e o número da publicação, além do título do artigo. Essa lista foi enviada para dois experts em pesquisa, com experiência em várias linhas de pesquisa em Contabilidade. Ambos eram mestres em Contabilidade há mais de 5 anos, e haviam apresentado mais de 60 artigos em eventos científicos e publicado mais de 35 artigos em revistas científicas, cada um.

O uso dos experts para classificar os artigos tem base no uso da técnica Delphi. Para Vergara (2015, p. 164) "o método Delphi é aquele que visa obter o consenso de opiniões de especialistas sobre o que está se investigando."

Já segundo Appolinário (2011, p. 124) o método Delphi consiste em uma "técnica de coleta de dados que pode ser considerada um tipo de entrevista não-estruturada, na qual obtém-se a opinião de um especialista reconhecido". 
Foi solicitado aos experts que respondessem as seguintes questões sobre os artigos:

São de Ciências Contábeis?

( ) $\operatorname{Sim}($ ) Não

Se são de Ciências Contábeis, em que área ele se enquadra?

( ) Controladoria e gerencial

( ) Usuários externos

( ) Mercado de capitais

( ) Educação e Pesquisa

( ) Contabilidade Pública

( ) Terceiro Setor

Esses dois especialistas classificaram, de forma independente, os 3.375 artigos quanto a pertencer à pesquisa em Contabilidade ou não. Os artigos que pertenciam à área de pesquisa Contabilidade foram classificados entre as linhas:

- Linha 1: Contabilidade gerencial e Controladoria,

- Linha 2: Contabilidade para usuários externos,

- Linha 3: Mercado de capitais,

- Linha 4: Educação e pesquisa em Contabilidade,

- Linha 5: Contabilidade pública, e

- Linha 6: Contabilidade para o terceiro setor.

Uma reunião via Skype $\AA$ com os dois experts foi realizada, em 16 de janeiro de 2016, para alinhar o entendimento dos critérios que seriam utilizados para classificar o artigo em cada linha. A diretriz para a classificação na linha 1 era tratar de contabilidade para tomada de decisão por usuário interno; para a linha 2, a diretriz era tratar de contabilidade para tomada de decisão por usuário externo; para linha 3, tratar de mercado financeiro; para linha 4 , era ser pesquisa sobre questões didáticopedagógicas, epistemológicas e metodológicas, incluindo estudos bibliométricos e sociométricos; e para as linhas 5 e 6 , os artigos deveriam tratar da contabilidade pública e do terceiro setor, respectivamente. 
Sobre a classificação, o expert A disse: "Eliminei os artigos que se tratavam das áreas de marketing, propaganda, gestão do conhecimento, administração, economia. Procurei manter os artigos que se enquadram nas áreas temáticas do Congresso USP."

Já o expert B afirmou: "A classificação foi feita com base nas linhas de pesquisa da FEA por meio da análise do título, primeiramente; depois pelo resumo; e, por fim, nas palavras-chave, como complemento. Os artigos que estavam fora do escopo das linhas da (PPGCC) FEA foram classificados como não-contábeis".

As divergências sobre pertencer ou não à pesquisa em Contabilidade, e sobre a classificação entre as seis linhas foram dirimidas pelo autor desta Tese. Os arquivos dos artigos remanescentes foram abertos para a coleta dos dados das demais variáveis. As observações com dados faltantes na planilha em Microsoft Excel® foram eliminadas da análise em todas as variáveis, exceto no caso da variável "Número de termos nas palavras-chave" em que houve o preenchimento dos dados faltantes com a média calculada dos dados presentes, já que a opção, por eliminar as observações com dados faltantes nesta variável, eliminaria a Revista Brasileira de Contabilidade da amostra.

Com isso chegou-se a uma amostra final de 2.540 observações, sobre as quais todas as análises foram realizadas. A seguir são apresentadas as variáveis que constituem hipóteses utilizadas nesta Tese.

\subsection{Hipóteses de pesquisa}

Algumas hipóteses de pesquisa foram testadas, visando explicar as diferentes taxas de citação dos artigos. Essas hipóteses podem ser organizadas em agrupamentos ou dimensões (indicadas em negrito), com indicação da literatura de apoio à construção da hipótese (entre parênteses), como mostrado a seguir:

Hipóteses relacionadas à autoria do artigo: 
H1 - A quantidade de autores impacta a quantidade de citações do artigo (Ayres \& Vars, 2000; Leimu \& Koricheva, 2005; Antonakis, Bastardoz, Liu, \& Schriesheim, 2014; Martinez-Blasco, Argilés-Bosch, García-Blandón, \& Zorita, 2016; Fox, Paine, \& Sauterey, 2016);

H2 - O gênero do primeiro autor impacta a quantidade de citações do artigo (Ayres \& Vars, 2000);

H3 - A proporção de autoras impacta a quantidade de citações do artigo;

H4 - A titulação do primeiro autor impacta a quantidade de citações do artigo (Ayres \& Vars, 2000);

H5 - A afiliação institucional do primeiro autor impacta a quantidade de citações do artigo (Ayres \& Vars, 2000; Leimu \& Koricheva, 2005; Stremersch et al., 2007; Mingers $\& X u, 2010)$.

Hipóteses relacionadas às características da publicação:

H6 - A revista impacta a quantidade de citações do artigo (Leimu \& Koricheva, 2005; Judge et al., 2007; Mingers \& Xu, 2010; Vanclay, 2013; Aragão, Oliveira, \& Lima, 2014);

H7 - O tipo de edição impacta a quantidade de citações do artigo (Martinez-Blasco et al.; 2016);

H8 - O estrato do Qualis da revista impacta a quantidade de citações do artigo;

H9 - A idade da revista impacta a quantidade de citações do artigo;

H10 - A posição do artigo na edição impacta a quantidade de citações do artigo (Ayres \& Vars, 2000; Judge et al., 2007; Stremersch et al., 2007). 
H11 - O número de termos no título impacta a quantidade de citações do artigo (Ayres \& Vars, 2000);

H12 - O número de termos nas palavras-chave impacta a quantidade de citações do artigo (Stremersch et al., 2007; Mingers \& Xu, 2010; Stremersch, Camacho, Vanneste, \& Verniers, 2015);

H13 - O número de páginas impacta a quantidade de citações do artigo (Ayres \& Vars, 2000; Leimu \& Koricheva, 2005; Judge et al., 2007; Stremersch et al., 2007; Mingers \& Xu, 2010; Vanclay, 2013; Fox et al., 2016);

H14 - O número de referências impacta a quantidade de citações do artigo (Judge et al., 2007; Stremersch et al., 2007; Mingers \& Xu, 2010; Antonakis et al., 2014; Fox et al., 2016);

H15 - A linha de pesquisa do artigo impacta a quantidade de citações do artigo (Ayres \& Vars, 2000; Stremersch et al., 2007; Antonakis et al., 2014; Stremersch et al., 2015); e,

H16 - A abordagem da análise de dados impacta a quantidade de citações do artigo (Antonakis et al., 2014).

Essas são as hipóteses estudadas com o objetivo de compreender as diferentes distribuições de citações entre os artigos. A literatura que as suporta é discutida, na sequência, no capítulo de revisão da literatura.

Fávero (2015) afirma que o uso de muitas variáveis explicativas depende dos estudos predecessores e da experiência e do bom senso do pesquisador. $O$ autor desta Tese defende que todas as características relacionadas a autoria do artigo, da publicação e do artigo em si influenciam a probabilidade de um artigo ser citado, em maior ou menor grau, mesmo porque a maioria das hipóteses de pesquisa derivam de pesquisas realizadas no exterior, compondo parte da literatura revisada. E, ainda, há 
hipóteses que o autor escolheu testar, com base em sua experiência na realização de pesquisas bibliométricas e sociométricas, com periódicos de Contabilidade no Brasil.

\subsection{As variáveis da análise}

A variável dependente desta Tese é o número de citação de cada artigo. Como não existe, atualmente, nenhum repositório que cubra a totalidade das revistas de Contabilidade brasileiras, a alternativa viável para identificar a quantidade de citações dos artigos foram os buscadores Microsoft Academic Search $®$ e o Google Acadêmicoß.

O buscador Google Acadêmico, segundo a definição da própria empresa,

[...] fornece uma maneira simples de pesquisar literatura acadêmica de forma abrangente. Você pode pesquisar várias disciplinas e fontes em um só lugar: artigos revisados por especialistas (peer reviewed), teses, livros, resumos e artigos de editoras acadêmicas, organizações profissionais, bibliotecas de pré-publicações, universidades e outras entidades acadêmicas. O Google Acadêmico ajuda a identificar as pesquisas mais relevantes do mundo acadêmico (Google Acadêmico, 2015).

Segundo o Google, a ferramenta funciona da seguinte forma:

O Google Acadêmico classifica os resultados de pesquisa segundo a relevância. Como na pesquisa da web com o Google, as referências mais úteis são exibidas no começo da página. A tecnologia de classificação do Google leva em conta o texto integral de cada artigo, o autor, a publicação em que o artigo saiu e a frequência com que foi citado em outras publicações acadêmicas (Google Acadêmico, 2015).

As pesquisas de Jacso (2005a), Jacso (2005b), Noruzi (2005), Pauly e Stergiou (2005), Bakkalbasi, Bauer, Glover e Wang (2006), Kousha e Thelwall (2007), Meho e Yang (2007), Schroeder (2007), Bar-llan (2008), Kousha e Thelwall (2008), Bornmann et al. (2009), Kulkarni, Aziz, Shams, e Busse (2009), Martell (2009), Onyancha (2009), Bar-llan (2010), García-Perez (2010), Mingers e Lipitakis (2010), Sanni e Zainab (2010), Sember, Marijan e Petrak (2010), Amara e Landry (2012), Bergman (2012), Harzing (2013), Delgado-López-Cózar e Cabezas-Clavijo (2013), Chan, Chang e Chang (2013), Ortega e Aguillo (2014) constituem uma literatura que analisa a capacidade de recuperação de citações do Google Acadêmico $®$ em diversas áreas e

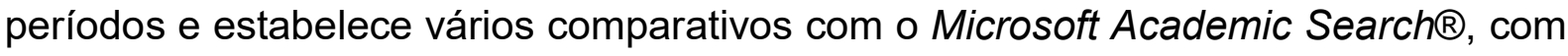
o Web of Science® (WoS) e com a Scopus ${ }$. 
Em resumo, esses trabalhos identificam que a Web of Science e a Scopus são mais seguras que o Google Acadêmico. Contudo, o Google Acadêmico tem demonstrado uma capacidade de recuperação de citações mais ampla que as outras bases, considerando que não identifica citações tão somente em outros artigos cadastrados dentro da base, como no caso da WoS e Scopus, mas abrange também as citações em teses, dissertações e monografias, artigos em anais de eventos científicos e outros documentos online. Os achados de cada uma das pesquisas antes relacionadas estão apresentados no Apêndice A deste estudo.

Há que se levar em consideração que o Google Acadêmico foi lançado em novembro de 2004 e, desde então, tanto a interface do sítio eletrônico quanto o algoritmo de buscas passaram por melhorias, o que é corroborado pela existência de maior número de críticas negativas nos anos de 2005 a 2007 e críticas mais favoráveis a partir de 2008. A implementação do Google Scholar Citations $®$, em novembro de 2011, e do Google Scholar Metrics $®$, em abril de 2012, também pode ter contribuído para a melhoria do algoritmo como métrica para citações.

Harzing e Van der Wal (2007) afirmam que os G-índex, H-índex e Fator de Impacto, apurados pelos Google Scholar, guardam fortíssimas correlações com o Journal Citation Reports (JCR), apurado pela ISI Web of Knowledge, e que esse fato permite que o Google Acadêmico democratize a análise das citações, independente dos recursos financeiros das instituições ao redor do mundo.

A coleta no número de citações utilizadas nesta Tese deu-se por meio de consulta realizada ao Google Acadêmico, durante o mês de abril de 2016. No entanto, três outras coletas exploratórias já haviam sido realizadas em abril de 2014, abril de 2015 e julho de 2015. As duas coletas inicias, inclusive, comportavam apenas as revistas mantidas por programas de pós-graduação em controladoria e contabilidade.

Woodridge (2010) alerta que é importante o pesquisador familiarizar-se com qualquer conjunto de dados, acrescentando que, se o próprio pesquisador fizer a entrada dos dados, deverá, consequentemente, saber tudo sobre eles. A consulta utilizou o

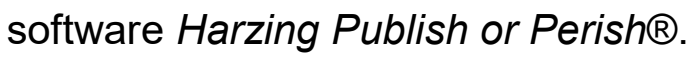


As variáveis utilizadas na análise englobam variáveis quantitativas e qualitativas. As variáveis quantitativas utilizadas foram:

- Número de termos no título do artigo,

- Número de termos nas palavras-chave do artigo,

- Número de páginas,

- Número de referências,

- Número de autores,

- Proporção de autoras,

- Idade da revista no ano que o artigo foi publicado, e

- Idade do artigo.

O número de termos no título do artigo e o número de termos nas palavras-chave do artigo foram identificados com o uso do aplicativo online Webxtoo/ $\AA$, que fez a contagem das palavras. $\mathrm{O}$ título e as palavras-chave foram copiados do arquivo do artigo e colados no campo específico do sítio eletrônico, e o número correspondente foi registrado na planilha. Os valores possíveis dessas variáveis, teoricamente, eram de $1 \mathrm{a}+\infty$. No entanto, como a Revista Brasileira de Contabilidade não utiliza palavras-chave, houve ocorrência de dados faltantes. A média de termos nas palavras-chave das demais 35 revistas foi utilizada para preencher os dados faltantes dessa revista. A média nas palavras-chave de cada artigo era 7 termos.

O número de páginas do artigo foi obtido abrindo todos os arquivos em pdf no programa Adobe Acrobat Reader $\AA$, que informa, em sua interface principal, quantas páginas o arquivo possui. Os valores possíveis dessa variável eram de $1 \mathrm{a}+\infty$.

O número de autores total e o número de referências foram obtidos por meio de contagem. Os valores possíveis para o número de autores eram de $1 \mathrm{a}+\infty$.

Já os valores possíveis para o número de referências eram de $0 \mathrm{a}+\infty$, porque, embora não seja usual, um artigo não precisa necessariamente ter alguma referência. De fato, houve a ocorrência de um artigo que não possuía nenhuma referência. 
A proporção de autoras foi obtida por meio da contagem de autores mulheres e dividido esse valor pelo número total de autores do artigo. Considerando que o número de autores variava de 1 a 6 e que em todos eles poderia haver diferentes quantidades de autores mulheres, os possíveis valores para essa variável eram $0 ; 0,16 ; 0,20 ; 0,25$; 0,$33 ; 0,40 ; 0,50 ; 0,60 ; 0,66 ; 0,75 ; 0,80$ e 1.

A idade da revista foi calculada com base no ano da mais antiga edição disponível online da revista, mesmo que tenha havido mudança de nome do periódico no período, subtraída do ano de publicação do artigo. Assim, a idade da revista registrada para um artigo publicado na Revista Contabilidade \& Finanças, em 2007, levou em consideração não apenas o período de 2001 a 2007, em que a revista possuía essa denominação, mas também os 12 anos de existência com a denominação de Caderno de Estudos. Os valores possíveis para essa variável eram de 0 a 23 , que eram os artigos publicados no mesmo ano que a revista foi criada até os artigos publicados, em 2012, na Revista Contabilidade \& Finanças e na Contabilidade Vista \& Revista.

Já a idade do artigo foi calculada subtraindo o ano em que o artigo foi publicado do ano de 2016, que foi o ano da coleta de dados usados nas análises. Os possíveis valores que essa variável podia assumir eram de 4 a 9 , que eram os artigos publicados de 2007 a 2012. A idade da revista e a idade do artigo foram calculadas automaticamente, pelo Microsoft Excel®.

Por sua vez, as variáveis independentes utilizadas nesta pesquisa foram:

- Revista,

- Tipo de edição,

- Posição do artigo,

- Gênero do primeiro autor,

- Titulação acadêmica do primeiro autor,

- IES do primeiro autor,

- Linha de pesquisa,

- Estrato do Qualis vigente no ano em que o artigo foi publicado, e

- Abordagem na análise de dados. 
As revistas utilizadas nesta pesquisa foram as encontradas na lista publicada no sítio eletrônico da Anpcont e no Blog do Nemac, no início de 2013. Atualmente, existem mais revistas listadas nesses sítios eletrônicos, entre elas revistas que já existiam durante o triênio 2010-2012, mas que não haviam sido identificadas nem por esses sítios eletrônicos nem pela tabela de periódicos do Qualis.

A Figura 5 elenca as revistas da amostra desta pesquisa, por idade. Na Figura, apresentam-se, ainda, a instituição que mantém a revista e a sigla utilizada na base de dados, considerando que os softwares SPSS e Stata limitam o número de caracteres e não reconhecem caracteres como espaços entre palavras, os quais foram substituídos por subtraços.

\begin{tabular}{|c|c|c|c|}
\hline Revista & Instituição & Ano & Sigla \\
\hline Revista de Contabilidade \& Finanças & USP & 1989 & RC\&F \\
\hline Contabilidade Vista \& Revista & UFMG & 1989 & CVR \\
\hline Contabilidade, Gestão e Governança & UNB & 1998 & CGG \\
\hline Revista Brasileira de Contabilidade & CFC & 1999 & RBC \\
\hline Revista Catarinense da Ciência Contábil & CRC SC & 2001 & Catarinense_CC \\
\hline ConTexto & UFRGS & 2001 & Contexto \\
\hline Revista de Contabilidade do Mestrado em Ciências Contábeis & UERJ & 2003 & RCMCC \\
\hline Contextus & UFC & 2003 & Contextus \\
\hline Revista Eletrônica de Contabilidade & UFSM & 2004 & R_Elet_Cont \\
\hline Revista Contemporânea de Contabilidade & UFSC & 2004 & RCC_UFSC \\
\hline Pensar Contábil & CRC RJ & 2004 & Pensar \\
\hline Brazilian Business Review & FUCAPE & 2004 & BBR \\
\hline BASE & UNISINOS & 2004 & Base \\
\hline Revista Universo Contábil & FURB & 2005 & RUC \\
\hline Revista Brasileira de Gestão de Negócios & FECAP & 2005 & RBGN \\
\hline Enfoque: Reflexão Contábil & UEM & 2005 & Enfoque \\
\hline Custos e @gronegócio online & UFRPE & 2005 & Custos_e_@agro \\
\hline Sociedade, Contabilidade e Gestão & UFRJ & 2006 & SCG \\
\hline CAP Accounting and Management & UTFPR & 2006 & CAP \\
\hline ABCustos & $A B C$ & 2006 & ABCustos \\
\hline Revista de Informação Contábil & UFPE & 2007 & RIC \\
\hline Revista de Educação e Pesquisa em Contabilidade & CFC & 2007 & REPEC \\
\hline Revista de Contabilidade e Organizações & USP/RP & 2007 & RCO \\
\hline Revista de Contabilidade da UFBA & UFBA & 2007 & RC_UFBA \\
\hline RACE: Revista de Administração, Contabilidade e Economia & UNOESC & 2007 & RACE \\
\hline Advances in Scientific and Applied Accounting & ANPCONT & 2008 & ASAA \\
\hline Revista de Contabilidade e Controladoria & UFPR & 2009 & RCC_UFPR \\
\hline Revista de Administração e Contabilidade da FAT & FAT & 2009 & RAC_FAT \\
\hline Revista Ambiente Contábil & UFRN & 2009 & Amb_Cont \\
\hline Revista de Estudos Contábeis & UEL & 2010 & R_Est_Cont \\
\hline Registro Contábil & UFAL & 2010 & Recont \\
\hline $\begin{array}{l}\text { RACEF - Revista de Administração, Contabilidade e Economia } \\
\text { da FUNDACE }\end{array}$ & FUNDACE & 2010 & RACEF \\
\hline Revista de Gestão, Finanças e Contabilidade & UNEB & 2011 & RGFC \\
\hline $\begin{array}{l}\text { Reunir: Revista de Administração, Contabilidade e } \\
\text { Sustentabilidade }\end{array}$ & UFCG & 2011 & Reunir \\
\hline
\end{tabular}




\begin{tabular}{|l|l|l|l|}
\hline \multicolumn{1}{|c|}{ Revista } & Instituição & \multicolumn{1}{c|}{ Ano } & \multicolumn{1}{c|}{ Sigla } \\
\hline Revista Razão Contábil \& Finanças & FATE & 2012 & Razao \\
\hline REAVI - Revista Eletrônica do Alto Vale do Itajaí & UDESC & 2012 & REAVI \\
\hline
\end{tabular}

Figura 5 - Revistas da Amostra por Instituição, Ano e Sigla

Os artigos são publicados em dois tipos de edição, para as quais foram adotadas as denominações de ordinária e especial. As edições ordinárias são as edições comuns que seguem o processo normal de editoração e avaliação das revistas. As edições especiais são as edições em que pode haver alterações do processo normal de editoração, como a editoria de um editor convidado ou a chamada de artigos para um tema específico.

$\mathrm{Na}$ amostra analisada, cinco periódicos apresentaram edições especiais. A Revista Contabilidade \& Finanças apresentou um número especial em 2007, em que apresentou um editorial chamado "30 anos de doutorado em contabilidade", assinado pelos professores Eliseu Martins e Sérgio de ludícibus. Essa edição publicou um total de nove artigos, sendo que o primeiro artigo da edição foi de autoria de Sérgio de ludícibus e Eliseu Martins, intitulado "Uma investigação e uma proposição sobre o conceito e o uso do valor justo". Esse artigo teve 66 citações até abril de 2016, e era - $9^{\circ}$ mais citado de toda a amostra. O segundo artigo dessa edição, de autoria de Ivam Ricardo Peleias, Glauco Peres da Silva, João Bosco Segreti e Amanda Russo Chirotto, tem por título: "Evolução do ensino da contabilidade no Brasil: uma análise histórica", e foi citado 111 vezes até abril de 2016, o que o torna o artigo mais citado de todos os artigos da amostra. A média de citações dos artigos dessa edição foi 39, sendo que o artigo escrito em português com menor número de citações teve 15 citações. Curiosamente, o único artigo publicado em inglês, nessa edição, teve apenas uma citação.

Observa-se que edições especiais não são incomuns na Revista Contabilidade \& Finanças, que publicou quatro números especiais entre 2003 e 2006, e uma edição especial em 2014, tendo apenas esta última estabelecido uma chamada temática, que foi sobre "História da contabilidade". 
A Revista de Contabilidade do Mestrado em Ciências Contábeis da UERJ publicou uma edição especial, em 2012, com a temática "Contabilidade Socioambiental" e teve o professor José Paulo Cosenza como editor convidado.

A revista Sociedade, Contabilidade e Gestão publicou edições especiais em 2010 e 2011, com os melhores trabalhos apresentados no I e II Congresso Nacional de Administração e Ciências Contábeis - AdCont. Embora o editorial dessas edições especiais explique que elas eram decorrentes da realização do AdCont, nos anos seguintes, até 2016, não houve outra edição especial, mesmo tendo o evento chegado em sua sétima edição.

A Revista de Educação e Pesquisa em Contabilidade publicou uma edição especial em 2011, em comemoração aos cinco anos de criação da revista. Já a revista Custos e @gronegócio online apresentou edições especiais em maio de 2008 e novembro de 2012, sem, contudo, indicação de chamada temática de trabalhos ou alterações no processo editorial. As edições especiais foram marcadas com "Especial", e as edições comuns foram marcadas como "Ordinária".

A posição dos artigos dentro da edição foi uma variável simples de ser operacionalizada. Cada artigo apresentado como o primeiro da lista da edição foi marcado como "Primeiro", e os demais foram marcados como "Outro".

Por outro lado, o gênero do primeiro autor não foi tão simples. Inicialmente, a classificação foi feita por meio da leitura do nome do primeiro autor. Nomes como José e Maria eram de fácil classificação. O problema foi a classificação de nomes andrógenos, como Joisse e Sidney, e nomes estrangeiros, como Jiri, por exemplo. Nesses casos, procedeu-se a uma busca na Plataforma Lattes pelo nome completo do autor. Quando o autor não possuía currículo cadastrado na Plataforma Lattes, procedeu-se à busca no Google. E quando não foi possível identificar com segurança o gênero no autor, a observação foi eliminada da amostra. O gênero foi dividido entre homem e mulher.

A identificação da titulação do primeiro autor também foi bastante complexa, pois, embora a grande maioria das revistas identifique essa informação logo após o nome 
do autor, nem todas o fazem. Nesses casos, procedeu-se a uma busca pelo currículo Lattes do autor para identificar a titulação que ele possuía no ano de publicação do artigo. Quando a Plataforma Lattes não esclarecia esse ponto, procedeu-se a buscas no Google e quando esta não foi suficiente para o esclarecimento, a observação foi eliminada.

Há que se registrar, ainda, que os dados originais, os quais compreendiam as categorias "graduando", "aluno de graduação", "acadêmico do curso de", "bacharelando", "bacharel", "contador", "administrador", "especialista", "especializando", "aluno de especialização", "aluno de pós-graduação", "mestrando", "aluno de mestrado", "mestre", "doutorando", "aluno de doutorado", "doutor”, "pósdoutorando", "pós-doutor", "livre-docente" e "professor titular", passaram por uma recategorização.

A reclassificação foi feita com a seguinte diretriz: autores que já concluíram o doutorado foram reclassificados como "doutor" (incluíram-se aqui as categorias doutor, pós-doutorando, pós-doutor, livre-docente, professor titular); autores que já concluíram o mestrado, mas não o doutorado, foram reclassificados como "mestre" (incluindo-se aqui as categorias mestre, doutorando, aluno de doutorado); autores que já concluíram a graduação, mas não o mestrado, foram reclassificados como "bacharel" (incluíram-se aqui as categorias bacharel, contador, administrador, especialista, especializando, aluno de especialização, aluno de pós-graduação, mestrando, aluno de mestrado); e os alunos que não concluíram a graduação foram classificados como "graduando".

A instituição de ensino superior do primeiro autor teve coleta semelhante às duas variáveis anteriores. Iniciou-se utilizando a instituição declarada pelo autor no artigo. Um problema nessa variável foi que alguns autores indicavam duas ou mais instituições, normalmente aquela em que cursaram o doutorado e/ou mestrado e aquela em que atuavam como docentes (instituição de vínculo). De fato, isso aconteceu com maior frequência numérica com quem fez doutorado na USP e atuava em outras instituições. 
Diante disso, a opção metodológica adotada nesta Tese foi marcar a primeira instituição indicada pelo autor, visto que a alternativa seria separar a classificação da IES de formação da classificação da IES de atuação; além disso, há os casos que os autores não identificam o tipo de vínculo, os casos em que só há o vínculo de formação, e há os casos que só há o vínculo de atuação, de modo que a amostra seria subdividida em subgrupos numericamente inferiores.

Sobre a afiliação institucional, quando a IES indicada pelo autor possuía um programa de pós-graduação stricto sensu em Contabilidade, a marcação foi feita com o nome da instituição, e quando não possuía essa informação, a marcação foi feita numa categoria agrupada denominada Outro. A Figura 6 mostra as opções registradas.

\begin{tabular}{|l|l|}
\hline \multicolumn{1}{|c|}{ Instituição de ensino superior } & \multicolumn{1}{c|}{ Sigla } \\
\hline Fundação Escola de Comércio Álvares Penteado & FECAP \\
\hline Fundação Instituto Capixaba de Pesquisas em Contabilidade, Economia e Finanças & FUCAPE \\
\hline Fundação Universidade Regional de Blumenau & FURB \\
\hline Outras instituições & OUTRO \\
\hline Pontifícia Universidade Católica de São Paulo & PUCSP \\
\hline Universidade do Estado do Rio de Janeiro & UERJ \\
\hline Universidade Federal da Bahia & UFBA \\
\hline Universidade Federal do Espírito Santo & UFES \\
\hline Universidade Federal de Minas Gerais & UFMG \\
\hline Universidade Federal da Paraíba & UFPB \\
\hline Universidade Federal de Pernambuco & UFPE \\
\hline Universidade Federal do Paraná & UFPR \\
\hline Universidade Federal do Rio de Janeiro & UFRJ \\
\hline Universidade Federal do Rio Grande do Norte & UFRN \\
\hline Universidade Federal de Santa Catarina & UFSC \\
\hline Universidade de Brasília & UNB \\
\hline Universidade do Vale do Rio dos Sinos & UNISINO \\
\hline Universidade Presbiteriana Mackenzie & S \\
\hline Universidade de São Paulo & UPM \\
\hline Universidade de São Paulo Ribeirão Preto & USP \\
\hline
\end{tabular}

Figura 6 - Instituição de ensino superior do primeiro autor e sigla

Um fato incomum observado foi a indentificação que alguns autores fizeram de sua afiliação institucional com o Programa Multi-institucional e Inter-regional de PósGraduação em Ciências Contábeis - UnB/UFPB/UFRN. Esses casos foram classificados como pertencentes à categoria UNB.

A classificação das revistas brasileiras de Contabilidade no Qualis, vigente nos triênios de 2007-2009 e 2010-2012, era possível em oito categorias: A2, B1, B2, B3, B4, B5, 
C e Não classificado - NC. Das 36 revistas da amostra, apenas sete (RACEF, REAVI, RGFC, Razão Contábil, Recont, Reunir e Revista de Estudos Contábeis) foram classificadas em apenas um estrato, e, nesses sete casos, isso ocorreu porque elas não existiam no triênio 2007-2009. As demais revistas tiveram mais de uma classificação durante o período analisado, sendo isso também levado em consideração nas análises.

A variável abordagem de dados foi dividida entre artigos com abordagem quantitativa e não-quantitativa. A escolha por essa classificação deve-se à hipótese de que o emprego de métodos quantitativos na análise dos dados impacta positivamente em relação aos métodos qualitativos. No entanto, parece não haver uma fronteira claramente delimitada entre método quantitativo e método qualitativo, o que se observa, segundo Goode e Hatt (1979), é um continuum entre esses dois polos.

Essa variável foi coletada por meio de informações identificadas dentro dos artigos. A quase totalidade dos artigos da amostra classificava a pesquisa em exploratória, descritiva ou explicativa. Na sequência, a maioria dos artigos identificava a técnica empregada na análise dos dados como, por exemplo: análise de regressão, análise de séries temporais, etnografia, grounded theory, análise de conteúdo, análise do discurso etc. Essas foram as técnicas marcadas na planilha e que, posteriormente, foram categorizadas entre pesquisas quantitativas ou não-quantitativas. Todas as técnicas estatísticas, como regressões, análise de agrupamentos, análise de correspondência, testes de hipóteses e similares, foram tratadas como abordagem quantitativa. Análise de conteúdo, estudos de caso, análise de discurso e similares foram classificadas como abordagem não-quantitativa.

Por opção metodológica deste pesquisador, pesquisas que se ativeram ao emprego de estatísticas descritivas, como mínimo, máximo, moda e medidas-resumo como média, desvio-padrão, variância e percentual, foram classificadas como abordagem não-quantitativa. Tomou-se essa medida visto que pesquisas qualitativas podem empregar essas informações e, ainda assim, a análise permanecer essencialmente qualitativa. Além de que, se a presença de estatísticas descritivas fosse causa suficiente para o artigo ser considerado de abordagem quantitativa, então grande parte das pesquisas seria classificada como quantitativa, inviabilizando a tentativa de 
medir o efeito do uso de métodos quantitativos pela desproporcionalidade das amostras.

\subsection{Procedimentos de análise empregados}

Nesta Tese, foram empregadas estatísticas descritivas, principalmente a média, o desvio-padrão, a moda, mediana, o mínimo e máximo, e os percentis das variáveis.

Utilizou-se o teste Kolmogorov-Smirnov para testar a normalidade das distribuições. Segundo Fávero, Belfiori, Silva e Chan (2009, p. 112), "o teste de KolmogorovSmirnov é um teste de aderência que compara a distribuição de frequência de um conjunto de valores observados da amostra com uma distribuição esperada ou teórica", no caso, distribuição normal.

Os testes Kruskal-Wallis e Mann-Whitney foram usados para testar as diferenças de médias entre as categorias. Segundo Fávero et al. (2009, p. 176), "O teste KruskalWallis verifica a probabilidade de que $k$ amostras $(k>2)$ independentes sejam provenientes da mesma população" e deve ser aplicado quando a suposição de normalidade não for atendida. Segundo os autores, para $k=2$, o teste de KruskalWallis é equivalente ao teste Mann-Whitney.

Nesta Tese, foi empregado o coeficiente de correlação linear de Pearson para identificar associações entre as variáveis quantitativas, e o teste de qui-quadrado para testar se havia associação entre as variáveis qualitativas.

Para Cooper e Schindler (2016, p. 473), "o coeficiente de correlação de Pearson varia de +1 , passando por 0 , até -1 [...] e revela a magnitude e a direção das relações." Segundo Fávero et al. (2009, p. 149), "o teste de qui-quadrado pode ser utilizado como uma extensão do teste binomial e é aplicado em uma amostra em que a variável nominal assume duas ou mais categorias. O teste compara as frequências observadas e esperadas em cada categoria".

A análise de correspondência (Anacor) foi utilizada para identificar a proximidade das categorias das variáveis qualitativas. Para Fávero et al. (2009, p. 272), a análise de 
correspondência é uma técnica de "interdependência que busca estudar a relação entre variáveis qualitativas, permitindo ao pesquisador a visualização de associações, por meio de mapas perceptuais que oferecem uma noção de proximidade [...] das categorias das variáveis não-métricas".

A regressão binomial negativa foi utilizada para identificar o quanto as variáveis explicativas influenciam o número de citações de um artigo. O procedimento stepwise foi empregado para eliminar as variáveis e dummies que não fossem estatisticamente significantes em um nível de significância de 5\%. A taxa de incidência estimada (irr incidence rate ratio) foi apresentada em percentual, em todas as variáveis que sobreviveram ao procedimento stepwise.

Fávero (2015, p. 198) explica que os modelos de regressão binomial negativa "são enquadrados nos chamados modelos de regressão de dados de contagem, sendo apropriados para estimação quando a variável dependente for quantitativa e com valores inteiros e não negativos [...] e quando houver superdispersão dos dados". Para Fávero et al. (2009, p. 365), o procedimento stepwise é frequentemente utilizado quando "o pesquisador deseja avaliar a significância estatística dos parâmetros de determinadas variáveis explicativas por meio da inclusão passo a passo apenas daquelas que se mostraram relevantes a determinado nível de confiança [...] e é bastante útil quando o pesquisador quer considerar um número grande de variáveis explicativas". Fávero (2015) explica, ainda, que a irr permite identificar o efeito, em percentual, de quanto se altera uma variável explicativa em uma unidade, ou com a presença ou não de uma categoria qualitativa. 


\section{ANÁLISE DOS DADOS}

Emancipate yourselves from mental slavery None but ourselves can free our minds Bob Marley

\subsection{Número de citações dos artigos}

A variável de interesse desta Tese é o número de citações de cada artigo. A Tabela 1 mostra a estatística descritiva das citações. Com média de 4,85 e desvio-padrão de 8,66, o número mínimo de citações recebidas pelos artigos da amostra foi zero e o máximo foi 111.

Tabela 1 - Estatística descritiva da variável citação
\begin{tabular}{l|r}
\hline Média & 4,85 \\
\hline Erro padrão & 0,171953 \\
\hline Mediana & 2 \\
\hline Moda & 0 \\
\hline Desvio padrão & 8,666138 \\
\hline Variância da amostra & 75,10195 \\
\hline Curtose & 38,12328 \\
\hline Assimetria & 5,038486 \\
\hline Intervalo & 111 \\
\hline Mínimo & 0 \\
\hline Máximo & 111 \\
\hline Soma & 12319 \\
\hline Contagem & 2540 \\
\hline
\end{tabular}

A Tabela 2 mostra a frequência absoluta, relativa e acumulada do número de artigos com a mesma quantidade de citações. Com percentil $1=$ zero, a mediana $=2$ e o percentil $3=6$, constata-se que $27,5 \%$ dos artigos não foram citados, mesmo passados quatro anos da data de sua publicação. Também foi possível identificar que os $10 \%$ dos artigos mais citados receberam $49,9 \%$ das citações, e que $1 \%$ dos artigos mais citados recebeu $13,1 \%$ das citações. Outra interpretação interessante é a de que um artigo que contabilizou 11 citações obteve mais citações que $90 \%$ dos outros artigos veiculados no mesmo período.

Tabela 2 - Frequência absoluta, relativa e acumuladas das citações dos artigos

\begin{tabular}{|c|c|c|c|c|c|c|c|}
\hline Citações & Freq. & Percent. & Acum. & Citações & Freq. & Percent. & Acum. \\
\hline 0 & 699 & 27,52 & 27,52 & 30 & 4 & 0,16 & 97,80 \\
\hline 1 & 356 & 14,02 & 41,54 & 31 & 5 & 0,20 & 97,99 \\
\hline
\end{tabular}




\begin{tabular}{l|r|r|r}
\hline Citações & \multicolumn{1}{|c|}{ Freq. } & Percent. & Acum. \\
\hline 2 & 286 & 11,26 & 52,80 \\
\hline 3 & 244 & 9,61 & 62,40 \\
\hline 4 & 165 & 6,50 & 68,90 \\
\hline 5 & 128 & 5,04 & 73,94 \\
\hline 6 & 109 & 4,29 & 78,23 \\
\hline 7 & 93 & 3,66 & 81,89 \\
\hline 8 & 65 & 2,56 & 84,45 \\
\hline 9 & 61 & 2,40 & 86,85 \\
\hline 10 & 45 & 1,77 & 88,62 \\
\hline 11 & 35 & 1,38 & 90,00 \\
\hline 12 & 27 & 1,06 & 91,06 \\
\hline 13 & 28 & 1,10 & 92,17 \\
\hline 14 & 17 & 0,67 & 92,83 \\
\hline 15 & 18 & 0,71 & 93,54 \\
\hline 16 & 15 & 0,59 & 94,13 \\
\hline 17 & 9 & 0,35 & 94,49 \\
\hline 18 & 13 & 0,51 & 95,00 \\
\hline 19 & 12 & 0,47 & 95,47 \\
\hline 20 & 5 & 0,20 & 95,67 \\
\hline 21 & 10 & 0,39 & 96,06 \\
\hline 22 & 6 & 0,24 & 96,30 \\
\hline 23 & 5 & 0,20 & 96,50 \\
\hline 24 & 6 & 0,24 & 96,73 \\
\hline 25 & 8 & 0,31 & 97,05 \\
\hline 26 & 4 & 0,16 & 97,20 \\
\hline 27 & 5 & 0,20 & 97,40 \\
\hline 28 & 3 & 0,12 & 97,52 \\
\hline 29 & 3 & 0,12 & 97,64 \\
\hline & & & \\
\hline & & &
\end{tabular}

\begin{tabular}{l|r|r|r}
\hline Citações & \multicolumn{1}{|c|}{ Freq. } & Percent. & \multicolumn{1}{c}{ Acum. } \\
\hline 32 & 5 & 0,20 & 98,19 \\
\hline 33 & 1 & 0,04 & 98,23 \\
\hline 34 & 4 & 0,16 & 98,39 \\
\hline 35 & 4 & 0,16 & 98,54 \\
\hline 37 & 2 & 0,08 & 98,62 \\
\hline 38 & 5 & 0,20 & 98,82 \\
\hline 39 & 3 & 0,12 & 98,94 \\
\hline 41 & 1 & 0,04 & 98,98 \\
\hline 42 & 2 & 0,08 & 99,06 \\
\hline 43 & 1 & 0,04 & 99,09 \\
\hline 44 & 2 & 0,08 & 99,17 \\
\hline 45 & 1 & 0,04 & 99,21 \\
\hline 46 & 2 & 0,08 & 99,29 \\
\hline 48 & 1 & 0,04 & 99,33 \\
\hline 49 & 1 & 0,04 & 99,37 \\
\hline 50 & 1 & 0,04 & 99,41 \\
\hline 52 & 1 & 0,04 & 99,45 \\
\hline 53 & 2 & 0,08 & 99,53 \\
\hline 62 & 1 & 0,04 & 99,57 \\
\hline 63 & 1 & 0,04 & 99,61 \\
\hline 66 & 2 & 0,08 & 99,69 \\
\hline 68 & 1 & 0,04 & 99,72 \\
\hline 79 & 1 & 0,04 & 99,76 \\
\hline 84 & 1 & 0,04 & 99,80 \\
\hline 85 & 1 & 0,04 & 99,84 \\
\hline 87 & 2 & 0,08 & 99,92 \\
\hline 107 & 1 & 0,04 & 99,96 \\
\hline 111 & 1 & 0,04 & 100,00 \\
\hline & & & \\
\hline
\end{tabular}

Algumas razões, que explicam porque um artigo não é citado, vão desde a falta de visibilidade da revista e mau funcionamento do site que hospeda os artigos até a incapacidade de despertar interesse nos leitores. No entanto, mais fácil do que angariar a atenção de leitores, a ponto de ser citado por terceiros, é ser citado pelos próprios autores do artigo. A não citação dos 699 artigos implica que nem seus autores os citaram, após passados, no mínimo, quatro anos de sua publicação. Esse fato pode indicar que esses artigos se tratam de pesquisas pontuais, que não se enquadram na agenda de pesquisa dos autores, pois, se assim fosse, os próprios autores os citariam quando revisassem a literatura de seus novos trabalhos e eles teriam, no mínimo, uma citação.

Conforme ilustra a Figura 7, a distribuição de citações não segue uma distribuição normal. 


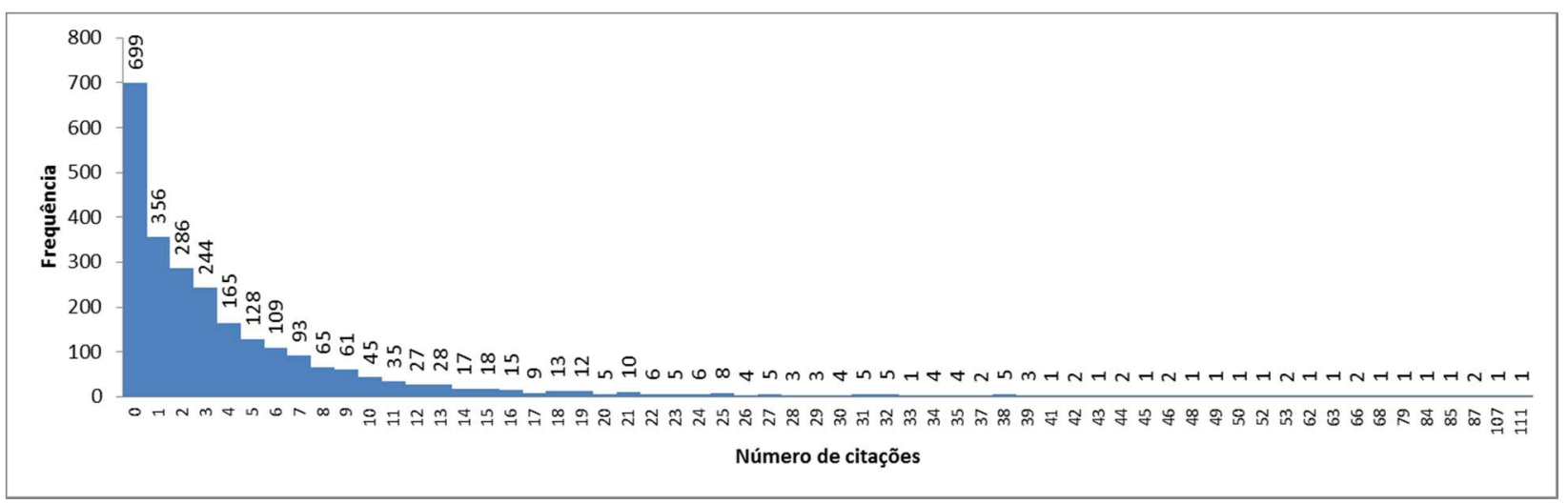

Figura 7 - Distribuição da variável citação

Trata-se de uma distribuição discreta, com dados de contagem. Segundo Fávero (2015), as regressões mais adequadas para dados de contagem são a Poisson e a Binomial negativa. No entanto, a Poisson precisa que a média e o desvio-padrão sejam valores próximos. Com média 4,85 e desvio-padrão 8,66 , pode haver um fenômeno de superdispersão, tornando o uso da regressão binomial negativa mais adequado, como será visto mais adiante.

A análise das citações envolveu variáveis qualitativas e quantitativas. As variáveis quantitativas utilizadas na análise desta Tese foram: Número de termos no título, Número de termos usados nas palavras-chave, Número de páginas, Número de referências, Número de autores, Proporção de autoria feminina, e Idade da Revista quando o artigo foi publicado.

Já as variáveis qualitativas utilizadas foram: Ano que o artigo foi publicado, Revista que o artigo foi publicado, Tipo de edição: ordinária ou especial, Posição do artigo na edição: Primeiro ou Outro, Gênero do $1^{\circ}$ autor, Titulação do $1^{\circ}$ autor, Instituição do $1^{\circ}$ autor, Área de pesquisa do artigo, estrato do Qualis da revista vigente no ano que o artigo foi publicado, e Abordagem da análise de dados: Quantitativa ou não.

\subsection{Número de palavras no título}

A literatura (Ayres \& Vars, 2000; Stremersch et al., 2007) indica que o número de palavras no título de um artigo influencia o quanto ele é citado. Para Ayres e Vars (2000), artigos com título mais curto são mais citados. Ao contrário, Stremersch, Verniers, e Verhoef (2007) acreditam que títulos mais longos, que descrevem melhor 
o conteúdo, tendem a ter mais chance de serem lidos e, consequentemente, de serem citados que artigos com títulos genéricos. Outra vantagem seria a de que artigos com títulos com mais palavras têm maior chance de serem recuperados em buscas com operadores booleanos.

Na sequência, a Tabela 3 permite visualizar a distribuição do número de palavras nos títulos dos artigos, e mostra a estatística descritiva desta variável.

Tabela 3 - Estatística descritiva do número de termos no título do artigo
\begin{tabular}{l|r}
\hline Média & 15,72401575 \\
\hline Erro padrão & 0,101685985 \\
\hline Mediana & 15 \\
\hline Modo & 14 \\
\hline Desvio padrão & 5,12481222 \\
\hline Variância da amostra & 26,26370029 \\
\hline Curtose & 0,298231156 \\
\hline Assimetria & 0,51967794 \\
\hline Intervalo & 32 \\
\hline Mínimo & 3 \\
\hline Máximo & 35 \\
\hline Soma & 39939 \\
\hline Contagem & 2540
\end{tabular}

Houve artigos com título composto de 3 a 35 palavras, sendo a média de 15,7 e o desvio-padrão de 5,12. Os artigos com títulos mais curtos intitulavam-se "Sustentabilidade e Contabilidade", "Relevância em auditoria", e "Gestão de investimentos". Com título mais longo são "O processo de criação de valor para o acionista comparado em cada nível de governança corporativa segmentado na Bovespa: um estudo com as empresas que compõem a carteira de ações do índice Brasil (IBRx 100)", "Análise da produção científica sobre os fluxos de caixa e a demonstração dos fluxos de caixa: um estudo da Revista de Contabilidade e Finanças da Universidade de São Paulo, no período de 1989 a 2009", e "As consequências, para o orçamento e contabilidade pública, da inscrição e do cancelamento de restos a pagar não processados realizados em capitais estaduais da região do nordeste do Brasil nos exercícios de 2008 e 2009".

A Figura 8 ilustra a distribuição de frequência da quantidade de termos usados nos títulos dos artigos. 


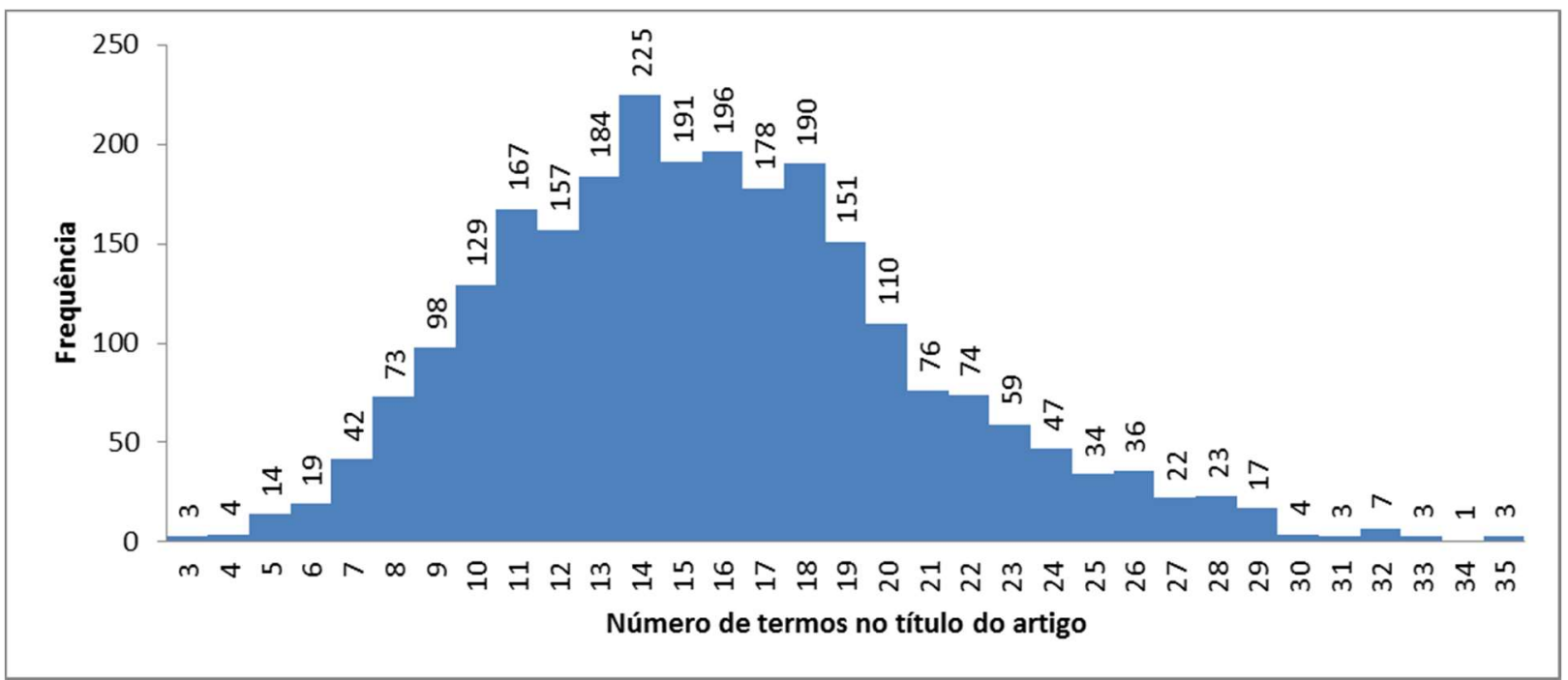

Figura 8 - Distribuição do número de termos no título do artigo

Pode se observar maior número de artigos com títulos compostos de 11 a 19 termos. O teste Kolmogov-Smirnov indica que essa não se trata de uma distribuição normal ( $p$ valor $=0,000)$.

Na Figura 9, estão apresentadas as médias de palavras usadas nos títulos dos artigos, por linha de pesquisa. 


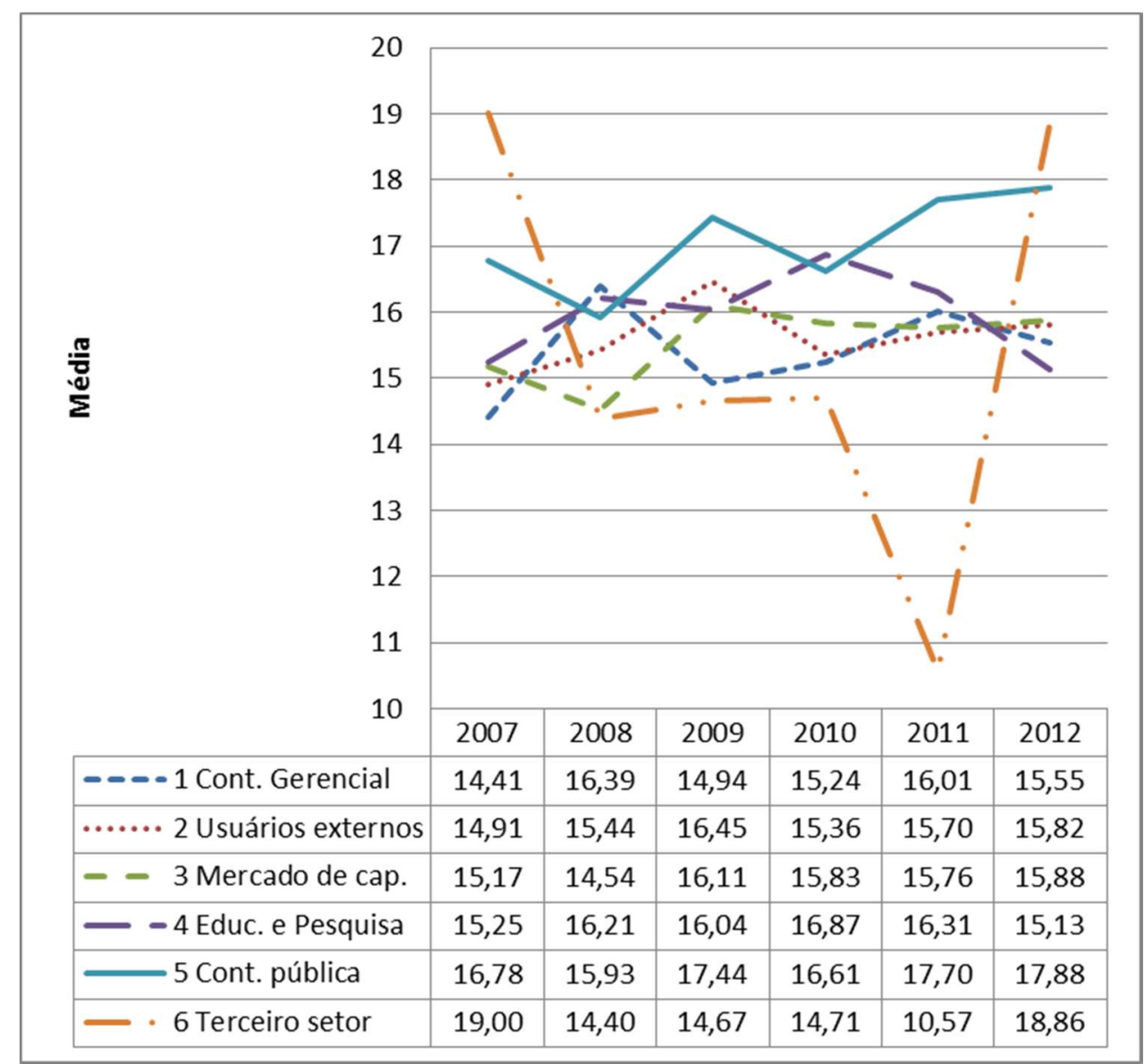

Figura 9 - Média de termos no título dos artigos por linha de pesquisa, por ano

Como se pode ver, as linhas de Contabilidade pública e Educação e pesquisa apresentam valores superiores às demais. Todas as linhas de pesquisa apresentaram uma tendência crescente da média de palavras usadas nos artigos, exceto pela linha de Contabilidade do terceiro setor, cuja tendência mostrou-se decrescente.

Meadows (1999) informa que o tamanho do título de livros e artigos sofreu uma drástica inversão desde os primórdios dos periódicos, quando os títulos dos livros eram extensos e os títulos dos artigos eram curtos. Hoje os títulos dos livros são curtos e os títulos dos artigos são cada vez mais descritivos, embora haja exceções em determinadas áreas.

\subsection{Número de termos usados nas palavras-chave}

A literatura (Stremersch et al., 2007; Mingers \& Xu, 2010; Stremersch et al., 2015) indica que o número de palavras-chave pode influenciar o quanto um artigo é citado. No entanto, optou-se, nesta Tese, por testar se o número de termos utilizados nas 
palavras-chave pode influenciar a quantidade de citações. Ou seja, se grupos de palavras-chave, que comportem mais termos descritivos do conteúdo da pesquisa, ajudam na recuperação do artigo em buscas com operadores booleanos.

Nesse sentido, a Tabela 4 mostra a estatística descritiva desta variável, obtida neste estudo.

Tabela 4 - Estatística descritiva do número de termos usados nas palavras-chave

\begin{tabular}{l|r}
\hline Média & 7,954330709 \\
\hline Erro padrão & 0,056554438 \\
\hline Mediana & 7 \\
\hline Modo & 7 \\
\hline Desvio padrão & 2,850253913 \\
\hline Variância da amostra & 8,123947366 \\
\hline Curtose & 2,569954149 \\
\hline Assimetria & 1,193024204 \\
\hline Intervalo & 21 \\
\hline Mínimo & 3 \\
\hline Máximo & 24 \\
\hline Soma & 20204 \\
\hline Contagem & 2540 \\
\hline
\end{tabular}

Com 7,95 termos, em média, por artigo e desvio-padrão de 2,85 termos, a mediana verificada foi 7 , indicando que $50 \%$ dos artigos usam até 7 termos dentro das palavraschave.

A Figura 10 mostra a distribuição de frequência do número de termos utilizados nas palavras-chave. 


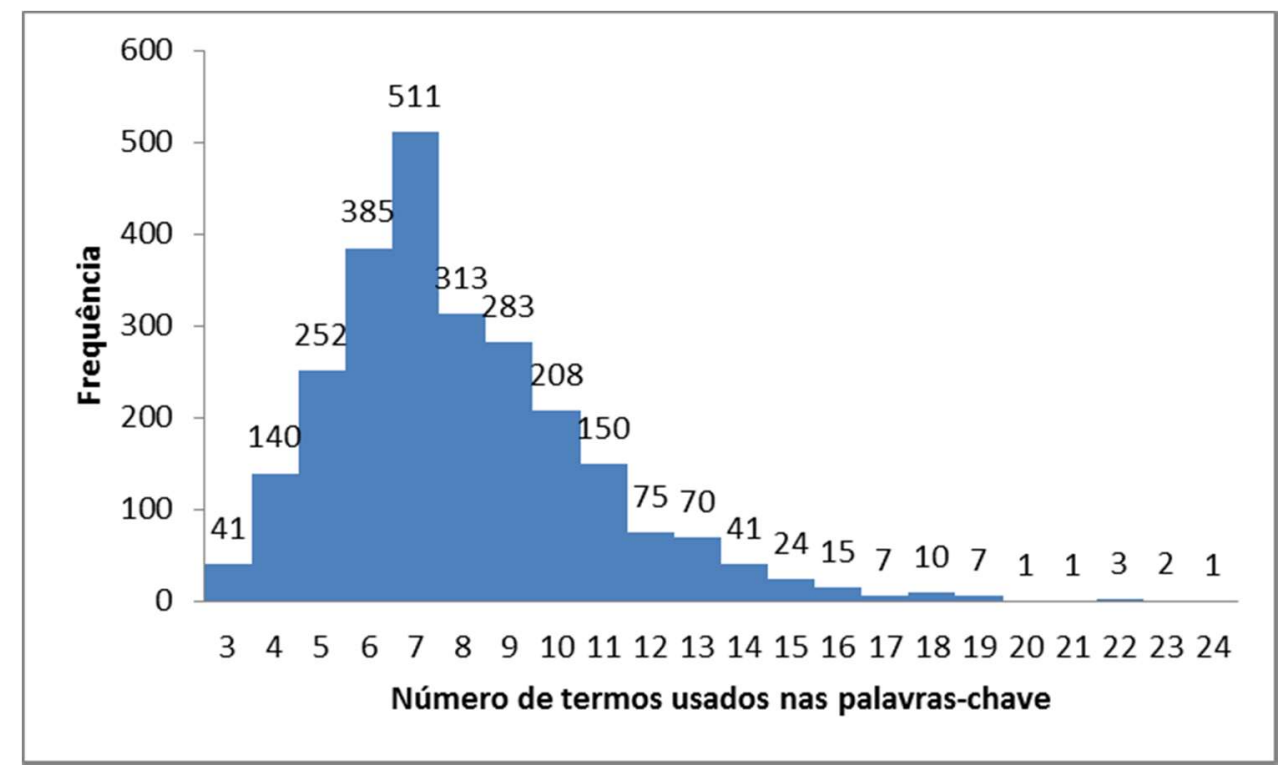

Figura 10 - Distribuição no número de termos usados nas palavras-chave

Ao contrário dos títulos, que têm média de termos maiores; as palavras-chave têm menos termos descritores. Há que se ressalvar aqui que a categoria de 7 palavrachaves está inflacionada, porque, na planilha de dados, a Revista Brasileira de Contabilidade não possuía o número de palavras-chave, e esses dados faltantes foram completados com a média das demais, que era 7. Logo, dentro dos 511 artigos com 7 palavras-chave, há 106 observações referentes à Revista Brasileira de Contabilidade.

As médias do número de termos nas palavras-chave por linha de pesquisa estão expostas na Figura 11. 


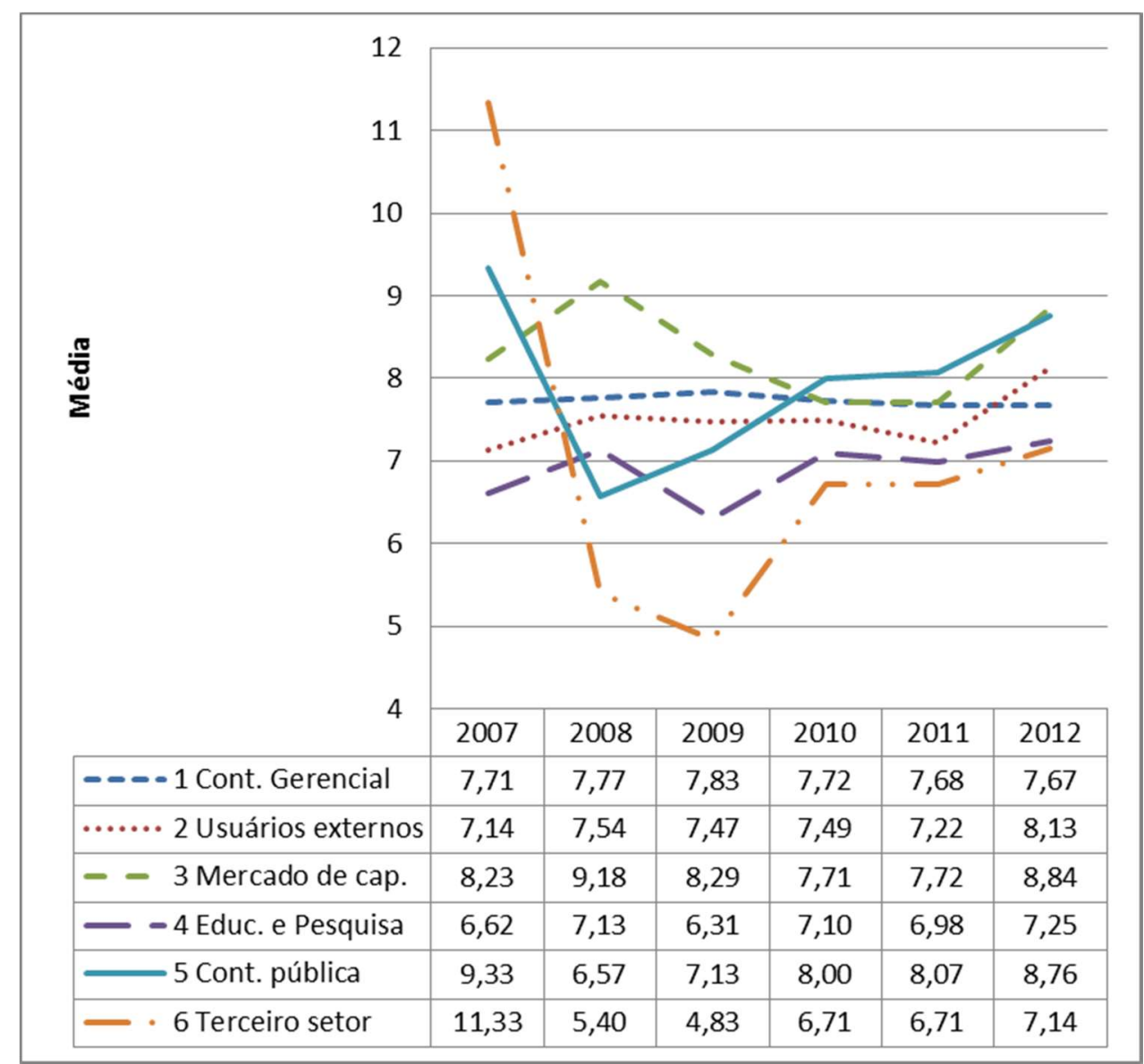

Figura 11 - Média de termos nas palavras-chave por linha de pesquisa, por ano

As médias de palavras-chave apresentaram tendência crescente nas linhas 2, Contabilidade para usuários externos; na linha 4, Educação e Pesquisa; e na linha 5, Contabilidade pública. Nas demais, as tendências foram decrescentes, sendo que na linha 1, Contabilidade gerencial, foi quase estável.

\subsection{Número de páginas}

A hipótese retirada da literatura (Ayres \& Vars, 2000; Leimu \& Koricheva, 2005; Judge et al. 2007; Stremersch et al., 2007; Mingers \& Xu, 2010; Vanclay, 2013; Fox et al., 2016) é de que artigos mais longos, normalmente, comportam revisão de literatura mais ampla ou análise de dados mais detalhada, e isso interfere no quanto ele é citado.

Na sequência, a Tabela 5 mostra a estatística descritiva desta variável, e a Figura 12 mostra a distribuição do número de páginas. 
Tabela 5 - Estatística descritiva do número de páginas dos artigos

\begin{tabular}{l|r}
\hline Média & 17,6315 \\
\hline Erro padrão & 0,106566 \\
\hline Mediana & 17 \\
\hline Moda & 16 \\
\hline Desvio padrão & 5,37074 \\
\hline Variância da amostra & 28,84485 \\
\hline Curtose & 1,962798 \\
\hline Assimetria & 0,864157 \\
\hline Intervalo & 52 \\
\hline Mínimo & 2 \\
\hline Máximo & 54 \\
\hline Soma & 44784 \\
\hline Contagem & 2540 \\
\hline
\end{tabular}

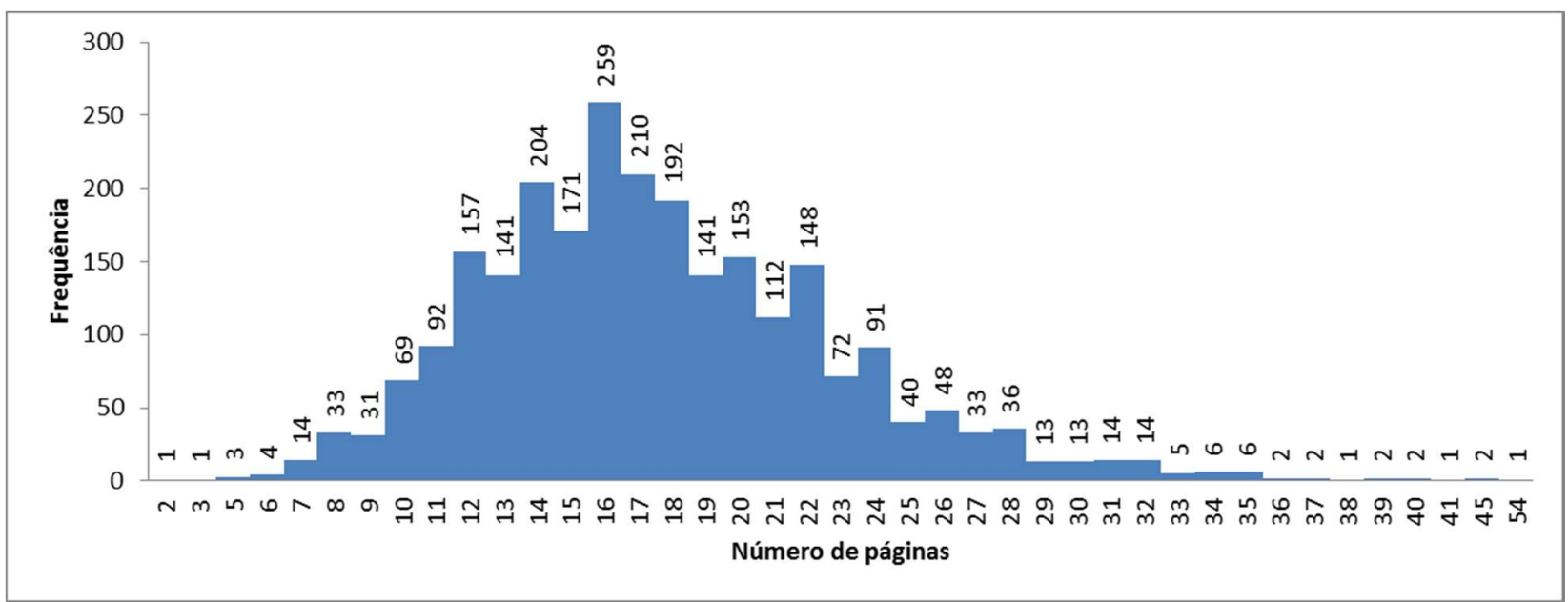

Figura 12 - Distribuição do número de páginas dos artigos

Os artigos da amostra têm, em média, 17 páginas. Isso ocorre porque a maior parte das revistas estabelece, como regra, entre 16 e 18 o limite de páginas quando se faz a submissão. A moda é 16 e a mediana 17. O menor artigo tinha apenas duas páginas, intitulava-se "Governança corporativa nas pequenas empresas", e não possuía nenhuma citação. O seguinte era um artigo com três páginas, e, na sequência, três artigos com cinco páginas, nenhum deles com citação. O maior artigo, "Gerenciamento dos custos operacionais em produtos conjuntos", tinha 54 páginas e possuía duas citações. Os artigos com 45 páginas possuíam uma e três citações, e o artigo com 41 páginas possuía duas citações.

Os percentis indicam que $25 \%$ artigos mais curtos tem até 14 páginas, $50 \%$ tem até 17 páginas, $75 \%$ tem até 21 páginas e que 90\% tem até 24 páginas. O teste Kolmogorov-Smirnov indica que não se trata de uma distribuição normal ( $p$-valor = 0,000). 
A Figura 13 mostra o número médio de páginas dos artigos por linha de pesquisa.

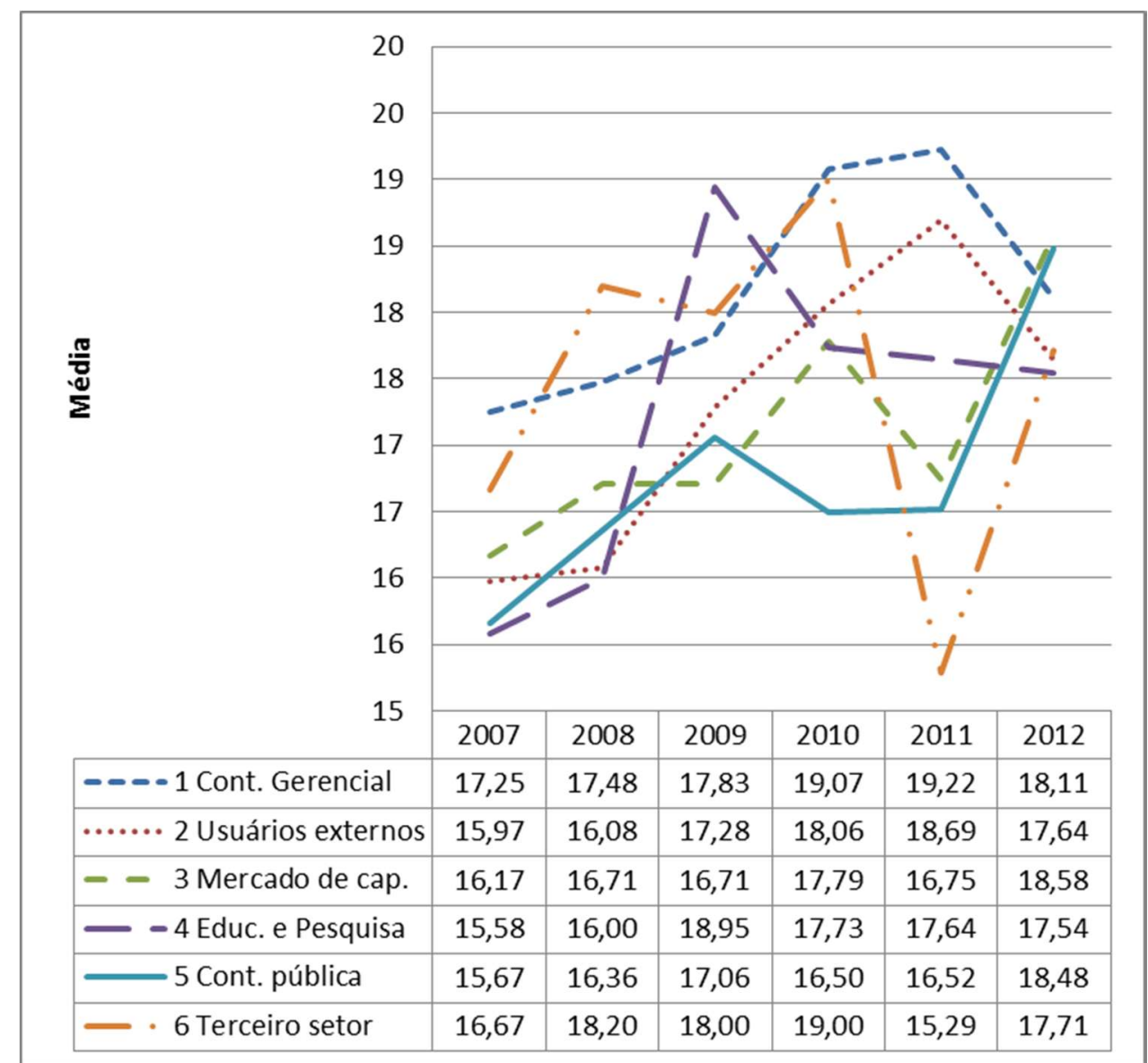

Figura 13 - Média do número de páginas por artigo por linha de pesquisa, por ano

O comprimento médio dos artigos apresentou uma tendência crescente em todas as linhas, com exceção da linha 6 , Contabilidade do terceiro setor, que mostrou uma tendência decrescente devido a média do ano de 2011. A tendência de crescimento do tamanho dos artigos tem um fator a seu favor, o aumento do número de revistas que oferecem versão exclusivamente eletrônica, pois isso elimina as limitações criadas pelo custo de impressão das revistas.

\subsection{Número de referências}

A literatura (Judge et al., 2007; Stremersch et al., 2007; Mingers \& Xu, 2010; Antonakis et al., 2014; Fox et al., 2016) informa que o número de referências de um artigo tem relação com a sua qualidade e, portanto, influencia na probabilidade de ele ser citado. Evidentemente, há que se tomar cuidado, porque nem sempre a referência de um estudo é feita devido a leitura dele. A literatura informa, inclusive, que alguns autores 
podem citar e referenciar determinadas pesquisas para dar mais credibilidade ao seu estudo e até mesmo citar artigos de uma revista ou de autoria de membros do corpo editorial para aumentar as chances de ser publicado por ela. Por outro lado, Martins (2002) afirma que o número de trabalhos que citava e referenciava a Revista de Contabilidade \& Finanças, publicados por ela entre 1989 e 2001, era tão baixo que parecia indicar que os autores desconheciam o conteúdo da revista, ou seja, não liam os artigos da revista em que queriam publicar.

A estatística descritiva do número de referências segue na Tabela 6.

Tabela 6 - Estatística descritiva do número de referências
\begin{tabular}{l|r}
\hline Média & 27,81614 \\
\hline Erro padrão & 0,283247 \\
\hline Mediana & 25 \\
\hline Moda & 19 \\
\hline Desvio padrão & 14,2752 \\
\hline Variância da amostra & 203,7815 \\
\hline Curtose & 7,159371 \\
\hline Assimetria & 1,805117 \\
\hline Intervalo & 168 \\
\hline Mínimo & 0 \\
\hline Máximo & 168 \\
\hline Soma & 70653 \\
\hline Contagem & 2540 \\
\hline
\end{tabular}

A Figura 14 ilustra a distribuição do número de referências.

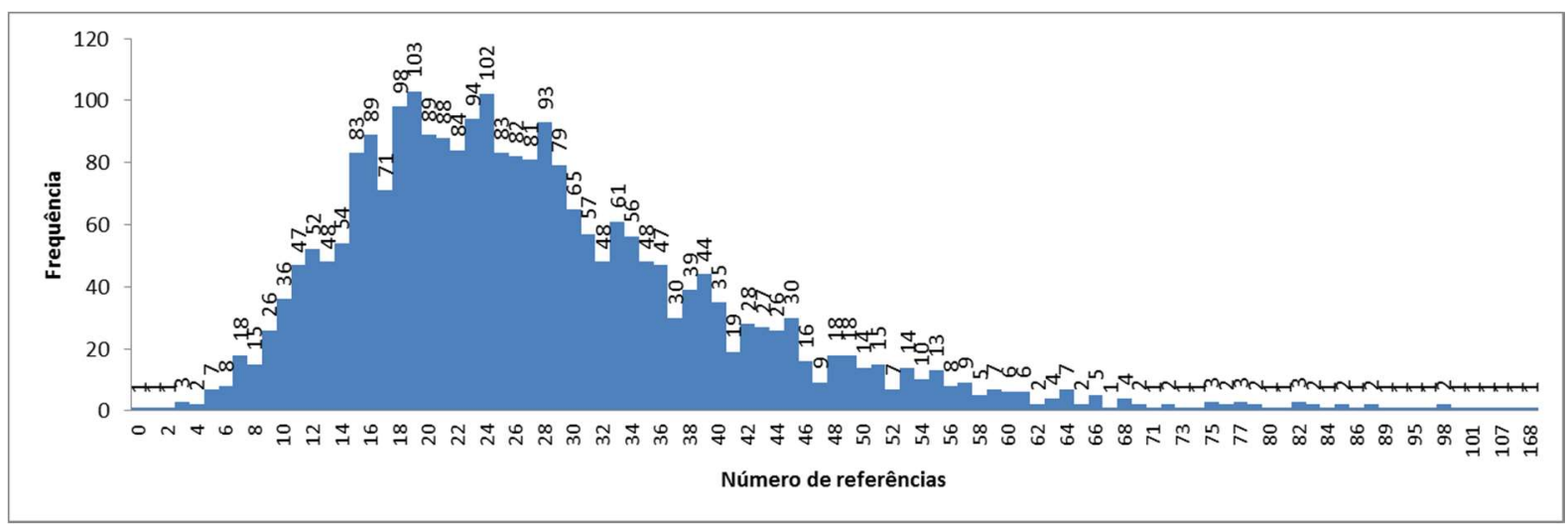

Figura 14 - Distribuição do número de referências

Em média, os artigos referenciaram 27 documentos, sendo o mínimo zero e o máximo 168, com uma moda de 19 e mediana de 25 . O artigo sem referência tem por título "Contabilidade: entre umas e outras" e teve 18 citações. É um artigo de opinião, de dois renomados autores, Sérgio de ludícibus e Lázaro Plácido Lisboa. De certa forma, 
isso explica a alta quantidade de citações, apesar da ausência de referências. Os artigos com uma e duas referências, mas de autores não tão famosos, obtiveram três e zero citações, respectivamente. Os cinco artigos com três e quatro referências não obtiveram nenhuma citação.

Houve cinco ocorrências de artigos que apresentaram mais de uma centena de referências. Os artigos com 101, 107, 168 referências não foram citados. O artigo com 104 referências foi citado uma vez, e o artigo com 114 referências foi citado cinco vezes.

Os percentis indicam que $25 \%$ dos artigos têm até 18 referências, $50 \%$ tem até 25 referências, $75 \%$ tem até 34 referências e $90 \%$ tem até 45 referências. Sobre a normalidade da distribuição, o teste Kolmogorov-Smirvov indica que não se trata de uma distribuição normal ( $p$-valor $=0,000)$.

A Figura 15 mostra as médias de referências usadas nos artigos, por linha. 


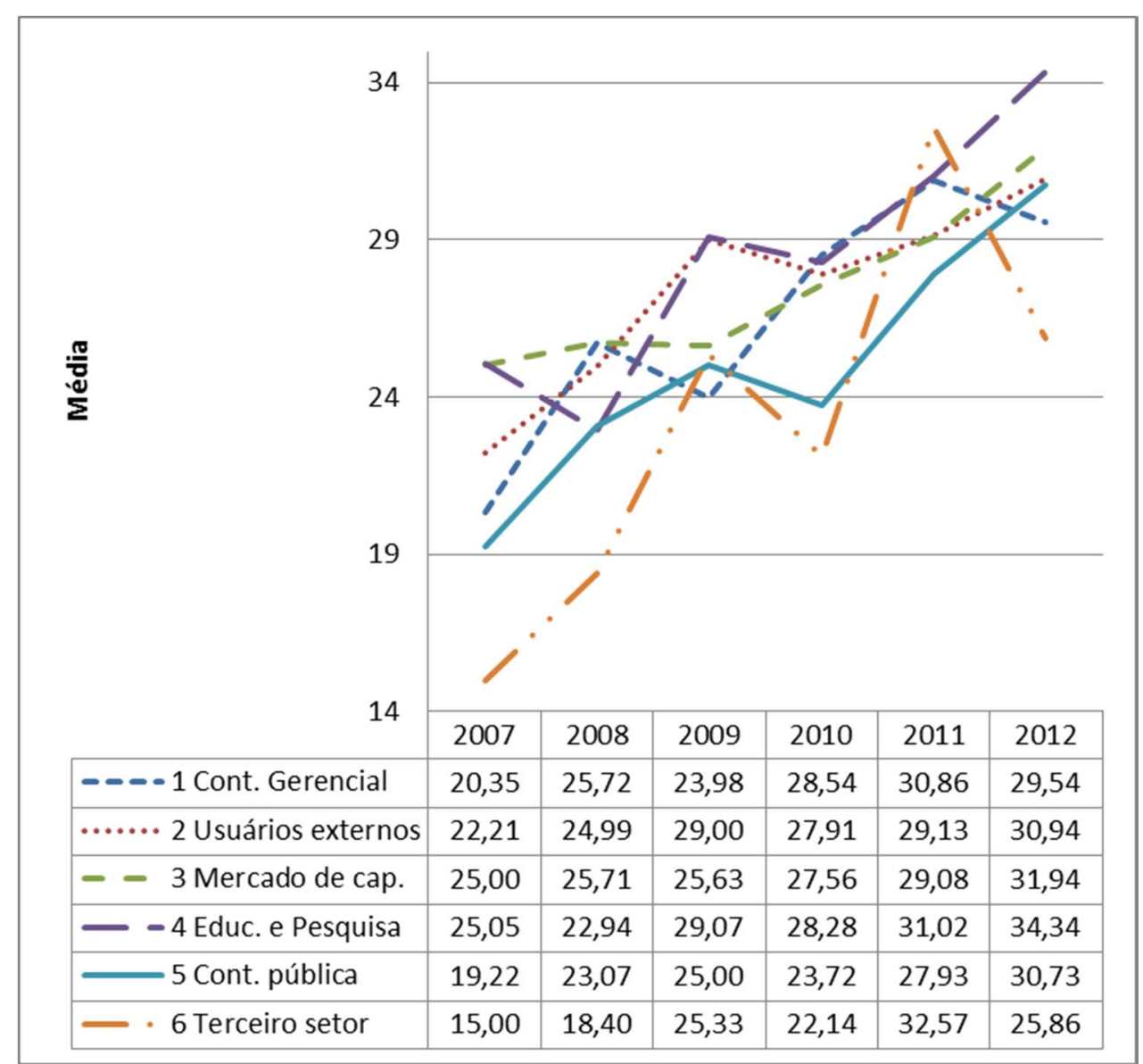

Figura 15 - Média do número de referências de cada artigo, por linha de pesquisa, por ano

Todas as linhas de pesquisas mostraram uma forte tendência crescente e convergente no número médio de referências utilizadas, com exceção da linha de pesquisa 6, Contabilidade de terceiro setor. Essa tendência pode indicar um aumento do esforço dos autores para revisar maior volume de literatura, mas também pode ser decorrente do aumento numérico da competitividade para publicação de artigos em revistas oriundas, principalmente, dos ambientes de pós-graduação. A linha 2, Contabilidade para usuários externos, e a linha 4, Educação e Pesquisa, foram as que apresentaram maiores médias no período analisado.

\subsection{Número de autores}

A literatura aponta (Ayres \& Vars, 2000; Leimu \& Koricheva, 2005; Antonakis et al., 2014; Martinez-Blasco et al., 2016; Fox et al., 2016) o número de autores como variável que afeta a quantidade de citações, bem como elenca algumas razões para isso. 
Um artigo com mais autores passa pelo crivo de mais pessoas, de forma que o esforço do conjunto para melhorar os achados ou eliminar erros é potencialmente maior e melhor que o esforço individual ou o empregado por menos autores. Outra situação é a de um artigo escrito por diversos docentes de pós-graduação e que, após a publicação, utilizam esse artigo em suas aulas. O número de estudantes expostos ao conteúdo do artigo e que podem vir a citá-lo em suas monografias, dissertações e teses é maior em um artigo com quatro docentes do que em um artigo com autor individual.

A estatística descritiva desta variável é apresentada na Tabela 7.

Tabela 7 - Estatística descritiva do número de autores por
\begin{tabular}{l|r}
\hline Média & 2,894882 \\
\hline Erro padrão & 0,021564 \\
\hline Mediana & 3 \\
\hline Moda & 3 \\
\hline Desvio padrão & 1,086806 \\
\hline Variância da amostra & 1,181147 \\
\hline Curtose & $-0,39894$ \\
\hline Assimetria & 0,187207 \\
\hline Intervalo & 5 \\
\hline Mínimo & 1 \\
\hline Máximo & 6 \\
\hline Soma & 7353 \\
\hline Contagem & 2540 \\
\hline
\end{tabular}

Os artigos têm em média 2,89 autores, com mediana e moda 3. O menor valor observado foi 1 e o maior foi 6 . Há que se levar em consideração que a maioria das revistas estabelece um número máximo de autores, sendo que, das 36 revistas analisadas nesta pesquisa, verificou-se, em janeiro de 2017, que 11 aceitam, no máximo, cinco autores; 12 aceitam, no máximo, quatro autores; e 13 são omissas sobre a limitação do número de autores em suas diretrizes para submissão de artigos (ou não as têm). Todas as pesquisas tiveram por autor pessoas físicas, não sendo atribuída autoria institucional a nenhum artigo. $O$ traçado da média desses dados estão demonstrados na Figura 16. 


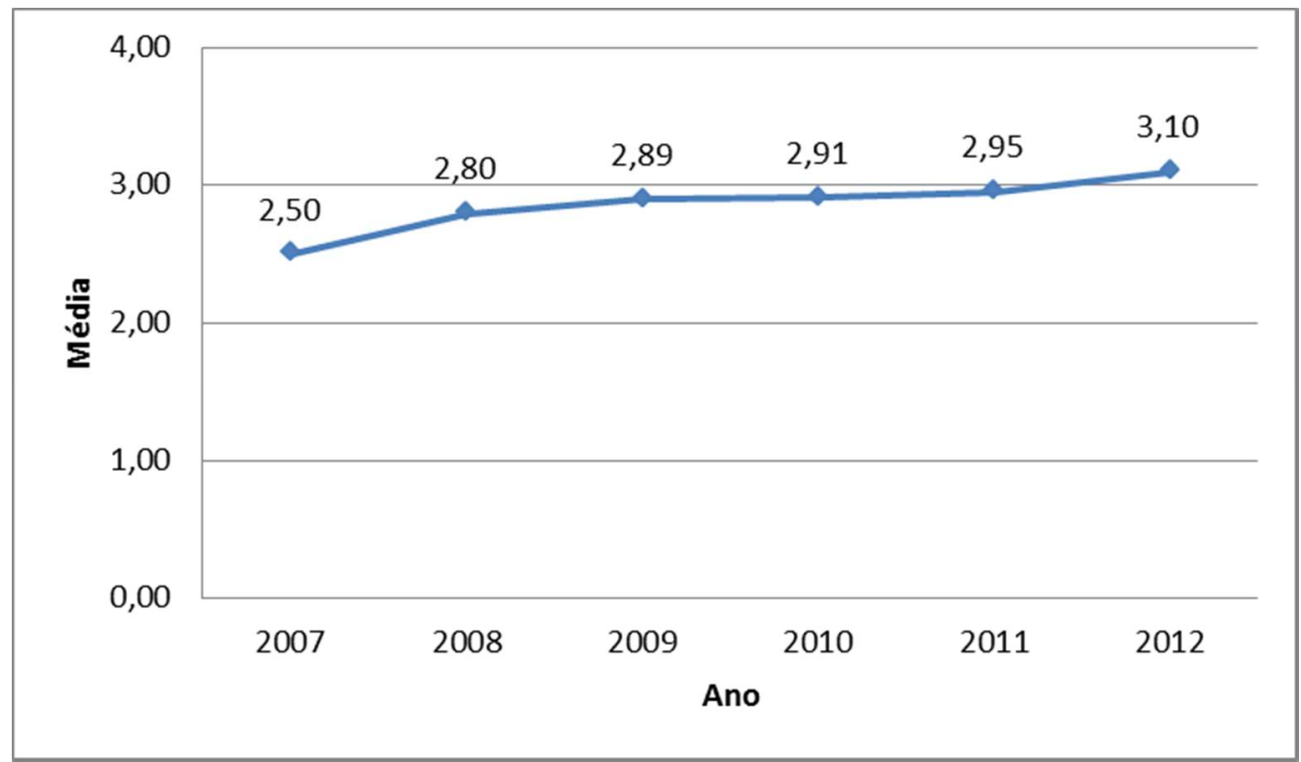

Figura 16 - Média do número de autores por artigo, por ano

Como se pode ver na Figura 16, a média de autores por artigo subiu de 2,50, em 2007, para 3,10, em 2012, seguindo uma suave tendência crescente. Tal aumento, inclusive, é respaldado pela transição da mediana de 2 para 3, no ano de 2007 para 2008, e da moda de 2 para 3, no ano de 2008 para 2009, conforme exposto na Tabela 8.

Tabela 8 - Estatística descritiva do número de autores por artigo, por ano

\begin{tabular}{l|r|r|r|r|r|r}
\hline Estatísticas & \multicolumn{1}{c}{$\mathbf{2 0 0 7}$} & $\mathbf{2 0 0 8}$ & $\mathbf{2 0 0 9}$ & $\mathbf{2 0 1 0}$ & $\mathbf{2 0 1 1}$ & $\mathbf{2 0 1 2}$ \\
\hline Média & 2,501695 & 2,796034 & 2,894872 & 2,907621 & 2,95112 & 3,098616 \\
\hline Erro padrão & 0,05918 & 0,060134 & 0,056523 & 0,052943 & 0,046706 & 0,043717 \\
\hline Mediana & 2 & 3 & 3 & 3 & 3 & 3 \\
\hline Moda & 2 & 2 & 3 & 3 & 3 & 3 \\
\hline Desvio padrão & 1,016445 & 1,129806 & 1,116239 & 1,101666 & 1,034928 & 1,05102 \\
\hline Variância da & 1,03316 & 1,276461 & 1,245989 & 1,213669 & 1,071075 & 1,104643 \\
amostra & 0,300736 & $-0,5064$ & $-0,35853$ & $-0,39539$ & $-0,3652$ & $-0,3758$ \\
\hline Curtose & 0,494309 & 0,265333 & 0,264404 & 0,256801 & 0,064734 & 0,008806 \\
\hline Assimetria & 5 & 5 & 5 & 5 & 5 & 5 \\
\hline Intervalo & 1 & 1 & 1 & 1 & 1 & 1 \\
\hline Mínimo & 6 & 6 & 6 & 6 & 6 & 6 \\
\hline Máximo & 738 & 987 & 1129 & 1259 & 1449 & 1791 \\
\hline Soma & 295 & 353 & 390 & 433 & 491 & 578 \\
\hline Contagem & & & & & &
\end{tabular}

Esse aumento pode ser explicado pela ampliação do número de redes de colaborações entre pesquisadores, pela expansão no número de programas de pósgraduação na área, e pela necessidade de capital humano no desenvolvimento de pesquisas, acerca de problemas mais complexos, por meio de metodologias mais robustas. Pode, ainda, ser explicado por fenômenos como a autoria honorária, na qual 
os autores originais da pesquisa convidam um autor que seja referência na área para aumentar a probabilidade de aprovação do artigo pelo editor da revista.

A Figura 17 mostra a distribuição do número de autores por artigo, verificado nesta pesquisa.

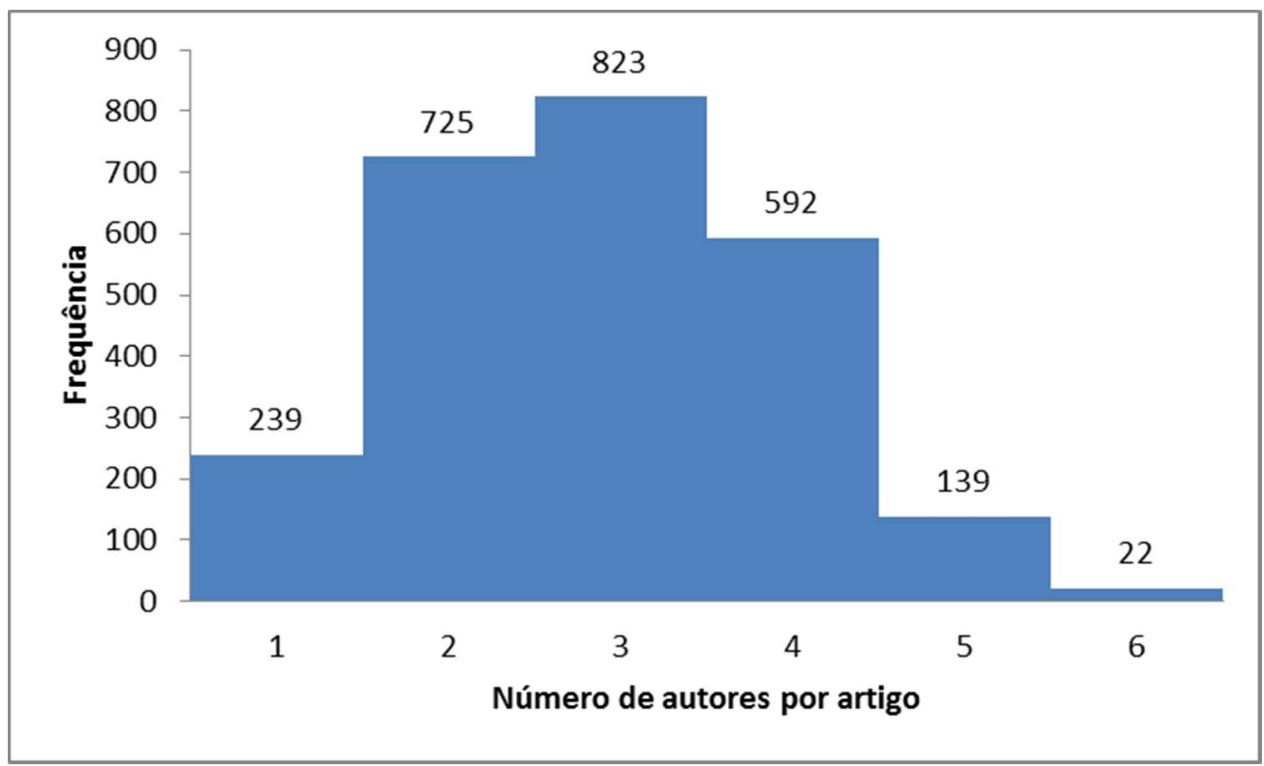

Figura 17 - Distribuição do número de autores por artigo

Os percentis indicam que $25 \%$ dos artigos tem até dois autores; $50 \%$, até três; $75 \%$, até quatro; e 90\% tem até cinco autores. O percentual de artigos com seis autores é pouco menos que $1 \%$. O teste Kolmogorov-Smirnov indica que essa distribuição não é normal $(p$-valor $=0.000)$.

A Figura 18 mostra a média de autores por artigo, por linha de pesquisa no período de 2007 a 2012. 


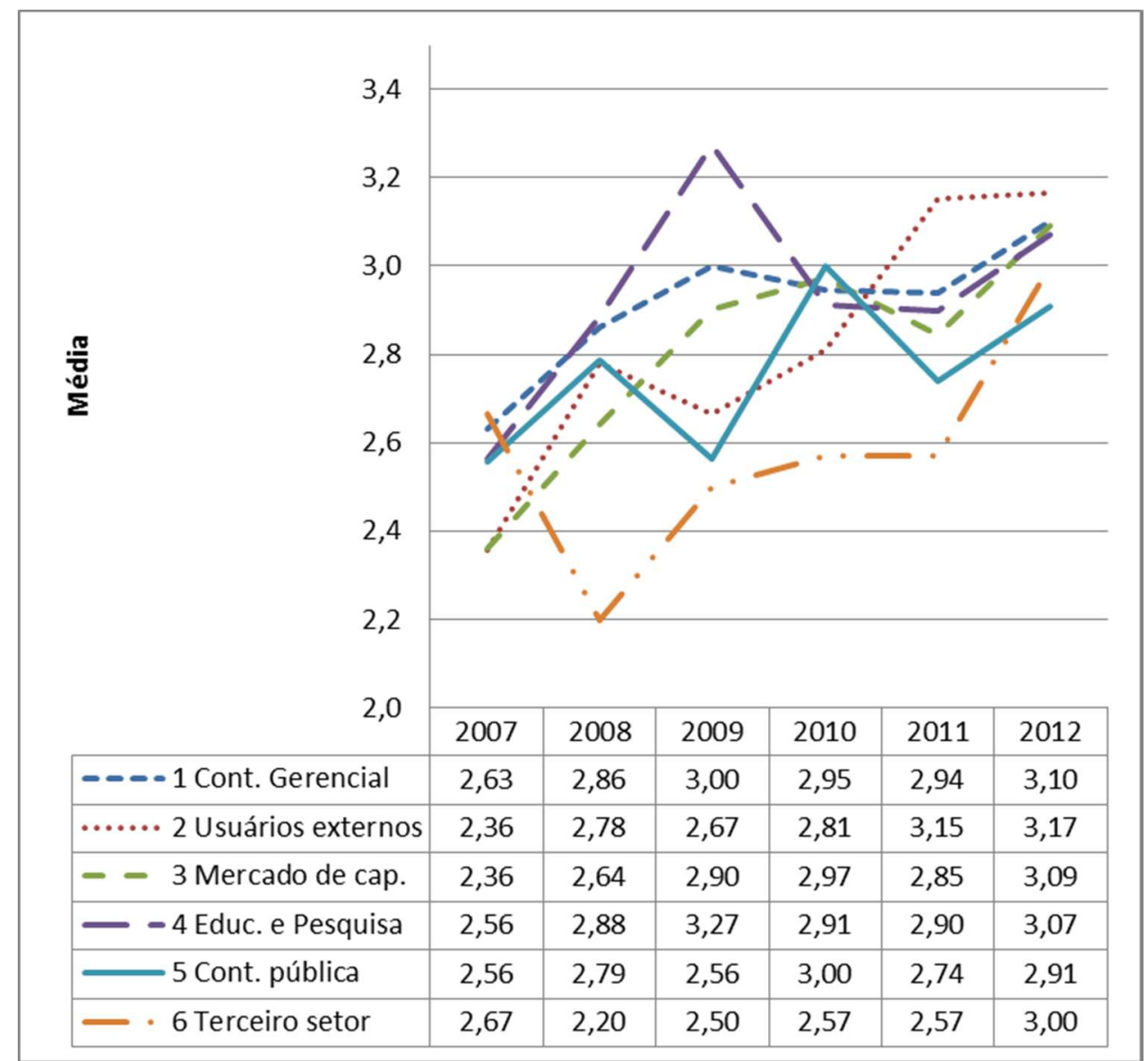

Figura 18 - Média do número de autores por artigo por linha de pesquisa, por ano

Todas as linhas de pesquisa apresentaram uma tendência crescente e convergente no número de autores por artigo. A linha 1, Contabilidade gerencial, foi a que apresentou maior média no período. No entanto, a linha 2, Contabilidade para usuários externos, além de demonstrar uma tendência de forte crescimento, apresentou as maiores médias no final do período.

Antunes, Mendonça Neto e Vieira (2014) afirmam que as pequenas contribuições ao artigo, que deveriam figurar nos agradecimentos, aparentemente têm balizado a efetiva atribuição de autoria. E, ainda, elencam os casos em que a participação em banca de qualificação ou defesa de dissertação e tese garante a coautoria ao avaliador, bem como o oferecimento de coautoria, por questões de amizade ou hierarquia funcional, ou coautoria cruzada, visando alavancar pontuação individual no âmbito gerencialista que permeia o ambiente da pós-graduação. 
Os autores são respaldados pela baixíssima frequência com que se encontra uma seção de agradecimentos nos artigos da amostra desta pesquisa, restando a alternativa de atribuir autoria a quem, a priori, não seria assim reconhecido.

Conforme Antunes, Okimura e Mendonça Neto (2015), tal situação ganha contornos mais relevantes visto que: i. não há consenso entre os pesquisadores brasileiros sobre o que acreditam ser os critérios de autoria; ii. essa falta de consenso deriva da prática dos autores; e iii. os autores não praticam, com a mesma intensidade, aquilo em que acreditam. Nesse sentido, uma das consequências naturais da flexibilidade na atribuição de autoria é o aumento do número de autores por artigo.

\subsection{Proporção de autoria feminina}

Nesta Tese, optou-se por estudar a variável gênero de duas formas: proporção de mulheres autoras em cada artigo, como variável quantitativa; e gênero do primeiro autor, como variável qualitativa. Considerando que o número mínimo de autores nos artigos analisados nesta pesquisa foi 1 e o máximo foram 6 , a proporção de autoria feminina poderia assumir um número limitado de opções, como mostra a Figura 19.

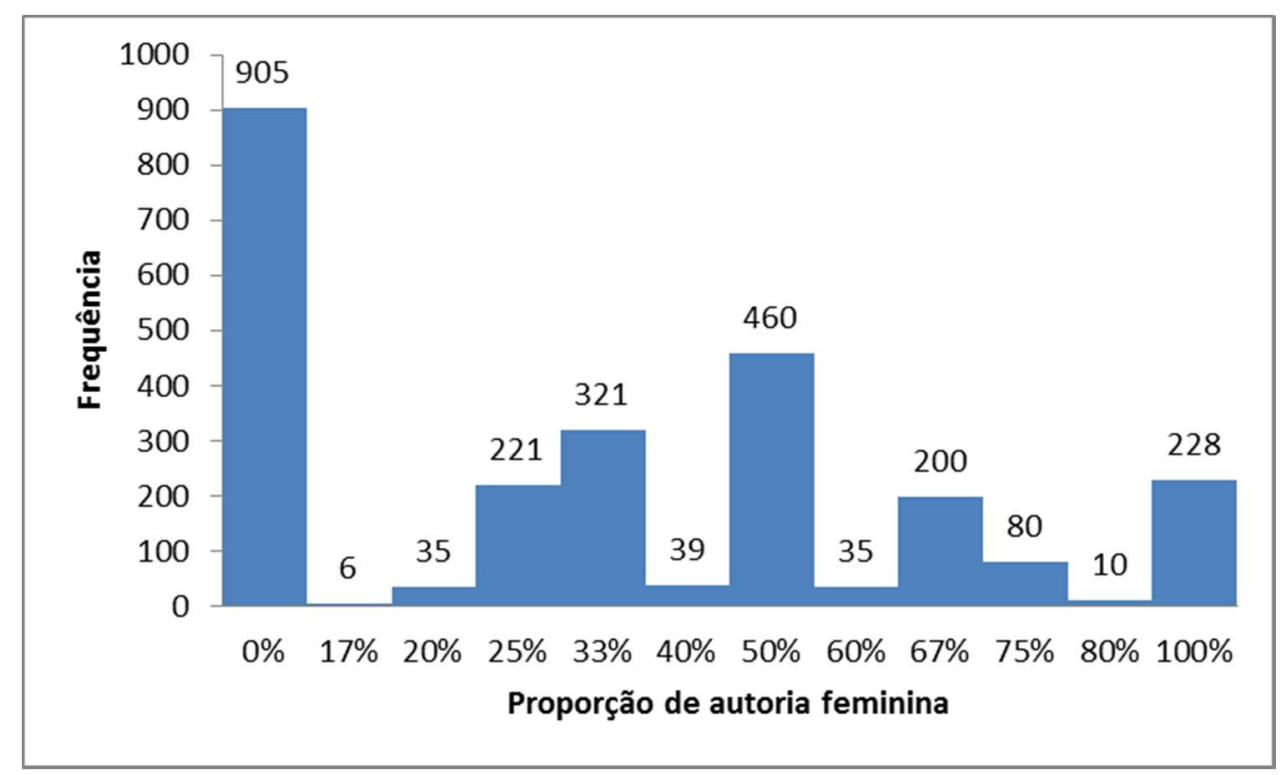

Figura 19 - Proporção de autoria do gênero feminino

Os valores fracionados, mostrados na Figura 19, refletem as possibilidades de proporção que a autoria feminina poderia assumir. Todos os artigos podiam ter $0 \%$ ou $100 \%$ de autoria feminina. Somente os artigos com número par de autores poderia 
assumir o percentual de 50\%, ou seja, somente os artigos com 2, 4 e 6 autores poderiam ter $50 \%$ de autoria feminina. Os percentuais de $25 \%$ e $75 \%$ de autorias femininas só podiam ocorrer em artigos com 4 autores. Os percentuais de $33 \%$ e $67 \%$ de autoria feminina só podiam ocorrer nos artigos com 3 e 6 autores, e os percentuais de $20 \%, 40 \%, 60 \%$ e $80 \%$ de autoria feminina só podiam ocorrer nos artigos com 5 autores.

A Tabela 9 mostra a estatística descritiva da proporção de autoria feminina.

Tabela 9 - Estatística descritiva da proporção de autori
\begin{tabular}{llr}
\hline Média & 0,341017 \\
\hline & Erro padrão & 0,006322 \\
\hline Mediana & 0,333333 \\
\hline Moda & 0 \\
\hline Desvio padrão & 0,318642 \\
\hline Variância da amostra & 0,101533 \\
\hline Curtose & $-0,68078$ \\
\hline Assimetria & 0,546678 \\
\hline Intervalo & 1 \\
\hline Mínimo & 0 \\
\hline Máximo & 1 \\
\hline Soma & 866,1833 \\
\hline Contagem & 2540 \\
\hline
\end{tabular}

Em média, mulheres respondem por um terço das autorias dos artigos da amostra. A moda, no entanto, foi zero. Chama a atenção o fato de que 905 artigos dos 2.540 analisados nesta pesquisa não tiveram nenhuma participação de autora (cerca de $35 \%$ do total). Apenas 228 artigos têm $100 \%$ de autoria feminina (cerca de 8,9\% do total), sendo que, destes, 62 têm só um autor (mulher).

Uma das possíveis razões para esta proporção de autoras é a predominância masculina em cursos de Ciências Contábeis existente no século XX. Neste começo de século $\mathrm{XXI}$, a proporção da estudantes mulheres em cursos de graduação em Ciências Contábeis e pós-graduação em Contabilidade tem crescido em instituições públicas e privadas e este fato deve impactar na proporção de autoria feminina com maior intensidade nos próximos anos.

A Figura 20 mostra a proporção de autoria feminina por linha de pesquisa. 


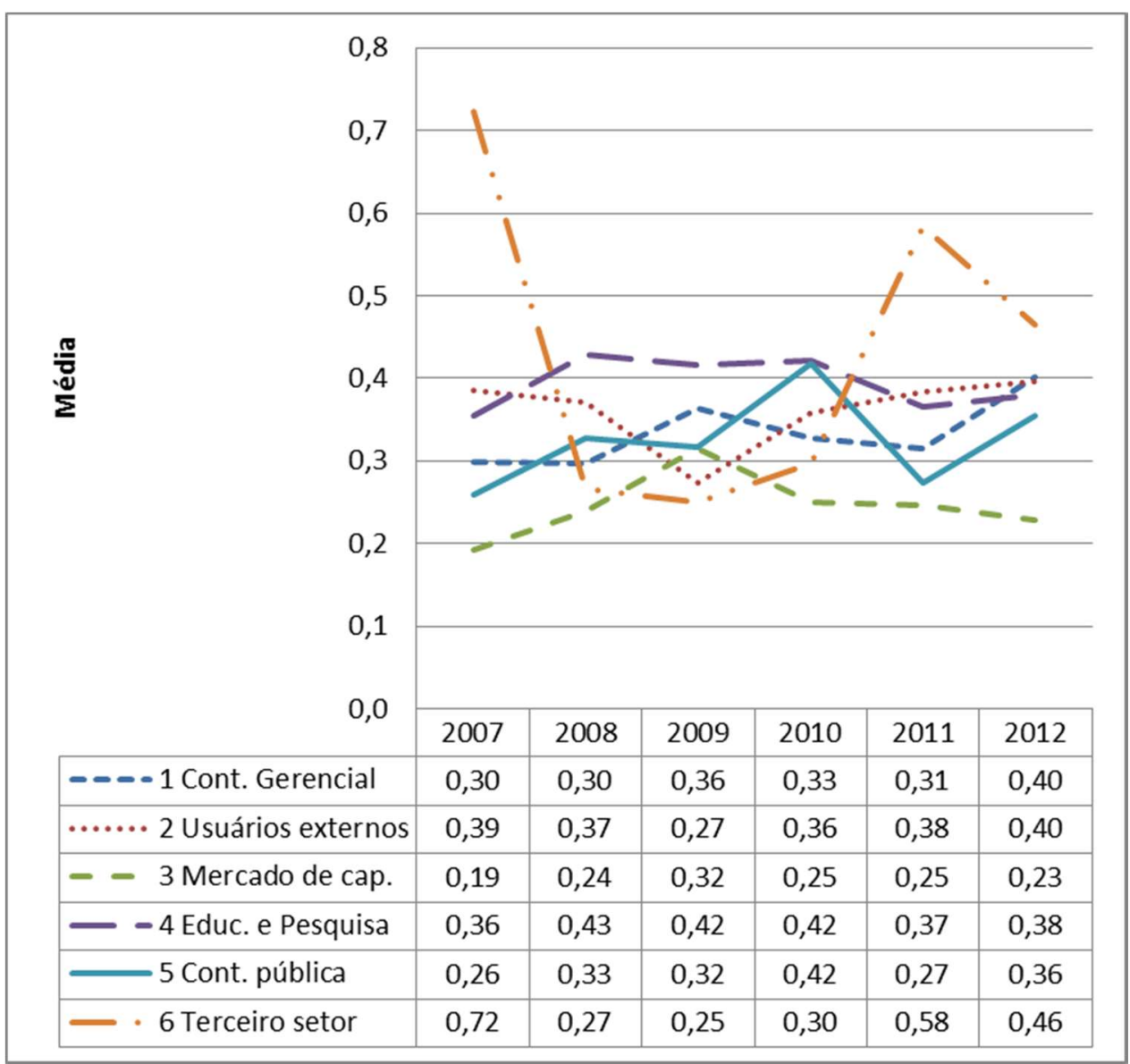

Figura 20 - Média da proporção de autoria do gênero feminino, por linha de pesquisa, por ano

A linha de pesquisa com maior taxa de autoria feminina é a linha 6, Contabilidade do terceiro setor, seguida da linha 4, Educação e Pesquisa. Ambas apresentam uma tendência decrescente, embora a tendência da linha 4 seja mais estável, enquanto a linha 6 apresenta alterações bruscas. Entre as linhas em que houve tendência crescente, a linha 1, Contabilidade gerencial e Controladoria, foi a que se mostrou mais acentuada nesse sentido.

\subsection{Idade da Revista quando o artigo foi publicado}

Considerando que revistas mais antigas e tradicionais costumam ser mais respeitadas e possuem maior reputação que as revistas mais jovens, mantidas as demais condições constantes, e que essas características influenciam a quantidade de citações dos artigos que veiculam, optou-se por analisar o impacto da idade da revista na quantidade de citações dos artigos. 
A Tabela 10 mostra a estatística descritiva da idade das revistas quando os artigos foram publicados.

Tabela 10 - Estatística descritiva da idade das revistas quando os artigos foram publicados

\begin{tabular}{l|r}
\hline Média & 6,464961 \\
\hline Erro padrão & 0,109651 \\
\hline Mediana & 5 \\
\hline Moda & 3 \\
\hline Desvio padrão & 5,526259 \\
\hline Variância da amostra & 30,53954 \\
\hline Curtose & 1,639084 \\
\hline Assimetria & 1,498511 \\
\hline Intervalo & 23 \\
\hline Mínimo & 0 \\
\hline Máximo & 23 \\
\hline Soma & 16421 \\
\hline Contagem & 2540 \\
\hline
\end{tabular}

Em média, as revistas possuíam seis anos de idade quando os artigos foram publicados, embora a mediana tenha sido cinco e a moda, três. Esses números revelam o quão novas são as revistas brasileiras de Contabilidade, incluindo o fato de 112 dos artigos da amostra terem sido publicados no ano de criação do periódico.

A Figura 21 mostra a distribuição dos artigos de acordo com a idade da revista quando foram publicados.

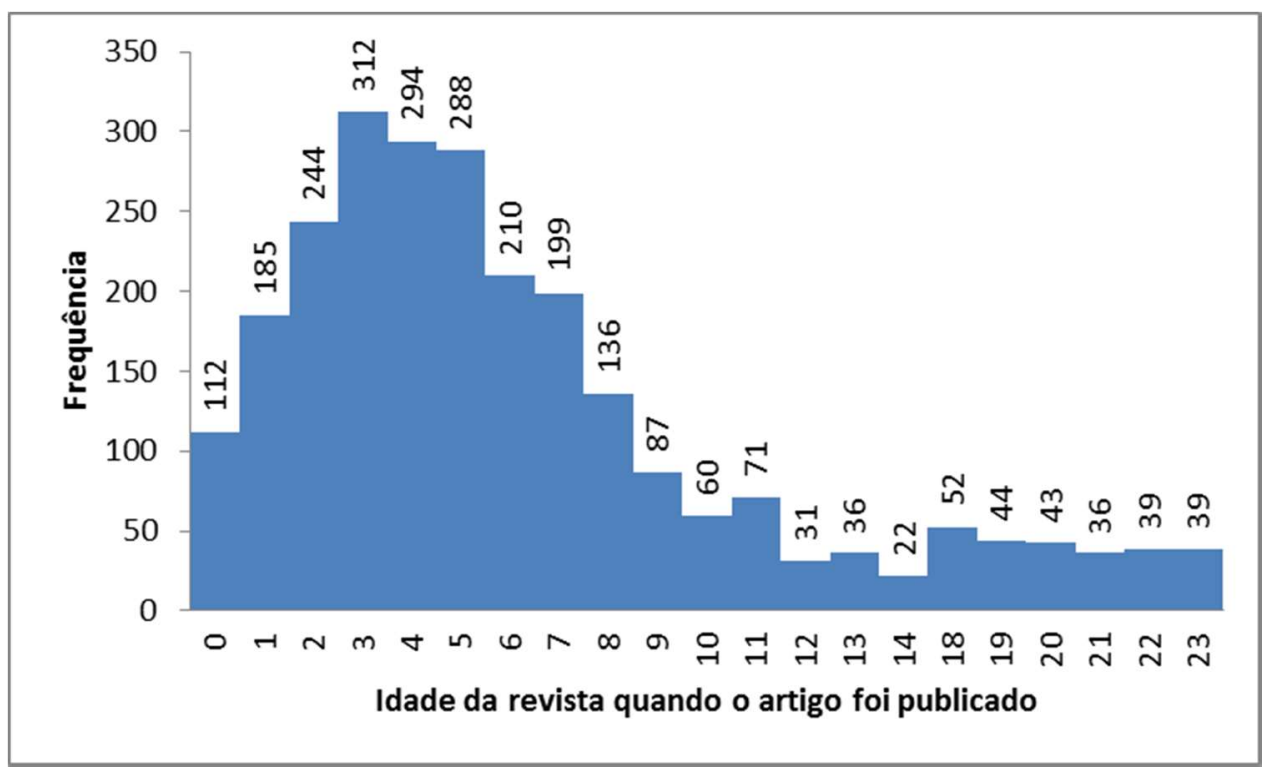

Figura 21 - Distribuição da idade da revista quando o artigo foi publicado 
As revistas mais antigas representam os periódicos que existem desde 1989, entre os quais pode-se elencar: a Revista de Contabilidade \& Finanças, da USP; e a Contabilidade Vista \& Revista, da UFMG. O teste Kolmogorov-Smirnov indica que a distribuição da idade das revistas não é normal ( $p$-valor $=0,000)$.

\subsection{Revista em que o artigo foi publicado}

A revista em que o artigo foi publicado é apontada pela literatura (Leimu \& Koricheva, 2005; Judge et al., 2007; Mingers \& Xu, 2010; Vanclay, 2013; Aragão et al., 2014) como um fator de forte influência sobre a taxa de citação de um artigo, já que ela pode estender o seu prestígio ao artigo que veicula, potencializando as citações que ele recebe. Em verdade, esses estudos utilizaram o Fator de impacto das revistas dentro dos modelos, mas, diante da inexistência do Fator de impacto das revistas brasileiras, optou-se por utilizá-las como variáveis dummy na análise de regressão.

A Tabela 11 mostra a média, o desvio-padrão, o número mínimo e máximo das citações por revista.

Tabela 11 - Estatísticas descritivas resumidas das citações das revistas e número de observações

\begin{tabular}{l|r|r|r|r|r}
\hline Rótulos de Linha & \multicolumn{1}{l|}{ Média } & Desvio-padrão & \multicolumn{1}{l}{ Mínimo } & \multicolumn{1}{l}{ Máximo } & Contagem \\
\hline RC\&F & 21,9 & 22,7 & 0 & 111 & 113 \\
\hline RCO & 7,3 & 9,7 & 0 & 84 & 124 \\
\hline REPEC & 7,2 & 11,2 & 0 & 87 & 102 \\
\hline CVR & 7,1 & 9,3 & 0 & 66 & 140 \\
\hline RBGN & 6,8 & 8,0 & 0 & 41 & 52 \\
\hline RCC_UFSC & 5,5 & 6,9 & 0 & 42 & 92 \\
\hline RUC & 5,4 & 6,5 & 0 & 37 & 191 \\
\hline CGG & 5,3 & 6,5 & 0 & 32 & 100 \\
\hline Base & 5,1 & 6,1 & 0 & 30 & 89 \\
\hline BBR & 5,1 & 5,6 & 0 & 27 & 73 \\
\hline Contextus & 5,1 & 5,8 & 0 & 26 & 27 \\
\hline RIC & 4,4 & 7,9 & 0 & 52 & 110 \\
\hline Contexto & 3,6 & 5,4 & 0 & 24 & 73 \\
\hline ASAA & 3,6 & 4,5 & 0 & 19 & 53 \\
\hline RCMCC & 3,1 & 3,2 & 0 & 12 & 98 \\
\hline Pensar & 3,1 & 4,8 & 0 & 32 & 108 \\
\hline SCG & 3,0 & 4,4 & 0 & 24 & 86 \\
\hline Enfoque & 3,0 & 3,5 & 0 & 15 & 94 \\
\hline RGFC & 2,9 & 3,4 & 0 & 15 & 22 \\
\hline RCC_UFPR & 2,8 & 4,2 & 0 & 25 & 68 \\
\hline ABCustos & 2,8 & 4,5 & 0 & 27 & 68 \\
\hline RBC & 2,5 & 3,5 & 0 & 18 & 106 \\
\hline RC_UFBA & 2,4 & 4,9 & 0 & 38 & 73 \\
\hline Custos e @gronegócio & 2,4 & 3,9 & 0 & 31 & 120 \\
\hline RACE & 2,3 & 4,0 & 0 & 16 & 27 \\
\hline
\end{tabular}




\begin{tabular}{l|r|r|r|r|r}
\hline Rótulos de Linha & \multicolumn{1}{|l|}{ Média } & Desvio-padrão & \multicolumn{1}{l|}{ Mínimo } & \multicolumn{1}{l}{ Máximo } & \multicolumn{1}{c}{ Contagem } \\
\hline CAP & 2,1 & 4,5 & 0 & 25 & 38 \\
\hline Reunir & 2,0 & 2,1 & 0 & 9 & 24 \\
\hline Amb_Cont & 1,7 & 2,6 & 0 & 15 & 47 \\
\hline Razao & 1,5 & 1,6 & 0 & 6 & 22 \\
\hline R_Cat_CC & 1,3 & 2,5 & 0 & 15 & 88 \\
\hline REAVI & 1,3 & 2,2 & 0 & 5 & 4 \\
\hline Recont & 1,1 & 1,7 & 0 & 7 & 31 \\
\hline R_Est_Cont & 1,1 & 1,3 & 0 & 5 & 28 \\
\hline RACEF & 1,1 & 1,5 & 0 & 4 & 17 \\
\hline RAC_FAT & 0,6 & 1,1 & 0 & 4 & 24 \\
\hline R_Elet_Cont & 0,1 & 0,3 & 0 & 1 & 8 \\
\hline Total Geral & 4,9 & 8,7 & 0 & 111 & 2540 \\
\hline
\end{tabular}

Faz-se, na sequência, breve relato sobre as cinco primeiras revistas apresentadas na Tabela. A revista com maior média de citação é a Revista de Contabilidade \& Finanças. Essa revista é uma das mais antigas; é mantida pelo programa de pósgraduação mais bem conceituado na subárea junto à Capes, no Brasil; e, ainda, é a pioneira em determinadas práticas editoriais, como a indexação na Plataforma Scielo (desde 2007), e em adotar a divulgação de uma versão em inglês de cada paper publicado (desde 2012), além do estabelecimento/adoção de diretrizes de boas práticas de publicação.

A Revista de Contabilidade e Organizações, a segunda com maior média de citações, é mantida pelo programa de pós-graduação em Contabilidade da USP Ribeirão Preto. A terceira revista com maior média e a primeira a não ser mantida por um programa de pós-graduação é a Revista de Educação e Pesquisa em Contabilidade, que é mantida pelo Conselho Federal de Contabilidade. A quarta revista com maior média de citações é a Contabilidade Vista \& Revista, periódico ligado ao programa de pósgraduação em Contabilidade da Universidade Federal de Minas Gerais, tão antiga quanto a Revista Contabilidade \& Finanças.

A Revista Brasileira de Gestão de Negócios, a quinta da lista, foi criada com esse nome em 2004 e é mantida pela Fundação Escola de Comércio Álvares Penteado. Essa revista, em específico, não pode ser associada exclusivamente ao programa de pós-graduação em Contabilidade da FECAP, deve também ser associada ao programa de Administração da mesma instituição, publicando, portanto, trabalhos que envolvem ambas as áreas. 
A seguir, na Tabela 12 , verifica-se a participação das revistas quanto às citações.

Tabela 12 - Participação de cada Revista entre os $10 \%$ e $1 \%$ de artigos mais citados

\begin{tabular}{l|r|r|r|r}
\hline \multicolumn{1}{c|}{ Rótulos de Linha } & top $\mathbf{1 0} \%$ & $\mathbf{\%}$ & top $\mathbf{1 \%}$ & $\mathbf{\%}$ \\
\hline ABCustos & 2 & $1 \%$ & 0 & $0 \%$ \\
\hline Amb_Cont & 1 & $0 \%$ & 0 & $0 \%$ \\
\hline ASAA & 4 & $2 \%$ & 0 & $0 \%$ \\
\hline Base & 11 & $4 \%$ & 0 & $0 \%$ \\
\hline BBR & 7 & $3 \%$ & 0 & $0 \%$ \\
\hline CAP & 1 & $0 \%$ & 0 & $0 \%$ \\
\hline CGG & 12 & $5 \%$ & 0 & $0 \%$ \\
\hline Contexto & 8 & $3 \%$ & 0 & $0 \%$ \\
\hline Contextus & 2 & $1 \%$ & 0 & $0 \%$ \\
\hline Custose @gronegócio & 4 & $2 \%$ & 0 & $0 \%$ \\
\hline CVR & 26 & $10 \%$ & 1 & $4 \%$ \\
\hline Enfoque & 4 & $2 \%$ & 0 & $0 \%$ \\
\hline Pensar & 5 & $2 \%$ & 0 & $0 \%$ \\
\hline R_Cat_CC & 1 & $0 \%$ & 0 & $0 \%$ \\
\hline RACE & 2 & $1 \%$ & 0 & $0 \%$ \\
\hline RBC & 4 & $2 \%$ & 0 & $0 \%$ \\
\hline RBGN & 5 & $2 \%$ & 0 & $0 \%$ \\
\hline RC\&F & 62 & $24 \%$ & 18 & $72 \%$ \\
\hline RC_UFBA & 2 & $1 \%$ & 0 & $0 \%$ \\
\hline RCC_UFPR & 2 & $1 \%$ & 0 & $0 \%$ \\
\hline RCC_UFSC & 9 & $4 \%$ & 0 & $0 \%$ \\
\hline RCMCC & 2 & $1 \%$ & 0 & $0 \%$ \\
\hline RCO & 21 & $8 \%$ & 2 & $8 \%$ \\
\hline REPEC & 15 & $6 \%$ & 2 & $8 \%$ \\
\hline RGFC & 1 & $0 \%$ & 0 & $0 \%$ \\
\hline RIC & 9 & $4 \%$ & 2 & $8 \%$ \\
\hline RUC & 27 & $11 \%$ & 0 & $0 \%$ \\
\hline SCG & 5 & $2 \%$ & 0 & $0 \%$ \\
\hline Total Geral & 254 & $100 \%$ & 25 & $100 \%$ \\
\hline & & & &
\end{tabular}

Conforme mostra a Tabela, apenas 28 revistas conseguiram ter artigos entre os $10 \%$ mais citados, e apenas cinco revistas conseguiram ter artigos entre o $1 \%$ mais citado. O primeiro evento não é inesperado, dado que várias das revistas, que não se encontram na Tabela 12, foram criadas no triênio de 2010-2012, o que penaliza a sua contagem acumulada de citações. Por outro lado, as revistas que já existiam em 2007 possuem artigos que estiveram expostos aos leitores por uma janela de tempo maior.

A Revista de Contabilidade \& Finanças desponta como a revista que detém a maior proporção de artigos entre os $10 \%$ e $1 \%$ mais citados, o que é corroborado pela sua taxa média de citação de 21,9 citações, em média, por artigo, exposto, anteriormente, na Tabela 11. 
Martinez-Blasco et al. (2016) apontam que existe diferença no número de citações dos artigos veiculados em edições ordinárias e edições especiais. Enquanto a edição ordinária trabalha nos moldes comuns de editoria e temáticas abrangidas pela linha editorial, as edições especiais podem ter temáticas próprias e renomados pesquisadores, como editores convidados, para comandar a edição de um número especial.

A Tabela 13 mostra a estatística descritiva das citações por tipo de edição.

Tabela 13 - Estatística descritiva das citações por tipo de edição
\begin{tabular}{|l|r|r}
\multicolumn{1}{c}{ Estatística } & Ordinária & \multicolumn{1}{c}{ Especial } \\
\hline Média & 4,786833 & 8,061224 \\
\hline Erro padrão & 0,166639 & 2,761095 \\
\hline Mediana & 2 & 2 \\
\hline Moda & 0 & 0 \\
\hline Desvio padrão & 8,316959 & 19,32767 \\
\hline Variância da amostra & 69,17181 & 373,5587 \\
\hline Curtose & 34,51298 & 17,98643 \\
\hline Assimetria & 4,784442 & 3,999806 \\
\hline Intervalo & 107 & 111 \\
\hline Mínimo & 0 & 0 \\
\hline Máximo & 107 & 111 \\
\hline Soma & 11924 & 395 \\
\hline Contagem & 2491 & 49 \\
\hline
\end{tabular}

A média de citações dos artigos publicados em edições especiais mostrou-se superior à média de citações de artigos publicados em edições ordinárias $(8,06>4,78)$, assim como o desvio-padrão. No entanto, embora seja indiscutível que a média dos artigos publicados em edições especiais seja, numericamente, maior que a média dos artigos publicados em edições ordinárias, há que se interpretar tais resultados com cautela.

Inicialmente, deve-se destacar que as edições especiais não estão distribuídas, de forma homogênea, pelos 36 periódicos analisados nesta Tese: apenas seis periódicos possuíam edições especiais no período de 2007 a 2012. Também é relevante observar que o teste Kolmogorov-Smirnov indica que as duas amostras não são normais, ambas com p-valor =0,000, e, ainda, que o teste Mann-Whitney indica que as diferenças calculadas, embora matematicamente diferentes em valor, não são estatisticamente diferentes ( $p$-valor $=0,600)$. 
Tabela 14 Participação de cada Tipo de edição entre os $10 \%$ e $1 \%$ de artigos mais citados

\begin{tabular}{l|r|r|r|r}
\hline Rótulos de Linha & \multicolumn{1}{|c|}{ top $\mathbf{1 0 \%}$} & \multicolumn{1}{c}{$\%$} & top 1\% & \multicolumn{1}{c}{$\%$} \\
\hline Especial & 7 & $3 \%$ & 2 & $8 \%$ \\
\hline Ordinária & 247 & $97 \%$ & 23 & $92 \%$ \\
\hline Total Geral & 254 & $100 \%$ & 25 & $100 \%$ \\
\hline
\end{tabular}

Os sete artigos que se encontram entre os $10 \%$ mais citados e os dois artigos que se encontram entre os $1 \%$ mais citados pertencem todos à edição especial da Revista Contabilidade \& Finanças, de 2007. Além de terem sido veiculados pela revista com maior taxa média de citação, todos esses artigos estiveram expostos aos leitores durante 9 anos, o maior prazo possível para o recorte temporal da amostra de artigos desta Tese.

Os dois artigos entre os mais citados tinham, como primeiro autor um homem, doutor, eram da linha 4, Educação e pesquisa, e a afiliação institucional dos primeiros autores era FECAP e PUC/SP.

\subsection{Posição do artigo na edição: Primeiro ou demais}

A literatura (Ayres \& Vars, 2000; Judge et al., 2007; Stremersch et al., 2007) aponta que ser o primeiro artigo de uma edição pode impactar no quanto ele é citado. Há duas formas pelas quais esta variável pode impactar o número de citações de um artigo. A primeira delas consiste em que um leitor escolhe ler uma revista e começa lendo os títulos dos artigos. O leitor que lê o primeiro artigo e não o acha interessante vai perdendo o interesse e, assim, a probabilidade de ele ler o último e depois citá-lo torna-se menor. A outra forma ocorre quando o editor escolhe um artigo, que julgue mais inovador, mais interessante ou, metodologicamente mais rigoroso que os demais, para estampar a revista como primeiro artigo (leading paper). Dessa forma, ele é mais citado também por essas razões, mas ganha mais visibilidade com a ajuda do editor.

A Tabela 15 mostra a estatística descritiva das citações por posição na edição.

Tabela 15 - Estatística descritiva das citações dos artigos pela posição na edição

\begin{tabular}{l|r|r}
\hline Estatística & Primeiro & Demais \\
\hline Média & 5,286747 & 4,764706 \\
\hline Erro padrão & 0,491751 & 0,181718 \\
\hline Mediana & 2 & 2 \\
\hline
\end{tabular}




\begin{tabular}{l|r|r}
\hline Estatística & Primeiro & \multicolumn{1}{|c}{ Demais } \\
\hline Moda & 0 & 0 \\
\hline Desvio padrão & 10,01772 & 8,376789 \\
\hline Variância da amostra & 100,3548 & 70,1706 \\
\hline Curtose & 41,96144 & 35,41662 \\
\hline Assimetria & 5,563271 & 4,809402 \\
\hline Intervalo & 107 & 111 \\
\hline Mínimo & 0 & 0 \\
\hline Máximo & 107 & 111 \\
\hline Soma & 2194 & 10125 \\
\hline Contagem & 415 & 2125 \\
\hline
\end{tabular}

Foi possível identificar que a média de citações dos artigos publicados em primeiro lugar nas edições é maior que a média de citações dos artigos publicados na sequência. A moda e mediana, no entanto, foram zero para ambas as posições. $O$ teste Kolmogorov-Smirnov indica que as distribuições das duas amostras não são normais, ambas com p-valor $=0,000$. O teste Mann-Whitney indica que a diferença das médias não é estatisticamente significante ( $p$-valor $=0,304$ ).

Num futuro próximo, possivelmente, o efeito de ser o primeiro artigo de uma edição sobre a quantidade de citações tenda a se tornar menor, na medida que os repositórios de artigos se limitarem ao arquivamento em formato eletrônico dos artigos, sujeitos à recuperação de dados por meio de pesquisa booleana, abandonando o formato impresso.

A Figura 22 mostra a média de citações dos artigos, segundo a posição na edição. 


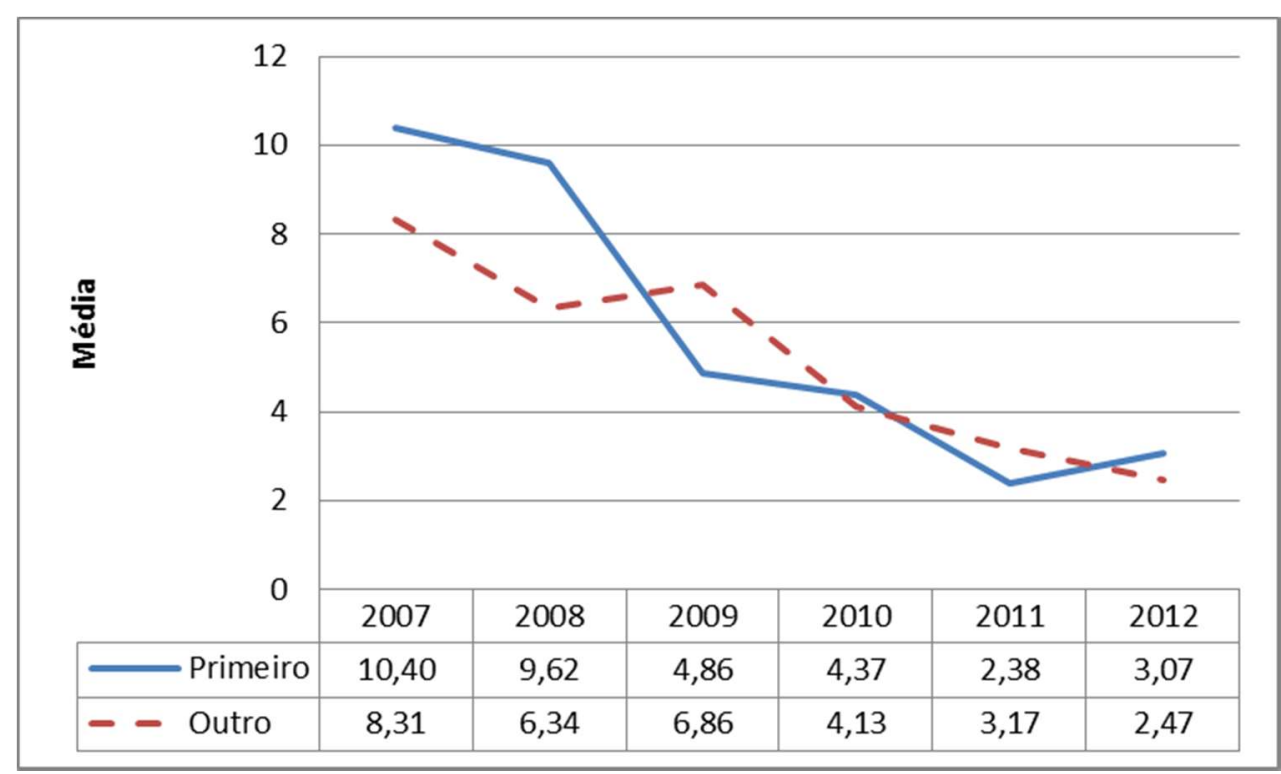

Figura 22 - Média de citações dos artigos de acordo com a posição na edição, por ano

Ser o primeiro artigo da edição mostrou render mais citações, em média, em quatro dos seis anos analisados. No entanto, a tendência indica que a diferença entre as posições está diminuindo ao longo do período, a ponto de a linha de tendência entre as duas séries cruzarem entre os anos de 2008 para 2009 e de 2010 para 2011.

Tabela 16 - Participação de cada posição na edição entre os 10\% e 1\% de artigos mais citados

\begin{tabular}{l|r|r|r|r}
\hline Rótulos de Linha & \multicolumn{1}{c}{ top $\mathbf{1 0 \%}$} & \multicolumn{1}{c}{$\%$} & top $\mathbf{1 \%}$ & \multicolumn{1}{c}{$\%$} \\
\hline Primeiro & 48 & $19 \%$ & 5 & $20 \%$ \\
\hline Outro & 206 & $81 \%$ & 20 & $80 \%$ \\
\hline Total Geral & 254 & $100 \%$ & 25 & $100 \%$ \\
\hline
\end{tabular}

A proporção de participação da primeira posição do artigo na edição foi de $19 \%$, e $20 \%$ entre os artigos mais citados. Os cinco artigos colocados na primeira posição da edição entre os $1 \%$ mais citados tinham primeiro autor homem; quatro deles eram doutores e um mestre; quatro publicados na Revista Contabilidade \& Finanças e um na Revista de Contabilidade e Organizações; quatro com afiliação institucional da USP e um da PUC/SP; três eram da linha 4, Educação e Pesquisa, um deles da linha 2, Usuários externos, e um da linha 3, Mercado de capitais. Nenhum dos cinco artigos contava com primeira autoria ou participação feminina.

\subsection{Gênero do primeiro autor}

O gênero dos autores é discutido na ciência da informação, e os estudos, principalmente os mais antigos, identificam que artigos de autoria feminina eram, em 
média, menos citados que de autoria masculina, na maioria das áreas da ciência. As exceções seriam as áreas da Ciência em que a atuação feminina é quantitativamente maior, como, por exemplo, enfermagem e serviço social. Considerando o que indicam Ayres e Vars (2000), ao observarem que o gênero do primeiro autor afeta a quantidade de citações, optou-se por analisar essa variável.

A Tabela 17 mostra a estatística descritiva das citações por gênero do primeiro autor:

Tabela 17 - Estatística descritiva das citações dos artigos pelo gênero do primeiro autor

\begin{tabular}{l|r|r}
\hline Estatística & Homem & \multicolumn{1}{l}{ Mulher } \\
\hline Média & 4,813499 & 4,922444 \\
\hline Erro padrão & 0,218596 & 0,274345 \\
\hline Mediana & 2 & 2 \\
\hline Moda & 0 & 0 \\
\hline Desvio padrão & 8,983735 & 8,003152 \\
\hline Variância da amostra & 80,7075 & 64,05045 \\
\hline Curtose & 41,949 & 24,57462 \\
\hline Assimetria & 5,404355 & 3,947804 \\
\hline Intervalo & 111 & 85 \\
\hline Mínimo & 0 & 0 \\
\hline Máximo & 111 & 85 \\
\hline Soma & 8130 & 4189 \\
\hline Contagem & 1689 & 851 \\
\hline
\end{tabular}

A média de citações de artigos com a primeira autora do gênero feminino é maior que a média de citações de artigos com o primeiro autor do gênero masculino (4,92 > $4,81)$. No entanto o teste Kolmogorov-Smirnov indica que as duas amostras não têm distribuição normal, ambas com $\mathrm{p}$-valor $=0,000$. O teste Mann-Whitney indica que a diferença das médias não é estatisticamente significante ( $p$-valor $=0,612)$.

A Figura 23 mostra a estatística descritiva das citações por gênero do primeiro autor ao longo do tempo. 


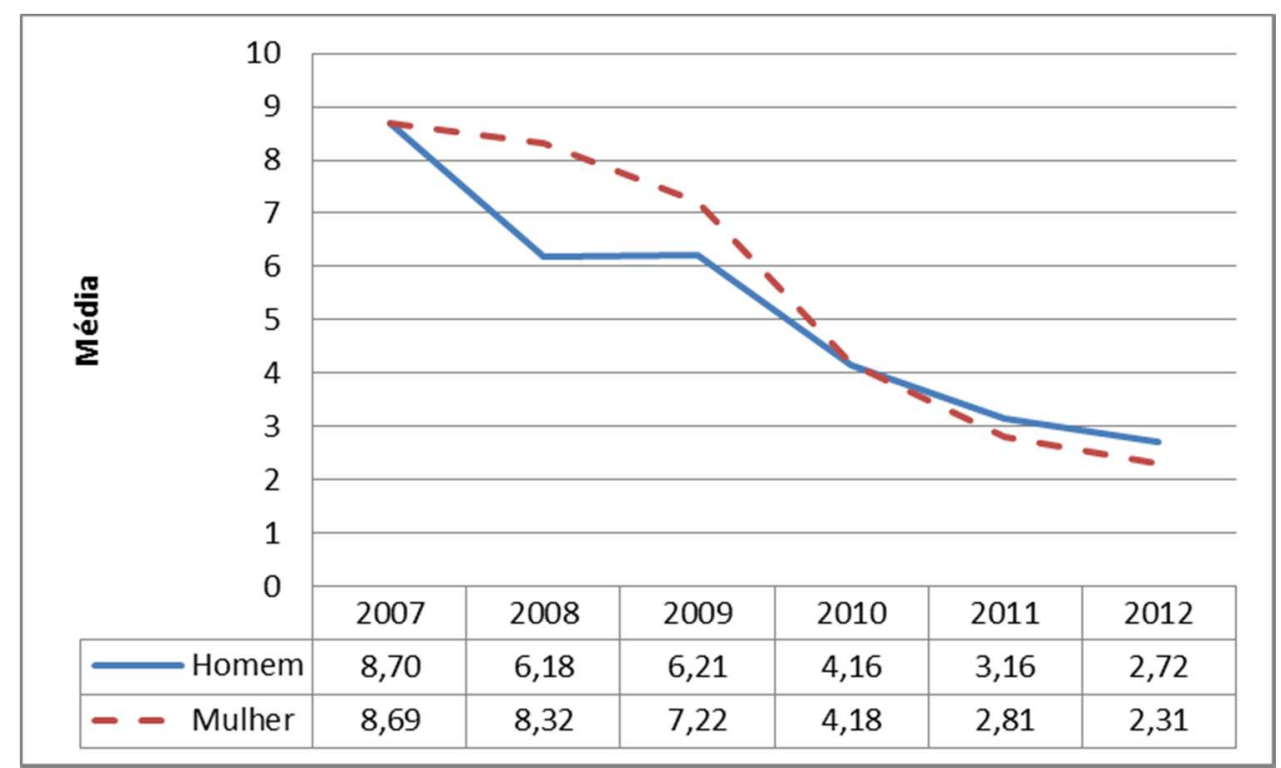

Figura 23 - Média de citações do artigo, por gênero do primeiro autor, por ano

Os artigos com mulher como primeiro autor tiveram maior média de citações que os artigos com primeiro autor homem em três dos seis anos analisados. No entanto, as linhas de tendência entre as duas categorias se cruzaram em 2011, ambas apresentando tendência decrescente.

Tabela 18 - Participação de cada Gênero do $1^{\circ}$ autor entre os $10 \%$ e $1 \%$ de artigos mais citados

\begin{tabular}{l|r|r|r|r}
\hline Rótulos de Linha & top $\mathbf{1 0 \%}$ & \multicolumn{1}{c}{$\%$} & top $\mathbf{1 \%}$ & \multicolumn{1}{c}{$\%$} \\
\hline Homem & 155 & $61 \%$ & 20 & $80 \%$ \\
\hline Mulher & 99 & $39 \%$ & 5 & $20 \%$ \\
\hline Total Geral & 254 & $100 \%$ & 25 & $100 \%$ \\
\hline
\end{tabular}

Já a proporção de artigos escritos por primeira autora caiu de $39 \%$, entre os $10 \%$ de artigos mais citados, para $20 \%$, entre os $1 \%$ de artigos mais citados. Quatro dos cinco artigos com primeiras autoras foram publicados pela Revista de Contabilidade \& Finanças, e um pela Revista de Informação Contábil. Quatro das primeiras autoras eram doutoras, e uma era mestra. Duas tinham afiliação institucional com a USP, uma com a FURB, e outras duas com IESs sem programa de pós-graduação stricto sensu em Contabilidade. Quatro artigos eram da linha 4, Educação e Pesquisa, e um era da linha 2, Usuários externos.

\subsection{Titulação ou grau do primeiro autor}

Acredita-se que esta variável, titulação ou grau do primeiro autor, possa ter influência no número de citações que um artigo recebe devido ao fato de que, de acordo com o 
senso comum, se espera que autores com maior experiência produzam pesquisas mais consistentes e de maior relevância para a academia.

Há que se registrar, contudo, que os dados encontrados passaram por uma recategorização. Os dados originais compreendiam as categorias "graduando", "bacharel", "especialista", “especializando", “mestrando”, “mestre”, “doutorando", "doutor", "pós-doutorando" e "pós-doutor".

Essa reclassificação foi feita com a seguinte diretriz: autores que já concluíram o doutorado foram categorizados como "doutor", incluindo as categorias doutor (788; $31,02 \%)$, pós-doutorando $(5 ; 0,20 \%)$ e pós-doutor $(20 ; 0,79 \%)$; autores que já concluíram o mestrado, mas não o doutorado foram reclassificados como "mestre", incluindo as categorias mestre $(664 ; 26,14 \%)$ e doutorando $(346 ; 13,62 \%)$; autores que já concluíram a graduação, mas não o mestrado, foram reclassificados como "bacharel", com as categorias bacharel (1; 0,04\%), especialista (68; 2,68\%), especializando $(19 ; 0,75 \%)$, mestrando $(347 ; 13,66 \%)$; e os alunos que não concluíram a graduação foram classificados como "graduando" (82; 3,23\%).

No entanto, cuidado deve ser tomado quando da análise desse fator, visto que nem todas as ciências têm por prática utilizar a sequência do nome dos autores para refletir o grau de contribuição. A ordenação dos autores pode ser feita, por exemplo, por ordem alfabética ou por ordem de titulação. Todavia, na área de Contabilidade no Brasil, embora não haja uma orientação formal de conhecimento do autor desta Tese, a prática da ordenação dos nomes dos autores leva em consideração o grau de contribuição para o desenvolvimento da pesquisa.

A Tabela 19 mostra a estatística descritiva da média de citações dos artigos, de acordo com o grau acadêmico do primeiro autor.

Tabela 19 - Estatística descritiva das citações dos artigos pela titulação do $1^{\circ}$ autor

\begin{tabular}{l|r|r|r|r}
\hline Estatística & Graduando & Bacharel & Mestre & Doutor \\
\hline Média & 3,292683 & 3,245669 & 5,075248 & 5,98032 \\
\hline Erro padrão & 0,704758 & 0,187289 & 0,279153 & 0,371125 \\
\hline Mediana & 1 & 2 & 2 & 3 \\
\hline Moda & 0 & 0 & 0 & 0 \\
\hline Desvio padrão & 6,381857 & 4,719527 & 8,871636 & 10,58194 \\
\hline Variância da amostra & 40,72809 & 22,27394 & 78,70593 & 111,9774 \\
\hline
\end{tabular}




\begin{tabular}{l|r|r|r|r}
\hline Curtose & 25,32566 & 13,16382 & 30,48392 & 31,41405 \\
\hline Assimetria & 4,418739 & 3,000356 & 4,415088 & 4,842787 \\
\hline Intervalo & 46 & 38 & 107 & 111 \\
\hline Mínimo & 0 & 0 & 0 & 0 \\
\hline Máximo & 46 & 38 & 107 & 111 \\
\hline Soma & 270 & 2061 & 5126 & 4862 \\
\hline Contagem & 82 & 635 & 1010 & 813 \\
\hline
\end{tabular}

Como esperado, a média de citações do artigo decresce junto com a titulação do primeiro autor, partindo do doutorado (média $=5,98$ ), para o mestrado ( édia $=5,07$ ), e o bacharelado (média $=3,24$ ). Observa-se, contudo, exceção no caso dos graduandos, que se mostrou, numericamente, maior que dos bacharéis (média = 3,29 $>$ média $=3,24)$, embora essa média tenha um desvio-padrão maior para os graduandos que para os bacharéis. Também é interessante notar que a mediana de citações por artigo dos graduandos é 1, dos bacharéis e mestres é 2 e dos doutores é 3. O artigo mais citado com primeiro autor graduando teve 46 citações; com primeiro autor bacharel, 38 citações; com primeiro autor mestre, 107 citações; e com primeiro autor doutor, 111 citações.

O teste Kolmogorov-Smirnov indica que as distribuições de frequência das quatro categorias não são normais, todas com p-valor $=0,000$. O teste Kruskal-Wallis indica que as diferenças das médias são estatisticamente significantes ( $p$-valor $=0,000$ ).

A Figura 24 mostra as médias de citação dos artigos, de acordo com a titulação do primeiro autor, ao longo do tempo. 


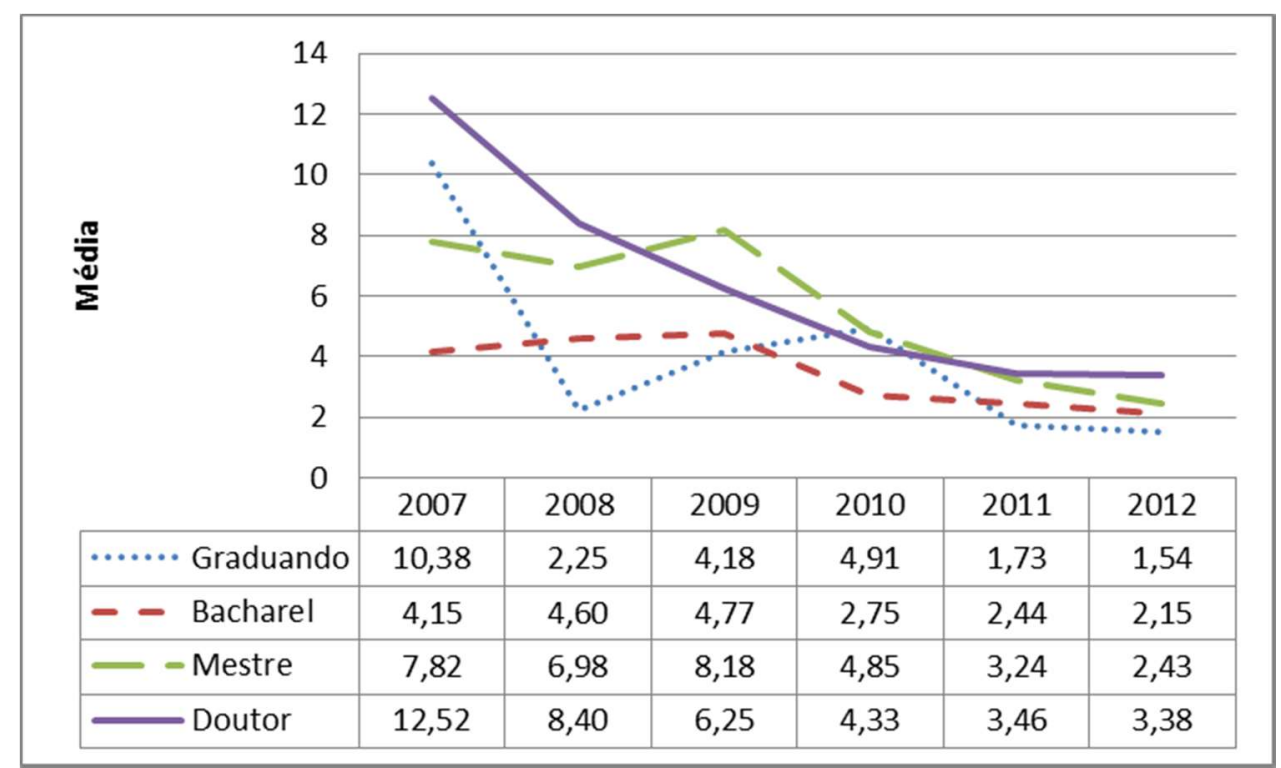

Figura 24 - Média de citações do artigo por grau acadêmico do primeiro autor, por ano

Os artigos com primeiros autores doutores foram os mais citados em quatro dos seis anos analisados. A média de citações de artigos com primeiro autor mestre foi a maior em 2009. A média de citações de artigos com primeiro autor graduando foi a maior em 2010.

Tabela 20 - Participação de cada Titulação do $1^{\circ}$ autor entre os $10 \%$ e $1 \%$ de artigos mais citados

\begin{tabular}{l|r|r|r|r}
\hline Rótulos de Linha & top 10\% & \multicolumn{1}{c|}{$\%$} & top 1\% & \multicolumn{1}{c}{$\%$} \\
\hline Graduando & 5 & $2 \%$ & 1 & $4 \%$ \\
\hline Bacharel & 34 & $13 \%$ & 0 & $0 \%$ \\
\hline Mestre & 111 & $44 \%$ & 10 & $40 \%$ \\
\hline Doutor & 104 & $41 \%$ & 14 & $56 \%$ \\
\hline Total Geral & 254 & $100 \%$ & 25 & $100 \%$ \\
\hline
\end{tabular}

Embora artigos com primeiro autor com grau acadêmico menor até apareçam na lista dos $10 \%$ de artigos mais citados, quando se trata do grupo de $1 \%$ mais citados, eles quase desaparecem. A proporção de primeiros autores doutores cresce de $41 \%$ para $56 \%$ entre os patamares $10 \%$ e $1 \%$ mais citados. Os artigos com primeiros autores não doutores, entre os mais citados, são da linha 3, Mercado de capitais (4/11), e da linha 2, Usuários externos (5/11). Há, ainda, um da linha 2, Contabilidade gerencial e Controladoria, e um artigo da linha 4, Educação e Pesquisa. Dos 11 artigos com primeiro autor não doutor, apenas um tem autoria feminina.

\subsection{Afiliação institucional do $1^{\circ}$ autor}


A literatura (Ayres \& Vars, 2000; Leimu \& Koricheva, 2005; Stremersch et al., 2007; Mingers \& Xu, 2010) aponta que instituições mais renomadas podem emprestar seu prestígio a autores individuais, de modo que seus trabalhos entram em maior evidência do que os de autores de instituições de menor prestígio. Também ocorre o fato de que instituições criam renome devido a qualidade do trabalho desenvolvido por seus pesquisadores. Ou seja, é o círculo virtuoso da pesquisa: instituições de maior prestígio atraem o interesse de pesquisadores de talento, que as mantêm entre as instituições de maior prestígio.

A Tabela 21 mostra a estatística descritiva das citações dos artigos, de acordo com a instituição do primeiro autor: 
Tabela 21 - Estatística descritiva das citações dos artigos, de acordo com a IES do $1^{\circ}$ autor

\begin{tabular}{|c|c|c|c|c|c|c|c|c|c|c|c|c|c|}
\hline IES & Média & Erro padrão & Mediana & Moda & $\begin{array}{l}\text { Desvio } \\
\text { padrão }\end{array}$ & $\begin{array}{l}\text { Variância } \\
\text { da amostra }\end{array}$ & Curtose & Assimetria & Intervalo & Mínimo & Máximo & Soma & Contagem \\
\hline FECAP & 10,53 & 6,3 & 4 & 4 & 26,1 & 680,4 & 16,4 & 4 & 111 & 0 & 111 & 179 & 17 \\
\hline UPM & 10,48 & 3,4 & 2 & 2 & 18,7 & 350,1 & 9,3 & 2,9 & 87 & 0 & 87 & 325 & 31 \\
\hline FUCAPE & 9,07 & 1,5 & 6,5 & 4 & 9,6 & 91,6 & 2,6 & 1,7 & 39 & 0 & 39 & 381 & 42 \\
\hline PUCSP & 8,86 & 3,9 & 2 & 0 & 18,4 & 337,5 & 6,9 & 2,8 & 66 & 0 & 66 & 195 & 22 \\
\hline USP & 7,8 & 0,6 & 3 & 0 & 12,6 & 159 & 20,1 & 3,9 & 107 & 0 & 107 & 2941 & 377 \\
\hline UFES & 7,79 & 2,9 & 4 & 4 & 10,9 & 119,1 & 9,5 & 2,9 & 43 & 0 & 43 & 109 & 14 \\
\hline UFPB & 6,69 & 1,6 & 5,5 & 3 & 8 & 64,2 & 9,3 & 2,8 & 38 & 0 & 38 & 174 & 26 \\
\hline USPRP & 5,29 & 1,5 & 3 & 3 & 8,1 & 66 & 14 & 3,4 & 42 & 0 & 42 & 164 & 31 \\
\hline UERJ & 4,67 & 1 & 2 & 0 & 7,6 & 58,2 & 8,1 & 2,8 & 35 & 0 & 35 & 285 & 61 \\
\hline UFRJ & 4,67 & 0,6 & 3 & 0 & 6,6 & 42,9 & 6,9 & 2,5 & 34 & 0 & 34 & 509 & 109 \\
\hline UNISINOS & 4,6 & 0,8 & 3 & 0 & 6,1 & 37,6 & 7 & 2,5 & 32 & 0 & 32 & 299 & 65 \\
\hline UFPE & 4,49 & 0,7 & 3 & 0 & 5,6 & 31,9 & 6,5 & 2,1 & 31 & 0 & 31 & 292 & 65 \\
\hline UFMG & 4,42 & 0,7 & 3 & 0 & 5,9 & 35,3 & 7,5 & 2,4 & 34 & 0 & 34 & 349 & 79 \\
\hline UFSC & 4,38 & 0,5 & 2 & 0 & 7,8 & 61,4 & 20,7 & 3,9 & 66 & 0 & 66 & 1051 & 240 \\
\hline FURB & 3,86 & 0,6 & 2 & 0 & 7,5 & 55,8 & 74,2 & 7,6 & 79 & 0 & 79 & 540 & 140 \\
\hline OUTRO & 3,81 & 0,2 & 2 & 0 & 6,6 & 43,6 & 34,3 & 4,6 & 85 & 0 & 85 & 3530 & 927 \\
\hline UNB & 3,72 & 0,4 & 2 & 0 & 5,6 & 31,2 & 23,2 & 3,9 & 46 & 0 & 46 & 595 & 160 \\
\hline UFBA & 3,17 & 0,7 & 2 & 0 & 4,7 & 22,4 & 15,2 & 3,4 & 27 & 0 & 27 & 133 & 42 \\
\hline UFPR & 3,1 & 0,5 & 2 & 0 & 3,3 & 11 & 1,6 & 1,4 & 13 & 0 & 13 & 155 & 50 \\
\hline UFRN & 2,69 & 0,7 & 1 & 0 & 4,7 & 22,6 & 10,2 & 2,9 & 24 & 0 & 24 & 113 & 42 \\
\hline
\end{tabular}


É interessante verificar como a dinâmica das posições que as instituições alcançam, de acordo com a média de citações por artigo, difere de indicadores governamentais de avaliação de programas de pós-graduação, de acordo com os conceitos atribuídos pela Capes, e de pesquisas que utilizam outros critérios, como a de Soares, Richartz e Murcia (2013) e Soares e Murcia (2016).

A avaliação por conceitos da Capes, que não contempla medidas de citações de artigos, atribuiu para os programas, nos triênios 2007-2009 e 2010-2012, os seguintes conceitos, respectivamente: USP (6 e 6), FURB (4 e 4), UFSC (4 e 4), FECAP (4 e 4), UPM ( 4 e 4 ) e USP/RP ( 4 e 4 ). A média de citações dos artigos, cujo primeiro autor indica ter afiliação institucional com a USP, fica em quinto; abaixo da FECAP, que fica em primeiro; da UPM, que fica em segundo; da FUCAPE, que fica em terceiro; e da USP/RP, que fica em quarto. A média de citações dos artigos, cujos primeiros autores têm como afiliação institucional a UFSC e FURB, fica em $14^{\circ}$ e $15^{\circ}$, respectivamente.

Soares et al. (2013), usando de indicadores que mensuram a quantidade de artigos produzidos por programas de pós-graduação stricto sensu acadêmicos em Contabilidade, no triênio 2007-2012, indicam que a USP $\left(1^{\circ}\right)$ e a FURB $\left(2^{\circ}\right)$ obtiveram o melhor desempenho no período; enquanto a FECAP $\left(12^{\circ}\right)$, a UPM $\left(8^{\circ}\right)$ e a PUC/SP $\left(13^{\circ}\right)$ não obtiveram posições tão altas no ranking. Soares e Múrcia (2016), usando os mesmos indicadores no período de 2010-2012, identificaram a FURB e a UFSC empatadas em primeiro lugar, a PUC/SP em $15^{\circ}$ e a FECAP em $16^{\circ}$.

Como visto na Tabela 21, as maiores médias de citação pertencem à FECAP, UPM, FUCAPE e PUC/SP, mostrando desempenho bastante distinto daquele baseado em indicadores decorrentes do volume de publicação.

A partir desses resultados, pode-se argumentar acerca da necessidade de que a avaliação institucional de programas incorpore medidas de ressonância da produção bibliográfica, como as taxas de citação, em acréscimo aos indicadores já usados. Pode-se acrescer, ainda, que a implementação desses indicadores se tornará mais fácil à medida que a biblioteca eletrônica Spell consolidar seus indicadores e ampliar 
sua cobertura, e que mais pesquisas usando o Google Acadêmico® ou Microsoft Academic Search $\circledast$ sejam realizadas usando as revistas brasileiras.

A Tabela 22 evidencia a participação de artigos, segundo a afiliação institucional do primeiro autor entre os $10 \%$ e $1 \%$ de artigos mais citados.

Tabela 22 - Participação de cada IES do $1^{\circ}$ autor entre os $10 \%$ e $1 \%$ de artigos mais citados

\begin{tabular}{l|r|r|r|r}
\hline Rótulos de Linha & top $\mathbf{1 0} \%$ & \multicolumn{1}{c|}{$\%$} & top 1\% & \multicolumn{1}{c}{$\%$} \\
\hline FECAP & 2 & $1 \%$ & 1 & $4 \%$ \\
\hline FUCAPE & 10 & $4 \%$ & 0 & $0 \%$ \\
\hline FURB & 7 & $3 \%$ & 1 & $4 \%$ \\
\hline OUTRO & 68 & $27 \%$ & 4 & $16 \%$ \\
\hline PUCSP & 3 & $1 \%$ & 2 & $8 \%$ \\
\hline UERJ & 6 & $2 \%$ & 0 & $0 \%$ \\
\hline UFBA & 1 & $0 \%$ & 0 & $0 \%$ \\
\hline UFES & 3 & $1 \%$ & 1 & $4 \%$ \\
\hline UFMG & 9 & $4 \%$ & 0 & $0 \%$ \\
\hline UFPB & 3 & $1 \%$ & 0 & $0 \%$ \\
\hline UFPE & 7 & $3 \%$ & 0 & $0 \%$ \\
\hline UFPR & 2 & $1 \%$ & 0 & $0 \%$ \\
\hline UFRJ & 10 & $4 \%$ & 0 & $0 \%$ \\
\hline UFRN & 2 & $1 \%$ & 0 & $0 \%$ \\
\hline UFSC & 20 & $8 \%$ & 1 & $4 \%$ \\
\hline UNB & 10 & $4 \%$ & 1 & $4 \%$ \\
\hline UNISINOS & 6 & $2 \%$ & 0 & $0 \%$ \\
\hline UPM & 8 & $3 \%$ & 3 & $12 \%$ \\
\hline USP & 72 & $28 \%$ & 11 & $44 \%$ \\
\hline USPRP & 5 & $2 \%$ & 0 & $0 \%$ \\
\hline Total Geral & 254 & $100 \%$ & 25 & $100 \%$ \\
\hline
\end{tabular}

A USP é a afiliação institucional do $1^{\circ}$ autor mais frequente entre os artigos mais citados e responde por $28 \%$ dos $10 \%$ mais citados, e $44 \%$ do grupo de $1 \%$ de artigos mais citados. As instituições que aparecem na sequência são a UPM e a PUC/SP, com $12 \%$ e $8 \%$, respectivamente.

\subsection{Linha de pesquisa do artigo}

As linhas são agrupamentos com características de pesquisa parecidas, em termos de rumo, campo específico do conhecimento, orientação teórica e procedimentos (Borges-Andrade, 2003). Nesta Tese, optou-se por dividir as pesquisas em seis grandes linhas: Controladoria e Contabilidade gerencial; Contabilidade para usuários externos; Mercado de capitais; Educação e Pesquisa; Contabilidade pública; e 
Contabilidade do Terceiro setor. Acredita-se que, devido as características de cada uma dessas linhas, as taxas de citação sejam quantitativamente afetadas.

Essa hipótese foi levantada após se constatar serem as pesquisas das duas primeiras linhas mais numerosas que as demais, o que poderia criar dinâmicas de citação diferentes umas das outras. As pesquisas de Ayres e Vars (2000), Stremersch et al. (2007), Antonakis et al. (2014) e Stremersch et al. (2015) também indicam a influência desta variável na quantidade de citações dos artigos.

Tabela 23 - Estatística descritiva das citações dos artigos, de acordo com a linha de pesquisa

\begin{tabular}{|c|c|c|c|c|c|c|}
\hline Estatística & $\begin{array}{l}\text { Contabilidad } \\
\text { e } \\
\text { gerencial }\end{array}$ & $\begin{array}{l}\text { Usuários } \\
\text { externos }\end{array}$ & $\begin{array}{l}\text { Mercado } \\
\text { de capitais }\end{array}$ & $\begin{array}{l}\text { Educação } \\
\text { e } \\
\text { Pesquisa }\end{array}$ & $\begin{array}{l}\text { Contabil. } \\
\text { pública }\end{array}$ & $\begin{array}{l}\text { Terceiro } \\
\text { setor }\end{array}$ \\
\hline Média & 3,231047 & 6,011976 & 5,404938 & 5,67562 & $\begin{array}{r}4,86324 \\
8\end{array}$ & $\begin{array}{r}3,22857 \\
1\end{array}$ \\
\hline Erro padrão & 0,177283 & 0,38915 & 0,485404 & 0,466977 & $\begin{array}{r}0,76736 \\
3\end{array}$ & $\begin{array}{r}0,56818 \\
4\end{array}$ \\
\hline Mediana & 2 & 3 & 3 & 3 & 2 & 3 \\
\hline Moda & 0 & 0 & 0 & 0 & 0 & 0 \\
\hline Desvio padrão & 5,110542 & 10,05785 & 9,768558 & 10,27349 & $\begin{array}{r}8,30029 \\
7\end{array}$ & $\begin{array}{r}3,36142 \\
2\end{array}$ \\
\hline Variância da amostra & 26,11764 & 101,1603 & 95,42473 & 105,5447 & $\begin{array}{r}68,8949 \\
3\end{array}$ & $\begin{array}{r}11,2991 \\
6\end{array}$ \\
\hline Curtose & 17,40998 & 18,77318 & 43,42973 & 38,61292 & $\begin{array}{r}25,7707 \\
3\end{array}$ & $\begin{array}{r}1,07460 \\
3\end{array}$ \\
\hline Assimetria & 3,540135 & 3,719432 & 5,50489 & 5,278689 & $\begin{array}{r}4,25820 \\
4\end{array}$ & $\begin{array}{r}1,20416 \\
1\end{array}$ \\
\hline Intervalo & 44 & 87 & 107 & 111 & 66 & 13 \\
\hline Mínimo & 0 & 0 & 0 & 0 & 0 & 0 \\
\hline Máximo & 44 & 87 & 107 & 111 & 66 & 13 \\
\hline Soma & 2685 & 4016 & 2189 & 2747 & 569 & 113 \\
\hline Contagem & 831 & 668 & 405 & 484 & 117 & 35 \\
\hline
\end{tabular}

A Tabela 23 mostra que, em ordem decrescente de média de citações, as áreas se ordenam como: Usuários externos (média $=6,01$ ), Educação e Pesquisa (média =5,67), Mercado de capitais (média = 5,40), Contabilidade pública (média = 4,86), Contabilidade gerencial e Controladoria (média = 3,23), e Contabilidade do Terceiro Setor (média $=3,22$ ). Enquanto as áreas de Contabilidade gerencial e Controladoria e Contabilidade pública têm mediana 2, as demais áreas têm mediana 3. $\mathrm{O}$ artigo com mais citações pertence a área de Educação e Pesquisa (111), seguido de Mercado de capitais (107), Usuários externos (87), Contabilidade pública (66), Contabilidade gerencial (44) e Terceiro setor (13). 
O teste Kolmogorov-Smirnov indica que as distribuições das citações das seis categorias não são normais, tendo as cinco primeiras p-valor $=0,000$, e a do Terceiro setor $p$-valor $=0,000$. O teste Kruskal-Wallis indica que as diferenças das médias são estatisticamente significantes ( $p$-valor $=0,000)$.

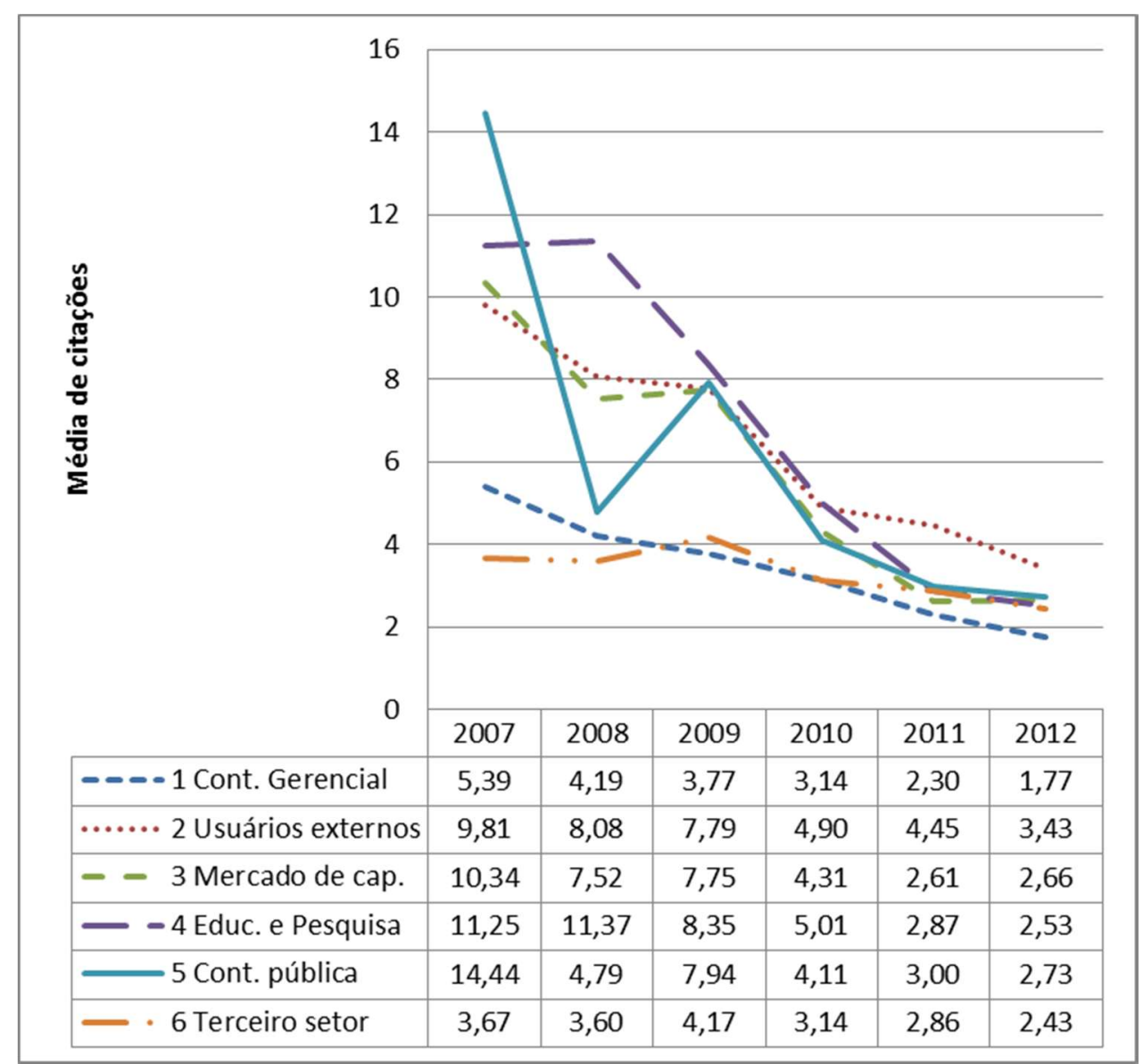

Figura 25 - Média de citações do artigo por linha de pesquisa, por ano

Os artigos de 2007 da linha Contabilidade pública foram, em média, os mais citados. Em 2008, 2009 e 2010 foi a vez dos artigos da linha Educação e pesquisa. Em 2011 e 2012 foram os artigos da linha Contabilidade para usuários externos. No entanto, um cuidado deve ser considerado quando se analisa a Figura 25, observando que os artigos mais citados, de quatro a cinco anos depois de publicados, são os da linha 2; mas os mais citados entre os publicados há seis, sete e oito anos são os da linha 4. $E$, finalmente, entre os publicados há nove anos, são os da linha 5 . Isso pode indicar que o pico de citações da linha 2 ocorra em uma janela de tempo mais curta que das demais linhas, talvez pela própria natureza das temáticas exploradas nessa linha. Interessante, ainda, observar que os artigos da linha 4, talvez pela mesma razão, têm uma janela de citação estendida. 
Tabela 24 - Participação de cada Linha de pesquisa entre os $10 \%$ e $1 \%$ de artigos mais citados

\begin{tabular}{l|r|r|r|r}
\hline \multicolumn{1}{c|}{ Rótulos de Linha } & \multicolumn{1}{c|}{ top $\mathbf{1 0} \%$} & \multicolumn{1}{c|}{ top $\mathbf{1 \%}$} & \multicolumn{1}{c}{$\boldsymbol{\%}$} \\
\hline 1. Cont. gerencial & 52 & $20 \%$ & 1 & $4 \%$ \\
\hline 2. Usuários externos & 83 & $33 \%$ & 10 & $40 \%$ \\
\hline 3. Mercado de cap. & 44 & $17 \%$ & 5 & $20 \%$ \\
\hline 4. Educ. e Pesquisa & 59 & $23 \%$ & 8 & $32 \%$ \\
\hline 5. Cont. pública & 15 & $6 \%$ & 1 & $4 \%$ \\
\hline 6. Terceiro setor & 1 & $0 \%$ & 0 & $0 \%$ \\
\hline Total Geral & 254 & $100 \%$ & 25 & $100 \%$ \\
\hline
\end{tabular}

Dos dez artigos mais citados da linha de Usuários externos, cinco têm primeiro autor doutor e cinco têm primeiro autor mestre. Um deles tem primeira autora enquanto os nove restantes têm primeiros autores. Quatro deles têm a USP como afiliação institucional do primeiro autor.

Dos oito artigos de Educação e Pesquisa, sete têm primeiro autor doutor e um tem primeiro autor mestre. Metade deles têm primeiro autor do gênero masculino e metade do gênero feminino. Metade deles têm a USP como afiliação institucional do primeiro autor.

O estabelecimento das estatísticas descritivas da Tabela 23 permite a redução do viés de comparação de impacto de pesquisas por meio do número de citações entre as seis linhas estudadas. Sabe-se agora que, se dois artigos, um da linha de Contabilidade gerencial e um da linha de Contabilidade para usuários externos, tiverem três citações cada, o primeiro já atingiu a média de citações de artigos daquela linha, enquanto que o segundo está na metade das citações. Outro exemplo consiste que um artigo com 13 citações na linha de Terceiro setor está no topo das citações para essa área, assim como um de 111 citações está no topo das citações da linha de Educação e Pesquisa. Caberia aos dirigentes de instituições de ensino e pesquisa, coordenadores de programas e representantes de órgãos avaliadores, ao estabelecerem metas e critérios de avaliação, aprofundar o conhecimento nessas diferenças entre linhas de pesquisa.

4.16 Estrato do Qualis da revista, vigente no ano que o artigo foi publicado 
O sistema de avaliação/classificação de periódicos Qualis é utilizado na avaliação da qualidade da pesquisa dos programas de pós-graduação e foi criado para classificar periódicos com a diretriz de que as revistas mais bem classificadas sejam aquelas que veiculam os melhores trabalhos, e aquelas classificadas em estratos mais baixos veiculem trabalhos de menor expressão.

Já o sistema de avaliação da Capes atribui pontuação diferenciada aos discentes e docentes que publicam em revistas de cada estrato. Não existem revistas de Contabilidade classificadas no estrato A1. Para cada um dos estratos em que há revistas de Contabilidade, a pontuação respectiva é: $\mathrm{A} 2=80$ pontos; $\mathrm{B} 1=60$ pontos; $\mathrm{B} 2=50$ pontos, $\mathrm{B} 3=30$ pontos, $\mathrm{B} 4=20$ pontos e $\mathrm{B} 5=10$ pontos.

A Tabela 25 exibe as estatísticas descritivas das citações por estrato do Qualis.

Tabela 25 - Estatística descritiva das citações dos artigos de acordo com o estrato Qualis da revista

\begin{tabular}{l|r|r|r|r|r|r|r|r}
\hline \multicolumn{1}{c|}{ Estatística } & \multicolumn{1}{c|}{$\mathrm{A} 2$} & \multicolumn{1}{c|}{$\mathrm{B} 1$} & \multicolumn{1}{c|}{$\mathrm{B} 2$} & \multicolumn{1}{c}{$\mathrm{B} 3$} & \multicolumn{1}{c}{$\mathrm{B} 4$} & \multicolumn{1}{c}{$\mathrm{B} 5$} & \multicolumn{1}{c}{$\mathrm{C}$} & \multicolumn{1}{c}{$\mathrm{NC}$} \\
\hline Média & 7,205128 & 8,667421 & 3,401247 & 5,383206 & 3,136139 & 2,403941 & 3,708108 & 3,51087 \\
\hline Erro padrão & 0,93412 & 0,68461 & 0,207153 & 0,339241 & 0,27306 & 0,28415 & 0,420614 & 0,549615 \\
\hline Mediana & 5 & 4 & 2 & 3 & 2 & 1 & 2 & 1,5 \\
\hline Moda & 2 & 0 & 0 & 0 & 0 & 0 & 0 & 0 \\
\hline Desvio padrão & 8,249926 & 14,3931 & 4,543209 & 8,682192 & 5,48843 & 4,048516 & 5,720975 & 5,271725 \\
\hline $\begin{array}{l}\text { Variância da } \\
\text { amostra }\end{array}$ & 68,06127 & 207,1612 & 20,64075 & 75,38045 & 30,12286 & 16,39048 & 32,72955 & 27,79109 \\
\hline Curtose & 5,619564 & 16,75439 & 5,890627 & 27,96823 & 31,98643 & 12,81246 & 11,20443 & 4,476253 \\
\hline Assimetria & 2,18469 & 3,656423 & 2,219875 & 4,288113 & 4,840911 & 3,151762 & 2,954646 & 2,162561 \\
\hline Intervalo & 44 & 111 & 28 & 87 & 52 & 27 & 38 & 24 \\
\hline Mínimo & 0 & 0 & 0 & 0 & 0 & 0 & 0 & 0 \\
\hline Máximo & 44 & 111 & 28 & 87 & 52 & 27 & 38 & 24 \\
\hline Soma & 562 & 3831 & 1636 & 3526 & 1267 & 488 & 686 & 323 \\
\hline Contagem & 78 & 442 & 481 & 655 & 404 & 203 & 185 & 92 \\
\hline
\end{tabular}

Pela análise da Tabela, constata-se que a média de citações dos artigos publicados em revistas do estrato B3 é maior que a média de citações dos artigos publicados em revistas do estrato $\mathrm{B} 2$, e a média de citações dos artigos do estrato B1 é maior que a média de citações dos artigos publicados em revistas do estrato A2. A média de citações em cada estrato, para o período de análise, não corrobora a pontuação atribuída aos estratos pelo Qualis.

No entanto, ressalva-se que se trata de uma média, a qual, por definição, é uma medida-resumo de uma variável. Além do que, pela identificação de Soares e Casa 
Nova (2016), a classificação no estrato do Qualis reflete apenas parcialmente a taxa média de citações dos artigos de uma revista. Esses autores identificaram, ainda, que havia revistas no estrato $\mathrm{A} 2$ com taxa média de citações, que não era estatisticamente diferente de revistas classificadas no estrato B3.

O teste Kolmogorov-Smirnov indica que as oito amostras não têm distribuição normal, tendo todas $p$-valor $=0,000$. O teste Kruskal-Wallis indica que as diferenças das médias são estatisticamente significantes ( $p$-valor $=0,000$ ).

A Figura 26 mostra a média de citações dos artigos por estrato do Qualis.

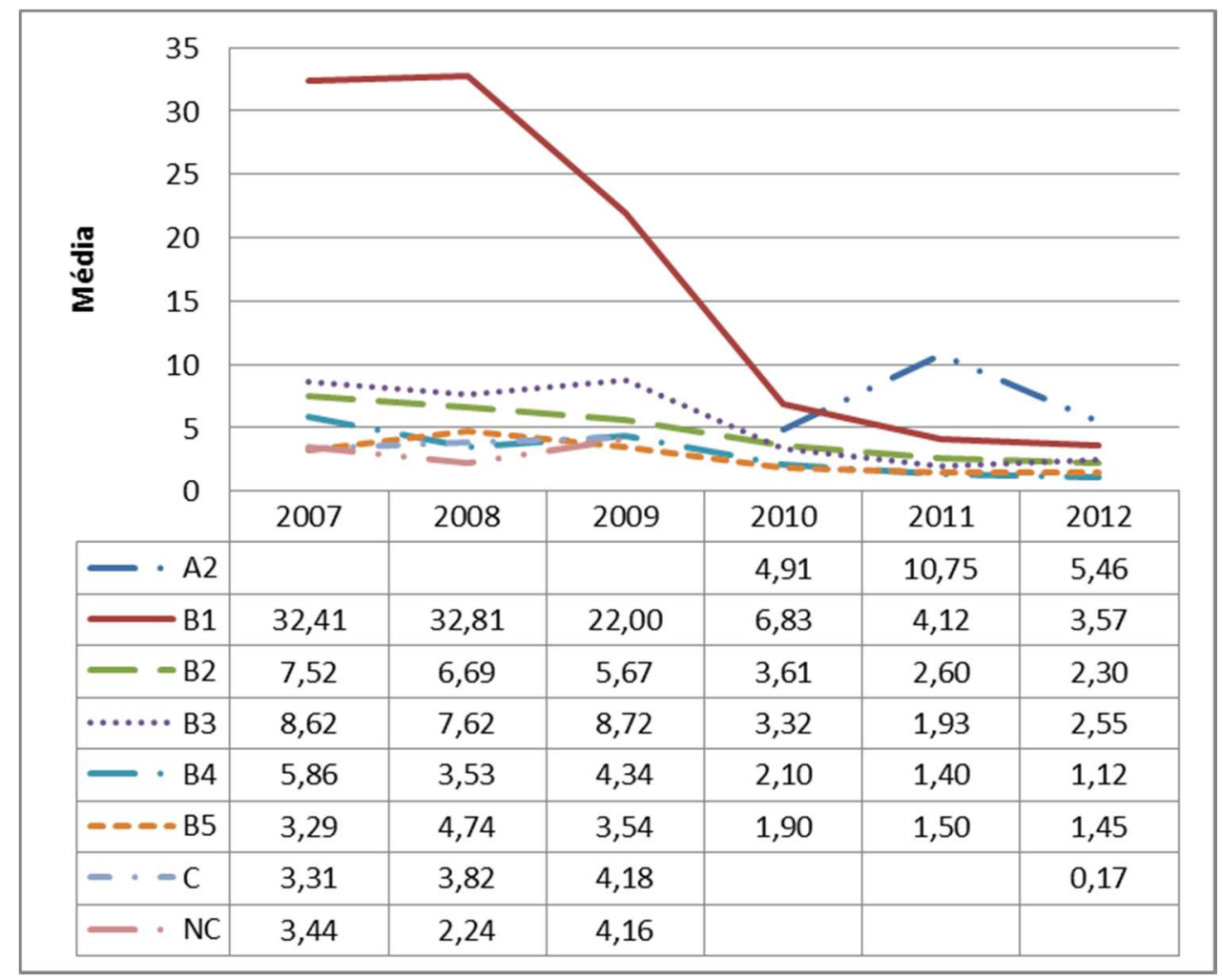

Figura 26 - Média de citações do artigo, por estrato do Qualis, por ano

Nenhuma das revistas da amostra estava classificada no estrato A2, no triênio 20072009. A Revista Contabilidade \& Finanças, que apresenta a maior média de citações no período, estava classificada como B1, no triênio 2007-2009, e subiu para o estrato A2, no triênio 2010-2012. Já, no triênio mais recente, a média de citações engloba a RC\&F e a Revista Brasileira de Gestão de Negócios. 
A Tabela 26 mostra a participação dos estratos do Qualis, nos grupos de artigos mais citados.

Tabela 26 - Participação de cada estrato do Qualis entre os 10\% e 1\% de artigos mais citados

\begin{tabular}{l|r|r|r|r}
\hline \multicolumn{1}{c|}{ Rótulos de Linha } & \multicolumn{1}{c|}{ top $\mathbf{1 0 \%}$} & \multicolumn{1}{c|}{$\boldsymbol{\text { top }} \mathbf{1 \%}$} & \multicolumn{1}{c}{$\boldsymbol{\%}$} \\
\hline A2 & 13 & $5 \%$ & 1 & $4 \%$ \\
\hline B1 & 82 & $32 \%$ & 17 & $68 \%$ \\
\hline B2 & 30 & $12 \%$ & 0 & $0 \%$ \\
\hline B3 & 82 & $32 \%$ & 5 & $20 \%$ \\
\hline B4 & 19 & $7 \%$ & 2 & $8 \%$ \\
\hline B5 & 7 & $3 \%$ & 0 & $0 \%$ \\
\hline C & 13 & $5 \%$ & 0 & $0 \%$ \\
\hline NC & 8 & $3 \%$ & 0 & $0 \%$ \\
\hline Total Geral & 254 & $100 \%$ & 25 & $100 \%$ \\
\hline
\end{tabular}

As proporções desta variável apresentam-se inesperadas. Esperava-se, a priori, que a participação do estrato A2 fosse superior aos demais e que o proporção de participação fosse decrescente, à medida que o estrato do Qualis fosse diminuindo. No entanto, há que se considerar que a alteração das revistas entre os estratos do Qualis, que ocorreu do triênio de 2007-2009 para 2010-2012, afetou sobremaneira essas proporções. Isso se deu porque muitas revistas foram classificadas para estratos mais altos, sendo que, no triênio mais antigo, foram favorecidos os artigos publicados e expostos aos leitores há mais tempo. As revistas tinham classificações em estratos mais baixos e, no triênio mais recente, no qual as revistas estão em estratos mais altos, os artigos estão expostos aos leitores há menos tempo. Isso explica, em parte, a divergência entre os Qualis das revistas e as proporções entre os grupos de artigos mais citados.

\subsection{Abordagem da análise de dados: Quantitativa ou não}

Esta variável constitui uma polêmica na ciência e é motivo de debates acalorados no âmbito epistemológico. Embora muitos pesquisadores acreditem que o problema de pesquisa determina a escolha do método, há muitos pesquisadores que entram em conflito quando se veem diante da escolha do emprego de métodos quantitativos ou qualitativos. Em linhas gerais, em ciências exatas e engenharias, o uso de métodos quantitativos é mais expressivo que os métodos qualitativos. Fenômeno diferente ocorre em ciências humanas e sociais aplicadas em que as abordagens qualitativas são usadas com relativa maior frequência. 
Além disso, parece não haver consenso sobre os limites bem definidos do campo da pesquisa qualitativa e da pesquisa quantitativa. Parece não haver dúvida que a análise de regressão pertença ao grupo de métodos quantitativos. Assim como, parece não haver dúvida de que a etnografia pertença ao grupo de métodos qualitativos. O problema surge em situações como o estudo de caso com uso de análise de séries temporais, o qual é classificado, por alguns, como método qualitativo e, por outros, como método quantitativo. Outra situação interessante é o emprego da estatística descritiva, que também é vista com ambiguidade. Há, ainda, a possibilidade de métodos mistos ou mixed methods.

Nesta Tese, após análise exploratória dos dados, optou-se por dividir as pesquisas entre aquelas que empregam métodos quantitativos e as que não empregam métodos quantitativos. No primeiro grupo, enquadram-se pesquisas que usam análise de regressão, análise fatorial, análise de correspondência, equações estruturais, análise discriminante, análise envoltória de dados, entre outras. No segundo grupo, se enquadram os estudos de caso qualitativos, a etnografia, a grounded theory, e inclui, ainda, os artigos que empregam a estatística descritiva.

Posto isso, a Tabela 27 resume as estatísticas descritivas dos artigos que utilizaram pesquisas quantitativas e não quantitativas.

Tabela 27 - Estatística descritiva das citações dos artigos de acordo com a abordagem da análise de dados

\begin{tabular}{l|r|r}
\hline Estatística & Quantitativa & Não-quantitativa \\
\hline Média & 5,115239 & 4,563473 \\
\hline Erro padrão & 0,244173 & 0,241453 \\
\hline Mediana & 2 & 2 \\
\hline Moda & 0 & 0 \\
\hline Desvio padrão & 8,867875 & 8,437054 \\
\hline Variância da amostra & 78,63921 & 71,18388 \\
\hline Curtose & 35,22747 & 42,01643 \\
\hline Assimetria & 4,851836 & 5,2754 \\
\hline Intervalo & 107 & 111 \\
\hline Mínimo & 0 & 0 \\
\hline Máximo & 107 & 111 \\
\hline Soma & 6747 & 5572 \\
\hline Contagem & 1319 & 1221 \\
\hline
\end{tabular}


A observação da Tabela 27 permite ver que os artigos que usaram abordagem quantitativa na análise de dados tiveram média de citação superior aos que utilizaram abordagem não-quantitativa. A moda, mediada e mínimo foram iguais nas duas categorias. No entanto, o máximo da abordagem não-quantitativa (111) foi superior ao máximo da abordagem quantitativa (107). Interessante ressaltar que os artigos da amostra em estudo dividiram-se de maneira muito próxima entre os dois grupos, sendo 1.319 artigos empregando métodos quantitativos, e 1.221, não-quantitativos.

O teste Kolmogorov-Smirnov indica que as duas amostras não são normais, ambas com $p$-valor $=0,000$. O teste Mann-Whitney indica que a diferença das médias é estatisticamente significante $(p$-valor $=0,002)$.

A Figura 27 mostra as médias de citações dos artigos, de acordo com a abordagem na análise de dados.

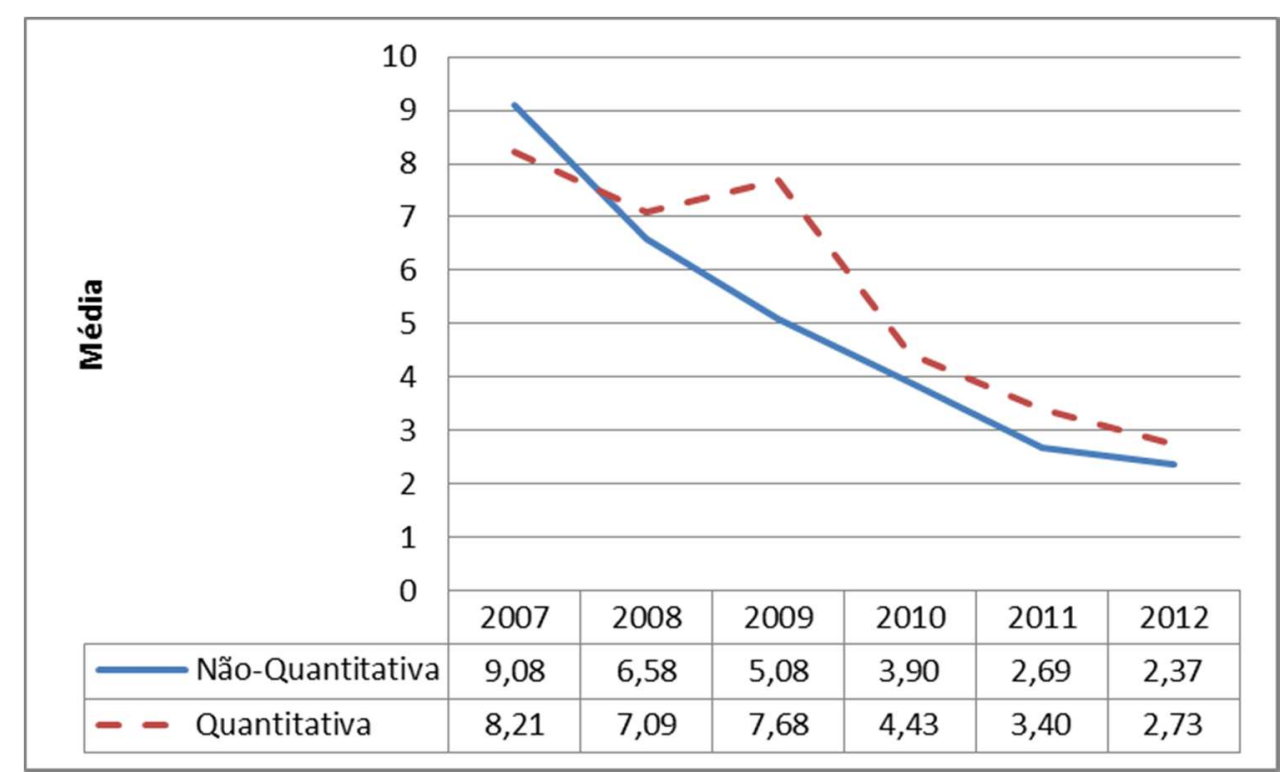

Figura 27 - Média de citações do artigo, de acordo com a abordagem dos dados, por ano

Os artigos com abordagem não-quantitativa do ano de 2007 são os únicos que tiveram média de citações maior que os artigos com abordagem de dados quantitativa em todo o período analisado. Nos cinco anos mais recentes, a média dos artigos com abordagem quantitativa de dados mostrou-se superior e, considerando que a diferença das médias foi estatisticamente significante, constitui-se um forte indicativo de que o uso de métodos quantitativos atrai mais citações para o artigo. Porém, deve- 
se ressaltar que o emprego de métodos qualitativo ou quantitativo pode estar relacionado com as linhas de pesquisa.

Tabela 28 - Participação de cada Abordagem de dados entre os $10 \%$ e $1 \%$ de artigos mais citados

\begin{tabular}{l|l|l|l|c}
\hline \multicolumn{1}{c|}{ Rótulos de Linha } & top $\mathbf{1 0} \%$ & $\mathbf{\%}$ & top 1\% & \% \\
\hline Não-Quantitativa & 120 & $47 \%$ & 14 & $56 \%$ \\
\hline Quantitativa & 134 & $53 \%$ & 11 & $44 \%$ \\
\hline Total Geral & 254 & $100 \%$ & 25 & $100 \%$ \\
\hline
\end{tabular}

Oito dos 14 artigos mais citados que usaram abordagem não-quantitativa são da linha de Educação e Pesquisa, enquanto que, dos 11 artigos que se utilizaram de abordagem quantitativa de dados, quatro são da linha de Mercado de capitais, e sete são da linha de Contabilidade para usuários externos.

\subsection{Ano em que o artigo foi publicado}

O ano em que o artigo foi publicado foi usado como uma variável dummy de controle em um dos modelos construídos (Modelo 5), para capturar o efeito de algum evento relacionado ao ano, como a reclassificação de periódicos no estrato Qualis, a aprovação da criação de novos programas de pós-graduação, a indexação de periódicos em determinadas revistas e outros eventos de natureza semelhante.

A Tabela 29 evidencia as estatísticas descritivas das citações, por ano.

Tabela 29 - Estatística descritiva das citações dos artigos, por ano

\begin{tabular}{l|r|r|r|r|r|r}
\hline Estatística & \multicolumn{1}{|c|}{2007} & \multicolumn{1}{c}{2008} & 2009 & 2010 & 2011 & \multicolumn{1}{c}{2012} \\
\hline Média & 8,698305 & 6,849858 & 6,533333 & 4,168591 & 3,050916 & 2,567474 \\
\hline Erro padrão & 0,874865 & 0,5976 & 0,486365 & 0,266355 & 0,22101 & 0,148251 \\
\hline Mediana & 4 & 3 & 3 & 2 & 1 & 1 \\
\hline Moda & 0 & 0 & 0 & 0 & 0 & 0 \\
\hline Desvio padrão & 15,0263 & 11,22789 & 9,604929 & 5,54249 & 4,897256 & 3,564185 \\
\hline Variância da amostra & 225,7896 & 126,0655 & 92,25467 & 30,7192 & 23,98312 & 12,70341 \\
\hline Curtose & 18,19324 & 17,94122 & 15,90391 & 11,10237 & 18,22718 & 8,462978 \\
\hline Assimetria & 3,827816 & 3,736111 & 3,256856 & 2,753215 & 3,618937 & 2,524787 \\
\hline Intervalo & 111 & 85 & 87 & 41 & 44 & 25 \\
\hline Mínimo & 0 & 0 & 0 & 0 & 0 & 0 \\
\hline Máximo & 111 & 85 & 87 & 41 & 44 & 25 \\
\hline Soma & 2566 & 2418 & 2548 & 1805 & 1498 & 1484 \\
\hline Contagem & 295 & 353 & 390 & 433 & 491 & 578 \\
\hline
\end{tabular}

A Figura 28 mostra a evolução das médias das citações por artigo, por ano. 


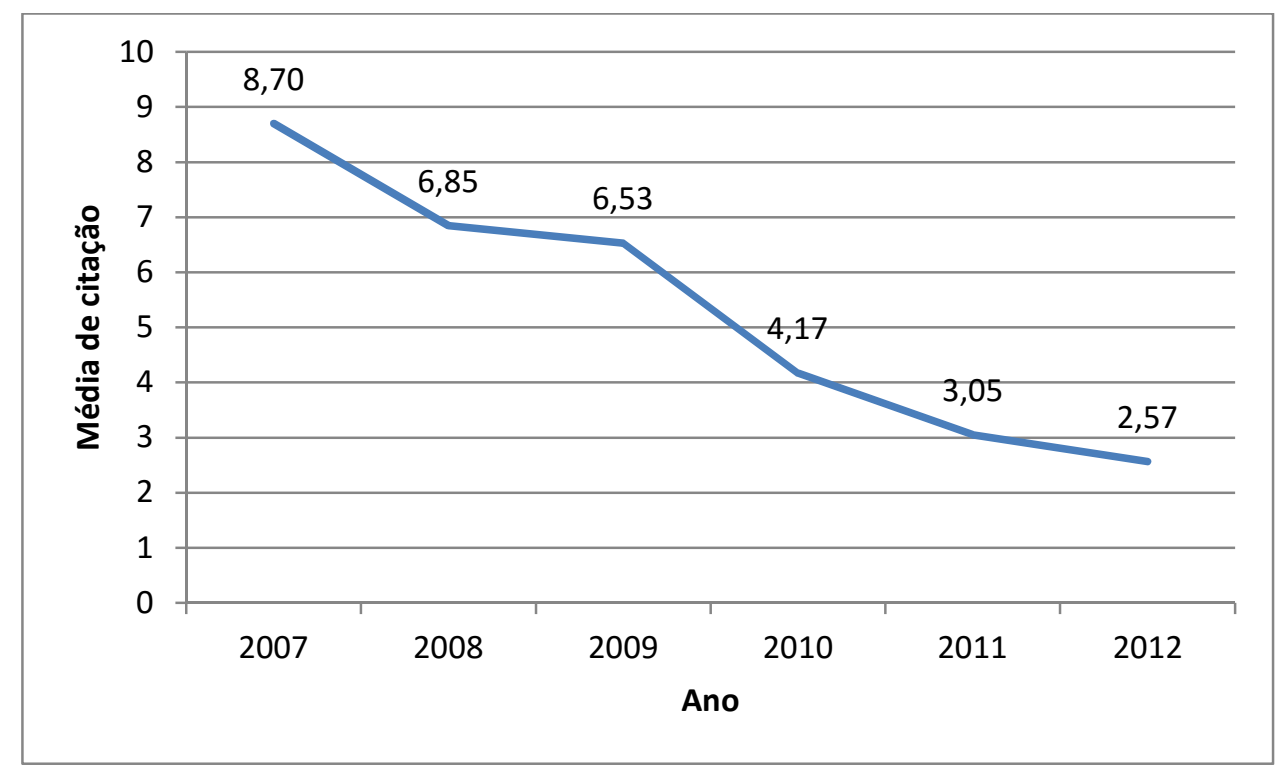

Figura 28 - Média de citações por artigo, por ano

Como se pode ver, a média de citações cresceu à medida que o artigo acumulou um número maior de anos de exposição aos leitores. Esse crescimento não é desprezível dado que em um intervalo de seis anos, de 2007 a 2012, a média aumentou 338\%, de 2,57 para 8,70, para os artigos da amostra.

\subsection{Análises de associação entre variáveis}

As análises das estatísticas descritivas das variáveis foram seguidas de análises de associação entre as variáveis. Para identificar a associação entre as variáveis quantitativas calculou-se o coeficiente de correlação linear $r$ de Pearson. Para identificar a associação entre as variáveis qualitativas, fez-se o teste qui-quadrado (chi-squared).

Os coeficientes da correlação linear $r$ de Pearson foram calculados de duas em duas, conforme resultados descritos na Tabela 30.

Tabela 30 - Coeficientes de correlação linear de Pearson entre as variáveis explicativas quantitativas

\begin{tabular}{l|r|r|l|l|l|l|l}
\hline & \multicolumn{5}{|c|}{ Número de } & $\begin{array}{l}\text { Proporção } \\
\text { de autoras }\end{array}$ & $\begin{array}{l}\text { Idade da } \\
\text { revista }\end{array}$ \\
\cline { 2 - 7 } & Palavras & $\begin{array}{l}\text { Termos } \\
\text { nalavras- } \\
\text { no título }\end{array}$ & Páginas & Referências & Autores & & \\
\hline $\begin{array}{l}\text { Número de } \\
\text { palavras } \\
\text { título }\end{array}$ & 1,000 & & & & & & \\
\hline $\begin{array}{l}\text { Número de } \\
\text { termos nas }\end{array}$ & 0,0734 & 1,000 & & & & & \\
\hline
\end{tabular}




\begin{tabular}{l|r|r|r|r|r|r|r}
\hline $\begin{array}{l}\text { palavras- } \\
\text { chave }\end{array}$ & & & & & & & \\
\hline $\begin{array}{l}\text { Número de } \\
\text { páginas }\end{array}$ & 0,0760 & 0,0746 & 1,000 & & & & \\
\hline $\begin{array}{l}\text { Número de } \\
\text { referências }\end{array}$ & $-0,0084$ & 0,0413 & 0,2613 & 1,000 & & & \\
\hline $\begin{array}{l}\text { Número de } \\
\text { autores }\end{array}$ & 0,1328 & $-0,0080$ & 0,0412 & 0,0442 & 1,000 & & \\
\hline $\begin{array}{l}\text { Proporção } \\
\text { de autoras }\end{array}$ & 0,0320 & $-0,0465$ & 0,0206 & 0,0157 & 0,0654 & 1,000 & \\
\hline $\begin{array}{l}\text { Idade da } \\
\text { revista }\end{array}$ & 0,0103 & 0,0357 & 0,1595 & 0,1428 & 0,0116 & $-0,0138$ & 1,000 \\
\hline
\end{tabular}

Também se identificou a relação dessas variáveis com a variável Citações, conforme mostrado na Tabela 31.

Tabela 31 - Coeficientes de correlação linear de Pearson das variáveis explicativas quantitativas com a variável dependente

\begin{tabular}{l|r}
\hline Variável & Correlação com as citações \\
\hline Número de palavras no título & $-0,0274$ \\
\hline Número de termos nas palavras-chave & 0,0365 \\
\hline Número de páginas & 0,0167 \\
\hline Número de referências & 0,1146 \\
\hline Número de autores & $-0,0186$ \\
\hline Proporção de autoras & $-0,0321$ \\
\hline Idade da revista & 0,2294 \\
\hline
\end{tabular}

Como mostram os coeficientes de correlação linear de Pearson, não há associações fortes entre as variáveis independentes com a variável dependente. Todas elas são menores que 0,30 .

Igualmente, foi feita uma análise de associação entre as variáveis qualitativas. Os resultados dos testes qui-quadrado entre as variáveis qualitativas estão apresentados na Tabela 32. 
Tabela 32 - Resultados do teste de qui-quadrado de associação entre as variáveis explicativas qualitativas

\begin{tabular}{|c|c|c|c|c|c|c|c|c|c|}
\hline & Revista & $\begin{array}{ll}\text { Tipo } & \text { de } \\
\text { edição } & \end{array}$ & $\begin{array}{ll}\text { Posição do } \\
\text { artigo na } \\
\text { revista }\end{array}$ & $\begin{array}{l}\text { Gênero do } \\
\text { primeiro } \\
\text { autor }\end{array}$ & $\begin{array}{l}\text { Titulação do } \\
\text { primeiro } \\
\text { autor }\end{array}$ & $\begin{array}{ll}\text { IES } & \text { do } \\
\text { primeiro } & \\
\text { autor } & \end{array}$ & $\begin{array}{ll}\text { Linha de } \\
\text { pesquisa }\end{array}$ & $\begin{array}{l}\text { Qualis da } \\
\text { revista }\end{array}$ & $\begin{array}{l}\text { Abordagem da } \\
\text { análise }\end{array}$ \\
\hline Revista & - & & & & & & & & \\
\hline Tipo de edição & $\begin{array}{r}234,6737 \\
0,000 \\
\end{array}$ & - & & & & & & & \\
\hline $\begin{array}{lr}\text { Posição do } \\
\text { artigo na revista }\end{array}$ & $\begin{array}{r}21,8183 \\
0,960\end{array}$ & $\begin{array}{r}0,1540 \\
0,695\end{array}$ & - & & & & & & \\
\hline $\begin{array}{l}\text { Gênero do } \\
\text { primeiro autor }\end{array}$ & $\begin{array}{r}63,1948 \\
0,002\end{array}$ & $\begin{array}{r}1,9619 \\
0,161\end{array}$ & $\begin{array}{r}1,0568 \\
0,304\end{array}$ & - & & & & & \\
\hline $\begin{array}{l}\text { Titulação do } \\
\text { primeiro autor }\end{array}$ & $\begin{array}{r}451,4397 \\
0,000 \\
\end{array}$ & $\begin{array}{r}5,5690 \\
0,135 \\
\end{array}$ & $\begin{array}{r}5,8637 \\
0,118 \\
\end{array}$ & $\begin{array}{r}84,4302 \\
0,000 \\
\end{array}$ & - & & & & \\
\hline $\begin{array}{l}\text { IES do primeiro } \\
\text { autor }\end{array}$ & $\begin{array}{r}1,9 \mathrm{e}+03 \\
0,000\end{array}$ & $\begin{array}{r}41,9632 \\
0,002 \\
\end{array}$ & $\begin{array}{r}23,6577 \\
0,210 \\
\end{array}$ & $\begin{array}{r}74,0206 \\
0,000 \\
\end{array}$ & $\begin{array}{r}494,8926 \\
0,000 \\
\end{array}$ & - & & & \\
\hline $\begin{array}{ll}\text { Linha } & \text { de } \\
\text { pesquisa } & \\
\end{array}$ & $\begin{array}{r}595,6540 \\
0,000 \\
\end{array}$ & $\begin{array}{r}2,2109 \\
0,819 \\
\end{array}$ & $\begin{array}{r}9,7689 \\
0,082 \\
\end{array}$ & $\begin{array}{r}21,3500 \\
0,001 \\
\end{array}$ & $\begin{array}{r}25,3053 \\
0,046 \\
\end{array}$ & $\begin{array}{r}232,8983 \\
0,000 \\
\end{array}$ & - & & \\
\hline $\begin{array}{l}\text { Qualis } \\
\text { revista }\end{array}$ & $\begin{array}{r}8,0 \mathrm{e}+03 \\
0,000 \\
\end{array}$ & $\begin{array}{r}45,4768 \\
0,000 \\
\end{array}$ & $\begin{array}{r}7,9198 \\
0,340 \\
\end{array}$ & $\begin{array}{r}7,9561 \\
0,336 \\
\end{array}$ & $\begin{array}{r}134,4715 \\
0,000 \\
\end{array}$ & $\begin{array}{r}326,7011 \\
0,000 \\
\end{array}$ & $\begin{array}{r}132,8681 \\
0,000 \\
\end{array}$ & - & \\
\hline $\begin{array}{l}\text { Abordagem da } \\
\text { análise }\end{array}$ & $\begin{array}{r}201,8581 \\
0,000 \\
\end{array}$ & $\begin{array}{r}0,2015 \\
0,654\end{array}$ & $\begin{array}{r}0,0262 \\
0,871 \\
\end{array}$ & $\begin{array}{r}12,4383 \\
0,000 \\
\end{array}$ & $\begin{array}{r}45,0296 \\
0,000 \\
\end{array}$ & $\begin{array}{r}103,7094 \\
0,000 \\
\end{array}$ & $\begin{array}{r}278,5069 \\
0,000 \\
\end{array}$ & $\begin{array}{r}112,1246 \\
0,000 \\
\end{array}$ & - \\
\hline
\end{tabular}


Há 23 associações entre as variáveis qualitativas, cujos resultados dos testes quiquadrado indicam não serem aleatórias em um nível de significância de 5\%. Uma análise mais atenta mostra que três, dessas associações, nem poderiam ser diferentes, dado que não são probabilísticas.

A Figura 29 sintetiza, com linhas contínuas, as relações probabilísticas; e, com linhas tracejadas, as relações determinísticas.

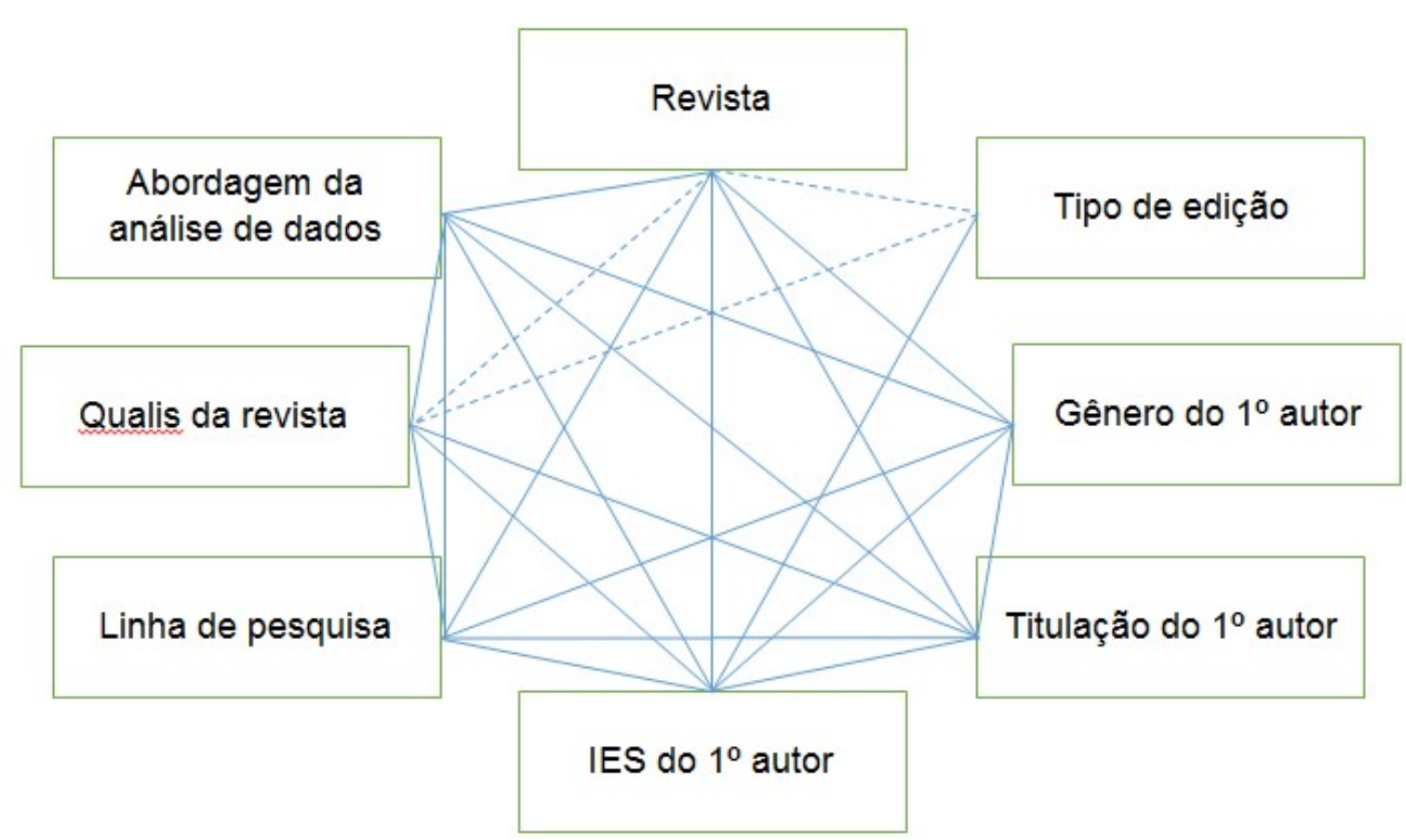

Figura 29 - Associações estatisticamente significantes, segundo o teste qui-quadrado

A relação Revista versus Qualis da revista não é aleatória, porque todos os artigos de uma revista tinham, obrigatoriamente, que estar agrupados dentro do mesmo estrato do Qualis. As revistas, reclassificadas de um estrato para outro, com a passagem do triênio, são exceção. Mesmo assim, todos os artigos publicados no mesmo triênio pertencem ao mesmo estrato do Qualis.

A relação entre Revista versus Tipo de edição também não é aleatória, porque apenas cinco, das 36 revistas, tiveram edição especial ao longo do período analisado.

O mesmo ocorreu com a relação Tipo de edição versus Qualis da revista. 


\subsection{Relação entre Revista e Gênero do primeiro autor}

De acordo com o resultado do teste de qui-quadrado, verificou-se uma relação que não pode ser considerada aleatória, em um nível de significância de $5 \%$ entre a Revista e o Gênero do primeiro autor.

Em virtude de a variável Gênero do primeiro autor possuir apenas duas categorias, não foi possível construir um mapa perceptual.

A Tabela 33 mostra quais revistas concentram os maiores percentuais de autores de cada gênero, em ordem decrescente de participação masculina.

Tabela 33 - Proporção dos artigos de cada revista, por gênero do primeiro autor

\begin{tabular}{|c|c|c|c|c|c|}
\hline Revista & Homem & $\%$ & Mulher & $\%$ & Total \\
\hline BBR & 63 & $86,3 \%$ & 10 & $13,7 \%$ & 73 \\
\hline CAP_Accounting & 30 & $78,9 \%$ & 8 & $21,1 \%$ & 38 \\
\hline $\mathrm{RIC}$ & 84 & $76,4 \%$ & 26 & $23,6 \%$ & 110 \\
\hline ASAA & 40 & $75,5 \%$ & 13 & $24,5 \%$ & 53 \\
\hline Contextus & 20 & $74,1 \%$ & 7 & $25,9 \%$ & 27 \\
\hline RC\&F & 83 & $73,5 \%$ & 30 & $26,5 \%$ & 113 \\
\hline $\mathrm{RCO}$ & 90 & $72,6 \%$ & 34 & $27,4 \%$ & 124 \\
\hline REPEC & 73 & $71,6 \%$ & 29 & $28,4 \%$ & 102 \\
\hline RCMCC & 70 & $71,4 \%$ & 28 & $28,6 \%$ & 98 \\
\hline RC_UFBA & 52 & $71,2 \%$ & 21 & $28,8 \%$ & 73 \\
\hline RAC_da_FAT & 17 & $70,8 \%$ & 7 & $29,2 \%$ & 24 \\
\hline Ambiente_Contabil & 33 & $70,2 \%$ & 14 & $29,8 \%$ & 47 \\
\hline CGG & 70 & $70,0 \%$ & 30 & $30,0 \%$ & 100 \\
\hline RCC_UFPR & 47 & $69,1 \%$ & 21 & $30,9 \%$ & 68 \\
\hline SCG & 59 & $68,6 \%$ & 27 & $31,4 \%$ & 86 \\
\hline Recont & 21 & $67,7 \%$ & 10 & $32,3 \%$ & 31 \\
\hline Custos_e_@agro & 79 & $65,8 \%$ & 41 & $34,2 \%$ & 120 \\
\hline RBGN & 34 & $65,4 \%$ & 18 & $34,6 \%$ & 52 \\
\hline RUC & 124 & $64,9 \%$ & 67 & $35,1 \%$ & 191 \\
\hline RACEF & 11 & $64,7 \%$ & 6 & $35,3 \%$ & 17 \\
\hline RBC & 68 & $64,2 \%$ & 38 & $35,8 \%$ & 106 \\
\hline Pensar_Contabil & 69 & $63,9 \%$ & 39 & $36,1 \%$ & 108 \\
\hline Base & 55 & $61,8 \%$ & 34 & $38,2 \%$ & 89 \\
\hline ABCustos & 42 & $61,8 \%$ & 26 & $38,2 \%$ & 68 \\
\hline CVR & 84 & $60,0 \%$ & 56 & $40,0 \%$ & 140 \\
\hline RACE & 16 & $59,3 \%$ & 11 & $40,7 \%$ & 27 \\
\hline Contexto & 43 & $58,9 \%$ & 30 & $41,1 \%$ & 73 \\
\hline RCC_UFSC & 54 & $58,7 \%$ & 38 & $41,3 \%$ & 92 \\
\hline Enfoque & 55 & $58,5 \%$ & 39 & $41,5 \%$ & 94 \\
\hline Reunir & 14 & $58,3 \%$ & 10 & $41,7 \%$ & 24 \\
\hline RGFC & 12 & $54,5 \%$ & 10 & $45,5 \%$ & 22 \\
\hline Catarinense_CC & 47 & $53,4 \%$ & 41 & $46,6 \%$ & 88 \\
\hline REAVI & 2 & $50,0 \%$ & 2 & $50,0 \%$ & 4 \\
\hline R_Est_Cont & 14 & $50,0 \%$ & 14 & $50,0 \%$ & 28 \\
\hline Razao_Cont & 11 & $50,0 \%$ & 11 & $50,0 \%$ & 22 \\
\hline
\end{tabular}




\begin{tabular}{l|r|c|r|r|r}
\hline Revista & Homem & \% & Mulher & \% & \multicolumn{1}{c}{ Total } \\
\hline R_Elet_Cont & 3 & $37,5 \%$ & 5 & $62,5 \%$ & 8 \\
\hline Total & 1689 & $66,5 \%$ & 851 & $33,5 \%$ & 2540 \\
\hline
\end{tabular}

Segundo mostrado na Tabela, a revista com maior número de artigos com primeiro autor do gênero masculino foi a Brazilian Business Review, mantida pela Fucape e classificada nos estratos $A 2$ e B1, nos triênios analisados nesta pesquisa. A segunda revista com maior percentual de primeiros autores homens foi a CAP Accounting and Management, mantida pela UTFPR e classificada nos estratos B5 e NC, no mesmo período. A terceira da lista foi a Revista de Informação Contábil, mantida pela UFPE e classificada nos estratos B3 e B4 do Qualis, nos triênios 2007-2009 e 2010-2012.

$\mathrm{Na}$ outra ponta da lista, encontra-se a única revista em que a proporção de primeiros autores do gênero feminino supera a de primeiros autores do gênero masculino, que foi a Revista Eletrônica de Contabilidade, mantida pela UFSM, classificada nos estratos C e NC do Qualis e descontinuada a partir de 2013. Outras três revistas tinham metade dos artigos com primeiro autor do gênero feminino: a Revista Razão Contábil e Finanças (Faculdade Ateneu - FATE e estrato B5, em 2010-2012); a Revista de Estudos Contábeis (UEL e estrato B4, em 2010-2012); e REAVI - Revista Eletrônica do Alto Vale do Itajaí (UDESC e estrato B1, no triênio 2010-2012).

\subsection{Relação entre Revista e Titulação do primeiro autor}

A relação entre Revista e Titulação do primeiro autor mostrou-se estatisticamente significante no teste qui-quadrado. A Tabela 34 mostra essa relação, ordenando as revistas por ordem decrescente de titulação mais alta do primeiro autor, que é doutorado. 
Tabela 34 - Proporção dos artigos de cada revista, pela titulação do primeiro autor

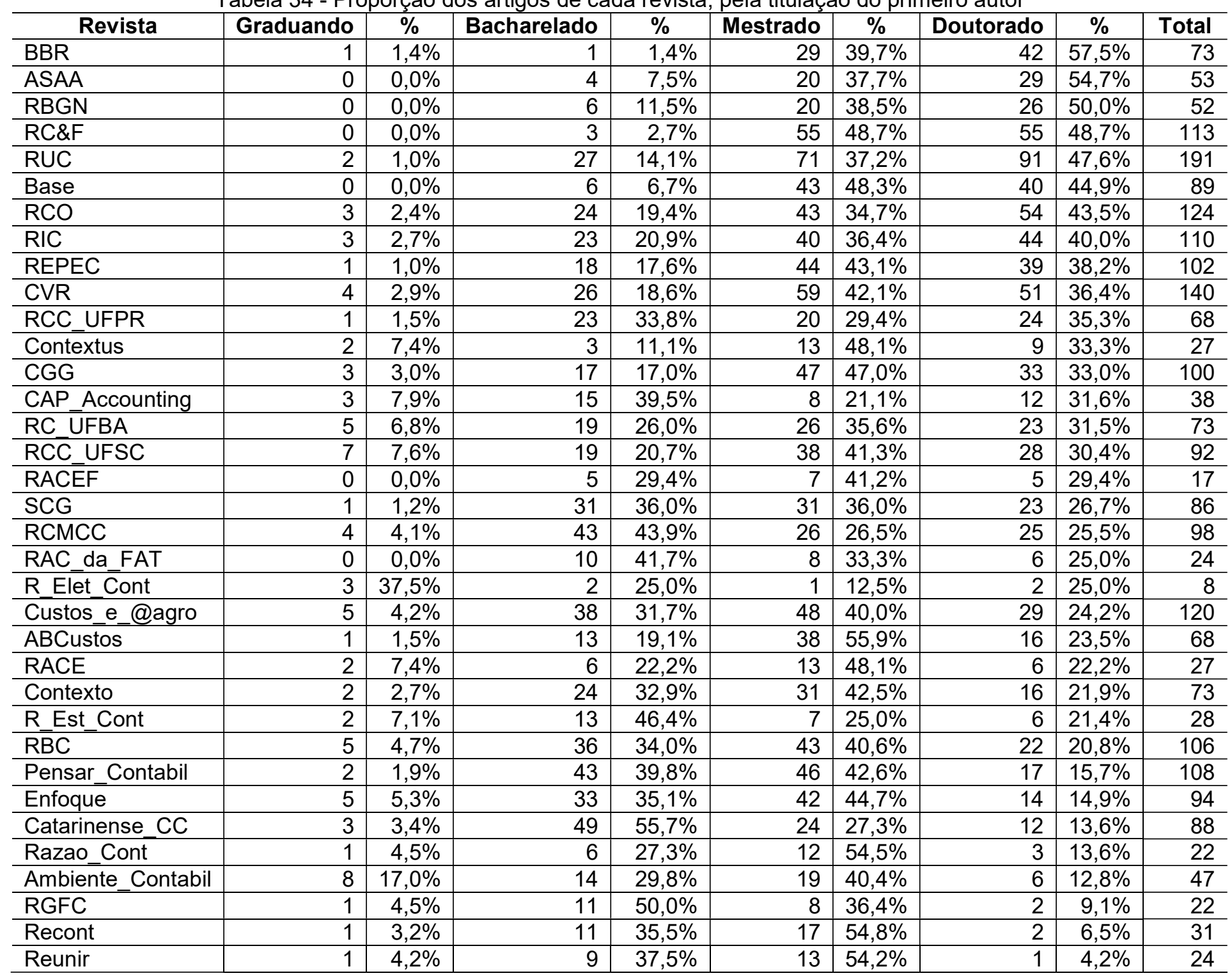




\begin{tabular}{l|r|c|r|r|r|r|r|r|r}
\hline \multicolumn{1}{c|}{ Revista } & Graduando & $\%$ & Bacharelado & \multicolumn{1}{c|}{$\%$} & Mestrado & $\%$ & Doutorado & $\%$ & Total \\
\hline REAVI & 0 & $0,0 \%$ & 4 & $100,0 \%$ & 0 & $0,0 \%$ & 0 & $0,0 \%$ & 4 \\
\hline Total & 82 & $3,2 \%$ & 635 & $25,0 \%$ & 1010 & $39,8 \%$ & 813 & $32,0 \%$ & 2540 \\
\hline
\end{tabular}


A Brazilian Business Review foi a revista que apresentou maior percentual de primeiros autores com doutorado, com uma taxa de $57,5 \%$ dos artigos. A segunda revista foi a Advances in Scientific and Applied Accounting, da Associação Nacional de Programas de Pós-Graduação em Ciências Contábeis (ANPCONT), que teve classificações $\mathrm{C}$ e B2, nos triênios analisados nesta pesquisa. A terceira revista da lista foi a Revista Brasileira de Gestão de Negócios. Essas três revistas foram as únicas que tinham o primeiro autor com titulação de doutor em, pelo menos, metade dos artigos de Contabilidade publicados.

$\mathrm{Na}$ outra extremidade estavam a REAVI, sem artigos com primeiro autor doutor; a Reunir: Revista de Administração, Contabilidade e Sustentabilidade, mantida pela UFGC e classificada no estrato B4, no triênio 2010-2012; e a revista Recont - Registro Contábil, mantida pela UFAL e classificada no estrato B3, em 2010-2012.

A análise permitiu desenhar o mapa perceptual dessa relação por meio da Anacor, como mostra a Figura 30 .

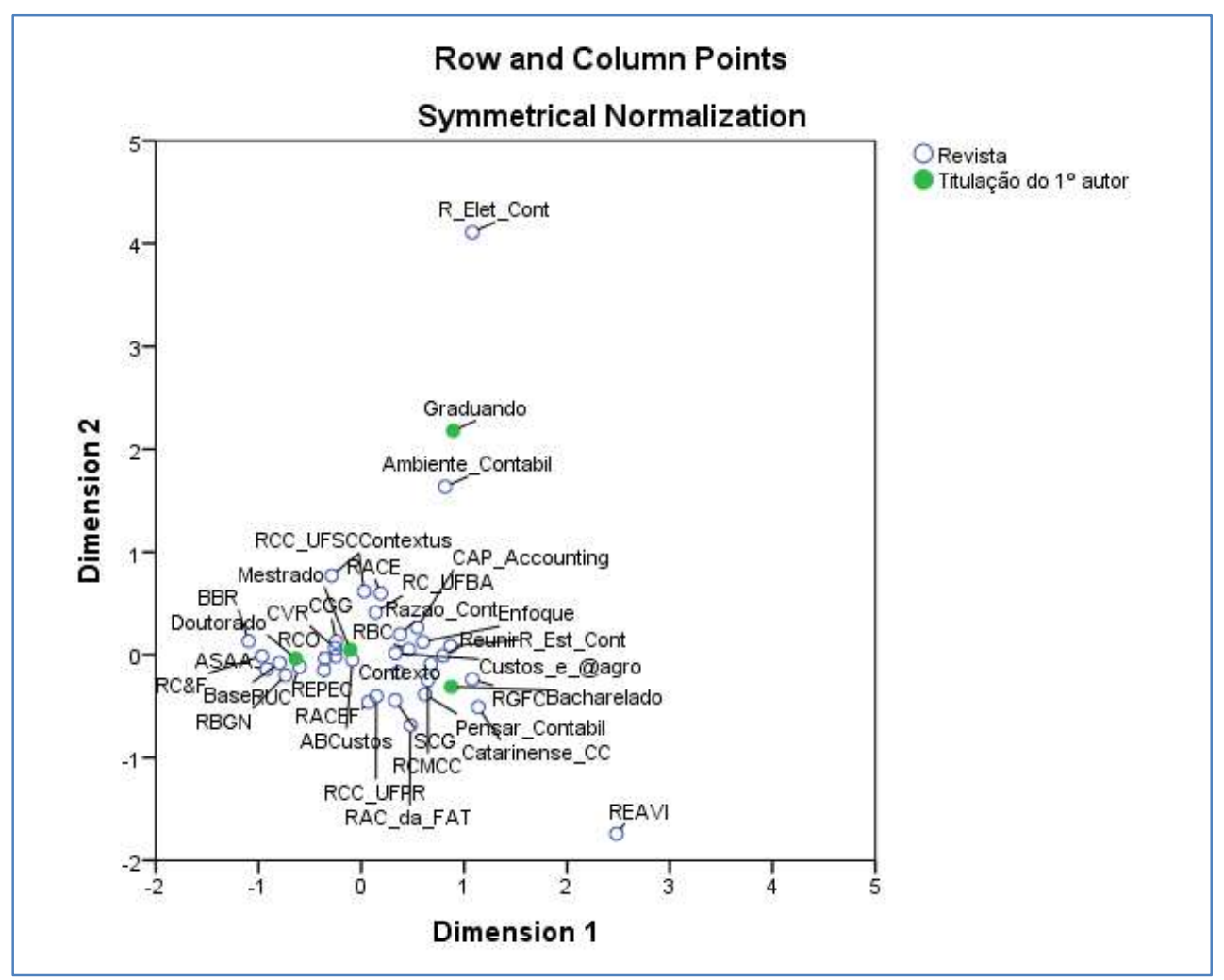

Figura 30 - Mapa perceptual da relação entre Revista e Titulação do $1^{\circ}$ autor 
A disposição dos pontos que representam a relação entre Revista e Titulação do primeiro autor mostrou-se nebulosa. Mesmo assim foi possível identificar uma aproximação da Revista Eletrônica de Contabilidade e da Revista Ambiente Contábil dos primeiros autores graduandos; e a REAVI mais próxima dos primeiros autores bacharéis, em contraposição a um maior distanciamento dos primeiros autores com titulação mais elevada.

\subsection{Relação entre Revista e IES do primeiro autor}

A relação entre Revista e IES do primeiro autor se mostrou estatisticamente significante de acordo com o teste de qui-quadrado. Nesta análise, buscou-se identificar a frequência com que autores de uma instituição publicam em uma determinada revista. Para isso foi usada a instituição do primeiro autor de instituição com programa de pós-graduação stricto sensu em Contabilidade. Os primeiros autores vinculados a outras instituições foram agrupados na categoria 'Outra', que acabou por se tornar a mais expressiva em todas as revistas, com exceção de três: Revista Ambiente Contábil, Revista de Contabilidade da UFBA e Revista de Informação Contábil.

A Tabela 35 mostra as frequências relativas das categorias. 
Tabela 35 - Proporção dos artigos de cada revista, de acordo com a IES do primeiro autor

\begin{tabular}{|c|c|c|c|c|c|c|c|c|c|c|c|c|c|c|c|c|c|c|c|c|c|}
\hline \multirow{2}{*}{ Revista } & \multirow[b]{2}{*}{$\begin{array}{l}\text { 足 } \\
\text { du } \\
\text { L }\end{array}$} & \multirow[b]{2}{*}{ 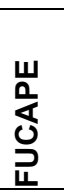 } & \multirow[b]{2}{*}{ 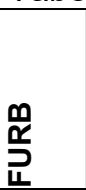 } & \multirow[b]{2}{*}{$\begin{array}{l}\mathbb{\nwarrow} \\
\text { 足 } \\
\text { o }\end{array}$} & \multirow[b]{2}{*}{ 点 } & \multirow[b]{2}{*}{ 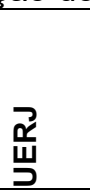 } & \multirow[b]{2}{*}{ 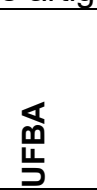 } & \multirow[b]{2}{*}{ 嵒 } & \multirow[b]{2}{*}{$\sum_{\frac{U}{J}}^{0}$} & \multirow[b]{2}{*}{$\begin{array}{l}\frac{m}{0} \\
\frac{0}{2}\end{array}$} & & & & & & & & & & & \\
\hline & & & & & & & & & & & $\begin{array}{l}\frac{\omega}{2} \\
\frac{u}{5}\end{array}$ & $\begin{array}{l}\frac{\alpha}{0} \\
\frac{1}{\partial}\end{array}$ & $\begin{array}{l}\vec{x} \\
\text { 点 }\end{array}$ & $\begin{array}{l}z \\
\mathbf{x} \\
\underline{u}\end{array}$ & $\begin{array}{l}\text { 足 } \\
\text { பّ }\end{array}$ & $\underline{m}$ & $\begin{array}{l}\mathscr{0} \\
\text { Z } \\
\frac{\mathbf{S}}{Z} \\
3\end{array}$ & $\begin{array}{l}\sum_{0} \\
S\end{array}$ & 离 & 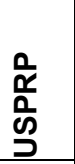 & 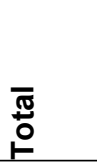 \\
\hline ABCustos & 0 & 0 & 8 & 18 & 0 & 4 & 2 & 0 & 1 & 3 & 1 & 1 & 4 & 0 & 8 & 0 & 7 & 1 & 10 & 0 & 68 \\
\hline$\%$ & $0 \%$ & $0 \%$ & $12 \%$ & $26 \%$ & $0 \%$ & $6 \%$ & $3 \%$ & $0 \%$ & $1 \%$ & $4 \%$ & $1 \%$ & $1 \%$ & $6 \%$ & $0 \%$ & $12 \%$ & $0 \%$ & $10 \%$ & $1 \%$ & $15 \%$ & $0 \%$ & $100 \%$ \\
\hline ASAA & 0 & 5 & 3 & 11 & 0 & 2 & 0 & 0 & 3 & 2 & 4 & 1 & 2 & 0 & 3 & 4 & 0 & 7 & 6 & 0 & 53 \\
\hline$\%$ & $0 \%$ & $9 \%$ & $6 \%$ & $21 \%$ & $0 \%$ & $4 \%$ & $0 \%$ & $0 \%$ & $6 \%$ & $4 \%$ & $8 \%$ & $2 \%$ & $4 \%$ & $0 \%$ & $6 \%$ & $8 \%$ & $0 \%$ & $13 \%$ & $11 \%$ & $0 \%$ & $100 \%$ \\
\hline Ambiente_Contabil & 0 & 0 & 0 & 11 & 0 & 0 & 0 & 0 & 0 & 1 & 1 & 1 & 1 & 13 & 4 & 12 & 0 & 0 & 3 & 0 & 47 \\
\hline$\%$ & $0 \%$ & $0 \%$ & $0 \%$ & $23 \%$ & $0 \%$ & $0 \%$ & $0 \%$ & $0 \%$ & $0 \%$ & $2 \%$ & $2 \%$ & $2 \%$ & $2 \%$ & $28 \%$ & $9 \%$ & $26 \%$ & $0 \%$ & $0 \%$ & $6 \%$ & $0 \%$ & $100 \%$ \\
\hline BBR & 1 & 5 & 2 & 39 & 0 & 0 & 2 & 0 & 1 & 3 & 1 & 0 & 0 & 0 & 0 & 4 & 0 & 4 & 9 & 2 & 73 \\
\hline$\%$ & $1 \%$ & $7 \%$ & $3 \%$ & $53 \%$ & $0 \%$ & $0 \%$ & $3 \%$ & $0 \%$ & $1 \%$ & $4 \%$ & $1 \%$ & $0 \%$ & $0 \%$ & $0 \%$ & $0 \%$ & $5 \%$ & $0 \%$ & $5 \%$ & $12 \%$ & $3 \%$ & $100 \%$ \\
\hline Base & 1 & 4 & 11 & 33 & 1 & 1 & 1 & 1 & 3 & 1 & 1 & 2 & 3 & 0 & 4 & 3 & 5 & 3 & 11 & 0 & 89 \\
\hline$\%$ & $1 \%$ & $4 \%$ & $12 \%$ & $37 \%$ & $1 \%$ & $1 \%$ & $1 \%$ & $1 \%$ & $3 \%$ & $1 \%$ & $1 \%$ & $2 \%$ & $3 \%$ & $0 \%$ & $4 \%$ & $3 \%$ & $6 \%$ & $3 \%$ & $12 \%$ & $0 \%$ & $100 \%$ \\
\hline CAP_Accounting & 0 & 0 & 2 & 25 & 0 & 0 & 0 & 0 & 0 & 0 & 0 & 1 & 0 & 0 & 6 & 2 & 0 & 0 & 2 & 0 & 38 \\
\hline$\%$ & $0 \%$ & $0 \%$ & $5 \%$ & $66 \%$ & $0 \%$ & $0 \%$ & $0 \%$ & $0 \%$ & $0 \%$ & $0 \%$ & $0 \%$ & $3 \%$ & $0 \%$ & $0 \%$ & $16 \%$ & $5 \%$ & $0 \%$ & $0 \%$ & $5 \%$ & $0 \%$ & $100 \%$ \\
\hline CGG & 1 & 3 & 16 & 25 & 0 & 5 & 5 & 0 & 3 & 5 & 1 & 2 & 2 & 0 & 8 & 13 & 2 & 0 & 8 & 1 & 100 \\
\hline$\%$ & $1 \%$ & $3 \%$ & $16 \%$ & $25 \%$ & $0 \%$ & $5 \%$ & $5 \%$ & $0 \%$ & $3 \%$ & $5 \%$ & $1 \%$ & $2 \%$ & $2 \%$ & $0 \%$ & $8 \%$ & $13 \%$ & $2 \%$ & $0 \%$ & $8 \%$ & $1 \%$ & $100 \%$ \\
\hline CVR & 1 & 3 & 8 & 37 & 2 & 4 & 3 & 0 & 13 & 1 & 5 & 1 & 8 & 1 & 12 & 6 & 3 & 1 & 25 & 6 & 140 \\
\hline$\%$ & $1 \%$ & $2 \%$ & $6 \%$ & $26 \%$ & $1 \%$ & $3 \%$ & $2 \%$ & $0 \%$ & $9 \%$ & $1 \%$ & $4 \%$ & $1 \%$ & $6 \%$ & $1 \%$ & $9 \%$ & $4 \%$ & $2 \%$ & $1 \%$ & $18 \%$ & $4 \%$ & $100 \%$ \\
\hline Contexto & 0 & 0 & 7 & 36 & 0 & 0 & 0 & 0 & 1 & 0 & 2 & 1 & 1 & 1 & 8 & 3 & 6 & 0 & 7 & 0 & 73 \\
\hline$\%$ & $0 \%$ & $0 \%$ & $10 \%$ & $49 \%$ & $0 \%$ & $0 \%$ & $0 \%$ & $0 \%$ & $1 \%$ & $0 \%$ & $3 \%$ & $1 \%$ & $1 \%$ & $1 \%$ & $11 \%$ & $4 \%$ & $8 \%$ & $0 \%$ & $10 \%$ & $0 \%$ & $100 \%$ \\
\hline Contextus & 0 & 0 & 1 & 13 & 1 & 0 & 0 & 0 & 0 & 1 & 0 & 2 & 1 & 0 & 2 & 1 & 1 & 1 & 3 & 0 & 27 \\
\hline$\%$ & $0 \%$ & $0 \%$ & $4 \%$ & $48 \%$ & $4 \%$ & $0 \%$ & $0 \%$ & $0 \%$ & $0 \%$ & $4 \%$ & $0 \%$ & $7 \%$ & $4 \%$ & $0 \%$ & $7 \%$ & $4 \%$ & $4 \%$ & $4 \%$ & $11 \%$ & $0 \%$ & $100 \%$ \\
\hline Custos_e_@agro & 2 & 0 & 3 & 54 & 3 & 0 & 1 & 0 & 0 & 1 & 1 & 5 & 5 & 2 & 8 & 12 & 5 & 2 & 13 & 3 & 120 \\
\hline$\%$ & $2 \%$ & $0 \%$ & $3 \%$ & $45 \%$ & $3 \%$ & $0 \%$ & $1 \%$ & $0 \%$ & $0 \%$ & $1 \%$ & $1 \%$ & $4 \%$ & $4 \%$ & $2 \%$ & $7 \%$ & $10 \%$ & $4 \%$ & $2 \%$ & $11 \%$ & $3 \%$ & $100 \%$ \\
\hline Enfoque & 0 & 1 & 5 & 28 & 0 & 0 & 0 & 1 & 4 & 0 & 1 & 5 & 0 & 3 & 21 & 7 & 1 & 0 & 15 & 2 & 94 \\
\hline$\%$ & $0 \%$ & $1 \%$ & $5 \%$ & $30 \%$ & $0 \%$ & $0 \%$ & $0 \%$ & $1 \%$ & $4 \%$ & $0 \%$ & $1 \%$ & $5 \%$ & $0 \%$ & $3 \%$ & $22 \%$ & $7 \%$ & $1 \%$ & $0 \%$ & $16 \%$ & $2 \%$ & $100 \%$ \\
\hline Pensar_Contabil & 0 & 0 & 4 & 32 & 0 & 17 & 3 & 0 & 4 & 0 & 1 & 1 & 24 & 1 & 10 & 5 & 2 & 0 & 3 & 1 & 108 \\
\hline$\%$ & $0 \%$ & $0 \%$ & $4 \%$ & $30 \%$ & $0 \%$ & $16 \%$ & $3 \%$ & $0 \%$ & $4 \%$ & $0 \%$ & $1 \%$ & $1 \%$ & $22 \%$ & $1 \%$ & $9 \%$ & $5 \%$ & $2 \%$ & $0 \%$ & $3 \%$ & $1 \%$ & $100 \%$ \\
\hline RACE & 0 & 0 & 4 & 12 & 1 & 0 & 2 & 0 & 0 & 0 & 0 & 1 & 0 & 0 & 7 & 0 & 0 & 0 & 0 & 0 & 27 \\
\hline$\%$ & $0 \%$ & $0 \%$ & $15 \%$ & $44 \%$ & $4 \%$ & $0 \%$ & $7 \%$ & $0 \%$ & $0 \%$ & $0 \%$ & $0 \%$ & $4 \%$ & $0 \%$ & $0 \%$ & $26 \%$ & $0 \%$ & $0 \%$ & $0 \%$ & $0 \%$ & $0 \%$ & $100 \%$ \\
\hline RACEF & 0 & 0 & 1 & 7 & 0 & 0 & 0 & 0 & 1 & 0 & 2 & 0 & 0 & 0 & 2 & 1 & 0 & 0 & 3 & 0 & 17 \\
\hline$\%$ & $0 \%$ & $0 \%$ & $6 \%$ & $41 \%$ & $0 \%$ & $0 \%$ & $0 \%$ & $0 \%$ & $6 \%$ & $0 \%$ & $12 \%$ & $0 \%$ & $0 \%$ & $0 \%$ & $12 \%$ & $6 \%$ & $0 \%$ & $0 \%$ & $18 \%$ & $0 \%$ & $100 \%$ \\
\hline RAC_da_FAT & 0 & 0 & 1 & 12 & 0 & 0 & 4 & 0 & 0 & 0 & 0 & 0 & 0 & 0 & 1 & 0 & 0 & 1 & 4 & 1 & 24 \\
\hline
\end{tabular}




\begin{tabular}{|c|c|c|c|c|c|c|c|c|c|c|c|c|c|c|c|c|c|c|c|c|c|}
\hline Revista & $\begin{array}{l}\text { 是 } \\
\text { 岁 }\end{array}$ & 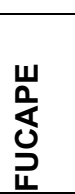 & $\begin{array}{l}\stackrel{m}{\widetilde{c}} \\
\stackrel{\underline{z}}{u}\end{array}$ & $\begin{array}{l}\overleftarrow{x} \\
\frac{1}{5} \\
0\end{array}$ & $\begin{array}{l}\text { के } \\
\text { Dू } \\
\text { Q }\end{array}$ & $\begin{array}{l}\text { 趉 } \\
\text { 茨 }\end{array}$ & 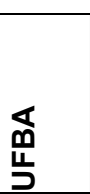 & $\begin{array}{l}\text { 岃 } \\
\text { 茨 }\end{array}$ & $\sum_{\frac{1}{J}}^{0}$ & $\begin{array}{l}\frac{m}{0} \\
\frac{0}{\partial}\end{array}$ & $\begin{array}{l}\frac{w}{0} \\
\frac{u}{\nu}\end{array}$ & $\begin{array}{l}\frac{\alpha}{a} \\
\frac{0}{\partial}\end{array}$ & $\begin{array}{l}\vec{x} \\
\frac{\alpha}{5}\end{array}$ & $\begin{array}{l}z \\
\text { 営 }\end{array}$ & $\begin{array}{l}0 \\
\mathscr{D} \\
\end{array}$ & $\underline{\underline{z}}$ & 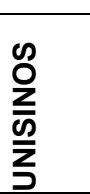 & $\begin{array}{l}\sum \\
\frac{\Sigma}{J}\end{array}$ & $\stackrel{0}{s}$ & 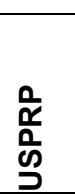 & ब \\
\hline$\%$ & $0 \%$ & $0 \%$ & $4 \%$ & $50 \%$ & $0 \%$ & $0 \%$ & $17 \%$ & $0 \%$ & $0 \%$ & $0 \%$ & $0 \%$ & $0 \%$ & $0 \%$ & $0 \%$ & $4 \%$ & $0 \%$ & $0 \%$ & $4 \%$ & $17 \%$ & $4 \%$ & $100 \%$ \\
\hline RBC & 0 & 0 & 1 & 59 & 1 & 1 & 1 & 0 & 1 & 1 & 3 & 1 & 2 & 3 & 15 & 4 & 6 & 0 & 7 & 0 & 106 \\
\hline$\%$ & $0 \%$ & $0 \%$ & $1 \%$ & $56 \%$ & $1 \%$ & $1 \%$ & $1 \%$ & $0 \%$ & $1 \%$ & $1 \%$ & $3 \%$ & $1 \%$ & $2 \%$ & $3 \%$ & $14 \%$ & $4 \%$ & $6 \%$ & $0 \%$ & $7 \%$ & $0 \%$ & $100 \%$ \\
\hline RBGN & 2 & 1 & 3 & 14 & 1 & 0 & 0 & 0 & 5 & 0 & 5 & 0 & 0 & 0 & 2 & 1 & 4 & 1 & 13 & 0 & 52 \\
\hline$\%$ & $4 \%$ & $2 \%$ & $6 \%$ & $27 \%$ & $2 \%$ & $0 \%$ & $0 \%$ & $0 \%$ & $10 \%$ & $0 \%$ & $10 \%$ & $0 \%$ & $0 \%$ & $0 \%$ & $4 \%$ & $2 \%$ & $8 \%$ & $2 \%$ & $25 \%$ & $0 \%$ & $100 \%$ \\
\hline RC\&F & 1 & 6 & 3 & 40 & 4 & 2 & 1 & 3 & 2 & 0 & 3 & 2 & 2 & 1 & 1 & 4 & 6 & 5 & 26 & 1 & 113 \\
\hline$\%$ & $1 \%$ & $5 \%$ & $3 \%$ & $35 \%$ & $4 \%$ & $2 \%$ & $1 \%$ & $3 \%$ & $2 \%$ & $0 \%$ & $3 \%$ & $2 \%$ & $2 \%$ & $1 \%$ & $1 \%$ & $4 \%$ & $5 \%$ & $4 \%$ & $23 \%$ & $1 \%$ & $100 \%$ \\
\hline RCC_UFPR & 1 & 1 & 3 & 20 & 0 & 2 & 0 & 1 & 10 & 0 & 2 & 5 & 3 & 0 & 4 & 4 & 1 & 0 & 11 & 0 & 68 \\
\hline$\%$ & $1 \%$ & $1 \%$ & $4 \%$ & $29 \%$ & $0 \%$ & $3 \%$ & $0 \%$ & $1 \%$ & $15 \%$ & $0 \%$ & $3 \%$ & $7 \%$ & $4 \%$ & $0 \%$ & $6 \%$ & $6 \%$ & $1 \%$ & $0 \%$ & $16 \%$ & $0 \%$ & $100 \%$ \\
\hline RCC_UFSC & 2 & 0 & 2 & 33 & 0 & 1 & 0 & 0 & 4 & 0 & 4 & 2 & 6 & 0 & 13 & 5 & 2 & 0 & 14 & 4 & 92 \\
\hline$\%$ & $2 \%$ & $0 \%$ & $2 \%$ & $36 \%$ & $0 \%$ & $1 \%$ & $0 \%$ & $0 \%$ & $4 \%$ & $0 \%$ & $4 \%$ & $2 \%$ & $7 \%$ & $0 \%$ & $14 \%$ & $5 \%$ & $2 \%$ & $0 \%$ & $15 \%$ & $4 \%$ & $100 \%$ \\
\hline RCMCC & 1 & 0 & 6 & 24 & 2 & 6 & 3 & 0 & 2 & 0 & 3 & 1 & 7 & 2 & 19 & 7 & 1 & 0 & 11 & 3 & 98 \\
\hline$\%$ & $1 \%$ & $0 \%$ & $6 \%$ & $24 \%$ & $2 \%$ & $6 \%$ & $3 \%$ & $0 \%$ & $2 \%$ & $0 \%$ & $3 \%$ & $1 \%$ & $7 \%$ & $2 \%$ & $19 \%$ & $7 \%$ & $1 \%$ & $0 \%$ & $11 \%$ & $3 \%$ & $100 \%$ \\
\hline RCO & 1 & 3 & 6 & 43 & 0 & 3 & 0 & 1 & 4 & 2 & 1 & 3 & 4 & 2 & 8 & 3 & 5 & 2 & 31 & 2 & 124 \\
\hline$\%$ & $1 \%$ & $2 \%$ & $5 \%$ & $35 \%$ & $0 \%$ & $2 \%$ & $0 \%$ & $1 \%$ & $3 \%$ & $2 \%$ & $1 \%$ & $2 \%$ & $3 \%$ & $2 \%$ & $6 \%$ & $2 \%$ & $4 \%$ & $2 \%$ & $25 \%$ & $2 \%$ & $100 \%$ \\
\hline RC_UFBA & 0 & 1 & 12 & 11 & 0 & 0 & 7 & 0 & 0 & 0 & 2 & 3 & 5 & 4 & 13 & 2 & 1 & 1 & 11 & 0 & 73 \\
\hline$\%$ & $0 \%$ & $1 \%$ & $16 \%$ & $15 \%$ & $0 \%$ & $0 \%$ & $10 \%$ & $0 \%$ & $0 \%$ & $0 \%$ & $3 \%$ & $4 \%$ & $7 \%$ & $5 \%$ & $18 \%$ & $3 \%$ & $1 \%$ & $1 \%$ & $15 \%$ & $0 \%$ & $100 \%$ \\
\hline REAVI & 0 & 0 & 1 & 1 & 0 & 0 & 0 & 0 & 0 & 0 & 0 & 0 & 0 & 0 & 1 & 1 & 0 & 0 & 0 & 0 & 4 \\
\hline$\%$ & $0 \%$ & $0 \%$ & $25 \%$ & $25 \%$ & $0 \%$ & $0 \%$ & $0 \%$ & $0 \%$ & $0 \%$ & $0 \%$ & $0 \%$ & $0 \%$ & $0 \%$ & $0 \%$ & $25 \%$ & $25 \%$ & $0 \%$ & $0 \%$ & $0 \%$ & $0 \%$ & $100 \%$ \\
\hline REPEC & 1 & 7 & 4 & 30 & 0 & 2 & 0 & 1 & 0 & 0 & 2 & 2 & 6 & 1 & 2 & 13 & 3 & 0 & 26 & 2 & 102 \\
\hline$\%$ & $1 \%$ & $7 \%$ & $4 \%$ & $29 \%$ & $0 \%$ & $2 \%$ & $0 \%$ & $1 \%$ & $0 \%$ & $0 \%$ & $2 \%$ & $2 \%$ & $6 \%$ & $1 \%$ & $2 \%$ & $13 \%$ & $3 \%$ & $0 \%$ & $25 \%$ & $2 \%$ & $100 \%$ \\
\hline RGFC & 0 & 0 & 0 & 11 & 1 & 0 & 2 & 0 & 1 & 0 & 0 & 1 & 0 & 0 & 1 & 2 & 0 & 0 & 3 & 0 & 22 \\
\hline$\%$ & $0 \%$ & $0 \%$ & $0 \%$ & $50 \%$ & $5 \%$ & $0 \%$ & $9 \%$ & $0 \%$ & $5 \%$ & $0 \%$ & $0 \%$ & $5 \%$ & $0 \%$ & $0 \%$ & $5 \%$ & $9 \%$ & $0 \%$ & $0 \%$ & $14 \%$ & $0 \%$ & $100 \%$ \\
\hline RIC & 1 & 0 & 8 & 23 & 2 & 4 & 1 & 1 & 4 & 0 & 3 & 1 & 8 & 1 & 11 & 7 & 1 & 0 & 33 & 1 & 110 \\
\hline$\%$ & $1 \%$ & $0 \%$ & $7 \%$ & $21 \%$ & $2 \%$ & $4 \%$ & $1 \%$ & $1 \%$ & $4 \%$ & $0 \%$ & $3 \%$ & $1 \%$ & $7 \%$ & $1 \%$ & $10 \%$ & $6 \%$ & $1 \%$ & $0 \%$ & $30 \%$ & $1 \%$ & $100 \%$ \\
\hline RUC & 1 & 1 & 2 & 92 & 0 & 2 & 1 & 1 & 7 & 1 & 1 & 4 & 2 & 0 & 11 & 16 & 2 & 1 & 45 & 1 & 191 \\
\hline$\%$ & $1 \%$ & $1 \%$ & $1 \%$ & $48 \%$ & $0 \%$ & $1 \%$ & $1 \%$ & $1 \%$ & $4 \%$ & $1 \%$ & $1 \%$ & $2 \%$ & $1 \%$ & $0 \%$ & $6 \%$ & $8 \%$ & $1 \%$ & $1 \%$ & $24 \%$ & $1 \%$ & $100 \%$ \\
\hline Catarinense_CC & 0 & 0 & 9 & 44 & 0 & 2 & 0 & 0 & 0 & 1 & 0 & 0 & 1 & 3 & 27 & 0 & 0 & 0 & 1 & 0 & 88 \\
\hline$\%$ & $0 \%$ & $0 \%$ & $10 \%$ & $50 \%$ & $0 \%$ & $2 \%$ & $0 \%$ & $0 \%$ & $0 \%$ & $1 \%$ & $0 \%$ & $0 \%$ & $1 \%$ & $3 \%$ & $31 \%$ & $0 \%$ & $0 \%$ & $0 \%$ & $1 \%$ & $0 \%$ & $100 \%$ \\
\hline R_Elet_Cont & 0 & 0 & 0 & 8 & 0 & 0 & 0 & 0 & 0 & 0 & 0 & 0 & 0 & 0 & 0 & 0 & 0 & 0 & 0 & 0 & 8 \\
\hline$\%$ & $0 \%$ & $0 \%$ & $0 \%$ & $100 \%$ & $0 \%$ & $0 \%$ & $0 \%$ & $0 \%$ & $0 \%$ & $0 \%$ & $0 \%$ & $0 \%$ & $0 \%$ & $0 \%$ & $0 \%$ & $0 \%$ & $0 \%$ & $0 \%$ & $0 \%$ & $0 \%$ & $100 \%$ \\
\hline R_Est_Cont & 0 & 0 & 2 & 17 & 1 & 0 & 1 & 0 & 0 & 0 & 0 & 1 & 0 & 0 & 0 & 0 & 0 & 0 & 6 & 0 & 28 \\
\hline$\%$ & $0 \%$ & $0 \%$ & $7 \%$ & $61 \%$ & $4 \%$ & $0 \%$ & $4 \%$ & $0 \%$ & $0 \%$ & $0 \%$ & $0 \%$ & $4 \%$ & $0 \%$ & $0 \%$ & $0 \%$ & $0 \%$ & $0 \%$ & $0 \%$ & $21 \%$ & $0 \%$ & $100 \%$ \\
\hline
\end{tabular}




\begin{tabular}{|c|c|c|c|c|c|c|c|c|c|c|c|c|c|c|c|c|c|c|c|c|c|}
\hline Revista & 这 & 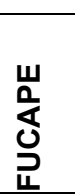 & 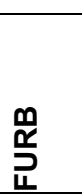 & $\begin{array}{l}\overleftarrow{⿱} \\
\stackrel{5}{5} \\
0\end{array}$ & $\begin{array}{l}\text { के } \\
\text { D્ } \\
\text { Q }\end{array}$ & $\begin{array}{l}\text { 疋 } \\
\stackrel{u}{J}\end{array}$ & $\begin{array}{l}\text { 吕 } \\
\text { 岂 }\end{array}$ & $\begin{array}{l}\text { 㟧 } \\
\end{array}$ & $\begin{array}{l}\sum_{J}^{0} \\
J\end{array}$ & $\begin{array}{l}\frac{0}{0} \\
\frac{0}{5}\end{array}$ & $\begin{array}{l}\frac{w}{0} \\
\frac{a}{\nu}\end{array}$ & $\begin{array}{l}\frac{\alpha}{0} \\
\frac{0}{\nu}\end{array}$ & $\begin{array}{l}\vec{R} \\
\frac{\alpha}{J}\end{array}$ & $\begin{array}{l}z \\
\text { zor } \\
\frac{u}{y}\end{array}$ & 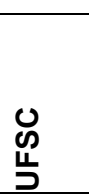 & $\underline{\mathbf{m}}$ & 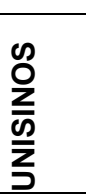 & $\begin{array}{l}\sum_{0} \\
I\end{array}$ & 今) & $\begin{array}{l}\frac{0}{\alpha} \\
\frac{\alpha}{\omega} \\
\frac{\rho}{\partial}\end{array}$ & $\begin{array}{l}\overline{\text { ग्ञ }} \\
\stackrel{0}{0}\end{array}$ \\
\hline Razao_Cont & 0 & 0 & 0 & 18 & 0 & 0 & 0 & 0 & 0 & 0 & 2 & 0 & 0 & 0 & 1 & 0 & 0 & 0 & 1 & 0 & 22 \\
\hline$\%$ & $0 \%$ & $0 \%$ & $0 \%$ & $82 \%$ & $0 \%$ & $0 \%$ & $0 \%$ & $0 \%$ & $0 \%$ & $0 \%$ & $9 \%$ & $0 \%$ & $0 \%$ & $0 \%$ & $5 \%$ & $0 \%$ & $0 \%$ & $0 \%$ & $5 \%$ & $0 \%$ & $100 \%$ \\
\hline Recont & 0 & 0 & 0 & 13 & 2 & 0 & 0 & 0 & 0 & 0 & 8 & 0 & 0 & 3 & 1 & 3 & 0 & 0 & 1 & 0 & 31 \\
\hline$\%$ & $0 \%$ & $0 \%$ & $0 \%$ & $42 \%$ & $6 \%$ & $0 \%$ & $0 \%$ & $0 \%$ & $0 \%$ & $0 \%$ & $26 \%$ & $0 \%$ & $0 \%$ & $10 \%$ & $3 \%$ & $10 \%$ & $0 \%$ & $0 \%$ & $3 \%$ & $0 \%$ & $100 \%$ \\
\hline Reunir & 0 & 0 & 0 & 10 & 0 & 0 & 0 & 0 & 0 & 3 & 0 & 0 & 0 & 1 & 1 & 8 & 0 & 0 & 1 & 0 & 24 \\
\hline$\%$ & $0 \%$ & $0 \%$ & $0 \%$ & $42 \%$ & $0 \%$ & $0 \%$ & $0 \%$ & $0 \%$ & $0 \%$ & $13 \%$ & $0 \%$ & $0 \%$ & $0 \%$ & $4 \%$ & $4 \%$ & $33 \%$ & $0 \%$ & $0 \%$ & $4 \%$ & $0 \%$ & $100 \%$ \\
\hline SCG & 0 & 1 & 2 & 23 & 0 & 3 & 2 & 4 & 5 & 0 & 5 & 0 & 12 & 0 & 5 & 7 & 1 & 1 & 14 & 1 & 86 \\
\hline$\%$ & $0 \%$ & $1 \%$ & $2 \%$ & $27 \%$ & $0 \%$ & $3 \%$ & $2 \%$ & $5 \%$ & $6 \%$ & $0 \%$ & $6 \%$ & $0 \%$ & $14 \%$ & $0 \%$ & $6 \%$ & $8 \%$ & $1 \%$ & $1 \%$ & $16 \%$ & $1 \%$ & $100 \%$ \\
\hline Total & 17 & 42 & 140 & 927 & 22 & 61 & 42 & 14 & 79 & 26 & 65 & 50 & 109 & 42 & 240 & 160 & 65 & 31 & 377 & 31 & 2540 \\
\hline$\%$ & $1 \%$ & $2 \%$ & $6 \%$ & $36 \%$ & $1 \%$ & $2 \%$ & $2 \%$ & $1 \%$ & $3 \%$ & $1 \%$ & $3 \%$ & $2 \%$ & $4 \%$ & $2 \%$ & $9 \%$ & $6 \%$ & $3 \%$ & $1 \%$ & $15 \%$ & $1 \%$ & $100 \%$ \\
\hline
\end{tabular}


Foi possível desenhar o mapa perceptual desta relação por meio da Anacor, conforme mostra a Figura 31:

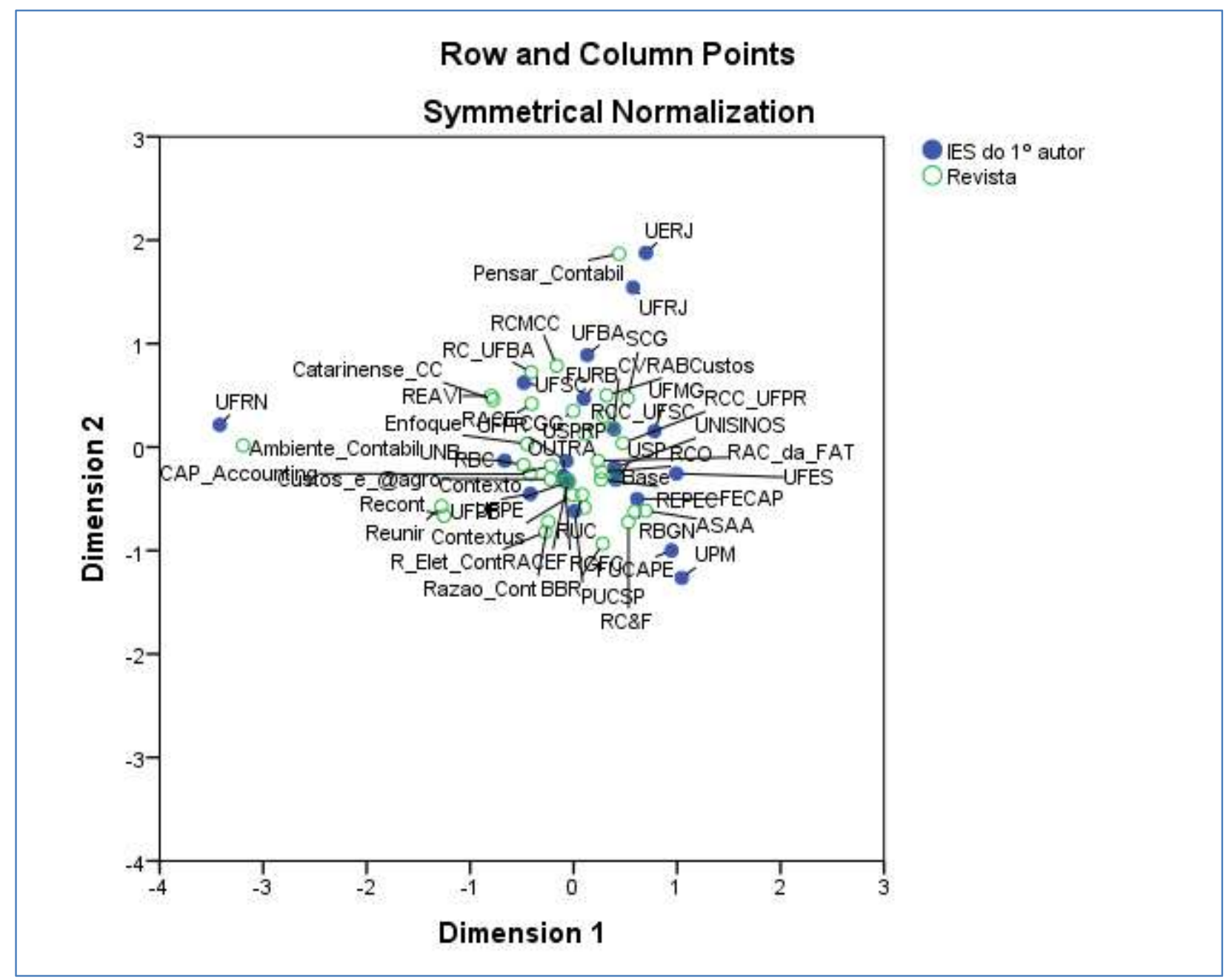

Figura 31 - Mapa perceptual da relação entre IES do primeiro autor e Revista

Embora tenha se apresentado nebulosa a disposição dos pontos que representam as Revistas e as Instituições do primeiro autor, pode-se verificar a proximidade entre a UFRN e a Revista Ambiente Contábil, e entre a UERJ e a UFRJ e a Revista Pensar Contábil. Os demais pontos gravitaram em torno da categoria Outra.

Ainda que possam haver críticas em relação à concentração de determinadas IES em algumas revistas, a dispersão se mostrou muito maior que no passado. Martins (2002) indica que, entre 1989 e 2001, apenas 10,5\% dos autores que publicaram na RC\&F tinham afiliação institucional que não era o EAC/FEA/USP. 
A relação entre Revista e Linha de pesquisa mostrou-se estatisticamente significativa, de acordo com o teste qui-quadrado. A Tabela 36 mostra essa relação, segundo as frequências absolutas e relativas. As células destacadas mostram a área em que mais se concentraram os artigos veiculados pelos periódicos da amostra. 
Tabela 36 - Proporção dos artigos de cada revista por Linha de pesquisa

\begin{tabular}{|c|c|c|c|c|c|c|c|c|c|c|c|c|c|}
\hline Revista & 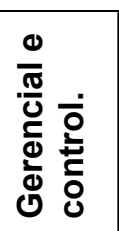 & o & 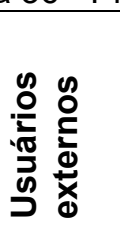 & o & 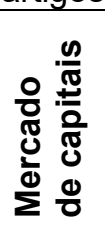 & ๙ & 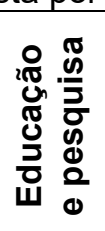 & ๙ & 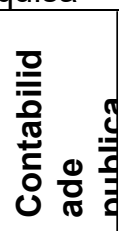 & & 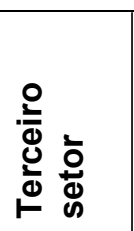 & o & $\begin{array}{l}\bar{\pi} \\
\text { 00 } \\
\vdash\end{array}$ \\
\hline ABCustos & 55 & $80,9 \%$ & 2 & $2,9 \%$ & 2 & $2,9 \%$ & 8 & $11,8 \%$ & 0 & $0,0 \%$ & 1 & $1,5 \%$ & 68 \\
\hline ASAA & 15 & $28,3 \%$ & 16 & $30,2 \%$ & 11 & $20,8 \%$ & 11 & $20,8 \%$ & 0 & $0,0 \%$ & 0 & $0,0 \%$ & 53 \\
\hline Ambiente_Contabil & 11 & $23,4 \%$ & 17 & $36,2 \%$ & 6 & $12,8 \%$ & 10 & $21,3 \%$ & 3 & $6,4 \%$ & 0 & $0,0 \%$ & 47 \\
\hline BBR & 19 & $26,0 \%$ & 14 & $19,2 \%$ & 34 & $46,6 \%$ & 4 & $5,5 \%$ & 1 & $1,4 \%$ & 1 & $1,4 \%$ & 73 \\
\hline Base & 36 & $40,4 \%$ & 19 & $21,3 \%$ & 21 & $23,6 \%$ & 11 & $12,4 \%$ & 2 & $2,2 \%$ & 0 & $0,0 \%$ & 89 \\
\hline CAP_Accounting & 11 & $28,9 \%$ & 5 & $13,2 \%$ & 13 & $34,2 \%$ & 7 & $18,4 \%$ & 0 & $0,0 \%$ & 2 & $5,3 \%$ & 38 \\
\hline CGG & 27 & $27,0 \%$ & 28 & $28,0 \%$ & 15 & $15,0 \%$ & 19 & $19,0 \%$ & 9 & $9,0 \%$ & 2 & $2,0 \%$ & 100 \\
\hline CVR & 35 & $25,0 \%$ & 36 & $25,7 \%$ & 25 & $17,9 \%$ & 29 & $20,7 \%$ & 10 & $7,1 \%$ & 5 & $3,6 \%$ & 140 \\
\hline Contexto & 18 & $24,7 \%$ & 23 & $31,5 \%$ & 11 & $15,1 \%$ & 18 & $24,7 \%$ & 2 & $2,7 \%$ & 1 & $1,4 \%$ & 73 \\
\hline Contextus & 7 & $25,9 \%$ & 9 & $33,3 \%$ & 6 & $22,2 \%$ & 4 & $14,8 \%$ & 1 & $3,7 \%$ & 0 & $0,0 \%$ & 27 \\
\hline Custos_e_@agro & 105 & $87,5 \%$ & 8 & $6,7 \%$ & 4 & $3,3 \%$ & 3 & $2,5 \%$ & 0 & $0,0 \%$ & 0 & $0,0 \%$ & 120 \\
\hline Enfoque & 25 & $26,6 \%$ & 31 & $33,0 \%$ & 10 & $10,6 \%$ & 22 & $23,4 \%$ & 4 & $4,3 \%$ & 2 & $2,1 \%$ & 94 \\
\hline Pensar_Contabil & 37 & $34,3 \%$ & 38 & $35,2 \%$ & 8 & $7,4 \%$ & 19 & $17,6 \%$ & 5 & $4,6 \%$ & 1 & $0,9 \%$ & 108 \\
\hline RACE & 14 & $51,9 \%$ & 4 & $14,8 \%$ & 3 & $11,1 \%$ & 3 & $11,1 \%$ & 3 & $11,1 \%$ & 0 & $0,0 \%$ & 27 \\
\hline RACEF & 6 & $35,3 \%$ & 3 & $17,6 \%$ & 4 & $23,5 \%$ & 3 & $17,6 \%$ & 0 & $0,0 \%$ & 1 & $5,9 \%$ & 17 \\
\hline RAC_da_FAT & 15 & $62,5 \%$ & 2 & $8,3 \%$ & 2 & $8,3 \%$ & 4 & $16,7 \%$ & 1 & $4,2 \%$ & 0 & $0,0 \%$ & 24 \\
\hline RBC & 26 & $24,5 \%$ & 32 & $30,2 \%$ & 7 & $6,6 \%$ & 34 & $32,1 \%$ & 5 & $4,7 \%$ & 2 & $1,9 \%$ & 106 \\
\hline RBGN & 19 & $36,5 \%$ & 6 & $11,5 \%$ & 17 & $32,7 \%$ & 6 & $11,5 \%$ & 3 & $5,8 \%$ & 1 & $1,9 \%$ & 52 \\
\hline RC\&F & 13 & $11,5 \%$ & 37 & $32,7 \%$ & 36 & $31,9 \%$ & 23 & $20,4 \%$ & 4 & $3,5 \%$ & 0 & $0,0 \%$ & 113 \\
\hline RCC_UFPR & 19 & $27,9 \%$ & 22 & $32,4 \%$ & 17 & $25,0 \%$ & 8 & $11,8 \%$ & 1 & $1,5 \%$ & 1 & $1,5 \%$ & 68 \\
\hline RCC_UFSC & 30 & $32,6 \%$ & 22 & $23,9 \%$ & 13 & $14,1 \%$ & 22 & $23,9 \%$ & 3 & $3,3 \%$ & 2 & $2,2 \%$ & 92 \\
\hline RCMCC & 30 & $30,6 \%$ & 28 & $28,6 \%$ & 14 & $14,3 \%$ & 19 & $19,4 \%$ & 6 & $6,1 \%$ & 1 & $1,0 \%$ & 98 \\
\hline RCO & 28 & $22,6 \%$ & 33 & $26,6 \%$ & 22 & $17,7 \%$ & 27 & $21,8 \%$ & 10 & $8,1 \%$ & 4 & $3,2 \%$ & 124 \\
\hline RC_UFBA & 17 & $23,3 \%$ & 14 & $19,2 \%$ & 15 & $20,5 \%$ & 23 & $31,5 \%$ & 4 & $5,5 \%$ & 0 & $0,0 \%$ & 73 \\
\hline REAVI & 1 & $25,0 \%$ & 1 & $25,0 \%$ & 0 & $0,0 \%$ & 2 & $50,0 \%$ & 0 & $0,0 \%$ & 0 & $0,0 \%$ & 4 \\
\hline REPEC & 12 & $11,8 \%$ & 31 & $30,4 \%$ & 12 & $11,8 \%$ & 38 & $37,3 \%$ & 8 & $7,8 \%$ & 1 & $1,0 \%$ & 102 \\
\hline RGFC & 9 & $40,9 \%$ & 3 & $13,6 \%$ & 3 & $13,6 \%$ & 3 & $13,6 \%$ & 2 & $9,1 \%$ & 2 & $9,1 \%$ & 22 \\
\hline RIC & 44 & $40,0 \%$ & 29 & $26,4 \%$ & 12 & $10,9 \%$ & 19 & $17,3 \%$ & 5 & $4,5 \%$ & 1 & $0,9 \%$ & 110 \\
\hline RUC & 51 & $26,7 \%$ & 72 & $37,7 \%$ & 27 & $14,1 \%$ & 30 & $15,7 \%$ & 9 & $4,7 \%$ & 2 & $1,0 \%$ & 191 \\
\hline
\end{tabular}




\begin{tabular}{|c|c|c|c|c|c|c|c|c|c|c|c|c|c|}
\hline Revista & 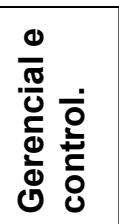 & ๙ீ & 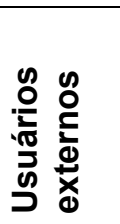 & ๙ & 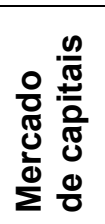 & ๙ & 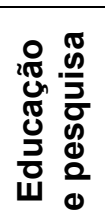 & oீ & 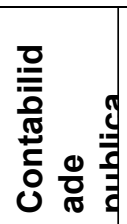 & ه & 递 & ๙ீ & $\begin{array}{l}\bar{\pi} \\
\stackrel{0}{0} \\
\end{array}$ \\
\hline Catarinense_CC & 32 & $36,4 \%$ & 27 & $30,7 \%$ & 9 & $10,2 \%$ & 14 & $15,9 \%$ & 5 & $5,7 \%$ & 1 & $1,1 \%$ & 88 \\
\hline R_Elet_Cont & 4 & $50,0 \%$ & 3 & $37,5 \%$ & 0 & $0,0 \%$ & 1 & $12,5 \%$ & 0 & $0,0 \%$ & 0 & $0,0 \%$ & 8 \\
\hline R_Est_Cont & 14 & $50,0 \%$ & 5 & $17,9 \%$ & 1 & $3,6 \%$ & 8 & $28,6 \%$ & 0 & $0,0 \%$ & 0 & $0,0 \%$ & 28 \\
\hline Razao_Cont & 9 & $40,9 \%$ & 6 & $27,3 \%$ & 1 & $4,5 \%$ & 3 & $13,6 \%$ & 3 & $13,6 \%$ & 0 & $0,0 \%$ & 22 \\
\hline Recont & 8 & $25,8 \%$ & 6 & $19,4 \%$ & 7 & $22,6 \%$ & 7 & $22,6 \%$ & 3 & $9,7 \%$ & 0 & $0,0 \%$ & 31 \\
\hline Reunir & 4 & $16,7 \%$ & 10 & $41,7 \%$ & 2 & $8,3 \%$ & 6 & $25,0 \%$ & 2 & $8,3 \%$ & 0 & $0,0 \%$ & 24 \\
\hline SCG & 25 & $29,1 \%$ & 26 & $30,2 \%$ & 15 & $17,4 \%$ & 16 & $18,6 \%$ & 3 & $3,5 \%$ & 1 & $1,2 \%$ & 86 \\
\hline Total & 831 & $32,7 \%$ & 668 & $26,3 \%$ & 405 & $15,9 \%$ & 484 & $19,1 \%$ & 117 & $4,6 \%$ & 35 & $1,4 \%$ & 2540 \\
\hline
\end{tabular}


Das 36 revistas da análise, 16 tiveram a área de Contabilidade gerencial e Controladoria como a linha mais frequente nos artigos publicados, e 14 tiveram a área de Contabilidade para usuários externos. As revistas restantes assim se dividiram: quatro revistas concentraram os artigos da linha de Educação e Pesquisa; e duas concentraram artigos da linha de Mercado de capitais.

Também foi possível perceber que algumas revistas constituem uma concentração em torno de uma linha de pesquisa e poderiam ser classificadas como revistas especializadas. Por exemplo, a ABCustos e a Custos e @gronegócio online chegaram a mais de $80 \%$ de seus artigos publicados na área de Contabilidade gerencial e Controladoria. A Brazilian Business Review concentrou $46 \%$ de seus artigos na área de Mercado de capitais.

Outras revistas mostraram um equilíbrio entre linhas de pesquisa, como a Contabilidade Vista \& Revista e a Revista de Contabilidade e Organizações, em que a maior concentração foi de $25,7 \%$ e $26,6 \%$, respectivamente, na linha de Contabilidade para Usuários externos; e a Recont: Registro Contábil, que teve maior concentração em Contabilidade gerencial e Controladoria, com 25,8\% dos artigos tratando de temas dessa linha.

Os dados tornaram possível desenhar o mapa perceptual desta relação por meio da Anacor, como mostra a Figura 32. 


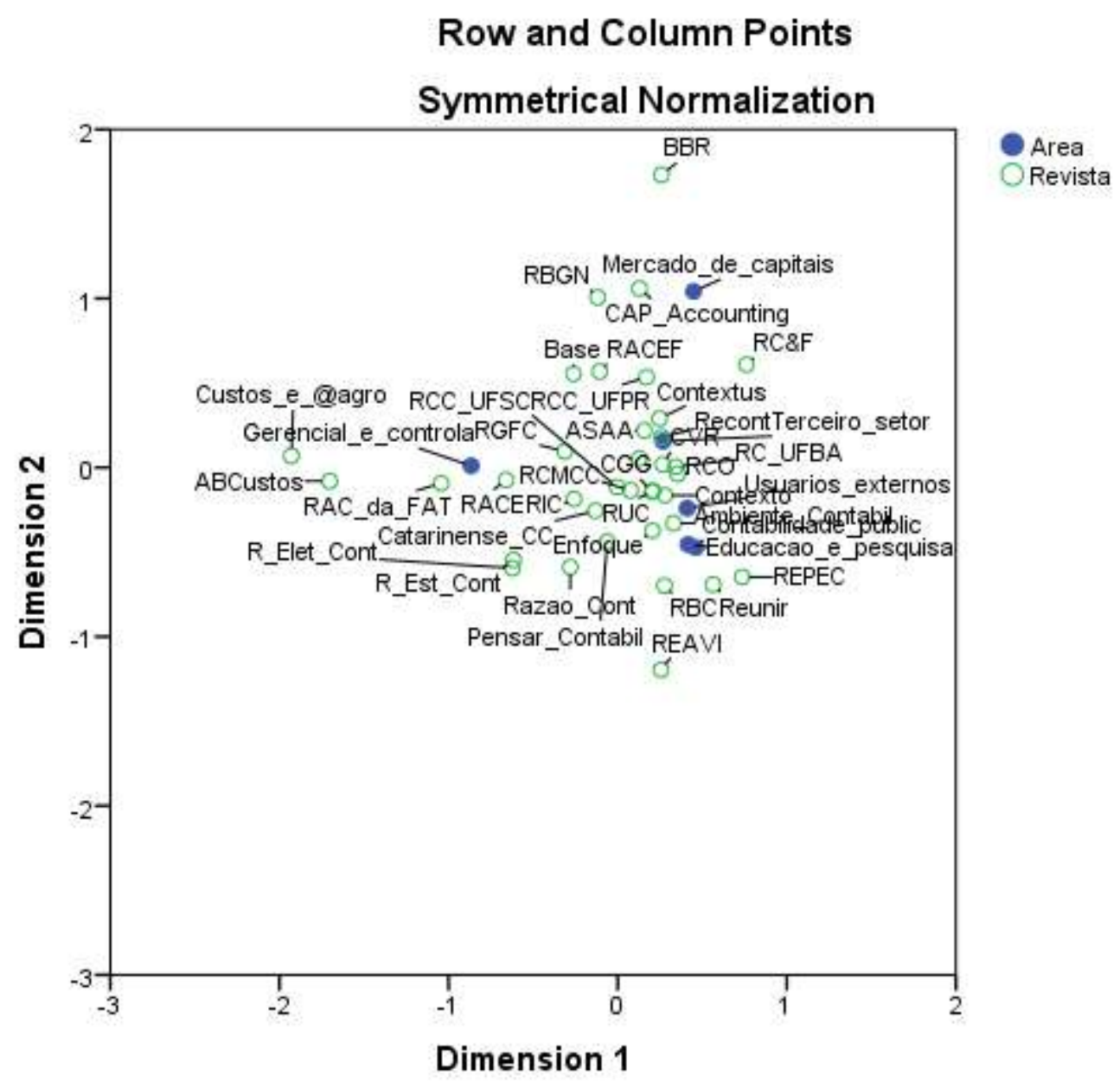

Figura 32 - Mapa perceptual da relação entre Linha de pesquisa e Revista

$\mathrm{Na}$ parte superior da Figura 32, pode-se notar a proximidade das revistas Brazilian Business Review, Revista Brasileira de Gestão de Negócios e CAP Accounting and Management com a linha de pesquisa de Mercado de capitais. Na parte esquerda é possível verificar as revistas ABCustos, Custos e @gronegócio online e Revista de Administração e Contabilidade da Faculdade Anísio Teixeira próximas da linha de Contabilidade gerencial e Controladoria e longe das demais. No canto inferior direito, próximas dos pontos que representam as linhas de Contabilidade pública e Educação e Pesquisa, encontram-se as revistas Reunir, Revista Brasileira de Contabilidade, REPEC e REAVI.

\subsection{Relação entre Revista e Abordagem da análise}


A associação entre Revista e Abordagem da análise mostrou-se estatisticamente significante, segundo o teste de qui-quadrado. Como a variável Abordagem de análise só possui duas categorias, não foi possível criar o mapa perceptual.

A Tabela 37 evidencia as revistas quanto à proporção das pesquisas que utilizam métodos quantitativos em suas análises, em ordem decrescente.

Tabela 37 - Proporção dos artigos de cada revista, de acordo com a abordagem dos dados

\begin{tabular}{|c|c|c|c|c|c|}
\hline Revista & Quantitativa & $\%$ & Não-Quantitativa & $\%$ & Total \\
\hline BBR & 61 & $83,6 \%$ & 12 & $16,4 \%$ & 73 \\
\hline RC\&F & 90 & $79,6 \%$ & 23 & $20,4 \%$ & 113 \\
\hline RACEF & 13 & $76,5 \%$ & 4 & $23,5 \%$ & 17 \\
\hline Contextus & 18 & $66,7 \%$ & 9 & $33,3 \%$ & 27 \\
\hline RBGN & 34 & $65,4 \%$ & 18 & $34,6 \%$ & 52 \\
\hline CVR & 89 & $63,6 \%$ & 51 & $36,4 \%$ & 140 \\
\hline ASAA & 33 & $62,3 \%$ & 20 & $37,7 \%$ & 53 \\
\hline RCC_UFSC & 57 & $62,0 \%$ & 35 & $38,0 \%$ & 92 \\
\hline Base & 55 & $61,8 \%$ & 34 & $38,2 \%$ & 89 \\
\hline Recont & 19 & $61,3 \%$ & 12 & $38,7 \%$ & 31 \\
\hline $\mathrm{RCO}$ & 74 & $59,7 \%$ & 50 & $40,3 \%$ & 124 \\
\hline Custos_e_@agro & 71 & $59,2 \%$ & 49 & $40,8 \%$ & 120 \\
\hline CGG & 57 & $57,0 \%$ & 43 & $43,0 \%$ & 100 \\
\hline RIC & 62 & $56,4 \%$ & 48 & $43,6 \%$ & 110 \\
\hline RUC & 104 & $54,5 \%$ & 87 & $45,5 \%$ & 191 \\
\hline RCC_UFPR & 37 & $54,4 \%$ & 31 & $45,6 \%$ & 68 \\
\hline REPEC & 51 & $50,0 \%$ & 51 & $50,0 \%$ & 102 \\
\hline RGFC & 11 & $50,0 \%$ & 11 & $50,0 \%$ & 22 \\
\hline R_Elet_Cont & 4 & $50,0 \%$ & 4 & $50,0 \%$ & 8 \\
\hline Reunir & 12 & $50,0 \%$ & 12 & $50,0 \%$ & 24 \\
\hline SCG & 43 & $50,0 \%$ & 43 & $50,0 \%$ & 86 \\
\hline RCMCC & 42 & $42,9 \%$ & 56 & $57,1 \%$ & 98 \\
\hline ABCustos & 29 & $42,6 \%$ & 39 & $57,4 \%$ & 68 \\
\hline Ambiente_Contabil & 19 & $40,4 \%$ & 28 & $59,6 \%$ & 47 \\
\hline Pensar_Contabil & 43 & $39,8 \%$ & 65 & $60,2 \%$ & 108 \\
\hline Contexto & 29 & $39,7 \%$ & 44 & $60,3 \%$ & 73 \\
\hline RC_UFBA & 28 & $38,4 \%$ & 45 & $61,6 \%$ & 73 \\
\hline CAP_Accounting & 14 & $36,8 \%$ & 24 & $63,2 \%$ & 38 \\
\hline Enfoque & 32 & $34,0 \%$ & 62 & $66,0 \%$ & 94 \\
\hline RAC_da_FAT & 8 & $33,3 \%$ & 16 & $66,7 \%$ & 24 \\
\hline R_Est_Cont & 9 & $32,1 \%$ & 19 & $67,9 \%$ & 28 \\
\hline Razao_Cont & 7 & $31,8 \%$ & 15 & $68,2 \%$ & 22 \\
\hline Catarinense_CC & 27 & $30,7 \%$ & 61 & $69,3 \%$ & 88 \\
\hline RACE & 8 & $29,6 \%$ & 19 & $70,4 \%$ & 27 \\
\hline RBC & 28 & $26,4 \%$ & 78 & $73,6 \%$ & 106 \\
\hline REAVI & 1 & $25,0 \%$ & 3 & $75,0 \%$ & 4 \\
\hline Total & 1319 & $51,9 \%$ & 1221 & $48,1 \%$ & 2540 \\
\hline
\end{tabular}

Das 36 revistas analisadas nesta Tese, 21 têm metade ou mais de seus artigos que empregam método quantitativo em sua abordagem. Nesse contexto, a Brazilian Business Review é a que mais veiculou artigos utilizando essa abordagem, chegando 
a $83,6 \%$ do total de artigos que publicou. A segunda revista que mais veiculou artigos com essa abordagem foi a Revista de Contabilidade \& Finanças, e a terceira foi a RACEF - Revista de Administração, Contabilidade e Economia da Fundace. As quarta e quinta revistas da lista são a Contextus - Revista Contemporânea de Economia e Gestão e a Revista Brasileira de Gestão de Negócios. Tornando a olhar a Figura 32, Mapa perceptual das revistas por linha de pesquisa, percebe-se que essas revistas orbitam em torno da área de Mercado de Capitais.

$\mathrm{Na}$ outra ponta da lista têm-se revistas, em sua maioria ligadas a instituições sem programa de pós-graduação em Contabilidade; são revistas criadas mais recentemente e que têm média de citação mais baixa.

\subsection{Relação entre Gênero do primeiro autor e Titulação do primeiro autor}

A relação entre o Gênero do primeiro autor e a Titulação do primeiro autor mostrouse estatisticamente significativa no teste de qui-quadrado. A Tabela 38 mostra que o percentual de primeiros autores mulheres diminui à medida que o título do primeiro autor aumenta. Enquanto os primeiros autores mulheres representam $56,1 \%$ dos autores graduandos, os primeiros autores homens representam $74,8 \%$ dos autores doutores.

Tabela 38 - Relação entre Gênero do primeiro autor e Titulação do primeiro autor

\begin{tabular}{l|r|r|r|r|r}
\hline \multicolumn{1}{c|}{ Titulação } & Homem & \multicolumn{1}{c|}{$\%$} & \multicolumn{1}{c|}{ Mulher } & \multicolumn{1}{c|}{$\%$} & \multicolumn{1}{c}{ Total } \\
\hline Graduando & 36 & $43,9 \%$ & 46 & $56,1 \%$ & 82 \\
\hline Bacharelado & 349 & $55,0 \%$ & 286 & $45,0 \%$ & 635 \\
\hline Mestrado & 696 & $68,9 \%$ & 314 & $31,1 \%$ & 1010 \\
\hline Doutorado & 608 & $74,8 \%$ & 205 & $25,2 \%$ & 813 \\
\hline Total & 1689 & $66,5 \%$ & 851 & $33,5 \%$ & 2540 \\
\hline
\end{tabular}

A diferença dessa relação entre Gênero do primeiro autor e Titulação do primeiro autor não foi inesperada, dado que a profissão de contador tem um estereótipo masculino e, historicamente, houve um percentual maior de homens matriculados nos cursos de graduação e pós-graduação em Contabilidade. Contudo, a partir da década de 2000, o número de matrículas de mulheres começou a aumentar, refletindo, por consequência, no aumento do número de primeiras autoras nos níveis iniciais de titulação. 


\subsection{Relação entre Gênero do primeiro autor e IES do primeiro autor}

O teste de qui-quadrado mostrou que a relação entre Gênero do primeiro autor e IES do primeiro autor é estatisticamente significante. Um cuidado precisa ser tomado na interpretação desse indicador, pois ele não indica que as instituições têm poucas ou muitas mulheres docentes ou discentes. Vale lembrar que ele foi construído com base na informação que o primeiro autor indicou como a instituição a que está/esteve vinculado, podendo se aplicar, inclusive, a egressos.

A Tabela 39 mostra que o número de artigos com primeiro autor homem predomina em todas as IES, à exceção da Unisinos. A instituição a que mais primeiros autores do gênero masculino declararam vínculo foi a UFBA, com $88,1 \%$ dos 42 artigos em que o primeiro autor declarou estar vinculado. Na sequência, foram a PUC/SP e a UFES com $86,4 \%$ e $85,7 \%$, respectivamente. A Unisinos foi a única instituição em que o percentual de primeiros autores mulheres foi maior que o de homens, com $53,8 \%$.

\begin{tabular}{|c|c|c|c|c|c|}
\hline IES_1_autor & Homem & $\%$ & Mulher & $\%$ & Total \\
\hline UFBA & 37 & $88,1 \%$ & 5 & $11,9 \%$ & 42 \\
\hline PUCSP & 19 & $86,4 \%$ & 3 & $13,6 \%$ & 22 \\
\hline UFES & 12 & $85,7 \%$ & 2 & $14,3 \%$ & 14 \\
\hline UPM & 25 & $80,6 \%$ & 6 & $19,4 \%$ & 31 \\
\hline UFPR & 39 & $78,0 \%$ & 11 & $22,0 \%$ & 50 \\
\hline UFRJ & 84 & $77,1 \%$ & 25 & $22,9 \%$ & 109 \\
\hline UNB & 120 & $75,0 \%$ & 40 & $25,0 \%$ & 160 \\
\hline USP & 281 & $74,5 \%$ & 96 & $25,5 \%$ & 377 \\
\hline UFRN & 31 & $73,8 \%$ & 11 & $26,2 \%$ & 42 \\
\hline UFPB & 19 & $73,1 \%$ & 7 & $26,9 \%$ & 26 \\
\hline FECAP & 12 & $70,6 \%$ & 5 & $29,4 \%$ & 17 \\
\hline UFMG & 53 & $67,1 \%$ & 26 & $32,9 \%$ & 79 \\
\hline UFPE & 43 & $66,2 \%$ & 22 & $33,8 \%$ & 65 \\
\hline FUCAPE & 27 & $64,3 \%$ & 15 & $35,7 \%$ & 42 \\
\hline OUTRA & 571 & $61,6 \%$ & 356 & $38,4 \%$ & 927 \\
\hline FURB & 86 & $61,4 \%$ & 54 & $38,6 \%$ & 140 \\
\hline UFSC & 147 & $61,3 \%$ & 93 & $38,8 \%$ & 240 \\
\hline USPRP & 18 & $58,1 \%$ & 13 & $41,9 \%$ & 31 \\
\hline UERJ & 35 & $57,4 \%$ & 26 & $42,6 \%$ & 61 \\
\hline UNISINOS & 30 & $46,2 \%$ & 35 & $53,8 \%$ & 65 \\
\hline Total & 1689 & $66,5 \%$ & 851 & $33,5 \%$ & 2540 \\
\hline
\end{tabular}

A ressalva anteriormente feita encontra respaldo no fato de que, em 2012, último ano do período analisado, havia 10 docentes permanentes no programa de pós-graduação 
da UFBA e, destes, 30\% eram mulheres; enquanto que, na Unisinos, havia 14 docentes permanentes e um era do gênero feminino, o que significa $7 \%$.

Ainda em 2012, a UFBA tinha 19 discentes matriculados no mestrado, dos quais sete, ou seja, 36\%, eram mulheres. A Unisinos, por sua vez, registrava 61 alunos de mestrado matriculados em seu programa, dos quais 26 , ou seja, $42 \%$, eram mulheres.

\subsection{Relação entre Gênero do primeiro autor e Linha de pesquisa}

A relação entre o Gênero do primeiro autor e a Linha de pesquisa mostrou-se estatisticamente significante, segundo o teste de qui-quadrado. A Tabela 40 mostra que há uma frequência maior de primeiros autores do gênero masculino nas linhas de Mercado de capitais $(75,3 \%)$ e Contabilidade gerencial e Controladoria $(67,1 \%)$; e menor frequência nas linhas de Contabilidade para usuários externos (63,8\%); e Educação e Pesquisa em Contabilidade (61,8\%).

Tabela 40 - Relação entre Gênero do primeiro autor e Linha de pesquisa

\begin{tabular}{l|r|r|r|r|r}
\hline \multicolumn{1}{c|}{ Linha de pesquisa } & Homem & \multicolumn{1}{c|}{ M } & Mulher & \multicolumn{1}{c|}{ T } & \multicolumn{1}{c}{ Total } \\
\hline Mercado de capitais & 305 & $75,3 \%$ & 100 & $24,7 \%$ & 405 \\
\hline Gerencial e controladoria & 558 & $67,1 \%$ & 273 & $32,9 \%$ & 831 \\
\hline Contabilidade pública & 78 & $66,7 \%$ & 39 & $33,3 \%$ & 117 \\
\hline Terceiro setor & 23 & $65,7 \%$ & 12 & $34,3 \%$ & 35 \\
\hline Usuários externos & 426 & $63,8 \%$ & 242 & $36,2 \%$ & 668 \\
\hline Educação e pesquisa & 299 & $61,8 \%$ & 185 & $38,2 \%$ & 484 \\
\hline Total & 1689 & $66,5 \%$ & 851 & $33,5 \%$ & 2540 \\
\hline
\end{tabular}

Retomando dados, é interessante observar que, segundo a Tabela 23, as linhas de Contabilidade para usuários externos e Educação e Pesquisa tiveram a maior taxa média de citações. Vale destacar que essa variável possui associação com outras variáveis qualitativas, e que serão abordadas nas seções seguintes.

\subsection{Relação entre Gênero do primeiro autor e Abordagem da análise}

O teste de qui-quadrado mostrou que a relação entre Gênero do primeiro autor e Abordagem da análise é estatisticamente significante, como mostra a Tabela 41: 
Tabela 41 - Relação entre Gênero do primeiro autor e Abordagem da análise

\begin{tabular}{l|r|r|r|r|r}
\hline \multicolumn{1}{c|}{ Abordagem } & Homem & \multicolumn{1}{c|}{$\%$} & Mulher & \multicolumn{1}{c|}{$\%$} & \multicolumn{1}{c}{ Total } \\
\hline Quantitativa & 919 & $69,7 \%$ & 400 & $30,3 \%$ & 1319 \\
\hline Não-quantitativa & 770 & $63,1 \%$ & 451 & $36,9 \%$ & 1221 \\
\hline Total & 1689 & $66,5 \%$ & 851 & $33,5 \%$ & 2540 \\
\hline
\end{tabular}

Artigos com primeiro autor do gênero masculino utilizaram métodos quantitativos na abordagem da análise de dados em $69,7 \%$ dos casos; enquanto que o uso de métodos quantitativos, quando o primeiro autor era mulher, foi de $30,3 \%$, o que indica uma proporção de, aproximadamente, 2 para 1. Por outro lado, entre os artigos com abordagem de dados não-quantitativa, o percentual de primeiros autores homens foi de $63,1 \%$, e de mulheres, $36,9 \%$.

Outra forma de se examinar essa relação é verificando as abordagens de pesquisa mais frequentemente utilizadas por pesquisadores de um dado gênero. Feita essa verificação, os resultado obtidos estão expostos na Tabela 42, conforme segue.

Tabela 42 - Relação entre Abordagem da análise e Gênero do primeiro autor

\begin{tabular}{l|r|r|r|r|r}
\hline \multicolumn{1}{c}{ Gênero } & Quantitativa & \multicolumn{1}{c}{$\%$} & Não-quantitativa & \% & \multicolumn{1}{c}{ Total } \\
\hline Homem & 919 & 54,4 & 770 & 45,6 & 1689 \\
\hline Mulher & 400 & 47,0 & 451 & 53,0 & 851 \\
\hline Total & 1319 & 51,9 & 1221 & 48,1 & 2540 \\
\hline
\end{tabular}

Nesse caso, verifica-se que $54 \%$ dos pesquisadores homens utilizaram pesquisa quantitativa, enquanto $53 \%$ das pesquisadoras mulheres utilizaram pesquisas nãoquantitativas.

Essa informação pode levantar a questão: Haveria uma predileção por determinada abordagem em decorrência do gênero? É possível que sim, e testar essa hipótese é uma sugestão para trabalhos futuros, buscando explorar os motivos que determinam essa aparente predileção.

\subsection{Relação entre Titulação do primeiro autor e IES do primeiro autor}

Segundo o teste de qui-quadrado houve associação estatisticamente significante entre as variáveis Titulação do primeiro autor e IES do primeiro autor. 
A Tabela 43 organizou as IES em ordem decrescente do percentual de primeiros autores com título de doutor.

Tabela 43 - Relação entre Titulação do primeiro autor e IES do primeiro autor

\begin{tabular}{|c|c|c|c|c|c|c|c|c|c|}
\hline IES do $1^{\circ}$ autor & Graduando & $\%$ & Bacharelado & $\%$ & Mestrado & $\%$ & Doutorado & $\%$ & Total \\
\hline USP & 2 & $0,5 \%$ & 19 & $5,0 \%$ & 113 & $30,0 \%$ & 243 & $64,5 \%$ & 377 \\
\hline UPM & 0 & $0,0 \%$ & 1 & $3,2 \%$ & 12 & $38,7 \%$ & 18 & $58,1 \%$ & 31 \\
\hline UFRJ & 1 & $0,9 \%$ & 30 & $27,5 \%$ & 35 & $32,1 \%$ & 43 & $39,4 \%$ & 109 \\
\hline UFPB & 1 & $3,8 \%$ & 7 & $26,9 \%$ & 8 & $30,8 \%$ & 10 & $38,5 \%$ & 26 \\
\hline UFSC & 18 & $7,5 \%$ & 75 & $31,3 \%$ & 61 & $25,4 \%$ & 86 & $35,8 \%$ & 240 \\
\hline PUCSP & 1 & $4,5 \%$ & 1 & $4,5 \%$ & 13 & $59,1 \%$ & 7 & $31,8 \%$ & 22 \\
\hline FECAP & 0 & $0,0 \%$ & 3 & $17,6 \%$ & 9 & $52,9 \%$ & 5 & $29,4 \%$ & 17 \\
\hline OUTRA & 35 & $3,8 \%$ & 254 & $27,4 \%$ & 374 & $40,3 \%$ & 264 & $28,5 \%$ & 927 \\
\hline UFPE & 1 & $1,5 \%$ & 22 & $33,8 \%$ & 24 & $36,9 \%$ & 18 & $27,7 \%$ & 65 \\
\hline UFBA & 1 & $2,4 \%$ & 13 & $31,0 \%$ & 17 & $40,5 \%$ & 11 & $26,2 \%$ & 42 \\
\hline USPRP & 2 & $6,5 \%$ & 13 & $41,9 \%$ & 9 & $29,0 \%$ & 7 & $22,6 \%$ & 31 \\
\hline UFES & 0 & $0,0 \%$ & 4 & $28,6 \%$ & 7 & $50,0 \%$ & 3 & $21,4 \%$ & 14 \\
\hline UFMG & 4 & $5,1 \%$ & 28 & $35,4 \%$ & 31 & $39,2 \%$ & 16 & $20,3 \%$ & 79 \\
\hline FUCAPE & 2 & $4,8 \%$ & 5 & $11,9 \%$ & 27 & $64,3 \%$ & 8 & $19,0 \%$ & 42 \\
\hline UNISINOS & 0 & $0,0 \%$ & 6 & $9,2 \%$ & 47 & $72,3 \%$ & 12 & $18,5 \%$ & 65 \\
\hline UERJ & 0 & $0,0 \%$ & 25 & $41,0 \%$ & 26 & $42,6 \%$ & 10 & $16,4 \%$ & 61 \\
\hline UNB & 3 & $1,9 \%$ & 58 & $36,3 \%$ & 73 & $45,6 \%$ & 26 & $16,3 \%$ & 160 \\
\hline FURB & 0 & $0,0 \%$ & 38 & $27,1 \%$ & 82 & $58,6 \%$ & 20 & $14,3 \%$ & 140 \\
\hline UFPR & 0 & $0,0 \%$ & 16 & $32,0 \%$ & 30 & $60,0 \%$ & 4 & $8,0 \%$ & 50 \\
\hline UFRN & 11 & $26,2 \%$ & 17 & $40,5 \%$ & 12 & $28,6 \%$ & 2 & $4,8 \%$ & 42 \\
\hline Total & 82 & $3,2 \%$ & 635 & $25,0 \%$ & 1010 & $39,8 \%$ & 813 & $32,0 \%$ & 2540 \\
\hline
\end{tabular}

Do total de autores que informaram ter a USP como afiliação institucional, 64,5\% afirmaram ter o título de doutor, sendo esse o maior percentual registrado. $\mathrm{Na}$ sequência, apareceram a Universidade Presbiteriana Mackenzie e a Universidade Federal do Rio de Janeiro, com 58,1\% e 39,4\%, respectivamente. As instituições com menores percentuais de primeiros autores com doutorado foram a Universidade Federal do Rio Grande do Norte, Universidade Federal do Paraná e Fundação Universidade Regional de Blumenau, com 4,8\%, 8\% e 14,3\%, respectivamente.

No entanto, dentre as três últimas citadas, a distribuição entre as demais categorias se mostrou bastante distinta. Enquanto a UFRN apresentou mais primeiros autores que possuíam título de bacharel $(40,5 \%)$ do que de mestre $(28,6 \%)$, a UFPR e a FURB apresentaram mais primeiros autores com título de mestre (60\% e 58,6\%) do que de bacharel (32\% e $27,1 \%)$. Além disso, a UFRN foi a IES em que mais primeiros autores eram graduandos quando publicaram seus artigos, em termos percentuais $(26,2 \%)$. 
Com os dados obtidos, foi possível desenhar o mapa perceptual da relação entre Titulação do primeiro autor e IES do primeiro autor por meio da Anacor, conforme mostra a Figura 33.

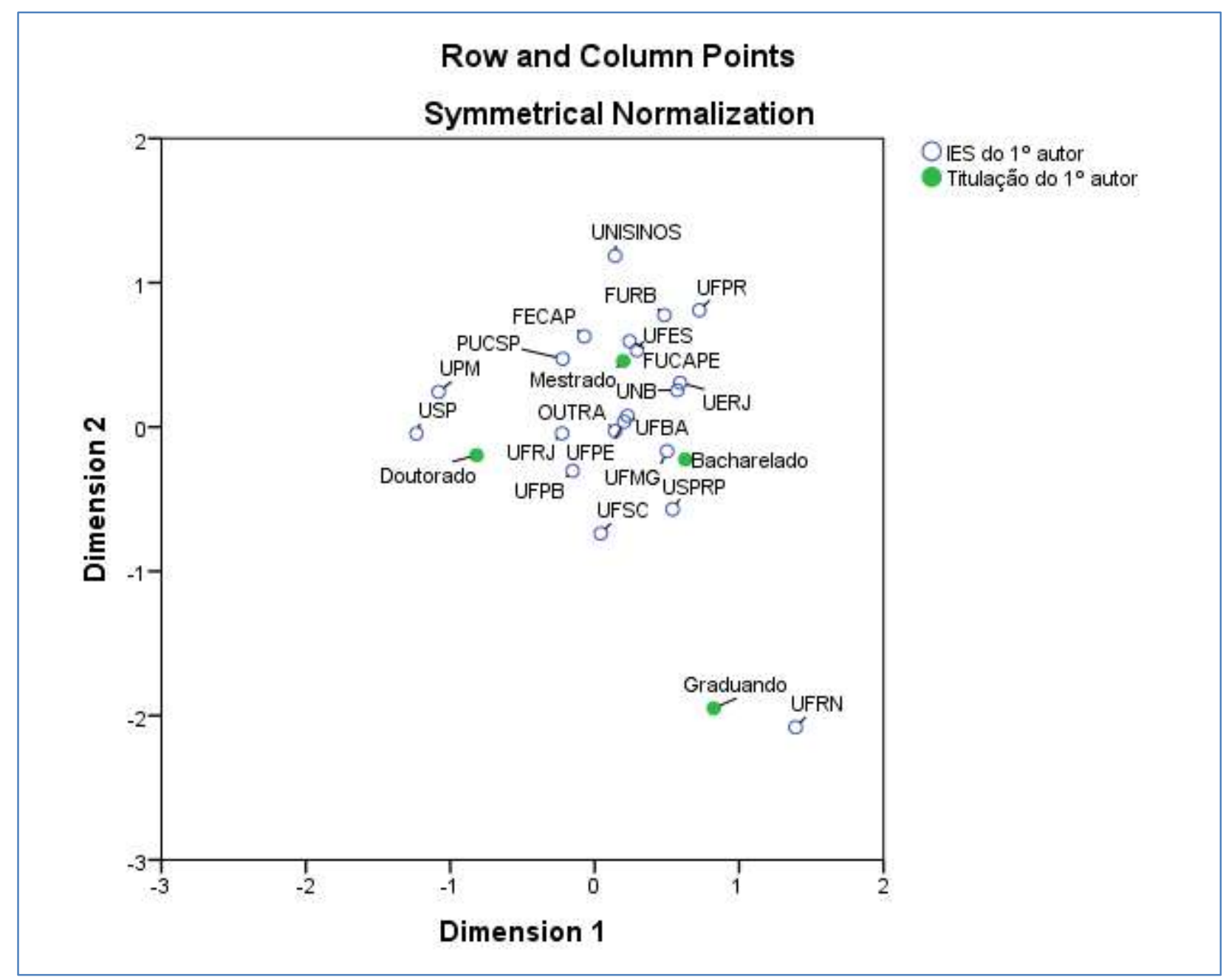

Figura 33 - Mapa perceptual da relação entre IES do $1^{\circ}$ autor e Titulação do $1^{\circ}$ autor

Observando o mapa, pode-se ver, próximo ao ponto graduando, a UFRN, e, não tão próximo, mas mais que as demais IES, a UFSC e a USP/RP. Em torno do grau de bacharel, está a UFMG. As IES mais próximas do ponto que representa o mestrado estão a Fucape e a UFES. As IES mais próximas do ponto que representa o doutorado são a USP, UPM, UFRJ e UFPB, como já indicava a Tabela 43.

\subsection{Relação entre Titulação do primeiro autor e Linha de pesquisa}

A relação entre Titulação do primeiro autor e linha de pesquisa mostrou-se estatisticamente significativa. A Tabela 44 evidencia que Contabilidade gerencial e 
Controladoria apresentou $34,8 \%$ de primeiros autores com doutorado e $41,5 \%$ de primeiros autores com mestrado. A área com menor percentual de primeiros autores com doutorado foi Contabilidade pública $(24,8 \%)$.

Tabela 44 - Relação entre Titulação do primeiro autor e Linha de pesquisa

\begin{tabular}{|c|c|c|c|c|c|c|c|c|c|}
\hline $\begin{array}{c}\text { Linha de } \\
\text { pesquisa }\end{array}$ & Graduando & $\%$ & Bacharelado & $\%$ & Mestrado & $\%$ & Doutorado & $\%$ & Total \\
\hline $\begin{array}{ll}\begin{array}{l}\text { Gerencial } \\
\text { controladoria }\end{array} & \mathrm{e} \\
\end{array}$ & 18 & $2,2 \%$ & 179 & $21,5 \%$ & 345 & $41,5 \%$ & 289 & $34,8 \%$ & 831 \\
\hline $\begin{array}{ll}\begin{array}{l}\text { Mercado } \\
\text { capitais }\end{array} & \text { de } \\
\end{array}$ & 14 & $3,5 \%$ & 91 & $22,5 \%$ & 165 & $40,7 \%$ & 135 & $33,3 \%$ & 405 \\
\hline $\begin{array}{ll}\begin{array}{l}\text { Educação } \\
\text { pesquisa }\end{array} & \text { e } \\
\end{array}$ & 16 & $3,3 \%$ & 131 & $27,1 \%$ & 180 & $37,2 \%$ & 157 & $32,4 \%$ & 484 \\
\hline $\begin{array}{l}\text { Usuários } \\
\text { externos }\end{array}$ & 29 & $4,3 \%$ & 186 & $27,8 \%$ & 259 & $38,8 \%$ & 194 & $29,0 \%$ & 668 \\
\hline Terceiro setor & 2 & $5,7 \%$ & 10 & $28,6 \%$ & 14 & $40,0 \%$ & 9 & $25,7 \%$ & 35 \\
\hline $\begin{array}{l}\text { Contabilidade } \\
\text { publica }\end{array}$ & 3 & $2,6 \%$ & 38 & $32,5 \%$ & 47 & $40,2 \%$ & 29 & $24,8 \%$ & 117 \\
\hline Total & 82 & $3,2 \%$ & 635 & $25,0 \%$ & 1010 & $39,8 \%$ & 813 & $32,0 \%$ & 2540 \\
\hline
\end{tabular}

O mapa perceptual da relação entre Titulação do primeiro autor e Área de pesquisa, elaborado por meio da Anacor, é mostrado na Figura 34. 


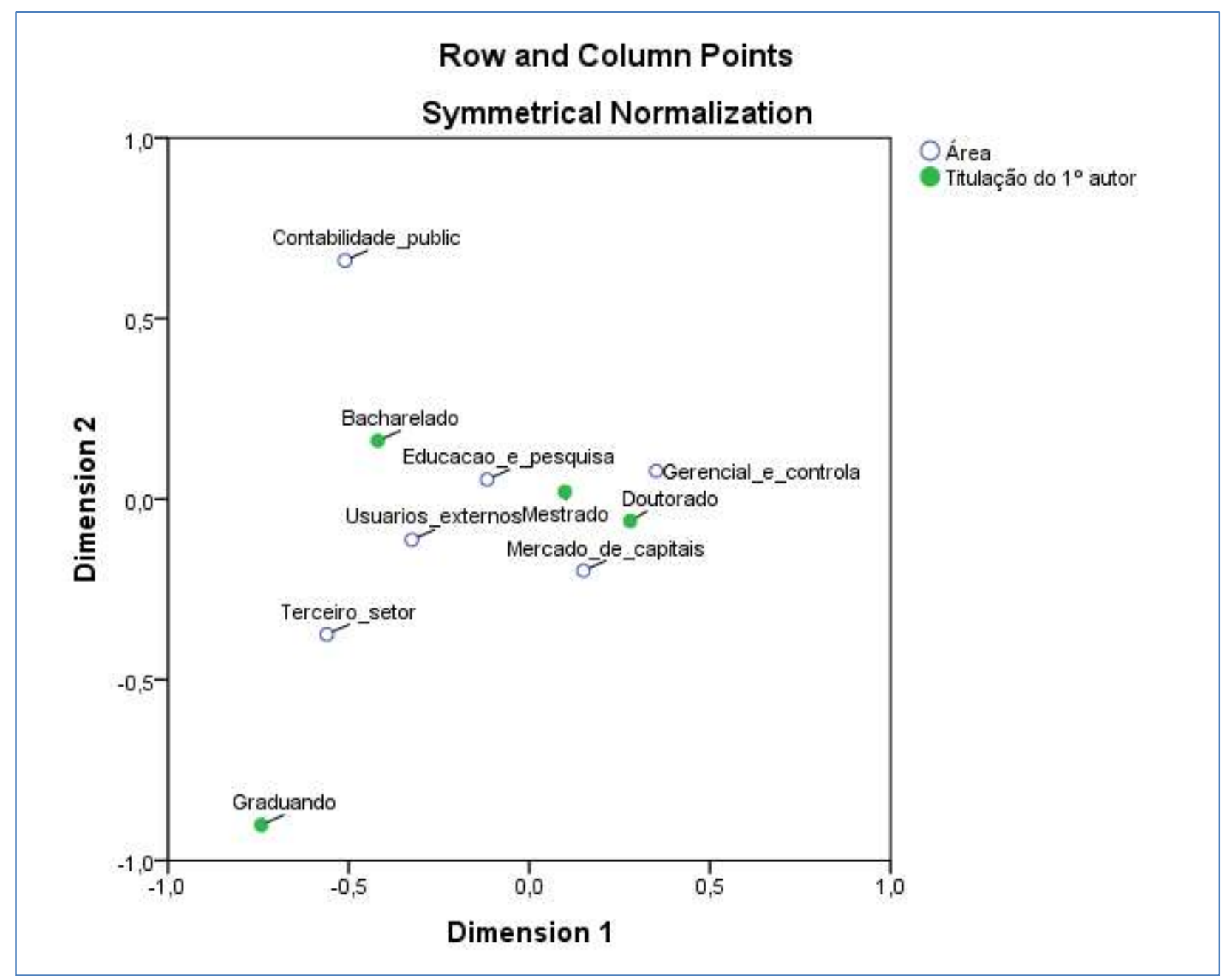

Figura 34 - Mapa perceptual da relação entre Linha de pesquisa e Titulação do $1^{\circ}$ autor

No mapa, observa-se que as linhas de pesquisa mais próximas do ponto que representa o primeiro autor com título de doutor são Contabilidade gerencial e Controladoria e Mercado de capitais. Essas duas linhas juntamente com Educação e Pesquisa estão quase equidistantes do ponto que representa os primeiros autores com título de mestre. Educação e Pesquisa juntamente com Contabilidade para usuários externos aparecem a uma distância parecida dos autores com grau de bacharel; e, longe de todas as áreas, à exceção de Terceiro setor, encontra-se o ponto que representa os primeiros autores graduandos.

\subsection{Relação entre Titulação do primeiro autor e Qualis da revista}

A Tabela 45 foi construída após o teste de qui-quadrado indicar que há associação estatisticamente significativa entre a Titulação do primeiro autor e o Qualis da revista. 
Nessa referida Tabela estão grifados os maiores percentuais de Titulação do primeiro autor.

Tabela 45 - Relação entre Titulação do primeiro autor e Qualis da revista

\begin{tabular}{l|r|r|r|r|r|r|r|r|r}
\hline $\begin{array}{c}\text { Qualis } \\
\text { vigente }\end{array}$ & Graduando & \% & Bacharelado & \% & Mestrado & \% & Doutorado & \% & Total \\
\hline A2 & 0 & $0,0 \%$ & 2 & $2,6 \%$ & 35 & $44,9 \%$ & 41 & $52,6 \%$ & 78 \\
\hline B1 & 8 & $1,8 \%$ & 61 & $13,8 \%$ & 194 & $43,9 \%$ & 179 & $40,5 \%$ & 442 \\
\hline B2 & 20 & $4,2 \%$ & 94 & $19,5 \%$ & 201 & $41,8 \%$ & 166 & $34,5 \%$ & 481 \\
\hline B3 & 20 & $3,1 \%$ & 178 & $27,2 \%$ & 240 & $36,6 \%$ & 217 & $33,1 \%$ & 655 \\
\hline B4 & 15 & $3,7 \%$ & 143 & $35,4 \%$ & 148 & $36,6 \%$ & 98 & $24,3 \%$ & 404 \\
\hline B5 & 9 & $4,4 \%$ & 67 & $33,0 \%$ & 89 & $43,8 \%$ & 38 & $18,7 \%$ & 203 \\
\hline C & 6 & $3,2 \%$ & 58 & $31,4 \%$ & 65 & $35,1 \%$ & 56 & $30,3 \%$ & 185 \\
\hline NC & 4 & $4,3 \%$ & 32 & $34,8 \%$ & 38 & $41,3 \%$ & 18 & $19,6 \%$ & 92 \\
\hline Total & 82 & $3,2 \%$ & 635 & $25,0 \%$ & 1010 & $39,8 \%$ & 813 & $32,0 \%$ & 2540 \\
\hline
\end{tabular}

Como era esperado, os artigos com primeiros autores com título de mestre e doutor foram mais frequentemente publicados em revistas classificadas nos estratos mais altos do Qualis; enquanto os artigos com os primeiros autores com título de bacharel e mestre foram, mais frequentemente, publicados em revistas classificadas nos estratos mais baixos do Qualis.

Com esses dados, foi possível desenhar o mapa perceptual da relação entre Titulação do primeiro autor e Área de pesquisa por meio da Anacor, como mostra a Figura 35. 


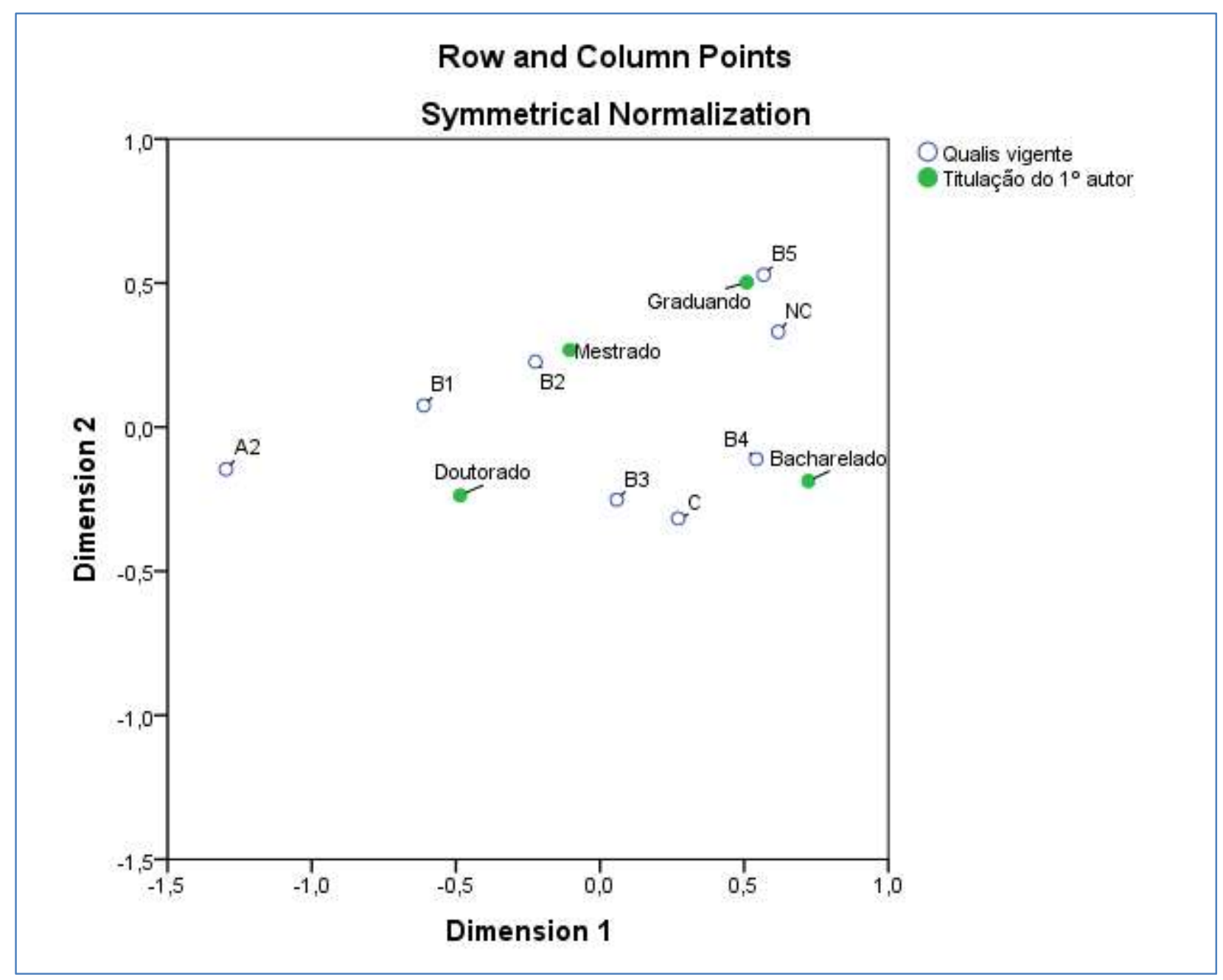

Figura 35 - Mapa perceptual da relação entre Qualis vigente e Titulação do primeiro autor

Observando o mapa, vê-se as revistas dos estratos A2, B1, B2 e B3 gravitando em torno dos primeiros autores doutores. As revistas dos estratos B5 e NC estão mais próximas dos primeiros autores graduandos. Finalmente, as revistas do estrato B2 estão mais próximas do ponto que representa os primeiros autores com mestrado; e as revistas dos estratos $\mathrm{B} 4$ e $\mathrm{C}$ são os que mais se aproximam dos primeiros autores com bacharelado.

Esse achado vai ao encontro do que se verifica, com frequência, na academia. Pesquisas desenvolvidas por autores com menor titulação, oriundas de trabalhos de conclusão de curso de graduação ou desenvolvidas por alunos de mestrado, são estimuladas a serem enviadas para revistas classificadas em estratos Qualis mais baixos, nos quais, supostamente, há menor concorrência. Já pesquisas desenvolvidas por mestres, doutores ou doutorandos são enviadas para revistas classificadas em estratos mais alto do Qualis. 


\subsection{Relação entre Titulação do primeiro autor e Abordagem da análise}

O teste de qui-quadrado mostrou que há associação estatisticamente significante entre a titulação do primeiro autor e a abordagem da análise, conforme demonstrado na Tabela 46.

Tabela 46 - Relação entre Titulação do primeiro autor e Abordagem da análise

\begin{tabular}{l|r|c|r|r|r|r|r|r|r}
\hline \multicolumn{1}{c|}{ Abordagem } & Graduando & \% & Bacharelado & \% & Mestrado & \% & Doutorado & $\%$ & Total \\
\hline Quantitativa & 26 & $2,0 \%$ & 274 & $20,8 \%$ & 572 & $43,4 \%$ & 447 & $33,9 \%$ & 1319 \\
\hline Não-quantitativa & 56 & $4,6 \%$ & 361 & $29,6 \%$ & 438 & $35,9 \%$ & 366 & $30,0 \%$ & 1221 \\
\hline Total & 82 & $3,2 \%$ & 635 & $25,0 \%$ & 1010 & $39,8 \%$ & 813 & $32,0 \%$ & 2540 \\
\hline
\end{tabular}

Observa-se, assim, que a abordagem quantitativa de análise de dados se dá em maior proporção quando o primeiro autor é mestre ou doutor (77,3\%). As abordagens nãoquantitativas se dão em maior proporção quando o primeiro autor é graduando ou bacharel $(34,2 \%)$. Esse fato pode ser explicado pela maior exposição que os alunos de mestrado e doutorado têm aos métodos quantitativos de análise de dados, enquanto cursam a pós-graduação.

A Tabela 47 expõe os resultados obtidos após se estabelecer a relação entre a abordagem da análise e a titulação do primeiro autor.

Tabela 47 - Relação entre Abordagem da análise e Titulação do primeiro autor

\begin{tabular}{l|r|r|r|r|r}
\hline \multicolumn{1}{c}{ Titulação } & Quantitativa & \multicolumn{1}{c}{ N } & Não-quantitativa & $\%$ & \multicolumn{2}{c}{ Total } \\
\hline Graduando & 26 & $31,7 \%$ & 56 & $68,3 \%$ & 82 \\
\hline Bacharelado & 274 & $43,1 \%$ & 361 & $56,9 \%$ & 635 \\
\hline Mestrado & 572 & $56,6 \%$ & 438 & $43,4 \%$ & 1010 \\
\hline Doutorado & 447 & $55,0 \%$ & 366 & $45,0 \%$ & 813 \\
\hline Total & 1319 & $51,9 \%$ & 1221 & $48,1 \%$ & 2540 \\
\hline
\end{tabular}

As abordagens quantitativas prevalecem nos artigos em que os autores são mestres ou doutores, enquanto que abordagens não-quantitativas prevalecem entre os artigos em que o primeiro autor ainda cursa a graduação ou concluiu o bacharelado.

Desse modo, pode-se inferir que o avanço dos estudos, ao longo da pós-graduação, permite aos autores conhecer e utilizar mais os métodos quantitativos, uma vez que existe uma maior oferta de disciplinas sobre métodos quantitativos nos cursos de pós- 
graduação da subárea. As disciplinas sobre métodos qualitativos ou epistemologia de pesquisa são ainda raras.

\subsection{Relação entre IES do primeiro autor e Área de pesquisa}

Buscou-se, ainda, verificar a associação entre a IES do primeiro autor e a área de pesquisa, segundo o teste de qui-quadrado. As células grifadas na Tabela 48 mostram quais áreas foram mais frequentes entre os primeiros autores de cada instituição. 
Tabela 48 - Relação entre IES do primeiro autor e Área de pesquisa

\begin{tabular}{|c|c|c|c|c|c|c|c|c|c|c|c|c|c|}
\hline $\begin{array}{l}\text { IES do } 1^{\circ} \\
\text { autor }\end{array}$ & $\begin{array}{l}\text { Gerencial } \\
\text { e control. }\end{array}$ & $\%$ & $\begin{array}{l}\text { Usuários } \\
\text { externos }\end{array}$ & $\%$ & $\begin{array}{l}\text { Mercado } \\
\text { de } \\
\text { capitais }\end{array}$ & $\%$ & $\begin{array}{c}\text { Educação } \\
\text { e } \\
\text { pesquisa }\end{array}$ & $\%$ & $\begin{array}{l}\text { Contab. } \\
\text { pública }\end{array}$ & $\%$ & $\begin{array}{l}\text { Terceiro } \\
\text { setor }\end{array}$ & $\%$ & Tota \\
\hline FECAP & 5 & $29,4 \%$ & 5 & $29,4 \%$ & 2 & $11,8 \%$ & 4 & $23,5 \%$ & 0 & $0,0 \%$ & 1 & $5,9 \%$ & 17 \\
\hline FUCAPE & 5 & $11,9 \%$ & 14 & $33,3 \%$ & 20 & $47,6 \%$ & 2 & $4,8 \%$ & 1 & $2,4 \%$ & 0 & $0,0 \%$ & 42 \\
\hline FURB & 41 & $29,3 \%$ & 33 & $23,6 \%$ & 17 & $12,1 \%$ & 43 & $30,7 \%$ & 3 & $2,1 \%$ & 3 & $2,1 \%$ & 140 \\
\hline OUTRA & 324 & $35,0 \%$ & 240 & $25,9 \%$ & 151 & $16,3 \%$ & 160 & $17,3 \%$ & 38 & $4,1 \%$ & 14 & $1,5 \%$ & 927 \\
\hline PUCSP & 6 & $27,3 \%$ & 6 & $27,3 \%$ & 4 & $18,2 \%$ & 5 & $22,7 \%$ & 0 & $0,0 \%$ & 1 & $4,5 \%$ & 22 \\
\hline UERJ & 23 & $37,7 \%$ & 17 & $27,9 \%$ & 2 & $3,3 \%$ & 12 & $19,7 \%$ & 7 & $11,5 \%$ & 0 & $0,0 \%$ & 61 \\
\hline UFBA & 15 & $35,7 \%$ & 9 & $21,4 \%$ & 5 & $11,9 \%$ & 8 & $19,0 \%$ & 3 & $7,1 \%$ & 2 & $4,8 \%$ & 42 \\
\hline UFES & 0 & $0,0 \%$ & 7 & $50,0 \%$ & 7 & $50,0 \%$ & 0 & $0,0 \%$ & 0 & $0,0 \%$ & 0 & $0,0 \%$ & 14 \\
\hline UFMG & 20 & $25,3 \%$ & 23 & $29,1 \%$ & 23 & $29,1 \%$ & 7 & $8,9 \%$ & 3 & $3,8 \%$ & 3 & $3,8 \%$ & 79 \\
\hline UFPB & 11 & $42,3 \%$ & 7 & $26,9 \%$ & 6 & $23,1 \%$ & 1 & $3,8 \%$ & 1 & $3,8 \%$ & 0 & $0,0 \%$ & 26 \\
\hline UFPE & 12 & $18,5 \%$ & 20 & $30,8 \%$ & 11 & $16,9 \%$ & 16 & $24,6 \%$ & 6 & $9,2 \%$ & 0 & $0,0 \%$ & 65 \\
\hline UFPR & 20 & $40,0 \%$ & 10 & $20,0 \%$ & 5 & $10,0 \%$ & 12 & $24,0 \%$ & 1 & $2,0 \%$ & 2 & $4,0 \%$ & 50 \\
\hline UFRJ & 40 & $36,7 \%$ & 34 & $31,2 \%$ & 11 & $10,1 \%$ & 17 & $15,6 \%$ & 7 & $6,4 \%$ & 0 & $0,0 \%$ & 109 \\
\hline UFRN & 10 & $23,8 \%$ & 7 & $16,7 \%$ & 5 & $11,9 \%$ & 12 & $28,6 \%$ & 8 & $19,0 \%$ & 0 & $0,0 \%$ & 42 \\
\hline UFSC & 86 & $35,8 \%$ & 75 & $31,3 \%$ & 19 & $7,9 \%$ & 46 & $19,2 \%$ & 11 & $4,6 \%$ & 3 & $1,3 \%$ & 240 \\
\hline UNB & 33 & $20,6 \%$ & 48 & $30,0 \%$ & 26 & $16,3 \%$ & 38 & $23,8 \%$ & 13 & $8,1 \%$ & 2 & $1,3 \%$ & 160 \\
\hline UNISINOS & 37 & $56,9 \%$ & 7 & $10,8 \%$ & 8 & $12,3 \%$ & 12 & $18,5 \%$ & 1 & $1,5 \%$ & 0 & $0,0 \%$ & 65 \\
\hline UPM & 9 & $29,0 \%$ & 5 & $16,1 \%$ & 8 & $25,8 \%$ & 9 & $29,0 \%$ & 0 & $0,0 \%$ & 0 & $0,0 \%$ & 31 \\
\hline USP & 126 & $33,4 \%$ & 92 & $24,4 \%$ & 68 & $18,0 \%$ & 74 & $19,6 \%$ & 13 & $3,4 \%$ & 4 & $1,1 \%$ & 377 \\
\hline USPRP & 8 & $25,8 \%$ & 9 & $29,0 \%$ & 7 & $22,6 \%$ & 6 & $19,4 \%$ & 1 & $3,2 \%$ & 0 & $0,0 \%$ & 31 \\
\hline Total & 831 & $32,7 \%$ & 668 & $26,3 \%$ & 405 & $15,9 \%$ & 484 & $19,1 \%$ & 117 & $4,6 \%$ & 35 & $1,4 \%$ & 2540 \\
\hline
\end{tabular}


Nota-se, analisando a Tabela, que, em metade das IES, as linhas de pesquisa dos artigos foram mais frequentemente em Contabilidade gerencial e Controladoria e Contabilidade para usuários externos. No entanto, a linha de Educação e Pesquisa mostrou-se entre as duas mais frequentes em sete instituições; e a linha de Mercado de capitais, em outras três instituições.

Os dados coletados possibilitaram desenhar o mapa perceptual dessa relação por meio da Anacor, como mostra a Figura 36.

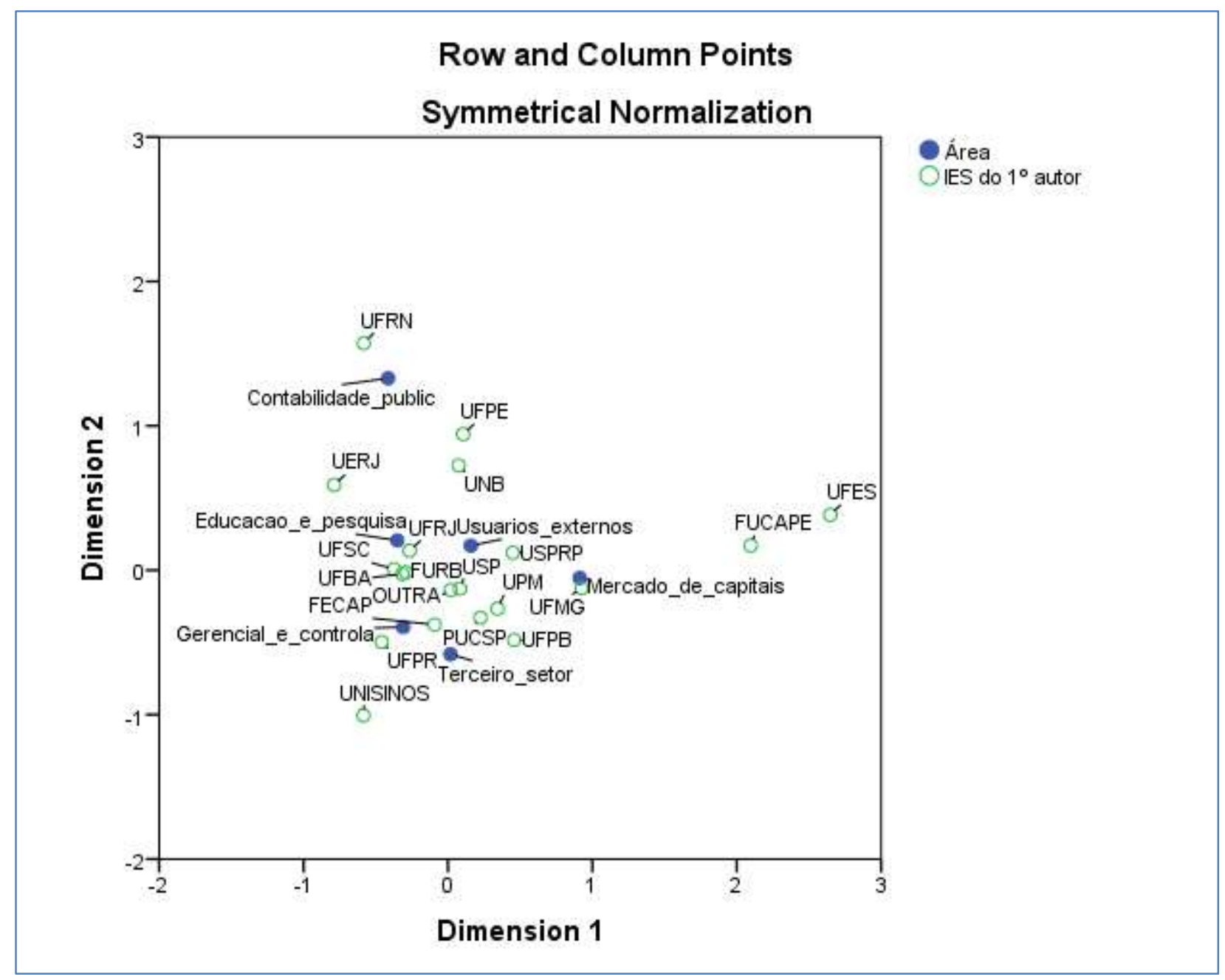

Figura 36 - Mapa perceptual da relação entre Linha de pesquisa e IES do $1^{\circ}$ autor

Observando a parte superior esquerda da Figura 36, pode-se ver a UFRN, a UFPE e a UERJ mais próximas da área de Contabilidade pública. Na parte inferior esquerda, pode-se ver a UFPR e FECAP mais próximas da área de Contabilidade gerencial e Controladoria. A UFMG é a instituição mais próxima da linha de Mercado de capitais. 
A FUCAPE e a UFES não aparecem tão próximas desta linha quanto a UFMG, mas essas três IES são as que mais se aproximam dela, distanciando-se das demais linhas de pesquisa.

\subsection{Relação entre IES do primeiro autor e Qualis da revista}

Mostrou-se, estatisticamente, significativa, de acordo com o teste qui-quadrado, a associação entre a IES do primeiro autor e o estrato Qualis das revistas onde os artigos foram publicados.

Faz-se aqui a mesma ressalva que foi feita na interpretação da IES do primeiro autor e do Gênero do primeiro autor, ou seja, não se pode inferir sobre a qualidade das pesquisas ou o desempenho do programa de pós-graduação com base nesses dados, já que eles refletem a IES que o primeiro autor indicou como afiliação quando publicou o artigo. Além disso, pode se tratar de egressos que estejam publicando em revistas de estratos maiores ou menores que os utilizados pelo programa atualmente.

Considerando essa ressalva, na Tabela 49, estão grifadas as categorias com maiores frequências relativas, por instituição.

Tabela 49 - Relação entre IES do primeiro autor e Qualis da revista

\begin{tabular}{|c|c|c|c|c|c|c|c|c|c|}
\hline $\begin{array}{l}\text { IES do } 1^{\circ} \\
\text { autor }\end{array}$ & A2 & B1 & B2 & B3 & B4 & B5 & C & NC & Total \\
\hline FECAP & 0 & 3 & 2 & 9 & 2 & 0 & 1 & 0 & 17 \\
\hline$\%$ & $0,0 \%$ & $17,6 \%$ & $11,8 \%$ & $52,9 \%$ & $11,8 \%$ & $0,0 \%$ & $5,9 \%$ & $0,0 \%$ & $100,0 \%$ \\
\hline FUCAPE & 5 & 11 & 11 & 10 & 1 & 1 & 3 & 0 & 42 \\
\hline$\%$ & $11,9 \%$ & $26,2 \%$ & $26,2 \%$ & $23,8 \%$ & $2,4 \%$ & $2,4 \%$ & $7,1 \%$ & $0,0 \%$ & $100,0 \%$ \\
\hline FURB & 1 & 28 & 34 & 31 & 23 & 8 & 15 & 0 & 140 \\
\hline$\%$ & $0,7 \%$ & $20,0 \%$ & $24,3 \%$ & $22,1 \%$ & $16,4 \%$ & $5,7 \%$ & $10,7 \%$ & $0,0 \%$ & $100,0 \%$ \\
\hline OUTRA & 34 & 162 & 141 & 219 & 145 & 107 & 74 & 45 & 927 \\
\hline$\%$ & $3,7 \%$ & $17,5 \%$ & $15,2 \%$ & $23,6 \%$ & $15,6 \%$ & $11,5 \%$ & $8,0 \%$ & $4,9 \%$ & $100,0 \%$ \\
\hline PUCSP & 2 & 5 & 4 & 6 & 4 & 1 & 0 & 0 & 22 \\
\hline$\%$ & $9,1 \%$ & $22,7 \%$ & $18,2 \%$ & $27,3 \%$ & $18,2 \%$ & $4,5 \%$ & $0,0 \%$ & $0,0 \%$ & $100,0 \%$ \\
\hline UERJ & 0 & 8 & 5 & 23 & 14 & 1 & 8 & 2 & 61 \\
\hline$\%$ & $0,0 \%$ & $13,1 \%$ & $8,2 \%$ & $37,7 \%$ & $23,0 \%$ & $1,6 \%$ & $13,1 \%$ & $3,3 \%$ & $100,0 \%$ \\
\hline UFBA & 1 & 3 & 10 & 8 & 12 & 5 & 3 & 0 & 42 \\
\hline$\%$ & $2,4 \%$ & $7,1 \%$ & $23,8 \%$ & $19,0 \%$ & $28,6 \%$ & $11,9 \%$ & $7,1 \%$ & $0,0 \%$ & $100,0 \%$ \\
\hline UFES & 2 & 4 & 4 & 2 & 0 & 0 & 0 & 2 & 14 \\
\hline$\%$ & $14,3 \%$ & $28,6 \%$ & $28,6 \%$ & $14,3 \%$ & $0,0 \%$ & $0,0 \%$ & $0,0 \%$ & $14,3 \%$ & $100,0 \%$ \\
\hline UFMG & 2 & 21 & 11 & 30 & 6 & 3 & 3 & 3 & 79 \\
\hline$\%$ & $2,5 \%$ & $26,6 \%$ & $13,9 \%$ & $38,0 \%$ & $7,6 \%$ & $3,8 \%$ & $3,8 \%$ & $3,8 \%$ & $100,0 \%$ \\
\hline UFPB & 3 & 3 & 7 & 1 & 8 & 0 & 4 & 0 & 26 \\
\hline$\%$ & $11,5 \%$ & $11,5 \%$ & $26,9 \%$ & $3,8 \%$ & $30,8 \%$ & $0,0 \%$ & $15,4 \%$ & $0,0 \%$ & $100,0 \%$ \\
\hline
\end{tabular}




\begin{tabular}{l|r|r|r|r|r|r|r|r|r}
\hline $\begin{array}{l}\text { IES do 10 } \\
\text { autor }\end{array}$ & A2 & B1 & B2 & B3 & B4 & B5 & C & NC & Total \\
\hline UFPE & 2 & 10 & 11 & 24 & 10 & 4 & 2 & 2 & 65 \\
\hline \% & $3,1 \%$ & $15,4 \%$ & $16,9 \%$ & $36,9 \%$ & $15,4 \%$ & $6,2 \%$ & $3,1 \%$ & $3,1 \%$ & $100,0 \%$ \\
\hline UFPR & 1 & 11 & 14 & 9 & 7 & 5 & 1 & 2 & 50 \\
\hline$\%$ & $2,0 \%$ & $22,0 \%$ & $28,0 \%$ & $18,0 \%$ & $14,0 \%$ & $10,0 \%$ & $2,0 \%$ & $4,0 \%$ & $100,0 \%$ \\
\hline UFRJ & 1 & 8 & 20 & 32 & 30 & 3 & 7 & 8 & 109 \\
\hline \% & $0,9 \%$ & $7,3 \%$ & $18,3 \%$ & $29,4 \%$ & $27,5 \%$ & $2,8 \%$ & $6,4 \%$ & $7,3 \%$ & $100,0 \%$ \\
\hline UFRN & 0 & 2 & 13 & 9 & 10 & 2 & 2 & 4 & 42 \\
\hline \% & $0,0 \%$ & $4,8 \%$ & $31,0 \%$ & $21,4 \%$ & $23,8 \%$ & $4,8 \%$ & $4,8 \%$ & $9,5 \%$ & $100,0 \%$ \\
\hline UFSC & 1 & 27 & 43 & 53 & 54 & 24 & 31 & 7 & 240 \\
\hline \% & $0,4 \%$ & $11,3 \%$ & $17,9 \%$ & $22,1 \%$ & $22,5 \%$ & $10,0 \%$ & $12,9 \%$ & $2,9 \%$ & $100,0 \%$ \\
\hline UNB & 3 & 23 & 52 & 39 & 22 & 7 & 9 & 5 & 160 \\
\hline \% & $1,9 \%$ & $14,4 \%$ & $32,5 \%$ & $24,4 \%$ & $13,8 \%$ & $4,4 \%$ & $5,6 \%$ & $3,1 \%$ & $100,0 \%$ \\
\hline UNISINOS & 3 & 17 & 10 & 12 & 10 & 4 & 5 & 4 & 65 \\
\hline$\%$ & $4,6 \%$ & $26,2 \%$ & $15,4 \%$ & $18,5 \%$ & $15,4 \%$ & $6,2 \%$ & $7,7 \%$ & $6,2 \%$ & $100,0 \%$ \\
\hline UPM & 3 & 9 & 11 & 3 & 3 & 2 & 0 & 0 & 31 \\
\hline \% & $9,7 \%$ & $29,0 \%$ & $35,5 \%$ & $9,7 \%$ & $9,7 \%$ & $6,5 \%$ & $0,0 \%$ & $0,0 \%$ & $100,0 \%$ \\
\hline USP & 13 & 76 & 73 & 129 & 39 & 24 & 16 & 7 & 377 \\
\hline$\%$ & $3,4 \%$ & $20,2 \%$ & $19,4 \%$ & $34,2 \%$ & $10,3 \%$ & $6,4 \%$ & $4,2 \%$ & $1,9 \%$ & $100,0 \%$ \\
\hline USPRP & 1 & 11 & 5 & 6 & 4 & 2 & 1 & 1 & 31 \\
\hline \% & $3,2 \%$ & $35,5 \%$ & $16,1 \%$ & $19,4 \%$ & $12,9 \%$ & $6,5 \%$ & $3,2 \%$ & $3,2 \%$ & $100,0 \%$ \\
\hline Total & 78 & 442 & 481 & 655 & 404 & 203 & 185 & 92 & 2540 \\
\hline \% & $3,1 \%$ & $17,4 \%$ & $18,9 \%$ & $25,8 \%$ & $15,9 \%$ & $8,0 \%$ & $7,3 \%$ & $3,6 \%$ & $100,0 \%$ \\
\hline & & & & & & & & & \\
\hline
\end{tabular}

Conforme demonstra a Tabela, apenas a FUCAPE, UFES, UFPR e UPM tiveram as frequências relativas altas nos estratos B1 e B2. As outras instituições, principalmente aquelas que têm maior frequência absoluta de artigos publicados, como FURB, UFRJ, UFSC e USP, tiveram frequência relativa maior no estrato $B 3$, no qual havia mais opções de revistas, comparado ao estrato B1.

Assim, foi possível desenhar o mapa perceptual desta relação por meio da Anacor, como mostra a Figura 37. 


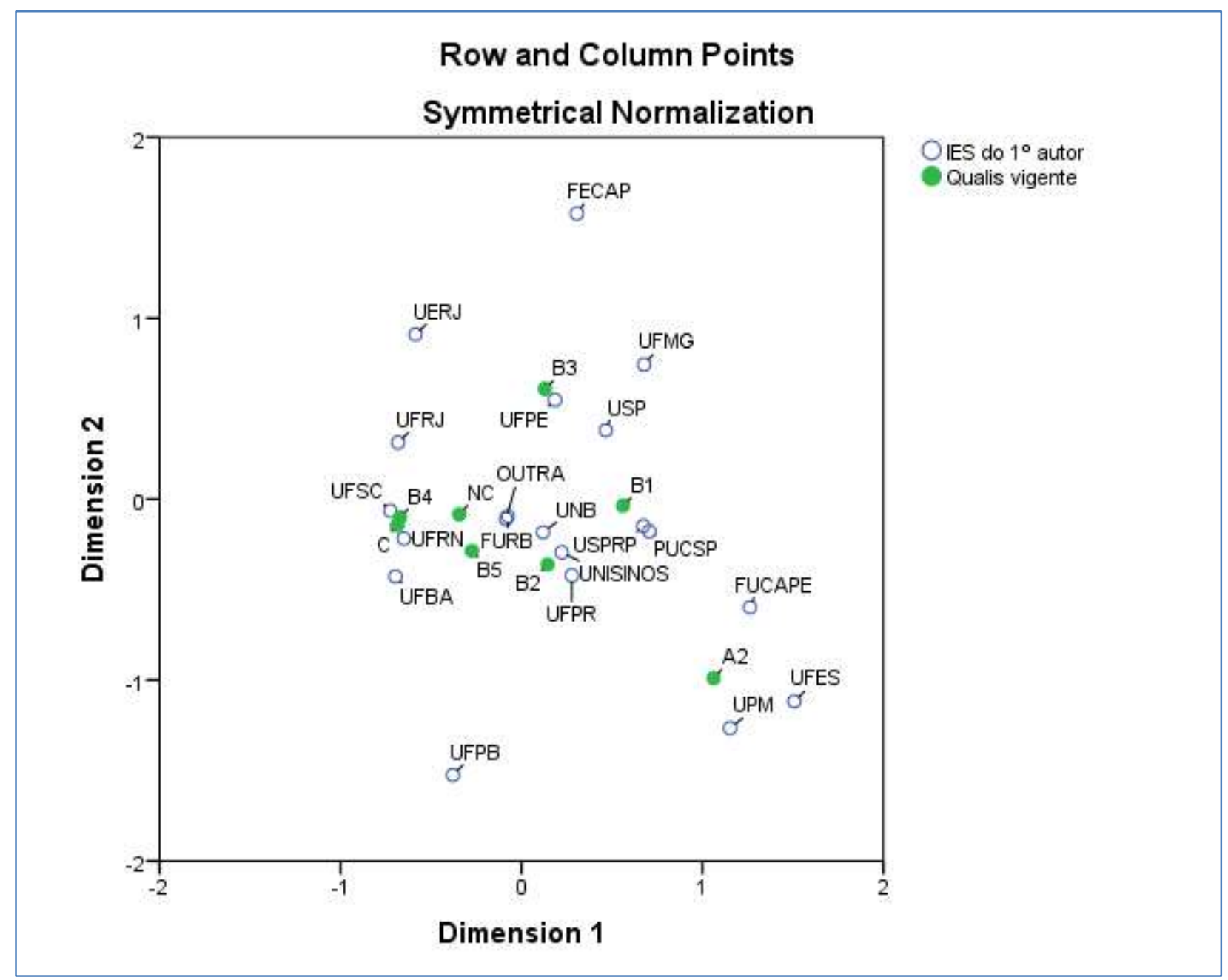

Figura 37 - Mapa perceptual da relação entre IES do $1^{\circ}$ autor e Qualis vigente

Analisando a Figura, nota-se que, em torno do estrato A2, o mais alto dentre as revistas da amostra, no canto inferior direito do mapa, encontram-se a FUCAPE, UFES e UPM. Próximas ao estrato B1, estão a USP/RP e PUC/SP. As IES mais próximas do estrato B2 são Unisinos e UFPR.

\subsection{Relação entre IES do primeiro autor e Abordagem da análise}

A relação entre IES do primeiro autor e Abordagem da análise também mostrou-se significativa estatisticamente. A Tabela 50 detalha essa relação.

Tabela 50 - Relação entre IES do primeiro autor e Abordagem da análise

\begin{tabular}{l|r|r|r|r|r}
\hline IES do 10 autor & Quantitativa & \multicolumn{1}{c}{$\%$} & Não-quantitativa & \multicolumn{1}{c|}{ Total } \\
\hline FUCAPE & 37 & $88,1 \%$ & 5 & $11,9 \%$ & 42 \\
\hline UFPB & 20 & $76,9 \%$ & 6 & $23,1 \%$ & 26 \\
\hline UPM & 23 & $74,2 \%$ & 8 & $25,8 \%$ & 31 \\
\hline UFES & 10 & $71,4 \%$ & 4 & $28,6 \%$ & 14 \\
\hline
\end{tabular}




\begin{tabular}{l|r|r|r|r|r}
\hline IES do $\mathbf{1}^{\mathbf{0}}$ autor & Quantitativa & $\%$ & Não-quantitativa & \multicolumn{1}{c|}{$\%$} & \multicolumn{1}{c}{ Total } \\
\hline UFMG & 55 & $69,6 \%$ & 24 & $30,4 \%$ & 79 \\
\hline USPRP & 20 & $64,5 \%$ & 11 & $35,5 \%$ & 31 \\
\hline USP & 219 & $58,1 \%$ & 158 & $41,9 \%$ & 377 \\
\hline UFPR & 29 & $58,0 \%$ & 21 & $42,0 \%$ & 50 \\
\hline UFRJ & 63 & $57,8 \%$ & 46 & $42,2 \%$ & 109 \\
\hline UFPE & 37 & $56,9 \%$ & 28 & $43,1 \%$ & 65 \\
\hline PUCSP & 12 & $54,5 \%$ & 10 & $45,5 \%$ & 22 \\
\hline UERJ & 32 & $52,5 \%$ & 29 & $47,5 \%$ & 61 \\
\hline UFBA & 22 & $52,4 \%$ & 20 & $47,6 \%$ & 42 \\
\hline OUTRA & 478 & $51,6 \%$ & 449 & $48,4 \%$ & 927 \\
\hline FECAP & 8 & $47,1 \%$ & 9 & $52,9 \%$ & 17 \\
\hline UNISINOS & 30 & $46,2 \%$ & 35 & $53,8 \%$ & 65 \\
\hline UNB & 71 & $44,4 \%$ & 89 & $55,6 \%$ & 160 \\
\hline UFRN & 16 & $38,1 \%$ & 26 & $61,9 \%$ & 42 \\
\hline FURB & 51 & $36,4 \%$ & 89 & $63,6 \%$ & 140 \\
\hline UFSC & 86 & $35,8 \%$ & 154 & $64,2 \%$ & 240 \\
\hline Total & 1319 & $51,9 \%$ & 1221 & $48,1 \%$ & 2540 \\
\hline
\end{tabular}

Conforme se observa na Tabela, FUCAPE, UFPB e UPM são as instituições que mais se utilizam de abordagem quantitativa em suas análises. Esse fato pode estar associado com a proximidade que essas instituições têm da linha de pesquisa em Mercado de capitais, como já visto na Figura 36. Essa linha, tradicionalmente, utiliza muitos métodos estatísticos. Já o uso de métodos não-quantitativos de análise é encabeçado pela UFSC, fato que pode estar ligado ao grande número de graduandos e bacharéis dessa instituição como primeiros autores das pesquisas, quando comparados às outras instituições, conforme visto na Tabela 43.

\subsection{Relação entre Linha de pesquisa e Qualis da revista}

A Tabela 51 mostra a relação existente entre a Linha de pesquisa e o estrato do Qualis da revista em que o artigo foi publicado. As células grifadas mostram as áreas mais frequentes.

Tabela 51 - Relação entre Linha de pesquisa e Qualis da revista

\begin{tabular}{|c|c|c|c|c|c|c|c|c|c|c|c|c|c|}
\hline $\begin{array}{l}\text { Linha/ } \\
\text { Qualis } \\
\text { vigente }\end{array}$ & 1 & $\%$ & 2 & $\%$ & 3 & $\%$ & 4 & $\%$ & 5 & $\%$ & 6 & $\%$ & Total \\
\hline $\mathrm{A} 2$ & 14 & $17,9 \%$ & 24 & $30,8 \%$ & 30 & $38,5 \%$ & 8 & $10,3 \%$ & 2 & $2,6 \%$ & 0 & $0,0 \%$ & 78 \\
\hline B1 & 121 & $27,4 \%$ & 109 & $24,7 \%$ & 94 & $21,3 \%$ & 91 & $20,6 \%$ & 20 & $4,5 \%$ & 7 & $1,6 \%$ & 442 \\
\hline B2 & 158 & $32,8 \%$ & 125 & $26,0 \%$ & 72 & $15,0 \%$ & 96 & $20,0 \%$ & 25 & $5,2 \%$ & 5 & $1,0 \%$ & 481 \\
\hline B3 & 172 & $26,3 \%$ & 187 & $28,5 \%$ & 104 & $15,9 \%$ & 137 & $20,9 \%$ & 40 & $6,1 \%$ & 15 & $2,3 \%$ & 655 \\
\hline B4 & 188 & $46,5 \%$ & 98 & $24,3 \%$ & 32 & $7,9 \%$ & 71 & $17,6 \%$ & 14 & $3,5 \%$ & 1 & $0,2 \%$ & 404 \\
\hline B5 & 85 & $41,9 \%$ & 45 & $22,2 \%$ & 25 & $12,3 \%$ & 37 & $18,2 \%$ & 7 & $3,4 \%$ & 4 & $2,0 \%$ & 203 \\
\hline$C$ & 61 & $33,0 \%$ & 52 & $28,1 \%$ & 28 & $15,1 \%$ & 33 & $17,8 \%$ & 9 & $4,9 \%$ & 2 & $1,1 \%$ & 185 \\
\hline $\mathrm{NC}$ & 32 & $34,8 \%$ & 28 & $30,4 \%$ & 20 & $21,7 \%$ & 11 & $12,0 \%$ & 0 & $0,0 \%$ & 1 & $1,1 \%$ & 92 \\
\hline
\end{tabular}




\begin{tabular}{l|l|l|l|l|l|l|l|l|l|l|l|l|l}
\hline $\begin{array}{l}\text { Linha/ } \\
\text { Qualis } \\
\text { vigente }\end{array}$ & 1 & $\%$ & 2 & $\%$ & 3 & $\%$ & 4 & $\%$ & 5 & $\%$ & 6 & $\%$ & Total \\
\hline Total & 831 & $32,7 \%$ & 668 & $26,3 \%$ & 405 & $15,9 \%$ & 484 & $19,1 \%$ & 117 & $4,6 \%$ & 35 & $1,4 \%$ & 2540 \\
\hline
\end{tabular}

Ao se analisar a Tabela, considerando que a linha de Contabilidade gerencial e Controladoria tem $32,7 \%$ dos artigos analisados, não foi surpresa que essa linha predominasse na maioria dos estratos. O que não era tão esperado era que a linha de Mercado de capitais predominasse no estrato mais alto, o $A 2$, e a área de Contabilidade para usuários externos predominasse no estrato B3.

Também pode-se notar em que estrato cada linha apresentou maiores valores absolutos: a linha de Contabilidade gerencial e Controladoria foi no estrato B4, enquanto as demais linhas foram no estrato B3. Nesse sentido, também foi possível desenhar o mapa perceptual desta relação por meio da Anacor, conforme mostrado na Figura 38. 


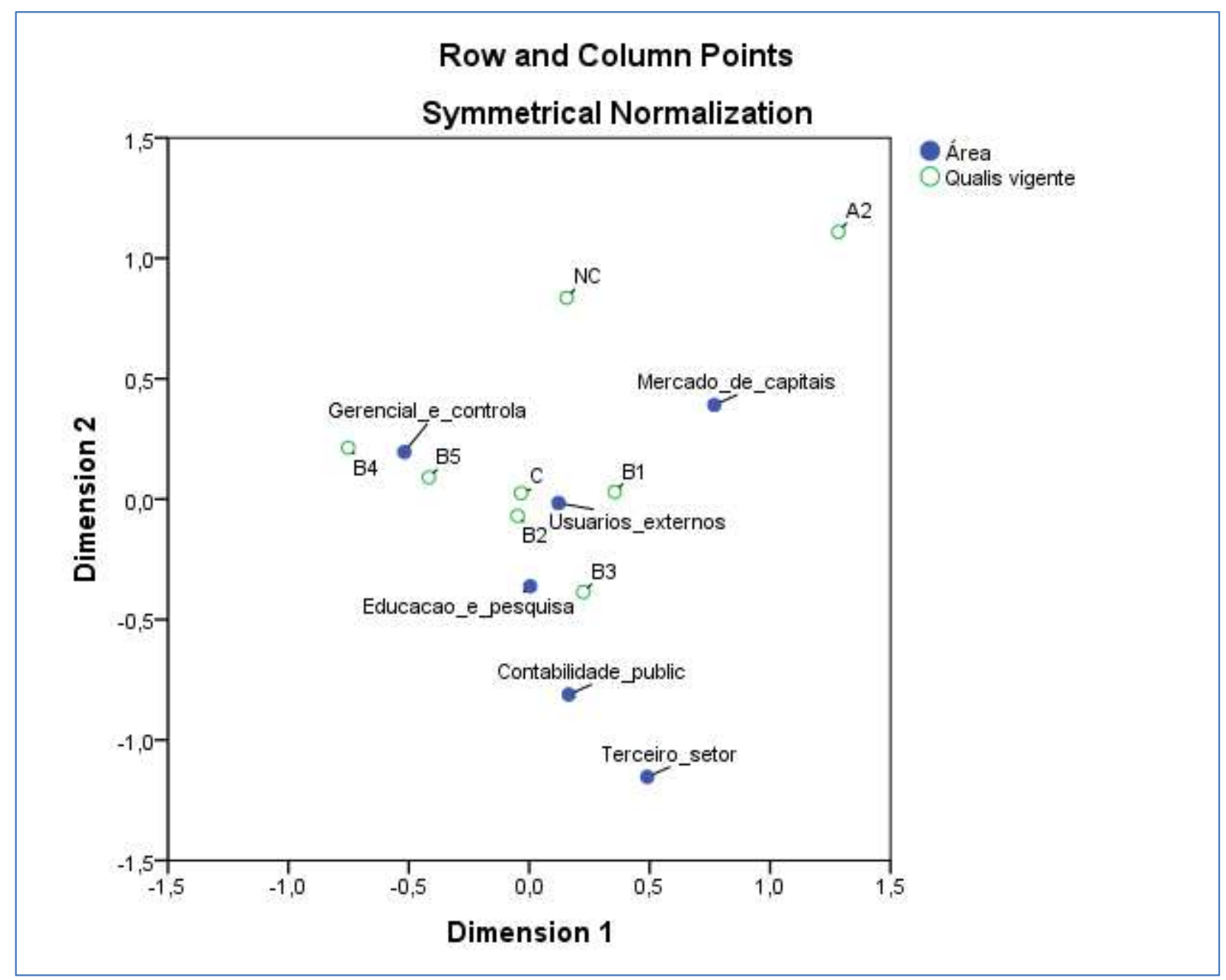

Figura 38 - Mapa perceptual da relação entre Linha de pesquisa e Qualis vigente

Segundo o mapa, observa-se que, enquanto a linha que mais se aproxima do estrato A2 é a de Mercado de capitais, a linha de Contabilidade gerencial e Controladoria se aproxima dos estratos B4 e B5, e a linha de Contabilidade para usuários externos mais se aproxima dos estratos B1, B2 e C.

\subsection{Relação entre Linha de pesquisa e Abordagem da análise}

A relação entre Linha de pesquisa e Abordagem da análise mostrou-se estatisticamente significativa em um nível de significância de 5\%.

A Tabela 52 mostra a proporção de cada tipo de abordagem de análise de dados, de acordo com a Linha de pesquisa. 
Tabela 52 - Relação entre Linha de pesquisa e Abordagem da análise

\begin{tabular}{l|r|r|r|r|r}
\hline \multicolumn{1}{c|}{ Área } & Quantitativa & $\%$ & Não-quantitativa & $\%$ & \multicolumn{1}{c}{ Total } \\
\hline Mercado de capitais & 323 & $79,8 \%$ & 82 & $20,2 \%$ & 405 \\
\hline Gerencial e controladoria & 496 & $59,7 \%$ & 335 & $40,3 \%$ & 831 \\
\hline Usuários externos & 300 & $44,9 \%$ & 368 & $55,1 \%$ & 668 \\
\hline Contabilidade pública & 52 & $44,4 \%$ & 65 & $55,6 \%$ & 117 \\
\hline Terceiro setor & 15 & $42,9 \%$ & 20 & $57,1 \%$ & 35 \\
\hline Educação e pesquisa & 133 & $27,5 \%$ & 351 & $72,5 \%$ & 484 \\
\hline Total & 1319 & $51,9 \%$ & 1221 & $48,1 \%$ & 2540 \\
\hline
\end{tabular}

A Tabela mostra que a linha que mais se utiliza de pesquisa quantitativa é a de Mercado de capitais $(79,8 \%)$, seguida da linha de Contabilidade gerencial e Controladoria (59,7\%). Nas demais linhas, mais da metade das pesquisas se utilizam de abordagens não-quantitativas. A linha de Educação e Pesquisa chega a ter um percentual de $72,5 \%$ de artigos com abordagem não-quantitativa de dados, seguida da linha de Terceiro setor, com um percentual de 57,1\%.

\subsection{Relação entre Qualis da revista e Abordagem da análise}

A última das associações entre variáveis qualitativas significantes, nesta Tese, foi a relação entre o Qualis da revista e a Abordagem da análise dos dados.

A Tabela 53 mostra que quanto maior é o Qualis da revista, maior é o percentual de artigos que se utilizam de abordagem de dados quantitativa. $\mathrm{O}$ estrato $\mathrm{A} 2$, o mais alto, chegou a ter abordagem quantitativa em $85,9 \%$ dos artigos, enquanto que os estratos C e NC têm percentuais próximos de $40 \%$.

Tabela 53 - Relação entre Qualis da revista e Abordagem da análise

\begin{tabular}{l|r|r|r|r|r}
\hline Qualis vigente & Quantitativa & \multicolumn{1}{c}{$\%$} & Não-quantitativa & \multicolumn{1}{c}{ \% } & \multicolumn{1}{c}{ Total } \\
\hline A2 & 67 & $85,9 \%$ & 11 & $14,1 \%$ & 78 \\
\hline B1 & 291 & $65,8 \%$ & 151 & $34,2 \%$ & 442 \\
\hline B2 & 258 & $53,6 \%$ & 223 & $46,4 \%$ & 481 \\
\hline B3 & 336 & $51,3 \%$ & 319 & $48,7 \%$ & 655 \\
\hline B4 & 180 & $44,6 \%$ & 224 & $55,4 \%$ & 404 \\
\hline B5 & 79 & $38,9 \%$ & 124 & $61,1 \%$ & 203 \\
\hline C & 72 & $38,9 \%$ & 113 & $61,1 \%$ & 185 \\
\hline NC & 36 & $39,1 \%$ & 56 & $60,9 \%$ & 92 \\
\hline Total & 1319 & $51,9 \%$ & 1221 & $48,1 \%$ & 2540 \\
\hline
\end{tabular}

\subsection{Outras análises e comentários finais}


Como verificado nas subseções anteriores, há diversas associações entre as características qualitativas dos artigos, mas pouca correlação entre variáveis quantitativas. Além disso, existem associações entre categorias de múltiplas variáveis como, por exemplo, a UPM e a FUCAPE, que se associam a revistas de Qualis mais altos e com pesquisas que empregam abordagem quantitativa e com autores com maior titulação.

A taxa média de citações de artigos com primeira autora é maior que a taxa média de citações de artigos com primeiro autor. Esse achado foi inesperado nesta pesquisa, embora vá ao encontro da pesquisa de Ayres e Vars (2000). Contudo, há que se levar em consideração que o gênero do primeiro autor está associado às outras cinco variáveis qualitativas. Os artigos com primeiras autoras apresentam maior frequência relativa em Revistas com menores médias de citação, em categorias mais baixas de titulação ou grau acadêmicos, principalmente bacharéis e graduandos. Por outro lado, os artigos com primeiras autoras são mais frequentes nas linhas de pesquisa Contabilidade para usuários externos e Educação e Pesquisa, que são as linhas com maiores taxas médias de citação, e na abordagem de dados não-quantitativa, que também possui média de citação maior que a outra categoria.

Diante desses achados, uma análise de correspondência múltipla foi gerada com todas as variáveis qualitativas, cujo mapa perceptual decorrente é apresentado na Figura 39. 
Joint Plot of Category Points

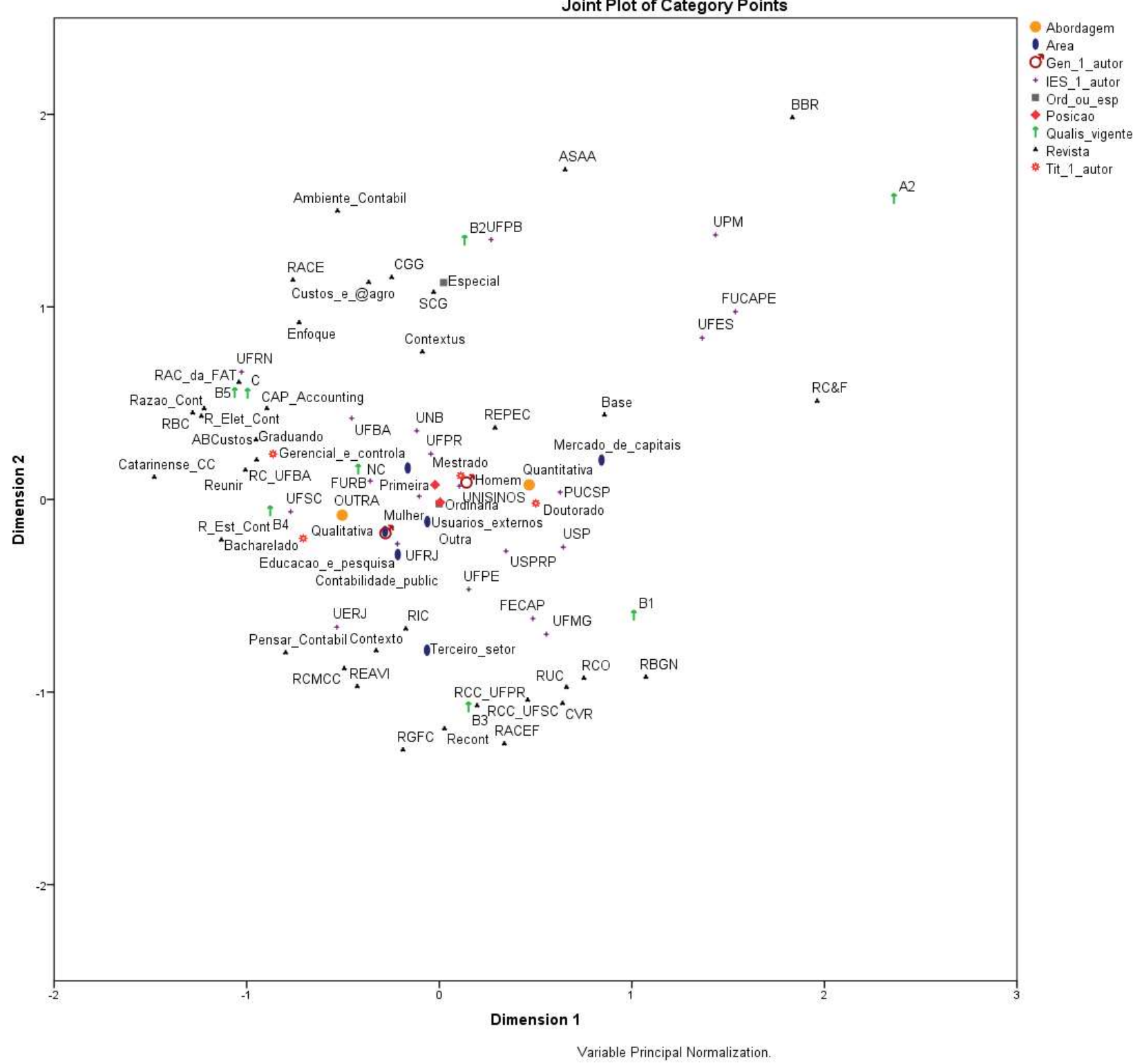

Figura 39 - Mapa perceptual da Anacor Múltipla 
A Figura evidencia o quão nebulosa é a relação entre as características qualitativas dos artigos. Constata-se apenas um distanciamento das revistas ASAA, BBR e RC\&F e das IES FUCAPE, UFES e UPM, que aparecem todas no canto superior direito do mapa, aproximando-se do estrato A2 do Qualis.

Diante da dificuldade de se atribuir maiores taxas de citação a determinados tipos de características, por eles terem características que se associam, optou-se por fazer uma análise de regressão binomial negativa para, assim, identificar os efeitos dessas características nas citações dos artigos, considerando a interação conjunta dessas variáveis.

\subsection{Regressão Binomial Negativa}

A regressão binomial negativa seguiu o passo a passo definido por Fávero (2015), tendo sido implementada com a utilização do software Stata ${ }^{\circ}$, versão 14.2. Os comandos utilizados encontram-se no Apêndice $\mathrm{K}$ a $\mathrm{R}$ desta Tese. Os outputs gerados, na íntegra, encontram-se, igualmente, nos Apêndices K a R. A variável dependente utilizada foi a quantidade de citações que cada artigo recebeu, e as variáveis independentes foram as sete variáveis quantitativas e as nove variáveis qualitativas, descritas nas seções anteriores.

Considerando as características dos dados, quando foi implementada a regressão no Stata ${ }^{\circledR}$, optou-se por utilizar o procedimento stepwise para eliminar as variáveis, ou dummies que não fossem estatisticamente diferentes de zero. O nível de significância adotado foi de $5 \%$.

A seguir, a Tabela 54 mostra o output obtido com a regressão binomial negativa das taxas estimadas de incidência (incidence rate ratio - irr).

Tabela 54 - Modelo 1, inclui todas as variáveis

\begin{tabular}{|c|c|c|c|c|c|c|}
\hline \multicolumn{3}{|l|}{ Number of obs $=2.540$} & \multicolumn{4}{|c|}{ Prob $>$ chi2 $=0,0000$} \\
\hline \multicolumn{3}{|l|}{ LR chi2(35) = 895,81 } & \multicolumn{4}{|c|}{ Log likelihood = -6163,8131 } \\
\hline \multicolumn{3}{|l|}{ Dispersion = mean } & \multicolumn{4}{|c|}{ Pseudo R2 = 0,0677 } \\
\hline Citações & IRR & Std. Err. & $\mathbf{z}$ & $P>z$ & {$[95 \%$ Con } & nterval] \\
\hline Constante & 5,35437 & 0,496241 & 18,1 & 0,000 & 4,464979 & 6,420922 \\
\hline Gerencial e Controladoria & 0,690259 & 0,039508 & $-6,48$ & 0,000 & 0,617011 & 0,772204 \\
\hline Mercado de capitais & 0,837807 & 0,058545 & $-2,53$ & 0,011 & 0,730572 & 0,960781 \\
\hline
\end{tabular}




\begin{tabular}{|c|c|c|c|c|c|c|}
\hline Mulher & 1,140216 & 0,059161 & 2,53 & 0,011 & 1,029964 & 1,262271 \\
\hline UFPB & 1,668297 & 0,385527 & 2,21 & 0,027 & 1,060642 & 2,624084 \\
\hline USP & 1,341479 & 0,096017 & 4,10 & 0,000 & 1,165894 & 1,543507 \\
\hline OUTRO & 0,811881 & 0,045004 & $-3,76$ & 0,000 & 0,728298 & 0,905056 \\
\hline Contextus & 2,506366 & 0,583936 & 3,94 & 0,000 & 1,587562 & 3,956931 \\
\hline Pensar & 1,359093 & 0,17513 & 2,38 & 0,017 & 1,05576 & 1,749578 \\
\hline RACEF & 0,185843 & 0,067613 & $-4,63$ & 0,000 & 0,091088 & 0,379165 \\
\hline RAC FAT & 0,160314 & 0,055713 & $-5,27$ & 0,000 & 0,081125 & 0,316801 \\
\hline $\mathrm{RBC}$ & 2,985967 & 0,4746 & 6,88 & 0,000 & 2,186714 & 4,07735 \\
\hline RBGN & 2,508768 & 0,423508 & 5,45 & 0,000 & 1,802056 & 3,49263 \\
\hline RC\&F & 125,7323 & 30,63501 & 19,84 & 0,000 & 77,99188 & 202,6957 \\
\hline RCC UFPR & 0,584618 & 0,094962 & $-3,30$ & 0,001 & 0,425215 & 0,803779 \\
\hline RCC_UFSC & 2,471866 & 0,325828 & 6,87 & 0,000 & 1,909081 & 3,200557 \\
\hline RCMCC & 1,85984 & 0,258833 & 4,46 & 0,000 & 1,41584 & 2,443077 \\
\hline $\mathrm{RCO}$ & 1,675167 & 0,195895 & 4,41 & 0,000 & 1,332042 & 2,106679 \\
\hline RC_UFBA & 0,63279 & 0,099728 & $-2,90$ & 0,004 & 0,464632 & 0,861807 \\
\hline REĀVI & 0,193426 & 0,135972 & $-2,34$ & 0,019 & 0,04877 & 0,767149 \\
\hline REPEC & 1,528122 & 0,194636 & 3,33 & 0,001 & 1,190532 & 1,961442 \\
\hline RGFC & 0,561126 & 0,151911 & $-2,13$ & 0,033 & 0,33008 & 0,953897 \\
\hline RUC & 1,888041 & 0,187835 & 6,39 & 0,000 & 1,55356 & 2,294535 \\
\hline Amb_Cont & 0,389344 & 0,078561 & $-4,67$ & 0,000 & 0,262169 & 0,578211 \\
\hline R Elet_Cont & 0,105424 & 0,113506 & $-2,09$ & 0,037 & 0,012779 & 0,869747 \\
\hline R_Est_Cont & 0,237246 & 0,06769 & $-5,04$ & 0,000 & 0,135624 & 0,415013 \\
\hline Razao & 0,293805 & 0,088236 & $-4,08$ & 0,000 & 0,163089 & 0,529291 \\
\hline Recont & 0,243438 & 0,065106 & $-5,28$ & 0,000 & 0,144126 & 0,411185 \\
\hline Reunir & 0,334397 & 0,091643 & $-4,00$ & 0,000 & 0,195428 & 0,572185 \\
\hline BBR & 2,31637 & 0,345191 & 5,64 & 0,000 & 1,729656 & 3,102103 \\
\hline Base & 2,057924 & 0,279339 & 5,32 & 0,000 & 1,577207 & 2,685159 \\
\hline CGG & 6,819441 & 1,11108 & 11,78 & 0,000 & 4,955231 & 9,384986 \\
\hline CVR & 46,1825 & 11,36901 & 15,57 & 0,000 & 28,50574 & 74,82085 \\
\hline Contexto & 3,083589 & 0,503658 & 6,89 & 0,000 & 2,238852 & 4,247052 \\
\hline Idade & 0,826841 & 0,01146 & $-13,72$ & 0,000 & 0,804682 & 0,84961 \\
\hline Número de referências & 1,010018 & 0,001841 & 5,47 & 0,000 & 1,006416 & 1,013633 \\
\hline
\end{tabular}

${ }^{*}$ Categorias omitidas: Revista $=$ ABCustos, Ordinário ou Especial $=$ Especial, Posição $=$ Outra, Gênero do primeiro autor $=$ Homem, Titulação do primeiro autor $=$ Bacharel, IES do primeiro autor $=$ FECAP, Linha de pesquisa $=$ Educação, Qualis da revista $=A 2$, Abordagem da análise de dados $=$ nãoquantitativa.

Sobre os dados da Tabela, cabe esclarecer que a área de pesquisa omitida quando as dummies foram criadas foi a área de Educação. As áreas de Contabilidade gerencial e Controladoria e de Mercado de capitais mantiveram-se no modelo após a aplicação do procedimento stepwise. A área de Contabilidade gerencial e Controladoria teve um irr =0,69; e a área de Mercado de capitais, um irr $=0,83$. Isso significa que, mantidas as demais condições constantes, um artigo pertencente à linha de Contabilidade gerencial e Controladoria obteve $31 \%(1-0,69=0,31)$ menos citações que um artigo da linha de Educação e Pesquisa, e um artigo da área de Mercado de capitais obteve $17 \%$ menos citações que um artigo da linha de Educação e Pesquisa. 
O gênero do primeiro autor também mostrou-se estatisticamente significante para o modelo com um irr $=1,14$. Isso significa que, mantidas as demais condições constantes, um artigo com primeiro autor do gênero feminino recebeu $14 \%$ mais de citações que um artigo com primeiro autor do gênero masculino.

A terceira das variáveis qualitativas que permaneceu no modelo foi a IES do primeiro autor, que permaneceu com três categorias. Mantidas as demais condições constantes, artigos com primeiro autor afiliado à USP tiveram 34\% e da UFPB 66\% mais citações que a categoria de referência, que são os artigos com primeiro autor da FECAP.

A última das variáveis qualitativas do modelo é a Revista em que o artigo foi publicado. Essa foi a variável que mais manteve categorias dentro do modelo. A categoria de referência para essa variável era a revista $A B C$ ustos. As revistas que mostraram maiores taxas de incidência estimada foram: Revista de Contabilidade \& Finanças (irr $=125,73$ ); Contabilidade Vista \& Revista (irr = 46,18); e Contabilidade, Gestão e Governança (irr =6,81). Por outro lado, a Revista Eletrônica de Contabilidade (irr = 0,10), a Revista de Administração e Contabilidade da FAT (irr = 0,16) e a RACEF (irr $=0,18$ ) apresentaram as menores taxas de incidência estimadas.

As únicas variáveis quantitativas retidas no modelo foram o número de referências (irr $=1,01$ ) e a idade da revista no ano em que o artigo foi publicado (irr $=0,82$ ). O primeiro achado vai ao encontro da literatura, que afirma que, quanto mais referências um artigo possui, mais citações ele receberá, tendo o irr dessa variável mostrado que essa relação é positiva e quantificada em $1 \%$ por referência extra. A idade da revista mostrou-se um achado contraintuitivo, pois era esperado que houvesse uma relação positiva entre a idade da revista e a quantidade de citações do artigo; e o irr dessa variável indicou que a cada ano a mais de idade que a revista tinha, o número de citações foi, mantidas as demais condições constantes, $18 \%$ menor.

O modelo gerado na ausência da variável Revista piora a regressão, como indica o pseudo $\mathrm{R}^{2}$ de McFadden, caindo de 0,0677, com a variável Revista, para 0,0318, sem a variável. Na ausência da variável Revista, a variável que mais manteve categorias no modelo foi a IES do primeiro autor. A Tabela 55 mostra os outputs dessa simulação. 
Tabela 55 - Modelo 2, sem a variável Revista

\begin{tabular}{|c|c|c|c|c|c|c|}
\hline & \multicolumn{4}{|c|}{ Prob $>$ chi2 $=0,0000$} \\
\hline \multicolumn{3}{|l|}{ LR chi2(19) = 420,89 } & \multicolumn{4}{|c|}{ Log likelihood $=-6401,2709$} \\
\hline \multicolumn{3}{|l|}{ Dispersion $=$ mean } & \multicolumn{4}{|c|}{ Pseudo R2 = 0,0318 } \\
\hline Citações & IRR & Std. Err. & $\mathbf{z}$ & $P>Z$ & {$[95 \%$ Cor } & Interval] \\
\hline Constante & 3,614656 & 0,357828 & 12,98 & 0,000 & 2,977169 & 4,388646 \\
\hline Gerencial e Controladoria & 0,63951 & 0,037619 & $-7,60$ & 0,000 & 0,569871 & 0,71766 \\
\hline UFPE & 0,606162 & 0,105404 & $-2,88$ & 0,004 & 0,431098 & 0,852318 \\
\hline UFPR & 0,543378 & 0,110616 & $-3,00$ & 0,003 & 0,364604 & 0,809809 \\
\hline UFRJ & 0,704858 & 0,097885 & $-2,52$ & 0,012 & 0,536901 & 0,925357 \\
\hline UFRN & 0,44006 & 0,099086 & $-3,65$ & 0,000 & 0,283042 & 0,684184 \\
\hline UFSC & 0,674152 & 0,070037 & $-3,80$ & 0,000 & 0,549955 & 0,826395 \\
\hline UNB & 0,58983 & 0,072588 & $-4,29$ & 0,000 & 0,463418 & 0,750724 \\
\hline UNISINOS & 0,654935 & 0,115367 & $-2,40$ & 0,016 & 0,463723 & 0,92499 \\
\hline FURB & 0,504909 & 0,064512 & $-5,35$ & 0,000 & 0,393057 & 0,648592 \\
\hline OUTRO & 0,544599 & 0,039197 & $-8,44$ & 0,000 & 0,472947 & 0,627107 \\
\hline UERJ & 0,657665 & 0,119068 & $-2,31$ & 0,021 & 0,461209 & 0,937802 \\
\hline UFBA & 0,490648 & 0,108193 & $-3,23$ & 0,001 & 0,318472 & 0,755906 \\
\hline UFMG & 0,572969 & 0,091989 & $-3,47$ & 0,001 & 0,418286 & 0,784856 \\
\hline B1 & 1,629426 & 0,1302 & 6,11 & 0,000 & 1,393218 & 1,905681 \\
\hline B3 & 1,410076 & 0,089223 & 5,43 & 0,000 & 1,245611 & 1,596255 \\
\hline Doutor & 1,275111 & 0,094329 & 3,29 & 0,001 & 1,103008 & 1,474067 \\
\hline Mestre & 1,211137 & 0,083716 & 2,77 & 0,006 & 1,057686 & 1,386851 \\
\hline Idade & 1,033268 & 0,00506 & 6,68 & 0,000 & 1,023399 & 1,043232 \\
\hline Número de referências & 1,00638 & 0,001986 & 3,22 & 0,001 & 1,002496 & 1,010279 \\
\hline
\end{tabular}

*Categorias omitidas: Revista = ABCustos, Ordinário ou Especial = Especial, Posição = Outra, Gênero do primeiro autor $=$ Homem, Titulação do primeiro autor $=$ Bacharel, IES do primeiro autor $=$ FECAP, Linha de pesquisa $=$ Educação, Qualis da revista $=A 2$, Abordagem da análise de dados $=$ nãoquantitativa.

Na ausência da variável Revista, o gênero do primeiro autor foi eliminado pelo procedimento stepwise, mas as variáveis Qualis da revista e Titulação do primeiro autor se tornaram relevantes. As variáveis quantitativas Idade da revista e Número de referências do artigo continuaram no modelo.

A área de Contabilidade gerencial e Controladoria apresentou uma taxa de incidência estimada de 0,63, ou seja, ainda menor que no modelo que incluía a variável Revista, o que indica que os artigos desta área, mantidas as demais condições constantes, apresentaram taxa de citações 37\% menor que da área de Educação e Pesquisa.

Quanto às categorias de IES do primeiro autor, as que apresentaram melhor desempenho foram a UFRJ (irr $=0,70)$, a UFSC (irr $=0,67)$ e a Unisinos e a UERJ (irr $=0,65)$. As que apresentaram o desempenho mais baixo foram a UFRN (irr =0,44), a UFBA $(i r r=0,49)$ e a FURB (irr = 0,50). No entanto, a USP e a UFPB, que apareciam no Modelo 1, deixaram de aparecer no Modelo 2. 
Os artigos publicados em revistas de estratos Qualis B1 e B3 apresentaram taxas de citação $62 \%$ e $41 \%$ maior, respectivamente, que a categoria de referência que era o estrato A2. Embora esse achado seja contra-intuitivo, atenta-se para o fato que a revista BBR era uma revista classificada no estrato A2, no triênio 2007-2009, e que, na pesquisa de Soares e Casa Nova (2016), apresentava taxa média de citação que não diferia estatisticamente de revistas do estrato B3.

Já a Titulação do primeiro autor se comportou como o esperado e segundo o que a literatura prevê, sendo que os artigos com primeiros autores com doutorado e com mestrado têm $27 \%$ e $21 \%$ mais citações, respectivamente, do que os artigos com primeiros autores graduandos ou bacharéis, mantidas as demais condições constantes.

O número de referências apresentou uma taxa de incidência estimada menor que o modelo anterior, mas, ainda assim, positiva. A variável Idade da revista começou a se comportar como esperado. Essa alteração de comportamento pode ser explicada pela relação nebulosa entre Idade da revista e Número de citações de artigos, como mostrado, a seguir, na Figura 40.

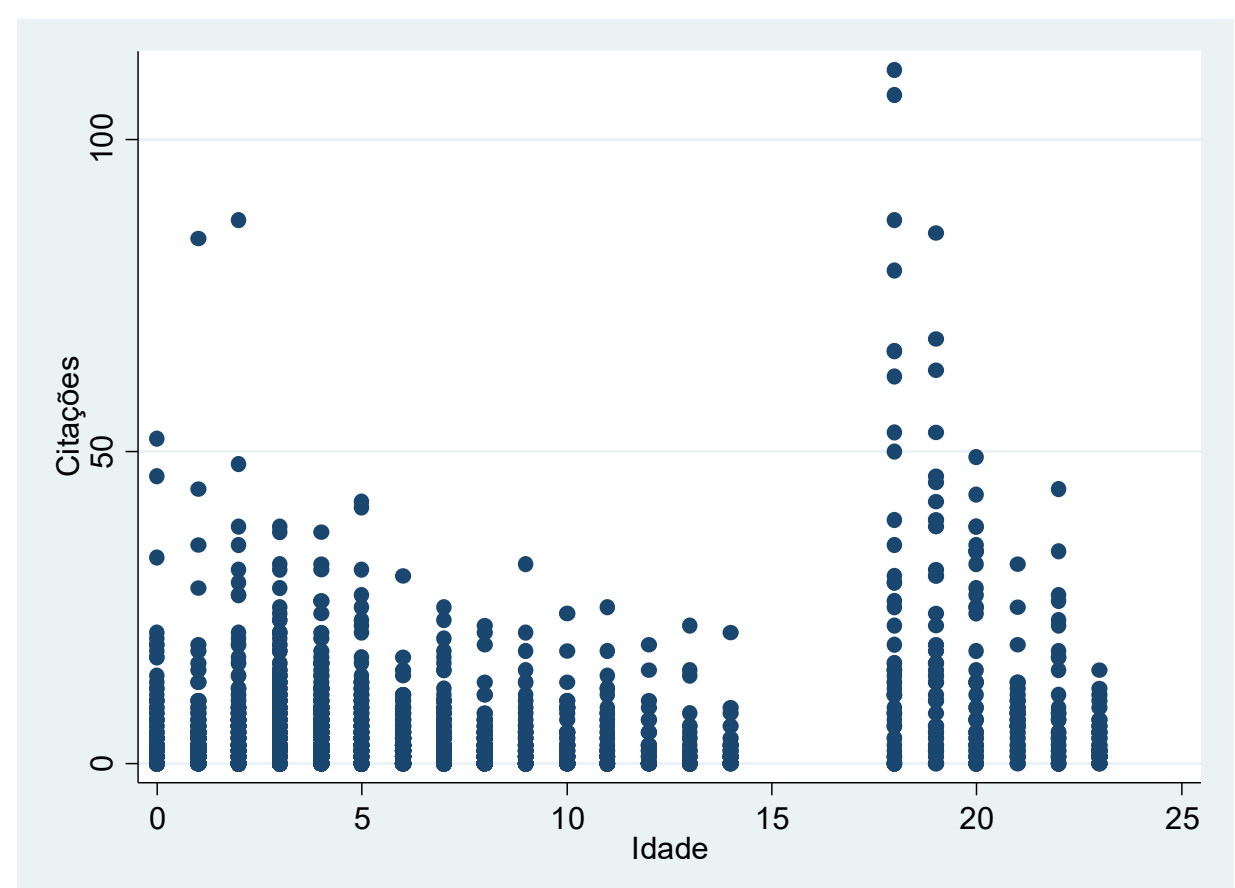

Figura 40 - Relação entre Citações e Idade da revista 
Destaca-se que há muitas revistas jovens na amostra, incluindo revistas criadas ao longo do período analisado nesta Tese. Também há que se considerar que a distribuição de Idade das revistas não foi aleatória, sendo que cada revista podia assumir apenas seis valores entre 2007 e 2012, se elas existissem antes desse período. Houve casos, como a Reavi, que só puderam assumir um valor de idade, pois foi criada em 2012.

O modelo gerado sem a variável Idade da revista está apresentado na Tabela 56. Esse modelo apresentou um pseudo R2 de McFadden de 0,0641, menor que o modelo gerado com a variável Idade da revista.

Tabela 56 - Modelo 3, sem a variável Idade da revista

\begin{tabular}{|c|c|c|c|c|c|c|}
\hline \multicolumn{3}{|l|}{ Number of obs $=2,540$} & \multicolumn{4}{|c|}{ Prob $>$ chi $2=0.0000$} \\
\hline \multirow{2}{*}{\multicolumn{3}{|c|}{ LR chi2(37) = 847.50}} & \multirow{2}{*}{\multicolumn{4}{|c|}{ Log likelihood = -6187.9691 }} \\
\hline \multicolumn{2}{|l|}{ Dispersion $=$ mean } & & & & & Pseudo R2 = 0,0641 \\
\hline Citações & IRR & Std. Err. & $\mathbf{z}$ & $\mathbf{P}>\mathbf{Z}$ & {$[95 \%$ Cor } & Interval] \\
\hline Constante & 0,606646 & 0,128009 & $-2,37$ & 0,018 & 0,401164 & 0,917378 \\
\hline Gerencial & 0,693679 & 0,039974 & $-6,35$ & 0,000 & 0,619594 & 0,776622 \\
\hline Marcado de capitais & 0,817251 & 0,05842 & $-2,82$ & 0,005 & 0,710408 & 0,940161 \\
\hline Mulher & 1,125379 & 0,059188 & 2,25 & 0,025 & 1,015151 & 1,247575 \\
\hline UFPB & 1,840966 & 0,433278 & 2,59 & 0,010 & 1,160681 & 2,919974 \\
\hline USP & 1,446238 & 0,104823 & 5,09 & 0,000 & 1,254714 & 1,666997 \\
\hline FUCAPE & 1,496809 & 0,285372 & 2,12 & 0,034 & 1,030107 & 2,174958 \\
\hline OUTRO & 0,830551 & 0,046763 & $-3,30$ & 0,001 & 0,743773 & 0,927454 \\
\hline B1 & 2,336787 & 0,427208 & 4,64 & 0,000 & 1,633066 & 3,343756 \\
\hline B2 & 2,775937 & 0,53499 & 5,30 & 0,000 & 1,902666 & 4,050015 \\
\hline B3 & 3,929267 & 0,756986 & 7,10 & 0,000 & 2,693549 & 5,731894 \\
\hline B4 & 5,761638 & 1,198599 & 8,42 & 0,000 & 3,832391 & 8,66208 \\
\hline B5 & 4,966837 & 1595 & 7,16 & 0,000 & 3,203156 & 7,701615 \\
\hline $\mathrm{C}$ & 7,018246 & 1,639113 & 8,34 & 0,000 & 4,440484 & 11,09243 \\
\hline $\mathrm{NC}$ & 5,699892 & 1,343899 & 7,38 & 0,000 & 3,590653 & 9,048149 \\
\hline Contextus & 1,633121 & 0,386965 & 2,07 & 0,038 & 1,026426 & 2,598417 \\
\hline RACEF & 0,373122 & 0,136729 & $-2,69$ & 0,007 & 0,181941 & 0,765192 \\
\hline RAC_FAT & 0,198144 & 0,070655 & $-4,54$ & 0,000 & 0,098505 & 0,39857 \\
\hline RBC & 0,622853 & 0,098018 & $-3,01$ & 0,003 & 0,457545 & 0,847887 \\
\hline RBGN & 3,25246 & 0,59096 & 6,49 & 0,000 & 2,27799 & 4,643784 \\
\hline RC\&F & 14,29709 & 2,186424 & 17,39 & 0,000 & 10,59437 & 19,2939 \\
\hline ASAA & 1,451294 & 0,270404 & 2,00 & 0,046 & 1,007303 & 2,090982 \\
\hline RCC_UFSC & 2,561394 & 0,372598 & 6,47 & 0,000 & 1,925993 & 3,406418 \\
\hline $\mathrm{RCO}$ & 2,995831 & 0,397543 & 8,27 & 0,000 & 2,309745 & 3,885712 \\
\hline RC_UFBA & 0,51659 & 0,088311 & $-3,86$ & 0,000 & 0,369516 & 0,722202 \\
\hline REPEC & 2,48752 & 0,320798 & 7,07 & 0,000 & 1,931938 & 3,202874 \\
\hline RUC & 2,309825 & 0,270461 & 7,15 & 0,000 & 1,836159 & 2,905679 \\
\hline R_Cat_CC & 0,329028 & 0,056225 & $-6,51$ & 0,000 & 0,235385 & 0,459925 \\
\hline R_Elet_Cont & 0,03585 & 0,038816 & $-3,07$ & 0,002 & 0,004294 & 0,299309 \\
\hline R_Est_Cont & 0,298283 & 0,085849 & $-4,20$ & 0,000 & 0,169685 & 0,524341 \\
\hline Razao & 0,502342 & 0,157392 & $-2,20$ & 0,028 & 0,271834 & 0,928315 \\
\hline Recont & 0,424375 & 0,114925 & $-3,17$ & 0,002 & 0,249594 & 0,721546 \\
\hline Reunir & 0,470391 & 0,130735 & $-2,71$ & 0,007 & 0,272827 & 0,81102 \\
\hline BBR & 4,09014 & 0,75542 & 7,63 & 0,000 & 2,847916 & 5,874206 \\
\hline
\end{tabular}




\begin{tabular}{l|r|r|r|r|r|r}
\hline Base & 2,594639 & 0,371649 & 6,66 & 0,000 & 1,959536 & 3,435585 \\
\hline CGG & 1,585678 & 0,225625 & 3,24 & 0,001 & 1,199771 & 2,095712 \\
\hline CVR & 2,870156 & 0,354351 & 8,54 & 0,000 & 2,253283 & 3,655909 \\
\hline Número de referências & 1,008839 & 0,001855 & 4,79 & 0,000 & 1,00521 & 1,012481 \\
\hline
\end{tabular}

${ }^{*}$ Categorias omitidas: Revista = ABCustos, Ordinário ou Especial = Especial, Posição = Outra, Gênero do primeiro autor $=$ Homem, Titulação do primeiro autor $=$ Bacharel, IES do primeiro autor $=$ FECAP, Linha de pesquisa $=$ Educação, Qualis da revista $=A 2$, Abordagem da análise de dados $=$ nãoquantitativa.

O comportamento de certas categorias das variáveis qualitativas no modelo gerado sem a variável Idade da revista se mostrou bastante parecido com o modelo gerado com a variável. Por exemplo, a linha Contabilidade gerencial e Controladoria apresentou irr $=0,69$ nos dois modelos, enquanto que a linha de Mercado de capitais apresentou um irr $=0,81$, levemente inferior ao do Modelo 1 , que era de 0,83. A variável Gênero do primeiro autor apresentou um irr = 1,12, também inferior ao Modelo 1 em que apresentou um irr = 1,14.

As IESs do primeiro autor USP, UFPB e Outro apresentaram taxas de incidência estimadas maiores que no modelo original $(1,44>1,34 ; 1,84>1,66 ; 0,83>0,81)$, além de que a FUCAPE foi incluída nesse modelo com irr =1,49. Ou seja, as três IES apresentaram desempenho em citações superior à categoria de referência, que era a FECAP. O desempenho das citações dos artigos com primeiros autores da categoria Outro, em que foram incluídas IESs sem programas de pós-graduação stricto sensu em Contabilidade e Controladoria, foi menor que a FECAP em 17\%.

A Tabela 57 mostra o comportamento das taxas de incidência estimadas para as Revistas.

Tabela 57 - Variação da taxa estimada de incidência entre os Modelos

\begin{tabular}{l|r|r|r}
\hline \multicolumn{1}{c|}{ Revista } & IRR no modelo original & IRR no modelo sem a Idade da revista & Variação \\
\hline Base & 2,057924 & 2,594639 & $\uparrow$ \\
\hline BBR & 2,31637 & 4,09014 & $\uparrow$ \\
\hline CGG & 6,819441 & 1,585678 & \\
\hline Contextus & 2,506366 & 1,633121 & $\downarrow$ \\
\hline CVR & 46,1825 & 2,870156 & $\downarrow$ \\
\hline R_Elet_Cont & 0,1054237 & 0,0358498 & \\
\hline R_Est_Cont & 0,2372464 & 0,2982827 & $\downarrow$ \\
\hline RACFAT & 0,160314 & 0,1981444 & $\uparrow$ \\
\hline RACEF & 0,1858426 & 0,3731218 & $\uparrow$ \\
\hline Razao & 0,2938047 & 0,5023417 & $\uparrow$ \\
\hline RBC & 2,985967 & 0,6228534 & \\
\hline RBGN & 2,508768 & 3,25246 & $\uparrow$ \\
\hline RC\&F & 125,7323 & 14,29709 & \\
\hline RC_UFBA & 0,6327897 & 0,5165897 & $\downarrow$ \\
\hline
\end{tabular}




\begin{tabular}{l|r|r|c}
\hline \multicolumn{1}{c|}{ Revista } & IRR no modelo original & IRR no modelo sem a Idade da revista & Variação \\
\hline RCC UFSC & 2,471866 & 2,561394 & $\uparrow$ \\
\hline Recont & 0,2434384 & 0,4243746 & $\uparrow$ \\
\hline REPEC & 1,528122 & 2,48752 & $\uparrow$ \\
\hline Reunir & 0,3343965 & 0,4703913 & $\uparrow$ \\
\hline
\end{tabular}

As taxas de incidência estimadas aumentaram em 11 revistas e diminuíram em sete revistas. As revistas Pensar Contábil (CRC/RJ), Revista de Controladoria e Contabilidade (UFPR), Revista do Mestrado em Ciências Contábeis (UERJ), Revista Contabilidade e Organizações (USP/RP), Revista de Gestão, Finanças e Contabilidade (UNEB), Revista Universo Contábil (FURB), Ambiente Contábil (UFRN), e Contexto (UFRGS), presentes no modelo original, não se mantiveram no modelo sem a variável Idade da revista. Por outro lado, a Revista Catarinense da Ciência Contábil e a ASAA (ANPCONT) foram incluídas. A variável número de referências manteve-se no modelo com um irr =1,008, levemente inferior ao do Modelo 1 que era $\operatorname{irr}=1,010$.

A grande diferença entre o Modelo 1 e o modelo sem a variável Idade da revista, no entanto, foi para a variável estrato Qualis da revista, que não aparecia inicialmente e que apareceu com todas as suas categorias no modelo com a ausência da ldade da revista, embora, ainda, não com o comportamento esperado. A taxa de incidência estimada de todos os estratos foi superior à taxa da categoria de referência que é a A2. No entanto, há que se considerar as taxas em conjunto. Por exemplo: a Revista Contabilidade \& Finanças apresentou uma taxa de 14,29 e era uma revista classificada no estrato A2. Ou seja, mantidas as demais condições constantes, esperava-se que um artigo publicado na Revista Contabilidade \& Finanças recebesse, em média, 14 citações. Já um artigo publicado na Contabilidade Vista \& Revista, que possuía irr $=2,87$ foi acrescido às citações referentes ao estrato Qualis a que ela pertence, que era de B1, no triênio 2010-2012, e que correspondia a um irr = 2,33, totalizando uma média de citações esperadas de 5,2 citações.

A previsão de citações do Modelo 1 indicaria que um artigo na Revista Contabilidade \& Finanças receberia 125 citações e na Contabilidade Vista \& Revista receberia 46 citações. A previsão feita, usando o modelo sem a variável Idade da revista, se mostrou mais próxima das médias de citações apresentadas nas estatísticas 
descritivas da Tabela 11, que são uma taxa média de citações $=21,9$ para a Revista Contabilidade \& Finanças e de 7,1 citações para a Contabilidade Vista \& Revista.

Ressalta-se, contudo, que, assim como os artigos de uma determinada revista poderiam ser classificados em categorias correspondentes a seis idades, em decorrência da faixa de tempo analisada nesta Tese, de modo que não se trata de uma distribuição totalmente aleatória, esses artigos só poderiam ser enquadrados em dois estratos do Qualis, em função da classificação que a revista recebeu da Capes, entre 2007 e 2012. Por isso, fez-se uma análise de regressão binomial negativa sem a Idade da revista e sem o estrato Qualis.

Sem as variáveis Idade da revista e Qualis da revista, o pseudo R2 de McFadden do modelo foi de 0,0554 , ou seja, menor que os dois modelos anteriores, que mantinham a variável Revista.

A Tabela 58 mostra as taxas de incidência estimadas para o modelo.

Tabela 58 - Modelo 4, sem as variáveis Idade da revista e estrato Qualis

\begin{tabular}{|c|c|c|c|c|c|c|}
\hline \multicolumn{3}{|c|}{ Number of obs $=2,540$} & \multicolumn{4}{|c|}{ Prob $>$ chi2 $=0.0000$} \\
\hline \multicolumn{3}{|c|}{ LR chi2(27) = 732.45} & \multicolumn{4}{|c|}{ Log likelihood = -6245.4937 } \\
\hline \multicolumn{3}{|c|}{ Dispersion $=$ mean } & \multicolumn{4}{|c|}{ Pseudo R2 = 0,0554 } \\
\hline Citações & IRR & Std. Err. & $\mathbf{z}$ & $\mathbf{P}>\mathbf{Z}$ & {$[95 \%$ Con } & Interval] \\
\hline Constante & 2,956893 & 0,228467 & 14,03 & 0,000 & 2,541364 & 3,440364 \\
\hline Quantitativa & 0,89767 & 0,046721 & $-2,07$ & 0,038 & 0,810613 & 0,994075 \\
\hline Gerencial & 0,746376 & 0,042055 & $-5,19$ & 0,000 & 0,668339 & 0,833525 \\
\hline Mulher & 1,143888 & 0,061339 & 2,51 & 0,012 & 1,029767 & 1,270655 \\
\hline UNB & 0,781495 & 0,086308 & $-2,23$ & 0,026 & 0,629389 & 0,970359 \\
\hline USP & 1,342268 & 0,102861 & 3,84 & 0,000 & 1,155073 & 1,5598 \\
\hline FURB & 0,754127 & 0,087678 & $-2,43$ & 0,015 & 0,600454 & 0,947128 \\
\hline OUTRO & 0,763225 & 0,045621 & $-4,52$ & 0,000 & 0,678849 & 0,858089 \\
\hline Contextus & 1,828165 & 0,434582 & 2,54 & 0,011 & 1,147287 & 2,913122 \\
\hline RACEF & 0,357707 & 0,131658 & $-2,79$ & 0,005 & 0,173873 & 0,735906 \\
\hline RAC FAT & 0,242389 & 0,085183 & $-4,03$ & 0,000 & 0,121724 & 0,48267 \\
\hline RBGN & 2,27404 & 0,389745 & 4,79 & 0,000 & 1,625219 & 3,181885 \\
\hline RC\&F & 6,975411 & 0,822473 & 16,47 & 0,000 & 5,536105 & 8,788915 \\
\hline RCC UFSC & 1,931575 & 0,255185 & 4,98 & 0,000 & 1,49093 & 2,502453 \\
\hline $\mathrm{RCO}$ & 2,269166 & 0,261524 & 7,11 & 0,000 & 1,810358 & 2,844253 \\
\hline REPEC & 2,225073 & 0,283092 & 6,29 & 0,000 & 1,733993 & 2,855231 \\
\hline $\mathrm{RIC}$ & 1,390005 & 0,173209 & 2,64 & 0,008 & 1,088799 & 1,774537 \\
\hline RUC & 1,795628 & 0,176641 & 5,95 & 0,000 & 1,480748 & 2,177467 \\
\hline Amb Cont & 0,591574 & 0,12049 & $-2,58$ & 0,010 & 0,396862 & 0,881818 \\
\hline $\mathrm{R}$ Cat_CC & 0,502981 & 0,079317 & $-4,36$ & 0,000 & 0,369251 & 0,685143 \\
\hline $\mathrm{R}$ Elet Cont & 0,057437 & 0,062013 & $-2,65$ & 0,008 & 0,006921 & 0,476665 \\
\hline R_Est_Cont & 0,401653 & 0,115266 & $-3,18$ & 0,001 & 0,228862 & 0,7049 \\
\hline Recont & 0,385746 & 0,104153 & $-3,53$ & 0,000 & 0,227234 & 0,654831 \\
\hline BBR & 1,891251 & 0,283733 & 4,25 & 0,000 & 1,409447 & 2,537756 \\
\hline Base & 1,71351 & 0,232902 & 3,96 & 0,000 & 1,312775 & 2,236571 \\
\hline
\end{tabular}




\begin{tabular}{l|r|r|r|r|r|r}
\hline CGG & 1,815879 & 0,233279 & 4,64 & 0,000 & 1,411679 & 2,335811 \\
\hline CVR & 2,281429 & 0,24768 & 7,60 & 0,000 & 1,844155 & 2,822386 \\
\hline Número de referências & 1,005075 & 0,001827 & 2,78 & 0,005 & 1,001501 & 1,008662 \\
\hline
\end{tabular}

${ }^{*}$ Categorias omitidas: Revista $=$ ABCustos, Ordinário ou Especial $=$ Especial, Posição = Outra, Gênero do primeiro autor $=$ Homem, Titulação do primeiro autor $=$ Bacharel, IES do primeiro autor $=$ FECAP, Linha de pesquisa $=$ Educação, Qualis da revista $=$ A2, Abordagem da análise de dados $=$ nãoquantitativa.

Neste modelo, as variáveis qualitativas Linha de pesquisa (irr $=0,74$ ) e Gênero do primeiro autor (irr $=1,14$ ) se comportaram de maneira similar aos modelos anteriores em que sobreviviam ao procedimento stepwise. A variável quantitativa Número de referências também apresentou comportamento similar (irr =1,005).

Já as variáveis IES do primeiro autor e Revista apresentaram diferenças. No primeiro caso, a UFPB e FUCAPE que permaneciam nos modelos que continham a variável Revista apareceram na sua ausência, sendo substituídas pela UNB e FURB. Estas, por sua vez, apresentaram taxas de incidência estimadas $22 \%$ e $25 \%$ menores, respectivamente, que a categoria de referência, que era a FECAP.

Ainda neste modelo, a variável Abordagem dos dados apareceu pela primeira vez, indicando que artigos com abordagem de dados quantitativa foram, mantidas as demais condições constantes, $11 \%$ menos citados que a categoria de referência que era o grupo de artigos que se utilizam de abordagem não-quantitativa.

No entanto, nenhum dos modelos anteriores comportou a variável Idade do artigo, que, segundo a literatura, afeta as taxas de citação. A Tabela 59 mostra as taxas de incidência estimadas do modelo que inclui a Idade do artigo.

Tabela 59 - Modelo 5 , com a variável Idade do artigo

\begin{tabular}{|c|c|c|c|c|c|c|}
\hline \multicolumn{3}{|l|}{ Number of obs $=2,540$} & \multicolumn{4}{|c|}{ Prob $>$ chi2 $=0.0000$} \\
\hline \multicolumn{3}{|c|}{ LR chi2(25) = 884.52} & \multicolumn{4}{|c|}{ Log likelihood $=-6169.455$} \\
\hline \multicolumn{3}{|l|}{ Dispersion $=$ mean } & Pseudo F & $=0,066$ & & \\
\hline Citações & IRR & Std. Err. & $\mathbf{z}$ & $P>Z$ & \multicolumn{2}{|c|}{ [95\% Conf. Interval] } \\
\hline Constante & 0,474705 & 0,072555 & $-4,87$ & 0,000 & 0,351824 & 0,640506 \\
\hline Gerencial & 0,683328 & 0,03877 & $-6,71$ & 0,000 & 0,611413 & 0,763701 \\
\hline Mercado de capitais & 0,859166 & 0,059749 & $-2,18$ & 0,029 & 0,749691 & 0,984627 \\
\hline Mulher & 1,114072 & 0,057763 & 2,08 & 0,037 & 1,006421 & 1,233237 \\
\hline UFPB & 1,817366 & 0,420065 & 2,58 & 0,010 & 1,155304 & 2,858831 \\
\hline USP & 1,372312 & 0,09789 & 4,44 & 0,000 & 1,19326 & 1,578232 \\
\hline OUTRO & 0,825647 & 0,045551 & $-3,47$ & 0,001 & 0,741027 & 0,91993 \\
\hline B1 & 1,419241 & 0,140542 & 3,54 & 0,000 & 1,168866 & 1,723247 \\
\hline B3 & 1,25304 & 0,0914 & 3,09 & 0,002 & 1,086116 & 1,445619 \\
\hline RACEF & 0,352141 & 0,128493 & $-2,86$ & 0,004 & 0,172235 & 0,719967 \\
\hline
\end{tabular}




\begin{tabular}{l|r|r|r|r|r|r}
\hline RAC_FAT & 0,321372 & 0,111305 & $-3,28$ & 0,001 & 0,163005 & 0,6336 \\
\hline RBGN & 1,603736 & 0,282648 & 2,68 & 0,007 & 1,135309 & 2,265434 \\
\hline RC\&F & 3,959368 & 0,497602 & 10,95 & 0,000 & 3,09492 & 5,065267 \\
\hline RCC_UFSC & 1,340523 & 0,187664 & 2,09 & 0,036 & 1,018854 & 1,763749 \\
\hline RCO & 1,583973 & 0,199574 & 3,65 & 0,000 & 1,237372 & 2,027661 \\
\hline REPEC & 1,750854 & 0,212777 & 4,61 & 0,000 & 1,379766 & 2,221747 \\
\hline RUC & 1,244452 & 0,137735 & 1,98 & 0,048 & 1,00177 & 1,545925 \\
\hline R_Cat_CC & 0,491984 & 0,076263 & $-4,58$ & 0,000 & 0,363083 & 0,666647 \\
\hline R_Elet_Cont & 0,080896 & 0,087233 & $-2,33$ & 0,020 & 0,009774 & 0,6695913 \\
\hline Recont & 0,472755 & 0,127496 & $-2,78$ & 0,005 & 0,278662 & 0,802038 \\
\hline BBR & 1,631172 & 0,23647 & 3,38 & 0,001 & 1,227726 & 2,167195 \\
\hline CGG & 1,582682 & 0,195953 & 3,71 & 0,000 & 1,241669 & 2,017352 \\
\hline CVR & 1,42502 & 0,170548 & 2,96 & 0,003 & 1,127062 & 1,801747 \\
\hline Idade do artigo & 1,25993 & 0,020344 & 14,31 & 0,000 & 1,22068 & 1,300441 \\
\hline Número de autores & 1,050253 & 0,024258 & 2,12 & 0,034 & 1,003768 & 1,098891 \\
\hline Número de referências & 1,012134 & 0,001862 & 6,56 & 0,000 & 1,008491 & 1,015789 \\
\hline
\end{tabular}

${ }^{*}$ Categorias omitidas: Revista $=$ ABCustos, Ordinário ou Especial = Especial, Posição = Outra, Gênero do primeiro autor $=$ Homem, Titulação do primeiro autor $=$ Bacharel, IES do primeiro autor $=$ FECAP, Linha de pesquisa $=$ Educação, Qualis da revista $=$ A2, Abordagem da análise de dados $=$ nãoquantitativa.

O modelo gerado com a inclusão da variável Idade do artigo e a exclusão da variável Idade da revista deteve o segundo maior pseudo $\mathrm{R}^{2}$ de McFadden $=0,0669$, menor apenas que o Modelo 1 , que possuía um pseudo $R^{2}$ de McFadden $=0,0677$. Este modelo comporta duas categorias da variável Linha de pesquisa, que são de Contabilidade gerencial e Controladoria e Mercado de capitais; a variável Gênero; três categorias da variável IES do primeiro autor, que são a UFPB, USP e Outro; duas categorias da variável Qualis da revista, que são o estrato B1 e B3; 14 categorias da variável Revista; e, ainda, três variáveis quantitativas, que são a Idade do artigo, o Número de autores e o Número de referências.

Segundo este modelo, artigos da linha de Contabilidade gerencial e Controladoria tiveram 32\% menos citações que artigos da linha de Educação e Pesquisa, que era a categoria de referência; e artigos da linha de Mercado de capitais tiveram 15\% menos citações que a categoria de referência. Artigos que tinham o primeiro autor do gênero feminino tiveram $11 \%$ mais citações que artigos cujos primeiros autores eram do gênero masculino.

Artigos em que a afiliação do primeiro autor era a UFPB tiveram $81 \%$ mais citações que a categoria de referência, que era a FECAP. Se a afiliação do primeiro autor era a USP, os artigos tiveram $37 \%$ mais citações que a categoria de referência. Se a afiliação do primeiro autor era de alguma IES sem programa de pós-graduação stricto 
sensu de Contabilidade ou Controladoria, então, o artigo teve $18 \%$ menos citações que a categoria de referência.

Se o artigo foi publicado em uma revista classificada no estrato B1 ele teve $41 \%$ mais citações que a categoria de referência. E, se foi publicado em uma revista com Qualis B3, teve $25 \%$ a mais de citações. As revistas que possuíram maiores taxas de citação foram a Revista Contabilidade \& Finanças, com $295 \%$ a mais de citações; a Revista de Educação e Pesquisa em Contabilidade, com $75 \%$ a mais de citações; e a Brazilian Business Review, com $63 \%$ a mais de citações. Já as que apresentaram menores taxas de citação foram: a Revista Eletrônica de Contabilidade, 92\% menor que a categoria de referência; a Revista de Administração e Contabilidade da FAT, 68\% menor; e a RACEF, com taxa de incidência estimada $65 \%$ menor.

A cada ano de Idade do artigo, sua taxa cresceu $25 \%$, e a cada autor a mais no artigo a taxa cresceu $5 \%$. Por fim, ainda segundo este modelo, a cada referência extra, a taxa de citação cresceu $1 \%$.

\subsection{E se não houvesse USP?}

A USP é a universidade que tem o programa de pós-graduação em Contabilidade mais antigo do país. Seu curso de mestrado data de 1970 e seu curso de doutorado data de 1978. A Revista Contabilidade \& Finanças tem seu acervo, referente aos anos de 2001 a 2016, na plataforma Scielo; e a versão que a precedeu, o Caderno de Estudos, tem seu acervo, referente aos anos de 1989 a 2000, na mesma plataforma. Nesta Tese, a taxa média de citações por artigos em que a afiliação institucional do primeiro autor era a USP foi de 7,8, sendo a quinta mais alta entre 19 instituições com programas de pós-graduação stricto sensu em Controladoria e Contabilidade. Autores afiliados à USP foram os primeiros autores em 377 dos 2.540 (14,8\%) artigos analisados nesta Tese, o que a torna a IES mais representativa proporcionalmente.

A taxa média de citação da Revista Contabilidade \& Finanças, no período de 2007 a 2012, foi de 21,9 citações por artigo, a mais alta entre os 36 periódicos analisados e três vezes mais alta que a taxa média de citação da segunda colocada, a Revista Contabilidade e Organizações, com 7,3 citações por artigo. A afiliação institucional 
com a USP mostrou-se significante em quatro dos cinco modelos de regressão analisados nesta Tese, e a Revista Contabilidade \& Finanças mostrou-se significante em todos os modelos em que se incluiu a variável Revista.

Diante desses fatos surgiu a curiosidade de saber como se comportariam os resultados desta pesquisa se não houvesse USP, como IES do primeiro autor nem como revista, dando origem às seguintes análises.

A Tabela 60 mostra a regressão binomial negativa gerada sem a categoria USP como IES do primeiro autor.

Tabela 60 - Modelo 6, sem a USP como categoria de IES do primeiro autor

\begin{tabular}{|c|c|c|c|c|c|c|}
\hline \multicolumn{3}{|l|}{ Number of obs $=2,163$} & \multicolumn{4}{|c|}{ Prob $>$ chi2 $=0.0000$} \\
\hline \multicolumn{3}{|l|}{ LR chi2(32) = 700.27} & \multicolumn{4}{|c|}{ Log likelihood = -5074.8596 } \\
\hline \multicolumn{3}{|l|}{ Dispersion = mean } & \multicolumn{4}{|c|}{ Pseudo R2 = 0,0645 } \\
\hline Citações & IRR & Std. Err. & $\mathbf{z}$ & $\mathbf{P}>\mathbf{Z}$ & {$[95 \%$ Con } & nterval] \\
\hline Constante & 5,329812 & 0,521555 & 17,10 & 0,000 & 4,399634 & 6,45665 \\
\hline Gerencial & 0,652247 & 0,040975 & $-6,8$ & 0,000 & 0,576684 & 0,73771 \\
\hline Mercado de capitais & 0,838298 & 0,06471 & $-2,28$ & 0,022 & 0,720597 & 0,975224 \\
\hline UFPB & 1,662863 & 0,386817 & 2,19 & 0,029 & 1,05402 & 2,623397 \\
\hline Outro & 0,825696 & 0,046039 & $-3,44$ & 0,001 & 0,740218 & 0,921046 \\
\hline Contextus & 2,447359 & 0,607404 & 3,61 & 0,000 & 1,504666 & 3,980661 \\
\hline Pensar & 1,351687 & 0,17789 & 2,29 & 0,022 & 1,044366 & 1,749442 \\
\hline RACEF & 0,154952 & 0,068114 & $-4,24$ & 0,000 & 0,065467 & 0,366748 \\
\hline RAC FAT & 0,162525 & 0,064184 & $-4,60$ & 0,000 & 0,074949 & 0,35243 \\
\hline RBC & 2,49038 & 0,417003 & 5,45 & 0,000 & 1,793642 & 3,457767 \\
\hline RBGN & 3,061424 & 0,590722 & 5,80 & 0,000 & 2,097387 & 4,468568 \\
\hline RC\&F & 91,29306 & 24,10929 & 17,09 & 0,000 & 54,40599 & 153,1894 \\
\hline RCC UFPR & 0,601221 & 0,107249 & $-2,85$ & 0,004 & 0,423831 & 0,852857 \\
\hline RCC UFSC & 2,264673 & 0,326244 & 5,67 & 0,000 & 1,707588 & 3,003502 \\
\hline RCMCC & 1,682405 & 0,250652 & 3,49 & 0,000 & 1,256363 & 2,252923 \\
\hline RCO & 1,570567 & 0,210887 & 3,36 & 0,001 & 1,207151 & 2,043389 \\
\hline RC UFBA & 0,558503 & 0,098602 & $-3,30$ & 0,001 & 0,395138 & 0,78941 \\
\hline REAVI & 0,20189 & 0,142732 & $-2,26$ & 0,024 & 0,050505 & 0,807046 \\
\hline REPEC & 1,509845 & 0,220974 & 2,82 & 0,005 & 1,133326 & 2,011454 \\
\hline RUC & 1,751088 & 0,19841 & 4,94 & 0,000 & 1,402366 & 2,186526 \\
\hline Amb Cont & 0,410797 & 0,086078 & $-4,25$ & 0,000 & 0,272438 & 0,619423 \\
\hline $\mathrm{R}$ Elet Cont & 0,103096 & 0,110996 & $-2,11$ & 0,035 & 0,012498 & 0,850481 \\
\hline R Est Cont & 0,251909 & 0,083769 & $-4,15$ & 0,000 & 0,131276 & 0,483393 \\
\hline Razao & 0,332432 & 0,102426 & $-3,57$ & 0,000 & 0,181735 & 0,608088 \\
\hline Recont & 0,243273 & 0,067202 & $-5,12$ & 0,000 & 0,141566 & 0,418051 \\
\hline Reunir & 0,35101 & 0,099046 & $-3,71$ & 0,000 & 0,201898 & 0,610249 \\
\hline BBR & 2,198687 & 0,350982 & 4,94 & 0,000 & 1,607993 & 3,006373 \\
\hline Base & 1,94815 & 0,288022 & 4,51 & 0,000 & 1,458067 & 2,60296 \\
\hline CGG & 5,781888 & 0,992377 & 10,22 & 0,000 & 4,130221 & 8,094053 \\
\hline CVR & 35,32484 & 9,35189 & 13,46 & 0,000 & 21,02487 & 59,35088 \\
\hline Contexto & 2,755738 & 0,477781 & 5,85 & 0,000 & 1,961821 & 3,870941 \\
\hline Idade & 0,843243 & 0,012579 & $-11,43$ & 0,000 & 0,818946 & 0,868261 \\
\hline Número de referências & 1,009712 & 0,002036 & 4,79 & 0,000 & 1,00573 & 1,01371 \\
\hline
\end{tabular}

${ }^{*}$ Categorias omitidas: Revista $=$ ABCustos, Ordinário ou Especial = Especial, Posição = Outra, Gênero do primeiro autor $=$ Homem, Titulação do primeiro autor $=$ Bacharel, IES do primeiro autor $=$ FECAP, 
Linha de pesquisa $=$ Educação, Qualis da revista $=\mathrm{A} 2$, Abordagem da análise de dados $=$ nãoquantitativa.

Com a retirada da USP como categoria da alternativa de IES do primeiro autor, houve alterações no modelo original. As variáveis Idade da revista e Número de referências permaneceram no modelo, assim como as categorias Contabilidade gerencial e Controladoria e Mercado de Capitais, na variável Linha de pesquisa; e UFPB e Outro, na variável IES do primeiro autor, embora o coeficiente de todas elas tenha se alterado.

A Revista foi a variável que mais sofreu alterações dentro do modelo. A Tabela 61 mostra os coeficientes comparativos entre o modelo original e o modelo sem a USP como IES do primeiro autor.

Tabela 61 - Variação da taxa estimada de incidência das revistas, entre os modelos

\begin{tabular}{|c|c|c|c|}
\hline Revista & Modelo original & Modelo sem USP & Variação \\
\hline Contextus & 2,506366 & 2,447359 & $\downarrow$ \\
\hline Pensar & 1,359093 & 1,351687 & $\downarrow$ \\
\hline RACEF & 0,185843 & 0,154952 & $\downarrow$ \\
\hline RAC_FAT & 0,160314 & 0,162525 & $\uparrow$ \\
\hline RBC & 2,985967 & 2,49038 & $\downarrow$ \\
\hline RBGN & 2,508768 & 3,061424 & $\uparrow$ \\
\hline RC\&F & 125,7323 & 91,29306 & $\downarrow$ \\
\hline RCC_UFPR & 0,584618 & 0,601221 & $\uparrow$ \\
\hline RCC_UFSC & 2,471866 & 2,264673 & $\downarrow$ \\
\hline RCMCC & 1,85984 & 1,682405 & $\downarrow$ \\
\hline $\mathrm{RCO}$ & 1,675167 & 1,570567 & \\
\hline RC_UFBA & 0,63279 & 0,558503 & $\downarrow$ \\
\hline REĀVI & 0,193426 & 0,20189 & $\uparrow$ \\
\hline REPEC & 1,528122 & 1,509845 & \\
\hline RUC & 1,888041 & 1,751088 & $\downarrow$ \\
\hline Amb_Cont & 0,389344 & 0,410797 & $\uparrow$ \\
\hline R_Elet_Cont & 0,105424 & 0,103096 & \\
\hline R_Est_Cont & 0,237246 & 0,251909 & $\uparrow$ \\
\hline Razao & 0,293805 & 0,332432 & $\uparrow$ \\
\hline Recont & 0,243438 & 0,243273 & \\
\hline Reunir & 0,334397 & 0,35101 & $\uparrow$ \\
\hline BBR & 2,31637 & 2,198687 & \\
\hline Base & 2,057924 & 1,94815 & \\
\hline CGG & 6,819441 & 5,781888 & \\
\hline CVR & 46,1825 & 35,32484 & \\
\hline Contexto & 3,083589 & 2,755738 & \\
\hline
\end{tabular}

As taxas de incidência estimada referentes a oito revistas aumentaram, enquanto as referentes às demais 18 revistas diminuíram. A Revista de Gestão, Finanças e Contabilidade não permaneceu no modelo. A taxa estimada da Revista Contabilidade 
\& Finanças reduziu de 125,73 para 91,29 , e da Contabilidade Vista \& Revista reduziu de 46,18 para 35,32. Embora a redução das taxas das duas revistas seja comparativamente significativa, este modelo prevê que, mantidas as demais condições constantes, um artigo publicado na RC\&F teria taxa de citações 91 vezes maior do que a categoria de referência, que era a revista $A B C u s t o s$.

A Tabela 62 mostra o modelo gerado ao se eliminar a Revista Contabilidade \& Finanças como categoria da variável Revista. O pseudo $\mathrm{R}^{2}$ de McFadden indica que este modelo é inferior ao anterior.

Tabela 62 - Modelo 7, sem a RC\&F como categoria de Revista

\begin{tabular}{|c|c|c|c|c|c|c|}
\hline \multicolumn{3}{|l|}{ Number of obs $=2.427$} & \multicolumn{4}{|c|}{ Prob $>$ chi $2=0,0000$} \\
\hline \multicolumn{3}{|l|}{ LR chi2(34) = 586,38 } & \multicolumn{4}{|c|}{ Log likelihood $=-5710,9828$} \\
\hline \multicolumn{3}{|l|}{ Dispersion $=$ mean } & \multicolumn{4}{|c|}{ Pseudo R2 = 0,0488 } \\
\hline Citações & IRR & Std. Err. & $\mathbf{z}$ & P>Z & {$[95 \%$ Con } & Interval] \\
\hline Constante & 5,45315 & 0,519673 & 17,8 & 0,000 & 4,524076 & 6,573022 \\
\hline Gerencial & 0,688933 & 0,040303 & $-6,37$ & 0,000 & 0,6143 & 0,772633 \\
\hline Mercado de capitais & 0,85749 & 0,063487 & $-2,08$ & 0,038 & 0,741665 & 0,991404 \\
\hline Mulher & 1,146686 & 0,061462 & 2,55 & 0,011 & 1,032335 & 1,273704 \\
\hline UFPB & 1,619861 & 0,377744 & 2,07 & 0,039 & 1,025608 & 2,558433 \\
\hline USP & 1,345239 & 0,10094 & 3,95 & 0,000 & 1,161261 & 1,558364 \\
\hline OUTRO & 0,797876 & 0,04583 & $-3,93$ & 0,000 & 0,712921 & 0,892953 \\
\hline B2 & 0,834865 & 0,064027 & $-2,35$ & 0,019 & 0,71835 & 0,970279 \\
\hline Contextus & 2,363421 & 0,556313 & 3,65 & 0,000 & 1,489983 & 3,748874 \\
\hline RACEF & 0,176451 & 0,064776 & $-4,73$ & 0,000 & 0,08593 & 0,36233 \\
\hline RAC_FAT & 0,151387 & 0,052949 & $-5,40$ & 0,000 & 0,076274 & 0,300473 \\
\hline $\mathrm{RBC}$ & 2,481603 & 0,401186 & 5,62 & 0,000 & 1,807689 & 3,406755 \\
\hline RBGN & 2,227154 & 0,380946 & 4,68 & 0,000 & 1,592778 & 3,11419 \\
\hline RCC_UFPR & 0,5459 & 0,089806 & $-3,68$ & 0,000 & 0,395442 & 0,753605 \\
\hline RCC UFSC & 2,199047 & 0,293989 & 5,89 & 0,000 & 1,692147 & 2,857795 \\
\hline RCMCC & 1,611987 & 0,227289 & 3,39 & 0,001 & 1,222764 & 2,125105 \\
\hline RCO & 1,551054 & 0,184624 & 3,69 & 0,000 & 1,228308 & 1,958603 \\
\hline RC_UFBA & 0,584679 & 0,093177 & $-3,37$ & 0,001 & 0,427825 & 0,799041 \\
\hline REAVI & 0,187893 & 0,133062 & $-2,36$ & 0,018 & 0,046893 & 0,752862 \\
\hline REPEC & 1,553102 & 0,200937 & 3,40 & 0,001 & 1,20524 & 2,001366 \\
\hline RGFC & 0,539116 & 0,147528 & $-2,26$ & 0,024 & 0,315321 & 0,921748 \\
\hline RUC & 1,700142 & 0,172491 & 5,23 & 0,000 & 1,393558 & 2,074176 \\
\hline Amb_Cont & 0,428532 & 0,089645 & $-4,05$ & 0,000 & 0,284394 & 0,645722 \\
\hline $\mathrm{R}$ Elet_Cont & 0,093797 & 0,101113 & $-2,20$ & 0,028 & 0,01134 & 0,775859 \\
\hline R_Est_Cont & 0,22839 & 0,06569 & $-5,13$ & 0,000 & 0,129973 & 0,401329 \\
\hline Razao & 0,286806 & 0,086956 & $-4,12$ & 0,000 & 0,158312 & 0,51959 \\
\hline Recont & 0,230689 & 0,062176 & $-5,44$ & 0,000 & 0,136021 & 0,391243 \\
\hline Reunir & 0,324192 & 0,089709 & $-4,07$ & 0,000 & 0,188478 & 0,557628 \\
\hline BBR & 2,269154 & 0,340105 & 5,47 & 0,000 & 1,691548 & 3,043994 \\
\hline Base & 1,995648 & 0,271563 & 5,08 & 0,000 & 1,528461 & 2,605635 \\
\hline CGG & 6,073361 & 0,993312 & 11,03 & 0,000 & 4,407711 & 8,368451 \\
\hline CVR & 32,69421 & 8,272996 & 13,78 & 0,000 & 19,91046 & 53,6859 \\
\hline Contexto & 2,605714 & 0,431725 & 5,78 & 0,000 & 1,8832 & 3,60543 \\
\hline Idade & 0,839675 & 0,012014 & $-12,21$ & 0,000 & 0,816454 & 0,863556 \\
\hline Número de referências & 1,010545 & 0,001932 & 5,49 & 0,000 & 1,006765 & 1,014339 \\
\hline
\end{tabular}


${ }^{*}$ Categorias omitidas: Revista $=$ ABCustos, Ordinário ou Especial $=$ Especial, Posição $=$ Outra, Gênero do primeiro autor $=$ Homem, Titulação do primeiro autor $=$ Bacharel, IES do primeiro autor $=$ FECAP, Linha de pesquisa $=$ Educação, Qualis da revista $=A 2$, Abordagem da análise de dados $=$ nãoquantitativa.

$\mathrm{Na}$ ausência da Revista Contabilidade \& Finanças, as variáveis Linha de pesquisa, Gênero do primeiro autor, IES do primeiro autor, Idade da revista e Número de referências apresentaram pequenas alterações. A categoria B2 do estrato Qualis ficou retido no modelo, indicando uma taxa média de citações $17 \%$ menor que a categoria de referência, que era o estrato A2.

A revista Pensar Contábil foi excluída desse modelo e houve alterações nas taxas de incidência estimadas. Como já se podia supor, com base nos modelos anteriores, a revista que assumiu a dianteira no desempenho em citações foi a Contabilidade Vista e Revista $(i r r=34,6)$.

O Modelo 8 foi gerado a partir das variáveis originais, eliminando as categorias USP como IES do primeiro autor e RC\&F como revista. Nesse cenário em que há 2.076 observações, o modelo gerado resultou de menor qualidade que o Modelo 1, como indica o pseudo $\mathrm{R}^{2}$ de McFadden = 0,0446.

Tabela 63 - Modelo 8, sem a USP como categoria de IES do primeiro autor e sem a RC\&F como categoria de Revista

\begin{tabular}{|c|c|c|c|c|c|c|}
\hline \multicolumn{3}{|c|}{ Number of obs $=2,076$} & \multicolumn{4}{|c|}{ Prob $>$ chi2 $=0,0000$} \\
\hline \multirow{2}{*}{\multicolumn{3}{|c|}{$\begin{array}{l}\text { LR chi2 }(30)=442,58 \\
\text { Dispersion = mean }\end{array}$}} & \multirow{2}{*}{\multicolumn{4}{|c|}{$\begin{array}{l}\text { Log likelihood }=-4735,5826 \\
\text { seudo } R 2=0.0446\end{array}$}} \\
\hline & \multicolumn{2}{|c|}{ Dispersion $=$ mean } & \multirow{2}{*}{\multicolumn{4}{|c|}{\begin{tabular}{|l|c|c|}
\multicolumn{3}{|c|}{ Pseudo R2 $=0,0446$} \\
$\mathbf{z}$ & $\mathbf{P}>\mathbf{z}$ & {$[95 \%$} \\
\end{tabular}}} \\
\hline Citações & IRR & Std. Err. & & & & \\
\hline Constante & 4,556833 & 0,43979 & 15,71 & 0,000 & 3,77148 & 5,505724 \\
\hline Gerencial & 0,690296 & 0,042319 & $-6,05$ & 0,000 & 0,612143 & 0,778428 \\
\hline Mulher & 1,124145 & 0,065178 & 2,02 & 0,044 & 1,00339 & 1,259433 \\
\hline UFPB & 1,678057 & 0,394094 & 2,20 & 0,028 & 1,059011 & 2,658965 \\
\hline OUTRO & 0,812865 & 0,047107 & $-3,58$ & 0,000 & 0,725588 & 0,910641 \\
\hline Contextus & 2,426386 & 0,605868 & 3,55 & 0,000 & 1,487356 & 3,958264 \\
\hline Pensar & 1,384445 & 0,18275 & 2,46 & 0,014 & 1,068846 & 1,793232 \\
\hline RACEF & 0,162233 & 0,071288 & $-4,14$ & 0,000 & 0,068565 & 0,38386 \\
\hline RAC FAT & 0,175921 & 0,069598 & $-4,39$ & 0,000 & 0,081015 & 0,382007 \\
\hline RBC & 2,416331 & 0,409916 & 5,20 & 0,000 & 1,732827 & 3,36944 \\
\hline RBGN & 3,034524 & 0,585188 & 5,76 & 0,000 & 2,079419 & 4,428321 \\
\hline RCC_UFSC & 2,342595 & 0,33959 & 5,87 & 0,000 & 1,763212 & 3,112361 \\
\hline RCMCC & 1,697354 & 0,25 & 3,53 & 0,000 & 1,265042 & 2,277402 \\
\hline $\mathrm{RCO}$ & 1,69011 & 0,226892 & 3,91 & 0,000 & 1,299104 & 2,198801 \\
\hline RC_UFBA & 0,58471 & 0,103505 & $-3,03$ & 0,002 & 0,413297 & 0,827217 \\
\hline REAVI & 0,233904 & 0,166055 & $-2,05$ & 0,041 & 0,058176 & 0,940435 \\
\hline REPEC & 1,632268 & 0,238614 & 3,35 & 0,001 & 1,225626 & 2,173827 \\
\hline$R U C$ & 1,820596 & 0,206484 & 5,28 & 0,000 & 1,457719 & 2,273805 \\
\hline Amb_Cont & 0,44244 & 0,092809 & $-3,89$ & 0,000 & 0,293292 & 0,667434 \\
\hline
\end{tabular}




\begin{tabular}{l|r|r|r|r|r|r}
\hline R_Elet_Cont & 0,100629 & 0,108485 & $-2,13$ & 0,033 & 0,012164 & 0,832492 \\
\hline R_Est_Cont & 0,26831 & 0,089602 & $-3,94$ & 0,000 & 0,139437 & 0,516293 \\
\hline Razao & 0,362694 & 0,112147 & $-3,28$ & 0,001 & 0,197854 & 0,66487 \\
\hline Recont & 0,259818 & 0,071942 & $-4,87$ & 0,000 & 0,151001 & 0,447054 \\
\hline Reunir & 0,395276 & 0,11186 & $-3,28$ & 0,001 & 0,226995 & 0,688311 \\
\hline BBR & 2,240912 & 0,358821 & 5,04 & 0,000 & 1,6373 & 3,067055 \\
\hline Base & 1,932195 & 0,285724 & 4,45 & 0,000 & 1,446037 & 2,5818 \\
\hline CGG & 5,463727 & 0,951869 & 9,75 & 0,000 & 3,883256 & 7,687445 \\
\hline CVR & 29,37296 & 7,892325 & 12,58 & 0,000 & 17,34744 & 49,73477 \\
\hline Contexto & 2,662802 & 0,466111 & 5,60 & 0,000 & 1,889471 & 3,752647 \\
\hline Idade & 0,855469 & 0,01285 & $-10,39$ & 0,000 & 0,830652 & 0,881028 \\
\hline Número de referências & 1,008835 & 0,002095 & 4,23 & 0,000 & 1,004736 & 1,01295 \\
\hline
\end{tabular}

${ }^{*}$ Categorias omitidas: Revista = ABCustos, Ordinário ou Especial = Especial, Posição = Outra, Gênero do primeiro autor $=$ Homem, Titulação do primeiro autor $=$ Bacharel, IES do primeiro autor $=$ FECAP, Linha de pesquisa $=$ Educação, Qualis da revista $=A 2$, Abordagem da análise de dados $=$ nãoquantitativa.

$\mathrm{Na}$ ausência da USP como IES do primeiro autor e da Revista Contabilidade \& Finanças, o modelo ainda reteve a categoria Contabilidade gerencial e Controladoria, da variável Linha de Pesquisa, mas não reteve mais a categoria Mercado de capitais. Vale lembrar que o teste de qui-quadrado mostrava uma associação estatisticamente significante entre Revista e Linha de pesquisa e que a Anacor revelou uma relação muito forte entre a linha de Mercado de capitais e a Revista Contabilidade \& Finanças.

O Gênero do primeiro autor ser feminino tornou a ser mostrado como estatisticamente significante segundo o modelo, bem como as variáveis Idade da revista e Número de referências. A variável estrato Qualis da revista, que possuía uma categoria estatisticamente significante na presença da USP como IES do primeiro autor foi excluída na ausência dessa categoria. A Contabilidade Vista \& Revista mostrou-se novamente a revista com melhor desempenho em citações, com uma taxa de incidência estimada de 29,37.

Assim, segundo o pseudo $\mathrm{R}^{2}$ de McFadden, o melhor dos modelos é o Modelo 1, como pode ser visto na Tabela 64, que apresenta um comparativo entre todos os modelos estudados nesta Tese.

Tabela 64 - Comparação entre os modelos elaborados

\begin{tabular}{c|l|r}
\hline Modelo & \multicolumn{1}{|c|}{ Característica } & $\begin{array}{c}\text { Pseudo R2 de } \\
\text { McFadden }\end{array}$ \\
\hline Modelo 1 & com todas as variáveis & 0,0677 \\
\hline Modelo 2 & sem a variável Revista & 0,0318 \\
\hline Modelo 3 & sem a variável Idade da revista & 0,0641 \\
\hline Modelo 4 & sem as variáveis Idade da revista e Qualis & 0,0554 \\
\hline Modelo 5 & com a variável Idade do artigo & 0,0669 \\
\hline
\end{tabular}




\begin{tabular}{l|l|r}
\hline Modelo 6 & sem a USP como categoria de IES do primeiro autor & 0,0645 \\
\hline Modelo 7 & sem a RC\&F como categoria de Revista & 0,0488 \\
\hline Modelo 8 & $\begin{array}{l}\text { sem a USP como categoria de IES do primeiro autor e } \\
\text { sem a RC\&F como categoria de Revista }\end{array}$ & 0,0446 \\
\hline
\end{tabular}

Ressalva-se que, embora o Modelo 5 tenha um pseudo $\mathrm{R}^{2}$ de McFadden 0,0008, menor que o Modelo 1, ele apresentou taxas de incidência estimadas mais em conformidade com a estatística descritiva, principalmente para a Revista Contabilidade \& Finanças e para Contabilidade Vista \& Revista.

A categoria Contabilidade gerencial e Controladoria, da variável Linha de pesquisa, apareceu em todos os modelos, enquanto que a categoria Mercado de capitais apareceu nos Modelos 1, 3, 5, 6 e 7. Todos os modelos indicam que os artigos dessas duas linhas são, em média, menos citados que da linha Educação e Pesquisa, que é a categoria de referência.

A variável Gênero do primeiro autor mostrou-se estatisticamente significante em seis modelos, não aparecendo apenas nos Modelos 2 e 6. Os modelos nos quais a variável apareceu indicam que os artigos com primeiras autoras são mais citados do que com primeiros autores. Resultado que surpreendente quando considerada a literatura.

As categorias UFPB e OUTRO, da variável IES do primeiro autor, também apareceram em todos os modelos. A USP apareceu em seis modelos; a Fucape, no Modelo 3; e a UNB e a FURB, no Modelo 4.

A variável Revista apareceu em todos os sete modelos nos quais foi incluída. 0 Modelo 5 foi o que reteve menos categorias (14 revistas), e o Modelo 1 reteve mais categorias (27 revistas). Aragão et al. (2014), em um estudo com quatro revistas brasileiras de contabilidade, já haviam detectado que essa variável influencia as citações.Com esta pesquisa, pode-se afirmar que essa influência é exercida por, pelo menos, outros 14 periódicos.

A variável Idade da revista foi incluída em seis modelos e, nesses modelos, ela se mostrou, estatisticamente, significante em cinco deles. Somente no Modelo 5 ela foi incluída na regressão, mas excluída pelo procedimento stepwise. 
As categorias Doutor e Mestre, da variável Titulação acadêmica do primeiro autor, mostraram-se significantes no Modelo 2. A abordagem quantitativa, na análise de dados, mostrou-se significante somente no Modelo 4. A variável Número de autores mostrou-se estatisticamente significativa somente no Modelo 5.

As categorias B1 e B3, da variável estrato do Qualis da revista, mostraram-se significantes nos Modelos 2 e 5. A categoria B2 mostrou-se significante no Modelo 7 . Todos os estratos mostram-se significantes no Modelo 3.

A única variável explicativa quantitativa que se mostrou, estatisticamente, significativa em todos os modelos foi o Número de referências, sempre no sentido positivo e na proporção entre $0,5 \%$ a $1,2 \%$.

As variáveis recorrentes em todos os modelos gerados permitem aceitar as hipóteses de influência da Afiliação institucional, da Revista, do Número de referências e da Linha de pesquisa, acarretando a aceitação das hipóteses H5, H6, H14 e H15.

A aceitação apenas parcial e a rejeição das demais hipóteses revelam que o cenário da pesquisa contábil brasileira, embora apresente a influência de fatores socialconstrutivistas no processo de citação dos artigos, mostra-se bastante flexível quando comparado com o cenário de pesquisa internacional, na área de Negócios, Direito e Sustentabilidade. Essa constatação é corroborada pelo fato de que menos variáveis mostraram-se estatisticamente significativas nesta Tese do que nas pesquisas conduzidas internacionalmente.

Por último, a Idade do artigo, que, segundo Aragão, Oliveira e Lima (2014), influencia as citações, acabou por se mostrar estatisticamente significante no Modelo 5. Esse resultado não se mostrou inesperado pois, como visto na Figura 28 , há uma tendência de crescimento do número de citações ao longo do período estudado. 


\section{CONCLUSÕES}

The dog days are over

The dog days are done

Florence and The Machine

Esta Tese tem por objetivo analisar o comportamento das citações do âmbito da pesquisa contábil brasileira. A literatura revisada indicou que o comportamento das citações pode caminhar entre duas propostas: universalista e social-construtivista. A primeira assume o pressuposto de que pesquisas são citadas devido a sua qualidade, inovação nos resultados, rigor metodológico ou contribuição teórica. A segunda pressupõe que pesquisas são citadas devido a características construídas e valorizadas pela comunidade científica, como fama do autor, tradição da instituição, fator de impacto do periódico, escolha de problemas de pesquisa ou adoção de técnicas que constituem o mainstream de determinada área.

Os resultados encontrados são assim detalhados: os artigos publicados em edições especiais (média $=8,0$ ) mostraram-se mais citados que os publicados em edições ordinárias (média $=4,7$ ), embora a diferença dessas médias não sejam consideradas estatisticamente significantes. Isso pode ocorrer porque as edições especiais não possuem necessariamente características de edições especiais. Algumas delas possuem as mesmas temáticas e os mesmos editores das edições ordinárias. Inclusive, o diagnóstico de que apenas 49 artigos, de 2.540 (2\%), veicularam por edições especiais é um indício de que os editores das revistas estão sendo tímidos com essa modalidade de edição. Um dos benefícios das edições especiais é que os procedimentos tradicionais do processo editorial podem ser flexibilizados, e essa flexibilização pode permitir que pesquisas que não se encaixam no que o pensamento kuhniano chama de ciência comum, encontre oportunidade para vir a público.

Quanto à posição na edição, os artigos publicados na primeira posição - leading articles - (média $=5,28)$ mostraram-se mais citados que os publicados na sequência (média $=4,7$ ), embora, novamente, a diferença dessas médias não seja estatisticamente significante. Todavia, há que se considerar o fato de que o processo de recuperação de informação está se tornando cada vez mais automatizado e as 
versões impressas, nas quais ser o primeiro artigo possibilitam uma maior visibilidade, estão deixando de existir. A migração para os acervos eletrônicos deve fazer com que a inventividade na atribuição de um título e a adequada escolha de palavras-chave, que reflitam o conteúdo do artigo, se sobreponham à vantagem da posição do artigo.

É interessante constatar que os artigos que tinham mulheres como primeiros autores ( média $=4,9$ ) foram ligeiramente mais citados que os artigos com homens como primeiros autores (média $=4,8$ ), sendo a diferença não significante estatisticamente. $\mathrm{O}$ fato de as primeiras autoras figurarem com mais frequência nas linhas de Contabilidade para usuários externos e Educação e Pesquisa, que são as duas linhas com maiores taxas de citação, contribui para elevar a média de citações dos artigos com primeira autora. No entanto, há mais fatores que podem estar influenciando essa média, por exemplo, a forma como as autoras escolhem a questão de pesquisa, a forma como definem o desenho da pesquisa, o tempo que dedicam ao desenvolvimento de um artigo, a performance da relação orientador(a) e aluno(a). E, ainda, acredita-se que essas questões não são aleatórias ao desempenho da quantidade de citações dos artigos que têm primeira autora.

Com relação à titulação do primeiro autor, os artigos mais citados, em ordem decrescente, tinham como primeiro autor doutores (média $=5,98$ ), mestres (média $=$ 5,07 ), graduandos (média $=3,29$ ), bacharéis (média $=3,24$ ). Essas diferenças mostraram-se estatisticamente significantes. Com exceção do fato de os artigos com primeiros autores graduandos terem média de citação maior que dos artigos com primeiros autores bacharéis, esse resultado converge com a expectativa existente. $A$ Ciência de informação identificou a existência de um processo de superespecialização das ciências, à medida que elas amadurecem, sendo que, entre os recursos para um pesquisador se apropriar de conhecimento suficiente para poder fazer uma contribuição original, estão o tempo de investigação em uma área, o entendimento das diversas teorias e o domínio de diferentes técnicas. E o processo de formação acadêmica, com todos os seus títulos, proporciona esses recursos a quem mais investe na sua própria formação científica.

Considerando-se a IES do primeiro autor, os artigos mais citados tinham como primeiro autor pesquisadores da FECAP (média 10,53), UPM (média = 10,48), 
FUCAPE (média = 9,07) e PUC-SP (média 8,86). Trata-se de resultados inesperados, porque esses programas têm conceitos menores junto à Capes. O programa em Ciências Contábeis da UPM, inclusive, é classificado como mestrado profissional pela Capes, o que não impediu que a média de citações de artigos com primeiro autor com sua afiliação institucional fosse maior do que a de vários programas acadêmicos. Também é curioso que as quatro maiores médias de citação, de acordo com a afiliação institucional, pentençam a instituições particulares de ensino. Na sequência dessas instituições aparece a primeira instituição pública que é a USP.

Para a linha de pesquisa, os artigos mais citados, em ordem decrescente, são de Contabilidade para usuários externos (média $=6,0$ ), Educação e Pesquisa (média = 5,6), Mercado de capitais (média $=5,4$ ), Contabilidade pública (média $=4,8$ ), Contabilidade gerencial e Controladoria (média $=3,23$ ) e Contabilidade do terceiro setor (média $=3,22$ ), com diferenças significantes estatisticamente. Considerando as palavras de ludícibus, Martins e Carvalho (2005), segundo os quais "a contabilidade nasceu gerencial", foi surpresa a média de citações desta linha ser mais baixa que as demais.

Foi igualmente surpreendente que a linha de Educação e Pesquisa, que até 2012 só existia formalmente no PPGCC/USP, apresentasse a segunda maior média de citações. No entanto, esses resultados se tornam menos surpreendentes quando se considera que foram publicados quase dois trabalhos de Contabilidade gerencial e Controladoria para cada trabalho publicado de Educação e Pesquisa, e, considerando que a média de referências por artigo entre as duas linhas é parecida, chega-se à conclusão que as citações dos artigos da linha de Contabilidade gerencial estão mais pulverizadas que as da linha de Educação e Pesquisa. Esta última, por sua vez, por possuir um menor quantitativo de artigos e livros para serem citados, acaba por concentrar as citações em um número menor de obras, o que aumenta a média de citações.

Já para o estrato do Qualis da revista, houve uma curiosa inversão: os artigos mais citados pertencem, em ordem decrescente, aos estratos $B 1$ (média $=8,6), A 2(7,2)$, B3 (média = 5,3), C (média = 3,7), NC (média 3,5), B2 (média = 3,4), B4 (média = 3,1), B5 (média $=2,4)$, com diferenças estatisticamente significativas entre as médias. A 
alteração da classificação dos estratos no triênio 2007-2009 para o ano de 2010-2012 descontinuou a uniformidade da avaliação. Somado a isso há a situação constatada por Soares e Casa Nova (2016), de que o Qualis reflete apenas parcialmente a quantidade de citações dos artigos, acabando por se admitir que o fato de a média de citações entre os estratos não guardarem uma correlação contínua não é um fato inesperado.

Para a abordagem da análise de dados, artigos que se utilizaram de abordagem quantitativa de dados tiveram uma média de citações superior (média $=5,1$ ) do que artigos com abordagens não-quantitativas (média $=4,5$ ), igualmente com diferenças estatisticamente significantes entre as médias. No entanto, esses resultados contradizem o diagnóstico feito pela regressão binomial negativa, que indicam exatamento o oposto, ou seja, que artigos que usam abordagem de dados quantitativa são $11 \%$ menos citados que os artigos que não adotam abordagem quantitativa. Deve-se, contudo, levar em consideração que artigos com abordagem quantitativa estão fortemente associados a artigos da linha de Mercado de capitais e Contabilidade gerencial e Controladoria, que possuem média de citação mais baixa que as demais linhas. No entanto, essa média foi detectada em apenas um dos oito modelos, de forma que a hipótese a ela relacionada não foi aceita.

Entre os achados surpreendentes estão as médias de citações de artigos com a primeira autoria feminina, da linha de pesquisa em Educação e Pesquisa e do estratos Qualis B1 (superior a A2) e B3 e C (superiores a B2).

Foi, ainda, possível mensurar que todas as variáveis explicativas quantitativas possuem baixa correlação com o número de citação dos artigos e apresentaram baixa correlação entre si, todas elas menores que $r=0,22$. O número de referências $(r=$ $0,11)$ e a idade da revista $(r=0,22)$ foram as variáveis com maior correlação com a quantidade de citações.

As nove variáveis explicativas qualitativas, por sua vez, apresentaram 23 pares de associações estatisticamente significantes, segundo o teste qui-quadrado. Devido ao número expressivo de associações entre as características qualitativas das pesquisas, procedeu-se a uma regressão binomial negativa para identificar o impacto 
conjunto de todas as variáveis, na quantidade de citações recebidas por um artigo. Foram testados oito modelos, com diferentes composições de variáveis, tendo sido utilizado o procedimento stepwise para o modelo original. Esse modelo foi, então, retestado, retirando-se a variável mais influente. Assim, retirou-se a variável "revista", que era a mais importante, para verificar qual variável se tornaria mais relevante; depois, retirou-se a variável "idade da revista"; e assim por diante. Os resultados discutidos, a seguir, referem-se a esses modelos testados.

O impacto da "quantidade de autores" sobre as citações foi estatisticamente significante somente na presença da variável "idade do artigo" e está positivamente relacionado com o aumento do número de citações, na proporção de $5 \%$ mais citações a cada autor adicionado. Esse resultado alinha-se com a maior parte das literaturas (Leimu \& Koricheva, 2005; Antonakis et al.; Martinez-Blasco et al., 2016; Fox et al., 2016). Em todos os demais modelos essa variável não se mostrou estatisticamente significante. Dessa forma, considera-se a H1 apenas parcialmente aceita. Pode-se, ainda, cogitar o fato de que as pequenas contribuições, que não são autorias de fato, estão contribuindo para o aumento do número médio de autores, mas não para o resultado final da pesquisa, como alertam Antunes et al. (2014).

O impacto do "gênero do primeiro autor" sobre as citações mostrou-se estatisticamente significante em seis dos oito modelos elaborados, não sendo estatisticamente significante apenas quando a variável "revista" foi removida do modelo e quando a categoria "USP" foi removida da variável IES do primeiro autor. Os modelos indicam que artigos com primeira autora são de $11 \%$ a $14 \%$ mais citados do que artigos com primeiro autor. Esse resultado mostra-se em concordância com a pesquisa de Ayres e Vars (2000). Assim sendo, considera-se a H2 parcialmente aceita.

O impacto da variável "proporção de autoras" na quantidade de citações do artigo não se mostrou estatisticamente significante em nenhum modelo. Desta forma, considerase a $\mathrm{H} 3$ rejeitada.

O impacto da "titulação do primeiro autor" na quantidade de citações do artigo mostrou-se relevante quando o primeiro autor era doutor ou mestre, mas apenas na 
ausência da variável "revista". O modelo indica que artigos com primeiro autor doutor são $27 \%$ mais citados; e artigos com primeiro autor mestre são $21 \%$ mais citados. A categoria de referência são os artigos com primeiro autor bacharel. Esse resultado alinha-se com a pesquisa de Ayres e Vars (2000). Dessa forma, a H4 foi considerada parcialmente aceita.

A variável "afiliação institucional", tratada como IES do primeiro autor, mostrou-se significante em quase todos os modelos, com variação nas categorias relevantes. Os modelos indicam que, quando a afiliação do primeiro autor era a USP, os artigos eram de $34 \%$ a $44 \%$ mais citados que a categoria de referência; e que, quando a afiliação do primeiro autor era de uma IES sem programa de pós-graduação stricto sensu em Contabilidade, os artigos eram de $17 \%$ a $46 \%$ menos citados que a categoria de referência. A categoria de referência era a FECAP. Na ausência da variável "revista", a "afiliação institucional" foi a variável que se mostrou mais relevante, dado o seu impacto no número de citações. O impacto da "afiliação institucional" está alinhado com a literatura (Ayres \& Vars, 2000; Leimu \& Koricheva, 2005; Stremersch et al., 2007; Mingers \& Xu, 2010). Diante disso considera-se a H5 aceita.

O impacto da "revista" na quantidade de citações mostrou-se estatisticamente significante em todos os modelos gerados, embora nem todas as revistas tenham se mostrado estisticamente significantes. O modelo mais abrangente incluiu 27 das 36 revistas analisadas. $O$ impacto da revista na quantidade de citações está alinhado com a literatura (Leimu \& Koricheva, 2005; Judge et al., 2007; Mingers \& Xu, 2010; Vanclay, 2013; Aragão et al., 2014). Dessa forma, considera-se a H6 aceita.

O impacto do "tipo de edição" na quantidade de citações não se mostrou estatisticamente significante em nenhum modelo, contradizendo a pesquisa de Martinez-Blasco et al. (2016). Dessa forma, rejeita-se a H7.

O impacto do "estrato do Qualis da revista" na quantidade de citações de um artigo mostrou-se estatisticamente significante somente na ausência das variáveis "revista" ou "idade da revista". Mas, como o Qualis reflete parcialmente as taxas médias de citações e tem uma associação não-aleatória com as revistas, acaba por se tornar relevante na ausência delas. Diante disso, considera-se a H8 parcialmente aceita. 
A variável "idade da revista" foi incluída em seis modelos, dentro dos quais se mostrou estatisticamente significante em cinco deles, exceto no modelo que incluía a variável "idade do artigo". Dessa forma considera-se a H9 parcialmente aceita.

A influência da "posição do artigo dentro da edição" mostrou-se estatisticamente insignificante em todos os modelos elaborados. Dessa forma, considera-se a hipótese H10 rejeitada. Esse fato contraria as pesquisas de Ayres e Vars (2000), Judge et al. (2007), Stremersch et al. (2007), que identificaram que ser o primeiro artigo da edição - leading article - proporcionava maiores taxas de citação.

O "número de termos no título" (Ayres \& Vars, 2000), o "número de palavras-chave" (Stremersch et al., 2007; Mingers \& Xu, 2010; Stremersch et al., 2015) e o número de páginas (Ayres \& Vars, 2000; Leimu \& Koricheva, 2005; Judge et al., 2007; Stremersch et al., 2007; Mingers \& Xu, 2010; Vanclay, 2013; Fox et al., 2016), que a literatura apontava como influentes, não permaneceram em nenhum dos modelos gerados nesta Tese. Dessa forma, as hipóteses H11, H12 e H13 foram rejeitadas.

O impacto do "número de referências nas citações" mostrou-se estatisticamente significante em todos os modelos gerados. Esse achado vai ao encontro da literatura analisada (Judge et al., 2007; Stremersch et al., 2007; Mingers \& Xu, 2010; Antonakis et al., 2014; Fox et al., 2016). De fato, os modelos indicam que a cada referência extra, mantidas as demais condições constantes, o artigo tem uma quantidade de citação de $0,2 \%$ a $1,2 \%$ maior. Dessa forma a $\mathrm{H} 14$ foi aceita.

O impacto da "linha de pesquisa" nas citações dos artigos mostrou-se estatisticamente significante em todos os modelos gerados, alinhando-se com as pesquisas de Ayres e Vars (2000); Stremersch et al. (2007); Antonakis et al. (2014); Stremersch et al. (2015). Segundo os oito modelos, a linha 1, Contabilidade gerencial e Controladoria, tem média de citação menor que a categoria de referência, que era a linha 4 , Educação e Pesquisa. Segundo cinco modelos, a linha 3, Mercado de capitais, tem média de citação menor que a categoria de referência. Enquanto os artigos da linha 3 são de $15 \%$ a $19 \%$ menos citados que a linha 4 , os artigos da linha 1 são de $26 \%$ e $37 \%$ menos citados que a linha 4 . Dessa forma, a H15 foi aceita. 
O impacto do "uso de métodos quantitativos nas citações" mostrou-se estatisticamente significante apenas na ausência das variáveis "idade da revista" e "estrato Qualis da revista". No entanto, o uso de métodos quantitativos causou redução de $11 \%$ nas citações dos artigos, contrariando a pesquisa de Antonakis et al. (2014), que encontraram uma associação positiva. Esse achado também contraria a média de citações dos dois grupos, já que a média do grupo de artigos com abordagem quantitativa era maior que a do outro grupo. No entanto, há que se considerar que essa variável mostra associação estatisticamente significativa com outras seis variáveis qualitativas e que são elas que aumentam a média de citações dos artigos dessa categoria. Diante disso, a H16 foi rejeitada.

Assim, foi possível concluir que o número de citações de um artigo sofre influência da afiliação institucional do primeiro autor, da revista em que o artigo foi publicado, da linha de pesquisa a que o artigo pertence e do número de referências do artigo.

As hipóteses aceitas sustentam a tese de que existem fatores social-construtivistas que influenciam o quanto um artigo é citado no âmbito da pesquisa contábil brasileira. Por outro lado, o número relativamente pequeno de hipóteses totalmente aceitas nesta Tese indica que há menos fatores social-construtivistas exercendo influência sobre taxas de citação dos artigos no Brasil do que no âmbito internacional da pesquisa em Negócios, Direito e Sustentabilidade.

Ressalta-se que há, ainda, várias oportunidades de pesquisa para se desenvolver no futuro. Há muitas variáveis que não foram contempladas nesta Tese e que podem ser estudadas por autores e autoras preocupados com a pesquisa acadêmica.

Uma das variáveis mais interessantes a ser investigada é o idioma em que o artigo é publicado. Embora as pesquisas internacionais indiquem que artigos publicados em inglês sejam, em média, mais citados que artigos publicados em outros idiomas, a exploração dos dados desta pesquisa causaram a impressão de que isto não ocorre nas revistas brasileiras. Uma hipótese que pode constituir a explicação para este fato é que as revistas brasileiras em sua maioria não são indexadas em grandes bases de dados internacionais, e a busca realizada em seus acervos é feita por pesquisadores 
lusófonos, com palavras-chave em português, de modo que as pesquisas em inglês não são recuperadas pelo sistema de arquivamento.

Outra variável interessante para ser investigada é qual parte dos artigos citados são citados pelos artigos citantes: se são os resultados, ou método, ou outra parte. Esta análise pode ainda se desdobrar entre os artigos mais mais citados e os citados medianamente, para identificar se de fato são as conclusões das pesquisas que atraem mais citações.

Por fim, autor desta Tese, em uma observação crítica e pessoal, interpreta o pequeno número de hipóteses totalmente aceitas como um bom indício para a área. Em outra interpretação, vê esses resultados como um indicativo de que a área de Contabilidade no Brasil é menos rígida do que as críticas que circulam no meio acadêmico fazem acreditar que ela seja. 


\section{REFERÊNCIAS}

Amara, N., \& Landry, R. (2012). Counting citations in the field of business and management: why use Google Scholar rather than the Web of Science. Scientometrics, 93(3), 553-581.

Appolinário, Fabio. (2011). Dicionário de metodologia científica: um guia para a produção do conhecimento científico. 2. ed. São Paulo: Atlas, 2011.

Antunes, M. T. P., Mendonça Neto, O. R., \& Vieira, A. M. (2014, setembro). Quem é o Autor? Alguns Questionamentos sobre a Atribuição de Autoria nos Textos Científicos no Campo das Ciências Contábeis no Brasil. Artigo apresentado no XXXVIII EnANPAD, Rio de Janeiro.

Antunes, M. T. P., Okimura, R., Mendonça Neto, O. R. (2015, abril). Who is the author? Who is the coauthor? An empirical study based on the perception of Brazilian Researchers. Artigo apresentado no $38^{\text {th }}$ European Accounting Association Annual Congress, Glasgow.

Anpcont. (2015, Setembro 14). Periódicos de Contabilidade. Disponível em: http://www.anpcont.org.br/periodicos-de-contabilidade.

Antonakis, J., Bastardoz, N., Liu, Y., \& Schriesheim, C. A. (2014). What makes articles highly cited?. The Leadership Quarterly, 25(1), 152-179.

Anthony, S.. (2014) 43Tbps over a single fiber: World's fastest network would let you download a movie in 0.2 seconds. Disponível em: http://www.extremetech.com/computing/187258-43tbps-over-a-single-fiber-worldsfastest-network-would-let-you-download-a-movie-in-0-2-milliseconds. Acesso em: 14 set. 2015.

Aragão, I. R. B. N., Oliveira, J. R. S., \& de Lima, G. A. S. F. (2014). Ressonância de Artigos e Fator de Impacto de Periódicos Brasileiros de Contabilidade. Revista de Educação e Pesquisa em Contabilidade (REPeC),8(1), 5-21.

Ayres, I., \& Vars, F. E. (2000). Determinants of citations to articles in elite law reviews. The Journal of Legal Studies, 29(S1), 427-450. 
Bakkalbasi, N., Bauer, K., Glover, J., \& Wang, L. (2006). Three options for citation tracking: Google Scholar, Scopus and Web of Science. Biomedical digital libraries, 3(1), 7.

Baldi, S. (1998). Normative versus social constructivist processes in the allocation of citations: A network-analytic model. American Sociological Review, 829-846.

Banks, D. (2009). Starting science in the vernacular. Notes on some early issues of the Philosophical Transactions and the Journal des Sçavans, 1665-1700. ASp. la revue du GERAS, (55), 5-22.

Bar-llan, J. (2008). Which h-index?-A comparison of WoS, Scopus and Google Scholar. Scientometrics, 74(2), 257-271.

Bar-llan, J. (2010). Citations to the "Introduction to informetrics" indexed by WOS, Scopus and Google Scholar. Scientometrics, 82(3), 495-506.

Bergh, D. D., \& Perry, J. (2006). Some predictors of SMJ article impact. Strategic Management Journal, 27(1), 81-100.

Bergman, E. M. L. (2012). Finding citations to social work literature: The relative benefits of using Web of Science, Scopus, or Google Scholar. The journal of academic librarianship, 38(6), 370-379.

Bettencourt, L. A., \& Houston, M. B. (2001). The impact of article method type and subject area on article citations and reference diversity in JM, JMR, and JCR. Marketing Letters, 12(4), 327-340.

Beyer, J. M., Chanove, R. G., \& Fox, W. B. (1995). The review process and the fates of manuscripts submitted to AMJ. Academy of Management Journal, 38(5), 12191260.

Bíblia Sagrada. Evangelho Segundo São Mateus. Disponível em: https://www.bibliaonline.com.br/. Acesso em: 14 set. 2015.

Blog do Nemac. (2013, Abril). Periódicos em Contabilidade. Disponível em: http://blogdonemac.blogspot.com.br/p/revistas-em-contabilidade.html. 
Borges-Andrade, J. E.. (2003). Em busca do conceito de linha de pesquisa. Revista de Administração Contemporânea, 7(2), 157-170. https://dx.doi.org/10.1590/S1415$\underline{65552003000200009}$

Bornmann, L., Marx, W., Schier, H., Rahm, E., Thor, A., \& Daniel, H. D. (2009). Convergent validity of bibliometric Google Scholar data in the field of chemistryCitation counts for papers that were accepted by Angewandte Chemie International Edition or rejected but published elsewhere, using Google Scholar, Science Citation Index, Scopus, and Chemical Abstracts. Journal of informetrics, 3(1), 27-35.

Chan, K. C., Chang, C. H., \& Chang, Y. (2013). Ranking of finance journals: Some Google Scholar citation perspectives. Journal of Empirical Finance, 21, 241-250.

Chubin, D. E., \& Moitra, S. D. (1975). Content analysis of references: adjunct or alternative to citation counting?. Social studies of science, 5(4), 423-441.

Cronin, B. (1984). The citation process. The role and significance of citations in scientific communication. London: Taylor Graham, 1984.

Delgado-López-Cózar, E., \& Cabezas-Clavijo, Á. (2013). Ranking journals: could Google scholar metrics be an alternative to journal citation reports and Scimago journal rank?. Learned publishing, 26(2), 101-113.

Fávero, L. P. (2015). Análise de dados - Modelos de Regressão com Excel, Stata e Spss. Rio de Janeiro: Elsevier.

Fávero, L. P., Belfiore, P., Silva., F. L., Chan, B. L. (2009). Análise de dados Modelagem Multivariada para toma de Decisões. São Paulo: Campus.

Fox, C. W., Paine, C. E., \& Sauterey, B. (2016). Citations increase with manuscript length, author number, and references cited in ecology journals. Ecology and Evolution, 6(21), 7717-7726.

Frezatti, F., \& Borba, J. A. (2000). Análise dos traços de tendência de uma amostra das revistas científicas da área de contabilidade publicadas na língua inglesa. Caderno de Estudos, (24), 50-78. 
García-Pérez, M. A. (2010). Accuracy and completeness of publication and citation records in the Web of Science, PsycINFO, and Google Scholar: A case study for the computation of $\mathrm{h}$ indices in Psychology. Journal of the American Society for Information Science and Technology, 61(10), 2070-2085.

Gil, A. C. (2002). Como elaborar projetos de pesquisa. São Paulo: Atlas.

Gilbert, G. N. (1977). Referencing as persuasion. Social Studies of Science, 7(1), 113122.

Glass, B. (1955). News and notes. Science, 21, 583-596.

Google Scholar (2015, Setembro 14). Sobre o Google Acadêmico. Disponível em: https://scholar.google.com.br/intl/pt-BR/scholar/about.html.

Harzing, A.W. (2007) Publish or Perish ${ }^{\circledR}$ Disponível em http://www.harzing.com/pop.htm.

Harzing, A. W. (2013). A preliminary test of Google Scholar as a source for citation data: a longitudinal study of Nobel prize winners. Scientometrics, 94(3), 1057-1075.

Harzing, A. W., \& Van der Wal, R. (2007). Google Scholar: the democratization of citation analysis. Ethics in science and environmental politics, 8(1), 61-73.

Hoffman, D. L., \& Holbrook, M. B. (1993). The intellectual structure of consumer research: A bibliometric study of author cocitations in the first 15 years of the Journal of Consumer Research. Journal of Consumer Research, 19(4), 505-517.

ludícibus, Sérgio de, Martins, Eliseu, \& Carvalho, L. Nelson. (2005). Contabilidade: aspectos relevantes da epopéia de sua evolução. Revista Contabilidade \& Finanças, 16(38), 7-19.

Jacso P. (2005b) Comparison and Analysis of the Citedness Scores in Web of Science and Google Scholar. In: Fox E.A., Neuhold E.J., Premsmit P., Wuwongse V. (eds) Digital Libraries: Implementing Strategies and Sharing Experiences. ICADL 2005. Lecture Notes in Computer Science, 3815. 
Jacso, P. (2005a). As we may search-Comparison of major features of the Web of Science, Scopus, and Google Scholar citation-based and citation-enhanced databases.

Judge, T. A., Cable, D. M., Colbert, A. E., \& Rynes, S. L. (2007). What causes a management article to be cited-article, author, or journal?. Academy of Management Journal, 50(3), 491-506.

Kaplan, N. (1965). The norms of citation behavior: Prolegomena to the footnote. American documentation, 16(3), 179-184.

King, J. (1987). A review of bibliometric and other science indicators and their role in research evaluation. Journal of information science, 13(5), 261-276.

Kousha, K., \& Thelwall, M. (2007). Google Scholar citations and Google Web/URL citations: A multi-discipline exploratory analysis. Journal of the American Society for Information Science and Technology, 58(7), 1055-1065.

Kousha, K., \& Thelwall, M. (2008). Sources of Google Scholar citations outside the Science Citation Index: A comparison between four science disciplines. Scientometrics, 74(2), 273-294.

Kulkarni, A. V., Aziz, B., Shams, I., \& Busse, J. W. (2009). Comparisons of citations in Web of Science, Scopus, and Google Scholar for articles published in general medical journals. Jama, 302(10), 1092-1096.

Laband, D. N., \& Piette, M. J. (1994). Favoritism versus search for good papers: Empirical evidence regarding the behavior of journal editors. Journal of Political Economy, 102(1), 194-203.

Law, R., Ye, Q., Chen, W., \& Leung, R. (2009). An analysis of the most influential articles published in tourism journals from 2000 to 2007: A Google Scholar approach. Journal of Travel \& Tourism Marketing, 26(7), 735-746.

Lawrence, S. (2001). Free online availability substantially increases a paper's impact. Nature, 411(6837), 521-521. 
Leimu, R., \& Koricheva, J. (2005). What determines the citation frequency of ecological papers? Trends in Ecology \& Evolution, 20(1), 28-32.

Lipetz, B. A. (1965). Improvement of the selectivity of citation indexes to science literature through inclusion of citation relationship indicators. American Documentation, 16(2), 81-90.

Martell, C. (2009). A citation analysis of college \& research libraries comparing Yahoo, Google, Google Scholar, and ISI Web of Knowledge with implications for promotion and tenure. College \& Research Libraries, 70(5), 460-473.

Martínez-Blasco, M., Argilés-Bosch, J. M., García-Blandón, J., \& Martínez De Ibarreta Zorita, C. (2016). Factores influyentes en las citaciones en contabilidad: un análisis de la REFC. Spanish Journal of Finance and Accounting/Revista Española de Financiación y Contabilidad, 45(4), 487-516.

Martins, G. A. (2002). Divulgação de trabalho: considerações sobre os doze anos do caderno de estudos. Revista Contabilidade \& Finanças, 13(30), 81-88.

Meadows, A. J. (1999). A comunicação científica. Brasília: Briquet de Lemos.

Meho, L. I., \& Yang, K. (2007). Impact of data sources on citation counts and rankings of LIS faculty: Web of Science versus Scopus and Google Scholar. Journal of the american society for information science and technology, 58(13), 2105-2125.

Merton, R. K. (1957). Priorities in scientific discovery: a chapter in the sociology of science. American sociological review, 635-659.

Merton, R. K. (1968). The Matthew effect in science. Science, 159(3810), 56-63.

Mingers, J., \& Lipitakis, E. (2010). Counting the citations: a comparison of Web of Science and Google Scholar in the field of business and management. Scientometrics, 85(2), 613-625.

Mingers, J., \& Xu, F. (2010). The drivers of citations in management science journals. European Journal of Operational Research, 205(2), 422-430. 
Noruzi, A. (2005). Google Scholar: The new generation of citation indexes. Libri, 55(4), 170-180.

Oliveira, M. C. (2002). Análise dos periódicos brasileiros de contabilidade. Revista Contabilidade \& Finanças, 13(29), 68-86.

Onyancha, O. B. (2009). A citation analysis of sub-Saharan African library and information science journals using Google Scholar. African Journal of Library, Archives and Information Science, 19(2), 101-116.

Ortega, J. L., \& Aguillo, I. F. (2014). Microsoft academic search and Google scholar citations: Comparative analysis of author profiles. Journal of the Association for Information Science and Technology, 65(6), 1149-1156.

Pauly, D., \& Stergiou, K. I. (2005). Equivalence of results from two citation analyses: Thomson ISI's Citation Index and Google's Scholar service. Ethics in Science and Environmental Politics, 2005, 33-35.

Peters, H. P. F., \& van Raan, A. F. (1994). On determinants of citation scores: A case study in chemical engineering. Journal of the American Society for Information Science, 45(1), 39-49.

Poincaré, H. (1905). Science and hypothesis. New York: Science Press.

Price, D. J. S. (1963). Little science, big science. Columbia University Press.

Ravetz, J. R. (1971). Scientific knowledge and its social problems.

Rossi, C. (1997, 2 de novembro). Globalização diminui distâncias e lança o mundo na era da incerteza. Folha de São Paulo. Disponível em: http://www1.folha.uol.com.br/fsp/1997/11/02/caderno_especial/1.html

Sanni, S. A., \& Zainab, A. N. (2010). Google Scholar as a source for citation and impact analysis for a non-ISI indexed medical journal. Malaysian Journal of Library \& Information Science, 15(3), 35-51.

Schroeder, R. (2007). Pointing users toward citation searching: using Google Scholar and Web of Science. Libraries and the Academy, 7(2), 243-248. 
Seglen, P. O. (1989). From bad to worse: evaluation by Journal Impact. Trends in biochemical Sciences, 14(8), 326-327.

Šember, M., Utrobičić, A., \& Petrak, J. (2010). Croatian medical journal citation score in web of science, scopus, and google scholar. Croatian medical journal, 51(2), 99103.

Soares, S. V., Richartz, F., \& Murcia, F. D. R. (2013). Ranking da pós-graduação em contabilidade no Brasil: análise dos programas de mestrado com base na produção científica em periódicos acadêmicos no triênio 2007-2009. Revista Universo Contábil, 9(3), 55-74.

Soares, S. V., \& Casa Nova, S. P. D. C. (2016). O Qualis reflete o impacto dos artigos de Revistas Brasileiras de Contabilidade? Revista de Gestão, Finanças e Contabilidade, 6(3), 6-23.

Soares, S. V., \& Murcia, F. D. R. (2016). Ranking dos programas de pós-graduação acadêmicos em contabilidade no Brasil, no triênio 2010-2012. Revista Catarinense da Ciência Contábil, 15(46), 74-87.

Stremersch, S., Verniers, I., \& Verhoef, P. C. (2007). The quest for citations: Drivers of article impact. Journal of Marketing, 71(3), 171-193.

Stremersch, S., Camacho, N., Vanneste, S., \& Verniers, I. (2015). Unraveling scientific impact: Citation types in marketing journals. International Journal of Research in Marketing, 32(1), 64-77.

Vanclay, J. K. (2013). Factors affecting citation rates in environmental science. Journal of Informetrics, 7(2), 265-271.

Vergara, Sylvia Constant. (2015). Métodos de pesquisa em administração. 6. ed. São Paulo, Atlas.

Webxtool. (2016). Disponível em: <http://webxtool.com/pt/ferramentas-seo/contadorde-palavras>. Acesso em: 15 dez. 2016.

Wooldridge, J. M. (2010). Introdução à econometria: uma abordagem moderna. Cengage Learning. 


\section{APÊNDICES}

\section{Apêndice A - Pesquisas sobre o uso do Google Acadêmico}

\begin{tabular}{|c|c|}
\hline Pesquisa & Resultados \\
\hline $\begin{array}{l}\text { Jacso } \\
(2005)\end{array}$ & $\begin{array}{l}\text { Comparação entre WoS, Scopus e Google Scholar. Coleta de dados em abril e maio } \\
\text { de } 2005 \text { com artigos de biblioteconomia e ciência da informação. O Google Scholar } \\
\text { recuperou, aproximadamente, um terço das citações do WoS e do Scopus. O autor } \\
\text { critica que o sistema não utiliza operadores de pesquisa booleana e encerra seu artigo } \\
\text { desejando a Gene Garfield um feliz aniversário. }\end{array}$ \\
\hline $\begin{array}{l}\text { Jacso } \\
(2005)\end{array}$ & $\begin{array}{l}\text { Comparação entre WoS e Google Scholar. Coleta de dados realizada em dezembro } \\
\text { de } 2004 \text { para artigos da revista Asian Pacific Journal of Allergy and Immunology. Os } \\
\text { resultados apontaram que, embora o Google Scholar tenha recuperado } 680 \text { e o WoS } \\
\text { recuperado } 675 \text {, o Google Scholar identificou } 595 \text { citações e o WoS identificou 1355, } \\
\text { ou seja, pouco menos da metade. }\end{array}$ \\
\hline $\begin{array}{l}\text { Noruzi } \\
(2005)\end{array}$ & $\begin{array}{l}\text { Comparação entre o WoS e o Google Scholar. Coleta de dados em setembro de 2005, } \\
\text { usando operadores booleanos. O autor aponta que o Google recuperou } 50 \% \text { mais } \\
\text { citações que o WoS, mas alerta que o Google Scholar não realizava pesquisas em } \\
\text { idiomas que usam letras chinesas, persas, árabes ou japonesas. }\end{array}$ \\
\hline $\begin{array}{l}\text { Pauly e } \\
\text { Stergiou } \\
(2005)\end{array}$ & $\begin{array}{l}\text { Comparação entre o WoS e o Google Scholar. Comparação de } 114 \text { artigos de } 11 \text { áreas } \\
\text { do conhecimento publicados entre } 1925 \text { e } 2004 \text {. Os autores concluíram que o WoS } \\
\text { recuperou mais citações que o Google Scholar para os artigos publicados entre } 1925 \\
\text { e } 1999 \text {, mas não houve diferença significativa nas citações dos artigos publicados } \\
\text { entre } 2000 \text { e } 2004 \text {. Os autores apontam os potenciais benefícios oriundos da } \\
\text { gratuidade do Google Scholar frente ao monopólio do ISI. }\end{array}$ \\
\hline $\begin{array}{l}\text { Bakkalbasi } \\
\text { et al. } \\
\text { (2006) }\end{array}$ & $\begin{array}{l}\text { Comparação entre WoS, Scopus e Google Scholar. Coleta de dados realizada entre } 7 \\
\text { e } 12 \text { de novembro de } 2005 \text { para artigos das áreas de oncologia e física da matéria } \\
\text { condensada publicados em } 1993 \text { e } 2003 \text {. O WoS recuperou mais citações na área de } \\
\text { física matéria condensada e para artigos de oncologia publicados em 1993. O Scopus } \\
\text { recuperou mais citações para artigos de oncologia de 2003. O Google Scholar foi o } \\
\text { que recuperou menos citações. }\end{array}$ \\
\hline $\begin{array}{l}\text { Kousha e } \\
\text { Thelwall } \\
\text { (2007) }\end{array}$ & $\begin{array}{l}\text { Comparação entre o Google Web/URL, o Google Scholar e o WoS. Coleta de dados } \\
\text { em setembro e outubro de } 2005 \text {. Existe uma ampla correlação entre as citações do } \\
\text { Google Scholar e do WoS. O Google Scholar é uma ferramenta possivelmente mais } \\
\text { adequada para análise de citações em ciências sociais que em ciências duras. }\end{array}$ \\
\hline $\begin{array}{l}\text { Meho \& } \\
\text { Yang } \\
(2007)\end{array}$ & $\begin{array}{l}\text { Comparação entre WoS, Scopus e Google Scholar. Coleta de dados em março de } \\
2006, \text { com } 30 \text { artigos da Current Science. Os autores afirmam que o Google Scholar } \\
\text { se destaca na cobertura de anais de eventos e jornais de idioma diferente do inglês, } \\
\text { aumentando significativamente as taxas de citação, mas criticam severamente a baixa } \\
\text { usabilidade do buscador. }\end{array}$ \\
\hline $\begin{array}{l}\text { Schroeder } \\
(2007)\end{array}$ & $\begin{array}{l}\text { Comparação entre WoS e Google Scholar em termos de recursos e capacidade de } \\
\text { cobertura. O autor conclui que o WoS apresenta como vantagens o fato de cobrir mais } \\
\text { revistas de prestígio e ferramentas de busca avançada enquanto o Google Scholar } \\
\text { cobre uma área maior de anais de eventos, livros e outros formatos de reportes de } \\
\text { pesquisa, de cobrir pesquisas em idioma não-inglês e recuperar mais citações. }\end{array}$ \\
\hline $\begin{array}{l}\text { Bar-Ilan } \\
(2008)\end{array}$ & $\begin{array}{l}\text { Comparação entre WoS, Scopus e Google Scholar. Coleta de dados realizada em } \\
\text { novembro de } 2006 \text { para o índice H de } 40 \text { pesquisadores israelenses. A autora } \\
\text { identificou que a diferença da capacidade de recuperação de citações para cálculo do } \\
\text { índice } \mathrm{H} \text { entre o Google Scholar e as demais bases varia conforme a área. O índice H } \\
\text { do Google Scholar para áreas de matemática e computação é } 30 \% \text { maior que nas } \\
\text { demais bases, enquanto que na área de física de alta energia é } 30 \% \text { menor. }\end{array}$ \\
\hline $\begin{array}{l}\text { Kousha e } \\
\text { Thelwall } \\
\text { (2008) }\end{array}$ & $\begin{array}{l}\text { Comparação entre o WoS e Google Scholar. Coleta de dados em janeiro de } 2006 \text {, por } \\
\text { duas pessoas. Os autores identificaram que o Google Scholar cobre uma variedade } \\
\text { de documentos mais ampla e por isso recupera taxas de citações superiores, para } \\
\text { artigos publicados em revistas de acesso aberto e, ainda, afirmam que essa amplitude } \\
\text { da cobertura Open Access pode impulsionar o movimento de acesso aberto. }\end{array}$ \\
\hline $\begin{array}{l}\text { Bornmann } \\
\text { et al. } \\
\text { (2009) }\end{array}$ & $\begin{array}{l}\text { Comparação entre Google Scholar, WoS, Scopus e Chemical Abstracts. Data e prazo } \\
\text { de coleta de dados incerta. Os autores apontam que as taxas de citação do SCI, } \\
\text { Scopus e Chemical Abstracts são muito similares entre si e diferentes das taxas do }\end{array}$ \\
\hline
\end{tabular}




\begin{tabular}{|c|c|}
\hline & $\begin{array}{l}\text { Google Scholar e fazem coro às críticas de Jacso (2004) de que o Google Scholar } \\
\text { "faz um trabalho realmente horrível de conexão entre artigos citantes e artigos citados". }\end{array}$ \\
\hline $\begin{array}{l}\text { Kulkarni et } \\
\text { al. (2009) }\end{array}$ & $\begin{array}{l}\text { Comparação entre WoS, Scopus e Google Scholar. Coleta de dados em } 2 \text { de junho de } \\
2008 \text { com } 328 \text { artigos de medicina, por quatro pessoas. Scopus e Google Scholar } \\
\text { recuperaram taxas maiores de citações que o WoS. A precisão na busca de citações } \\
\text { pelo Google Scholar foi levemente menor que as demais. O Google Scholar cobre } \\
\text { livros, dissertações e teses, e revistas de acesso aberto. }\end{array}$ \\
\hline $\begin{array}{l}\text { Martell } \\
(2009)\end{array}$ & $\begin{array}{l}\text { Comparação entre Yahoo, Google, Google Scholar e WoS. Coleta de dados no verão } \\
\text { e outono de } 2007 \text { de } 217 \text { artigos publicados entre } 2000 \text { e } 2006 \text { na revista College \& } \\
\text { Research Libraries. O autor aponta que o Yahoo e Google não possuem motores de } \\
\text { busca adequados para recuperar citações. Por outro lado, o Google Scholar recuperou } \\
\text { uma taxa média de citações para os artigos maior que o dobro da taxa recuperada } \\
\text { pelo WoS. }\end{array}$ \\
\hline $\begin{array}{l}\text { Onyancha } \\
\text { (2009) }\end{array}$ & $\begin{array}{l}\text { Estabelece uma complexa avaliação dos periódicos da África Subsaariana. O autor } \\
\text { critica que os métodos tradicionais de análise de citaçóes do ISI não podem ser } \\
\text { utilizados para esses periódicos porque a maioria dos periódicos em questão não estão } \\
\text { indexados no ISI, e a maioria das instituições africanas não pode pagar as altas taxas } \\
\text { de assinatura do ISI. O autor concluiu que o Google Scholar permitiu a comparação do } \\
\text { impacto de revistas que o ISI não cobre, permitindo uma análise com o software } \\
\text { Publish or Perish que seria inviável de outra maneira. Sobre as restrições do Google } \\
\text { Scholar, o autor as classifica como "retificáveis". }\end{array}$ \\
\hline $\begin{array}{l}\text { Bar-Ilan } \\
(2010)\end{array}$ & $\begin{array}{l}\text { Comparação entre WoS, Scopus e Google Scholar. Coleta de dados em } 22 \text { de março } \\
\text { de } 2008 \text { usando um único título: o livro 'Introduction to Infometrics'. O WoS e o Scopus } \\
\text { cobriram aproximadamente } 90 \% \text { das citações recuperadas um pelo outro. O Google } \\
\text { Scholar cobriu } 30 \% \text { menos que as citações encontradas pelos demais, porém } \\
\text { encontrou } 108 \text { citações que não haviam sido encontradas pelos demais, o que } \\
\text { representa um acréscimo de } 30 \% \text { de citações não catalogadas pelos demais. A autora } \\
\text { alerta ainda para a baixa usabilidade do buscador. }\end{array}$ \\
\hline $\begin{array}{l}\text { Garcia- } \\
\text { Perez } \\
\text { (2010) }\end{array}$ & $\begin{array}{l}\text { Comparação entre WoS, Psyclnfo e Google Scholar. Coleta de dados em outubro e } \\
\text { novembro de } 2009 \text {, artigos de quatro psicólogos espanhóis. Em ordem decrescente de } \\
\text { recuperação de volume de citações estão: Google Scholar, Psyclnfo e WoS. O autor } \\
\text { identificou citações incorretas na ordem de } 0,3 \% \text { no WoS, 1,1\% no Psyclnfo e } 16,5 \% \\
\text { no Google Scholar. }\end{array}$ \\
\hline $\begin{array}{l}\text { Mingers \& } \\
\text { Lipitakis } \\
(2010)\end{array}$ & $\begin{array}{l}\text { Comparação entre WoS e Google Scholar na área de negócios e gestão. Coleta de } \\
\text { dados de três faculdades de negócios inglesas. Os autores identificaram que WoS não } \\
\text { recupera nem metade das revistas, artigos e citações recuperados pelo Google } \\
\text { Scholar. Todavia, os autores alertam para a confiabilidade e a falta de transparência } \\
\text { do Google Scholar. }\end{array}$ \\
\hline $\begin{array}{l}\text { Sanni e } \\
\text { Zainab } \\
(2010)\end{array}$ & $\begin{array}{l}\text { Desenvolve uma avaliação das citações do Medical Journal of Malaysia. Os autores } \\
\text { identificaram que o Google se mostrou uma alternativa viável para análise de citações } \\
\text { mais ampla e menos restritiva que o ISI (WoS). }\end{array}$ \\
\hline $\begin{array}{l}\text { Sember, } \\
\text { Marijan e } \\
\text { Petrak } \\
(2010)\end{array}$ & $\begin{array}{l}\text { Comparação entre WoS, Scopus e Google Scholar. Coleta de dados feita entre os } \\
\text { meses de janeiro e março de } 2009 \text { dos artigos do Croatian Medical Journal. Em ordem } \\
\text { crescente de recuperação de citações: WoS, Scopus e Google Scholar. O Google } \\
\text { Scholar recuperou } 22 \% \text { de citações únicas, não recuperadas pelos demais sistemas. }\end{array}$ \\
\hline $\begin{array}{l}\text { Amara e } \\
\text { Landry } \\
(2012)\end{array}$ & $\begin{array}{l}\text { Comparação entre WoS e Google Scholar na área de negócios e gestão. Coleta de } \\
\text { dados de } 1.286 \text { pesquisadores canadenses da área de negócios entre abril e junho de } \\
2010 \text {. Os autores concluíram que a abrangência do Google Scholar é muito superior a } \\
\text { do WoS mas que, apesar disso, havia uma forte correspondência entre os autores } \\
\text { mais citados no Google Scholar com os autores citados no WoS. }\end{array}$ \\
\hline $\begin{array}{l}\text { Bergman } \\
(2012)\end{array}$ & $\begin{array}{l}\text { Comparação entre WoS, Scopus e Google Scholar. Os resultados mostraram que o } \\
\text { WoS recuperou a menor taxa de citação seguida de perto pelo Scopus. O Google } \\
\text { Scholar recuperou uma taxa de citação substancialmente superior aos anteriores, mas } \\
\text { os autores afirmam que o Google Scholar pode não ser tão confiável quanto os demais. }\end{array}$ \\
\hline $\begin{array}{l}\text { Harzing } \\
\text { (2013) }\end{array}$ & $\begin{array}{l}\text { Comparação entre WoS e Google Scholar. Analisou a estabilidade, abrangência e } \\
\text { imparcialidade do Google Scholar por meio de um estudo longitudinal das citações de } \\
20 \text { laureados com o prêmio Nobel em química, economia, medicina e física. Coleta de } \\
\text { dados em abril e setembro de } 2011 \text { e janeiro de } 2012 \text {. A autora apontou que o Google } \\
\text { Scholar mostrou estabilidade e abrangência. A taxa de erro na recuperação de artigos } \\
\text { foi de } 0,5 \% \text {. }\end{array}$ \\
\hline
\end{tabular}




\begin{tabular}{|l|l|}
\hline $\begin{array}{l}\text { Delgado- } \\
\text { López- } \\
\text { Cózar e } \\
\text { Cabezas- } \\
\text { Clavijo } \\
(2013)\end{array}$ & $\begin{array}{l}\text { Comparação entre o Google Scholar Metrics, o JCR e o Scimago journal rank. Dados } \\
\text { coletados em janeiro de 2013. Os autores concluem que, mesmo com baixa } \\
\text { transparência acerca da cobertura do Google Scholar, ele ordena as pesquisas de } \\
\text { forma muito similar aos demais buscadores e que, provavelmente, o recurso será o } \\
\text { maior concorrente das versões pagas. }\end{array}$ \\
\hline $\begin{array}{l}\text { Chan et al. } \\
(2013)\end{array}$ & $\begin{array}{l}\text { Analisa o desempenho de 23 revistas, usando Scholar Google. Coleta de dados, entre } \\
\text { julho e setembro de 2011, de 23 periódicos de finanças. Os autores identificaram que } \\
\text { revistas de alto fator de impacto tendem a apresentar mediana de citações alta e taxas } \\
\text { de artigos não citados baixa, grande proporção de artigos de líderes acadêmicos e } \\
\text { que, em geral, membros do corpo editorial têm alto impacto nas citações. Os autores } \\
\text { ainda identificaram que o topo do ranking de revistas, construído com base do Google } \\
\text { Scholar, é similar ao dos rankings desenvolvidos em outras pesquisas. }\end{array}$ \\
\hline $\begin{array}{l}\text { Ortega \& } \\
\text { Aguillo } \\
(2014)\end{array}$ & $\begin{array}{l}\text { Comparação entre o Microsoft Academic Search e Google Scholar Citations. Coleta } \\
\text { de dados em junho de 2012. O Google Scholar Citations abrange mais documentos e } \\
\text { citações que o Microsoft Academic Search, mas possui um viés mais forte na área de } \\
\text { informática e ciências da computação, enquanto o Microsoft Academic Search } \\
\text { apresentou mais equilíbrio entre áreas. Por outro lado, o Microsoft Academic Search } \\
\text { apresenta problemas de duplicação de perfis e menor taxa de atualização. }\end{array}$ \\
\hline
\end{tabular}

Figura 41 - Pesquisas sobre o uso do Google Acadêmico 
Apêndice B - Relação entre número de citações e número de termos no título do artigo

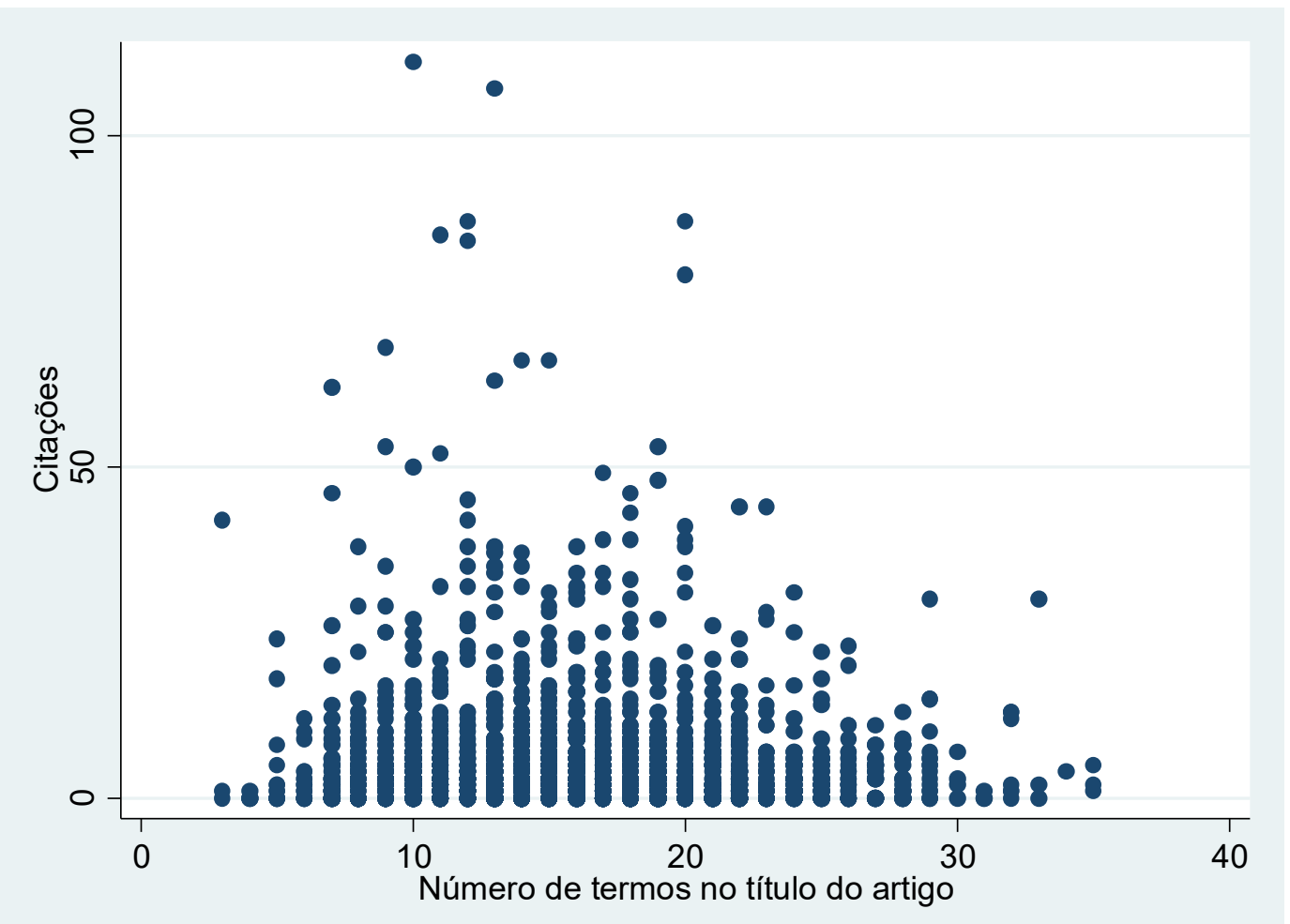

Figura 42 - Relação entre número de citações e número de termos no título do artigo 
Apêndice C - Relação entre número de citações e número de termos nas palavras-chave

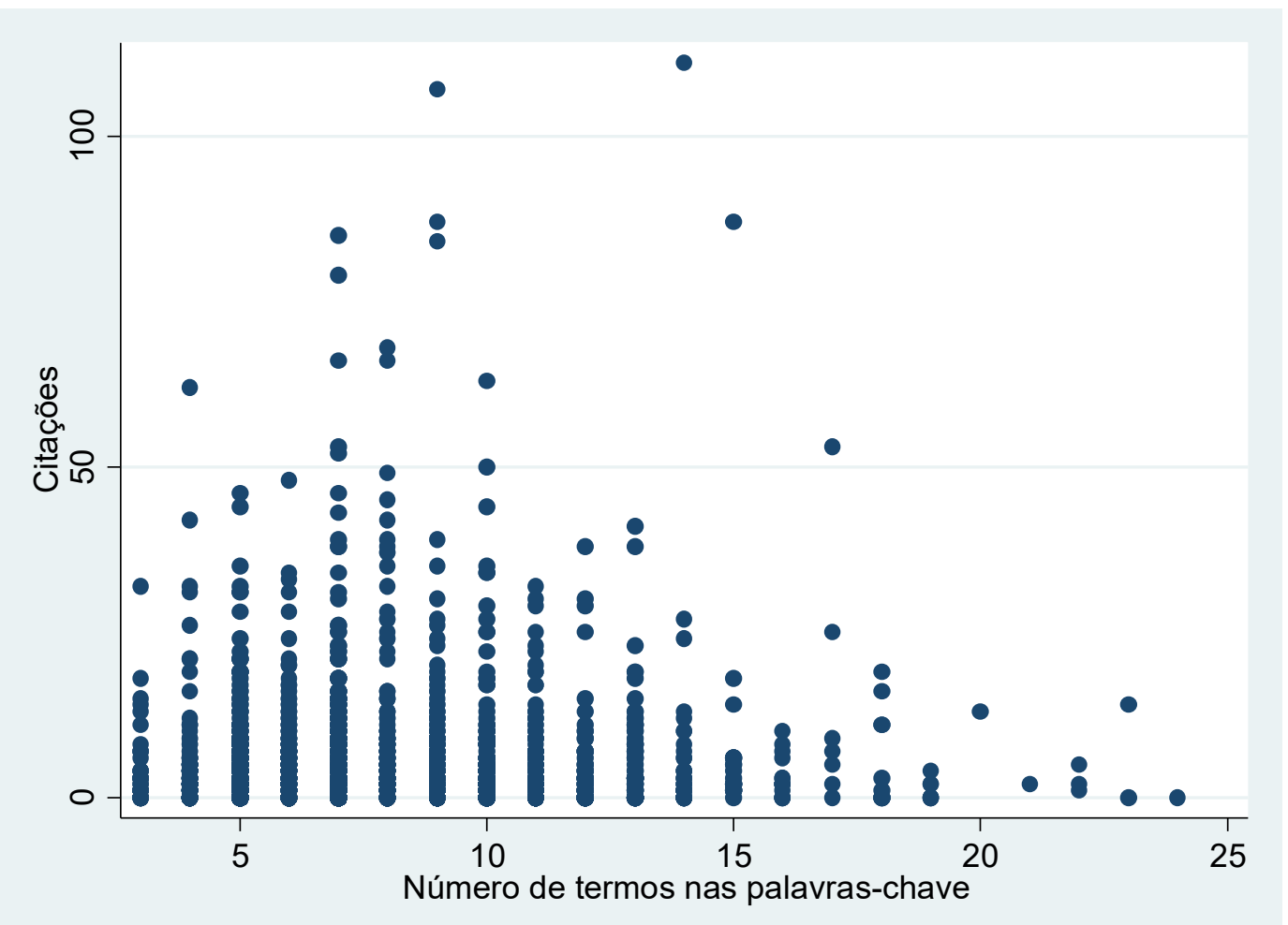

Figura 43 - Relação entre número de citações e número de termos nas palavras-chave 
Apêndice $D$ - Relação entre número de citações e número de páginas

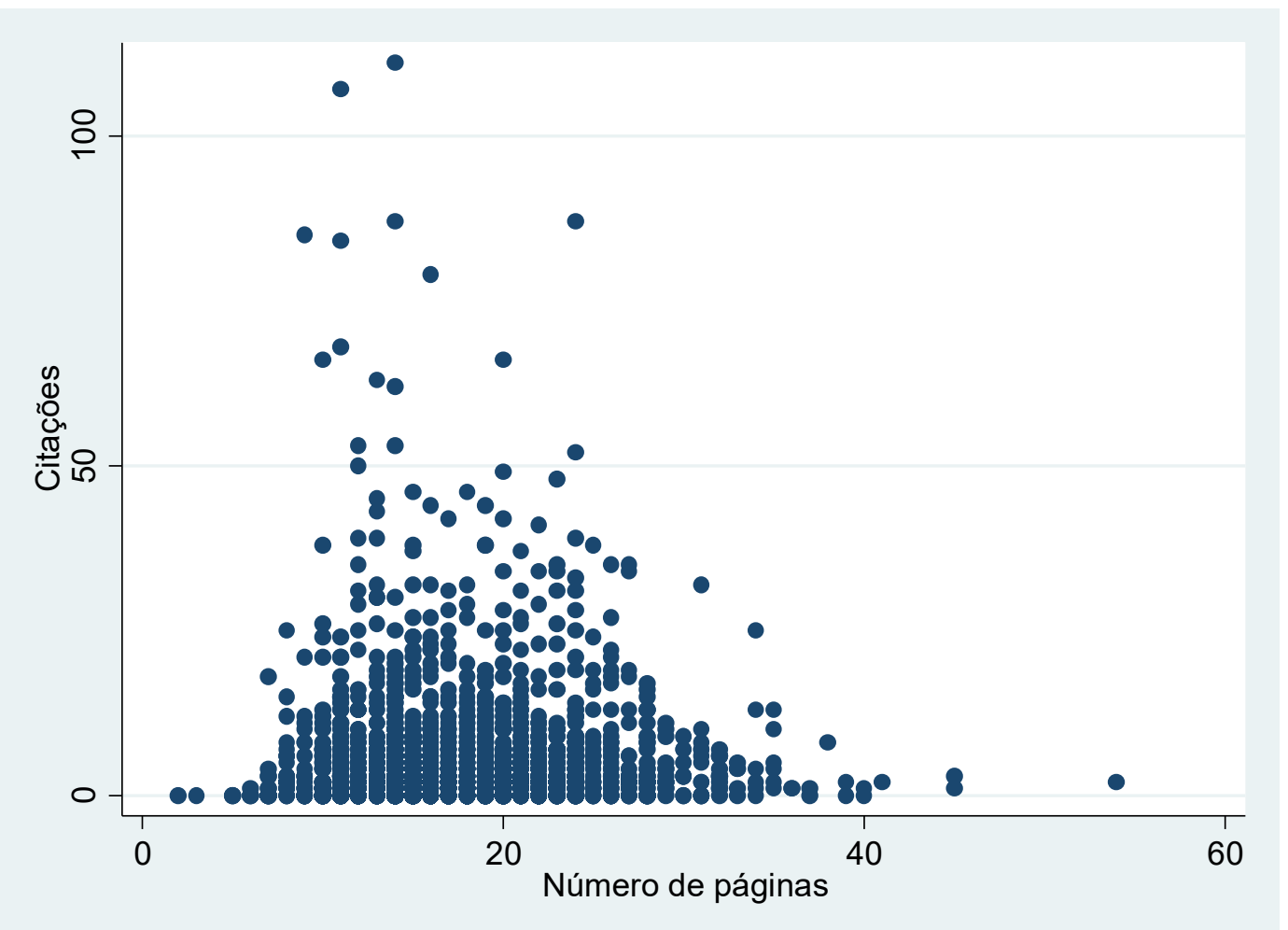

Figura 44 - Relação entre número de citações e número de páginas 
Apêndice E - Relação entre número de citações e número de referências

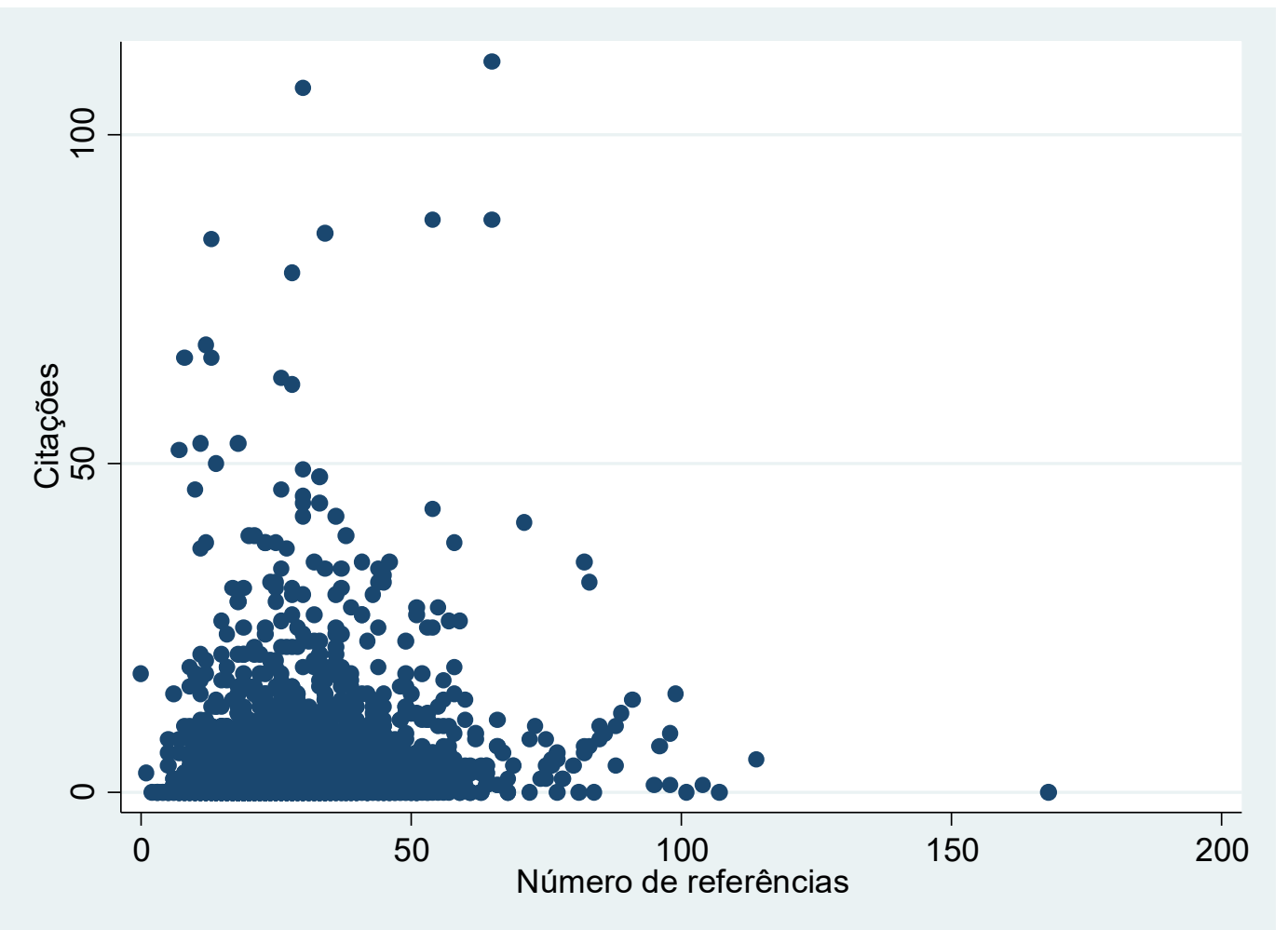

Figura 45 - Relação entre número de citações e número de referências 
Apêndice F - Relação entre número de citações e número de autores

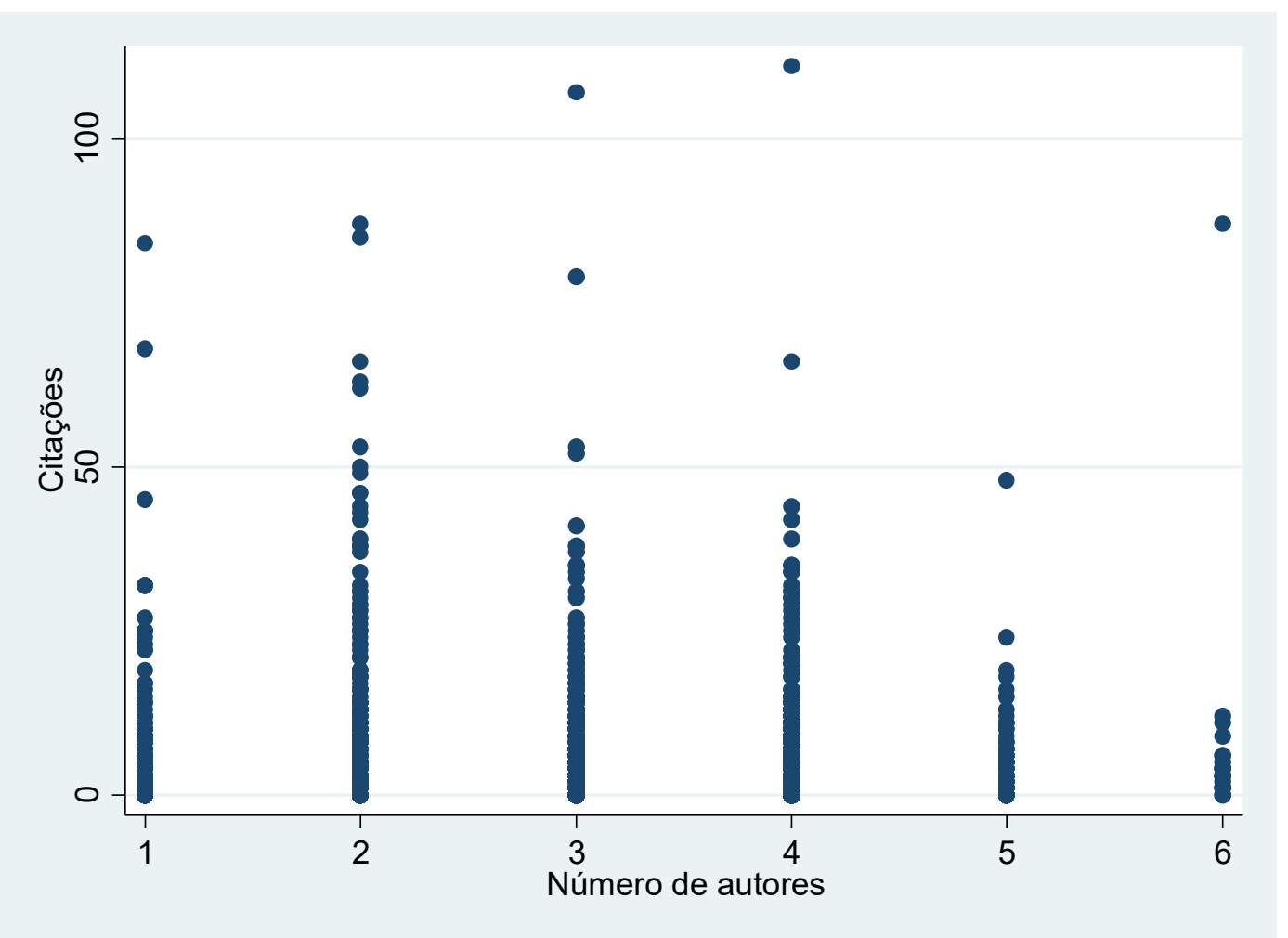

Figura 46 - Relação entre número de citações e número de autores 
Apêndice G - Relação entre número de citações e proporção de autoras

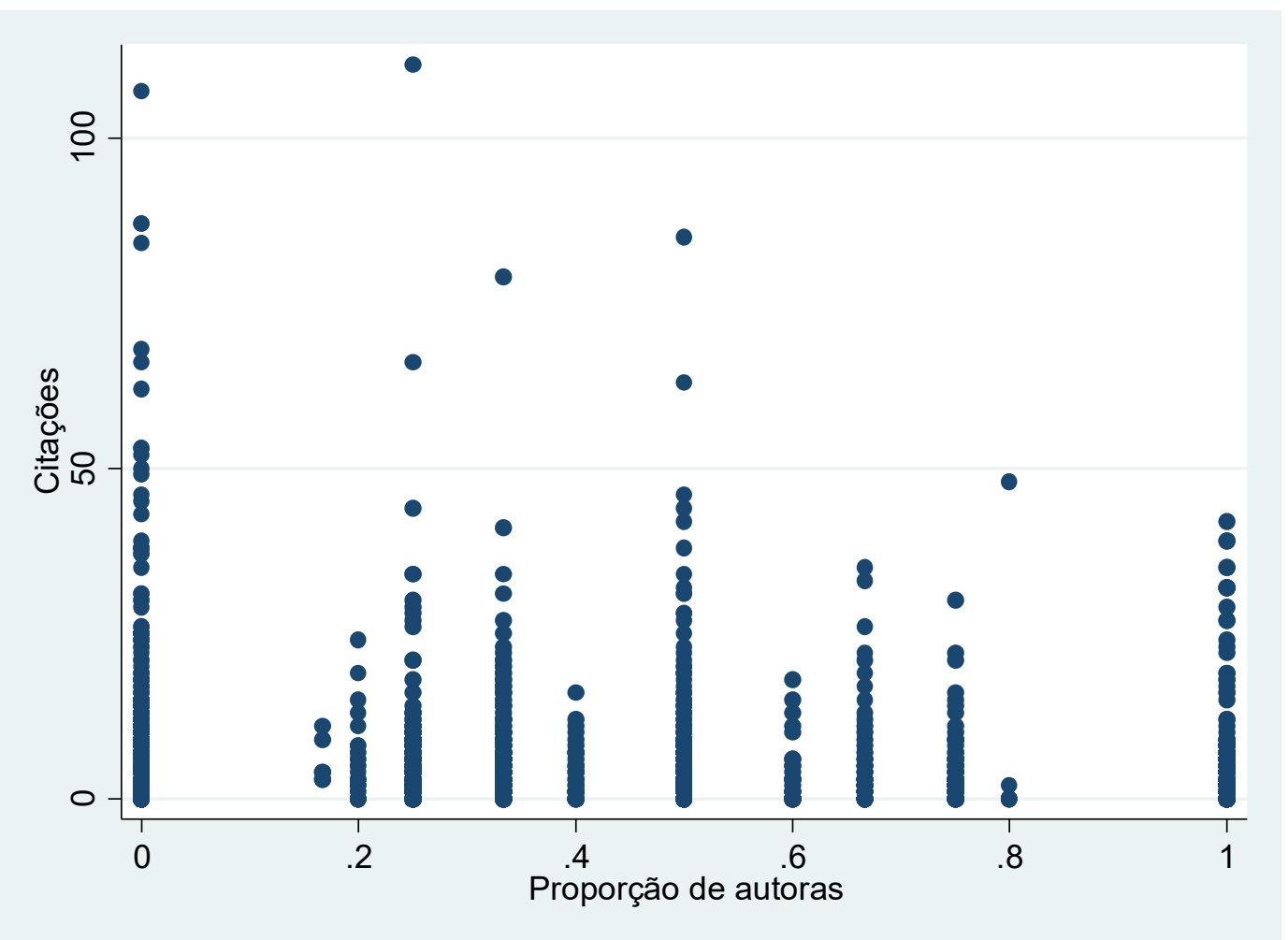

Figura 47 - Relação entre número de citações e proporção de autoras 
Apêndice H - Relação entre número de citações e idade da revista

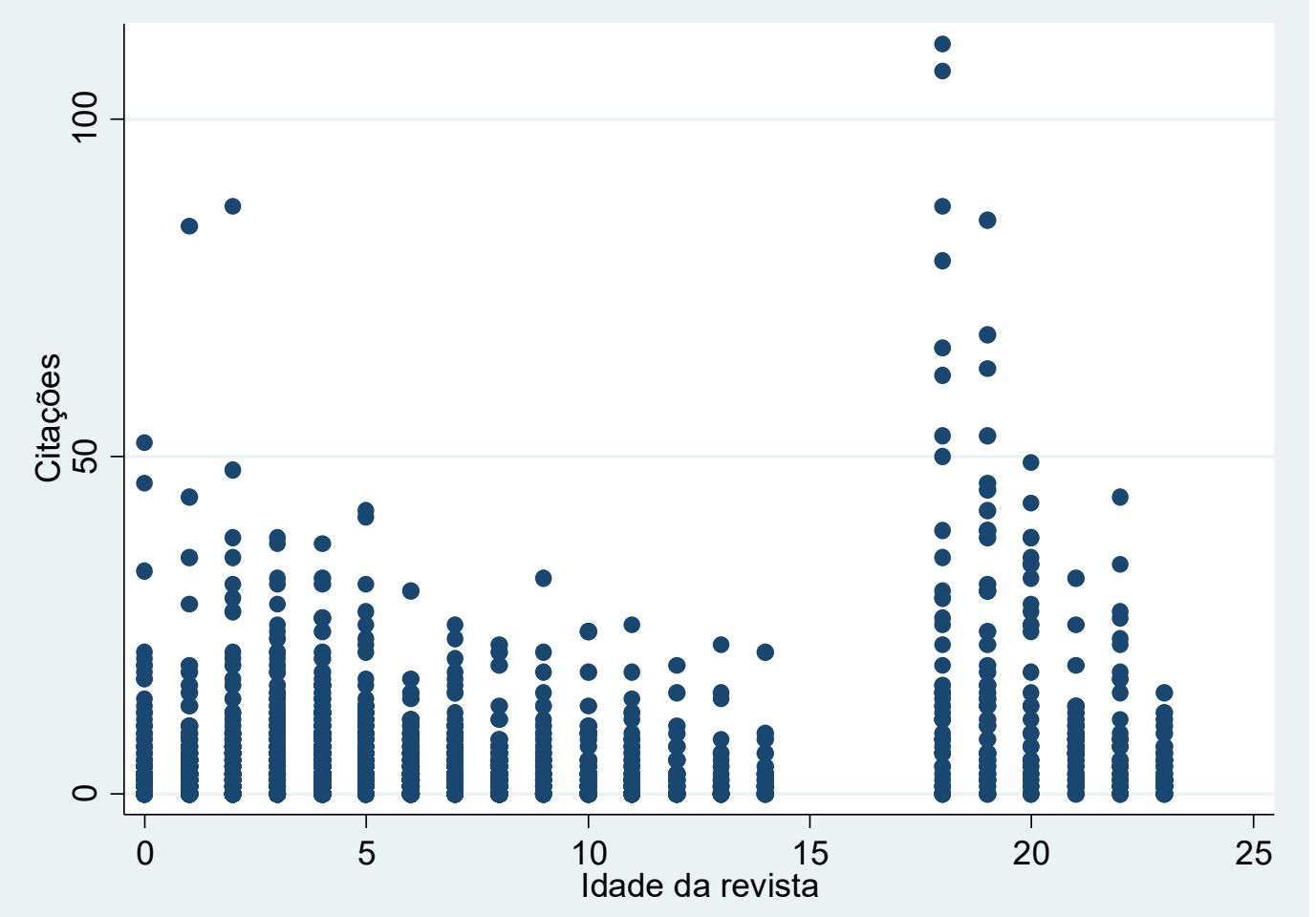

Figura 48 - Relação entre número de citações e idade da revista 
Apêndice I - Média de citações dos artigos por revista, por ano

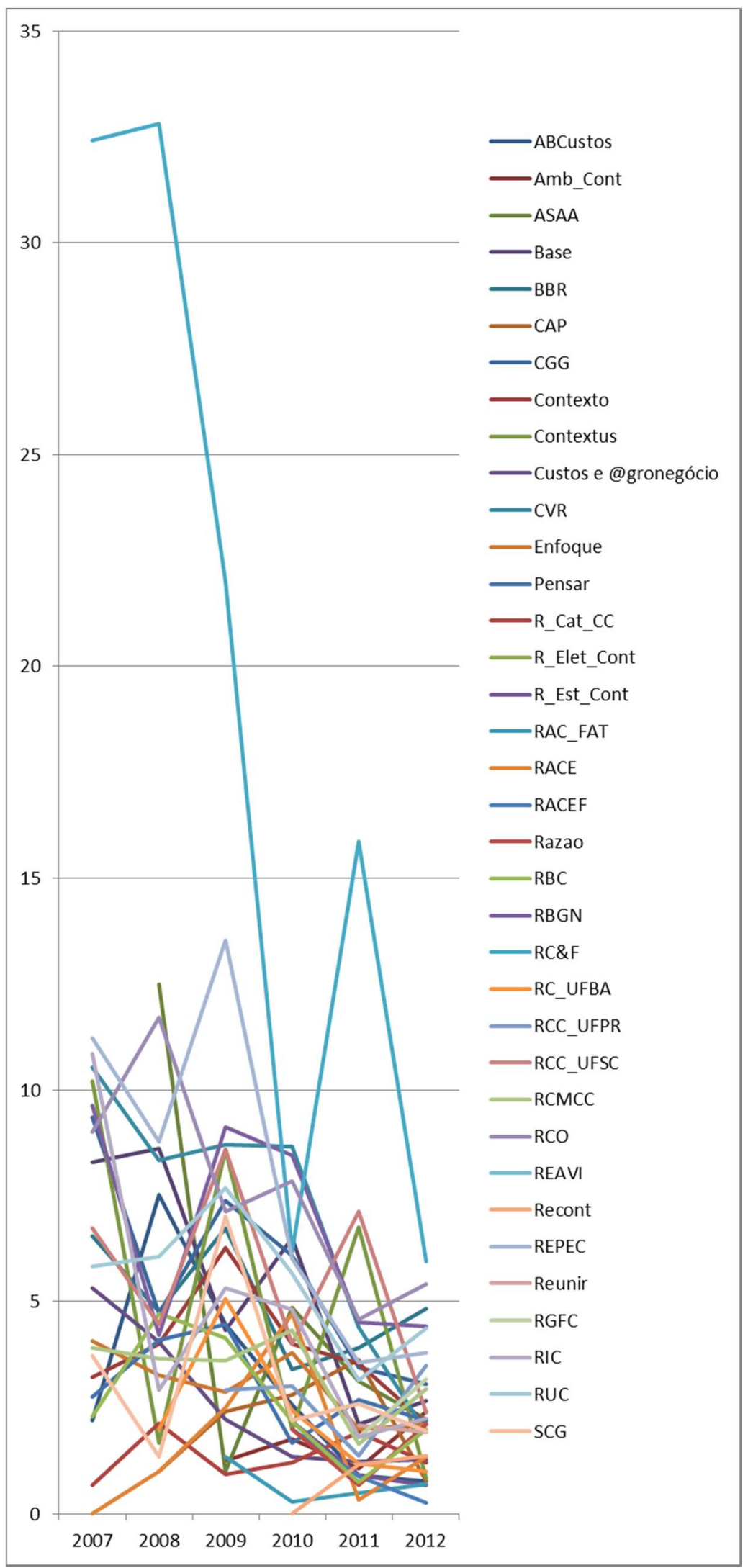

Figura 49 - Média de citações dos artigos por revista, por ano 
Apêndice $\mathrm{J}$ - Média de citações dos artigos por IES do $1^{\circ}$ autor, por ano

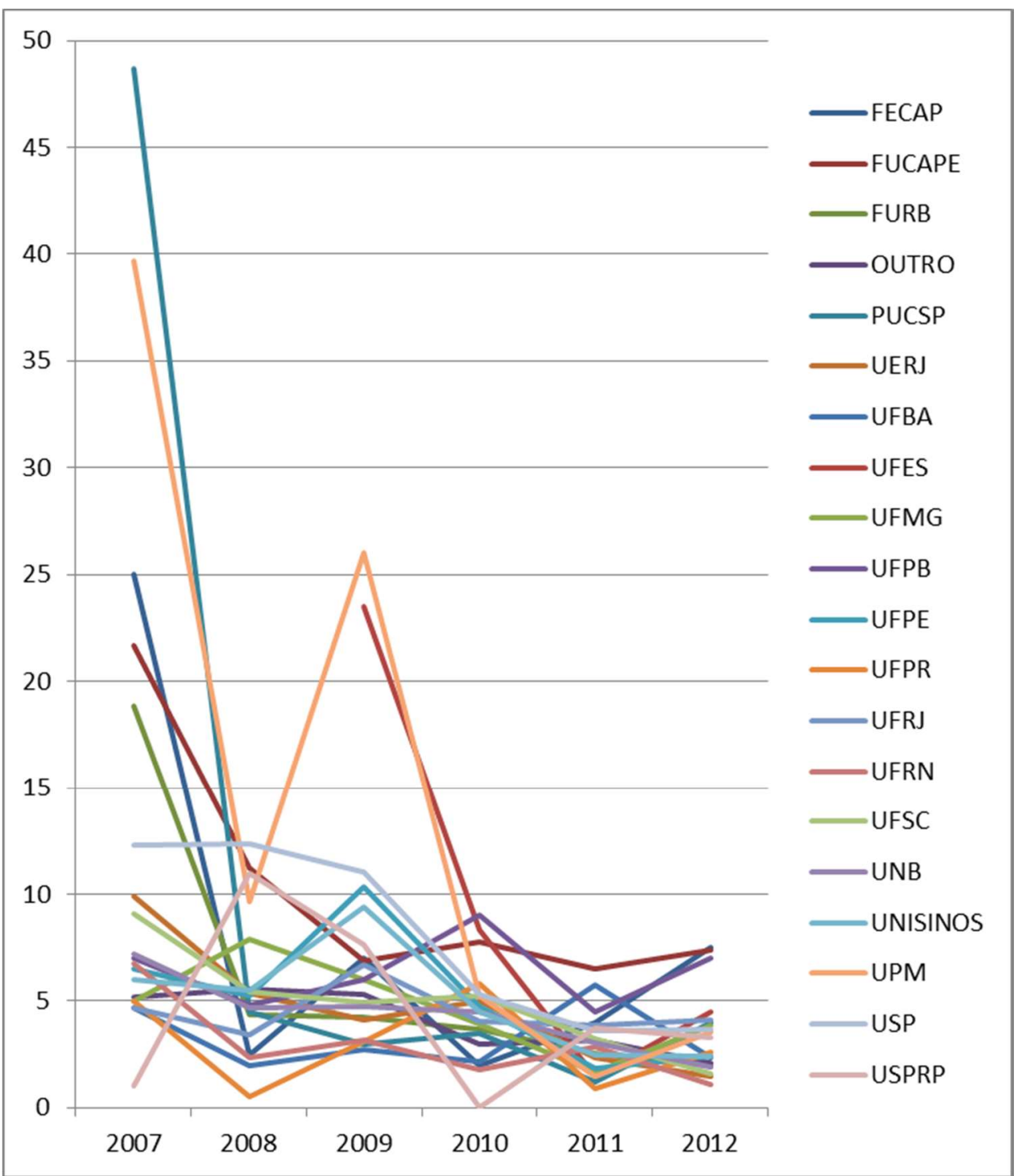

Figura 50 - Média de citações dos artigos por IES do $1^{\circ}$ autor, por ano 


\section{Apêndice K - Saídas do Stata do Modelo 1 - Com todas as variáveis}

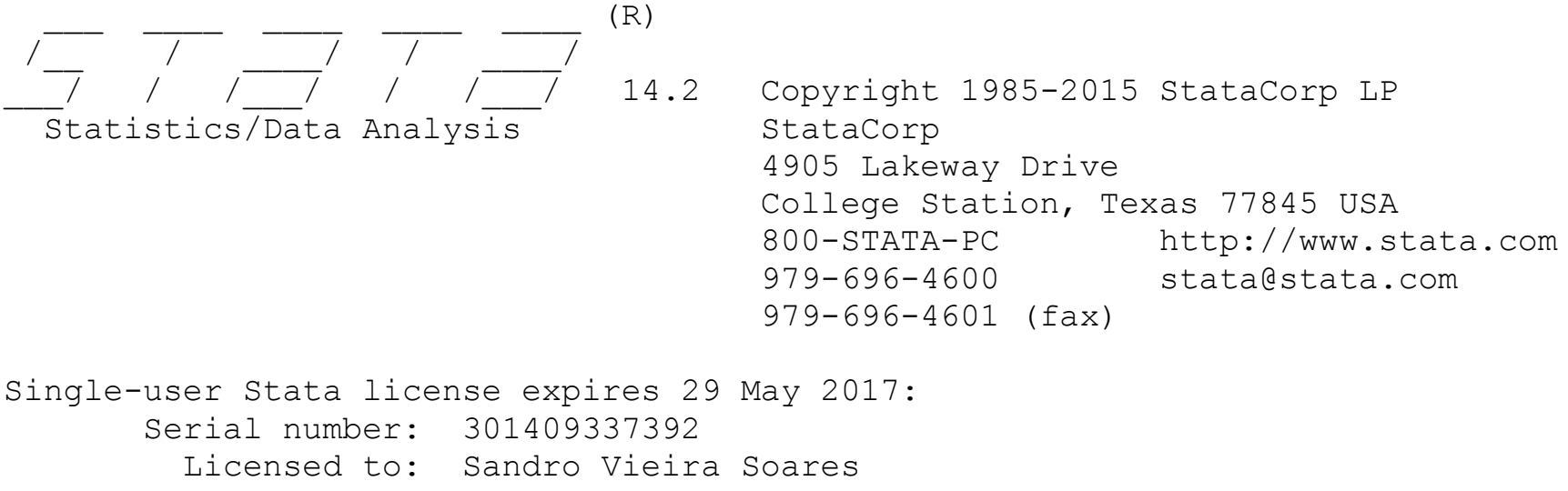

Notes:

1. Unicode is supported; see help unicode_advice.

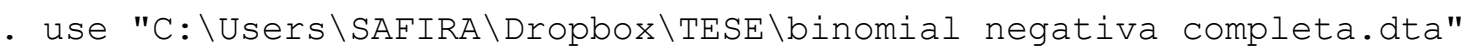

- desc

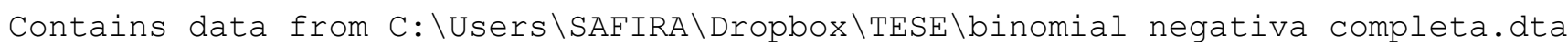
obs: $\quad 2,540$

vars: $\quad 21$

size: $\quad 200,660$

29 Jan $2017 \quad 16: 45$

\begin{tabular}{|c|c|c|c|c|}
\hline \multicolumn{2}{|c|}{ storage } & \multicolumn{2}{|c|}{ display value } & variable label \\
\hline \multirow{2}{*}{\multicolumn{5}{|c|}{ 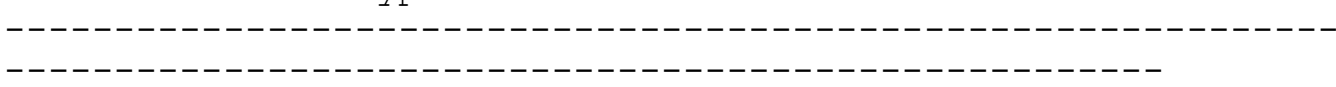 }} \\
\hline & & & & \\
\hline n_de_controle & int & $\div 8.0 \mathrm{~g}$ & & $\mathrm{~N}$ de_Controle \\
\hline cītacoes & int & $\div 8.0 \mathrm{~g}$ & & cītacoes \\
\hline criacao & int & $\div 8.0 \mathrm{~g}$ & & Criacao \\
\hline n_p_tit & byte & $\div 8.0 \mathrm{~g}$ & & N_p_Tit \\
\hline n_p_p_chave & byte & $\div 8.0 \mathrm{~g}$ & & N_p_p_chave \\
\hline n_pag & byte & $\div 8.0 \mathrm{~g}$ & & N_pag \\
\hline n_ref & int & $\div 8.0 \mathrm{~g}$ & & N_Ref \\
\hline n autores & byte & $\div 8.0 \mathrm{~g}$ & & $\mathrm{~N}^{-}$autores \\
\hline n_mulheres & byte & $\div 8.0 \mathrm{~g}$ & & $\mathrm{~N}^{-}$mulheres \\
\hline prop_mulher & float & $\div 8.0 \mathrm{~g}$ & & Prop mulher \\
\hline idade & byte & $\div 8.0 \mathrm{~g}$ & & Idade \\
\hline revista & str20 & $\div 20 \mathrm{~s}$ & & Revista \\
\hline anod & str 4 & $\div 9 s$ & & Ano \\
\hline ord_ou_esp & str3 & $\div 9 s$ & & Ord_ou_Esp \\
\hline posícao & str3 & $\div 9 s$ & & Posicao \\
\hline gen_1_autor & str3 & $\div 9 s$ & & Gen_1_autor \\
\hline tit_1_autor & $\operatorname{str} 9$ & $\div 9 s$ & & Tit_1_autor \\
\hline ies_1_autor & str 8 & $\div 9 s$ & & IES-1_autor \\
\hline $\operatorname{are\overline {a}}-$ & str 3 & $\div 9 s$ & & Areā - \\
\hline qualis vigente & str2 & $\div 9 s$ & & Qualis vigente \\
\hline abordagem & str 6 & $\div 9 s$ & & Abordaḡem \\
\hline
\end{tabular}

Sorted by:

- tab citacoes 


\begin{tabular}{|c|c|c|c|c|}
\hline Citacoes & | & Freq. & Percent & Cum. \\
\hline-- & + & ---- & -------- & ------ \\
\hline 0 & | & 699 & 27.52 & 27.52 \\
\hline 1 & | & 356 & 14.02 & 41.54 \\
\hline 2 & | & 286 & 11.26 & 52.80 \\
\hline 3 & | & 244 & 9.61 & 62.40 \\
\hline 4 & | & 165 & 6.50 & 68.90 \\
\hline 5 & | & 128 & 5.04 & 73.94 \\
\hline 6 & | & 109 & 4.29 & 78.23 \\
\hline 7 & | & 93 & 3.66 & 81.89 \\
\hline 8 & | & 65 & 2.56 & 84.45 \\
\hline 9 & | & 61 & 2.40 & 86.85 \\
\hline 10 & | & 45 & 1.77 & 88.62 \\
\hline 11 & | & 35 & 1.38 & 90.00 \\
\hline 12 & i & 27 & 1.06 & 91.06 \\
\hline 13 & | & 28 & 1.10 & 92.17 \\
\hline 14 & | & 17 & 0.67 & 92.83 \\
\hline 15 & | & 18 & 0.71 & 93.54 \\
\hline 16 & | & 15 & 0.59 & 94.13 \\
\hline 17 & | & 9 & 0.35 & 94.49 \\
\hline 18 & | & 13 & 0.51 & 95.00 \\
\hline 19 & | & 12 & 0.47 & 95.47 \\
\hline 20 & | & 5 & 0.20 & 95.67 \\
\hline 21 & i & 10 & 0.39 & 96.06 \\
\hline 22 & | & 6 & 0.24 & 96.30 \\
\hline 23 & | & 5 & 0.20 & 96.50 \\
\hline 24 & i & 6 & 0.24 & 96.73 \\
\hline 25 & I & 8 & 0.31 & 97.05 \\
\hline 26 & 1 & 4 & 0.16 & 97.20 \\
\hline 27 & | & 5 & 0.20 & 97.40 \\
\hline 28 & | & 3 & 0.12 & 97.52 \\
\hline 29 & | & 3 & 0.12 & 97.64 \\
\hline 30 & i & 4 & 0.16 & 97.80 \\
\hline 31 & | & 5 & 0.20 & 97.99 \\
\hline 32 & | & 5 & 0.20 & 98.19 \\
\hline 33 & i & 1 & 0.04 & 98.23 \\
\hline 34 & | & 4 & 0.16 & 98.39 \\
\hline 35 & | & 4 & 0.16 & 98.54 \\
\hline 37 & i & 2 & 0.08 & 98.62 \\
\hline 38 & | & 5 & 0.20 & 98.82 \\
\hline 39 & 1 & 3 & 0.12 & 98.94 \\
\hline 41 & i & 1 & 0.04 & 98.98 \\
\hline 42 & | & 2 & 0.08 & 99.06 \\
\hline 43 & | & 1 & 0.04 & 99.09 \\
\hline 44 & | & 2 & 0.08 & 99.17 \\
\hline 45 & i & 1 & 0.04 & 99.21 \\
\hline 46 & 1 & 2 & 0.08 & 99.29 \\
\hline 48 & i & 1 & 0.04 & 99.33 \\
\hline 49 & | & 1 & 0.04 & 99.37 \\
\hline 50 & | & 1 & 0.04 & 99.41 \\
\hline 52 & i & 1 & 0.04 & 99.45 \\
\hline 53 & i & 2 & 0.08 & 99.53 \\
\hline 62 & 1 & 1 & 0.04 & 99.57 \\
\hline 63 & i & 1 & 0.04 & 99.61 \\
\hline 66 & | & 2 & 0.08 & 99.69 \\
\hline 68 & | & 1 & 0.04 & 99.72 \\
\hline 79 & | & 1 & 0.04 & 99.76 \\
\hline 84 & | & 1 & 0.04 & 99.80 \\
\hline 85 & i & 1 & 0.04 & 99.84 \\
\hline 87 & | & 2 & 0.08 & 99.92 \\
\hline 107 & | & 1 & 0.04 & 99.96 \\
\hline 111 & | & 1 & 0.04 & 100.00 \\
\hline Total & | & 2,540 & 100.00 & \\
\hline
\end{tabular}


- hist citacoes, discrete freq ( start=0, width=1)

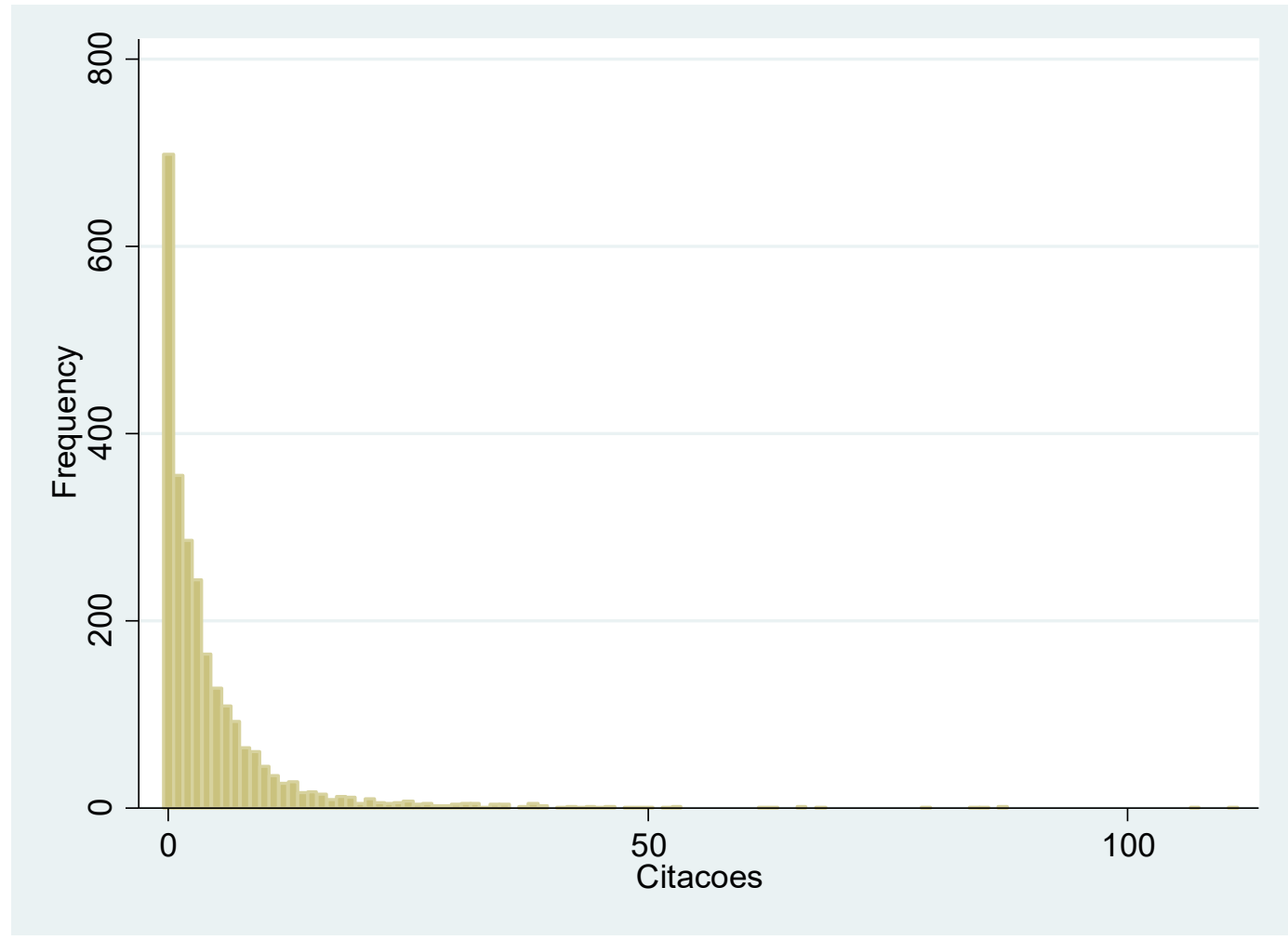

- tabstat citacoes, stats (mean var)

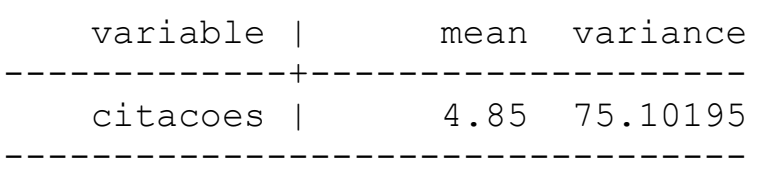

$\cdot$

- xi i.revista i.ord_ou_esp i.posicao i.gen_1_autor i.tit_1_autor i.ies_1_autor i.area i.qualis_vigente $i$.abordagem

i.revista Irevista_1-36

i.ord_ou_esp

i.posícāo

Iord_ou es 1-2

Iposīcā̄ 1-2

(_Irevista_1 for rev a==ABCustos omitted)

i.gen 1 autor

Igen 1 aút 1-2

(_Iord_ou_es_1 for ord_ou p $==E s p$ omitted)

i.tit ${ }^{-}$-autor

i.ies_1_autor

i. area

i.qualis_vige e

Itit 1 aut $1-4$

(_Iposicao_1 for posicāo==Out omitted)

-Iies_1_aut_1-20

( Igen 1 aut 1 for gen 1 r==Hom omitted)

(_Itit_1_aut_1 for tit $\sim r==$ Bacharel omitted)

Iarea $\overline{1}-6$

(_Iies_1_aut_1 for ies_ r $==$ FECAP omitted)

Iqualis_vi_1-8

( Iarea $\overline{1}$ for area $==E d \bar{u}$ omitted)

i. abordaḡem

- Iabordagem_1-2

(_Iqualis_vi_1 for qualis_ $\sim==A 2$ omitted)

(_Iabordagem_1 for abor m==Quali omitted)

.

- quietly stepwise, pr(0.05): poisson citacoes n_p_tit n_p_p_chave n_pag n_ref

n_autores prop_mulher idade_I*

.

- predict lambda

(option $\mathrm{n}$ assumed; predicted number of events) 
- gen yasterisco $=\left((\text { citacoes-lambda })^{\wedge} 2-\right.$ citacoes $) /$ lambda

- reg yasterisco lambda, nocons

$\begin{array}{rrrrrr}\text { Source | } & \text { SS } & \text { df } & \text { MS } & \text { Number of obs } & = \\ 2,540 \\ -1\end{array}$

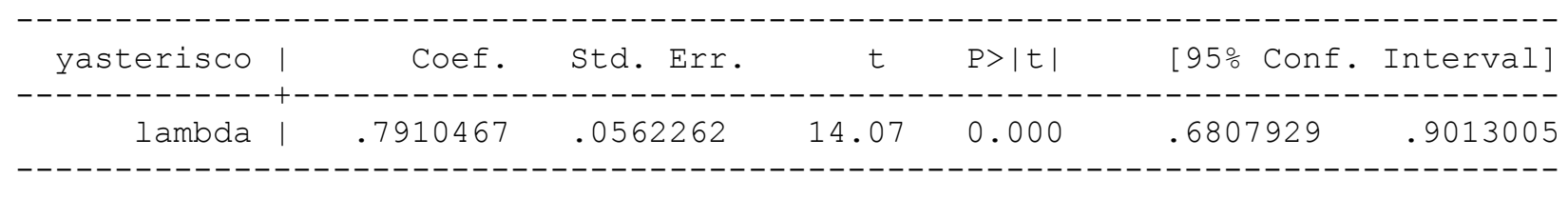

- quietly stepwise, pr(0.05): poisson citacoes n_p_tit n_p_p_chave n_pag n_ref n_autores prop_mulher idade _ I*

.

$\cdot$

- poisgof

$\begin{array}{llr}\text { Deviance goodness-of-fit } & = & 13204.58 \\ \text { Prob }>\text { chi2(2476) } & =0.0000 \\ \text { Pearson goodness-of-fit } & = & 16106.7 \\ \text { Prob }>\text { chi2(2476) } & =0.0000\end{array}$

.

$\cdot$

- stepwise, pr(0.05): nbreg citacoes n_p_tit n_p_p_chave n_pag n_ref n_autores prop_mulher idade _I*

$\mathrm{p}=0.9972>=0.0500$ begin with full model

$\mathrm{p}=0.9793>=0.0500$ removing Itit 1 aut 3

$\mathrm{p}=0.9504>=0.0500$ removing Iies_1_aut_5

$\mathrm{p}=0.9423>=0.0500$

$\mathrm{p}=0.9456>=0.0500$

$\mathrm{p}=0.9396>=0.0500$

$\mathrm{p}=0.9171>=0.0500$

$\mathrm{p}=0.8330>=0.0500$

$\mathrm{p}=0.8067>=0.0500$

$\mathrm{p}=0.7479>=0.0500$

$\mathrm{p}=0.7233>=0.0500$

$\mathrm{p}=0.7090>=0.0500$

$\mathrm{p}=0.6881>=0.0500$

$\mathrm{p}=0.7567>=0.0500$

$\mathrm{p}=0.6109>=0.0500$

$\mathrm{p}=0.5690>=0.0500$

$\mathrm{p}=0.4959>=0.0500$

$\mathrm{p}=0.4287>=0.0500$

$\mathrm{p}=0.4622>=0.0500$

$\mathrm{p}=0.4185>=0.0500$

$\mathrm{p}=0.4065>=0.0500$

$\mathrm{p}=0.3732>=0.0500$

$\mathrm{p}=0.3481>=0.0500$

$\mathrm{p}=0.3574>=0.0500$

removing Irevista_2 $\overline{8}$

removing Iies 1 aūt 15

removing ${ }^{-}$Iies ${ }^{-}$aut 13

removing - Itit_ ${ }^{-}{ }^{-}$aut_ ${ }^{4}$

removing Irevista_2

removing Itit 1 aūt 2

removing Irevista_6

removing Iies_1_aut_18

removing Iies 1 aut 8

removing Iies_1_aut_20

removing Iareā $\overline{5}$

removing ${ }^{-}$Iarea 4

removing Iabordagem_2

removing Irevista $1 \overline{4}$

removing Iposicao_2

removing Iies 1 aut 12

removing -Iies_1_aut_ ${ }^{-}$

removing Iies_1_aut_9

removing $\bar{n} \_p \_t \bar{i} t$

removing prop mulher

removing Iies_1_aut_14

removing _Iies_1-aut_11 
$\mathrm{p}=0.2764>=0.0500$

$\mathrm{p}=0.3337>=0.0500$

$\mathrm{p}=0.7006>=0.0500$

$\mathrm{p}=0.6171>=0.0500$

$\mathrm{p}=0.2754>=0.0500$

$\mathrm{p}=0.2590>=0.0500$

$\mathrm{p}=0.2635>=0.0500$

$\mathrm{p}=0.3101>=0.0500$

$\mathrm{p}=0.2387>=0.0500$

$\mathrm{p}=0.2193>=0.0500$

$\mathrm{p}=0.1986>=0.0500$

$\mathrm{p}=0.1846>=0.0500$

$\mathrm{p}=0.2323>=0.0500$

$\mathrm{p}=0.1582>=0.0500$

$\mathrm{p}=0.1415>=0.0500$

$\mathrm{p}=0.1248>=0.0500$

$\mathrm{p}=0.1440>=0.0500$

$\mathrm{p}=0.1614>=0.0500$

$\mathrm{p}=0.1842>=0.0500$

$\mathrm{p}=0.1437>=0.0500$

$\mathrm{p}=0.1024>=0.0500$ removing n_pag

removing Iqualis vi 3

removing Iqualis vi-8

removing Iqualis ${ }^{-}{ }^{-} 7$

removing Iqualis vi_5

removing Iies 1 aut 6

removing Irevista $3 \bar{\sigma}$

removing _Iqualis_vi_ 6

removing Iies_1_aut_2

removing $\overline{\mathrm{n}} \mathrm{p} \mathrm{p}$ - chave

removing Iies 1 aut 17

removing Iies_1_aut_16

removing Iies 1 aut 3

removing Iarea $\overline{6}$

removing Iord_ou_es_2

removing Iqualis_vi_4

removing Iqualis vi 2

removing _Irevistā_ $1 \overline{2}$

removing Irevista_11

removing Irevista 30

removing $\bar{n}$ autores

Negative binomial regression

Number of obs LR chi2(35)

Prob > chi2

Pseudo R2

$\begin{array}{lr}= & 2,540 \\ = & 895.81 \\ = & 0.0000 \\ = & 0.0677\end{array}$

$\begin{array}{ll}\text { Dispersion } & =\text { mean } \\ \text { Log likelihood } & =-6163.8131\end{array}$

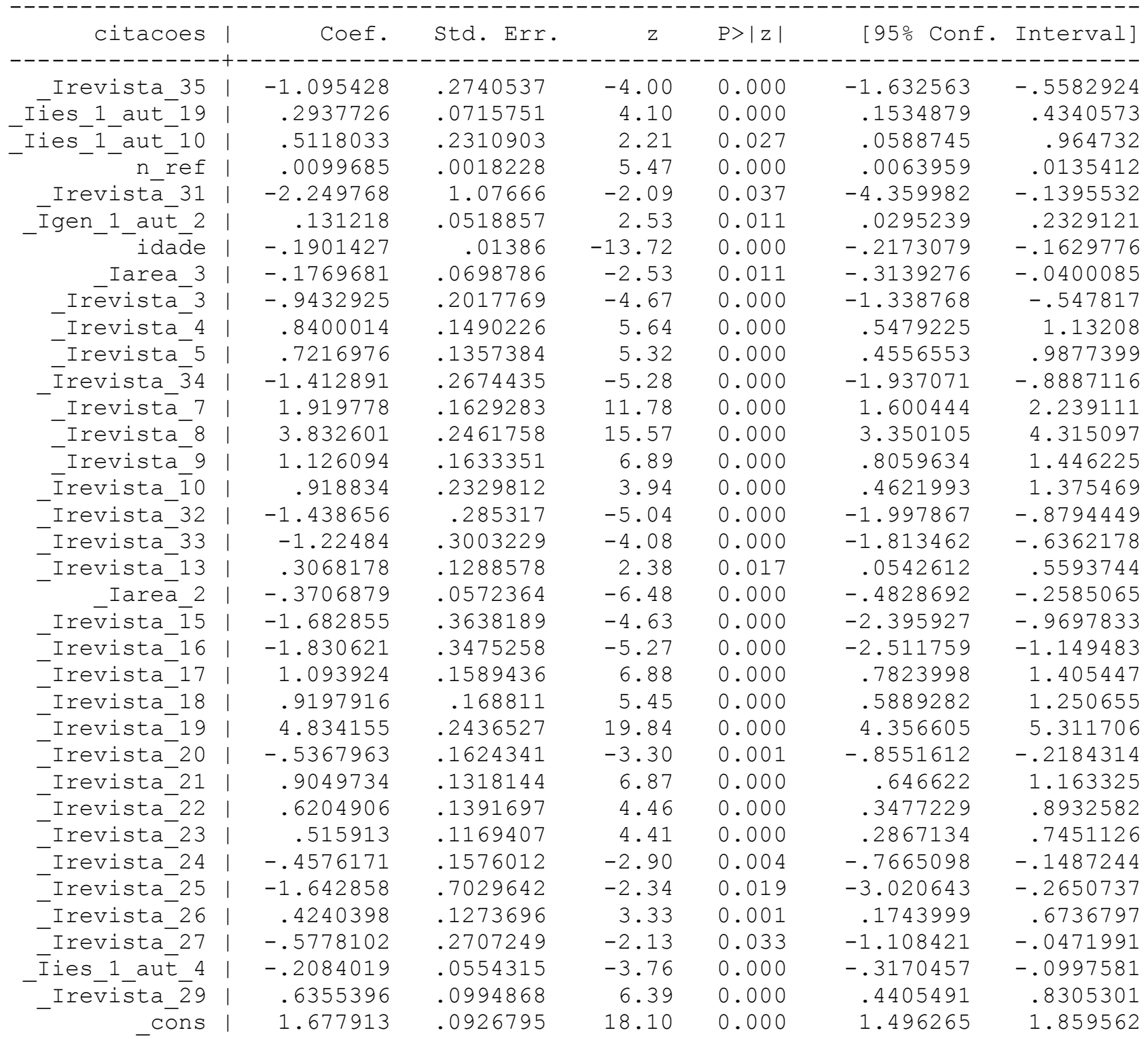




\begin{tabular}{|c|c|c|c|c|}
\hline /Inalpha | & .1323816 & .0389107 & .0561179 & .2086452 \\
\hline alpha & 114151 & --------1 & 1057720 & \\
\hline aLpha & 1.141544 & .0444183 & 1.057722 & 1.232008 \\
\hline
\end{tabular}

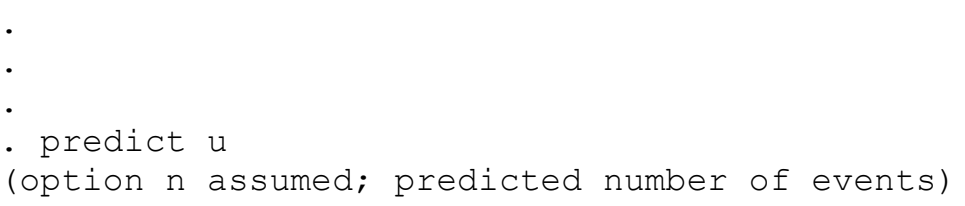

$\cdot$

- stepwise, pr(0.05): nbreg citacoes n_p_tit n_p_p_chave n_pag n_ref n_autores prop_mulher idade_I*, irr begin with full model

$\mathrm{p}=0.9972>=0.0500$

$\mathrm{p}=0.9793>=0.0500$

$\mathrm{p}=0.9504>=0.0500$

$\mathrm{p}=0.9423>=0.0500$

$\mathrm{p}=0.9456>=0.0500$

$\mathrm{p}=0.9396>=0.0500$

$\mathrm{p}=0.9171>=0.0500$

$\mathrm{p}=0.8330>=0.0500$

$\mathrm{p}=0.8067>=0.0500$

$\mathrm{p}=0.7479>=0.0500$

$\mathrm{p}=0.7233>=0.0500$

$\mathrm{p}=0.7090>=0.0500$

$\mathrm{p}=0.6881>=0.0500$

$\mathrm{p}=0.7567>=0.0500$

$\mathrm{p}=0.6109>=0.0500$

$\mathrm{p}=0.5690>=0.0500$

$\mathrm{p}=0.4959>=0.0500$

$\mathrm{p}=0.4287>=0.0500$

$\mathrm{p}=0.4622>=0.0500$

$\mathrm{p}=0.4185>=0.0500$

$\mathrm{p}=0.4065>=0.0500$

$\mathrm{p}=0.3732>=0.0500$

$\mathrm{p}=0.3481>=0.0500$

$\mathrm{p}=0.3574>=0.0500$

$\mathrm{p}=0.2764>=0.0500$

$\mathrm{p}=0.3337>=0.0500$

$\mathrm{p}=0.7006>=0.0500$

$\mathrm{p}=0.6171>=0.0500$

$\mathrm{p}=0.2754>=0.0500$

$\mathrm{p}=0.2590>=0.0500$

$\mathrm{p}=0.2635>=0.0500$

$\mathrm{p}=0.3101>=0.0500$

$\mathrm{p}=0.2387>=0.0500$

$\mathrm{p}=0.2193>=0.0500$

$\mathrm{p}=0.1986>=0.0500$

$\mathrm{p}=0.1846>=0.0500$

$\mathrm{p}=0.2323>=0.0500$

$\mathrm{p}=0.1582>=0.0500$

$\mathrm{p}=0.1415>=0.0500$

$\mathrm{p}=0.1248>=0.0500$

$\mathrm{p}=0.1440>=0.0500$

$\mathrm{p}=0.1614>=0.0500$

$\mathrm{p}=0.1842>=0.0500$

$\mathrm{p}=0.1437>=0.0500$

$\mathrm{p}=0.1024>=0.0500$

removing Itit_ 1 aut 3

removing ${ }^{-}$Iies ${ }^{-}$- aut 5

removing Irevista_ $2 \overline{8}$

removing Iies 1 aut 15

removing Iies_1 aut 13

removing ${ }^{-}$Itit ${ }^{-}{ }^{-}$aut ${ }^{-} 4$

removing Irevista_2

removing Itit_1_aut_2

removing Irevista 6

removing Iies_1_aut_18

removing Iies_1_aut_ 8

removing Iies 1 aut 20

removing _tarea $\overline{5}$

removing Iarea 4

removing Iabordagem 2

removing Irevista $1 \overline{4}$

removing Iposicao 2

removing Iies_1_aut_12

removing ${ }^{-}$Iies ${ }^{-}{ }^{-}$aut ${ }^{-} 7$

removing Iies_1_aut_9

removing $\bar{n} \_p$ t $\bar{i} t$

removing prop mulher

removing Iies 1 aut 14

removing - Iies_1_aut_11

removing $\bar{n} \_p a g$

removing Iqualis vi 3

removing Iqualis ${ }^{-}{ }^{-}{ }^{-} 8$

removing Iqualis vi 7

removing Iqualis_vi_5

removing Iies 1 aut 6

removing Irevista_ $3 \overline{6}$

removing Iqualis $\overline{v i} 6$

removing _Iies_1_aut_2

removing $\bar{n}$ _p_p_chave

removing Iies 1 aut 17

removing Iies 1 aut 16

removing Iies 1 - aut 3

removing Iare $\bar{a} \overline{6}$

removing Iord ou es 2

removing Iqualis_vi_4

removing Iqualis vi 2

removing Irevistā_ $1 \overline{2}$

removing Irevista 11

removing Irevista 30

removing $\overline{\mathrm{n}}$ autores 


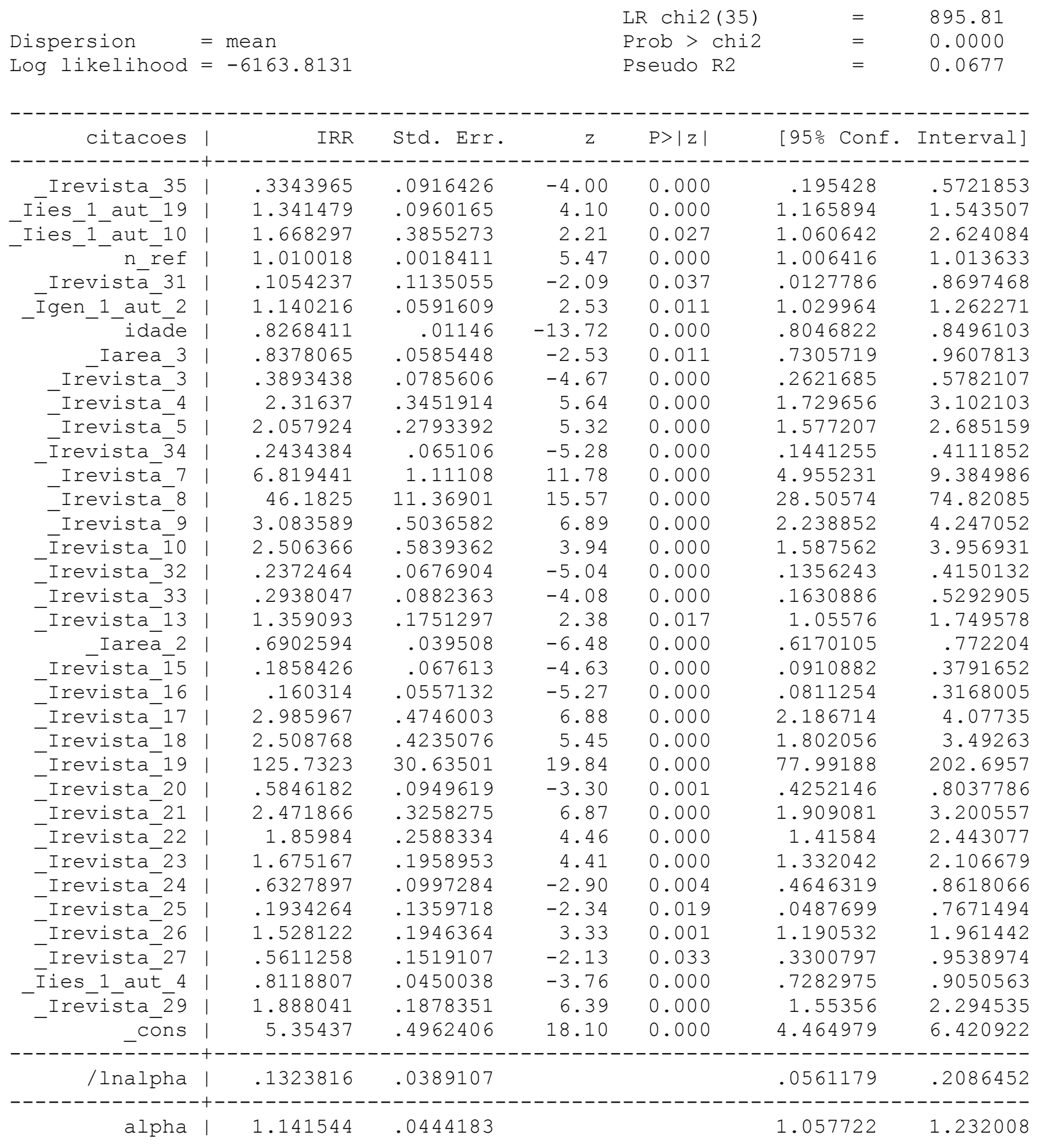

LR test of alpha=0: chibar2(01) $=7290.41$

Prob $>=$ chibar $2=0.000$

.

-

- quietly stepwise, pr(0.05): poisson citacoes n_p_tit n_p_p_chave n_pag n_ref n_autores prop_mulher idade _ I*

- prcounts prpoisson, plot

- quietly stepwise, pr(0.05): nbreg citacoes n_p_tit n_p_p_chave n_pag n_ref n_autores prop_mulher idade _I*

- prcounts proneg, plot 
- graph twoway (scatter prbnegobeq prbnegpreq prpoissonpreq prbnegval, connect (1 1

1))

(note: named style 1 not found in class connectstyle, default attributes used) (note: named style 1 not found in class connectstyle, default attributes used) (note: named style 1 not found in class connectstyle, default attributes used)
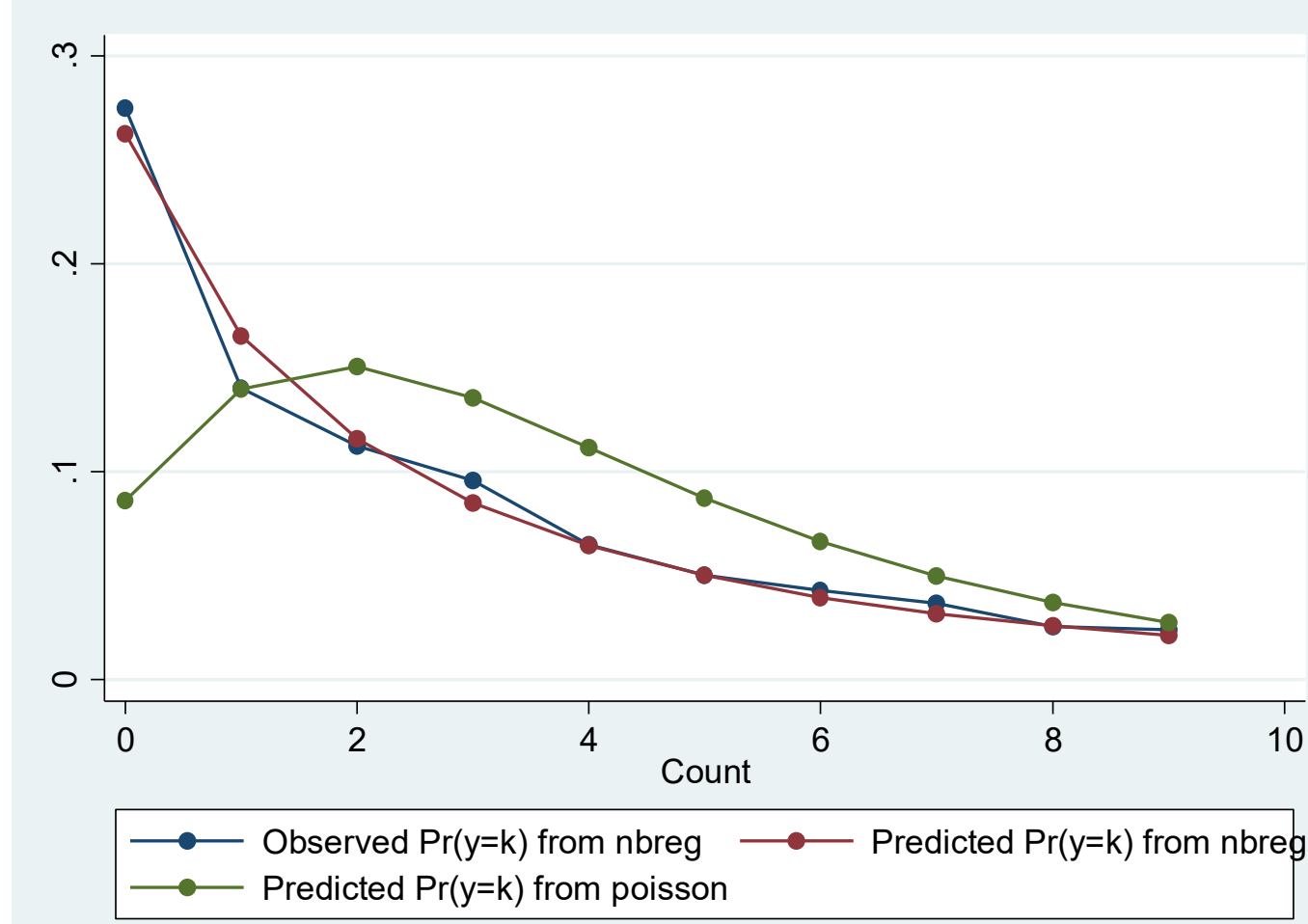

$\cdot$

- countfit citacoes n_p_tit n_p_p_chave n_pag n_ref n_autores prop_mulher idade _ I*, prm nograph noestimates nofit

Comparison of Mean Observed and Predicted Count

\begin{tabular}{|c|c|c|c|}
\hline Model & $\begin{array}{c}\text { Maximum } \\
\text { Difference }\end{array}$ & $\begin{array}{c}\text { At } \\
\text { Value }\end{array}$ & $\begin{array}{l}\text { Mean } \\
\mid \text { Diff| }\end{array}$ \\
\hline & & & \\
\hline PRM & 0.189 & 0 & 0.040 \\
\hline
\end{tabular}

PRM: Predicted and actual probabilities

$\begin{array}{lcccc}\text { Count } & \text { Actual } & \text { Predicted } & \text { | Diff| } & \text { Pearson } \\ ------1 & 0.189 & 1053.875 \\ 0 & 0.275 & 0.086 & 0.140 \\ 1 & 0.140 & 0.140 & 0.000 & 0.001 \\ 2 & 0.113 & 0.151 & 0.038 & 24.764 \\ 3 & 0.096 & 0.136 & 0.040 & 29.702 \\ 4 & 0.065 & 0.112 & 0.047 & 49.527 \\ 5 & 0.050 & 0.087 & 0.037 & 39.399 \\ 6 & 0.043 & 0.066 & 0.023 & 20.818 \\ 7 & 0.037 & 0.050 & 0.013 & 8.623 \\ 8 & 0.026 & 0.037 & 0.011 & 8.890 \\ 9 & 0.024 & 0.028 & 0.004 & 1.176 \\ --------------------------------------- \\ \text { Sum } & 0.869 & 0.892 & 0.402 & 1236.776\end{array}$

- countfit citacoes n_p_tit n_p_p_chave n_pag n_ref n_autores prop_mulher idade _I*, nbreg nograph noestimatès nofit

Comparison of Mean Observed and Predicted Count 


\begin{tabular}{|c|c|c|c|}
\hline Model & $\begin{array}{c}\text { Maximum } \\
\text { Difference }\end{array}$ & $\begin{array}{c}\text { At } \\
\text { Value }\end{array}$ & $\begin{array}{l}\text { Mean } \\
\mid \text { Diff| }\end{array}$ \\
\hline NBRM & -0.027 & 1 & 0.007 \\
\hline
\end{tabular}

NBRM: Predicted and actual probabilities

$\begin{array}{lcccc}\text { Count } & \text { Actual } & \text { Predicted } & \text { | Diff| } & \text { Pearson } \\ -----------1 & 0.014 & 1.898 \\ 0 & 0.275 & 0.261 & 0.014 \\ 1 & 0.140 & 0.167 & 0.027 & 10.745 \\ 2 & 0.113 & 0.117 & 0.004 & 0.417 \\ 3 & 0.096 & 0.086 & 0.010 & 3.110 \\ 4 & 0.065 & 0.065 & 0.000 & 0.001 \\ 5 & 0.050 & 0.050 & 0.000 & 0.004 \\ 6 & 0.043 & 0.039 & 0.003 & 0.770 \\ 7 & 0.037 & 0.032 & 0.005 & 2.074 \\ 8 & 0.026 & 0.026 & 0.000 & 0.000 \\ 9 & 0.024 & 0.021 & 0.003 & 1.155 \\ --------------------------------------- \\ \text { Sum } & 0.869 & 0.863 & 0.067 & 20.172\end{array}$

- graph twoway mspline u citacoes || mspline lambda citacoes ||, legend(label(1 "Binomial Negativo") label(2 "Poisson"))

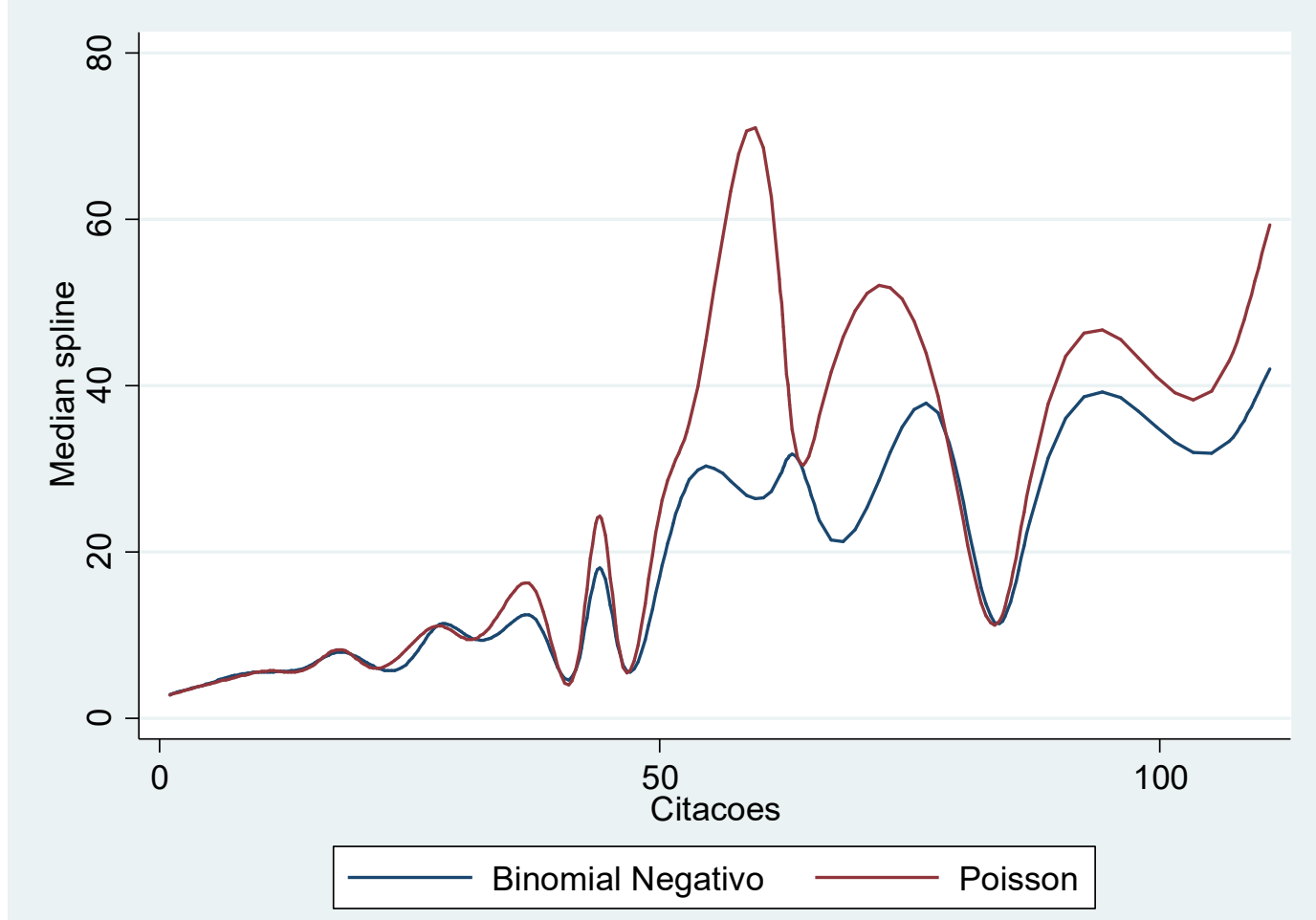

- gen lncitacoes=ln (citacoes)

(699 missing values generated)

- quietly reg lncitacoes n_p_tit n_p_p_chave n_pag n_ref n_autores prop_mulher idade I* 
- predict yhat

(option xb assumed; fitted values)

- gen eyhat $=\exp ($ yhat $)$

$\cdot$

- graph twoway lfit u citacoes || lfit lambda citacoes || lfit eyhat citacoes ||, legend(label(1 "Binomial Negativo") label (2 "Poisso

$>$ n") label (3 "OLS"))

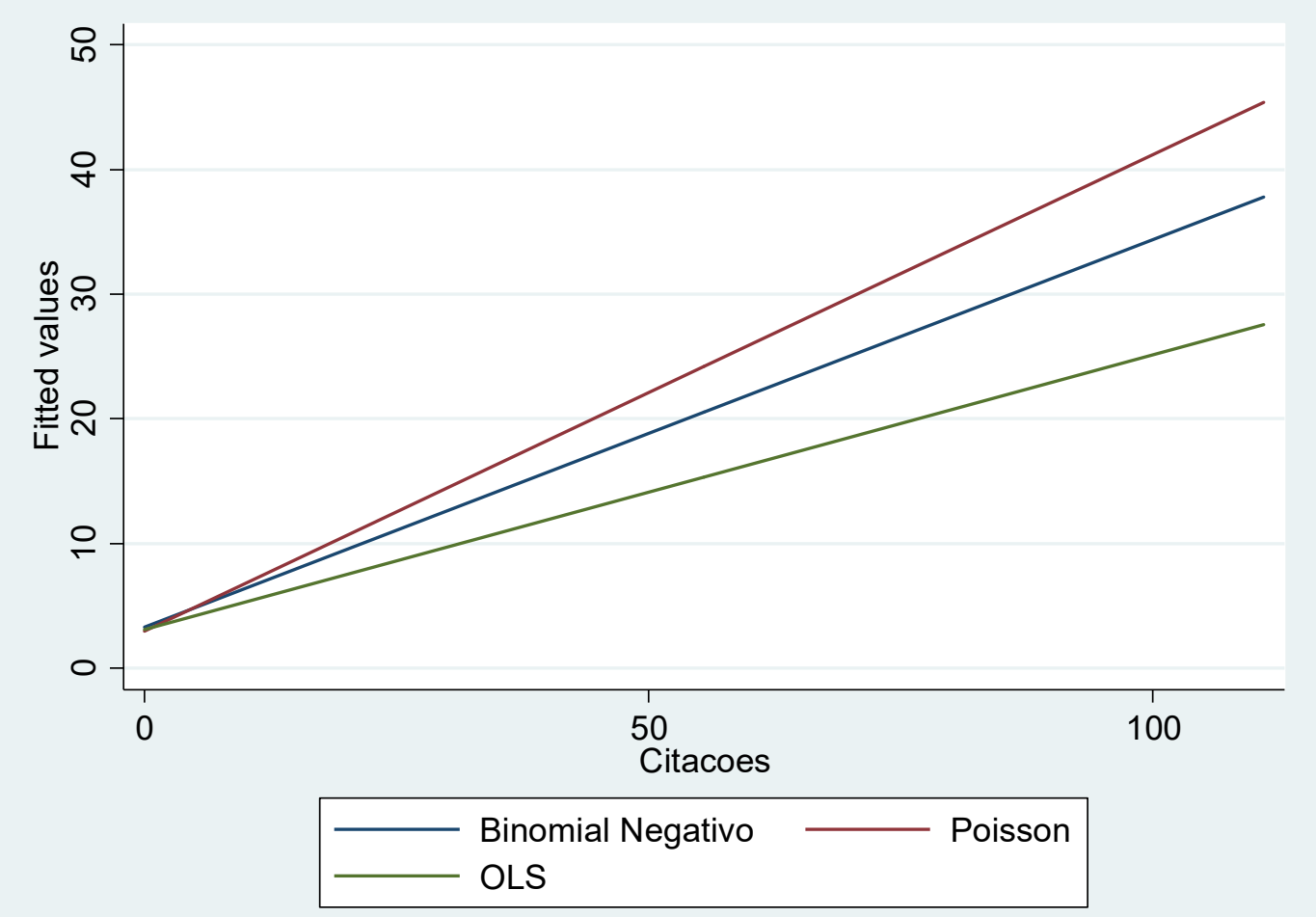


Apêndice $L$ - Saídas do Stata do Modelo 2 - sem a variável Revista

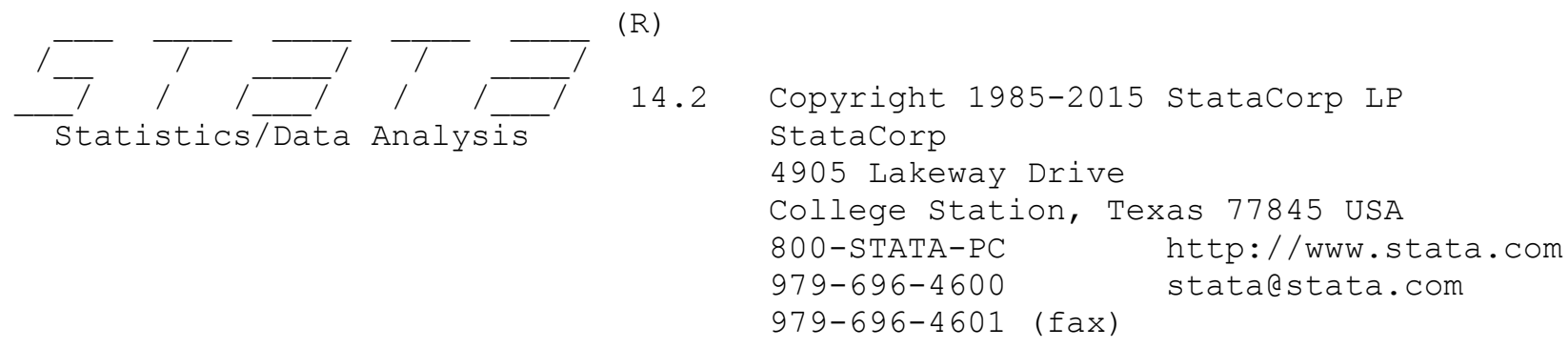

Single-user Stata license expires 29 May 2017:

Serial number: 301409337392

Licensed to: Sandro Vieira Soares

Notes:

1. Unicode is supported; see help unicode_advice.

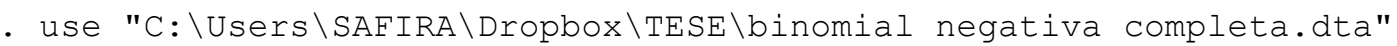

- desc

Contains data from C: \Users \SAFIRA \Dropbox\TESE\binomial negativa completa.dta obs: $\quad 2,540$

vars: $\quad 21$

size: $\quad 200,660$

29 Jan 2017 16:45

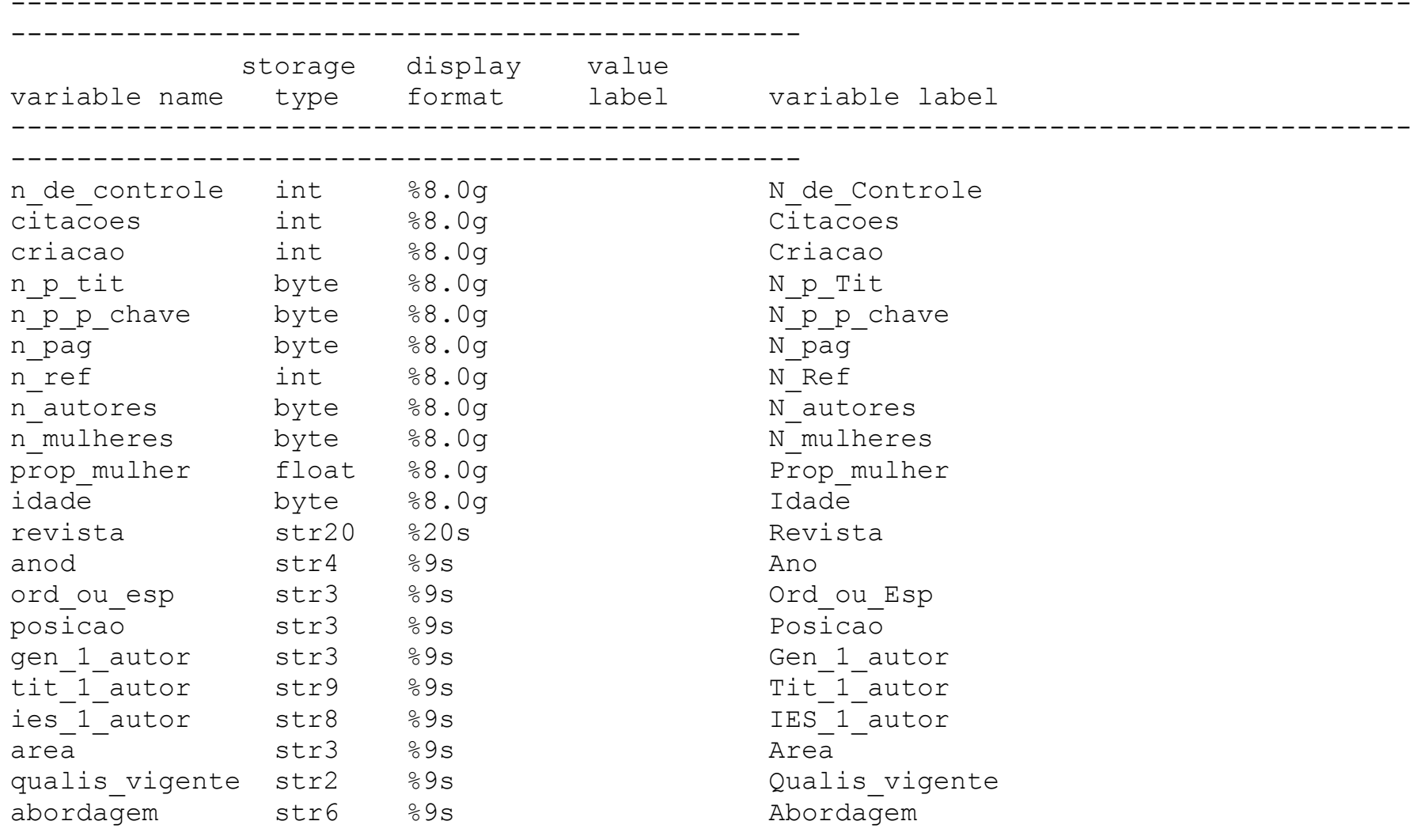

Sorted by: 
- tab citacoes

\begin{tabular}{|c|c|c|c|c|}
\hline Citacoes & 1 & Freq. & Percent & Cum. \\
\hline------- & + & ----- & -------- & ------ \\
\hline 0 & | & 699 & 27.52 & 27.52 \\
\hline 1 & | & 356 & 14.02 & 41.54 \\
\hline 2 & | & 286 & 11.26 & 52.80 \\
\hline 3 & | & 244 & 9.61 & 62.40 \\
\hline 4 & | & 165 & 6.50 & 68.90 \\
\hline 5 & | & 128 & 5.04 & 73.94 \\
\hline 6 & | & 109 & 4.29 & 78.23 \\
\hline 7 & | & 93 & 3.66 & 81.89 \\
\hline 8 & | & 65 & 2.56 & 84.45 \\
\hline 9 & | & 61 & 2.40 & 86.85 \\
\hline 10 & | & 45 & 1.77 & 88.62 \\
\hline 11 & | & 35 & 1.38 & 90.00 \\
\hline 12 & | & 27 & 1.06 & 91.06 \\
\hline 13 & | & 28 & 1.10 & 92.17 \\
\hline 14 & | & 17 & 0.67 & 92.83 \\
\hline 15 & | & 18 & 0.71 & 93.54 \\
\hline 16 & | & 15 & 0.59 & 94.13 \\
\hline 17 & | & 9 & 0.35 & 94.49 \\
\hline 18 & | & 13 & 0.51 & 95.00 \\
\hline 19 & | & 12 & 0.47 & 95.47 \\
\hline 20 & | & 5 & 0.20 & 95.67 \\
\hline 21 & | & 10 & 0.39 & 96.06 \\
\hline 22 & | & 6 & 0.24 & 96.30 \\
\hline 23 & | & 5 & 0.20 & 96.50 \\
\hline 24 & | & 6 & 0.24 & 96.73 \\
\hline 25 & 1 & 8 & 0.31 & 97.05 \\
\hline 26 & 1 & 4 & 0.16 & 97.20 \\
\hline 27 & | & 5 & 0.20 & 97.40 \\
\hline 28 & 1 & 3 & 0.12 & 97.52 \\
\hline 29 & I & 3 & 0.12 & 97.64 \\
\hline 30 & | & 4 & 0.16 & 97.80 \\
\hline 31 & | & 5 & 0.20 & 97.99 \\
\hline 32 & I & 5 & 0.20 & 98.19 \\
\hline 33 & I & 1 & 0.04 & 98.23 \\
\hline 34 & 1 & 4 & 0.16 & 98.39 \\
\hline 35 & I & 4 & 0.16 & 98.54 \\
\hline 37 & i & 2 & 0.08 & 98.62 \\
\hline 38 & 1 & 5 & 0.20 & 98.82 \\
\hline 39 & I & 3 & 0.12 & 98.94 \\
\hline 41 & i & 1 & 0.04 & 98.98 \\
\hline 42 & 1 & 2 & 0.08 & 99.06 \\
\hline 43 & I & 1 & 0.04 & 99.09 \\
\hline 44 & | & 2 & 0.08 & 99.17 \\
\hline 45 & 1 & 1 & 0.04 & 99.21 \\
\hline 46 & 1 & 2 & 0.08 & 99.29 \\
\hline 48 & i & 1 & 0.04 & 99.33 \\
\hline 49 & I & 1 & 0.04 & 99.37 \\
\hline 50 & | & 1 & 0.04 & 99.41 \\
\hline 52 & i & 1 & 0.04 & 99.45 \\
\hline 53 & I & 2 & 0.08 & 99.53 \\
\hline 62 & | & 1 & 0.04 & 99.57 \\
\hline 63 & i & 1 & 0.04 & 99.61 \\
\hline 66 & I & 2 & 0.08 & 99.69 \\
\hline 68 & | & 1 & 0.04 & 99.72 \\
\hline 79 & i & 1 & 0.04 & 99.76 \\
\hline 84 & I & 1 & 0.04 & 99.80 \\
\hline 85 & 1 & 1 & 0.04 & 99.84 \\
\hline 87 & i & 2 & 0.08 & 99.92 \\
\hline 107 & I & 1 & 0.04 & 99.96 \\
\hline 111 & i & 1 & 0.04 & 100.00 \\
\hline otal & I &, 540 & 100.00 & \\
\hline
\end{tabular}


- hist citacoes, discrete freq ( $\operatorname{start}=0$, width=1)

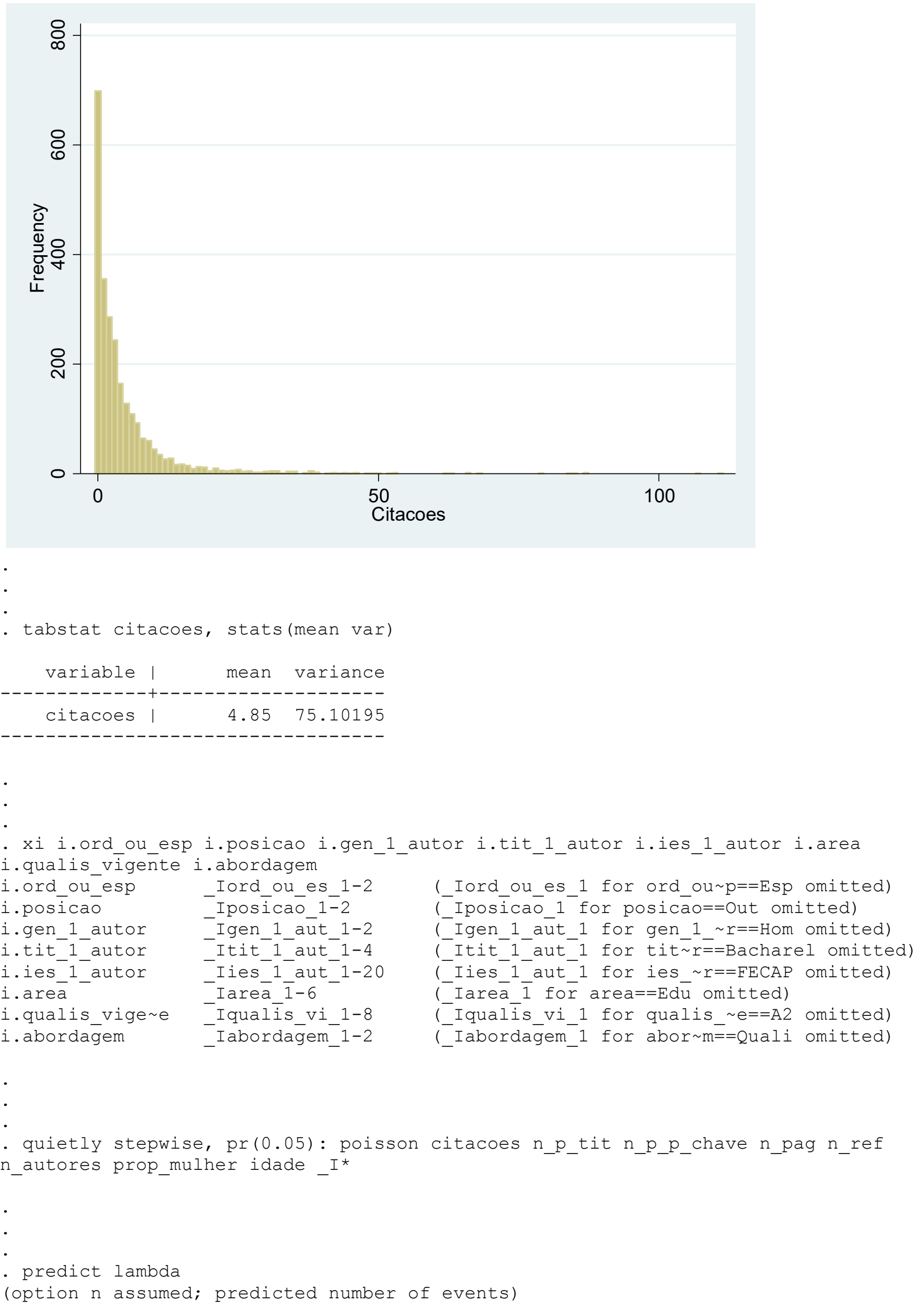


- gen yasterisco $=\left((\text { citacoes-lambda })^{\wedge} 2-\right.$ citacoes $) /$ lambda

- reg yasterisco lambda, nocons

$\begin{array}{rrrrrr}\text { Source | } & \text { SS } & \text { df } & \text { MS } & \text { Number of obs } & = \\ 2,540 \\ -1\end{array}$

- quietly stepwise, pr(0.05): poisson citacoes n_p_tit n_p_p_chave n_pag n_ref n_autores prop_mulher idade_ _*

•

- poisgof

$\begin{array}{llr}\text { Deviance goodness-of-fit } & = & 17085.98 \\ \text { Prob }>\text { chi2(2501) } & = & 0.0000 \\ & & \\ \text { Pearson goodness-of-fit } & = & 23320.86 \\ \text { Prob }>\text { chi2 }(2501) & = & 0.0000\end{array}$

•

.

- stepwise, pr(0.05): nbreg citacoes n_p_tit n_p_p_chave n_pag n_ref n_autores prop_mulher idade_I*

$\mathrm{p}=0.9580>=0.0500$

begin with full model

$\mathrm{p}=0.9411>=0.0500$

$\mathrm{p}=0.9191>=0.0500$

$\mathrm{p}=0.9133>=0.0500$

$\mathrm{p}=0.8768>=0.0500$

$\mathrm{p}=0.9069>=0.0500$

$\mathrm{p}=0.8803>=0.0500$

$\mathrm{p}=0.8310>=0.0500$

$\mathrm{p}=0.8159>=0.0500$

$\mathrm{p}=0.7885>=0.0500$

$\mathrm{p}=0.7533>=0.0500$

$\mathrm{p}=0.7509>=0.0500$

$\mathrm{p}=0.5527>=0.0500$

$\mathrm{p}=0.5414>=0.0500$

$\mathrm{p}=0.4681>=0.0500$

$\mathrm{p}=0.4473>=0.0500$

$\mathrm{p}=0.6043>=0.0500$

$\mathrm{p}=0.4773>=0.0500$

$\mathrm{p}=0.2394>=0.0500$

$\mathrm{p}=0.2009>=0.0500$

$\mathrm{p}=0.1593>=0.0500$

$\mathrm{p}=0.1477>=0.0500$

$\mathrm{p}=0.1267>=0.0500$

removing $\mathrm{n}$ _p_p_chave

removing _. Iqualis_vi_8

removing Iies 1 aut 10

removing Iposicāo_2-

removing Iies_1_aut_18

removing Iies_1_aut_19

removing _ord_oües_- 2

removing $\bar{n}$ autores

removing $\overline{\text { Iies_1}}$ _aut_2

removing Iare $\bar{a} \overline{4}$

removing Itit_- 1 _aut_3

removing _Iaborāāgem_2

removing $\bar{n}$ pag

removing Iarea 5

removing Iies_- 1 aut_5

removing Iqualis ${ }^{-}{ }^{-}{ }^{5}$

removing Iqualis vi 7

removing _Iies_1_āut_- 8

removing $\bar{n} \_p \_t \bar{i} t$

removing prop_mulher

removing Igen 1 aut 2

removing Iies_1_aut_20

removing _Iqualis_tvi_3 
$\mathrm{p}=0.0731>=0.0500$ removing Iarea_3

$\mathrm{p}=0.0784>=0.0500$ removing Iarea 6

$\mathrm{p}=0.0566>=0.0500$ removing Iqualis_vi_6

Negative binomial regression

Number of obs

$=2,540$

Dispersion $\quad=$ mean

Log likelihood $=-6401.2709$

LR chi2(19)

Prob > chi2

420.89

Pseudo R2

0.0000

0.0318

\begin{tabular}{|c|c|c|c|c|c|c|}
\hline citacoes | & Coef. & Std. Err. & z & $\mathrm{P}>|\mathrm{z}|$ & [95\% Conf. & Interval] \\
\hline \multicolumn{7}{|c|}{-----------------+-------------} \\
\hline Iies_1_aut_15 | & -.3943002 & .1038888 & -3.80 & 0.000 & -.5979185 & -.1906819 \\
\hline Iies_1_aut_17 & -.4232195 & .1761499 & -2.40 & 0.016 & -.768467 & -.0779721 \\
\hline$-\bar{I}$ are $\bar{a} 2$ & -.447053 & .0588241 & -7.60 & 0.000 & -.5623462 & -.3317599 \\
\hline$-n$ n_éf & .0063596 & .001973 & 3.22 & 0.001 & .0024925 & .0102266 \\
\hline Iqualis_vì_2 & .4882279 & .0799053 & 6.11 & 0.000 & .3316163 & .6448395 \\
\hline $\bar{I}$ ies_1_aut_ $\overline{1} 4$ & -.8208437 & .2251652 & -3.65 & 0.000 & -1.262159 & -.379528 \\
\hline-- idāade & .0327265 & .004 & 6.68 & 0.000 & .0231292 & .0423238 \\
\hline Iies_1_aut_11 & -.500608 & .1738868 & -2.88 & 0.004 & -.8414199 & -.1597961 \\
\hline Iies_1_aut_16 & -.5279215 & .123 & -4.29 & 0.000 & -.769 & 67171 \\
\hline -Iies_1_aut_13 & -.349759 & .1388716 & -2.52 & 0.012 & -.6219424 & -.0775756 \\
\hline - Itit_-ín_aut_2 & .2430329 & .073977 & 3.29 & 0.001 & .0980406 & .3880252 \\
\hline $\bar{I}$ ies_ $\overline{1}$ aut_ $\overline{1} 2$ & -.6099494 & .20 & -3.00 & 0.003 & -1.008943 & -.2109563 \\
\hline 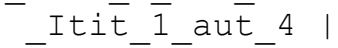 & .1915599 & .069 & 2.77 & 0.006 & .0560838 & .327036 \\
\hline -Iies_1-aut_o & -.5569231 & .1605478 & -3.47 & 0.001 & -.871591 & -.2422551 \\
\hline Iies_1_aut_3 & -.683377 & 7702 & -5.35 & 0.000 & -.933802 & -.4329519 \\
\hline Iies 1 -aut 4 & -.6077054 & 9744 & -8.44 & 0.000 & -.7487726 & -.4666382 \\
\hline -Iqualis_vín_4 & .3436433 & .063 & 5.43 & 0.000 & .2196263 & .4676602 \\
\hline Iies_1_aut_6 & -.4190604 & .1810464 & -2.31 & 0.021 & -.7739048 & -.064216 \\
\hline Iies_1_aut 7 & -.7120293 & .2205099 & -3.23 & 0.001 & -1.144221 & -.2798378 \\
\hline$-{ }_{-}{ }_{-} \operatorname{cons}$ & 1.284997 & .098 & 12.98 & 0.000 & 1.090973 & 1.479021 \\
\hline /lnalpha & .4049194 & 6194 & & & .3351067 & .4747321 \\
\hline & & & & & & \\
\hline alpha & 1.499182 & .0533999 & & & 1.39809 & 1.607583 \\
\hline
\end{tabular}

LR test of alpha=0: $\operatorname{chibar} 2(01)=1.1 e+04$

Prob $>=$ chibar $2=0.000$

$\cdot$

- predict u

(option $\mathrm{n}$ assumed; predicted number of events)

•

.

- stepwise, pr(0.05): nbreg citacoes n_p_tit n_p_p_chave n_pag n_ref n_autores prop_mulher idade_I*, irr

$\mathrm{p}=0.9580>=0.0500$

$\mathrm{p}=0.9411>=0.0500$

$\mathrm{p}=0.9191>=0.0500$

$\mathrm{p}=0.9133>=0.0500$

$\mathrm{p}=0.8768>=0.0500$

$\mathrm{p}=0.9069>=0.0500$

$\mathrm{p}=0.8803>=0.0500$

$\mathrm{p}=0.8310>=0.0500$

$\mathrm{p}=0.8159>=0.0500$

$\mathrm{p}=0.7885>=0.0500$

$\mathrm{p}=0.7533>=0.0500$

$\mathrm{p}=0.7509>=0.0500$

$\mathrm{p}=0.5527>=0.0500$

$\mathrm{p}=0.5414>=0.0500$

$\mathrm{p}=0.4681>=0.0500$ begin with full model

removing $\mathrm{n}$ _p_p_chave

removing Iqualis_vi_8

removing Iies_1_aut_10

removing Iposicāo_2

removing Iies 1 aūt 18

removing Iies_1_aut 19

removing Iord ou es 2

removing $\bar{n}$ autores

removing $\bar{I}$ ies 1 aut 2

removing _Iarea $\overline{4}$

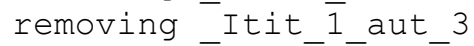

removing Iaborāāgem_2

removing $\bar{n}$ pag

removing Iarea 5

removing ${ }_{-}$Iies_ ${ }^{1}$ _aut_5 
$\mathrm{p}=0.4473>=0.0500$

$\mathrm{p}=0.6043>=0.0500$

$\mathrm{p}=0.4773>=0.0500$

$\mathrm{p}=0.2394>=0.0500$

$\mathrm{p}=0.2009>=0.0500$

$\mathrm{p}=0.1593>=0.0500$

$\mathrm{p}=0.1477>=0.0500$

$\mathrm{p}=0.1267>=0.0500$

$\mathrm{p}=0.0731>=0.0500$

$\mathrm{p}=0.0784>=0.0500$

$\mathrm{p}=0.0566>=0.0500$ removing _ Iqualis_vi_5 removing Iqualis ${ }^{-}{ }^{-}{ }^{-}$ removing Iies_1_aut_o removing $\bar{n} \_p_{-} t \bar{i} t$ removing prop_mulher removing Igen_1_aut_2 removing ${ }^{-}$Iies ${ }^{-}$- aut 20 removing Iqualis_vi_3 removing Iarea_3 removing Iarea 6 removing _Iqualis_vi_ 6

Negative binomial regression

Number of obs LR chi2(19)

Prob > chi2

Pseudo R2

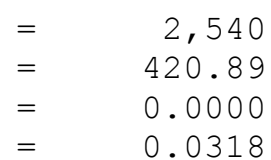

0.0000

$\begin{array}{ll}\text { Dispersion } & =\text { mean } \\ \text { Log likelihood } & =-6401.2709\end{array}$

(1)

\begin{tabular}{|c|c|c|c|c|c|c|c|}
\hline citacoes & I & IRR & Std. Err. & z & $P>|z|$ & [95\% Conf. & Interval] \\
\hline \multicolumn{8}{|c|}{ 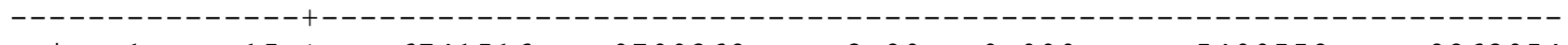 } \\
\hline _Iies_1_aut_15 & I & .6741516 & .0700368 & -3.80 & 0.000 & .5499552 & .8263954 \\
\hline Iies_1_aut_17 & | & .6549348 & .1153667 & -2.40 & 0.016 & .4637234 & .9249902 \\
\hline - Iareā_2 & । & .63951 & .0376186 & -7.60 & 0.000 & .5698705 & .7176596 \\
\hline$n \_r \bar{e} f$ & | & 1.00638 & .0019856 & 3.22 & 0.001 & 1.002496 & 1.010279 \\
\hline _Iqualis_vi_2 & | & 1.629426 & .1301998 & 6.11 & 0.000 & 1.393218 & 1.905681 \\
\hline Iies_1_aut_tin & | & .4400602 & .0990862 & -3.65 & 0.000 & .2830422 & .6841842 \\
\hline-- idāde & | & 1.033268 & .0050596 & 6.68 & 0.000 & 1.023399 & 1.043232 \\
\hline Iies_1_aut_11 & | & .606162 & .1054036 & -2.88 & 0.004 & .431098 & .8523175 \\
\hline _Iies_1_aut_16 & | & .5898297 & .0725878 & -4.29 & 0.000 & .463418 & .7507241 \\
\hline Iies_1_aut_13 & | & .704858 & .0978848 & -2.52 & 0.012 & .5369006 & .9253571 \\
\hline - Itit_s aut_2 & | & 1.275111 & .0943289 & 3.29 & 0.001 & 1.103008 & 1.474067 \\
\hline - & । & .5433783 & .1106164 & -3.00 & 0.003 & .3646043 & .8098094 \\
\hline Itit_s_aut_4 & । & 1.211137 & .0837159 & 2.77 & 0.006 & 1.057686 & 1.386851 \\
\hline Iies_1_aut_9 & & .5729694 & .091989 & -3.47 & 0.001 & .4182855 & .7848559 \\
\hline _Iies_1_aut_3 & & .504909 & .0645123 & -5.35 & 0.000 & .3930565 & .6485917 \\
\hline Iies_1_aut_4 & & .5445991 & .0391972 & -8.44 & 0.000 & .4729467 & .627107 \\
\hline Iqualis_vi_4 & | & 1.410076 & .0892227 & 5.43 & 0.000 & 1.245611 & 1.596255 \\
\hline Iies_1_aut_6 & & .6576645 & .1190678 & -2.31 & 0.021 & .4612086 & .9378024 \\
\hline Iies_1_aut_7 & & .4906475 & .1081926 & -3.23 & 0.001 & .318472 & .7559063 \\
\hline$-{ }_{-} \operatorname{con} s$ & | & 3.614656 & .3578279 & 12.98 & 0.000 & 2.977169 & 4.388646 \\
\hline & & 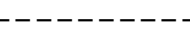 & - & & & --------- & --------- \\
\hline / Inalpha & 1 & .4049194 & .0356194 & & & .3351067 & .4747321 \\
\hline alpha & I & 1.499182 & .0533999 & & & 1.39809 & 1.607583 \\
\hline
\end{tabular}

LR test of alpha=0: chibar2(01) $=1.1 e+04$

Prob $>=$ chibar $2=0.000$

.

•

- quietly stepwise, pr(0.05): poisson citacoes n_p_tit n_p_p_chave n_pag n_ref n_autores prop_mulher idade_I*

- prcounts prpoisson, plot

- quietly stepwise, pr(0.05): nbreg citacoes n_p_tit n_p_p_chave n_pag n_ref n_autores prop_mulher idade _I*

- prcounts proneg, plot

- graph twoway (scatter prbnegobeq prbnegpreq prpoissonpreq prbnegval, connect (1 1 1)) 
(note: named style 1 not found in class connectstyle, default attributes used) (note: named style 1 not found in class connectstyle, default attributes used) (note: named style 1 not found in class connectstyle, default attributes used)

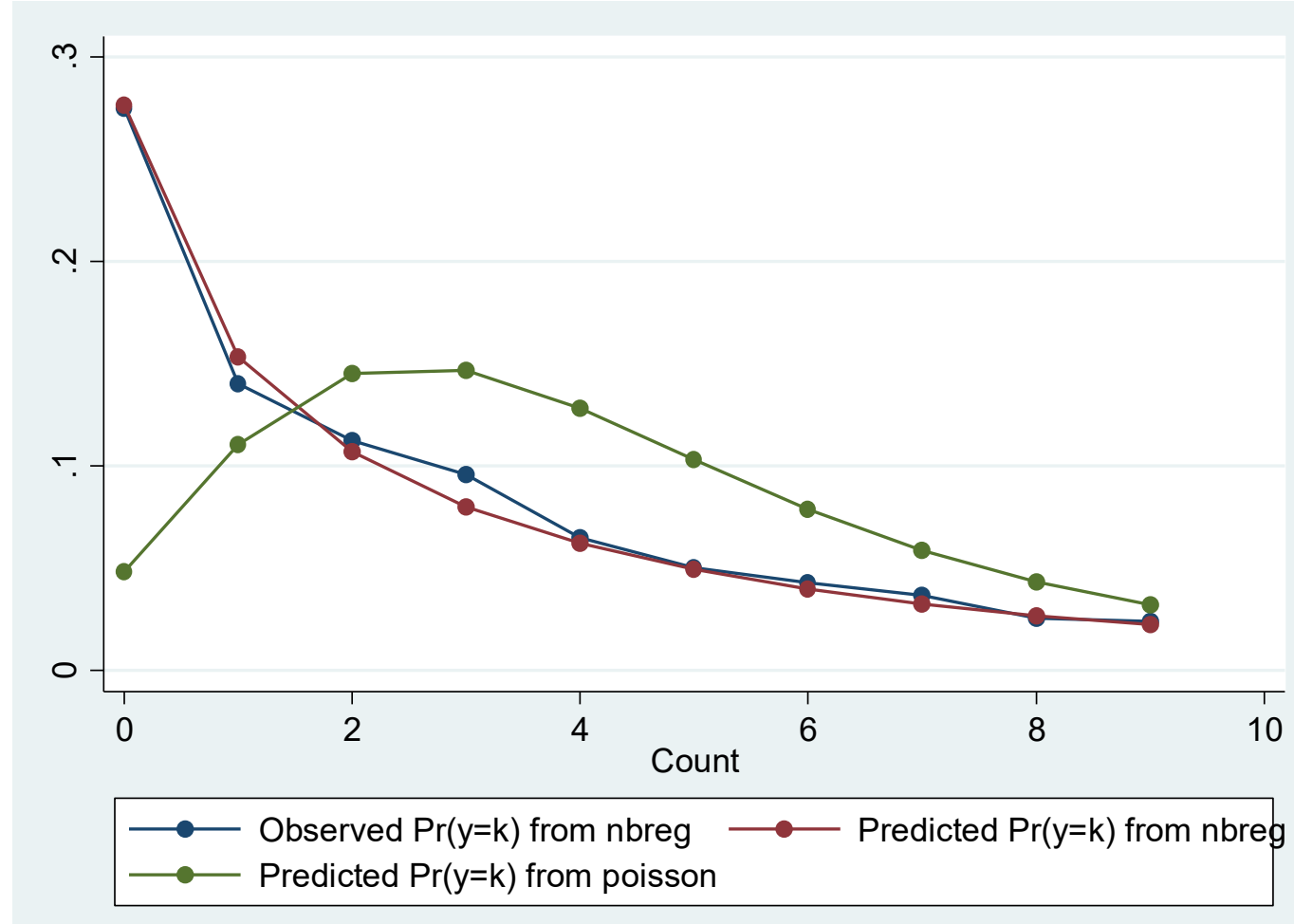

$\cdot$

- countfit citacoes n_p_tit n_p_p_chave n_pag n_ref n_autores prop_mulher idade_I*, prm nograph noestimates nofit

Comparison of Mean Observed and Predicted Count

\begin{tabular}{|c|c|c|c|}
\hline Model & $\begin{array}{c}\text { Maximum } \\
\text { Difference }\end{array}$ & $\begin{array}{c}\text { At } \\
\text { Value }\end{array}$ & $\begin{array}{l}\text { Mean } \\
\mid \text { Diff| }\end{array}$ \\
\hline PRM & 0.227 & 0 & 0.054 \\
\hline
\end{tabular}

PRM: Predicted and actual probabilities

\begin{tabular}{lcccc} 
Count & Actual & Predicted & $\mid$ Diff| & \multicolumn{1}{l}{ Pearson } \\
\hline 0 & 0.275 & 0.048 & 0.227 & 2713.356 \\
1 & 0.140 & 0.110 & 0.030 & 20.369 \\
2 & 0.113 & 0.145 & 0.033 & 18.785 \\
3 & 0.096 & 0.147 & 0.051 & 45.016 \\
4 & 0.065 & 0.129 & 0.064 & 80.053 \\
5 & 0.050 & 0.103 & 0.053 & 68.891 \\
6 & 0.043 & 0.079 & 0.036 & 42.004 \\
7 & 0.037 & 0.059 & 0.022 & 21.507 \\
8 & 0.026 & 0.043 & 0.018 & 18.654 \\
9 & 0.024 & 0.032 & 0.008 & 5.007 \\
-------------------------------------- \\
Sum & 0.869 & 0.897 & 0.541 & 3033.644
\end{tabular}

- countfit citacoes n_p_tit n_p_p_chave n_pag n_ref n_autores prop_mulher idade _ I*, nbreg nograph noestimates nofit

Comparison of Mean Observed and Predicted Count

$\begin{array}{cccc} & \text { Maximum } & \text { At } & \text { Mean } \\ \text { Model } & \text { Difference } & \text { Value } & \mid \text { Diff } \mid\end{array}$



NBRM
0.015
3
0.005

NBRM: Predicted and actual probabilities

\begin{tabular}{|c|c|c|c|c|}
\hline Count & Actual & Predicted & | Diff | & Pearson \\
\hline \multicolumn{5}{|c|}{-------------------------------------------------------} \\
\hline 0 & 0.275 & 0.276 & 0.000 & 0.002 \\
\hline 1 & 0.140 & 0.154 & 0.014 & 3.291 \\
\hline 2 & 0.113 & 0.108 & 0.005 & 0.553 \\
\hline 3 & 0.096 & 0.081 & 0.015 & 7.559 \\
\hline 4 & 0.065 & 0.062 & 0.003 & 0.260 \\
\hline 5 & 0.050 & 0.049 & 0.001 & 0.042 \\
\hline 6 & 0.043 & 0.040 & 0.003 & 0.583 \\
\hline 7 & 0.037 & 0.033 & 0.004 & 1.277 \\
\hline 8 & 0.026 & 0.027 & 0.001 & 0.156 \\
\hline 9 & 0.024 & 0.022 & 0.002 & 0.304 \\
\hline Sum & 0.869 & 0.852 & 0.048 & 14.027 \\
\hline
\end{tabular}

- graph twoway mspline u citacoes I| mspline lambda citacoes ||, legend(label(1 "Binomial Negativo") label(2 "Poisson"))

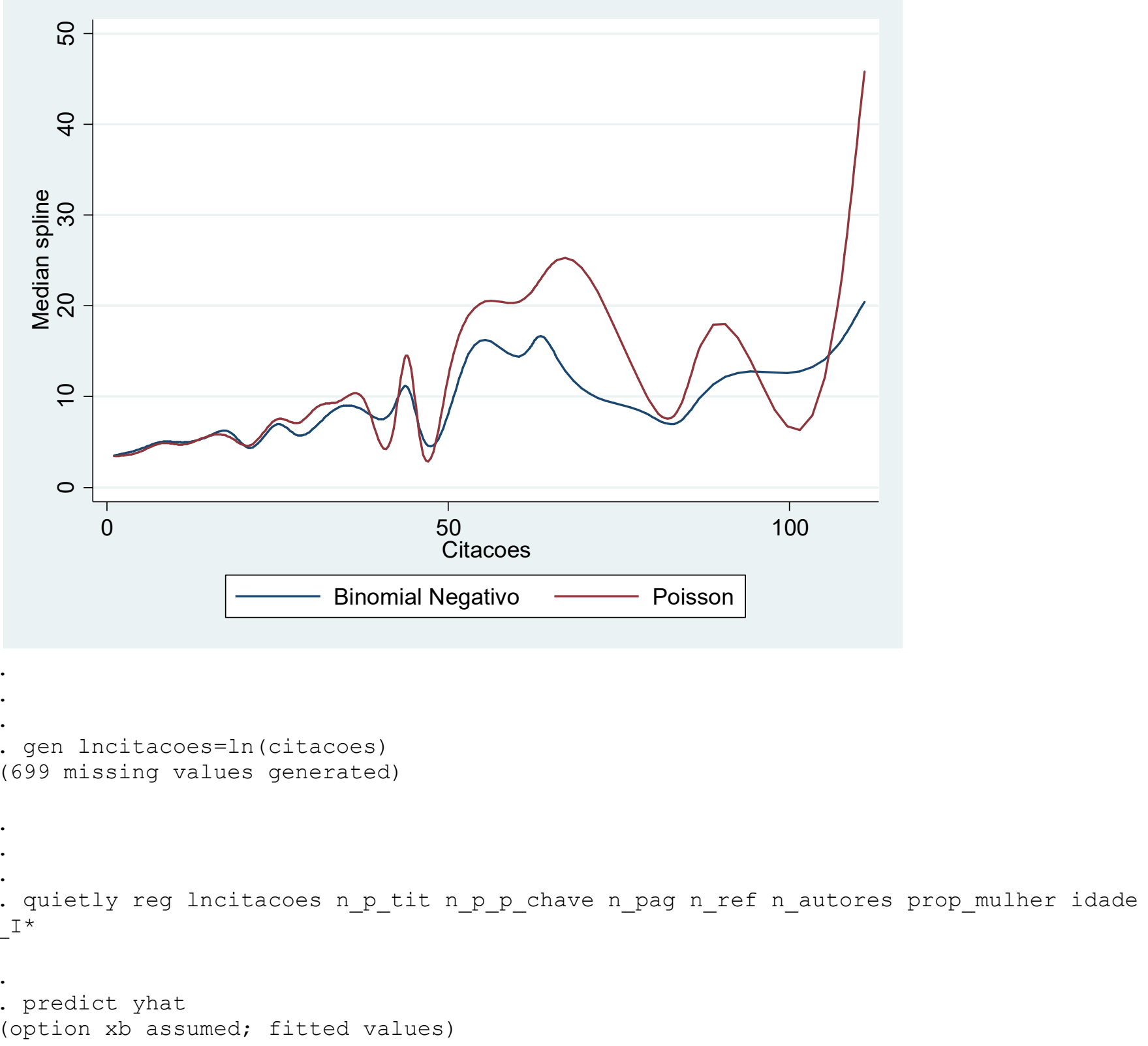


- gen eyhat = exp (yhat)

- graph twoway lfit u citacoes II lfit lambda citacoes I| lfit eyhat citacoes |I, legend(label (1 "Binomial Negativo") label (2 "Poisso

$>\mathrm{n} "$ ) label (3 "OLS"))

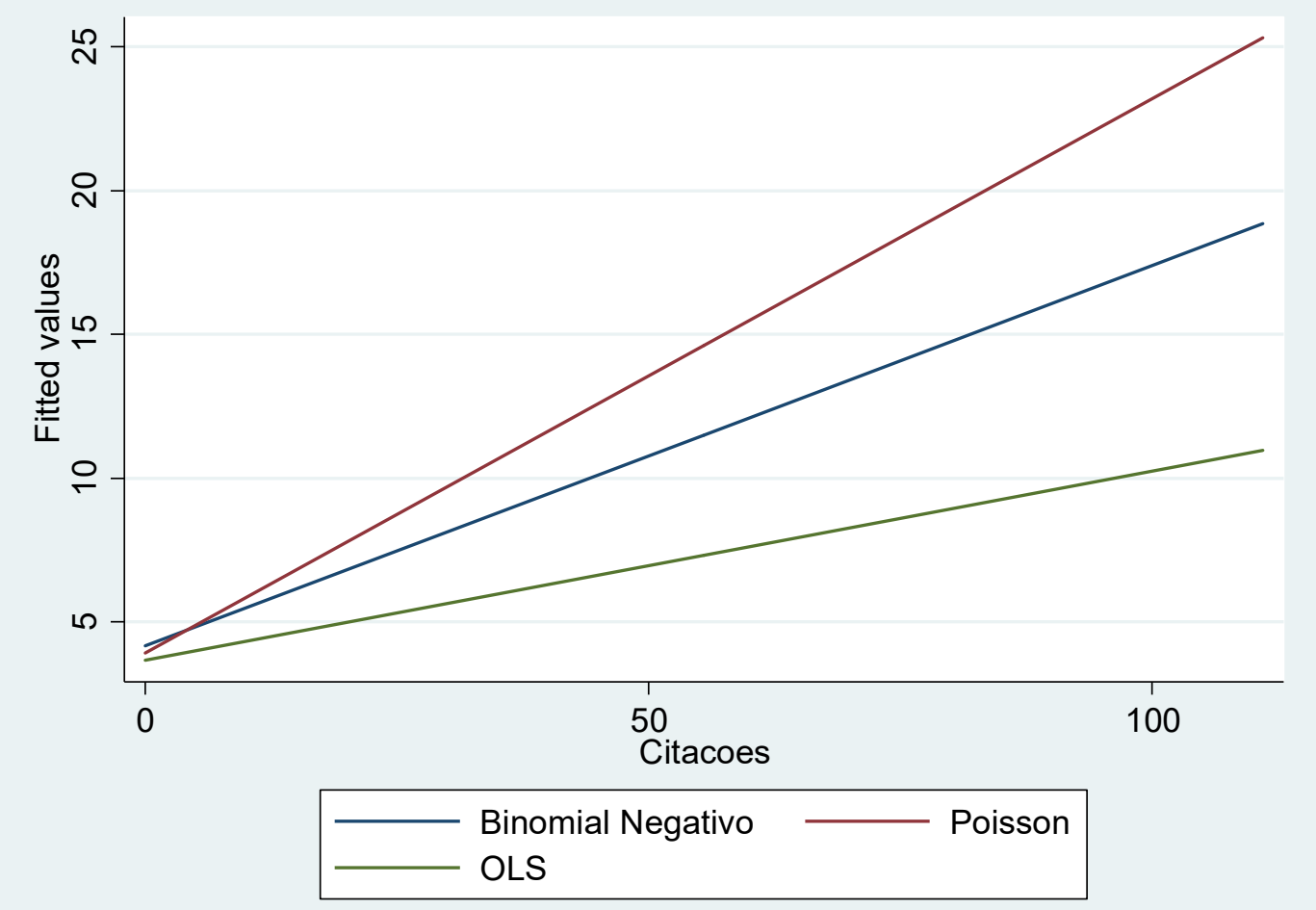


Apêndice M - Saídas do Stata do Modelo 3 - Sem a variável Idade da revista

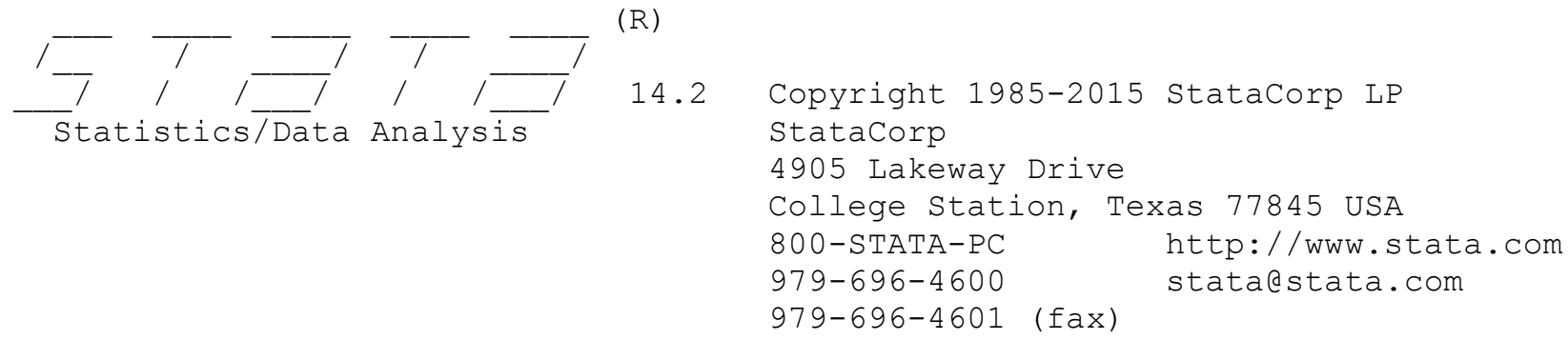

Single-user Stata license expires 29 May 2017:

Serial number: 301409337392

Licensed to: Sandro Vieira Soares

Notes:

1. Unicode is supported; see help unicode advice.

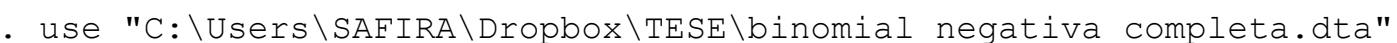

- desc

Contains data from C: \Users \SAFIRA \Dropbox\TESE\binomial negativa completa.dta obs: $\quad 2,540$

vars: 21

size: $\quad 200,660$

29 Jan 2017 16:45

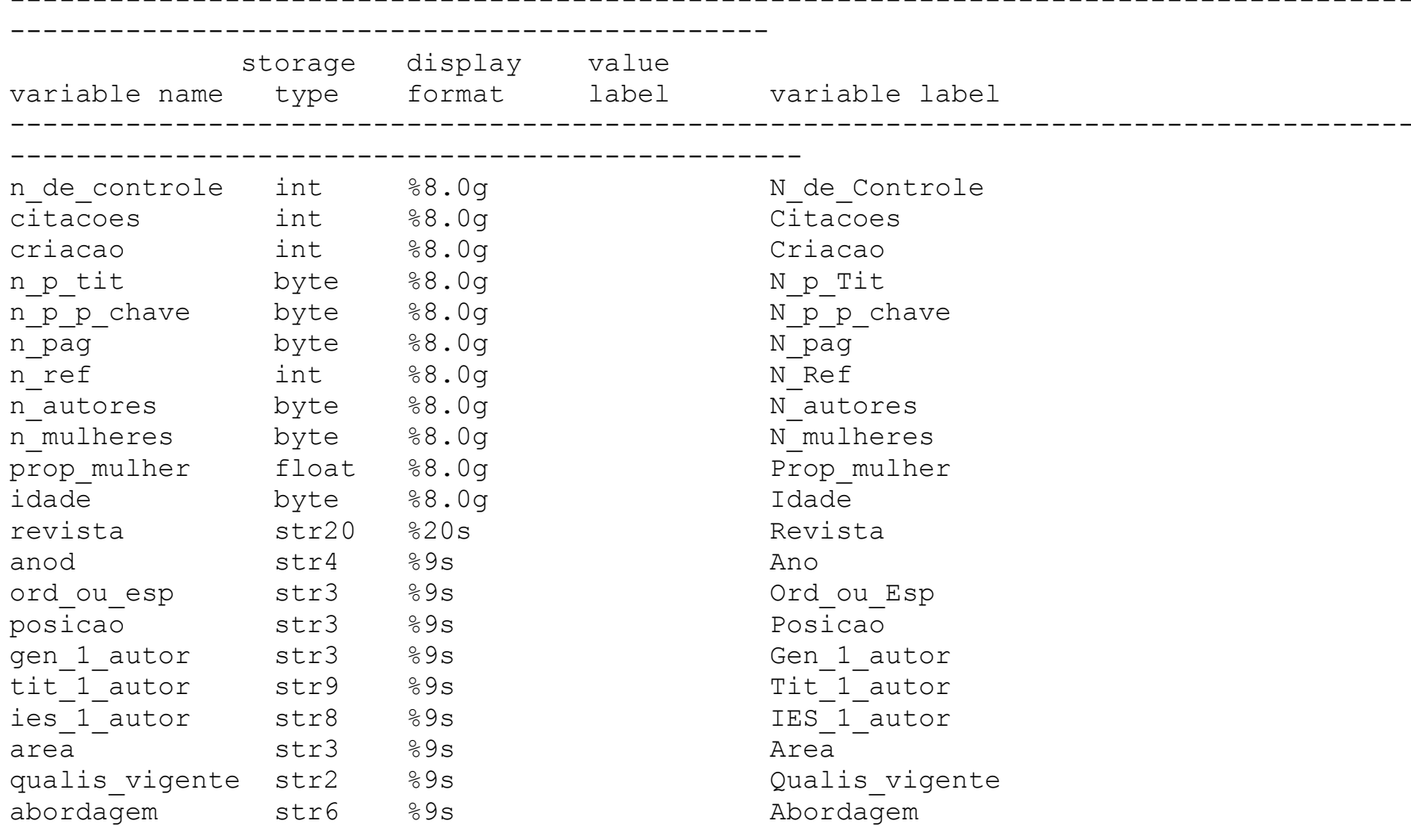

Sorted by:

- tab citacoes

Freq. $\quad$ Percent

Cum . 


\begin{tabular}{|c|c|c|c|c|}
\hline 0 & | & 699 & 27.52 & 27.52 \\
\hline 1 & I & 356 & 14.02 & 41.54 \\
\hline 2 & i & 286 & 11.26 & 52.80 \\
\hline 3 & | & 244 & 9.61 & 62.40 \\
\hline 4 & I & 165 & 6.50 & 68.90 \\
\hline 5 & i & 128 & 5.04 & 73.94 \\
\hline 6 & | & 109 & 4.29 & 78.23 \\
\hline 7 & | & 93 & 3.66 & 81.89 \\
\hline 8 & | & 65 & 2.56 & 84.45 \\
\hline 9 & | & 61 & 2.40 & 86.85 \\
\hline 10 & i & 45 & 1.77 & 88.62 \\
\hline 11 & | & 35 & 1.38 & 90.00 \\
\hline 12 & | & 27 & 1.06 & 91.06 \\
\hline 13 & | & 28 & 1.10 & 92.17 \\
\hline 14 & | & 17 & 0.67 & 92.83 \\
\hline 15 & I & 18 & 0.71 & 93.54 \\
\hline 16 & | & 15 & 0.59 & 94.13 \\
\hline 17 & | & 9 & 0.35 & 94.49 \\
\hline 18 & I & 13 & 0.51 & 95.00 \\
\hline 19 & | & 12 & 0.47 & 95.47 \\
\hline 20 & 1 & 5 & 0.20 & 95.67 \\
\hline 21 & I & 10 & 0.39 & 96.06 \\
\hline 22 & | & 6 & 0.24 & 96.30 \\
\hline 23 & I & 5 & 0.20 & 96.50 \\
\hline 24 & I & 6 & 0.24 & 96.73 \\
\hline 25 & | & 8 & 0.31 & 97.05 \\
\hline 26 & I & 4 & 0.16 & 97.20 \\
\hline 27 & I & 5 & 0.20 & 97.40 \\
\hline 28 & i & 3 & 0.12 & 97.52 \\
\hline 29 & | & 3 & 0.12 & 97.64 \\
\hline 30 & I & 4 & 0.16 & 97.80 \\
\hline 31 & I & 5 & 0.20 & 97.99 \\
\hline 32 & 1 & 5 & 0.20 & 98.19 \\
\hline 33 & I & 1 & 0.04 & 98.23 \\
\hline 34 & I & 4 & 0.16 & 98.39 \\
\hline 35 & I & 4 & 0.16 & 98.54 \\
\hline 37 & I & 2 & 0.08 & 98.62 \\
\hline 38 & I & 5 & 0.20 & 98.82 \\
\hline 39 & | & 3 & 0.12 & 98.94 \\
\hline 41 & I & 1 & 0.04 & 98.98 \\
\hline 42 & | & 2 & 0.08 & 99.06 \\
\hline 43 & | & 1 & 0.04 & 99.09 \\
\hline 44 & I & 2 & 0.08 & 99.17 \\
\hline 45 & 1 & 1 & 0.04 & 99.21 \\
\hline 46 & I & 2 & 0.08 & 99.29 \\
\hline 48 & I & 1 & 0.04 & 99.33 \\
\hline 49 & i & 1 & 0.04 & 99.37 \\
\hline 50 & I & 1 & 0.04 & 99.41 \\
\hline 52 & I & 1 & 0.04 & 99.45 \\
\hline 53 & I & 2 & 0.08 & 99.53 \\
\hline 62 & I & 1 & 0.04 & 99.57 \\
\hline 63 & I & 1 & 0.04 & 99.61 \\
\hline 66 & I & 2 & 0.08 & 99.69 \\
\hline 68 & I & 1 & 0.04 & 99.72 \\
\hline 79 & I & 1 & 0.04 & 99.76 \\
\hline 84 & I & 1 & 0.04 & 99.80 \\
\hline 85 & | & 1 & 0.04 & 99.84 \\
\hline 87 & I & 2 & 0.08 & 99.92 \\
\hline 107 & I & 1 & 0.04 & 99.96 \\
\hline 111 & I & 1 & 0.04 & 100.00 \\
\hline
\end{tabular}




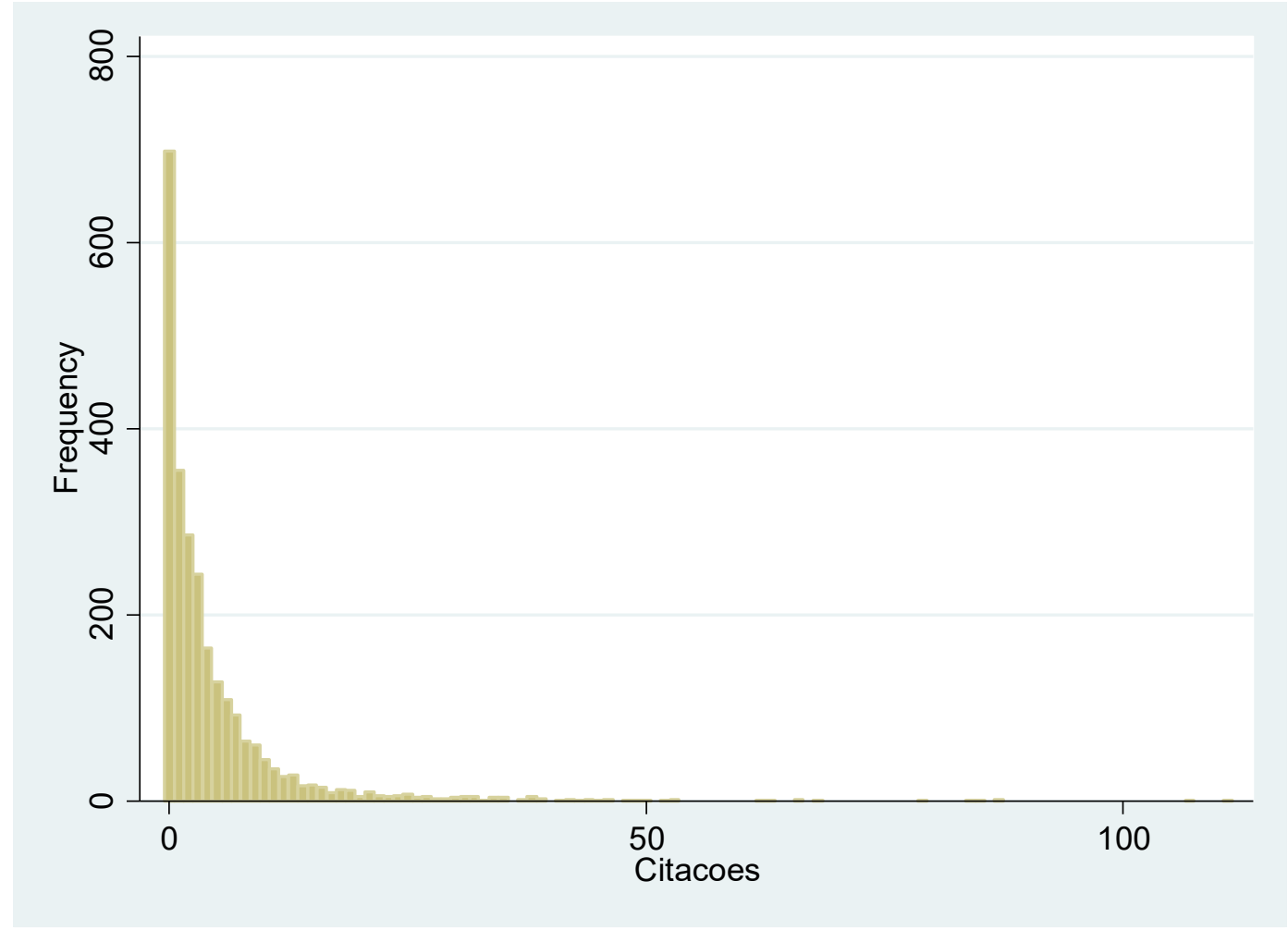

- hist citacoes, discrete freq

( $\operatorname{start}=0$, width=1)

- tabstat citacoes, stats(mean var)

$\begin{array}{ccc}\text { variable | mean } & \text { variance } \\ \text { Citacoes | } & 4.85 & 75.10195\end{array}$

.

-

- xi i.revista i.ord_ou_esp i.posicao i.gen_1_autor i.tit_1_autori.ies_1_autor i.area $i$.qualis vigeñte $i$.abordagem

i.revista - Irevista_1-36

i.ord_ou_esp _Iord_ou_es_1-2

i.posicao $\quad$ Iposicaó_1-2

i.gen_1_autor

i.tit_1_autor

- Igen_1_aut_1-2

Itit_1_aut_1-4

i.ies_1_autor

i. area

i.qualis_vige e

i. abordaḡem

Iies_1_aut_1-20

- Iarea $\overline{1}-6$

- Iqualís_vi_1-8

- Iabordagem_1-2

(_Irevista_1 for rev a==ABCustos omitted)

(_Iord_ou_es_1 for ord_ou p = =Esp omitted)

(Iposicao 1 for posicāo==Out omitted)

(_Igen_1_aut_1 for gen_1_ r==Hom omitted)

(_Itit_1_aut_1 for tit $\overline{ }^{-}=-=$Bacharel omitted)

('Iies ${ }^{-}{ }^{-}$aut ${ }^{1}$ for ies $\sim r==$ FECAP omitted)

('Iareā $\overline{1}$ for area $==$ Edu $\bar{u}$ omitted)

(_Iqualis_vi_1 for qualis_ e==A2 omitted)

(_Iabordagem_1 for abor m==Quali omitted)

.

$\cdot$

- quietly stepwise, pr(0.05): poisson citacoes n_p_tit n_p_p_chave n_pag n_ref n_autores prop_mulher_ _* 
- predict lambda

(option $n$ assumed; predicted number of events)

.

$\cdot$

- gen yasterisco $=\left((\text { citacoes-lambda })^{\wedge} 2-\right.$ citacoes $) /$ lambda

- reg yasterisco lambda, nocons

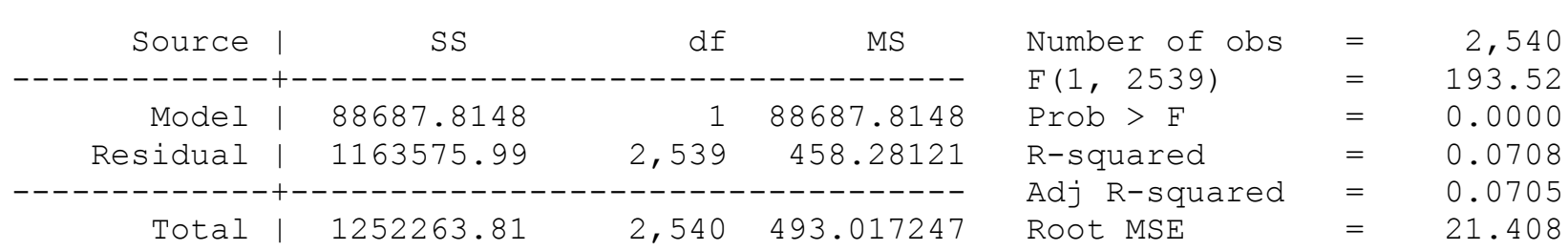

\begin{tabular}{|c|c|c|c|c|c|c|}
\hline yasterisco | & Coef. & Std. Err. & t & $P>|t|$ & [95\% Conf. & Interval] \\
\hline lambda & .8360506 & .0600989 & 13.91 & 0.000 & .7182027 & .9538984 \\
\hline
\end{tabular}

- quietly stepwise, pr(0.05): poisson citacoes n_p_tit n_p_p_chave n_pag n_ref n_autores prop_mulher_ _*

.

- poisgof

$\begin{array}{llr}\text { Deviance goodness-of-fit } & = & 13553.99 \\ \text { Prob }>\text { chi2(2480) } & & 0.0000 \\ & \\ \text { Pearson goodness-of-fit } & = & 16713.8 \\ \text { Prob }>\text { chi2(2480) } & =0.0000\end{array}$

$\cdot$

- stepwise, pr(0.05): nbreg citacoes n_p_tit n_p_p_chave n_pag n_ref n_autores prop_mulher_I*

$\mathrm{p}=0.9970>=0.0500$

$\mathrm{p}=0.9630>=0.0500$

$\mathrm{p}=0.9533>=0.0500$

$\mathrm{p}=0.9410>=0.0500$

$\mathrm{p}=0.8979>=0.0500$

$\mathrm{p}=0.8958>=0.0500$

$\mathrm{p}=0.8855>=0.0500$

$\mathrm{p}=0.8792>=0.0500$

$\mathrm{p}=0.8535>=0.0500$

$\mathrm{p}=0.8471>=0.0500$

$\mathrm{p}=0.8049>=0.0500$

$\mathrm{p}=0.8318>=0.0500$

$\mathrm{p}=0.8323>=0.0500$

$\mathrm{p}=0.6471>=0.0500$

$\mathrm{p}=0.5286>=0.0500$

$\mathrm{p}=0.5351>=0.0500$

$\mathrm{p}=0.5398>=0.0500$

$\mathrm{p}=0.4913>=0.0500$

$\mathrm{p}=0.4765>=0.0500$

begin with full model

removing Iies_1_aut_5

removing Iarea $\overline{5}$

removing Iies_- 1 _aut_13

removing - Itit_ ${ }^{-}{ }^{-}$aut_${ }^{-}$

removing Iarea $\overline{4}$

removing Irevišta 25

removing Iies_1_aut_20

removing _ttit_1_aut_3

removing Irevista $3^{-}$

removing Itit_1 aut 4

removing ${ }^{-}$Iies 1 aut 18

removing Iies 1 aut 15

removing ${ }^{-}$Iies ${ }^{-}$aut 8

removing Irevista $1 \overline{4}$

removing Irevista_20

removing Iies_1_aut_12

removing Iposīcāo $2^{-}$

removing Iies 1 aūt 11

removing _Iies_1_aut_ ${ }^{-}$ 
$\mathrm{p}=0.4005>=0.0500$

$\mathrm{p}=0.3941>=0.0500$

$\mathrm{p}=0.3707>=0.0500$

$\mathrm{p}=0.4442>=0.0500$

$\mathrm{p}=0.4318>=0.0500$

$\mathrm{p}=0.4083>=0.0500$

$\mathrm{p}=0.3259>=0.0500$

$\mathrm{p}=0.3341>=0.0500$

$\mathrm{p}=0.3029>=0.0500$

$\mathrm{p}=0.2517>=0.0500$

$\mathrm{p}=0.2494>=0.0500$

$\mathrm{p}=0.2725>=0.0500$

$\mathrm{p}=0.2216>=0.0500$

$\mathrm{p}=0.2102>=0.0500$

$\mathrm{p}=0.1985>=0.0500$

$\mathrm{p}=0.1891>=0.0500$

$\mathrm{p}=0.1872>=0.0500$

$\mathrm{p}=0.1732>=0.0500$

$\mathrm{p}=0.1610>=0.0500$

$\mathrm{p}=0.1766>=0.0500$

$\mathrm{p}=0.2053>=0.0500$

$\mathrm{p}=0.2009>=0.0500$

$\mathrm{p}=0.1612>=0.0500$ removing $n$ _autores removing prop mulher removing Irevista 13 removing Irevista 27 removing Irevista_22 removing Irevista_11 removing $\bar{n}$ _p_tit removing $\overline{\text { I }}$ ies_1_aut_ 9 removing Iord_ou es_-2 removing Iies_ ${ }^{-}{ }^{-}{ }^{-}{ }^{-}{ }^{-14}$ removing Irevista_ ${ }^{-}$ removing Iies 1 aūt 6 removing Iies_ 1 aut 16 removing $\bar{n}$ _p_p_chave removing Iies_1_aut_3 removing Irevista_2 $\overline{8}$ removing Iabordagè 2 removing Iies_1_aut_17 removing _Irevista_9 removing Irevista_36 removing Irevista- 12 removing $\bar{n}$ pag removing _Iarea_6

Negative binomial regression

Number of obs

LR chi2(37)

Prob > chi2

Pseudo R2
$=$

$=847$

$=\quad 0.0000$

$=0.0641$

$\begin{array}{ll}\text { Dispersion } & =\text { mean } \\ \text { Log likelihood } & =-6187.9691\end{array}$

\begin{tabular}{|c|c|c|c|c|c|c|}
\hline citacoes & Coef. & Std. Err. & z & $P>|z|$ & [95\% Conf. & Interval] \\
\hline & & & & & 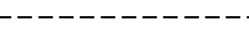 & 10 \\
\hline Iarea_2 & -.3657461 & .0576256 & -6.35 & 0.000 & -.4786903 & -.2528019 \\
\hline Iqualis_vi_8 & 1.740447 & .2357763 & 7.38 & 0.000 & 1.278334 & 2.20256 \\
\hline Irevista_ $\overline{3} 4$ & -.8571388 & .2708108 & -3.17 & 0.002 & -1.387918 & -.3263594 \\
\hline$n_{-} \bar{r} e f$ & .0088002 & .0018386 & 4.79 & 0.000 & .0051966 & .0124038 \\
\hline gen_1_aut_2 & .1181197 & .052594 & 2.25 & 0.025 & .0150374 & .221202 \\
\hline qualis_vi_vi & 1.948513 & .2335502 & 8.34 & 0.000 & 1.490763 & 2.406263 \\
\hline _Irevista_2 & .3724553 & .186319 & 2.00 & 0.046 & .0072768 & .7376337 \\
\hline Irevista_ $\overline{3} 3$ & -.6884747 & .3133172 & -2.20 & 0.028 & -1.302565 & -.0743844 \\
\hline Irevistā_4 & 1.408579 & .184693 & 7.63 & 0.000 & 1.046588 & 1.770571 \\
\hline Irevista_5 & .9534475 & .1432372 & 6.66 & 0.000 & .6727077 & 1.234187 \\
\hline ies_1_aut_4 & -.1856656 & .0563039 & -3.30 & 0.001 & -.2960191 & -.075312 \\
\hline Irēvista_7 & .461012 & .142289 & 3.24 & 0.001 & .1821307 & .7398933 \\
\hline Irevista_8 & 1.054367 & .1234605 & 8.54 & 0.000 & .8123883 & 1.296345 \\
\hline qualis_vi_2 & .848777 & .1828185 & 4.64 & 0.000 & .4904593 & 1.207095 \\
\hline Irevista_ $\overline{1} 0$ & .4904927 & .236948 & 2.07 & 0.038 & .0260832 & .9549023 \\
\hline Iareā_3 & -.2018097 & .0714839 & -2.82 & 0.005 & -.3419156 & -.0617037 \\
\hline Irevista_ $\overline{3} 5$ & -.7541904 & .2779277 & -2.71 & 0.007 & -1.298919 & -.2094622 \\
\hline$\overline{\text { Iqualis_vi__5 }}$ & 1.751222 & .2080309 & 8.42 & 0.000 & 1.343489 & 2.158955 \\
\hline Iqualis_vi_3 & 1.020988 & .192724 & 5.30 & 0.000 & .6432562 & 1.398721 \\
\hline Irevista_15 & -.9858503 & .3664463 & -2.69 & 0.007 & -1.704072 & -.2676288 \\
\hline Irevista_16 & -1.618759 & .3565819 & -4.54 & 0.000 & -2.317647 & -.9198716 \\
\hline Irevista_17 & -.4734442 & .1573685 & -3.01 & 0.003 & -.7818807 & -.1650076 \\
\hline Irevista_18 & 1.179412 & .1816962 & 6.49 & 0.000 & .8232935 & 1.53553 \\
\hline -Irevista_19 & 2.660056 & .152928 & 17.39 & 0.000 & 2.360322 & 2.959789 \\
\hline Iíes_1_aut_19 & .3689656 & .0724799 & 5.09 & 0.000 & .2269076 & .5110235 \\
\hline _Irévista_21 & .9405516 & .1454669 & 6.47 & 0.000 & .6554417 & 1.225661 \\
\hline Iíes_1_aut_10 & .6102907 & .2353534 & 2.59 & 0.010 & .1490066 & 1.071575 \\
\hline Irēvista-23 & 1.097222 & .1326986 & 8.27 & 0.000 & .8371372 & 1.357306 \\
\hline -Irevista_24 & -.6605063 & .1709499 & -3.86 & 0.000 & -.9955618 & -.3254507 \\
\hline Iqualis_ví_4 & 1.368453 & .1926531 & 7.10 & 0.000 & .9908597 & 1.746046 \\
\hline _Irevista_ $\overline{2} 6$ & .9112862 & .1289628 & 7.07 & 0.000 & .6585237 & 1.164049 \\
\hline Iies_1_aut_2 & .4033358 & .1906533 & 2.12 & 0.034 & .0296622 & .7770095 \\
\hline Iqualis_vi_6 & 1.602783 & .2238035 & 7.16 & 0.000 & 1.164137 & 2.04143 \\
\hline Irevista_29 & .8371716 & .1170917 & 7.15 & 0.000 & .6076761 & 1.066667 \\
\hline
\end{tabular}




\begin{tabular}{|c|c|c|c|c|c|c|}
\hline Irevista_30 | & -1.111612 & .1708807 & -6.51 & 0.000 & -1.446532 & -.7766922 \\
\hline -Irevista-31 & -3.328416 & 1.082743 & -3.07 & 0.002 & -5.450553 & -1.206279 \\
\hline Irevista_32 & -1.209714 & .2878117 & -4.20 & 0.000 & -1.773814 & -.6456131 \\
\hline - cons | & -.4998101 & .211011 & -2.37 & 0.018 & -.9133841 & -.086236 \\
\hline /lnalpha & .1621438 & .0385228 & & & .0866405 & \\
\hline Inh? & 17176020 & 015301 & & & & \\
\hline alpha | & 1.176029 & .045304 & & & 1.090 & 1.26 \\
\hline
\end{tabular}

LR test of alpha=0: chibar2 $(01)=7516.29$

Prob $>=$ chibar $2=0.000$

- predict u

(option $\mathrm{n}$ assumed; predicted number of events)

$\cdot$

- stepwise, pr(0.05): nbreg citacoes n_p_tit n_p_p_chave n_pag n_ref n_autores prop_mulher_I*, irr

$\mathrm{p}=0.9970>=0.0500$

$\mathrm{p}=0.9630>=0.0500$

$\mathrm{p}=0.9533>=0.0500$

$\mathrm{p}=0.9410>=0.0500$

$\mathrm{p}=0.8979>=0.0500$

$\mathrm{p}=0.8958>=0.0500$

$\mathrm{p}=0.8855>=0.0500$

$\mathrm{p}=0.8792>=0.0500$

$\mathrm{p}=0.8535>=0.0500$

$\mathrm{p}=0.8471>=0.0500$

$\mathrm{p}=0.8049>=0.0500$

$\mathrm{p}=0.8318>=0.0500$

$\mathrm{p}=0.8323>=0.0500$

$\mathrm{p}=0.6471>=0.0500$

$\mathrm{p}=0.5286>=0.0500$

$\mathrm{p}=0.5351>=0.0500$

$\mathrm{p}=0.5398>=0.0500$

$\mathrm{p}=0.4913>=0.0500$

$\mathrm{p}=0.4765>=0.0500$

$\mathrm{p}=0.4005>=0.0500$

$\mathrm{p}=0.3941>=0.0500$

$\mathrm{p}=0.3707>=0.0500$

$\mathrm{p}=0.4442>=0.0500$

$\mathrm{p}=0.4318>=0.0500$

$\mathrm{p}=0.4083>=0.0500$

$\mathrm{p}=0.3259>=0.0500$

$\mathrm{p}=0.3341>=0.0500$

$\mathrm{p}=0.3029>=0.0500$

$\mathrm{p}=0.2517>=0.0500$

$\mathrm{p}=0.2494>=0.0500$

$\mathrm{p}=0.2725>=0.0500$

$\mathrm{p}=0.2216>=0.0500$

$\mathrm{p}=0.2102>=0.0500$

$\mathrm{p}=0.1985>=0.0500$

$\mathrm{p}=0.1891>=0.0500$

$\mathrm{p}=0.1872>=0.0500$

$\mathrm{p}=0.1732>=0.0500$

$\mathrm{p}=0.1610>=0.0500$

$\mathrm{p}=0.1766>=0.0500$

$\mathrm{p}=0.2053>=0.0500$

$\mathrm{p}=0.2009>=0.0500$

$\mathrm{p}=0.1612>=0.0500$

begin with full model

removing Iies_1_aut_5

removing Iarea $\overline{5}$

removing _Iies_- 1 _aut_13

removing _ttit_1_aut_2

removing Iarea $\overline{4}$

removing Irevista_25

removing Iies_1_aut_20

removing - Itit_1_aut_3

removing Irevista_3

removing Itit_1 aut 4

removing Iies_ ${ }^{-}$-aut_18

removing ${ }^{-}$Iies ${ }^{-}{ }^{-}$aut ${ }^{-} 15$

removing Iies_1_aut_8

removing _Irevista_1 $\overline{4}$

removing Irevista-20

removing Iies_1_aut_ 12

removing Iposicāo_2

removing Iies_1 aut 11

removing Iies_1_aut ${ }^{-}$

removing $\bar{n}$-autores

removing prop_mulher

removing Irevista_13

removing Irevista_27

removing Irevista_22

removing _Irevista_ 11

removing $\bar{n} \mathrm{p}$ tit

removing _ $\overline{\text { I }}$ és_1_aut_9

removing -Iord_ou es_- 2

removing Iies_1_aut_14

removing Irevis̄̄a_ ${ }^{-}$

removing _Iies_1_aut_ 6

removing Iies_1_aut_16

removing $\bar{n} \_p \_p \_c h a v e$

removing Iies 1 aut 3

removing _Irevista_ $2 \overline{8}$

removing _Iabordagem_2

removing Iies_1_aut_17

removing - Irevista_9

removing Irevista_36

removing Irevista_12

removing $\bar{n}$ pag

removing _Iarea_6 
Negative binomial regression

Number of obs

LR chi2 (37)

Prob > chi2

Pseudo R2

$\begin{array}{lr}= & 2,540 \\ = & 847.50 \\ = & 0.0000 \\ = & 0.0641\end{array}$

Log likelihood $=-6187.9691$

\begin{tabular}{|c|c|c|c|c|c|c|}
\hline citacoes & IRR & Std. Err. & z & $\mathrm{P}>|\mathrm{z}|$ & [95\% Conf. & Interval] \\
\hline 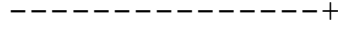 & & & & & & --------- \\
\hline _Iarea_2 & .6936789 & .0399737 & -6.35 & 0.000 & .6195944 & .7766217 \\
\hline Iquāis_vi_8 & 5.699892 & 1.343899 & 7.38 & 0.000 & 3.590653 & 9.048149 \\
\hline _Irevista_ $\overline{3} 4$ & .4243746 & .1149252 & -3.17 & 0.002 & .2495944 & .7215458 \\
\hline n_zef & 1.008839 & .0018549 & 4.79 & 0.000 & 1.00521 & 1.012481 \\
\hline Igen 1 aut 2 & 1.125379 & .0591881 & 2.25 & 0.025 & 1.015151 & 1.247575 \\
\hline Iqualis_vi-7 & 7.018246 & 1.639113 & 8.34 & 0.000 & 4.440484 & 11.09243 \\
\hline Irevista-2 & 1.451294 & .2704035 & 2.00 & 0.046 & 1.007303 & 2.090982 \\
\hline Irevista_ $\overline{3} 3$ & .5023417 & .1573923 & -2.20 & 0.028 & .2718336 & .9283148 \\
\hline -Irevistā_4 & 4.09014 & .7554204 & 7.63 & 0.000 & 2.847916 & 5.874206 \\
\hline Irevista_5 & 2.594639 & .3716489 & 6.66 & 0.000 & 1.959536 & 3.435585 \\
\hline İ̈es_1_aut_4 & .8305513 & .0467633 & -3.30 & 0.001 & .7437732 & .9274541 \\
\hline _Irevista_7 & 1.585678 & .2256245 & 3.24 & 0.001 & 1.199771 & 2.095712 \\
\hline -Irevista-8 & 2.870156 & .354351 & 8.54 & 0.000 & 2.253283 & 3.655909 \\
\hline Iqualis_vi_z 2 & 2.336787 & .427208 & 4.64 & 0.000 & 1.633066 & 3.343756 \\
\hline _Irevista_- $\overline{1} 0$ & 1.633121 & .3869647 & 2.07 & 0.038 & 1.026426 & 2.598417 \\
\hline - Iareā 3 & .8172505 & .0584203 & -2.82 & 0.005 & .7104082 & .9401614 \\
\hline _Irevista_ $\overline{3} 5$ & .4703913 & .1307347 & -2.71 & 0.007 & .2728267 & .8110203 \\
\hline 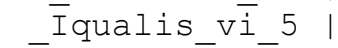 & 5.761638 & 1.198599 & 8.42 & 0.000 & 3.832391 & 8.66208 \\
\hline Iqualis_vi_3 & 2.775937 & .5349898 & 5.30 & 0.000 & 1.902666 & 4.050015 \\
\hline Irevista_ $\overline{1} 5$ & .3731218 & .1367291 & -2.69 & 0.007 & .1819412 & .7651917 \\
\hline Irevista_16 & .1981444 & .0706547 & -4.54 & 0.000 & .0985051 & .3985702 \\
\hline Irevista_-17 & .6228534 & .0980175 & -3.01 & 0.003 & .4575447 & .8478873 \\
\hline Irevista_18 & 3.25246 & .5909596 & 6.49 & 0.000 & 2.27799 & 4.643784 \\
\hline -Irevista_19 & 14.29709 & 2.186424 & 17.39 & 0.000 & 10.59437 & 19.2939 \\
\hline I'ies_1_aut_19 & 1.446238 & .1048232 & 5.09 & 0.000 & 1.254714 & 1.666997 \\
\hline - Irēevista-21 & 2.561394 & .372598 & 6.47 & 0.000 & 1.925993 & 3.406418 \\
\hline Iíes_1_aut_10 & 1.840966 & .4332776 & 2.59 & 0.010 & 1.160681 & 2.919974 \\
\hline Irēvista-23 & 2.995831 & .3975427 & 8.27 & 0.000 & 2.309745 & 3.885712 \\
\hline Irevista-24 & .5165897 & .0883109 & -3.86 & 0.000 & .3695158 & .7222018 \\
\hline İqualis_vī_t4 & 3.929267 & .7569855 & 7.10 & 0.000 & 2.693549 & 5.731894 \\
\hline Irevista_ $\overline{2} 6$ & 2.48752 & .3207976 & 7.07 & 0.000 & 1.931938 & 3.202874 \\
\hline İies_1_aut_2 & 1.496809 & .2853717 & 2.12 & 0.034 & 1.030107 & 2.174958 \\
\hline Iqualis_vi_6 & 4.966837 & 1.111595 & 7.16 & 0.000 & 3.203156 & 7.701615 \\
\hline - Irevista_̄29 & 2.309825 & .2704612 & 7.15 & 0.000 & 1.836159 & 2.905679 \\
\hline -Irevista_30 & .329028 & .0562246 & -6.51 & 0.000 & .2353851 & .4599248 \\
\hline -Irevista_31 & .0358498 & .0388162 & -3.07 & 0.002 & .0042939 & .2993089 \\
\hline -Irevista_32 & .2982827 & .0858492 & -4.20 & 0.000 & .1696845 & .524341 \\
\hline - $\quad$ cons | & .6066459 & .128009 & -2.37 & 0.018 & .4011643 & .9173777 \\
\hline & ---------- & & & & ---------- & --ー-ー-ー-- \\
\hline /lnalpha & .1621438 & .0385228 & & & .0866405 & .2376471 \\
\hline alpha | & 1.176029 & .045304 & & & 1.090505 & 1.268262 \\
\hline
\end{tabular}

LR test of alpha=0: chibar2(01) $=7516.29$

Prob $>=$ chibar $2=0.000$

(1)

- quietly stepwise, pr(0.05): poisson citacoes n_p_tit n_p_p_chave n_pag n_ref n_autores prop_mulher_I*

- prcounts prpoisson, plot

- quietly stepwise, pr(0.05): nbreg citacoes n_p_tit n_p_p_chave n_pag n_ref

n_autores prop_mulher_ _* 
- prcounts prbneg, plot

- graph twoway (scatter prbnegobeq prbnegpreq prpoissonpreq prbnegval, connect (1 1 1))

(note: named style 1 not found in class connectstyle, default attributes used) (note: named style 1 not found in class connectstyle, default attributes used) (note: named style 1 not found in class connectstyle, default attributes used)
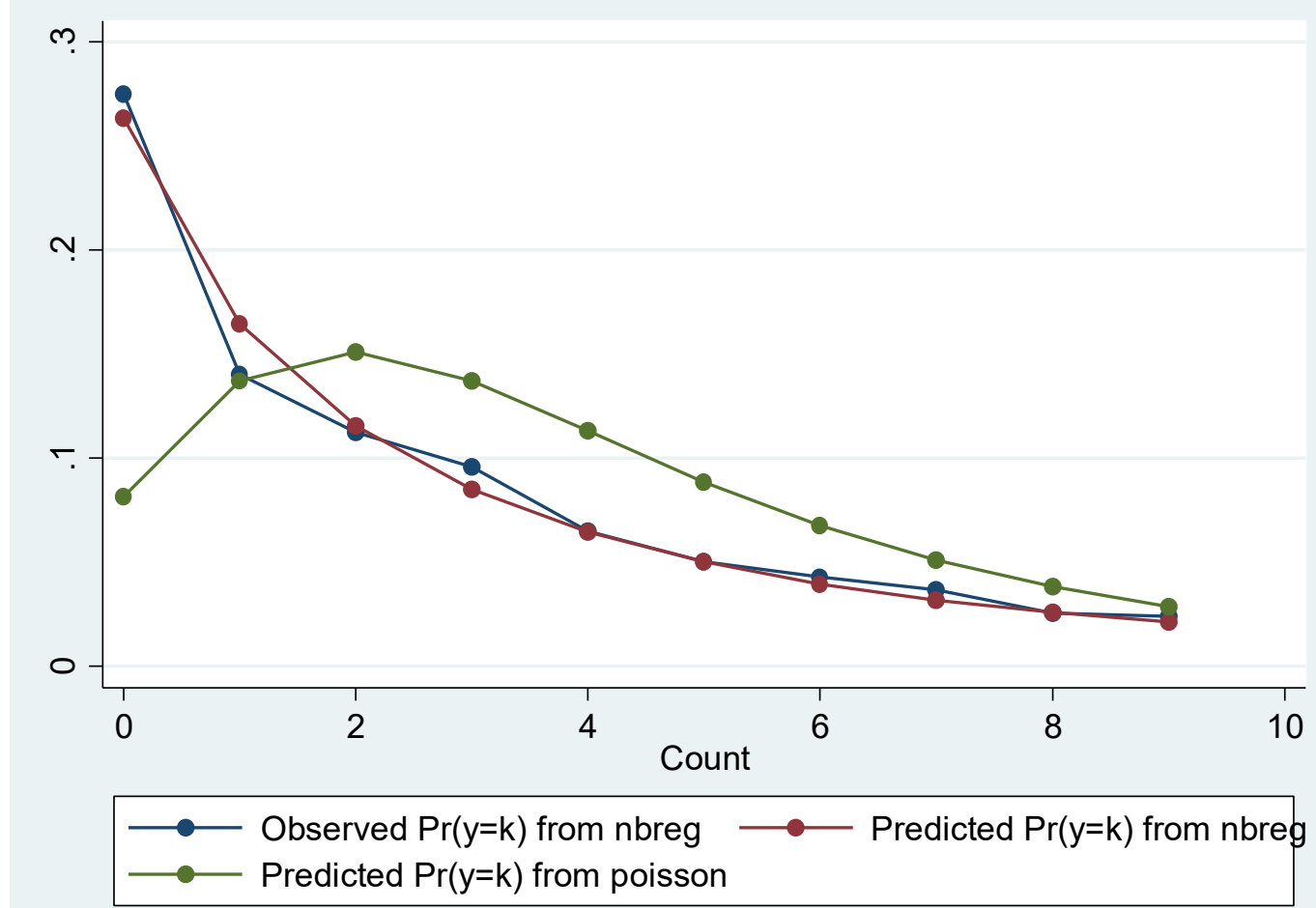

- countfit citacoes n_p_tit n_p_p_chave n_pag n_ref n_autores prop_mulher_I*, prm nograph noestimates nofit

Comparison of Mean Observed and Predicted Count

\begin{tabular}{|c|c|c|c|}
\hline Model & $\begin{array}{c}\text { Maximum } \\
\text { Difference }\end{array}$ & $\begin{array}{c}\text { At } \\
\text { Value }\end{array}$ & $\begin{array}{l}\text { Mean } \\
\mid \text { Diff } \mid\end{array}$ \\
\hline PRM & 0.193 & 0 & 0.042 \\
\hline
\end{tabular}

PRM: Predicted and actual probabilities

\begin{tabular}{|c|c|c|c|c|}
\hline Count & Actual & Predicted & |Diff| & Pearson \\
\hline 0 & 0.275 & 0.082 & 0.193 & 1155.169 \\
\hline 1 & 0.140 & 0.137 & 0.003 & 0.140 \\
\hline 2 & 0.113 & 0.151 & 0.038 & 24.673 \\
\hline 3 & 0.096 & 0.137 & 0.041 & 30.960 \\
\hline 4 & 0.065 & 0.113 & 0.048 & 51.488 \\
\hline 5 & 0.050 & 0.088 & 0.038 & 41.419 \\
\hline 6 & 0.043 & 0.067 & 0.025 & 22.708 \\
\hline 7 & 0.037 & 0.051 & 0.014 & 10.176 \\
\hline 8 & 0.026 & 0.038 & 0.013 & 10.542 \\
\hline 9 & 0.024 & 0.029 & 0.005 & 1.862 \\
\hline & & & & \\
\hline & 369 & 0.894 & 0.417 & 1349. \\
\hline
\end{tabular}


- countfit citacoes n_p_tit n_p_p_chave n_pag n_ref n_autores prop_mulher_I*, nbreg nograph noestimates nofit

Comparison of Mean Observed and Predicted Count

\begin{tabular}{|c|c|c|c|}
\hline & Maximum & At & Mean \\
\hline Model & Difference & Value & $|\operatorname{Diff}|$ \\
\hline NBRM & -0.025 & 1 & 0.006 \\
\hline
\end{tabular}

NBRM: Predicted and actual probabilities

\begin{tabular}{|c|c|c|c|c|}
\hline Count & Actual & Predicted & |Diff| & Pearson \\
\hline & & ---------- & ------ & -------- \\
\hline 0 & 0.275 & 0.263 & 0.012 & 1.503 \\
\hline 1 & 0.140 & 0.165 & 0.025 & 9.787 \\
\hline 2 & 0.113 & 0.116 & 0.003 & 0.264 \\
\hline 3 & 0.096 & 0.085 & 0.011 & 3.415 \\
\hline 4 & 0.065 & 0.065 & 0.000 & 0.003 \\
\hline 5 & 0.050 & 0.050 & 0.000 & 0.004 \\
\hline 6 & 0.043 & 0.040 & 0.003 & 0.729 \\
\hline 7 & 0.037 & 0.032 & 0.005 & 1.959 \\
\hline 8 & 0.026 & 0.026 & 0.000 & 0.001 \\
\hline 9 & 0.024 & 0.021 & 0.003 & 1.040 \\
\hline & & (a) & & ------ \\
\hline Sum & 0.869 & 0.862 & 0.064 & 18.704 \\
\hline
\end{tabular}

- graph twoway mspline u citacoes || mspline lambda citacoes ||, legend(label(1 "Binomial Negativo") label (2 "Poisson"))

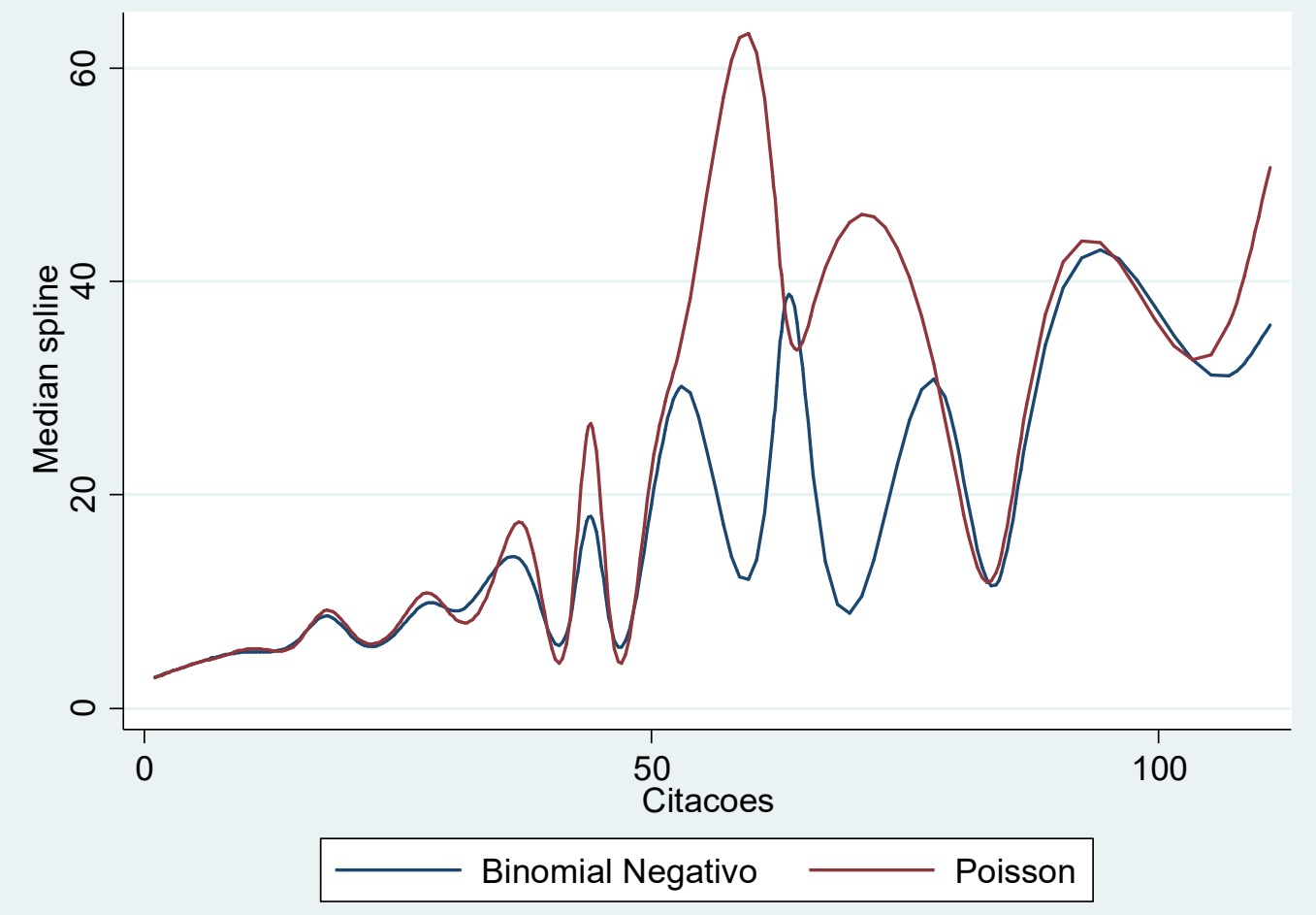

- gen lncitacoes=ln (citacoes)

(699 missing values generated) 
- quietly reg lncitacoes n_p_tit n_p_p_chave n_pag n_ref n_autores prop_mulher_ I*

- predict yhat

(option xb assumed; fitted values)

- gen eyhat $=\exp ($ yhat $)$

$\cdot$

- graph twoway lfit u citacoes || lfit lambda citacoes || lfit eyhat citacoes ||, legend(label(1 "Binomial Negativo") label (2 "Poisso

$>$ n") label (3 "OLS"))

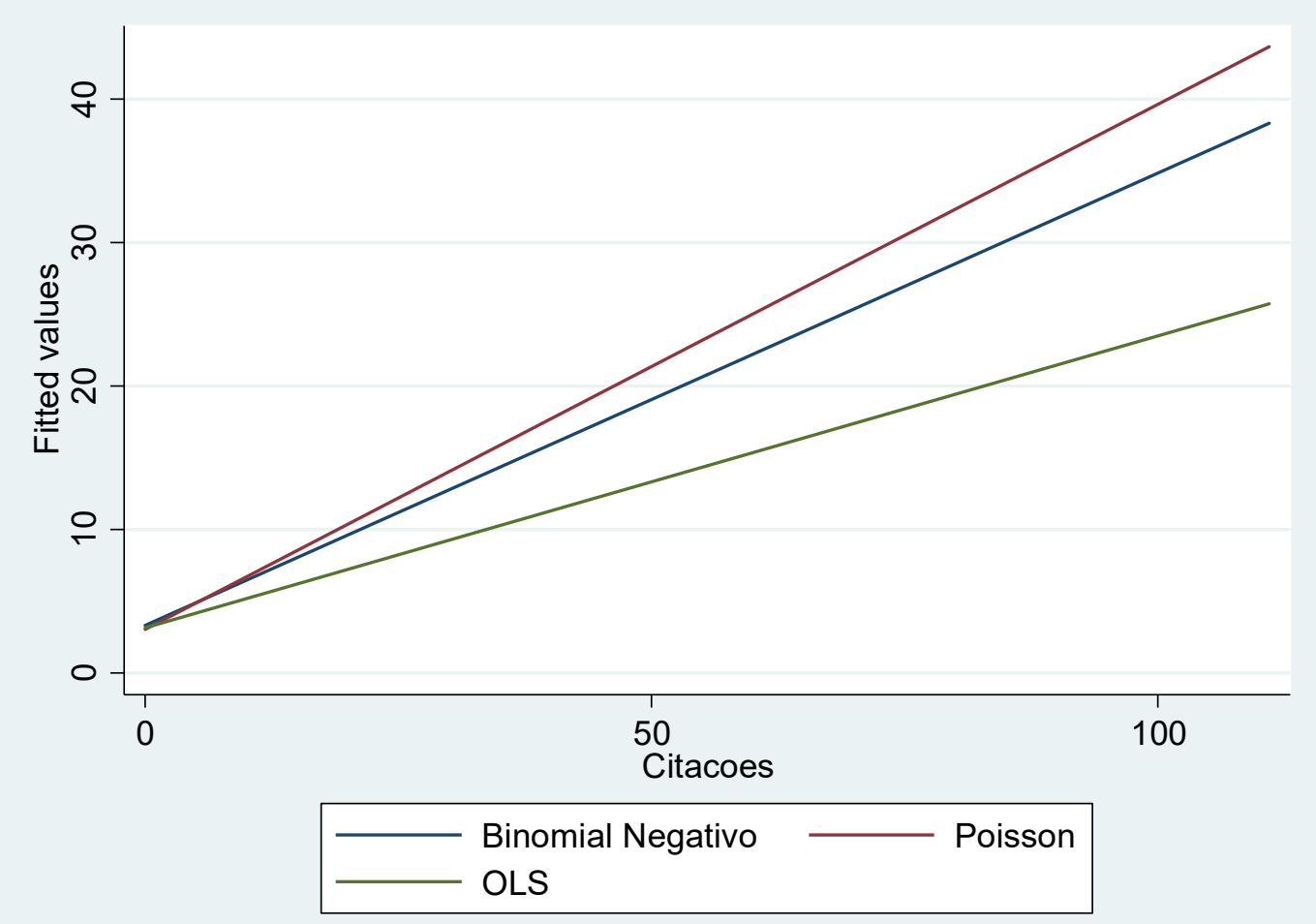


Apêndice N - Saídas do Stata do Modelo 4 - sem as variáveis Idade da revista e Qualis

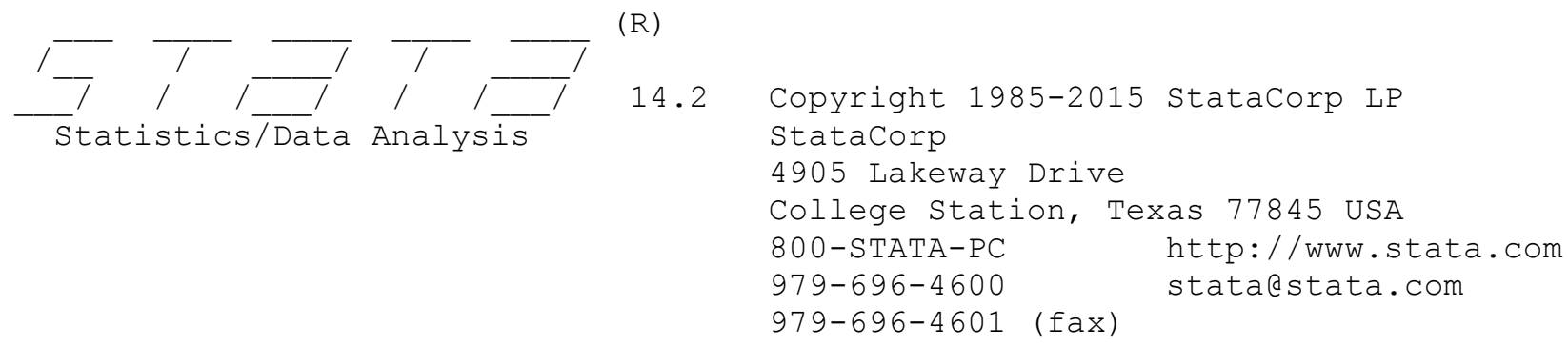

Single-user Stata license expires 29 May 2017:

Serial number: 301409337392

Licensed to: Sandro Vieira Soares

Notes:

1. Unicode is supported; see help unicode_advice.

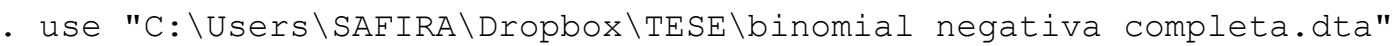

- desc

Contains data from C: \Users \SAFIRA \Dropbox\TESE\binomial negativa completa.dta obs: $\quad 2,540$

vars: 21

size: $\quad 200,660$

29 Jan $2017 \quad 16: 45$

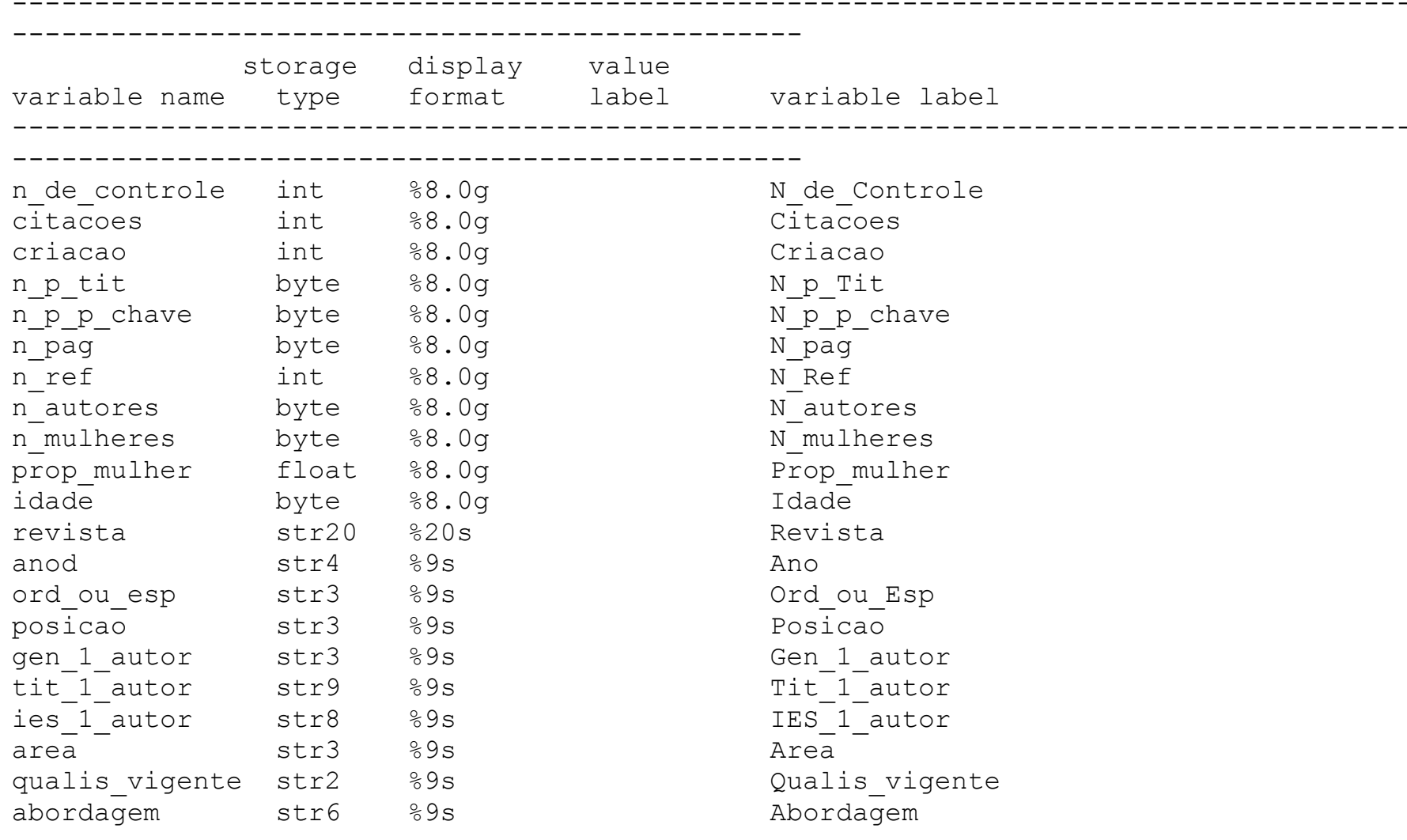

Sorted by:

- tab citacoes

Citacoes I Freq. Percent Cum. 


\begin{tabular}{|c|c|c|c|c|}
\hline 0 & | & 699 & 27.52 & 27.52 \\
\hline 1 & | & 356 & 14.02 & 41.54 \\
\hline 2 & 1 & 286 & 11.26 & 52.80 \\
\hline 3 & | & 244 & 9.61 & 62.40 \\
\hline 4 & | & 165 & 6.50 & 68.90 \\
\hline 5 & | & 128 & 5.04 & 73.94 \\
\hline 6 & | & 109 & 4.29 & 78.23 \\
\hline 7 & | & 93 & 3.66 & 81.89 \\
\hline 8 & | & 65 & 2.56 & 84.45 \\
\hline 9 & i & 61 & 2.40 & 86.85 \\
\hline 10 & i & 45 & 1.77 & 88.62 \\
\hline 11 & i & 35 & 1.38 & 90.00 \\
\hline 12 & i & 27 & 1.06 & 91.06 \\
\hline 13 & | & 28 & 1.10 & 92.17 \\
\hline 14 & | & 17 & 0.67 & 92.83 \\
\hline 15 & i & 18 & 0.71 & 93.54 \\
\hline 16 & i & 15 & 0.59 & 94.13 \\
\hline 17 & | & 9 & 0.35 & 94.49 \\
\hline 18 & i & 13 & 0.51 & 95.00 \\
\hline 19 & 1 & 12 & 0.47 & 95.47 \\
\hline 20 & | & 5 & 0.20 & 95.67 \\
\hline 21 & | & 10 & 0.39 & 96.06 \\
\hline 22 & | & 6 & 0.24 & 96.30 \\
\hline 23 & i & 5 & 0.20 & 96.50 \\
\hline 24 & I & 6 & 0.24 & 96.73 \\
\hline 25 & 1 & 8 & 0.31 & 97.05 \\
\hline 26 & I & 4 & 0.16 & 97.20 \\
\hline 27 & I & 5 & 0.20 & 97.40 \\
\hline 28 & | & 3 & 0.12 & 97.52 \\
\hline 29 & i & 3 & 0.12 & 97.64 \\
\hline 30 & I & 4 & 0.16 & 97.80 \\
\hline 31 & | & 5 & 0.20 & 97.99 \\
\hline 32 & i & 5 & 0.20 & 98.19 \\
\hline 33 & | & 1 & 0.04 & 98.23 \\
\hline 34 & | & 4 & 0.16 & 98.39 \\
\hline 35 & i & 4 & 0.16 & 98.54 \\
\hline 37 & I & 2 & 0.08 & 98.62 \\
\hline 38 & | & 5 & 0.20 & 98.82 \\
\hline 39 & i & 3 & 0.12 & 98.94 \\
\hline 41 & I & 1 & 0.04 & 98.98 \\
\hline 42 & | & 2 & 0.08 & 99.06 \\
\hline 43 & i & 1 & 0.04 & 99.09 \\
\hline 44 & | & 2 & 0.08 & 99.17 \\
\hline 45 & | & 1 & 0.04 & 99.21 \\
\hline 46 & i & 2 & 0.08 & 99.29 \\
\hline 48 & | & 1 & 0.04 & 99.33 \\
\hline 49 & | & 1 & 0.04 & 99.37 \\
\hline 50 & i & 1 & 0.04 & 99.41 \\
\hline 52 & I & 1 & 0.04 & 99.45 \\
\hline 53 & | & 2 & 0.08 & 99.53 \\
\hline 62 & I & 1 & 0.04 & 99.57 \\
\hline 63 & I & 1 & 0.04 & 99.61 \\
\hline 66 & | & 2 & 0.08 & 99.69 \\
\hline 68 & i & 1 & 0.04 & 99.72 \\
\hline 79 & | & 1 & 0.04 & 99.76 \\
\hline 84 & | & 1 & 0.04 & 99.80 \\
\hline 85 & i & 1 & 0.04 & 99.84 \\
\hline 87 & | & 2 & 0.08 & 99.92 \\
\hline 107 & | & 1 & 0.04 & 99.96 \\
\hline 111 & i & 1 & 0.04 & 100.00 \\
\hline
\end{tabular}


- hist citacoes, discrete freq

( start=0, width=1)

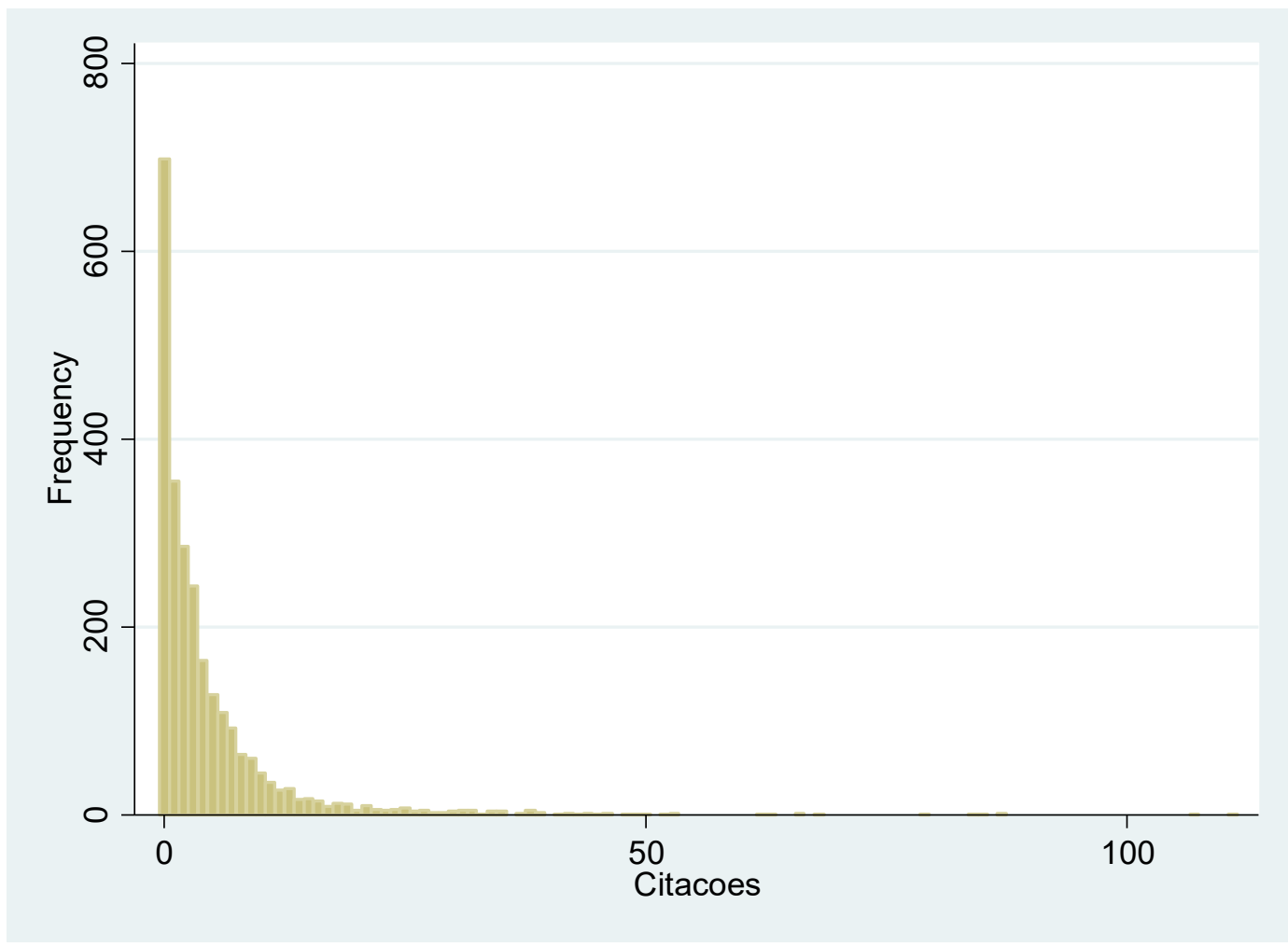

- tabstat citacoes, stats (mean var)

variable | mean variance

citacoes | $\quad 4.85 \quad 75.10195$

- xi i.revista i.ord_ou_esp i.posicao i.gen_1_autor i.tit_1_autor i.ies_1_autor i.area i.abordagem

i.revista

i.ord ou esp

i.posicāo

i.gen_1_autor

i.tit 1 -autor

i.ies 1 autor

i. area

i. abordagem

Irevista $1-36$

Iord ou es 1-2

Iposícāo 1-2

-Igen_1_aut_1-2

Itit 1 aut $1-4$

Iies 1 aut $1-20$

Iarea $\overline{1}-6$

Iabordagem_1-2
( Irevista 1 for rev a==ABCustos omitted)

( Iord ou es 1 for ord ou p==Esp omitted)

(_Iposicao_1 for posicao==Out omitted)

(_Igen_1_aut_1 for gen_1_ r ==Hom omitted)

( Itit ${ }^{-}$aut 1 for tit $\sim r==$ Bacharel omitted)

(_Iies 1 -aut 1 for ies $\sim r==F E C A P$ omitted)

(_Iarea_1 for area $==E d \bar{u}$ omitted)

(_Iabordagem_1 for abor m==Quali omitted)

- quietly stepwise, pr(0.05): poisson citacoes n p tit n p p chave n pag n ref n_autores prop_mulher_I*

- predict lambda

(option $\mathrm{n}$ assumed; predicted number of events) 
- gen yasterisco $=\left((\text { citacoes-lambda })^{\wedge} 2-\right.$ citacoes $) /$ lambda

- reg yasterisco lambda, nocons

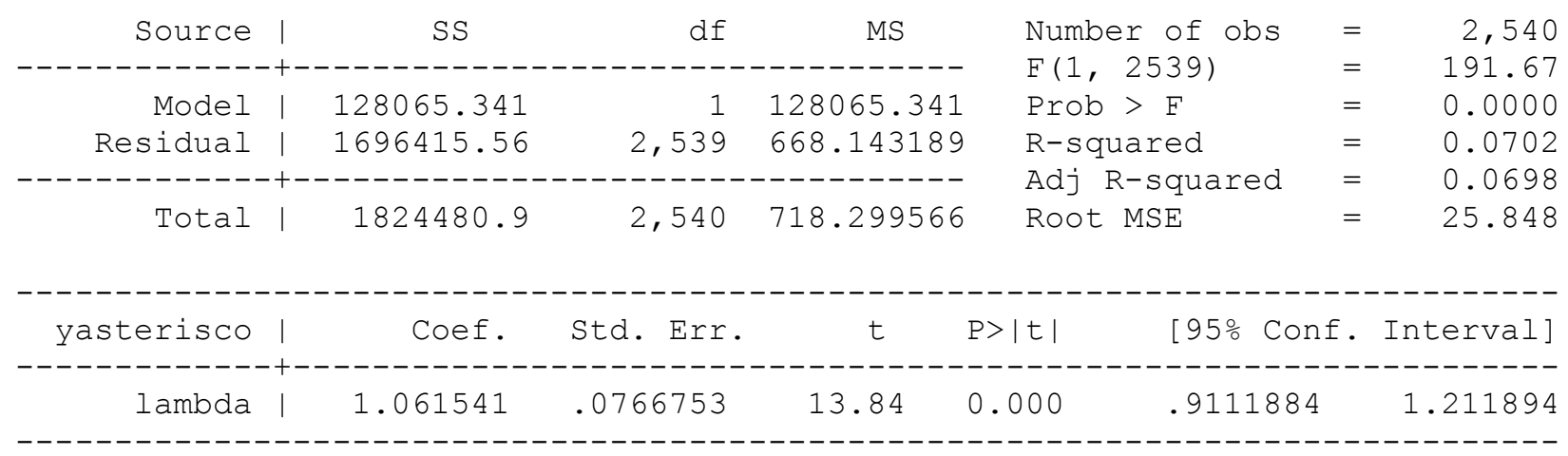

-

.

- quietly stepwise, pr(0.05): poisson citacoes n_p_tit n_p_p_chave n_pag n_ref n_autores prop_mulher_ _ ${ }^{\star}$

$\cdot$

.

- poisgof

\begin{tabular}{|c|c|c|}
\hline $\begin{array}{l}\text { Deviance goodness-of-fit } \\
\text { Prob > chi2(2483) }\end{array}$ & $\begin{array}{l}= \\
=\end{array}$ & $\begin{array}{r}14638.11 \\
0.0000\end{array}$ \\
\hline Pearson goodness-o & & 1852 \\
\hline rob > chi2(2483) & $=$ & \\
\hline
\end{tabular}

$\cdot$

•

- stepwise, pr(0.05): nbreg citacoes n_p_tit n_p_p_chave n_pag n_ref n_autores prop_mulher_ _ *

$\mathrm{p}=0.9952>=0.0500$

begin with full model

$\mathrm{p}=0.9780>=0.0500$

removing Iies_1_aut_18

$\mathrm{p}=0.9597>=0.0500$

$\mathrm{p}=0.9457>=0.0500$

$\mathrm{p}=0.9277>=0.0500$

$\mathrm{p}=0.9170>=0.0500$

$\mathrm{p}=0.8983>=0.0500$

$\mathrm{p}=0.8916>=0.0500$

$\mathrm{p}=0.7998>=0.0500$

$\mathrm{p}=0.7651>=0.0500$

$\mathrm{p}=0.8110>=0.0500$

$\mathrm{p}=0.7956>=0.0500$

$\mathrm{p}=0.8171>=0.0500$

$\mathrm{p}=0.7422>=0.0500$

$\mathrm{p}=0.6468>=0.0500$

$\mathrm{p}=0.5910>=0.0500$

$\mathrm{p}=0.5358>=0.0500$

$\mathrm{p}=0.5195>=0.0500$

removing Irevista $2 \overline{7}$

removing Iarea_4

removing _Irevista_22

removing $\bar{n} \_p a g$

removing - Irevista_2

removing _Itit_1_aut_2

removing $\bar{n}$ autores

removing _ $\overline{\text { Iies_}} 1$ _aut_2

removing Irevista_ $1 \overline{3}$

removing Irevista_ 11

removing - Irevista_ 12

removing -Irevista_36

removing Itit_1 aut 4

removing - Itit_ ${ }^{-}$-aut_3

removing - Iies_ ${ }^{-}{ }^{-}$aut_ 8

removing prop_mu $\bar{l}$ her

removing Iarēa_5

$\mathrm{p}=0.5021>=0.0500$

$\mathrm{p}=0.4948>=0.0500$

$\mathrm{p}=0.5777>=0.0500$

$\mathrm{p}=0.6039>=0.0500$

removing _Iposicao_2

removing -Iies_1_aut_13

removing Iies_1_aut 15

removing Iies_1_aut_20

$\mathrm{p}=0.5947>=0.0500$

removing _Iies_1_aut_5 
$\mathrm{p}=0.4562>=0.0500$

$\mathrm{p}=0.4452>=0.0500$

$\mathrm{p}=0.3636>=0.0500$

$\mathrm{p}=0.2654>=0.0500$

$\mathrm{p}=0.2585>=0.0500$

$\mathrm{p}=0.2730>=0.0500$

$\mathrm{p}=0.2144>=0.0500$

$\mathrm{p}=0.2433>=0.0500$

$\mathrm{p}=0.2251>=0.0500$

$\mathrm{p}=0.2215>=0.0500$

$\mathrm{p}=0.2475>=0.0500$

$\mathrm{p}=0.2373>=0.0500$

$\mathrm{p}=0.2122>=0.0500$

$\mathrm{p}=0.1814>=0.0500$

$\mathrm{p}=0.1760>=0.0500$

$\mathrm{p}=0.1515>=0.0500$

$\mathrm{p}=0.1361>=0.0500$

$\mathrm{p}=0.1376>=0.0500$

$\mathrm{p}=0.0930>=0.0500$

$\mathrm{p}=0.1228>=0.0500$

$\mathrm{p}=0.0776>=0.0500$

$\mathrm{p}=0.0758>=0.0500$ removing Irevista_14

removing Irevista-20

removing Iies_1_aut_ 11

removing _Irevista_ $2 \overline{5}$

removing $\bar{n}$ p tit

removing Iordou es_2

removing Iies_1_aut_ 6

removing Iies_1_aut_14

removing $\overline{\mathrm{n}} \mathrm{p}$ _p_chave

removing Iies_1_aut_9

removing ${ }^{-}$Iies ${ }^{-}{ }^{-}$aut ${ }^{-} 7$

removing Irevista 6

removing Irevista 17

removing Iies 1 aüt 12

removing Irevista_ $3 \overline{5}$

removing Iarea 3

removing ${ }^{-}$Iarea 6

removing _Irevista_24

removing Iies_1_aūt_17

removing Irevista 9 -

removing Irevista 33

removing Iies_1 aūt_10

Negative binomial regression

Number of obs LR $\operatorname{chi} 2(27)$

Prob > chi2

Pseudo R2 $=\quad 2,540$

732.45

0.0000

0.0554

Log likelihood $=-6245.4937$

\begin{tabular}{|c|c|c|c|c|c|c|}
\hline citacoes & Coef. & Std. Err. & z & $\mathrm{P}>|\mathrm{z}|$ & [95\% Conf. & Interval] \\
\hline & & & & & & \\
\hline _Iies_1_aut_4 & -.2702024 & .0597739 & -4.52 & 0.000 & -.387357 & -.1530477 \\
\hline Igen_1_aut_2 & .1344328 & .0536234 & 2.51 & 0.012 & .0293328 & .2395328 \\
\hline _Irevista_ 29 & .5853549 & .0983729 & 5.95 & 0.000 & .3925475 & .7781622 \\
\hline$-\quad n \_\overline{r e f}$ & .0050624 & .0018178 & 2.78 & 0.005 & .0014996 & .0086252 \\
\hline Iies_1_aut_19 & .2943609 & .0766325 & 3.84 & 0.000 & .144164 & .4445578 \\
\hline Irevista_23 & .8194125 & .115251 & 7.11 & 0.000 & .5935247 & 1.0453 \\
\hline - Iareā 2 & -.2925257 & .056345 & -5.19 & 0.000 & -.4029599 & -.1820916 \\
\hline Irēevista-3 & -.5249681 & .2036762 & -2.58 & 0.010 & -.9241661 & -.1257701 \\
\hline _Irevista_4 & .6372387 & .150024 & 4.25 & 0.000 & .3431972 & .9312803 \\
\hline -Irevista_5 & .5385436 & .135921 & 3.96 & 0.000 & .2721434 & .8049439 \\
\hline _- Irevista_ $\overline{2} 8$ & .3293073 & .1246106 & 2.64 & 0.008 & .0850749 & 5396 \\
\hline _Irevistā 7 & .5965696 & .1284664 & 4.64 & 0.000 & .34478 & .8483591 \\
\hline -Irevista_8 & .824802 & .1085636 & 7.60 & 0.000 & .6120213 & 1.037583 \\
\hline - $\bar{I} r e v i s t a \_\overline{3} 1$ & -2.857072 & 1.079678 & -2.65 & 0.008 & -4.973201 & -.7 \\
\hline Irevista_10 & .6033126 & .2377149 & 2.54 & 0.011 & .1374001 & 9225 \\
\hline I'ies_1_aut_16 & -.2465471 & .1104398 & -2.23 & 0.026 & -.4630052 & -.0300891 \\
\hline Irēvista-34 & -.9525753 & .270 & -3.53 & 0.000 & -1.481773 & 33776 \\
\hline -Irevista_26 & .7997899 & .1272283 & 6.29 & 0.000 & .550427 & 1.049153 \\
\hline İies_1_aut_3 & -.2821948 & .1162645 & -2.43 & 0.015 & -.510069 & -.0543207 \\
\hline _Irevista_ $\overline{1} 5$ & -1.028041 & .3680617 & -2.79 & 0.005 & -1.749429 & -.3066534 \\
\hline -Irevista_16 & -1.417211 & .3514289 & -4.03 & 0.000 & -2.105999 & -.7284232 \\
\hline -Irevista_32 & -.9121673 & .2869787 & -3.18 & 0.001 & -1.474635 & -.3496995 \\
\hline -Irevista_18 & .8215581 & .1713887 & 4.79 & 0.000 & .4856425 & 1.157474 \\
\hline -Irevista_19 & 1.942391 & .1179104 & 16.47 & 0.000 & 1.711291 & 2.173491 \\
\hline Iabordage $\overline{\text { I }}$ _2 & -.1079533 & .0520474 & -2.07 & 0.038 & -.2099644 & -.0059423 \\
\hline _Irevista_ $\overline{2} 1$ & .6583359 & .1321124 & 4.98 & 0.000 & .3994003 & .9172715 \\
\hline -Irevista_30 & -.6872034 & .1576945 & -4.36 & 0.000 & -.9962789 & -.3781278 \\
\hline- cons & 1.084139 & .0772658 & 14.03 & 0.000 & .9327011 & 1.235577 \\
\hline & & 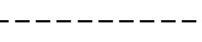 & & & ---------1 & ---------- \\
\hline /lnalpha & .2325953 & .0375684 & & & .1589626 & .3062281 \\
\hline & 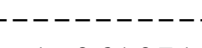 & & & & & \\
\hline alpha | & 1.261871 & .0474065 & & & 1.172294 & 1.358292 \\
\hline
\end{tabular}

LR test of alpha=0: chibar2 $(01)=8612.72$

Prob $>=$ chibar $2=0.000$ 
.

- stepwise, pr(0.05): nbreg citacoes n_p_tit n_p_p_chave n_pag n_ref n_autores prop_mulher_I*, irr

$\mathrm{p}=0.9952>=0.0500$

$\mathrm{p}=0.9780>=0.0500$

$\mathrm{p}=0.9597>=0.0500$

$\mathrm{p}=0.9457>=0.0500$

$\mathrm{p}=0.9277>=0.0500$

$\mathrm{p}=0.9170>=0.0500$

$\mathrm{p}=0.8983>=0.0500$

$\mathrm{p}=0.8916>=0.0500$

$\mathrm{p}=0.7998>=0.0500$

$\mathrm{p}=0.7651>=0.0500$

$\mathrm{p}=0.8110>=0.0500$

$\mathrm{p}=0.7956>=0.0500$

$\mathrm{p}=0.8171>=0.0500$

$\mathrm{p}=0.7422>=0.0500$

$\mathrm{p}=0.6468>=0.0500$

$\mathrm{p}=0.5910>=0.0500$

$\mathrm{p}=0.5358>=0.0500$

$\mathrm{p}=0.5195>=0.0500$

$\mathrm{p}=0.5021>=0.0500$

$\mathrm{p}=0.4948>=0.0500$

$\mathrm{p}=0.5777>=0.0500$

$\mathrm{p}=0.6039>=0.0500$

$\mathrm{p}=0.5947>=0.0500$

$\mathrm{p}=0.4562>=0.0500$

$\mathrm{p}=0.4452>=0.0500$

$\mathrm{p}=0.3636>=0.0500$

$\mathrm{p}=0.2654>=0.0500$

$\mathrm{p}=0.2585>=0.0500$

$\mathrm{p}=0.2730>=0.0500$

$\mathrm{p}=0.2144>=0.0500$

$\mathrm{p}=0.2433>=0.0500$

$\mathrm{p}=0.2251>=0.0500$

$\mathrm{p}=0.2215>=0.0500$

$\mathrm{p}=0.2475>=0.0500$

$\mathrm{p}=0.2373>=0.0500$

$\mathrm{p}=0.2122>=0.0500$

$\mathrm{p}=0.1814>=0.0500$

$\mathrm{p}=0.1760>=0.0500$

$\mathrm{p}=0.1515>=0.0500$

$\mathrm{p}=0.1361>=0.0500$

$\mathrm{p}=0.1376>=0.0500$

$\mathrm{p}=0.0930>=0.0500$

$\mathrm{p}=0.1228>=0.0500$

$\mathrm{p}=0.0776>=0.0500$

$\mathrm{p}=0.0758>=0.0500$

begin with full model

removing Iies_1_aut_18

removing _Irevista_a_ $2 \overline{7}$

removing Iarea_4

removing Irevista_22

removing $\bar{n} \_p a g$

removing Irevista_2

removing - Itit_1_aūt_2

removing $\bar{n}$ autores

removing İies_1_aut_2

removing Irevista $1 \overline{3}$

removing Irevista_11

removing Irevista 12

removing _Irevista_36

removing - Itit_1_aūt_4

removing - Itit_1_aut_3

removing Iies_ ${ }^{-}$aut_8

removing prop_mulher

removing Iarea_5

removing Iposicao_2

removing Iies_1_aūt_13

removing Iies_ 1 -aut_ 15

removing - Iies_ ${ }^{-}$-aut_20

removing _Iies_1_aut_5

removing Irevista $1 \overline{4}$

removing _Irevista_20

removing Iies_1_aut_11

removing Irevista_ $2 \overline{5}$

removing $\bar{n}$ _p_tit

removing _ $\overline{\text { Iord_ou_es_2 }}$

removing -Iies_1_aut_6

removing Iies_1_aut_14

removing $\bar{n} \_p \_p$ _chave

removing $\overline{\text { I }}$ ies_- 1 _aut_9

removing Iies ${ }^{-}$aut 7

removing Irevis̄̄a $6^{-}$

removing -Irevista_17

removing Iies_1_aut_12

removing _Irevista_ $3 \overline{5}$

removing Iarea_3

removing Iarea-6

removing Irevista_24

removing Iies 1 aūt 17

removing Irevista_9

removing Irevista-33

removing _Iies_1_aut_10

Negative binomial regression

Number of obs

$=$

2,540

LR chi2 (27)

Prob > chi2

Dispersion = mean

Log likelihood $=-6245.4937$

Pseudo R2

732.45

$\begin{array}{ll}= & 0.0000 \\ = & 0.0554\end{array}$

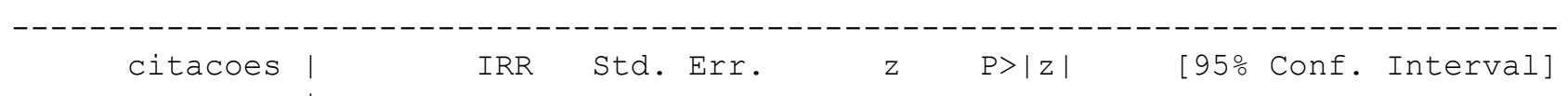




\begin{tabular}{|c|c|c|c|c|c|c|}
\hline _Iies_1_aut_4 & .763225 & .0456209 & -4.52 & 0.000 & .6788487 & .8580888 \\
\hline -Igen_1_aut_2 & 1.143888 & .0613392 & 2.51 & 0.012 & 1.029767 & 1.270655 \\
\hline - Irevista_ 29 & 1.795628 & .1766411 & 5.95 & 0.000 & 1.480748 & 2.177467 \\
\hline$-\quad n \_\bar{r} e f$ & 1.005075 & .001827 & 2.78 & 0.005 & 1.001501 & 1.008662 \\
\hline Iies_1_aut_19 & 1.342268 & .1028614 & 3.84 & 0.000 & 1.155073 & 1.5598 \\
\hline _Irevista_23 & 2.269166 & .2615237 & 7.11 & 0.000 & 1.810358 & 2.844253 \\
\hline - _Iareā_2 & .746376 & .0420545 & -5.19 & 0.000 & .6683389 & .833525 \\
\hline _Irēvista_3 & .5915742 & .1204896 & -2.58 & 0.010 & .3968622 & .8818175 \\
\hline -Irevista_4 & 1.891251 & .283733 & 4.25 & 0.000 & 1.409447 & 2.537756 \\
\hline -Irevista_5 & 1.71351 & .2329019 & 3.96 & 0.000 & 1.312775 & 2.236571 \\
\hline _- Irevista_ $\overline{2} 8$ & 1.390005 & .1732094 & 2.64 & 0.008 & 1.088799 & 1.774537 \\
\hline -_Irevistā 7 & 1.815879 & .2332794 & 4.64 & 0.000 & 1.411679 & 2.335811 \\
\hline -Irevista_8 & 2.281429 & .24768 & 7.60 & 0.000 & 1.844155 & 2.822386 \\
\hline _- & .0574367 & .0620131 & -2.65 & 0.008 & .006921 & .4766646 \\
\hline - Irevista_10 & 1.828165 & .4345819 & 2.54 & 0.011 & 1.147287 & 2.913122 \\
\hline Iîes_1_aut_16 & .7814945 & .0863081 & -2.23 & 0.026 & .6293893 & .970359 \\
\hline _Irēvista-34 & .3857463 & .104153 & -3.53 & 0.000 & .2272344 & .6548314 \\
\hline Irevista_26 & 2.225073 & .2830922 & 6.29 & 0.000 & 1.733993 & 2.855231 \\
\hline - $\bar{I}$ ies_1_aut_3 & .7541267 & .0876781 & -2.43 & 0.015 & .6004541 & .9471283 \\
\hline -_Irevista_ $\overline{15}$ & .357707 & .1316582 & -2.79 & 0.005 & .1738733 & .7359057 \\
\hline - Irevista_16 & .2423891 & .0851825 & -4.03 & 0.000 & .121724 & .482669 \\
\hline Irevista-32 & .4016528 & .1152658 & -3.18 & 0.001 & .2288622 & .704899 \\
\hline -Irevista_18 & 2.27404 & .3897447 & 4.79 & 0.000 & 1.625219 & 3.1818 \\
\hline -Irevista_19 & 6.975411 & .8224732 & 16.47 & 0.000 & 5.536105 & 8.7889. \\
\hline $\bar{I}$ abordage $\bar{m} 2$ & .8976695 & .0467214 & -2.07 & 0.038 & .8106131 & .99407 \\
\hline _Irevista_ $\overline{2} 1$ & 1.931575 & .2551851 & 4.98 & 0.000 & 1.49093 & 2.50245 \\
\hline -Irevista_30 & .5029808 & .0793173 & -4.36 & 0.000 & .3692509 & .685142 \\
\hline- & 2.956893 & .2284666 & 14.03 & 0.000 & 2.541364 & 3.44036 \\
\hline & & & & & & --------- \\
\hline / Inalpha & .2325953 & .0375684 & & & .1589626 & .30622 \\
\hline & & & & & & \\
\hline alpha | & 1.261871 & .0474065 & & & 1.172294 & 1.3582 \\
\hline
\end{tabular}

LR test of alpha=0: $\operatorname{chibar2}(01)=8612.72$

Prob $>=$ chibar $2=0.000$

.

•

- quietly stepwise, pr(0.05): poisson citacoes n_p_tit n_p_p_chave n_pag n_ref n_autores prop_mulher_I*

- prcounts prpoisson, plot

- quietly stepwise, pr(0.05): nbreg citacoes n_p_tit n_p_p_chave n_pag n_ref

n_autores prop_mulher_ _ ${ }^{*}$

- prcounts proneg, plot

- graph twoway (scatter prbnegobeq prbnegpreq prpoissonpreq prbnegval, connect (1 1 1))

(note: named style 1 not found in class connectstyle, default attributes used) (note: named style 1 not found in class connectstyle, default attributes used) (note: named style 1 not found in class connectstyle, default attributes used) 


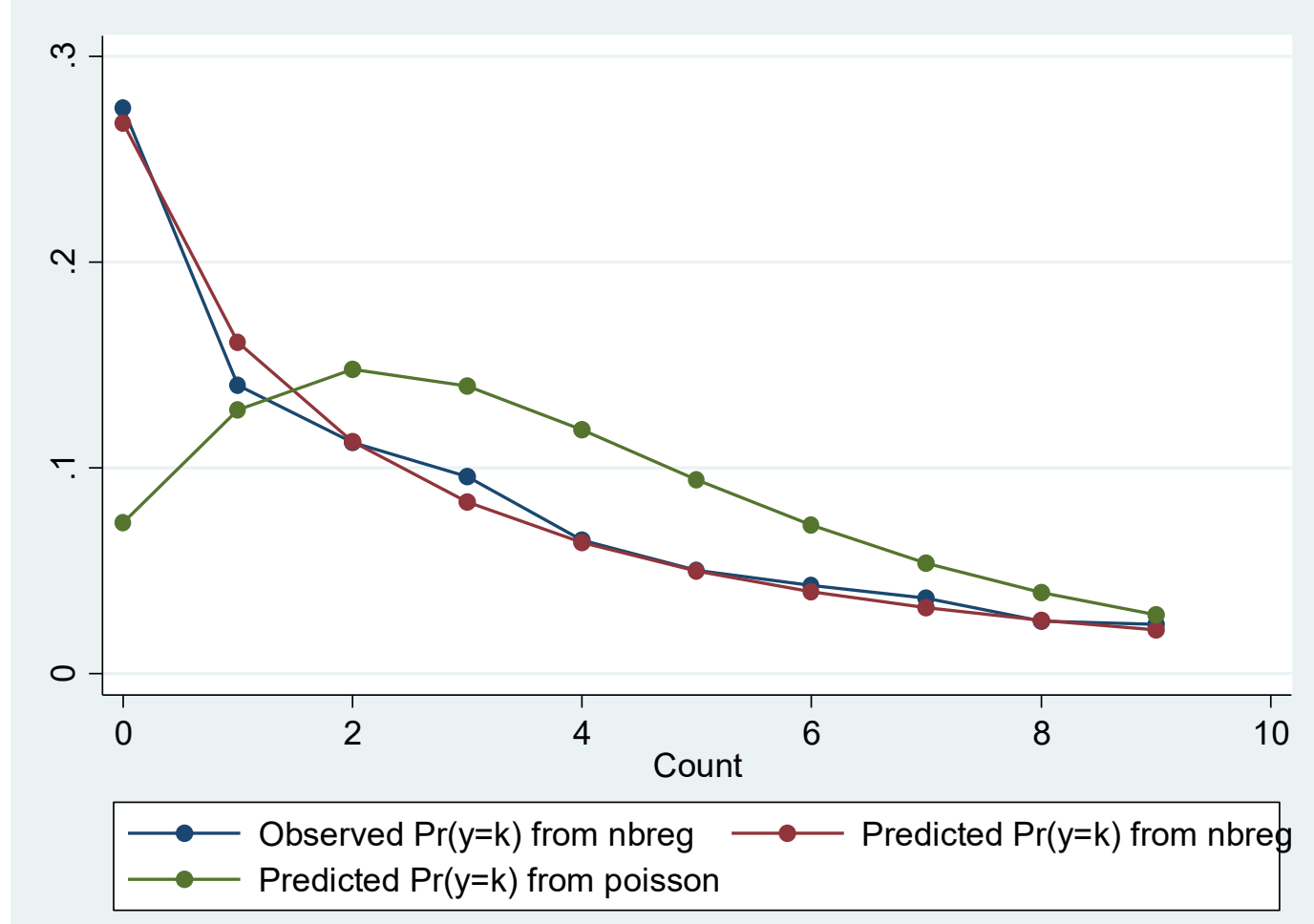

- countfit citacoes n_p_tit n_p_p_chave n_pag n_ref n_autores prop_mulher__*, prm nograph noestimates nofit

Comparison of Mean Observed and Predicted Count

$\begin{array}{lccc} & \text { Maximum } & \text { At } & \text { Mean } \\ \text { Model } & \text { Difference } & \text { Value } & \mid \text { Diff } \mid \\ ------1 & 0 & 0.045\end{array}$

PRM: Predicted and actual probabilities

\begin{tabular}{|c|c|c|c|c|}
\hline Count & Actual & Predicted & |Diff | & Pearson \\
\hline \multicolumn{5}{|c|}{--------------------------------------------------} \\
\hline 0 & 0.275 & 0.074 & 0.202 & 1400.564 \\
\hline 1 & 0.140 & 0.128 & 0.012 & 2.738 \\
\hline 2 & 0.113 & 0.148 & 0.035 & 21.410 \\
\hline 3 & 0.096 & 0.140 & 0.044 & 34.810 \\
\hline 4 & 0.065 & 0.119 & 0.054 & 61.577 \\
\hline 5 & 0.050 & 0.094 & 0.044 & 51.998 \\
\hline 6 & 0.043 & 0.072 & 0.029 & 30.104 \\
\hline 7 & 0.037 & 0.054 & 0.017 & 13.918 \\
\hline 8 & 0.026 & 0.039 & 0.014 & 12.287 \\
\hline 9 & 0.024 & 0.029 & 0.005 & 1.831 \\
\hline & 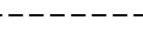 & ------- & & ------ \\
\hline & 0.869 & 0.897 & 0.455 & 1631.2 \\
\hline
\end{tabular}

- countfit citacoes n_p_tit n_p_p_chave n_pag n_ref n_autores prop_mulher _ I*, nbreg nograph noestimates nofit

Comparison of Mean Observed and Predicted Count

\begin{tabular}{|c|c|c|c|}
\hline Model & $\begin{array}{c}\text { Maximum } \\
\text { Difference }\end{array}$ & $\begin{array}{c}\text { At } \\
\text { Value }\end{array}$ & $\begin{array}{l}\text { Mean } \\
\mid \text { Diff| }\end{array}$ \\
\hline IRPM & -0.022 & 1 & 0.006 \\
\hline
\end{tabular}

NBRM: Predicted and actual probabilities 


$\begin{array}{lcccc}\text { Count } & \text { Actual } & \text { Predicted } & \mid \text { Diff| } & \text { Pearson } \\ ------1 & \\ 0 & 0.275 & 0.267 & 0.008 & 0.667 \\ 1 & 0.140 & 0.162 & 0.022 & 7.690 \\ 2 & 0.113 & 0.114 & 0.001 & 0.024 \\ 3 & 0.096 & 0.084 & 0.012 & 4.443 \\ 4 & 0.065 & 0.064 & 0.001 & 0.034 \\ 5 & 0.050 & 0.050 & 0.000 & 0.009 \\ 6 & 0.043 & 0.040 & 0.003 & 0.672 \\ 7 & 0.037 & 0.032 & 0.005 & 1.727 \\ 8 & 0.026 & 0.026 & 0.000 & 0.020 \\ 9 & 0.024 & 0.021 & 0.003 & 0.782 \\ ---------------------------------------- \\ \text { Sum } & 0.869 & 0.860 & 0.056 & 16.069\end{array}$

- graph twoway mspline u citacoes || mspline lambda citacoes ||, legend(label(1 "Binomial Negativo") label(2 "Poisson"))

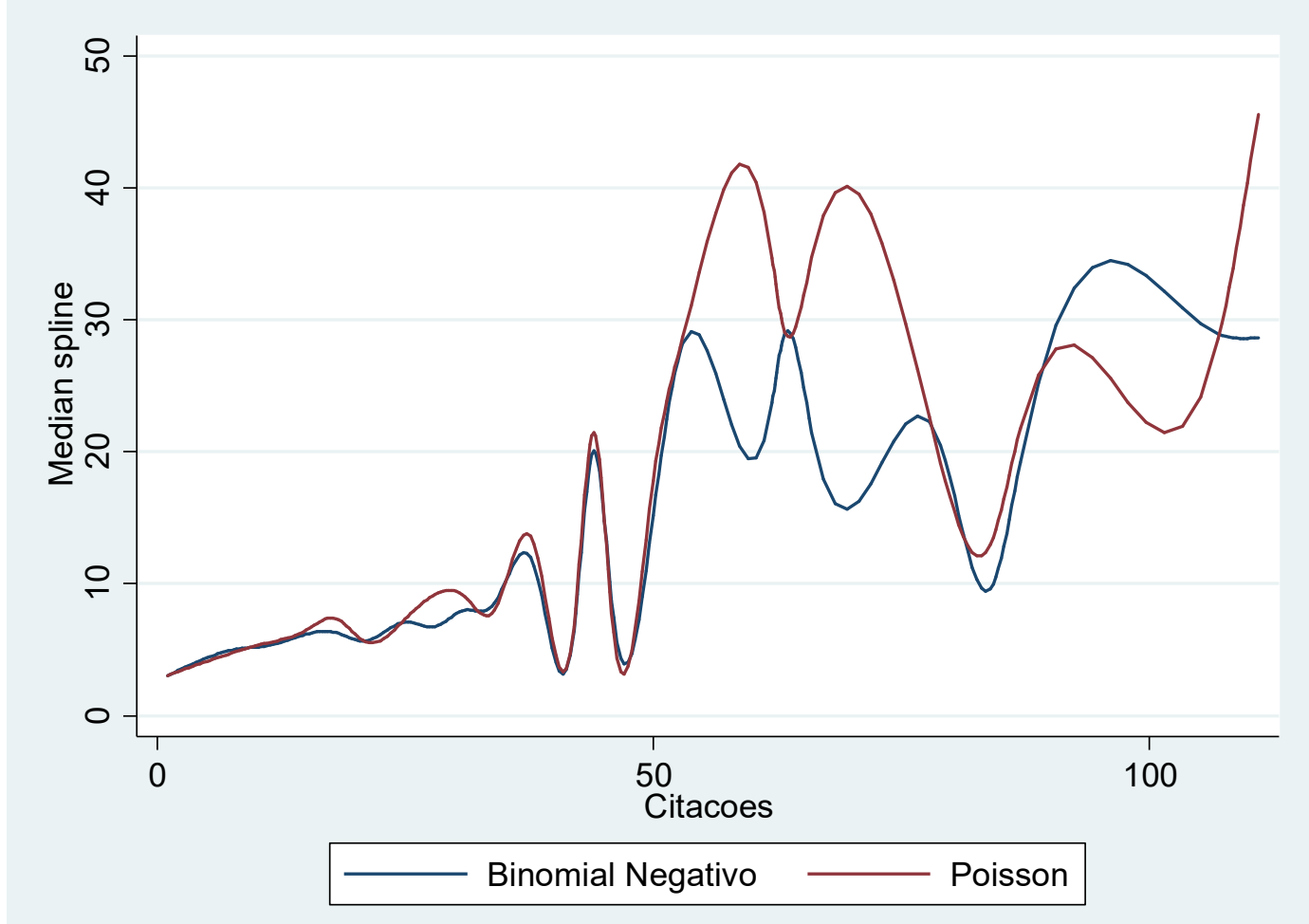$$
\cdot
$$

- gen lncitacoes=ln (citacoes)

(699 missing values generated)

$\cdot$

- quietly reg lncitacoes n_p_tit n_p_p_chave n_pag n_ref n_autores prop_mulher _ I*

- predict yhat

(option xb assumed; fitted values)

- gen eyhat $=\exp ($ yhat) 
- graph twoway lfit u citacoes || lfit lambda citacoes || lfit eyhat citacoes ||, legend(label(1 "Binomial Negativo") label (2 "Poisso

$>$ n") label (3 "OLS"))

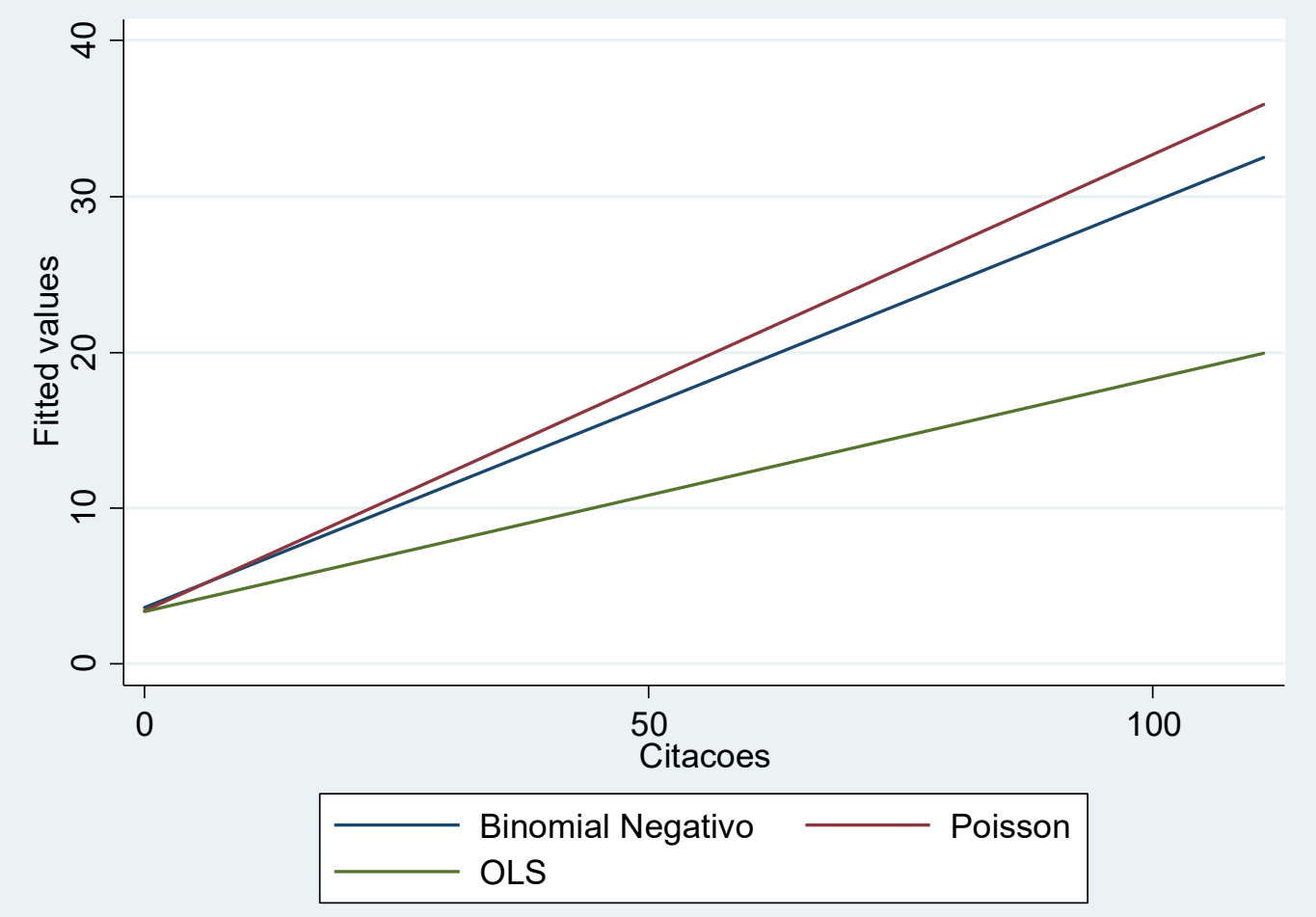




\section{Apêndice 0 - Saídas do Stata do Modelo 5 - Com a variável idade do artigo}

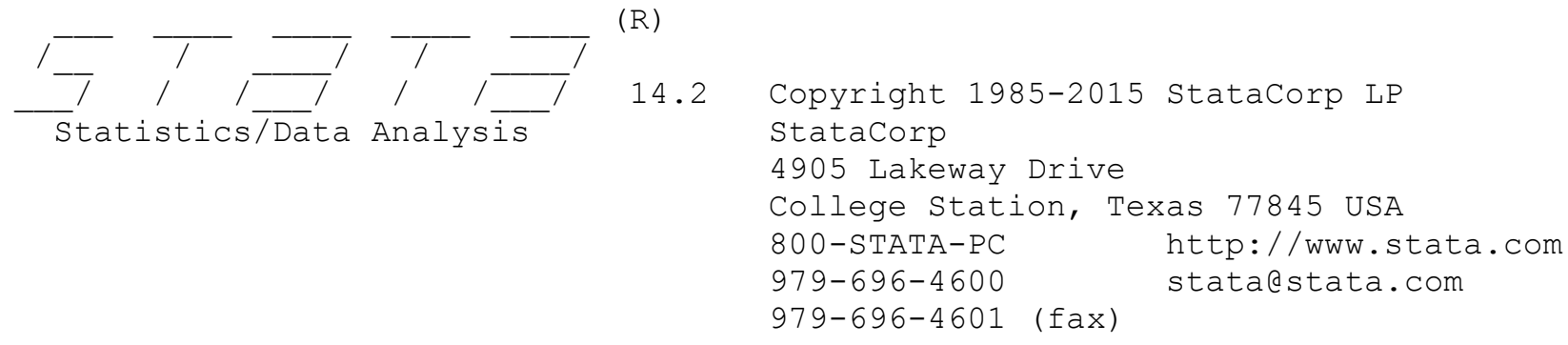

Single-user Stata license expires 29 May 2017:

Serial number: 301409337392

Licensed to: Sandro Vieira Soares

Notes:

1. Unicode is supported; see help unicode_advice.

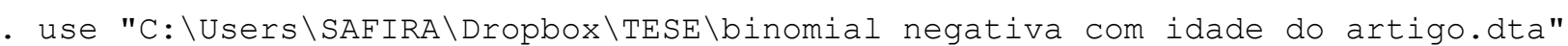

- desc

Contains data from $C: \backslash U$ sers \SAFIRA \Dropbox \TESE\binomial negativa com idade do artigo.dta
obs: $\quad 2,540$
size: $\quad 200,660$
11 Jan $201721: 06$

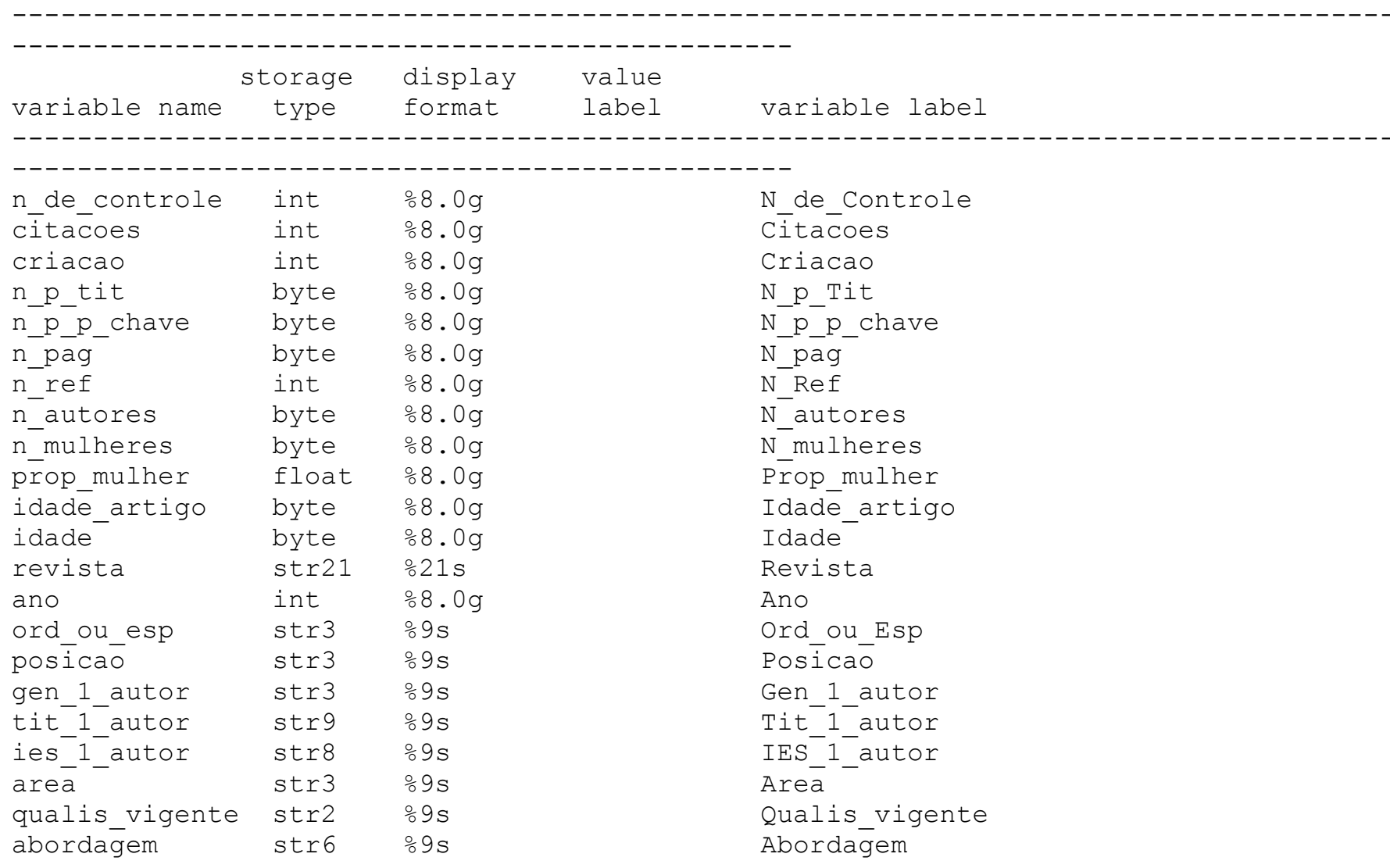

Sorted by:

- tab citacoes

Citacoes | Freq. Percent Cum. 


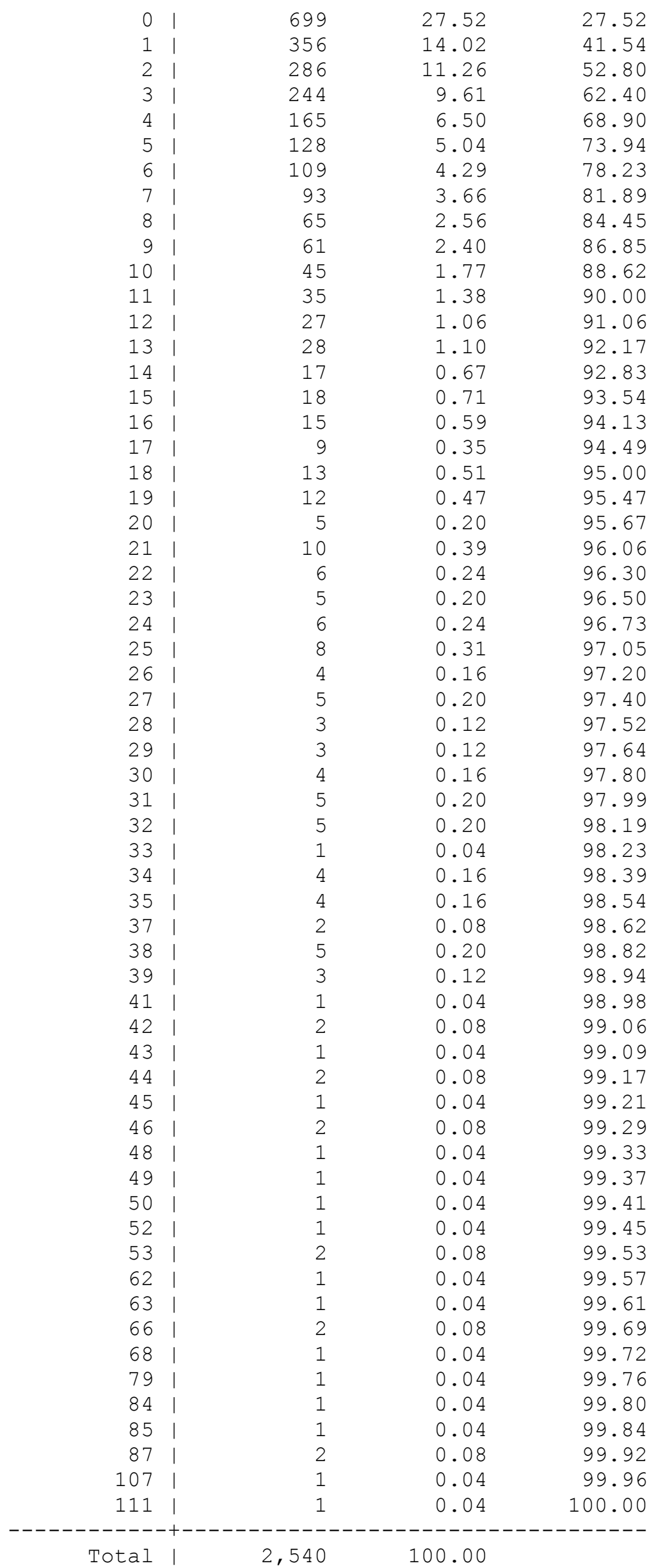




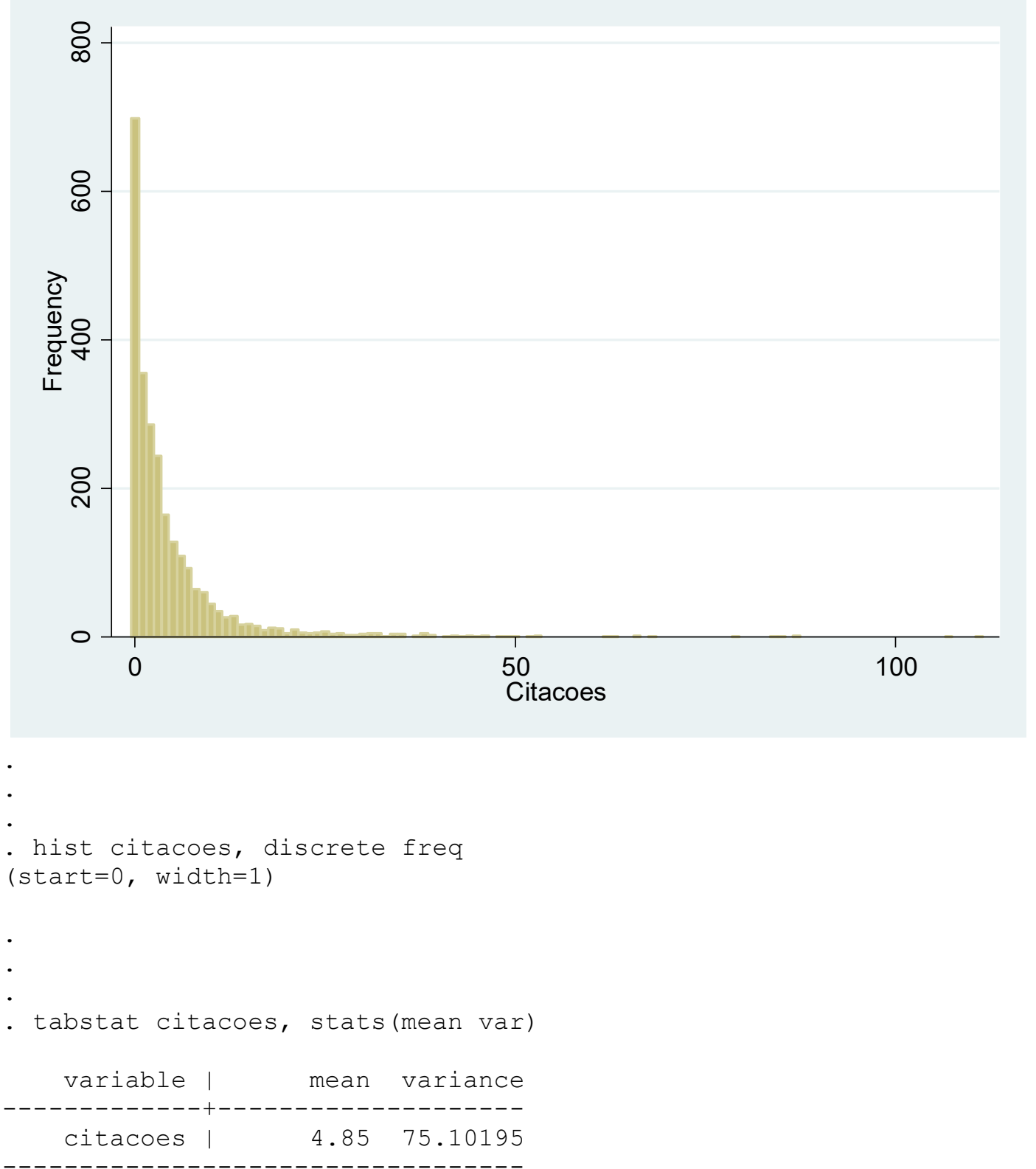

- xi i.revista i.ord_ou_esp i.posicao i.gen_1_autor i.tit_1_autor i.ies_1_autor i.area i.qualis_vigeñte ${ }^{-}$i.abordagem

i.revista

i.ord_ou_esp

i.posicāo

i.gen_1_autor

i.tit-1-autor

i.ies_-1-autor

i. area

i.qualis_vige e

i. abordaḡem

-Irevista_1-36
-Iord_ou_es_1-2
-Iposicao_1-2
- Igen_1_aut_1-2
- Itit_1_aut_1-4
- Iies_1_aut_1-20
- Iarea_1-6
- Iqualis_vi_1-8
- Iabordagem_1-2

( Irevista 1 for rev a==ABCustos omitted) ( Iord ou es 1 for ord ou p==Esp omitted) (_Iposicaó1 ${ }^{-}$for posicāo==Out omitted)

(_Igen_1_aut_1 for gen_1_ r==Hom omitted)

('Itit ${ }^{-}{ }^{-}$aut ${ }^{-1}$ for tit ${ }^{-}==$Bacharel omitted)

('Iies_1 aut 1 for ies_r==FECAP omitted)

('Iareā $\overline{1}$ for area $==E d \bar{u}$ omitted)

(Iqualis_vi 1 for qualis $\sim e==\mathrm{A} 2$ omitted)

('Iabordagem_1 for abor $\mathrm{m}==$ Quali omitted)

$\cdot$

$\cdot$

- quietly stepwise, pr(0.05): poisson citacoes n_p_tit n_p_p_chave n_pag n_ref n_autores prop_mulher idade_artigo_I*

$\cdot$

- predict lambda

(option $\mathrm{n}$ assumed; predicted number of events) 
- gen yasterisco $=(($ citacoes-lambda)^2 - citacoes $) /$ lambda

- reg yasterisco lambda, nocons

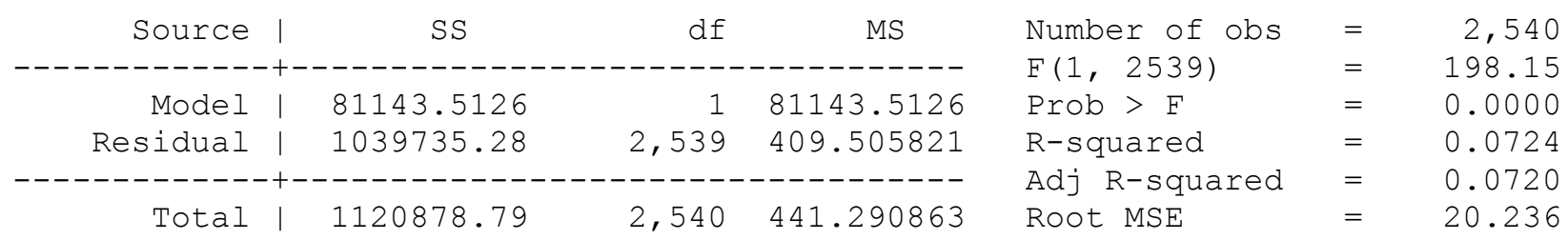

\begin{tabular}{|c|c|c|c|c|c|c|}
\hline yasterisco | & Coef. & Std. Err. & t & $P>|t|$ & [95\% Conf. & Interval] \\
\hline lambda & .7902025 & .056136 & 14.08 & 0.000 & .6801255 & .9002796 \\
\hline
\end{tabular}

.

-

- quietly stepwise, pr(0.05): poisson citacoes n_p_tit n_p_p_chave n_pag n_ref n_autores prop_mulher idade_artigo _ I*

.

- poisgof

$\begin{array}{llr}\text { Deviance goodness-of-fit } & = & 13218.1 \\ \text { Prob }>\text { chi2(2481) } & =0.0000 \\ \text { Pearson goodness-of-fit } & = & 16110.72 \\ \text { Prob }>\text { chi2(2481) } & = & 0.0000\end{array}$

- stepwise, pr(0.05): nbreg citacoes n_p_tit n_p_p_chave n_pag n_ref n_autores prop_mulher idade_artigo_I*

$\mathrm{p}=0.9823>=0.0500$

$\mathrm{p}=0.9821>=0.0500$

$\mathrm{p}=0.9683>=0.0500$

$\mathrm{p}=0.9417>=0.0500$

$\mathrm{p}=0.9529>=0.0500$

$\mathrm{p}=0.9359>=0.0500$

$\mathrm{p}=0.9251>=0.0500$

$\mathrm{p}=0.8357>=0.0500$

$\mathrm{p}=0.8406>=0.0500$

$\mathrm{p}=0.8154>=0.0500$

$\mathrm{p}=0.8648>=0.0500$

$\mathrm{p}=0.7479>=0.0500$

$\mathrm{p}=0.7266>=0.0500$

$\mathrm{p}=0.7204>=0.0500$

$\mathrm{p}=0.7057>=0.0500$

$\mathrm{p}=0.7500>=0.0500$

$\mathrm{p}=0.6935>=0.0500$

$\mathrm{p}=0.6273>=0.0500$

$\mathrm{p}=0.6299>=0.0500$

$\mathrm{p}=0.5737>=0.0500$

$\mathrm{p}=0.5350>=0.0500$

$\mathrm{p}=0.4935>=0.0500$

$\mathrm{p}=0.4874>=0.0500$

$\mathrm{p}=0.4648>=0.0500$

$\mathrm{p}=0.4635>=0.0500$ begīn with full model

removing Itit_1_aut_3

removing Iies_ ${ }^{-}$aut 5

removing Irevista_ $3 \overline{5}$

removing Iies_1_aut_15

removing Iies_1_aut 13

removing Irevista_ $1 \overline{4}$

removing - Itit_1_aut_ 4

removing Irevis̄̄a_6-

removing Itit 1 aūt 2

removing Irevista_1̄

removing Irevista-13

removing Iies 1 aūt 18

removing Irevista $1 \overline{2}$

removing _Iies_1_aūt_8

removing Iarea $\overline{4}$

removing Iarea 5

removing Iies_ $\overline{1}$ aut 20

removing _Irevista_ $2 \overline{0}$

removing Iabordagem 2

removing Irevista_ $2 \overline{5}$

removing Irevista_ 22

removing Iposicao 2

removing Irevista 33

removing Iies_1 aūt_12

removing Irevista_3 
$\mathrm{p}=0.4619>=0.0500$

$\mathrm{p}=0.4436>=0.0500$

$\mathrm{p}=0.4205>=0.0500$

$\mathrm{p}=0.3986>=0.0500$

$\mathrm{p}=0.3560>=0.0500$

$\mathrm{p}=0.3987>=0.0500$

$\mathrm{p}=0.8122>=0.0500$

$\mathrm{p}=0.8137>=0.0500$

$\mathrm{p}=0.3724>=0.0500$

$\mathrm{p}=0.3483>=0.0500$

$\mathrm{p}=0.3283>=0.0500$

$\mathrm{p}=0.2420>=0.0500$

$\mathrm{p}=0.2588>=0.0500$

$\mathrm{p}=0.2784>=0.0500$

$\mathrm{p}=0.2389>=0.0500$

$\mathrm{p}=0.2296>=0.0500$

$\mathrm{p}=0.2433>=0.0500$

$\mathrm{p}=0.2344>=0.0500$

$\mathrm{p}=0.2210>=0.0500$

$\mathrm{p}=0.2016>=0.0500$

$\mathrm{p}=0.1894>=0.0500$

$\mathrm{p}=0.1910>=0.0500$

$\mathrm{p}=0.1766>=0.0500$

$\mathrm{p}=0.1810>=0.0500$

$\mathrm{p}=0.2155>=0.0500$

$\mathrm{p}=0.1398>=0.0500$

$\mathrm{p}=0.0721>=0.0500$

$\mathrm{p}=0.0700>=0.0500$

$\mathrm{p}=0.0616>=0.0500$

$\mathrm{p}=0.0533>=0.0500$ removing Iies_1_aut_ 7

removing ${ }_{-}$Iies_1_aut_ 9

removing $\bar{n} \mathrm{p}$ tit

removing Irevista 28

removing Irevista_17

removing Iqualis_vi_ 7

removing Iqualis_vi_3

removing Iqualis_vi_8

removing Irevista_ $2 \overline{4}$

removing $\bar{p} r o p$ mulhèr

removing _Iies_1_aut_2

removing Iqualis vi 6

removing Irevista $3 \bar{\sigma}$

removing Iqualis_vi_5

removing Iies_1 aut_11

removing Iies_1_aut_ 6

removing Iies_ ${ }^{-}$aut 14

removing $\bar{n}$ _p_p_chave

removing _ Irevista_9

removing Irevista 27

removing Iies 1 aút 17

removing Iare $\bar{a} \overline{6}$

removing $\bar{n}$ pag

removing I Iies_1_aut_3

removing - Iies_1_aut_16

removing _ord_oües_- 2

removing Irevistā_10

removing Irevista-2

removing Irevista 5

removing Irevista_32
Negative binomial regression
Number of obs

LR chi2 (25)

Prob > chi2

Pseudo R2
$=$

$=\quad 884.52$

$=0.0000$

$\begin{array}{ll}\text { Dispersion } & =\text { mean } \\ \text { Log likelihood } & =-6169.455\end{array}$
0.0000
0.0669

\begin{tabular}{|c|c|c|c|c|c|c|}
\hline citacoes I & Coef. & Std. Err. & z & $\mathrm{P}>|\mathrm{z}|$ & [95\% Conf. & Interval] \\
\hline--------- & ---- & --------- & ----- & & -ー-ー-ー-ー-ー & --------- \\
\hline Irevista_34 & -.7491776 & .269688 & -2.78 & 0.005 & -1.277756 & -.2205988 \\
\hline Irevista_26 & .5601038 & .1215277 & 4.61 & 0.000 & .3219139 & .7982938 \\
\hline Irevista-30 & -.7093101 & .1550104 & -4.58 & 0.000 & -1.013125 & -.4054954 \\
\hline $\mathrm{n}_{-} \overline{\mathrm{ref}}$ & .0120605 & .0018393 & 6.56 & 0.000 & .0084555 & .0156655 \\
\hline n_autōres & .0490311 & .0230975 & 2.12 & 0.034 & .0037609 & .0943013 \\
\hline Igen 1 aut 2 & .1080215 & .0518485 & 2.08 & 0.037 & .0064002 & .2096427 \\
\hline idadēēartiḡo & .2310561 & .016147 & 14.31 & 0.000 & .1994085 & .2627037 \\
\hline Iies_1_aut_10 & .5973884 & .2311392 & 2.58 & 0.010 & .1443639 & 1.050413 \\
\hline Irevista-29 & .2186954 & .110679 & 1.98 & 0.048 & .0017685 & .4356224 \\
\hline - Irevistā 4 & .4892988 & .1449695 & 3.38 & 0.001 & .2051638 & .7734337 \\
\hline I- $r e v i s t a \_\overline{2} 1$ & .2930599 & .1399932 & 2.09 & 0.036 & .0186784 & .5674415 \\
\hline 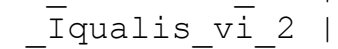 & .3501222 & .0990264 & 3.54 & 0.000 & .156034 & .5442105 \\
\hline Irevista-7 & .459121 & 8108 & 3.71 & 0.000 & .2164564 & 357 \\
\hline -Irevista_8 & .3541858 & .1196813 & 2.96 & 0.003 & .1196147 & .5887568 \\
\hline $\bar{I}$ revista $\overline{3} 1$ & -2.514586 & 1.078335 & -2.33 & 0.020 & -4.628085 & -.4010877 \\
\hline -Irevista_23 & .4599363 & .1259956 & 3.65 & 0.000 & .2129895 & 58831 \\
\hline _Iareāa_3 & -.1517933 & .0695425 & -2.18 & 0.029 & -.2880941 & -.0154924 \\
\hline Iarea-2 & -.3807811 & .0567367 & -6.71 & 0.000 & -.491983 & -.2695792 \\
\hline 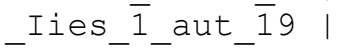 & .3164971 & .0713319 & 4.44 & 0.000 & .176689 & .4563051 \\
\hline _Iquāi is_vī_4 & .2255729 & .0729426 & 3.09 & 0.002 & .082608 & .3685377 \\
\hline - Irevista_ $\overline{15}$ & -1.043723 & .3648906 & -2.86 & 0.004 & -1.758896 & -.3285505 \\
\hline - Irevista_16 & -1.135156 & .3463425 & -3.28 & 0.001 & -1.813975 & -.4563373 \\
\hline - $\bar{I}$ ies_1_aut_t4 & -.1915883 & .0551695 & -3.47 & 0.001 & -.2997185 & -.083458 \\
\hline - Irevisista_̄is & .4723357 & .1762434 & 2.68 & 0.007 & .1269049 & .8177664 \\
\hline -Irevista_19 & 1.376084 & .125677 & 10.95 & 0.000 & 1.129762 & 1.622407 \\
\hline - cons & -.7450614 & .1528417 & -4.87 & 0.000 & -1.044626 & -.4454973 \\
\hline
\end{tabular}




\begin{tabular}{|c|c|c|c|c|}
\hline /Inalpha | & .1385776 & .0388522 & .0624288 & .2147265 \\
\hline alpha | & 1.148639 & .0446271 & 1.064419 & 1.239523 \\
\hline
\end{tabular}

LR test of alpha=0: chibar2 $(01)=7263.79$

Prob $>=$ chibar $2=0.000$

.

- predict u

(option $\mathrm{n}$ assumed; predicted number of events)

$\cdot$

- stepwise, pr(0.05): nbreg citacoes n_p_tit n_p_p_chave n_pag n_ref n_autores prop mulher idade artigo I*, irr begin with full model

$\mathrm{p}=0.9823>=0.0500$

removing Itit_1 aut_3

$\mathrm{p}=0.9821>=0.0500$

removing ${ }^{-}$Iies ${ }^{-}{ }^{-}$aut 5

$\mathrm{p}=0.9683>=0.0500$

removing Irevista $3 \overline{5}$

$\mathrm{p}=0.9417>=0.0500$

removing Iies_1_aút_15

$\mathrm{p}=0.9529>=0.0500$

$\mathrm{p}=0.9359>=0.0500$

removing Iies_ 1 aut 13

$\mathrm{p}=0.9251>=0.0500$

removing Irevista $1 \overline{4}$

$\mathrm{p}=0.8357>=0.0500$

removing Itit 1 aut 4

$\mathrm{p}=0.8406>=0.0500$

removing Irevista_6

$\mathrm{p}=0.8154>=0.0500$

removing _ttit_1_aūt_2

$\mathrm{p}=0.8648>=0.0500$

removing Irevista $1 \overline{1}$

$\mathrm{p}=0.7479>=0.0500$

$\mathrm{p}=0.7266>=0.0500$

removing _Irevista_13

$\mathrm{p}=0.7204>=0.0500$

removing Iies_1_aut_18

removing Irevista_ $1 \overline{2}$

$\mathrm{p}=0.7057>=0.0500$

removing -Iies_1_aut__8

$\mathrm{p}=0.7500>=0.0500$

$\mathrm{p}=0.6935>=0.0500$

$\mathrm{p}=0.6273>=0.0500$

$\mathrm{p}=0.6299>=0.0500$

$\mathrm{p}=0.5737>=0.0500$

removing Iarea $\overline{4}$

removing Iarea_5

removing Iies_- 1 aut 20

removing Irevista_ $2 \overline{0}$

removing Iabordagè _2

$\mathrm{p}=0.5350>=0.0500$

removing Irevista $2 \overline{5}$

$\mathrm{p}=0.4935>=0.0500$

removing Irevista 22

$\mathrm{p}=0.4874>=0.0500$

removing Iposicao 2

$\mathrm{p}=0.4648>=0.0500$

$\mathrm{p}=0.4635>=0.0500$

removing Irevista_33

removing Iies_1_aut_12

removing _Irevista_3

$\mathrm{p}=0.4619>=0.0500$

removing -Iies_1_aut_ 7

$\mathrm{p}=0.4436>=0.0500$

$\mathrm{p}=0.4205>=0.0500$

removing - Iies_1_aut_9

removing $\overline{\mathrm{n}} \mathrm{p}$ t $\overline{\mathrm{i}} \mathrm{t}$

$\mathrm{p}=0.3986>=0.0500$

$\mathrm{p}=0.3560>=0.0500$

removing Irevista_28

removing - Irevista_17

$\mathrm{p}=0.3987>=0.0500$

$\mathrm{p}=0.8122>=0.0500$

$\mathrm{p}=0.8137>=0.0500$

$\mathrm{p}=0.3724>=0.0500$

$\mathrm{p}=0.3483>=0.0500$

$\mathrm{p}=0.3283>=0.0500$

$\mathrm{p}=0.2420>=0.0500$

$\mathrm{p}=0.2588>=0.0500$

$\mathrm{p}=0.2784>=0.0500$

$\mathrm{p}=0.2389>=0.0500$

$\mathrm{p}=0.2296>=0.0500$

removing Iqualis $\overline{v i} 7$

removing _Iqualis_vi_3

removing _qualis_vi_8

removing Irevistā_ $2 \overline{4}$

removing prop mulhèr

removing _Iies___aut_2

removing Iqualis_vi_ 6

removing Irevista $3 \overline{6}$

removing Iqualis_vi_5

removing Iies_1_aut_11

removing ${ }^{-}$Iies_ ${ }^{-}$-aut_ 6

$\mathrm{p}=0.2433>=0.0500$

$\mathrm{p}=0.2344>=0.0500$

$\mathrm{p}=0.2210>=0.0500$

removing Iies_ 1 aut 14

removing $\bar{n} \_p \_p \_c h a v e$

removing _ Irevista_9

$\mathrm{p}=0.2016>=0.0500$

$\mathrm{p}=0.1894>=0.0500$

$\mathrm{p}=0.1910>=0.0500$

removing Irevista_27

removing Iies_1_aut_17

$\mathrm{p}=0.1766>=0.0500$

removing Iarea $\overline{-} \overline{6}$

removing $\bar{n} \_p a g$ 
$\mathrm{p}=0.1810>=0.0500$

$\mathrm{p}=0.2155>=0.0500$

$\mathrm{p}=0.1398>=0.0500$

$\mathrm{p}=0.0721>=0.0500$

$\mathrm{p}=0.0700>=0.0500$

$\mathrm{p}=0.0616>=0.0500$

$\mathrm{p}=0.0533>=0.0500$ removing Iies_1_aut_3

removing Iies_1_aut_16

removing Iord ou es ${ }^{-} 2$

removing Irevistā $1 \overline{0}$

removing - Irevista_2

removing Irevista 5

removing _Irevista_32

Negative binomial regression

Number of obs LR chi2 (25)

Prob > chi2

Pseudo R2

$\begin{array}{lr}= & 2,540 \\ = & 884.52 \\ = & 0.0000 \\ = & 0.0669\end{array}$

$\begin{array}{ll}\text { Dispersion } & =\text { mean } \\ \text { Log likelihood } & =-6169.455\end{array}$

\begin{tabular}{|c|c|c|c|c|c|c|}
\hline citacoes | & IRR & Std. Err. & z & $P>|z|$ & [95\% Conf. & Interval] \\
\hline Irevista 34 & 4727552 & 1274964 & -278 & 0005 & 2786618 & 802038 \\
\hline Irevista 26 & 1.750854 & .2127774 & 4.61 & 0.000 & 1.379766 & 2.221747 \\
\hline -Irevista-30 & .4919835 & .0762625 & -4.58 & 0.000 & .3630826 & .6666465 \\
\hline $\mathrm{n}$ ref & 1.012134 & .0018616 & 6.56 & 0.000 & 1.008491 & 1.015789 \\
\hline n_autores & 1.050253 & .0242582 & 2.12 & 0.034 & 1.003768 & 1.098891 \\
\hline Igen_1_aut_2 & 1.114072 & .057763 & 2.08 & 0.037 & 1.006421 & 1.233237 \\
\hline - idadēēartiḡo & 1.25993 & .0203441 & 14.31 & 0.000 & 1.22068 & 1.300441 \\
\hline Iies_1_aut_10 & 1.817366 & .4200645 & 2.58 & 0.010 & 1.155304 & 2.858831 \\
\hline Irēvista-29 & 1.244452 & .1377348 & 1.98 & 0.048 & 1.00177 & 1.545925 \\
\hline - Irevistā 4 & 1.631172 & .2364701 & 3.38 & 0.001 & 1.227726 & 2.167195 \\
\hline _- & 1.340523 & .1876641 & 2.09 & 0.036 & 1.018854 & 1.763749 \\
\hline Iqualis_vín_2 & 1.419241 & .1405424 & 3.54 & 0.000 & 1.168866 & 1.723247 \\
\hline Irevista-7 & 1.582682 & .1959531 & 3.71 & 0.000 & 1.241669 & 2.017352 \\
\hline -Irevista_8 & 1.42502 & .1705483 & 2.96 & 0.003 & 1.127062 & 1.801747 \\
\hline Irevista_$\overline{3} 1$ & .0808964 & .0872334 & -2.33 & 0.020 & .0097735 & .6695913 \\
\hline Irevista 23 & 1.583973 & .1995736 & 3.65 & 0.000 & 1.237372 & 2.027661 \\
\hline _Iareā_3 & .8591659 & .0597486 & -2.18 & 0.029 & .749691 & .984627 \\
\hline -Iarea_2 & .6833275 & .0387698 & -6.71 & 0.000 & .6114128 & .7637008 \\
\hline 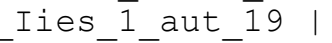 & 1.372312 & .0978897 & 4.44 & 0.000 & 1.19326 & 1.578232 \\
\hline Iquāiss ví 4 & 1.25304 & .0914 & 3.09 & 0.002 & 1.086116 & 1.445619 \\
\hline _Irevista_ $\overline{1} 5$ & .3521412 & .128493 & -2.86 & 0.004 & .172235 & .7199666 \\
\hline Irevista_16 & .3213719 & .1113048 & -3.28 & 0.001 & .1630049 & .6336001 \\
\hline $\bar{I}$ ies_1 aut 4 & .8256468 & .0455505 & -3.47 & 0.001 & .7410268 & .9199297 \\
\hline Irevista_ $\overline{1} 8$ & 1.603736 & .2826479 & 2.68 & 0.007 & 1.135309 & 2.265434 \\
\hline Irevista_19 & 3.959368 & .4976016 & 10.95 & 0.000 & 3.09492 & 5.065267 \\
\hline- cons & .4747051 & .0725547 & -4.87 & 0.000 & .3518235 & .6405057 \\
\hline /Inalpha | & .1385776 & .0388522 & & & .0624288 & .2147265 \\
\hline alpha | & 1.148639 & .0446271 & & & 1.064419 & 1.239523 \\
\hline
\end{tabular}

LR test of alpha=0: $\operatorname{chibar} 2(01)=7263.79$

Prob $>=$ chibar $2=0.000$

- quietly stepwise, pr(0.05): poisson citacoes n_p_tit n_p_p_chave n_pag n_ref n_autores prop_mulher idade_artigo_I*

- prcounts prpoisson, plot

- quietly stepwise, pr(0.05): nbreg citacoes n_p_tit n_p_p_chave n_pag n_ref

n_autores prop_mulher idade_artigo_I*

- prcounts prbneg, plot

- graph twoway (scatter prbnegobeq prbnegpreq prpoissonpreq prbnegval, connect (1 1 1))

(note: named style 1 not found in class connectstyle, default attributes used) 
(note: named style 1 not found in class connectstyle, default attributes used) (note: named style 1 not found in class connectstyle, default attributes used)
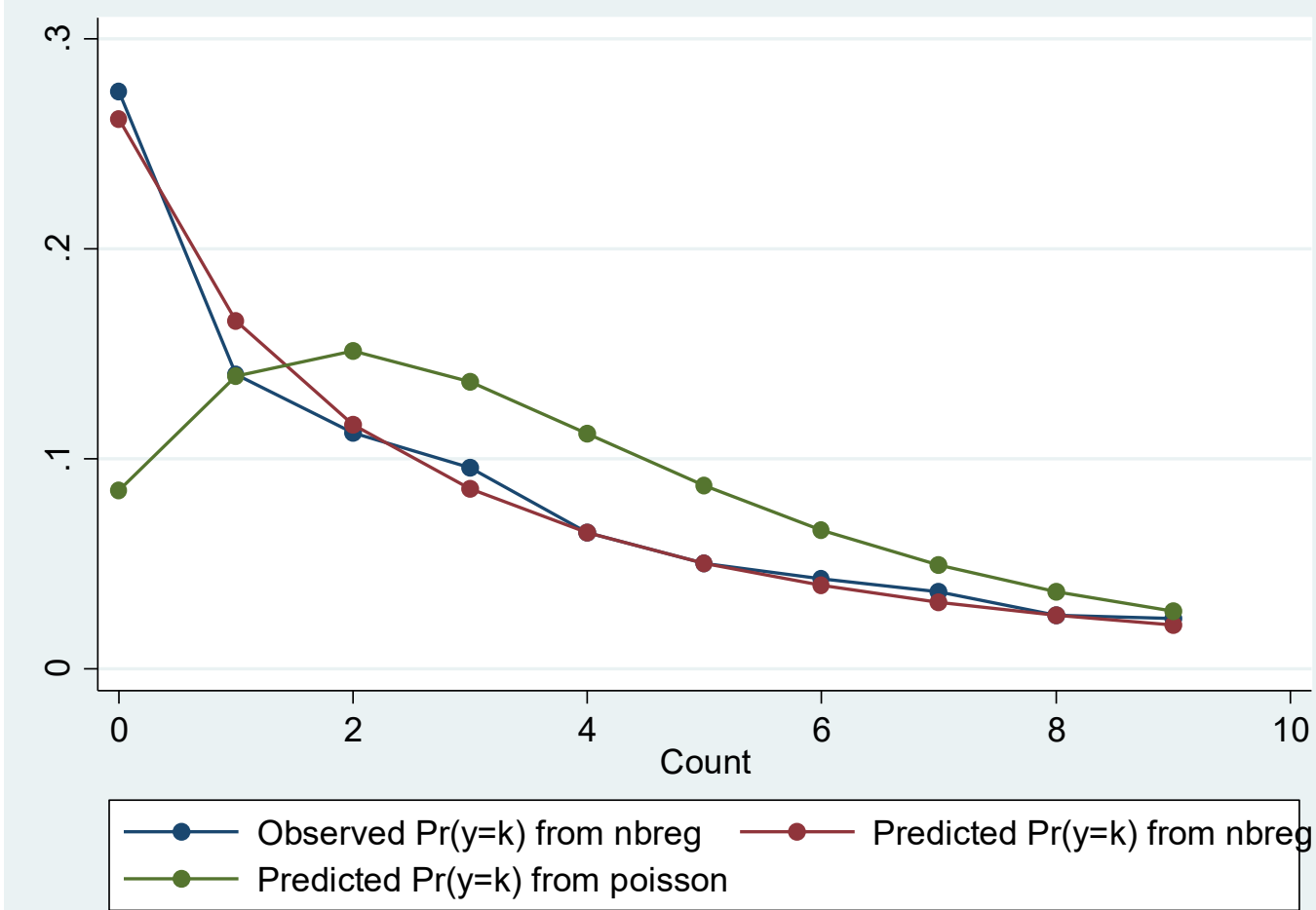

- countfit citacoes n_p_tit n_p_p_chave n_pag n_ref n_autores prop_mulher idade artigo I*, prm nograph noestimates nofit Comparison of ${ }^{-}$Mean Observed and Predicted Count

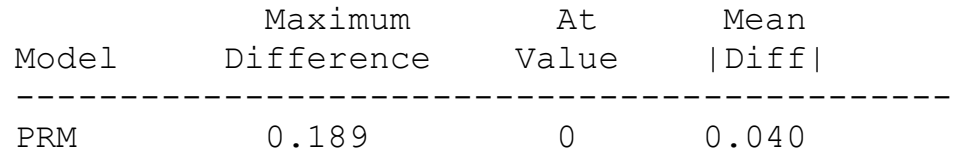

PRM: Predicted and actual probabilities

\begin{tabular}{|c|c|c|c|c|}
\hline Count & Actual & Predicted & | Diff| & Pearson \\
\hline & ------1 & ---------- & ------ & --------- \\
\hline 0 & 0.275 & 0.086 & 0.189 & 1055.584 \\
\hline 1 & 0.140 & 0.140 & 0.000 & 0.002 \\
\hline 2 & 0.113 & 0.151 & 0.038 & 24.794 \\
\hline 3 & 0.096 & 0.136 & 0.040 & 29.780 \\
\hline 4 & 0.065 & 0.112 & 0.047 & 49.595 \\
\hline 5 & 0.050 & 0.087 & 0.037 & 39.428 \\
\hline 6 & 0.043 & 0.066 & 0.023 & 20.830 \\
\hline 7 & 0.037 & 0.050 & 0.013 & 8.630 \\
\hline 8 & 0.026 & 0.037 & 0.011 & 8.897 \\
\hline 9 & 0.024 & 0.028 & 0.004 & 1.178 \\
\hline Sum & 0.869 & 0.892 & 0.402 & 1238.718 \\
\hline
\end{tabular}

- countfit citacoes n_p_tit n_p_p_chave n_pag n_ref n_autores prop_mulher idade artigo I*, nbrēeg nograph noestimatēs nofit

Comparison of Mean Observed and Predicted Count

\begin{tabular}{|c|c|c|c|}
\hline Model & $\begin{array}{c}\text { Maximum } \\
\text { Difference }\end{array}$ & $\begin{array}{c}\text { At } \\
\text { Value }\end{array}$ & $\begin{array}{l}\text { Mean } \\
\mid \text { Diff| }\end{array}$ \\
\hline NBRM & -0.027 & 1 & 0.007 \\
\hline
\end{tabular}

NBRM: Predicted and actual probabilities 


\begin{tabular}{lcccc} 
Count & Actual & Predicted & $\mid$ Diff| & \multicolumn{1}{c}{ Pearson } \\
------1 & 0.014 & 1.904 \\
0 & 0.275 & 0.261 & 0.014 \\
1 & 0.140 & 0.167 & 0.027 & 10.724 \\
2 & 0.113 & 0.117 & 0.004 & 0.418 \\
3 & 0.096 & 0.086 & 0.010 & 3.098 \\
4 & 0.065 & 0.065 & 0.000 & 0.000 \\
5 & 0.050 & 0.050 & 0.000 & 0.003 \\
6 & 0.043 & 0.039 & 0.003 & 0.763 \\
7 & 0.037 & 0.032 & 0.005 & 2.064 \\
8 & 0.026 & 0.026 & 0.000 & 0.000 \\
9 & 0.024 & 0.021 & 0.003 & 1.151 \\
---------------------------------------- \\
Sum & 0.869 & 0.863 & 0.067 & 20.125
\end{tabular}

- graph twoway mspline u citacoes || mspline lambda citacoes ||, legend(label(1 "Binomial Negativo") label(2 "Poisson"))

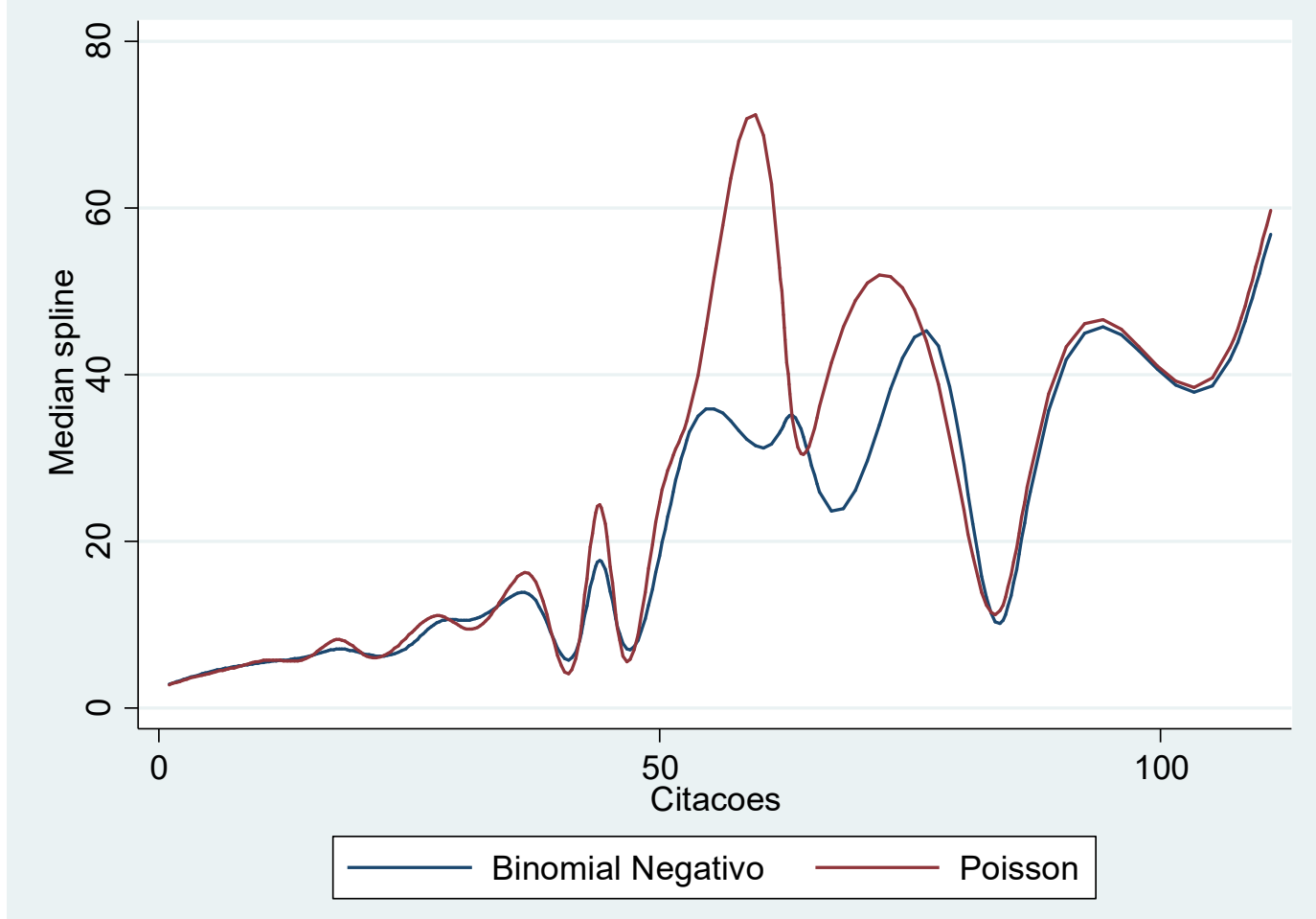

- gen lncitacoes=ln (citacoes)

(699 missing values generated)

.

- quietly reg lncitacoes n_p_tit n_p_p_chave n_pag n_ref n_autores prop_mulher idade_artigo _I*

- predict yhat

(option xb assumed; fitted values)

- gen eyhat $=\exp ($ yhat $)$

$\cdot$

- graph twoway lfit u citacoes || lfit lambda citacoes || lfit eyhat citacoes ||, legend(label(1 "Binomial Negativo") label (2 "Poisso 
> n") label (3 "OLS"))

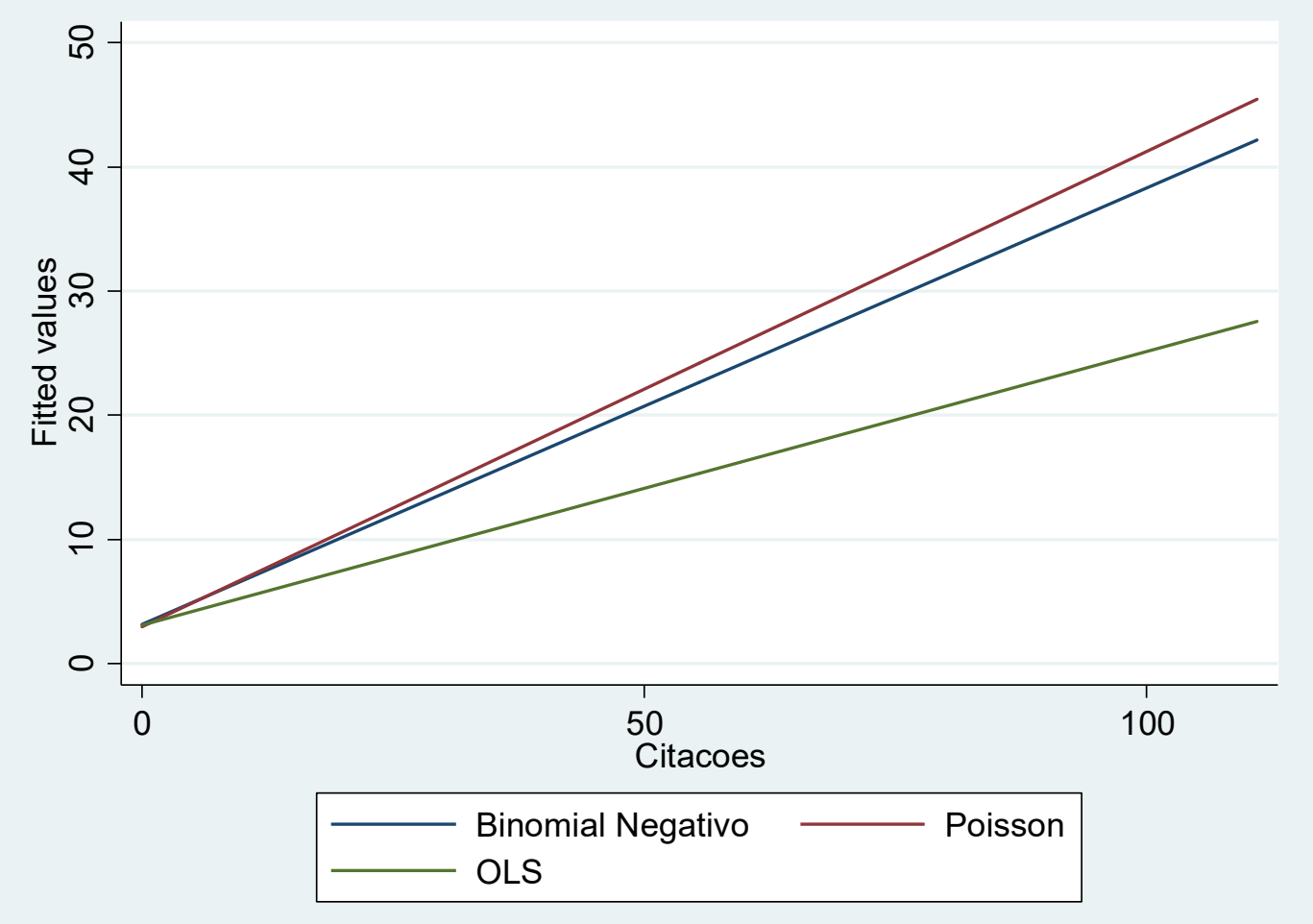




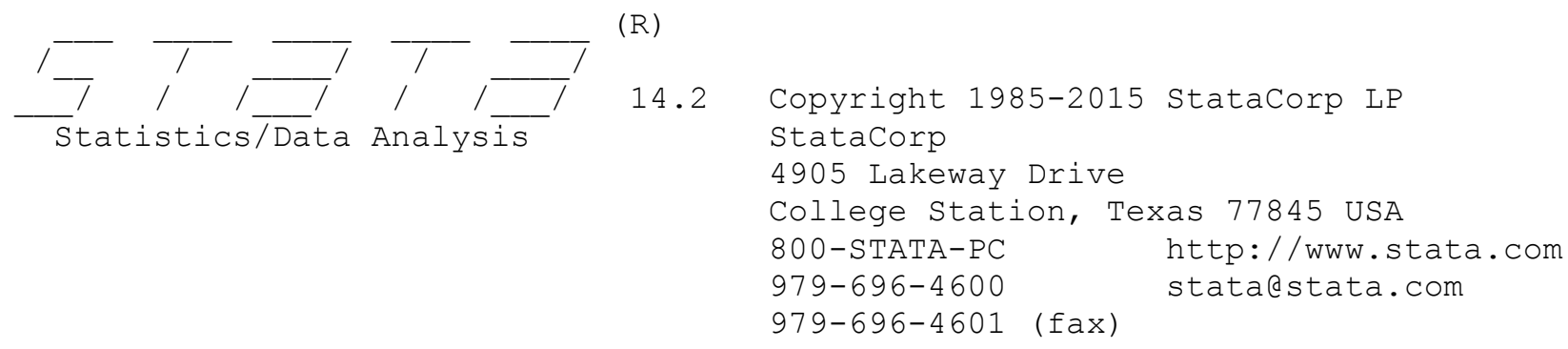

Single-user Stata license expires 29 May 2017:

Serial number: 301409337392

Licensed to: Sandro Vieira Soares

Notes:

1. Unicode is supported; see help unicode_advice.

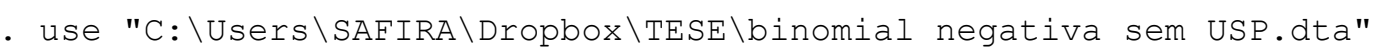

- desc

Contains data from C: \Users \SAFIRA \Dropbox \TESE\binomial negativa sem USP.dta obs: $\quad 2,163$

vars: 21

size: $\quad 170,877$

29 Jan $2017 \quad 20: 13$

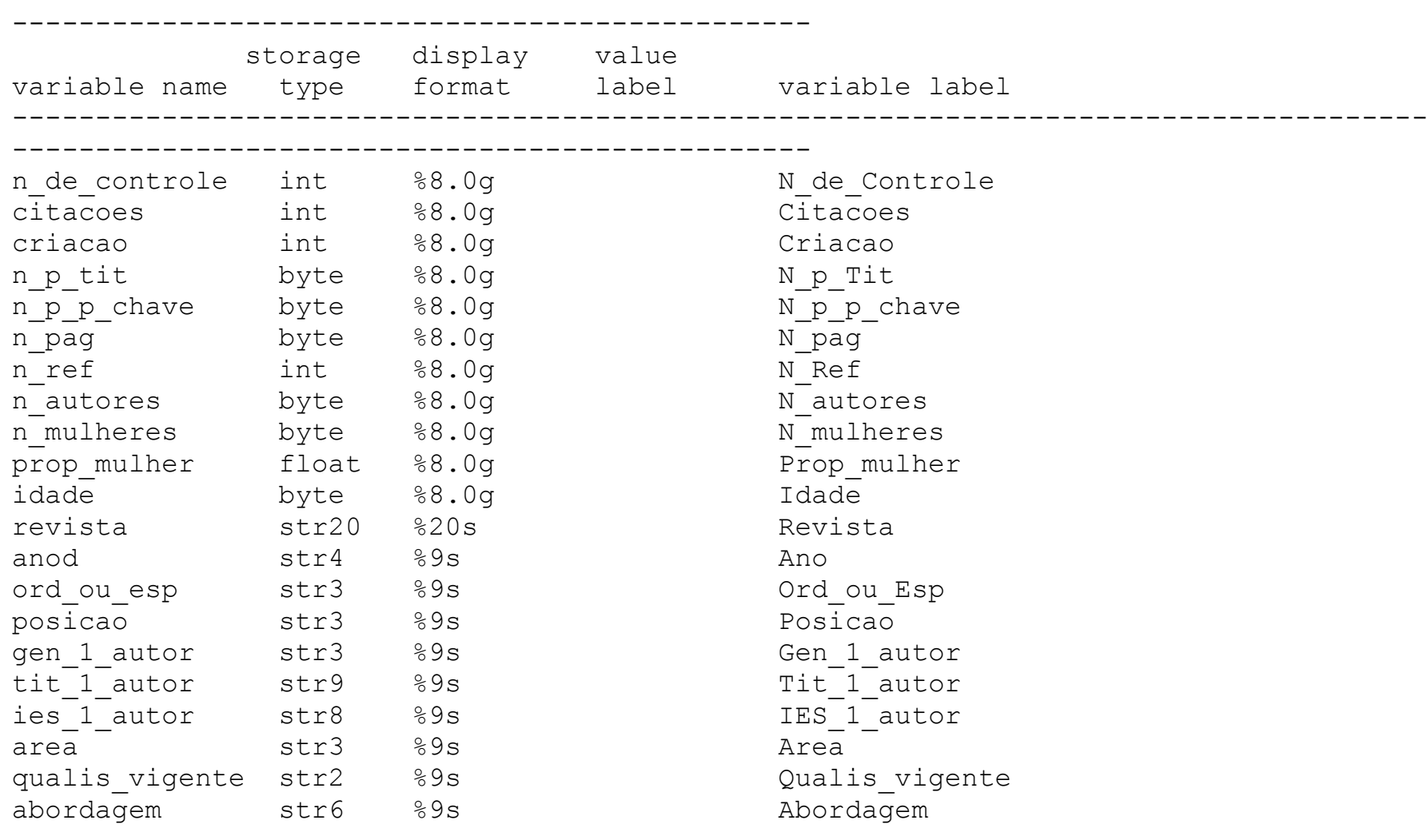

Sorted by: ies_1_autor

- tab citacoes

Citacoes I $\quad$ Freq. Percent Cum. 


\begin{tabular}{|c|c|c|c|c|}
\hline 0 & | & 633 & 29.26 & 29.26 \\
\hline 1 & I & 311 & 14.38 & 43.64 \\
\hline 2 & I & 250 & 11.56 & 55.20 \\
\hline 3 & i & 200 & 9.25 & 64.45 \\
\hline 4 & I & 143 & 6.61 & 71.06 \\
\hline 5 & I & 107 & 4.95 & 76.01 \\
\hline 6 & i & 95 & 4.39 & 80.40 \\
\hline 7 & 1 & 79 & 3.65 & 84.05 \\
\hline 8 & | & 58 & 2.68 & 86.73 \\
\hline 9 & i & 49 & 2.27 & 89.00 \\
\hline 10 & | & 32 & 1.48 & 90.48 \\
\hline 11 & | & 24 & 1.11 & 91.59 \\
\hline 12 & i & 19 & 0.88 & 92.46 \\
\hline 13 & I & 22 & 1.02 & 93.48 \\
\hline 14 & I & 10 & 0.46 & 93.94 \\
\hline 15 & i & 15 & 0.69 & 94.64 \\
\hline 16 & | & 12 & 0.55 & 95.19 \\
\hline 17 & | & 5 & 0.23 & 95.42 \\
\hline 18 & i & 10 & 0.46 & 95.89 \\
\hline 19 & | & 8 & 0.37 & 96.26 \\
\hline 20 & 1 & 4 & 0.18 & 96.44 \\
\hline 21 & | & 8 & 0.37 & 96.81 \\
\hline 22 & | & 5 & 0.23 & 97.04 \\
\hline 23 & i & 4 & 0.18 & 97.23 \\
\hline 24 & | & 3 & 0.14 & 97.36 \\
\hline 25 & | & 4 & 0.18 & 97.55 \\
\hline 26 & i & 4 & 0.18 & 97.73 \\
\hline 27 & I & 4 & 0.18 & 97.92 \\
\hline 28 & | & 2 & 0.09 & 98.01 \\
\hline 29 & | & 1 & 0.05 & 98.06 \\
\hline 30 & | & 3 & 0.14 & 98.20 \\
\hline 31 & । & 4 & 0.18 & 98.38 \\
\hline 32 & i & 5 & 0.23 & 98.61 \\
\hline 33 & | & 1 & 0.05 & 98.66 \\
\hline 34 & । & 3 & 0.14 & 98.80 \\
\hline 35 & i & 3 & 0.14 & 98.94 \\
\hline 38 & I & 4 & 0.18 & 99.12 \\
\hline 39 & | & 3 & 0.14 & 99.26 \\
\hline 41 & i & 1 & 0.05 & 99.31 \\
\hline 42 & I & 2 & 0.09 & 99.40 \\
\hline 43 & I & 1 & 0.05 & 99.45 \\
\hline 44 & i & 1 & 0.05 & 99.49 \\
\hline 45 & I & 1 & 0.05 & 99.54 \\
\hline 46 & I & 1 & 0.05 & 99.58 \\
\hline 49 & i & 1 & 0.05 & 99.63 \\
\hline 50 & | & 1 & 0.05 & 99.68 \\
\hline 62 & I & 1 & 0.05 & 99.72 \\
\hline 66 & i & 2 & 0.09 & 99.82 \\
\hline 79 & I & 1 & 0.05 & 99.86 \\
\hline 85 & I & 1 & 0.05 & 99.91 \\
\hline 87 & i & 1 & 0.05 & 99.95 \\
\hline 111 & I & 1 & 0.05 & 100.00 \\
\hline
\end{tabular}

.

- hist citacoes, discrete freq

( start $=0$, width=1) 


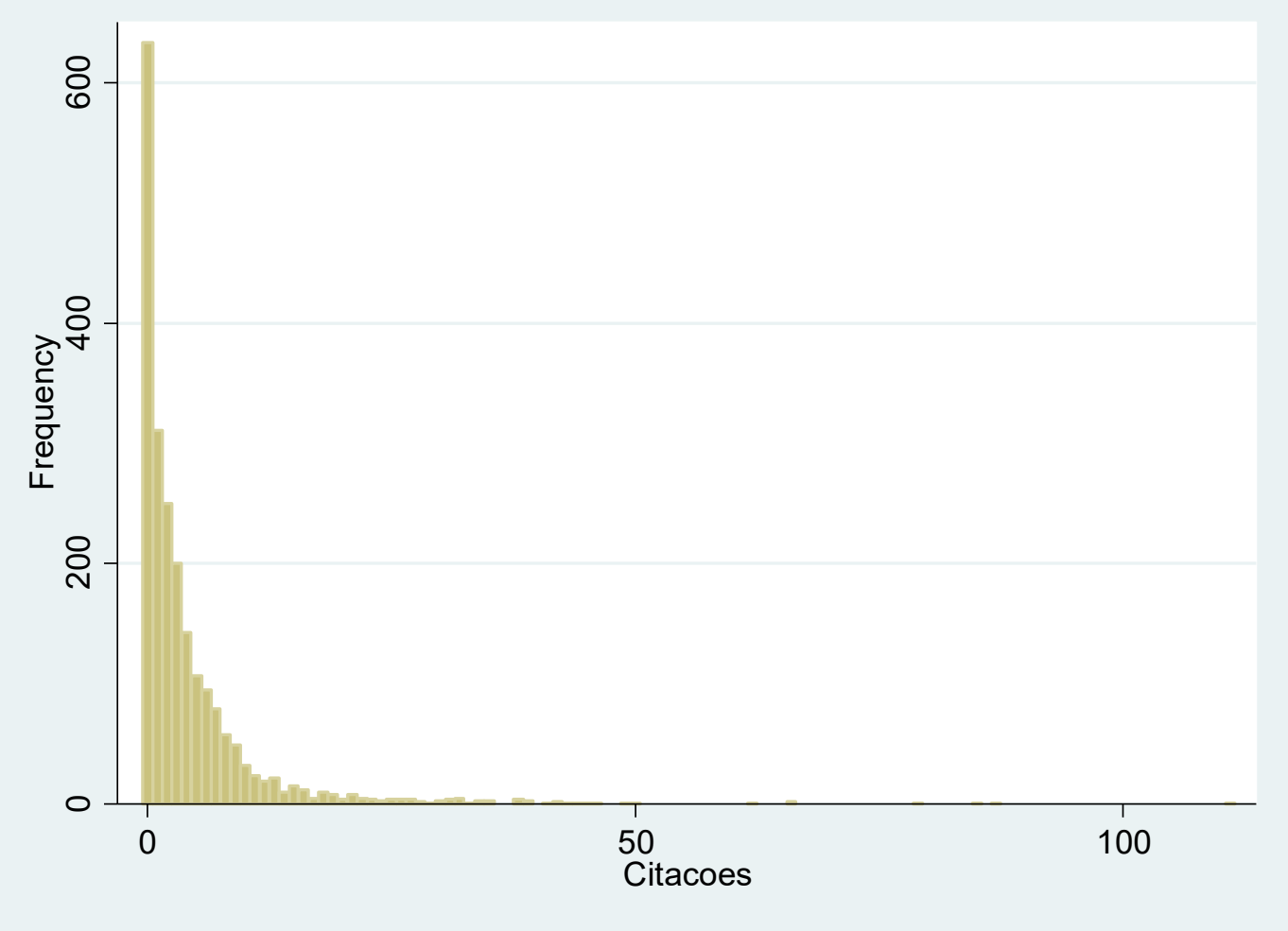

- tabstat citacoes, stats (mean var)

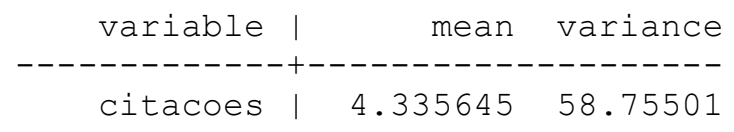

$\cdot$

- xi i.revista i.ord_ou_esp i.posicao i.gen_1_autor i.tit_1_autor i.ies_1_autor i.area i.qualis vigente ${ }^{-} i$.abordagem

i.revista - Irevista_1-36

i.ord_ou_esp

i.posicāo

- Iord_ou_es_1-2

- Iposicaōi-2

(_Irevista_1 for rev a==ABCustos omitted)

(_Iord_ou_es_1 for ord_ou p $==$ Esp omitted)

i.gen 1 autor

- Igen_1_aut_1-2

(Iposicao 1 for posicāo==Out omitted)

i.tit_1_autor

- Itit_1_aut_1-4

(_Igen_1_aut_1 for gen_1_ r ==Hom omitted)

i.ies_1_autor

Iies 1 aut $1-19$

(_Itit_1_aut_1 for tit $\sim r==$ Bacharel omitted)

i. area

Iarea $\overline{1}-6$

( Iies 1 aut 1 for ies $\sim r==$ FECAP omitted)

i.qualis_vige e

-Iqualis_vi_1-8

( Iarea $\overline{1}$ for area $==E d \bar{u}$ omitted)

i. abordagem

_Iabordagem_1-2

(_Iqualis_vi_1 for qualis_ $\sim==A 2$ omitted)

(_Iabordagem_1 for abor m=-Quali omitted)

$\cdot$

- quietly stepwise, pr(0.05): poisson citacoes n_p_tit n_p_p_chave n_pag n_ref n_autores prop_mulher idade_I*

- predict lambda

(option $\mathrm{n}$ assumed; predicted number of events)

- gen yasterisco $=\left((\text { citacoes-lambda })^{\wedge} 2-\right.$ citacoes $) /$ lambda 
- reg yasterisco lambda, nocons

$\begin{array}{rrrrrr}\text { Source | } & \text { SS } & \text { df } & \text { MS } & \text { Number of obs } & = \\ 2,163 \\ -1\end{array}$

- quietly stepwise, pr(0.05): poisson citacoes n_p_tit n_p_p_chave n_pag n_ref n_autores prop_mulher idade_I*

.

$\cdot$

- poisgof

$\begin{array}{llr}\text { Deviance goodness-of-fit } & = & 10148.49 \\ \text { Prob }>\text { chi2(2103) } & & 0.0000 \\ & \\ \text { Pearson goodness-of-fit } & =11988.15 \\ \text { Prob }>\text { chi2(2103) } & =0.0000\end{array}$

(1)

- stepwise, pr(0.05): nbreg citacoes n_p_tit n_p_p_chave n_pag n_ref n_autores prop_mulher idade_I*

$\mathrm{p}=0.9804>=0.0500$

begin with full model

$\mathrm{p}=0.9733>=0.0500$

$\mathrm{p}=0.9526>=0.0500$

$\mathrm{p}=0.9190>=0.0500$

$\mathrm{p}=0.9089>=0.0500$

$\mathrm{p}=0.9213>=0.0500$

$\mathrm{p}=0.8967>=0.0500$

$\mathrm{p}=0.8793>=0.0500$

$\mathrm{p}=0.7671>=0.0500$

$\mathrm{p}=0.7664>=0.0500$

$\mathrm{p}=0.7575>=0.0500$

$\mathrm{p}=0.7280>=0.0500$

$\mathrm{p}=0.7237>=0.0500$

$\mathrm{p}=0.6978>=0.0500$

$\mathrm{p}=0.6712>=0.0500$

$\mathrm{p}=0.6088>=0.0500$

$\mathrm{p}=0.6214>=0.0500$

$\mathrm{p}=0.5739>=0.0500$

$\mathrm{p}=0.5587>=0.0500$

$\mathrm{p}=0.5722>=0.0500$

$\mathrm{p}=0.4683>=0.0500$

$\mathrm{p}=0.5022>=0.0500$

$\mathrm{p}=0.4356>=0.0500$

$\mathrm{p}=0.4345>=0.0500$

$\mathrm{p}=0.4101>=0.0500$

$\mathrm{p}=0.3931>=0.0500$

$\mathrm{p}=0.3541>=0.0500$

removing Iies_1_aut_5

removing Itit ${ }^{-}$aut 3

removing Irevista $2 \overline{8}$

removing prop_mulhèr

removing _Iies_1_aut_15

removing Iies_1_aut_13

removing Irevista_2

removing Itit_1 aūt 4

removing Iabor rāäem_2

removing Iies_1_aut_8

removing _Irevista_ $1 \overline{4}$

removing _Iies_1_aut_18

removing _Iposicāo_2

removing Iarea 4

removing Iies $\overline{1}$ aut 19

removing Iqualis_vi_8

removing Iqualis_vi_3

removing $\bar{n}$ p tit

removing İarea_5

removing _Irevista_6

removing Iies_1_aut 7

removing Iies 1 aut 12

removing _Iqualis_vi_ ${ }^{7}$

removing $\bar{n}$ pag

removing Ittit_1 aut 2

removing $\bar{n}$ p_p_chave

removing _Iies_1_aut_9 
$\mathrm{p}=0.3424>=0.0500$

$\mathrm{p}=0.3296>=0.0500$

$\mathrm{p}=0.2904>=0.0500$

$\mathrm{p}=0.3147>=0.0500$

$\mathrm{p}=0.2474>=0.0500$

$\mathrm{p}=0.3136>=0.0500$

$\mathrm{p}=0.1612>=0.0500$

$\mathrm{p}=0.1625>=0.0500$

$\mathrm{p}=0.1508>=0.0500$

$\mathrm{p}=0.1117>=0.0500$

$\mathrm{p}=0.1404>=0.0500$

$\mathrm{p}=0.2185>=0.0500$

$\mathrm{p}=0.1831>=0.0500$

$\mathrm{p}=0.2565>=0.0500$

$\mathrm{p}=0.1273>=0.0500$

$\mathrm{p}=0.1757>=0.0500$

$\mathrm{p}=0.1456>=0.0500$

$\mathrm{p}=0.1034>=0.0500$

$\mathrm{p}=0.0681>=0.0500$

$\mathrm{p}=0.0642>=0.0500$ removing _Iies_1_aut_14 removing ${ }^{-}$Iies ${ }^{-}{ }^{-}$aut 6 removing Iies 1 aut 17 removing _Iies_1_aut_11 removing Iies_1_aut_16 removing Iies_1_aut_3 removing Iare $\bar{a} \bar{\sigma}$ removing _ord_ou_es_2 removing Igen_1_aut_2 removing ${ }^{-}$Iqualis $\overline{\text { s }} \mathrm{vi}^{-}{ }^{-}$ removing Irevistā_ $3 \overline{6}$ removing Iqualis_vi_5 removing Iqualis vi 4 removing Iqualis vi 2 removing Irevistā $1 \overline{2}$ removing Irevista_30 removing Irevista-11 removing Iies_1_aut_2 removing Irevista_a_ $2 \overline{7}$ removing $\bar{n}$ _autores

Negative binomial regression

Number of obs

LR chi2(32)

Prob > chi2

Pseudo R2
$=$

$-2,163$

$=\quad 700.27$

$=0.0000$

$=0.0645$

Log likelihood $=-5074.8596$

\begin{tabular}{|c|c|c|c|c|c|c|}
\hline citacoes & Coef. & Std. Err. & z & $\mathrm{P}>|\mathrm{z}|$ & [95\% Conf. & Interval] \\
\hline 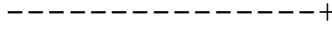 & & & & & & \\
\hline _Irevista_35 & -1.04694 & .2821749 & -3.71 & 0.000 & -1.599993 & -.4938877 \\
\hline Irevista 29 & .5602373 & .1133065 & 4.94 & 0.000 & .3381606 & .782314 \\
\hline $\bar{I}$ ies_1_aut_4 & -.1915285 & .0557575 & -3.44 & 0.001 & -.3008111 & -.0822459 \\
\hline n ref & .0096653 & .0020163 & 4.79 & 0.000 & .0057135 & .0136172 \\
\hline Iies_1_aut_10 & .5085407 & .2326212 & 2.19 & 0.029 & .0526115 & .96447 \\
\hline - & -.4273322 & .0628217 & -6.80 & 0.000 & -.5504604 & -.304204 \\
\hline - ida $\overline{d e}$ & -.1705005 & .0149172 & -11.43 & 0.000 & -.1997375 & -.1412634 \\
\hline Irevista_33 & -1.101321 & .3081105 & -3.57 & 0.000 & -1.705207 & -.4974356 \\
\hline _Irevistā 3 & -.8896557 & .2095387 & -4.25 & 0.000 & -1.300344 & -.4789674 \\
\hline -Irevista-4 & .7878605 & .1596325 & 4.94 & 0.000 & .4749866 & 1.100734 \\
\hline -Irevista_5 & .6668803 & .1478439 & 4.51 & 0.000 & .3771115 & .9566491 \\
\hline - $\bar{I} r e v i s t a \_\overline{3} 4$ & -1.41357 & .276239 & -5.12 & 0.000 & -1.954988 & -.8721512 \\
\hline Irevistā 7 & 1.75473 & .1716355 & 10.22 & 0.000 & 1.418331 & 2.09113 \\
\hline - Irevista-8 & 3.564587 & .2647397 & 13.46 & 0.000 & 3.045706 & 4.083467 \\
\hline -Irevista_9 & 1.013685 & .1733767 & 5.85 & 0.000 & .6738733 & 1.353498 \\
\hline Irevista $\overline{1} 0$ & .8950093 & .2481875 & 3.61 & 0.000 & .4085708 & 1. 381448 \\
\hline Irevista_31 & -2.272092 & 1.076621 & -2.11 & 0.035 & -4.38223 & -.1619532 \\
\hline -Irevista_32 & -1.378689 & .3325387 & -4.15 & 0.000 & -2.030453 & -.7269253 \\
\hline Irevista_13 & .3013535 & .1316061 & 2.29 & 0.022 & .0434103 & .5592966 \\
\hline _Iareāa_3 & -.176382 & .0771919 & -2.28 & 0.022 & -.3276754 & -.0250886 \\
\hline Irevista_ $\overline{1} 5$ & -1.864641 & .4395804 & -4.24 & 0.000 & -2.726203 & -1.00308 \\
\hline Irevista-16 & -1.816926 & .3949163 & -4.60 & 0.000 & -2.590948 & -1.042904 \\
\hline Irevista 17 & .9124355 & .1674457 & 5.45 & 0.000 & .584248 & 1.240623 \\
\hline Irevista_18 & 1.11888 & .1929566 & 5.80 & 0.000 & .7406922 & 1.497068 \\
\hline Irevista_19 & 4.514075 & .2640868 & 17.09 & 0.000 & 3.996474 & 5.031675 \\
\hline Irevista-20 & -.5087923 & .1783854 & -2.85 & 0.004 & -.8584212 & -.1591633 \\
\hline Irevista_21 & .8174306 & .144058 & 5.67 & 0.000 & .5350821 & 1.099779 \\
\hline Irevista-22 & .5202246 & .1489843 & 3.49 & 0.000 & .2282207 & .8122285 \\
\hline Irevista 23 & .4514365 & .1342746 & 3.36 & 0.001 & .1882631 & .7146099 \\
\hline -Irevista_24 & -.5824951 & .1765466 & -3.30 & 0.001 & -.9285202 & -.23647 \\
\hline Irevista-25 & -1.600031 & .7069803 & -2.26 & 0.024 & -2.985687 & -.214375 \\
\hline -Irevista_26 & .412007 & .1463551 & 2.82 & 0.005 & .1251564 & .6988577 \\
\hline$-\quad$ cons & 1.673316 & .0978562 & 17.10 & 0.000 & 1.481521 & 1.865111 \\
\hline / Inalpha & .1434256 & .0433676 & & & .0584268 & .2284245 \\
\hline & & & & & 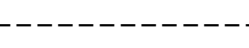 & --------- \\
\hline alpha & 1.154221 & .0500558 & & & 1.060167 & 1.256619 \\
\hline
\end{tabular}


LR test of alpha=0: chibar2(01) $=5255.94$

Prob $>=$ chibar $2=0.000$

$\cdot$

- predict u

(option $\mathrm{n}$ assumed; predicted number of events)

- stepwise, pr(0.05): nbreg citacoes n_p_tit n_p_p_chave n_pag n_ref n_autores prop_mulher idade_I*, irr begin with full model

$\mathrm{p}=0.9804>=0.0500$ removing Iies_1_aut_5

$\mathrm{p}=0.9733>=0.0500$

$\mathrm{p}=0.9526>=0.0500$

$\mathrm{p}=0.9190>=0.0500$ removing ${ }^{-}$Itit ${ }^{-}{ }^{-}$aut 3

removing _Irevista_ $2 \overline{8}$

$\mathrm{p}=0.9089>=0.0500$

removing prop_mulher

$\mathrm{p}=0.9213>=0.0500$

$\mathrm{p}=0.8967>=0.0500$

removing Iies_1_aut_15

$\mathrm{p}=0.8793>=0.0500$

$\mathrm{p}=0.7671>=0.0500$

$\mathrm{p}=0.7664>=0.0500$

$\mathrm{p}=0.7575>=0.0500$

$\mathrm{p}=0.7280>=0.0500$

$\mathrm{p}=0.7237>=0.0500$

$\mathrm{p}=0.6978>=0.0500$

$\mathrm{p}=0.6712>=0.0500$

$\mathrm{p}=0.6088>=0.0500$

$\mathrm{p}=0.6214>=0.0500$

$\mathrm{p}=0.5739>=0.0500$

$\mathrm{p}=0.5587>=0.0500$

$\mathrm{p}=0.5722>=0.0500$

$\mathrm{p}=0.4683>=0.0500$

$\mathrm{p}=0.5022>=0.0500$

$\mathrm{p}=0.4356>=0.0500$

$\mathrm{p}=0.4345>=0.0500$

$\mathrm{p}=0.4101>=0.0500$

$\mathrm{p}=0.3931>=0.0500$

$\mathrm{p}=0.3541>=0.0500$

$\mathrm{p}=0.3424>=0.0500$

$\mathrm{p}=0.3296>=0.0500$

$\mathrm{p}=0.2904>=0.0500$

$\mathrm{p}=0.3147>=0.0500$

$\mathrm{p}=0.2474>=0.0500$

$\mathrm{p}=0.3136>=0.0500$

$\mathrm{p}=0.1612>=0.0500$

$\mathrm{p}=0.1625>=0.0500$

$\mathrm{p}=0.1508>=0.0500$

$\mathrm{p}=0.1117>=0.0500$

$\mathrm{p}=0.1404>=0.0500$

$\mathrm{p}=0.2185>=0.0500$

$\mathrm{p}=0.1831>=0.0500$

$\mathrm{p}=0.2565>=0.0500$

$\mathrm{p}=0.1273>=0.0500$

$\mathrm{p}=0.1757>=0.0500$

$\mathrm{p}=0.1456>=0.0500$

$\mathrm{p}=0.1034>=0.0500$

$\mathrm{p}=0.0681>=0.0500$

$\mathrm{p}=0.0642>=0.0500$

removing Iies ${ }^{-}$aut 13

removing Irevista_2

removing - Itit_1_aūt_4

removing Iaborāāgem_2

removing Iies_1 aut 8

removing _Irevista_14

removing _Iies_1_aút_18

removing -Iposīcāo_2-

removing Iarea 4

removing _Iies_í1_aut_19

removing Iqualis̄s_vi_8

removing Iqualis_vi_3

removing $\bar{n}$ _p_tit

removing I $\overline{\text { Iarea_5 }}$

removing Irevista 6

removing _Iies_1_aut_ 7

removing Iies_ ${ }^{-}$aut_ 12

removing Iqualis_vi_ ${ }^{7}$

removing $\bar{n}$ pag

removing Ittit_1_aut_2

removing $\bar{n} \_\mathrm{p} \_\mathrm{p} \_$chave

removing $\overline{\text { I }}$ ies_- ${ }^{-}$_aut_9

removing - Iies_1_aut_14

removing - Iies_ ${ }^{-}$-aut_ 6

removing Iies_1_aut_17

removing Iies_1 aut 11

removing Iies_1 aut 16

removing Iies_1_aut_3

removing Iarea $\overline{6}$

removing Iord_ou_es_2

removing - Igen_1_aut_2

removing Iqua $\bar{l}$ is vi ${ }^{-} 6$

removing Irevista $3 \overline{6}$

removing Iqualis_vi_5

removing _Iqualis_vi_4

removing Iqualis ${ }^{-}{ }^{-} 2$

removing Irevistā_ $1 \overline{2}$

removing Irevista_30

removing - Irevista_11

removing Iies_1_aut_2

removing Irevista $2 \overline{7}$

removing $\bar{n}$ _autores

Negative binomial regression
Number of obs

LR chi2(32)

Prob > chi2
$=$

Dispersion = mean $=\quad 700.27$

$=0.0000$ 


\begin{tabular}{|c|c|c|c|c|c|c|}
\hline citacoes & IRR & Std. Err. & z & $\mathrm{P}>|\mathrm{z}|$ & [95\% Conf. & Interval] \\
\hline & & & & & & - \\
\hline Irevista_35 & .35101 & .0990462 & -3.71 & 0.000 & .2018979 & .6102493 \\
\hline Irevista_29 & 1.751088 & .1984097 & 4.94 & 0.000 & 1.402366 & 2.186526 \\
\hline İies_1_aut_4 & .8256961 & .0460387 & -3.44 & 0.001 & .7402176 & .9210455 \\
\hline n_ref & 1.009712 & .0020359 & 4.79 & 0.000 & 1.00573 & 1.01371 \\
\hline Iies_1_aut_10 & 1.662863 & .3868172 & 2.19 & 0.029 & 1.05402 & 2.623397 \\
\hline - & .6522468 & .0409752 & -6.80 & 0.000 & .5766843 & .7377103 \\
\hline- ida $\overline{d e}$ & .8432427 & .0125788 & -11.43 & 0.000 & .8189457 & .8682606 \\
\hline Irevista_33 & .3324316 & .1024257 & -3.57 & 0.000 & .1817348 & .608088 \\
\hline _Irevistā3 & .4107972 & .0860779 & -4.25 & 0.000 & .2724381 & .6194227 \\
\hline -Irevista_4 & 2.198687 & .3509819 & 4.94 & 0.000 & 1.607993 & 3.006373 \\
\hline -Irevista_5 & 1.94815 & .2880222 & 4.51 & 0.000 & 1.458067 & 2.60296 \\
\hline - & .2432733 & .0672016 & -5.12 & 0.000 & .1415662 & .4180513 \\
\hline _Irevista_ 7 & 5.781888 & .9923772 & 10.22 & 0.000 & 4.130221 & 8.094053 \\
\hline -Irevista_8 & 35.32484 & 9.35189 & 13.46 & 0.000 & 21.02487 & 5088 \\
\hline -Irevista_9 & 2.755738 & .4777808 & 5.85 & 0.000 & 1.961821 & 3.870941 \\
\hline - $\bar{I} r e v i s t a \_\overline{1} 0$ & 2.447359 & .6074038 & 3.61 & 0.000 & 1.504666 & 3.98 \\
\hline Irevista_31 & .1030963 & .1109957 & -2.11 & 0.035 & .0124975 & 0481 \\
\hline Irevista_32 & .2519086 & .0837693 & -4.15 & 0.000 & .1312761 & .483393 \\
\hline Irevista_13 & 1.351687 & .1778902 & 2.29 & 0.022 & 1.044366 & 1.749442 \\
\hline _Iarea_3 & .8382977 & .0647098 & -2.28 & 0.022 & .7205969 & .9752235 \\
\hline Irevista_ $\overline{1} 5$ & .1549518 & .0681138 & -4.24 & 0.000 & .0654674 & .3667 \\
\hline Irevista_16 & .1625246 & .0641836 & -4.60 & 0.000 & .074949 & .3524297 \\
\hline Irevista_17 & 2.49038 & .4170034 & 5.45 & 0.000 & 1.793642 & 3.457767 \\
\hline Irevista_18 & 3.061424 & .5907218 & 5.80 & 0.000 & 2.097387 & 4.468568 \\
\hline Irevista_19 & 91.29306 & 24.10929 & 17.09 & 0.000 & 54.40599 & 153.1894 \\
\hline Irevista_20 & .6012212 & .1072491 & -2.85 & 0.004 & .4238307 & $\$ 2857$ \\
\hline -Irevista_21 & 2.264673 & .3262443 & 5.67 & 0.000 & 1.707588 & 3.003502 \\
\hline Irevista_22 & 1.682405 & .250652 & 3.49 & 0.000 & 1.256363 & 2.252923 \\
\hline Irevista_23 & 1.570567 & .2108872 & 3.36 & 0.001 & 1.207151 & 2.043389 \\
\hline -Irevista_24 & .5585031 & .0986019 & -3.30 & 0.001 & .395138 & .7894095 \\
\hline Irevista_25 & .2018903 & .1427324 & -2.26 & 0.024 & .0505048 & .8070457 \\
\hline Irevista_26 & 1.509845 & .2209735 & 2.82 & 0.005 & 1.133326 & 2.011454 \\
\hline -cons & 5.329812 & .521555 & 17.10 & 0.000 & 4.399634 & 6.45665 \\
\hline & & 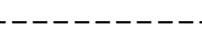 & & & ---------- & --------- \\
\hline /lnalpha | & .1434256 & .0433676 & & & .0584268 & .2284245 \\
\hline alpha & 1.154221 & .0500558 & & & 1.060167 & 1.256619 \\
\hline
\end{tabular}

.

-

- quietly stepwise, pr(0.05): poisson citacoes n_p_tit n_p_p_chave n_pag n_ref n_autores prop_mulher idade_ _*

- prcounts prpoisson, plot

- quietly stepwise, pr(0.05): nbreg citacoes n_p_tit n_p_p_chave n_pag n_ref n_autores prop_mulher idade _ I*

- prcounts proneg, plot - 9 1))

(note: named style 1 not found in class connectstyle, default attributes used) (note: named style 1 not found in class connectstyle, default attributes used) 
(note: named style 1 not found in class connectstyle, default attributes used)

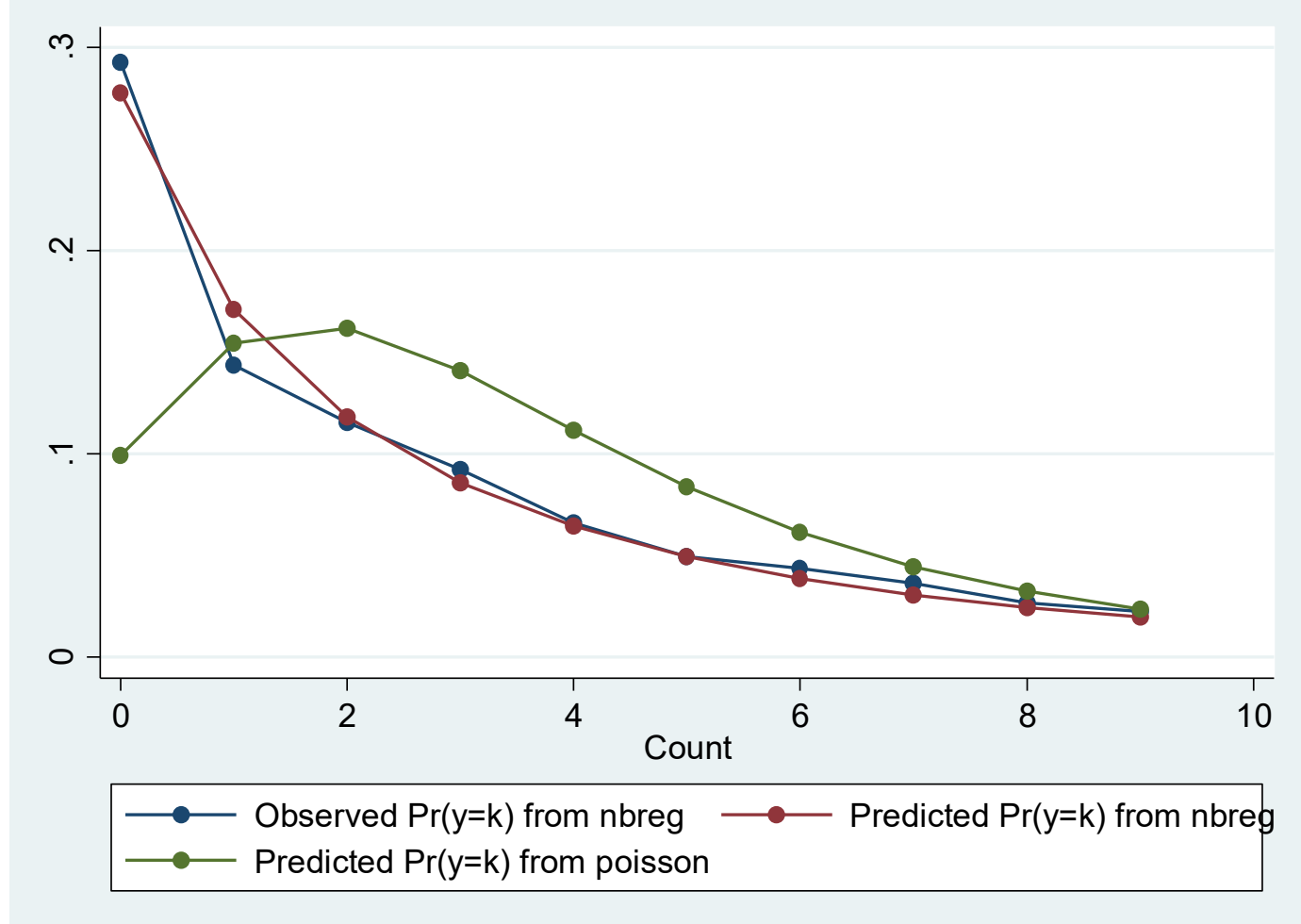

- countfit citacoes n_p_tit n_p_p_chave n_pag n_ref n_autores prop_mulher idade _ I*, prm nograph noestimates nofit

Comparison of Mean Observed and Predicted Count

\begin{tabular}{|c|c|c|c|}
\hline Model & $\begin{array}{c}\text { Maximum } \\
\text { Difference }\end{array}$ & $\begin{array}{c}\text { At } \\
\text { Value }\end{array}$ & $\begin{array}{l}\text { Mean } \\
\mid \text { Diff | }\end{array}$ \\
\hline PRM & 0.193 & 0 & 0.041 \\
\hline
\end{tabular}

PRM: Predicted and actual probabilities

\begin{tabular}{|c|c|c|c|c|}
\hline Count & Actual & Predicted & |Diff| & Pearson \\
\hline & ------- & ---------- & ------ & -------- \\
\hline 0 & 0.293 & 0.099 & 0.193 & 813.991 \\
\hline 1 & 0.144 & 0.155 & 0.011 & 1.817 \\
\hline 2 & 0.116 & 0.162 & 0.047 & 29.003 \\
\hline 3 & 0.092 & 0.141 & 0.049 & 36.198 \\
\hline 4 & 0.066 & 0.111 & 0.045 & 39.867 \\
\hline 5 & 0.049 & 0.084 & 0.034 & 30.271 \\
\hline 6 & 0.044 & 0.061 & 0.017 & 10.697 \\
\hline 7 & 0.037 & 0.045 & 0.008 & 3.147 \\
\hline 8 & 0.027 & 0.032 & 0.006 & 2.097 \\
\hline 9 & 0.023 & 0.024 & 0.001 & 0.097 \\
\hline Sum & 0.890 & 0.915 & 0.412 & 967. \\
\hline
\end{tabular}

- countfit citacoes n_p_tit n_p_p_chave n_pag n_ref n_autores prop_mulher idade _ I*, nbreg nograph noestimātēs nofit

Comparison of Mean Observed and Predicted Count

\begin{tabular}{|c|c|c|c|}
\hline Mod & $\begin{array}{c}\text { Maximum } \\
\text { Difference }\end{array}$ & $\begin{array}{c}\text { At } \\
\text { Value }\end{array}$ & Mean \\
\hline & -ー-ー-ーー-ー- & - - - - - & ------ \\
\hline BRM & -0.029 & 1 & 0.007 \\
\hline
\end{tabular}

NBRM: Predicted and actual probabilities 


\begin{tabular}{|c|c|c|c|c|}
\hline Count & Actual & Predicted & |Diff| & Pearson \\
\hline 0 & 0.293 & 0.276 & 0.016 & 2.128 \\
\hline 1 & 0.144 & 0.173 & 0.029 & 10.787 \\
\hline 2 & 0.116 & 0.120 & 0.004 & 0.314 \\
\hline 3 & 0.092 & 0.087 & 0.006 & 0.843 \\
\hline 4 & 0.066 & 0.065 & 0.001 & 0.074 \\
\hline 5 & 0.049 & 0.049 & 0.000 & 0.001 \\
\hline 6 & 0.044 & 0.038 & 0.006 & 1.760 \\
\hline 7 & 0.037 & 0.030 & 0.006 & 2.795 \\
\hline 8 & 0.027 & 0.024 & 0.003 & 0.599 \\
\hline 9 & 0.023 & 0.020 & 0.003 & 1.018 \\
\hline Sum & 0.890 & 0.882 & 0.075 & 20.318 \\
\hline
\end{tabular}

- graph twoway mspline u citacoes I| mspline lambda citacoes ||, legend(label(1 "Binomial Negativo") label (2 "Poisson"))

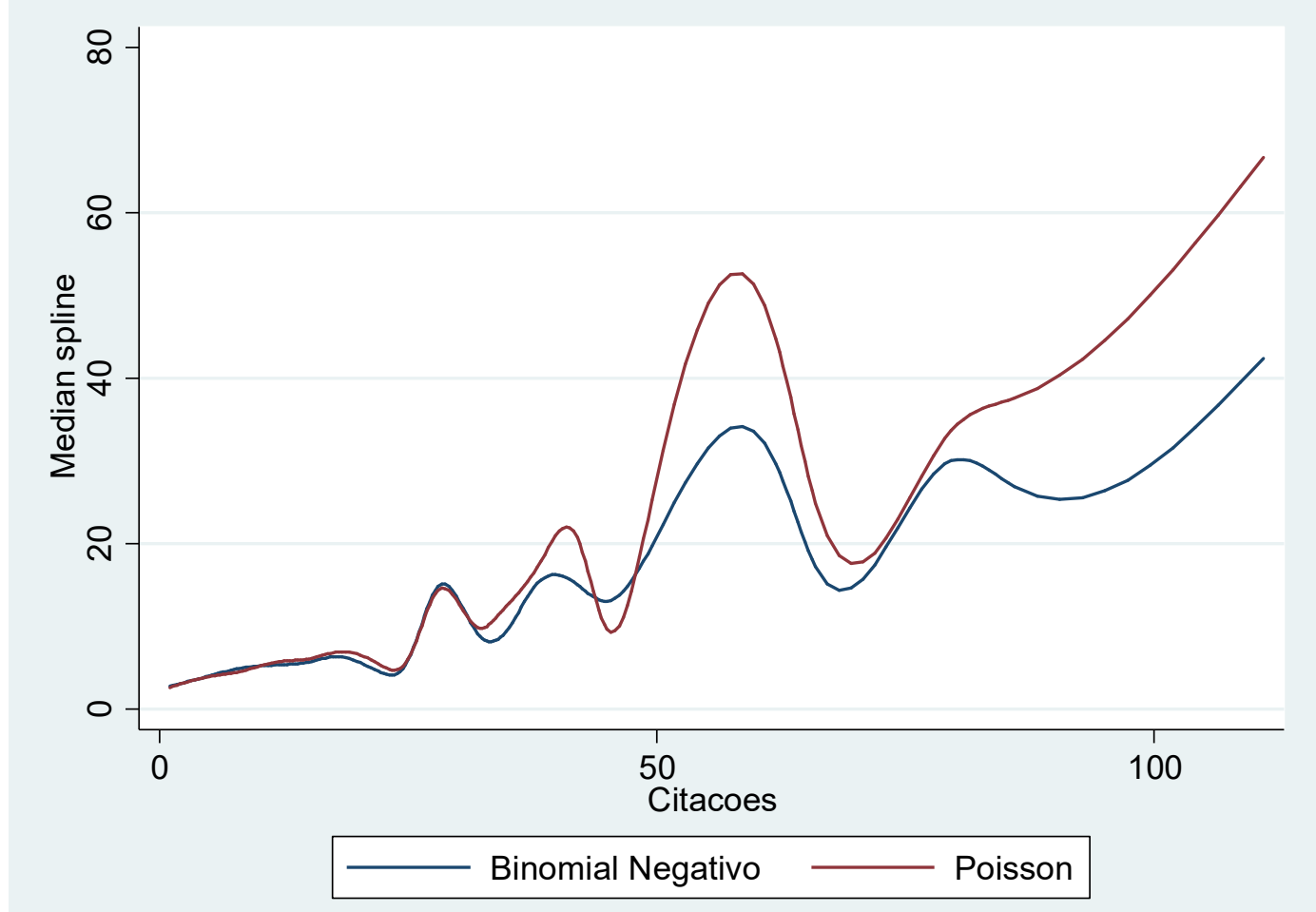

- gen lncitacoes=ln (citacoes)

(633 missing values generated)

- quietly reg lncitacoes $n \_p$ _tit $n \_p \_p \_c h a v e n \_p a g ~ n \_r e f n$ _autores prop mulher idade I $^{\star}$

- predict yhat

(option xb assumed; fitted values)

- gen eyhat $=\exp ($ yhat $)$ 
- graph twoway lfit u citacoes || lfit lambda citacoes || lfit eyhat citacoes ||, legend(label(1 "Binomial Negativo") label (2 "Poisso

$>$ n") label (3 "OLS"))

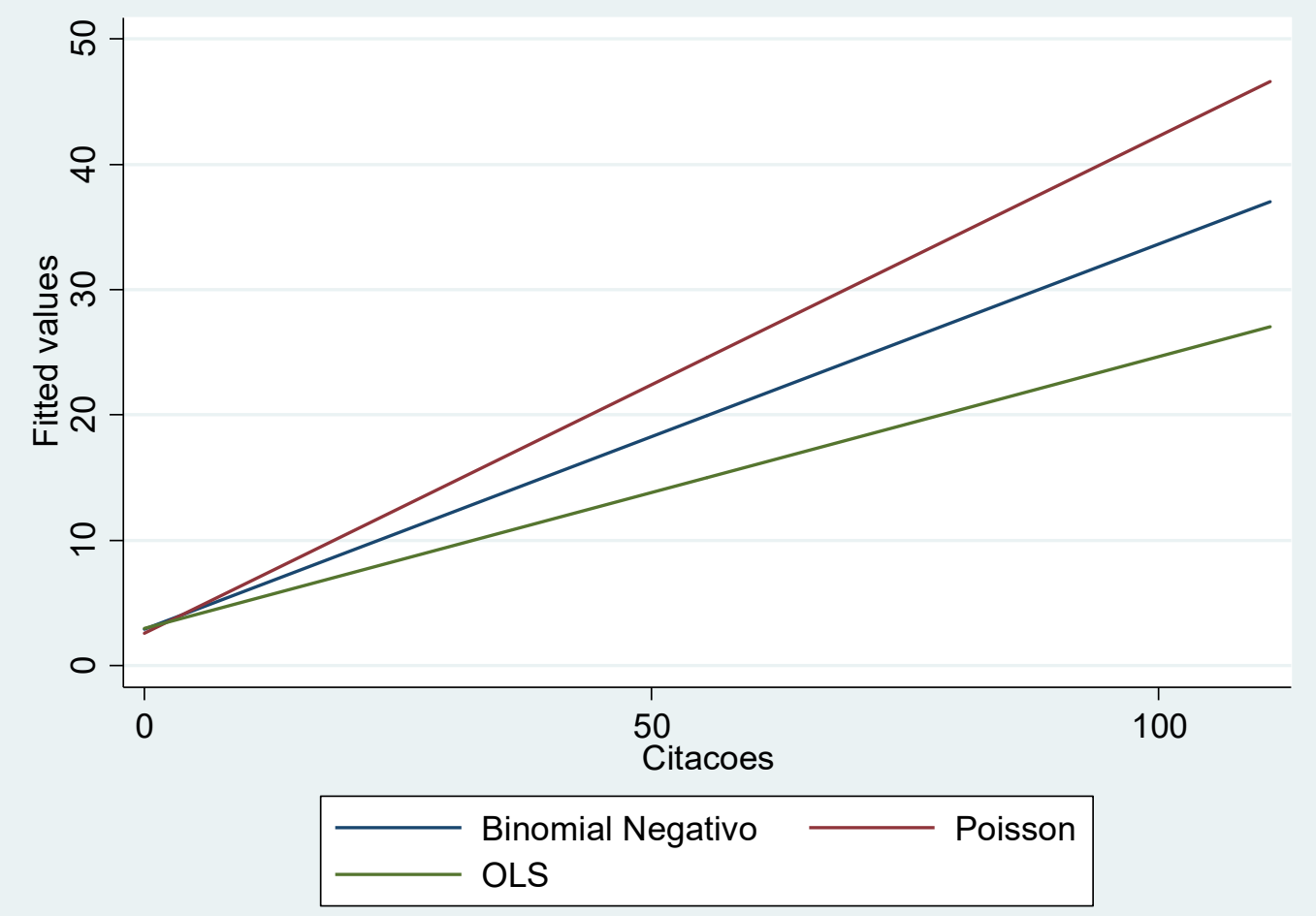


Apêndice Q - Saídas do Stata do Modelo 7 - Sem a RC\&F como categoria de Revista

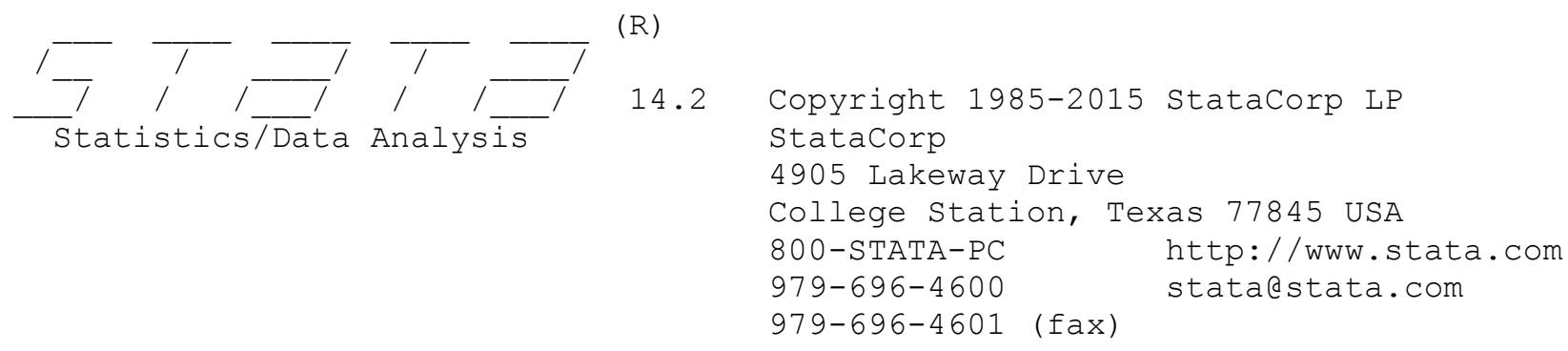

Single-user Stata license expires 29 May 2017: Serial number: 301409337392

Licensed to: Sandro Vieira Soares

Notes:

1. Unicode is supported; see help unicode_advice.

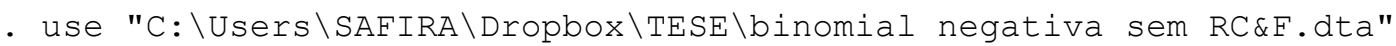

- tab citacoes

\begin{tabular}{|c|c|c|c|c|}
\hline Citacoes & I & Freq. & Percent & Cum. \\
\hline 0 & 1 & 693 & 28.55 & $28 \quad 55$ \\
\hline 1 & | & 350 & 14.42 & 42.97 \\
\hline 2 & | & 282 & 11.62 & 54.59 \\
\hline 3 & | & 242 & 9.97 & 64.57 \\
\hline 4 & 1 & 161 & 6.63 & 71.20 \\
\hline 5 & 1 & 124 & 5.11 & 76.31 \\
\hline 6 & | & 102 & 4.20 & 80.51 \\
\hline 7 & 1 & 92 & 3.79 & 84.30 \\
\hline 8 & 1 & 60 & 2.47 & 86.77 \\
\hline 9 & | & 58 & 2.39 & 89.16 \\
\hline 10 & 1 & 43 & 1.77 & 90.94 \\
\hline 11 & | & 28 & 1.15 & 92.09 \\
\hline 12 & | & 24 & 0.99 & 93.08 \\
\hline 13 & 1 & 26 & 1.07 & 94.15 \\
\hline 14 & | & 17 & 0.70 & 94.85 \\
\hline 15 & | & 13 & 0.54 & 95.39 \\
\hline 16 & | & 12 & 0.49 & 95.88 \\
\hline 17 & i & 8 & 0.33 & 96.21 \\
\hline 18 & | & 10 & 0.41 & 96.62 \\
\hline 19 & 1 & 11 & 0.45 & 97.07 \\
\hline 20 & 1 & 5 & 0.21 & 97.28 \\
\hline 21 & | & 10 & 0.41 & 97.69 \\
\hline 22 & 1 & 3 & 0.12 & 97.82 \\
\hline 23 & | & 4 & 0.16 & 97.98 \\
\hline 24 & | & 5 & 0.21 & 98.19 \\
\hline 25 & | & 5 & 0.21 & 98.39 \\
\hline 26 & | & 3 & 0.12 & 98.52 \\
\hline 27 & | & 3 & 0.12 & 98.64 \\
\hline 28 & | & 2 & 0.08 & 98.72 \\
\hline 29 & | & 2 & 0.08 & 98.81 \\
\hline 30 & | & 1 & 0.04 & 98.85 \\
\hline 31 & 1 & 4 & 0.16 & 99.01 \\
\hline 32 & i & 4 & 0.16 & 99.18 \\
\hline 33 & | & 1 & 0.04 & 99.22 \\
\hline 34 & | & 2 & 0.08 & 99.30 \\
\hline 35 & | & 3 & 0.12 & 99.42 \\
\hline 37 & | & 2 & 0.08 & 99.51 \\
\hline 38 & | & 2 & 0.08 & 99.59 \\
\hline 39 & | & 1 & 0.04 & 99.63 \\
\hline
\end{tabular}




\begin{tabular}{r|rrr}
41 & 1 & 0.04 & 99.67 \\
42 & 1 & 0.04 & 99.71 \\
44 & 1 & 0.04 & 99.75 \\
46 & 1 & 0.04 & 99.79 \\
48 & 1 & 0.04 & 99.84 \\
52 & 1 & 0.04 & 99.88 \\
66 & 1 & 0.04 & 99.92 \\
84 & 1 & 0.04 & 99.96 \\
87 & 1 & 0.04 & 100.00 \\
---1 & 2,427 & 100.00 &
\end{tabular}

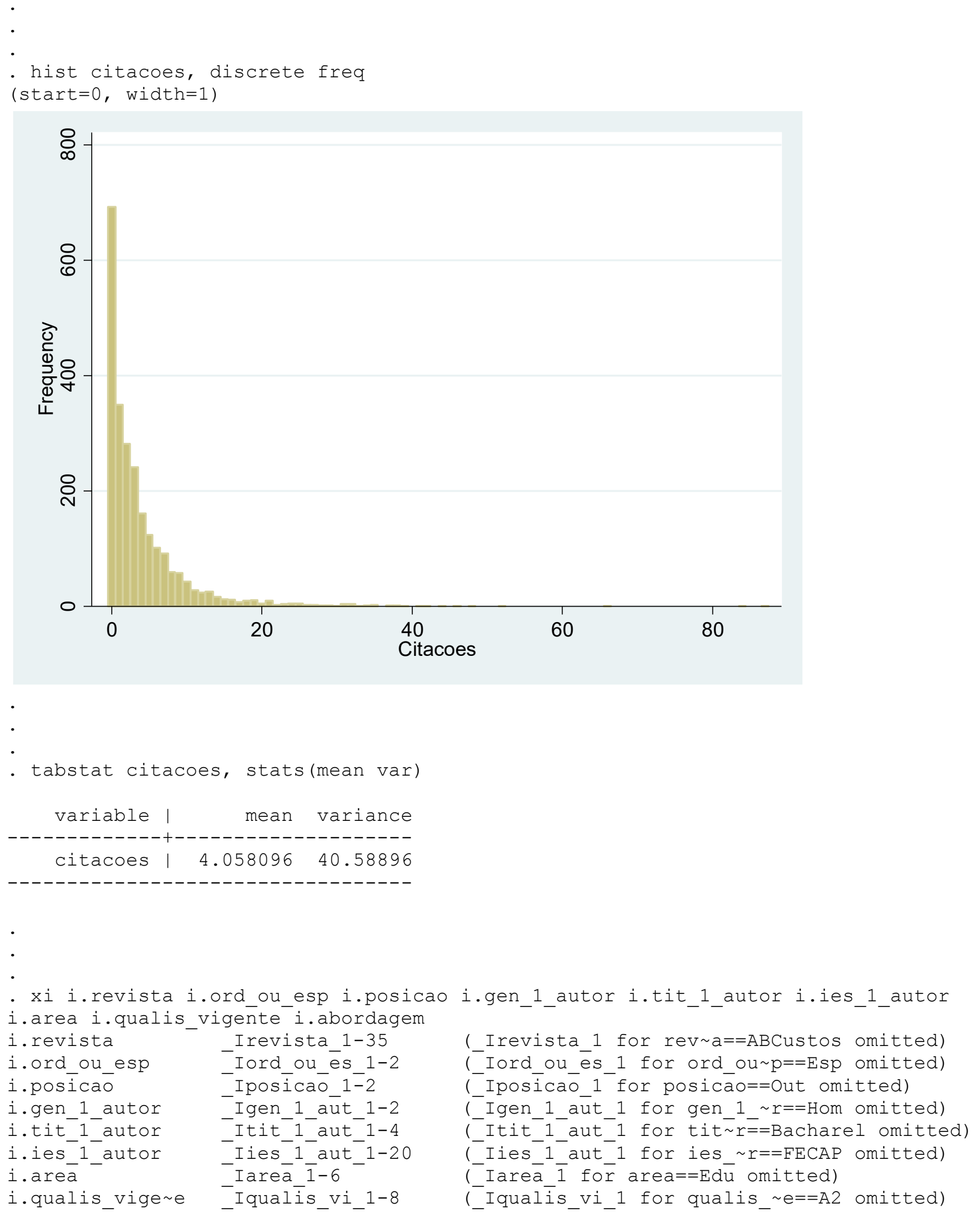


- quietly stepwise, pr(0.05): poisson citacoes n_p_tit n_p_p_chave n_pag n_ref n_autores prop_mulher idade _ I*

- predict lambda

(option $\mathrm{n}$ assumed; predicted number of events)

- gen yasterisco $=\left((\text { citacoes-lambda })^{\wedge} 2-\right.$ citacoes $) /$ lambda

- reg yasterisco lambda, nocons

\begin{tabular}{r|rrrrr} 
Source | & SS & df & MS & Number of obs & $=$ \\
2,427 \\
-1
\end{tabular}

\begin{tabular}{|c|c|c|c|c|c|c|}
\hline yasterisco | & Coef. & Std. Err. & $t$ & $P>|t|$ & [95\% Conf. & Interval] \\
\hline lambda | & 1.175984 & .0814691 & 14.43 & 0.000 & 1.016227 & 1.3357 \\
\hline
\end{tabular}

- quietly stepwise, pr(0.05): poisson citacoes n_p_tit n_p_p_chave n_pag n_ref n_autores prop_mulher idade_I*

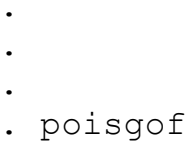

$$
\begin{array}{llr}
\begin{array}{l}
\text { Deviance goodness-of-fit } \\
\text { Prob }>\text { chi2(2372) }
\end{array} & 11713.54 \\
& = & 0.0000 \\
\text { Pearson goodness-of-fit } & = & 14420.76 \\
\text { Prob }>\text { chi2(2372) } & = & 0.0000
\end{array}
$$
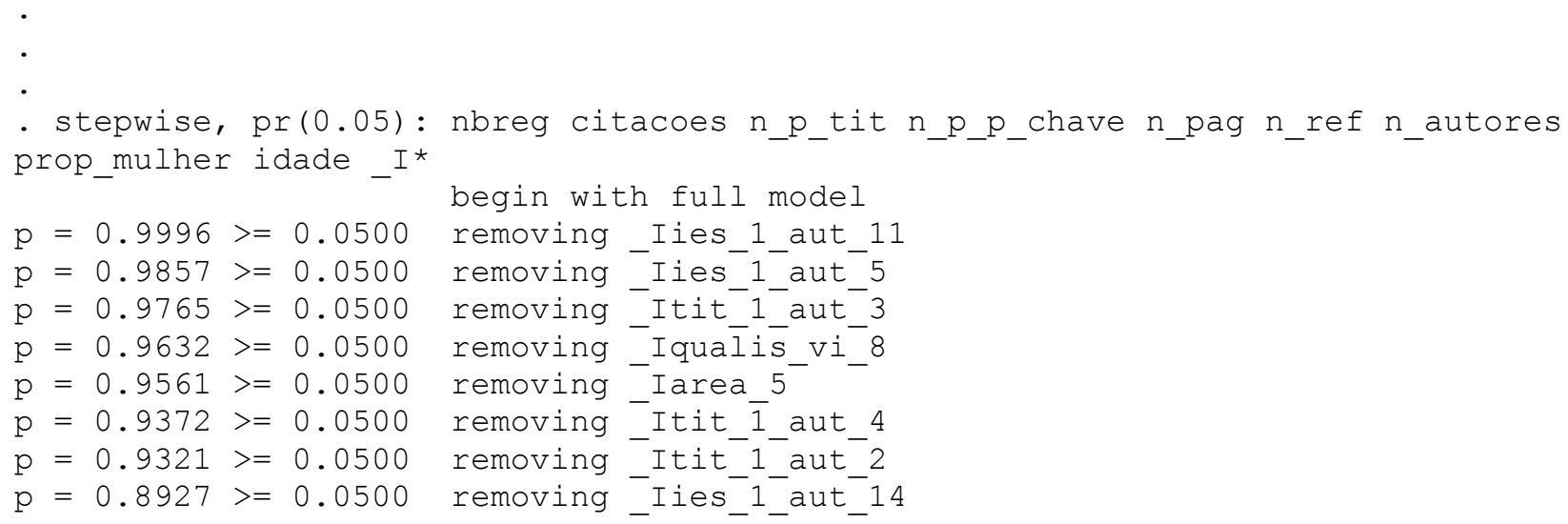
$\mathrm{p}=0.8880>=0.0500$

$\mathrm{p}=0.8870>=0.0500$

$\mathrm{p}=0.8477>=0.0500$

$\mathrm{p}=0.8339>=0.0500$

$\mathrm{p}=0.8698>=0.0500$

$\mathrm{p}=0.9022>=0.0500$

$\mathrm{p}=0.8050>=0.0500$

$\mathrm{p}=0.7530>=0.0500$

$\mathrm{p}=0.6653>=0.0500$

$\mathrm{p}=0.6839>=0.0500$

$\mathrm{p}=0.6299>=0.0500$

$\mathrm{p}=0.6157>=0.0500$

$\mathrm{p}=0.6143>=0.0500$

$\mathrm{p}=0.6582>=0.0500$

$\mathrm{p}=0.6069>=0.0500$

$\mathrm{p}=0.5696>=0.0500$

$\mathrm{p}=0.5492>=0.0500$

$\mathrm{p}=0.4982>=0.0500$

$\mathrm{p}=0.5015>=0.0500$

$\mathrm{p}=0.4931>=0.0500$

$\mathrm{p}=0.4662>=0.0500$

$\mathrm{p}=0.3905>=0.0500$

$\mathrm{p}=0.3696>=0.0500$

$\mathrm{p}=0.3640>=0.0500$

$\mathrm{p}=0.2709>=0.0500$

$\mathrm{p}=0.2794>=0.0500$

$\mathrm{p}=0.2355>=0.0500$

$\mathrm{p}=0.2306>=0.0500$

$\mathrm{p}=0.2368>=0.0500$

$\mathrm{p}=0.2336>=0.0500$

$\mathrm{p}=0.1629>=0.0500$

$\mathrm{p}=0.1695>=0.0500$

$\mathrm{p}=0.1404>=0.0500$

$\mathrm{p}=0.1214>=0.0500$

$\mathrm{p}=0.0898>=0.0500$

$\mathrm{p}=0.0594>=0.0500$

$\mathrm{p}=0.0637>=0.0500$ removing Iies_1_aut_7 removing Irevista ${ }^{-}$ removing Irevista- 6 removing _Iies_1_aut_6 removing Iies_1_aut_3 removing Iies_ 1 aut_16 removing Iqualis vi_ 2 removing Irevistā $2 \overline{7}$ removing Iies_1 aut 12 removing Iies_ ${ }^{-}$-aut 9 removing _Iarea_ $\overline{4}$ removing _Iabordagem_2 removing Iqualis $\mathrm{vi}^{-} 7$ removing Iqualis ${ }^{-}{ }^{-}{ }^{5}$ removing Iqualis vi 4 removing Iposicao_2 removing Iqualis $\bar{v} i$ removing Iies_1_aut_17 removing Irevista_1 $\overline{4}$ removing $\bar{n}$ _p_tit

removing $n$ pàg

removing İies_1_aut_18

removing prop_mūher

removing Iies 1 aut 8

removing Irevista_ $3 \overline{5}$

removing Irevista_29

removing $\bar{n}$ _p_p_chave

removing Irevista 12

removing Iies_1_aut_13

removing Iies_1_aut_20

removing Iies 1 aut 15

removing Iarea $\overline{\bar{\sigma}}$

removing Irevista_11

removing Iies_1_autt2

removing Iord_oūes_- 2

removing $\bar{n}$ autores

removing _Irevista_13

Negative binomial regression

Number of obs

LR chi2 (34)

Prob > chi2

Pseudo R2 $=\quad 2,427$

$=\quad 586.38$

$=0.0000$

$=0.0488$

$\begin{array}{ll}\text { Dispersion } & =\text { mean } \\ \text { Log likelihood } & =-5710.9828\end{array}$

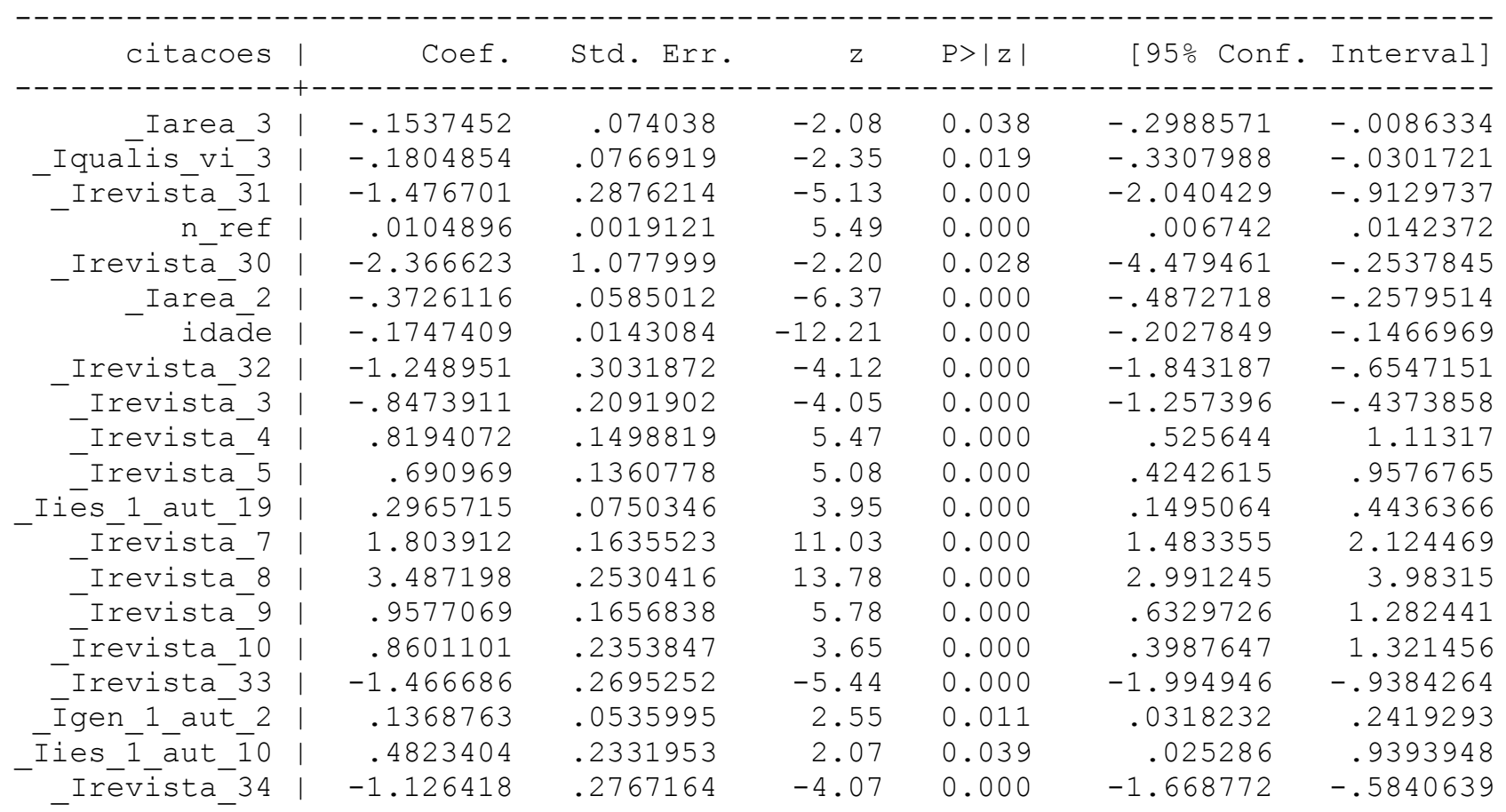




\begin{tabular}{|c|c|c|c|c|c|c|}
\hline _Irevista_15 & -1.73471 & .3671038 & -4.73 & 0.000 & -2.45422 & -1.0152 \\
\hline Irevista_16 & -1.887914 & .3497594 & -5.40 & 0.000 & -2.57343 & -1.202398 \\
\hline Irevista 17 & .9089047 & .161664 & 5.62 & 0.000 & .5920491 & 1.22576 \\
\hline - Irevista_-18 & .8007243 & .1710463 & 4.68 & 0.000 & .4654798 & 1.135969 \\
\hline -Irevista_19 & -.6053189 & .1645089 & -3.68 & 0.000 & -.9277505 & -.2828874 \\
\hline -Irevista_20 & .7880241 & .1336893 & 5.89 & 0.000 & .5259979 & 1.05005 \\
\hline -Irevista_21 & .4774676 & .1409994 & 3.39 & 0.001 & .2011138 & .7538214 \\
\hline -Irevista_22 & .4389344 & .1190313 & 3.69 & 0.000 & .2056374 & .6722315 \\
\hline -Irevista_23 & -.5366927 & .1593648 & -3.37 & 0.001 & -.8490419 & -.224343 \\
\hline -Irevista_24 & -1.671882 & .7081806 & -2.36 & 0.018 & -3.05989 & -.283873 \\
\hline -Irevista_25 & .4402544 & .1293776 & 3.40 & 0.001 & .186679 & .693829 \\
\hline Irevista 26 & -.617824 & .2736479 & -2.26 & 0.024 & -1.154164 & -.0814839 \\
\hline $\bar{I}$ Ies_1_aut_4 & -.2258028 & .0574406 & -3.93 & 0.000 & -.3383843 & -.113221 \\
\hline _Irevista_z $\overline{2} 8$ & .530712 & .101457 & 5.23 & 0.000 & .3318599 & .729564 \\
\hline- cons & 1.696193 & .0952978 & 17.80 & 0.000 & 1.509413 & 1.88297 \\
\hline & & & & & $2-5=2-5$ & --------- \\
\hline alpha & .1560801 & .0402832 & & & .0771265 & .2350 \\
\hline lpha & 1.1 & .047 & & & 1.080179 & \\
\hline
\end{tabular}

LR test of alpha=0: chibar2 $(01)=6011.66$

Prob $>=$ chibar $2=0.000$

.

- predict u

(option $\mathrm{n}$ assumed; predicted number of events)

.

.

- stepwise, pr(0.05): nbreg citacoes n_p_tit n_p_p_chave n_pag n_ref n_autores prop_mulher idade_I*, irr begin with full model

$\mathrm{p}=0.9996>=0.0500$

$\mathrm{p}=0.9857>=0.0500$

$\mathrm{p}=0.9765>=0.0500$

$\mathrm{p}=0.9632>=0.0500$

$\mathrm{p}=0.9561>=0.0500$

$\mathrm{p}=0.9372>=0.0500$

$\mathrm{p}=0.9321>=0.0500$

$\mathrm{p}=0.8927>=0.0500$

$\mathrm{p}=0.8880>=0.0500$

$\mathrm{p}=0.8870>=0.0500$

$\mathrm{p}=0.8477>=0.0500$

$\mathrm{p}=0.8339>=0.0500$

$\mathrm{p}=0.8698>=0.0500$

$\mathrm{p}=0.9022>=0.0500$

$\mathrm{p}=0.8050>=0.0500$

$\mathrm{p}=0.7530>=0.0500$

$\mathrm{p}=0.6653>=0.0500$

$\mathrm{p}=0.6839>=0.0500$

$\mathrm{p}=0.6299>=0.0500$

$\mathrm{p}=0.6157>=0.0500$

$\mathrm{p}=0.6143>=0.0500$

$\mathrm{p}=0.6582>=0.0500$

$\mathrm{p}=0.6069>=0.0500$

$\mathrm{p}=0.5696>=0.0500$

$\mathrm{p}=0.5492>=0.0500$

$\mathrm{p}=0.4982>=0.0500$

$\mathrm{p}=0.5015>=0.0500$

$\mathrm{p}=0.4931>=0.0500$

$\mathrm{p}=0.4662>=0.0500$

$\mathrm{p}=0.3905>=0.0500$

$\mathrm{p}=0.3696>=0.0500$

$\mathrm{p}=0.3640>=0.0500$ removing Iies 1 aut 11

removing Iies 1 aut 5

removing - Itit ${ }^{-}{ }^{-}$aut ${ }^{-} 3$

removing Iqua $\bar{l}$ is_vi_-8

removing Iarea 5

removing Itit $\overline{1}$ aut 4

removing - Itit_ ${ }^{-}{ }^{-}$aut_${ }^{-}$

removing Iies ${ }^{-}$- aut 14

removing ${ }^{-}$Iies ${ }^{-}{ }^{-}$aut ${ }^{-} 7$

removing Irevis̄̄a_2-

removing Irevista_6

removing Iies 1 aūt 6

removing -Iies_1_aut_3

removing Iies_ ${ }^{-}$-aut_16

removing Iqualis vi ${ }^{-} 2$

removing Irevistā_ $2 \overline{7}$

removing Iies_1_aut_12

removing Iies_1 aut 9

removing ${ }^{\text {Iarea }} \overline{4}$

removing Iabordagem 2

removing Iqualis $\mathrm{vi}^{-} 7$

removing Iqualis_vi_5

removing Iqualis ${ }^{-}{ }^{-}{ }^{4}$

removing Iposicao $2^{-}$

removing _Iqualis_vi_ 6

removing Iies 1 aut 17

removing _Irevista_ $1 \overline{4}$

removing $\bar{n} \_p \_t i t$

removing n_pàg

removing İies 1 aut 18

removing prop_mulher

removing _Iies__ ${ }^{1}$ aut_ 8 
$\mathrm{p}=0.2709>=0.0500$

$\mathrm{p}=0.2794>=0.0500$

$\mathrm{p}=0.2355>=0.0500$

$\mathrm{p}=0.2306>=0.0500$

$\mathrm{p}=0.2368>=0.0500$

$\mathrm{p}=0.2336>=0.0500$

$\mathrm{p}=0.1629>=0.0500$

$\mathrm{p}=0.1695>=0.0500$

$\mathrm{p}=0.1404>=0.0500$

$\mathrm{p}=0.1214>=0.0500$

$\mathrm{p}=0.0898>=0.0500$

$\mathrm{p}=0.0594>=0.0500$

$\mathrm{p}=0.0637>=0.0500$ removing Irevista_35

removing Irevista 29

removing $\bar{n} \mathrm{p} p$ chave

removing Irevista 12

removing Iies_1_aut_13

removing Iies ${ }^{-}$aut 20

removing Iies_1_aut_15

removing Iarea $\overline{-} \overline{6}$

removing Irevista_11

removing Iies 1 aūt 2

removing Iord ou es_es 2

removing $\bar{n}$ autores

removing $\overline{\text { Irevista } 13}$

Negative binomial regression

Number of obs

LR chi2(34)

Prob > chi2

Pseudo R2

$\begin{array}{lr}= & 2,427 \\ = & 586.38 \\ = & 0.0000 \\ = & 0.0488\end{array}$

Log likelihood $=-5710.9828$

\begin{tabular}{|c|c|c|c|c|c|c|c|}
\hline citacoes & | & IRR & std. Err. & z & $P>|z|$ & [95\% Conf. & Interval] \\
\hline--------- & & & & & & & --------- \\
\hline Iarea 3 & | & .8574904 & .0634869 & -2.08 & 0.038 & .7416654 & .9914038 \\
\hline Iqualis_vi_3 & । & .8348648 & .0640274 & -2.35 & 0.019 & .7183497 & .9702785 \\
\hline Irevista_ $\overline{3} 1$ & i & .2283898 & .0656898 & -5.13 & 0.000 & .1299729 & .401329 \\
\hline - n n_ef & i & 1.010545 & .0019322 & 5.49 & 0.000 & 1.006765 & 1.014339 \\
\hline Irevistā_30 & 1 & .093797 & .101113 & -2.20 & 0.028 & .0113395 & .775859 \\
\hline Iareà 2 & | & .6889328 & .0403034 & -6.37 & 0.000 & .6143 & .7726328 \\
\hline$-\quad$ ida $\overline{d e}$ & i & .8396745 & .0120144 & -12.21 & 0.000 & .8164538 & .8635557 \\
\hline Irevista_32 & । & .2868055 & .0869557 & -4.12 & 0.000 & .1583121 & .51959 \\
\hline _Irevistā_3 & i & .4285315 & .0896446 & -4.05 & 0.000 & .2843935 & .6457223 \\
\hline -Irevista_4 & i & 2.269154 & .3401052 & 5.47 & 0.000 & 1.691548 & 3.043994 \\
\hline Irevista 5 & | & 1.995648 & .2715633 & 5.08 & 0.000 & 1.528461 & 2.605635 \\
\hline Iiēs_1_aut_̄ig & i & 1.345239 & .1009395 & 3.95 & 0.000 & 1.161261 & 1.558364 \\
\hline I $\bar{r} e \bar{v}$ istā 7 & i & 6.073361 & .9933122 & 11.03 & 0.000 & 4.407711 & 8.368451 \\
\hline Irevista_8 & | & 32.69421 & 8.272996 & 13.78 & 0.000 & 19.91046 & 53.6859 \\
\hline Irevista-9 & 1 & 2.605714 & .4317246 & 5.78 & 0.000 & 1.8832 & 3.60543 \\
\hline - & i & 2.363421 & .556313 & 3.65 & 0.000 & 1.489983 & 3.748874 \\
\hline -Irevista_33 & 1 & .2306887 & .0621764 & -5.44 & 0.000 & .136021 & .391243 \\
\hline _. Igen_1_aut_2 & i & 1.146686 & .0614618 & 2.55 & 0.011 & 1.032335 & 1.273704 \\
\hline 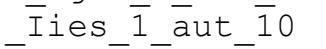 & | & 1.619861 & .377744 & 2.07 & 0.039 & 1.025608 & 2.558433 \\
\hline Irévista_34 & | & .3241924 & .0897094 & -4.07 & 0.000 & .1884783 & .5576276 \\
\hline Irevista 15 & 1 & .1764513 & .064776 & -4.73 & 0.000 & .0859302 & .36233 \\
\hline -Irevista_16 & i & .1513873 & .0529491 & -5.40 & 0.000 & .0762735 & .3004728 \\
\hline Irevista_17 & | & 2.481603 & .4011857 & 5.62 & 0.000 & 1.807689 & 3.406755 \\
\hline -Irevista_18 & i & 2.227154 & .3809464 & 4.68 & 0.000 & 1.592778 & 3.11419 \\
\hline - Irevista-19 & i & .5459003 & .0898055 & -3.68 & 0.000 & .3954423 & .7536047 \\
\hline Irevista_20 & 1 & 2.199047 & .293989 & 5.89 & 0.000 & 1.692147 & 2.857795 \\
\hline Irevista-21 & | & 1.611987 & .2272892 & 3.39 & 0.001 & 1.222764 & 2.125105 \\
\hline -Irevista_22 & i & 1.551054 & .1846239 & 3.69 & 0.000 & 1.228308 & 1.958603 \\
\hline Irevista_23 & 1 & .5846788 & .0931772 & -3.37 & 0.001 & .4278246 & .7990406 \\
\hline Irevista-24 & i & .1878931 & .1330623 & -2.36 & 0.018 & .0468928 & .752862 \\
\hline Irevista-25 & i & 1.553102 & .2009366 & 3.40 & 0.001 & 1.20524 & 2.001366 \\
\hline Irevista_26 & | & .5391163 & .1475281 & -2.26 & 0.024 & .315321 & .9217476 \\
\hline $\bar{I}$ ies_1_aut 4 & i & .7978755 & .0458304 & -3.93 & 0.000 & .7129213 & .8929531 \\
\hline _Irevista_z $\overline{2} 8$ & i & 1.700142 & .1724914 & 5.23 & 0.000 & 1.393558 & 2.074176 \\
\hline$-\quad$ cons & | & 5.45315 & .5196732 & 17.80 & 0.000 & 4.524076 & 6.573022 \\
\hline & & & & & & & -ー-ー-ー-ー- \\
\hline / Inalpha & | & .1560801 & .0402832 & & & .0771265 & .2350338 \\
\hline alpha & | & 1.16892 & .0470879 & & & 1.080179 & 1.264952 \\
\hline
\end{tabular}

LR test of alpha $=0: \operatorname{chibar} 2(01)=6011.66$

Prob $>=$ chibar $2=0.000$ 
- quietly stepwise, pr(0.05): poisson citacoes n_p_tit n_p_p_chave n_pag n_ref

n_autores prop_mulher idade_I*

- prcounts prpoisson, plot

- quietly stepwise, pr(0.05): nbreg citacoes n_p_tit n_p_p_chave n_pag n_ref

n_autores prop_mulher idade _ I*

- prcounts prbneg, plot

- graph twoway (scatter prbnegobeq prbnegpreq prpoissonpreq prbnegval, connect (1 1 1))

(note: named style 1 not found in class connectstyle, default attributes used)

(note: named style 1 not found in class connectstyle, default attributes used)

(note: named style 1 not found in class connectstyle, default attributes used)
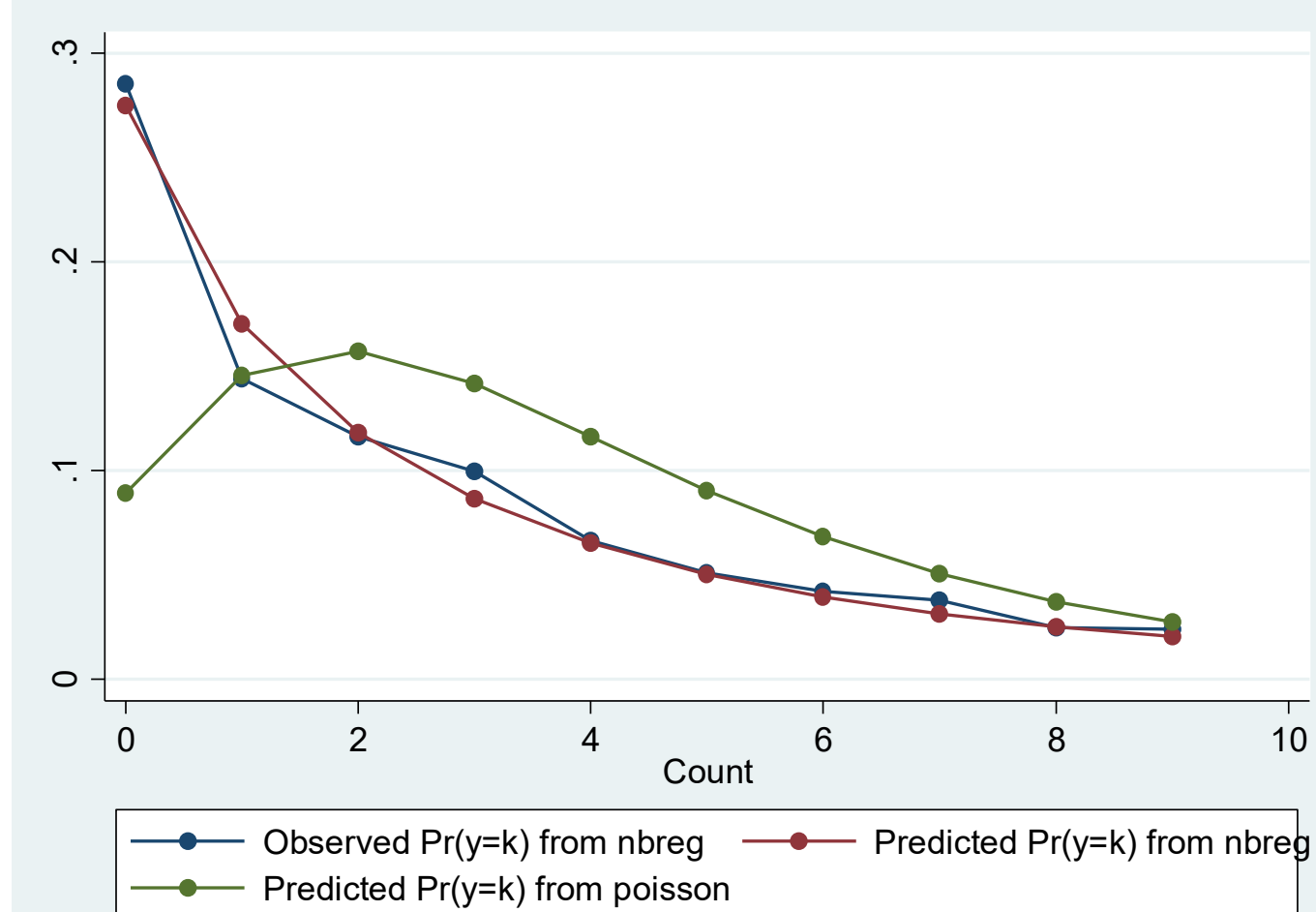

- countfit citacoes n_p_tit n_p_p_chave n_pag n_ref n_autores prop_mulher idade _ I*, prm nograph noestimates nofit

Comparison of Mean Observed and Predicted Count

\begin{tabular}{|c|c|c|c|}
\hline Model & $\begin{array}{c}\text { Maximum } \\
\text { Difference }\end{array}$ & $\begin{array}{c}\text { At } \\
\text { Value }\end{array}$ & $\begin{array}{l}\text { Mean } \\
\mid \text { Diff| }\end{array}$ \\
\hline PRM & 0.196 & 0 & 0.043 \\
\hline
\end{tabular}

PRM: Predicted and actual probabilities

$\begin{array}{lccrr}\text { Count } & \text { Actual } & \text { Predicted } & \text { | Diff } & \text { Pearson } \\ -0 & 0.286 & 0.089 & 0.196 & 1043.465 \\ 1 & 0.144 & 0.146 & 0.002 & 0.043 \\ 2 & 0.116 & 0.158 & 0.042 & 26.594 \\ 3 & 0.100 & 0.142 & 0.042 & 30.739\end{array}$




$\begin{array}{lcccr}4 & 0.066 & 0.116 & 0.050 & 52.353 \\ 5 & 0.051 & 0.090 & 0.039 & 41.577 \\ 6 & 0.042 & 0.068 & 0.026 & 24.227 \\ 7 & 0.038 & 0.050 & 0.012 & 7.511 \\ 8 & 0.025 & 0.037 & 0.012 & 9.934 \\ 9 & 0.024 & 0.027 & 0.003 & 0.977 \\ -1 & 0.892 & 0.925 & 0.425 & 1237.419\end{array}$

- countfit citacoes n_p_tit n_p_p_chave n_pag n_ref n_autores prop_mulher idade_I*, nbreg nograph noestimates nofit

Comparison of Mean Observed and Predicted Count

\begin{tabular}{|c|c|c|c|}
\hline Model & $\begin{array}{c}\text { Maximum } \\
\text { Difference }\end{array}$ & $\begin{array}{c}\text { At } \\
\text { Value }\end{array}$ & $\begin{array}{l}\text { Mean } \\
\mid \text { Diff| }\end{array}$ \\
\hline NBRM & -0.027 & 1 & 0.007 \\
\hline
\end{tabular}

NBRM: Predicted and actual probabilities

\begin{tabular}{|c|c|c|c|c|}
\hline Count & Actual & Predicted & |Diff| & Pearson \\
\hline & ------- & ---------- & ------ & --------- \\
\hline 0 & 0.286 & 0.274 & 0.011 & 1.130 \\
\hline 1 & 0.144 & 0.171 & 0.027 & 10.393 \\
\hline 2 & 0.116 & 0.119 & 0.003 & 0.170 \\
\hline 3 & 0.100 & 0.087 & 0.013 & 4.668 \\
\hline 4 & 0.066 & 0.065 & 0.001 & 0.046 \\
\hline 5 & 0.051 & 0.050 & 0.001 & 0.044 \\
\hline 6 & 0.042 & 0.039 & 0.003 & 0.477 \\
\hline 7 & 0.038 & 0.031 & 0.007 & 3.511 \\
\hline 8 & 0.025 & 0.025 & 0.000 & 0.014 \\
\hline 9 & 0.024 & 0.020 & 0.003 & 1.433 \\
\hline Sum & 0.892 & 0.883 & 0.070 & 21.884 \\
\hline
\end{tabular}

\footnotetext{
-

- graph twoway mspline u citacoes || mspline lambda citacoes ||, legend(label(1 "Binomial Negativo") label (2 "Poisson"))
}

$\cdot$ 


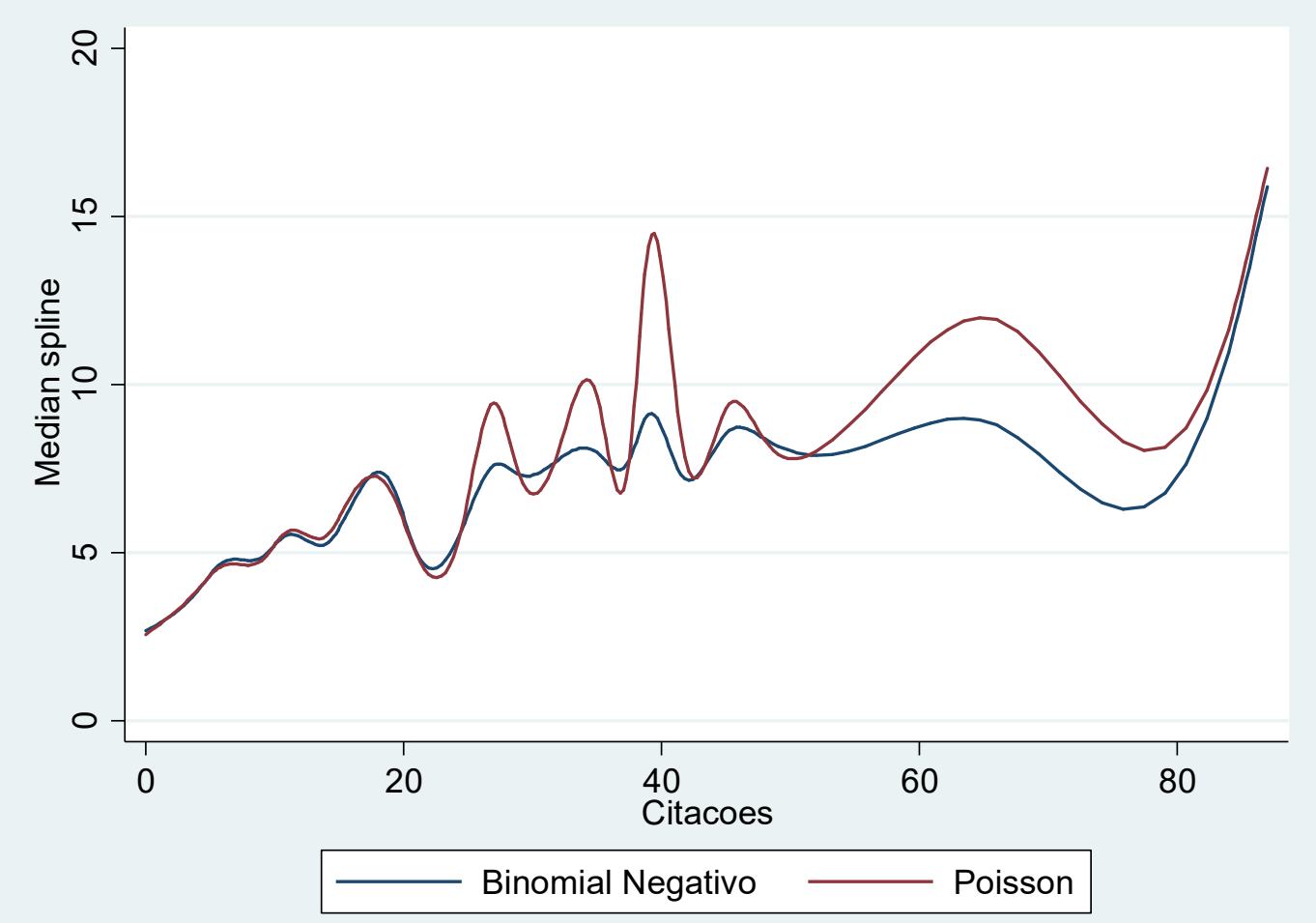

gen lncitacoes=ln (citacoes)

(693 missing values generated)

- quietly reg lncitacoes n_p_tit n_p_p_chave n_pag n_ref n_autores prop_mulher idade I*

- predict yhat

(option xb assumed; fitted values)

- gen eyhat $=\exp ($ yhat $)$

$\cdot$

- graph twoway lfit u citacoes || lfit lambda citacoes || lfit eyhat citacoes ||, legend(label(1 "Binomial Negativo") label (2 "Poisso

$>$ n") label (3 "OLS")) 


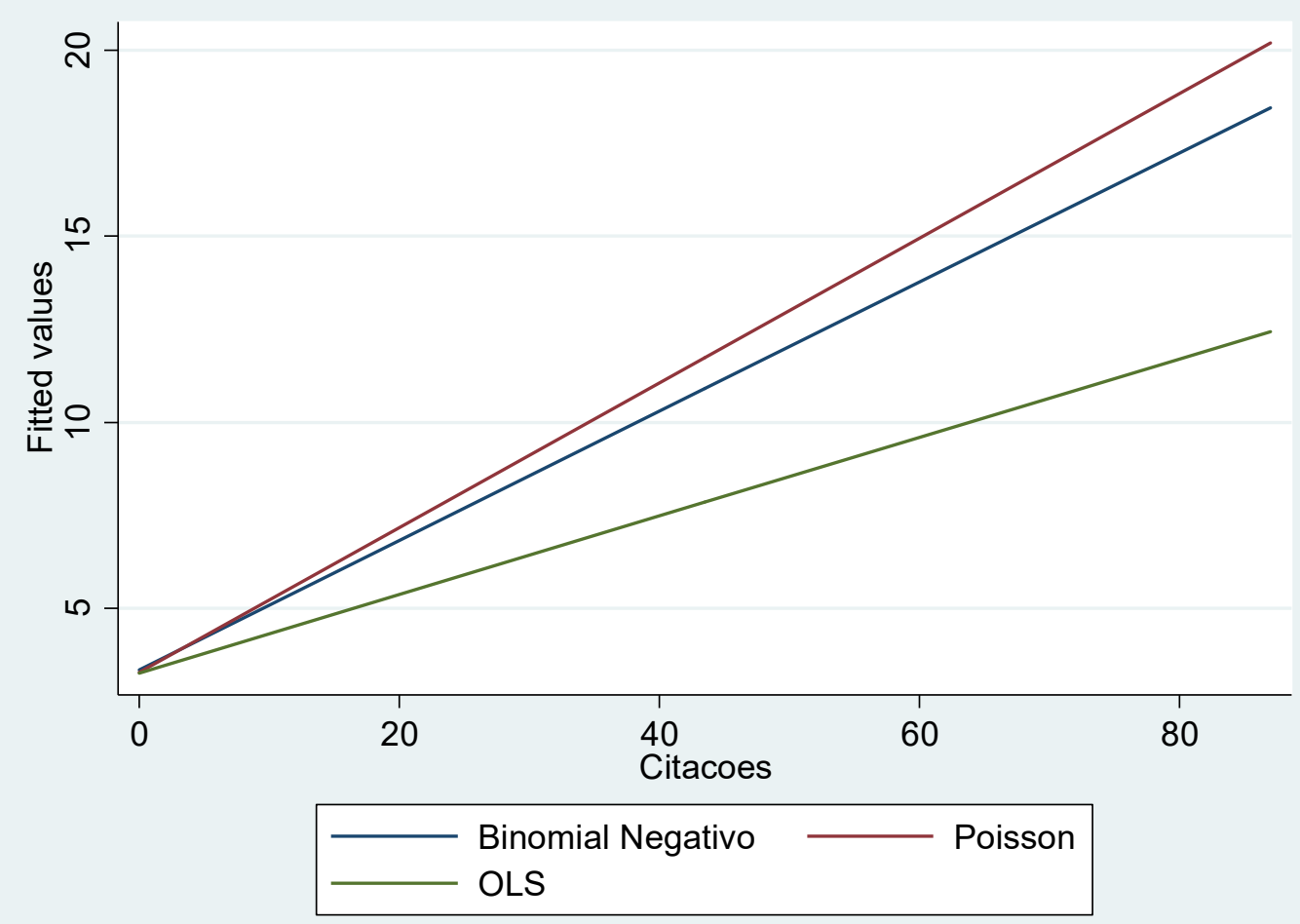


Apêndice R - Saídas do Stata do Modelo 8 - sem a USP como categoria de IES do primeiro autor e sem a RC\&F como categoria de Revista

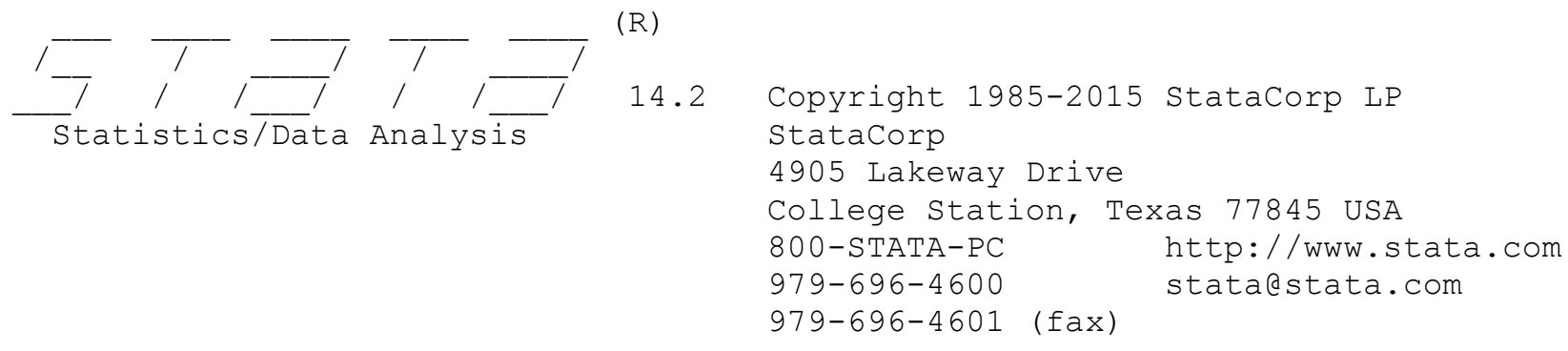

Single-user Stata license expires 29 May 2017:

Serial number: 301409337392

Licensed to: Sandro Vieira Soares

Notes:

1. Unicode is supported; see help unicode_advice.

- use "C: \Users \SAFIRA \Dropbox \TESE\binomial negativa sem USP e sem RC\&F.dta"

- desc

Contains data from C: \Users \SAFIRA \Dropbox\TESE\binomial negativa sem USP e sem $\mathrm{RC} \& \mathrm{~F} \cdot \mathrm{dta}$
obs:
2,076
vars:
21
size:
164,004
29 Jan $2017 \quad 20: 43$

\begin{tabular}{|c|c|c|c|c|}
\hline variable name & $\begin{array}{l}\text { storage } \\
\text { type }\end{array}$ & $\begin{array}{l}\text { display } \\
\text { format }\end{array}$ & $\begin{array}{l}\text { value } \\
\text { label }\end{array}$ & variable label \\
\hline \multicolumn{5}{|c|}{-------------------------------------------------} \\
\hline n_de_controle & int & $\div 8.0 \mathrm{~g}$ & & N_de_Controle \\
\hline citacoes & int & $\div 8.0 \mathrm{~g}$ & & Cìitacoes \\
\hline criacao & int & $\div 8.0 \mathrm{~g}$ & & Criacao \\
\hline n_p_tit & byte & $\div 8.0 \mathrm{~g}$ & & N_p_Tit \\
\hline n_p_P_chave & byte & $\div 8.09$ & & N_P_P_chave \\
\hline n_pag & byte & $\div 8.0 \mathrm{~g}$ & & N_pag \\
\hline n_ref & int & $\div 8.0 \mathrm{~g}$ & & N_Ref \\
\hline n_autores & byte & $\div 8.0 \mathrm{~g}$ & & N_autores \\
\hline n_mulheres & byte & $\div 8.0 \mathrm{~g}$ & & $\mathrm{~N}_{-}^{-}$mulheres \\
\hline prop_mulher & float & $\div 8.0 \mathrm{~g}$ & & Prop_mulher \\
\hline idade & byte & $\div 8.0 \mathrm{~g}$ & & Idade \\
\hline revista & str20 & $\div 20 \mathrm{~s}$ & & Revista \\
\hline anod & str4 & $\div 9 s$ & & Ano \\
\hline ord_ou_esp & str 3 & $\div 9 \mathrm{~s}$ & & Ord_ou_Esp \\
\hline posicao & str 3 & $\div 9 \mathrm{~s}$ & & Posicao \\
\hline gen_1_autor & str 3 & $\div 9 \mathrm{~s}$ & & Gen_1_autor \\
\hline tit_1_autor & strg & $\div 9 \mathrm{~s}$ & & Tit_1_autor \\
\hline ies_1_autor & $\operatorname{str} 8$ & $\div 9 \mathrm{~s}$ & & IES_1_autor \\
\hline $\operatorname{are} \bar{a}-$ & str 3 & $\div 9 \mathrm{~s}$ & & Area - \\
\hline qualis_vigente & str2 & $\div 9 \mathrm{~s}$ & & Qualis_vigente \\
\hline abordaḡem & str 6 & $\div 9 s$ & & Abordaḡem \\
\hline
\end{tabular}

Sorted by: ies_1_autor

tab citacoes 


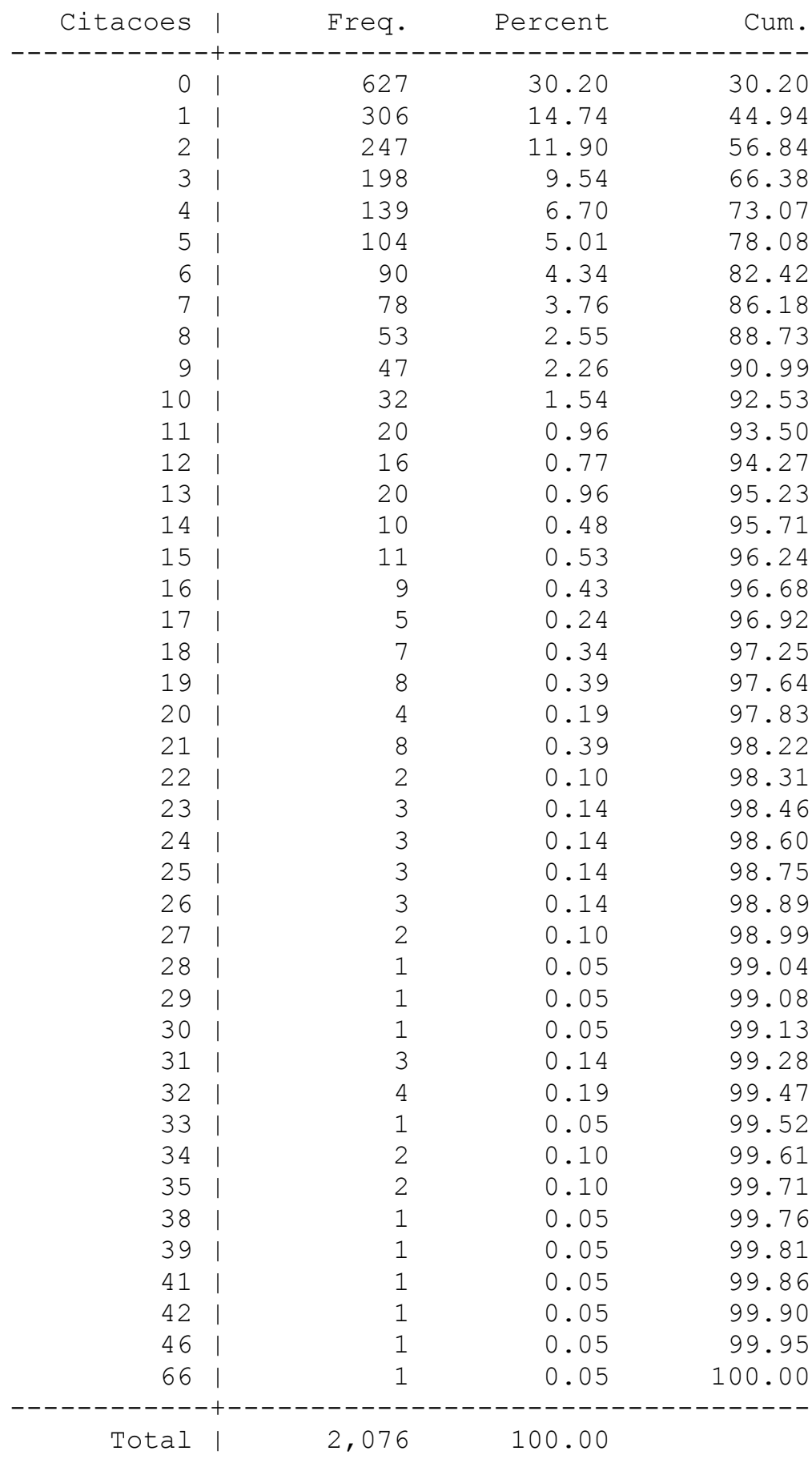

- hist citacoes, discrete freq ( $\operatorname{start}=0$, width=1) 


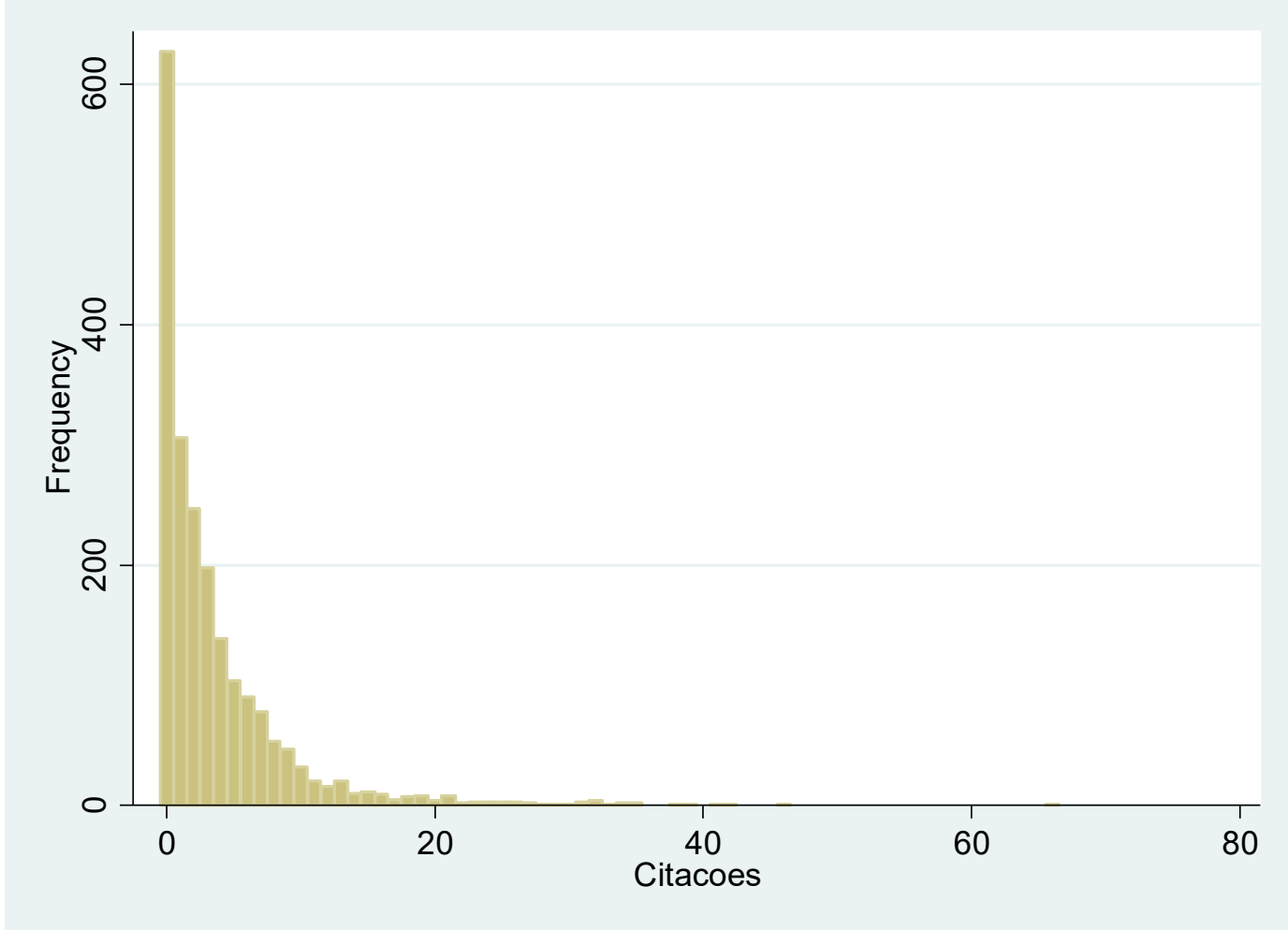

$\cdot$

- tabstat citacoes, stats (mean var)

variable | mean variance

citacoes | 3.65992329 .88236

- xi i.revista i.ord_ou_esp i.posicao i.gen_1_autor i.tit_1_autor i.ies_1_autor i.area i.qualis_vigeñte

i.revista Irevista_1-35

i.ord ou esp

i.posícāo

i.gen_1_autor

i.tit 1 autor

i.ies_1-autor

i. $\operatorname{are} \bar{a}$

i.qualis vige e

i. abordaḡem

Iord ou es 1-2

_Iposicao_1-2

-Igen_1_aut_1-2

- Itit 1 - aut $1-4$

- Iies_1_aut_1-19

- Iareā $\overline{1}-6$

Iqualis vi 1-8

_ Iabordaḡem_1-2
( Irevista 1 for rev a==ABCustos omitted) (_Iord_ou_es_1 for ord_ou p==Esp omitted)

(_Iposicao_1 for posicāo==Out omitted)

(_Igen_1_aut_1 for gen_1_ r==Hom omitted)

(' Itit ${ }^{-}{ }^{-}$aut ${ }^{-1}$ for tit ${ }^{-}==$Bacharel omitted)

('Iies ${ }^{-}{ }^{-}$aut 1 for ies $\sim r==$ FECAP omitted)

(_Iarea_ $\overline{1}$ for area $==E d \bar{u}$ omitted)

('Iqualis vi 1 for qualis $\sim e==\mathrm{A} 2$ omitted)

(_Iabordagem_1 for abor $\mathrm{m}^{-}=$=Quali omitted)

.

- quietly stepwise, pr(0.05): poisson citacoes n_p_tit n_p_p_chave n_pag n_ref n_autores prop_mulher idade _ I*

.

$\cdot$

- predict lambda

(option $\mathrm{n}$ assumed; predicted number of events) 
- gen yasterisco $=\left((\text { citacoes-lambda })^{\wedge} 2-\operatorname{citacoes}\right) /$ lambda

- reg yasterisco lambda, nocons

\begin{tabular}{|c|c|c|c|c|c|c|}
\hline Source | & SS & $d f$ & MS & Number of obs & $=$ & 2,076 \\
\hline--------+ & & & ---------- & $F(1,2075)$ & $=$ & 217.66 \\
\hline Model & 41772.5359 & 1 & 41772.5359 & Prob > F & $=$ & 0.0000 \\
\hline Residual | & 398232.759 & 2,075 & 191.919402 & R-squared & $=$ & 0.0949 \\
\hline----------+ & ---------- & ------- & ----------- & Adj R-squared & $=$ & 0.094 \\
\hline Total | & 440005.295 & 2,076 & 211.948601 & Root MSE & $=$ & 13. \\
\hline
\end{tabular}

\begin{tabular}{|c|c|c|c|c|c|c|}
\hline yasterisco | & Coef. & Std. Err. & t & $P>|t|$ & [95\% Conf. & Interval] \\
\hline lambda | & 1.022874 & .0693324 & 14.75 & 0.000 & .8869056 & 1.158842 \\
\hline
\end{tabular}

•

$\cdot$

- quietly stepwise, pr(0.05): poisson citacoes n_p_tit n_p_p_chave n_pag n_ref n_autores prop_mulher idade _I*

.

- poisgof

$\begin{array}{llr}\text { Deviance goodness-of-fit } & = & 8983.451 \\ \text { Prob }>\text { chi2(2024) } & & 0.0000 \\ \text { Pearson goodness-of-fit } & = & 10710.7 \\ \text { Prob }>\text { chi2(2024) } & =0.0000\end{array}$

$\cdot$

.

- stepwise, pr(0.05): nbreg citacoes n_p_tit n_p_p_chave n_pag n_ref n_autores prop mulher idade_I*

$\mathrm{p}=0.9733>=0.0500$

begin with full model

$\mathrm{p}=0.9680>=0.0500$

$\mathrm{p}=0.9637>=0.0500$

$\mathrm{p}=0.9515>=0.0500$

$\mathrm{p}=0.9634>=0.0500$

$\mathrm{p}=0.9577>=0.0500$

$\mathrm{p}=0.9599>=0.0500$

$\mathrm{p}=0.9421>=0.0500$

$\mathrm{p}=0.9341>=0.0500$

$\mathrm{p}=0.9452>=0.0500$

$\mathrm{p}=0.9286>=0.0500$

$\mathrm{p}=0.9022>=0.0500$

$\mathrm{p}=0.8608>=0.0500$

$\mathrm{p}=0.8033>=0.0500$

$\mathrm{p}=0.7809>=0.0500$

$\mathrm{p}=0.7320>=0.0500$

$\mathrm{p}=0.7181>=0.0500$

$\mathrm{p}=0.7223>=0.0500$

$\mathrm{p}=0.7085>=0.0500$

$\mathrm{p}=0.6632>=0.0500$

$\mathrm{p}=0.6560>=0.0500$

$\mathrm{p}=0.6509>=0.0500$

$\mathrm{p}=0.6278>=0.0500$

$\mathrm{p}=0.4193>=0.0500$

$\mathrm{p}=0.4344>=0.0500$

removing Itit_ 1 aut 3

removing Iqualis vis ${ }^{-} 3$

removing Iies_1_aut_5

removing Iies_1_aut 7

removing Iies_1 aut 6

removing Iies_1_aut_14

removing _Iies_1_aut_11

removing ${ }^{-}$tit ${ }^{-}$- aut 4

removing Iies_1_aut_16

removing Iies 1 -aut 3

removing Iqualis_vi_8

removing Irevista $2 \overline{7}$

removing prop mulher

removing _Iabordagem_2

removing Irevista $2^{-}$

removing Iposicao-2

removing _Iies_1_aut_17

removing Irevista_ $1 \overline{4}$

removing $\bar{n} p$ tit

removing $\overline{\text { I }}$ ies_1_aut_9

removing Iies_1_aut_12

removing Irevista_6

removing Iarea 4

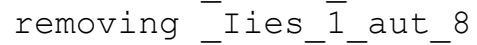

removing _Iarea_ $\overline{5}$ 
$\mathrm{p}=0.4482>=0.0500$

$\mathrm{p}=0.4330>=0.0500$

$\mathrm{p}=0.4218>=0.0500$

$\mathrm{p}=0.3959>=0.0500$

$\mathrm{p}=0.3384>=0.0500$

$\mathrm{p}=0.4490>=0.0500$

$\mathrm{p}=0.3087>=0.0500$

$\mathrm{p}=0.2087>=0.0500$

$\mathrm{p}=0.2353>=0.0500$

$\mathrm{p}=0.1888>=0.0500$

$\mathrm{p}=0.2515>=0.0500$

$\mathrm{p}=0.1711>=0.0500$

$\mathrm{p}=0.1100>=0.0500$

$\mathrm{p}=0.0986>=0.0500$

$\mathrm{p}=0.0815>=0.0500$

$\mathrm{p}=0.1015>=0.0500$

$\mathrm{p}=0.0995>=0.0500$

$\mathrm{p}=0.1487>=0.0500$

$\mathrm{p}=0.0863>=0.0500$

$\mathrm{p}=0.1139>=0.0500$

$\mathrm{p}=0.0842>=0.0500$

$\mathrm{p}=0.0790>=0.0500$

$\mathrm{p}=0.0525>=0.0500$ removing n_pag

removing Irevista 29

removing $\bar{n} \mathrm{p} p$ chave

removing İies_1 aut 18

removing Iqualis vi 2

removing Irevistā $2 \overline{6}$

removing -Itit_1_aut_2

removing Iies_1_aut_19

removing Iies_1_aut_13

removing Irevista $1 \overline{9}$

removing Iqualis $\overline{v i} 4$

removing Iarea 6

removing Iies_- 1 aut_15

removing _Irevis̄̄a_1 $1 \overline{2}$

removing Iqualis $\bar{v} i 7$

removing Irevista $\bar{a} \overline{5}$

removing Iqualis $\bar{v} i$

removing _Iqualis_vi_5

removing Iies_1_aut_2

removing Iare $\bar{a} \overline{3}$

removing Iord ou es 2

removing Irevistā $1 \overline{1}$

removing $\bar{n}$ _autores

Negative binomial regression

Number of obs

LR chi2(30)

Prob > chi2

Pseudo R2
$=$

$=442$

$=\quad 0.0000$

$=0.0446$

$\begin{array}{ll}\text { Dispersion } & =\text { mean } \\ \text { Log likelihood } & =-4735.5826\end{array}$

\begin{tabular}{|c|c|c|c|c|c|c|c|}
\hline citacoes & | & Coef. & Std. Err. & z & $P>|z|$ & [95\% Conf. & Interval] \\
\hline Troriata 20 & 1 & 500160 & & 520 & & & 021450 \\
\hline -Irevista_28 & 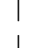 & .599164 & 4157 & 5.28 & 000 & $.3768^{\circ}$ & .8214547 \\
\hline & 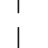 & $\begin{array}{l}-1.341 / 14 \\
-1.315611\end{array}$ & $\begin{array}{r}.2768918 \\
3339503\end{array}$ & $\begin{array}{l}-4.87 \\
-3.94\end{array}$ & $\begin{array}{l}0.000 \\
0.000\end{array}$ & $\begin{array}{l}-1.890412 \\
-1.970142\end{array}$ & $\begin{array}{l}-.8050162 \\
-.6610807\end{array}$ \\
\hline - n_ref & | & .0087958 & .0020771 & 4.23 & 0.000 & .0047249 & .0128668 \\
\hline Irevistā 25 & | & .4899703 & .1461857 & 3.35 & 0.001 & .2034515 & .776489 \\
\hline Iareāa 2 & | & -.3706345 & .0613048 & -6.05 & 0.000 & -.4907898 & -.2504792 \\
\hline$-\quad$ ida $\overline{d e}$ & i & -.1561055 & .0150204 & -10.39 & 0.000 & -.185545 & -.1266661 \\
\hline Iies 1 aut 4 & | & -.2071902 & .0579518 & -3.58 & 0.000 & -.3207736 & -.0936067 \\
\hline Irēvista-3 & | & -.8154513 & .2097673 & -3.89 & 0.000 & -1.226588 & -.404315 \\
\hline -Irevista_4 & | & .8068831 & .1601227 & 5.04 & 0.000 & .4930484 & 1.120718 \\
\hline Irevista-5 & | & .6586568 & .1478752 & 4.45 & 0.000 & .3688267 & .948487 \\
\hline Iiès 1 aut $\overline{1} 0$ & | & .5176364 & .2348516 & 2.20 & 0.028 & .0573357 & .977937 \\
\hline _Irevistā_7 & | & 1.698131 & .1742161 & 9.75 & 0.000 & 1.356674 & 2.039588 \\
\hline Irevista-8 & | & 3.380075 & .2686936 & 12.58 & 0.000 & 2.853445 & 3.906704 \\
\hline Irevista 9 & | & .979379 & .1750453 & 5.60 & 0.000 & .6362967 & 1.322461 \\
\hline - $\bar{I}$ revista_ $\overline{1} 0$ & | & .8864029 & .2496998 & 3.55 & 0.000 & .3970003 & 1.375805 \\
\hline Irevista_30 & | & -2.296318 & 1.078074 & -2.13 & 0.033 & -4.409304 & -.1833321 \\
\hline Irevista-34 & | & -.9281705 & .2829926 & -3.28 & 0.001 & -1.482826 & -.3735153 \\
\hline -Irevista_13 & | & .3252992 & .1320025 & 2.46 & 0.014 & .0665792 & .5840193 \\
\hline -Irevista-32 & | & -1.014195 & .309205 & -3.28 & 0.001 & -1.620226 & -.4081643 \\
\hline Irevista 15 & | & -1.818725 & .43942 & -4.14 & 0.000 & -2.679972 & -.9574775 \\
\hline - Irevista_16 & | & -1.737721 & .3956214 & -4.39 & 0.000 & -2.513125 & -.9623175 \\
\hline Irevista-17 & | & .8822502 & .169644 & 5.20 & 0.000 & .549754 & 1.214746 \\
\hline -Irevista_18 & i & 1.110055 & .1928434 & 5.76 & 0.000 & .7320885 & 1.488021 \\
\hline$\overline{\text { Igen_1_aut_2 }}$ & | & .117023 & .05798 & 2.02 & 0.044 & .0033843 & .2306618 \\
\hline Irevisista_ $\overline{2} 0$ & | & .8512593 & .144963 & 5.87 & 0.000 & .567137 & 1.135382 \\
\hline -Irevista_21 & i & .5290704 & .1499849 & 3.53 & 0.000 & .2351053 & .8230354 \\
\hline Irevista 22 & | & .5247935 & .1342467 & 3.91 & 0.000 & .2616747 & .7879122 \\
\hline - Irevista-23 & | & -.5366387 & .1770186 & -3.03 & 0.002 & -.8835887 & -.1896887 \\
\hline Irevista 24 & | & -1.452845 & .7099278 & -2.05 & 0.041 & -2.844278 & -.0614123 \\
\hline$-\operatorname{cōns}$ & i & 1.516628 & .0965122 & 15.71 & 0.000 & 1.327468 & 1.705788 \\
\hline & & & & & & & --------- \\
\hline / Inalpha & | & .1657378 & .0447582 & & & .0780134 & .2534622 \\
\hline
\end{tabular}


- predict u

(option $\mathrm{n}$ assumed; predicted number of events)

$\cdot$

- stepwise, pr(0.05): nbreg citacoes n_p_tit n_p_p_chave n_pag n_ref n_autores prop mulher idade I*, irr begin with full model

$\mathrm{p}=0.9733>=0.0500$ removing Itit_1_aut_3

$\mathrm{p}=0.9680>=0.0500$

$\mathrm{p}=0.9637>=0.0500$

$\mathrm{p}=0.9515>=0.0500$

$\mathrm{p}=0.9634>=0.0500$

$\mathrm{p}=0.9577>=0.0500$

$\mathrm{p}=0.9599>=0.0500$

$\mathrm{p}=0.9421>=0.0500$

$\mathrm{p}=0.9341>=0.0500$

$\mathrm{p}=0.9452>=0.0500$

$\mathrm{p}=0.9286>=0.0500$

$\mathrm{p}=0.9022>=0.0500$

$\mathrm{p}=0.8608>=0.0500$

$\mathrm{p}=0.8033>=0.0500$

$\mathrm{p}=0.7809>=0.0500$

$\mathrm{p}=0.7320>=0.0500$

$\mathrm{p}=0.7181>=0.0500$

$\mathrm{p}=0.7223>=0.0500$

$\mathrm{p}=0.7085>=0.0500$

$\mathrm{p}=0.6632>=0.0500$

$\mathrm{p}=0.6560>=0.0500$

$\mathrm{p}=0.6509>=0.0500$

$\mathrm{p}=0.6278>=0.0500$

$\mathrm{p}=0.4193>=0.0500$

$\mathrm{p}=0.4344>=0.0500$

$\mathrm{p}=0.4482>=0.0500$

$\mathrm{p}=0.4330>=0.0500$

$\mathrm{p}=0.4218>=0.0500$

$\mathrm{p}=0.3959>=0.0500$

$\mathrm{p}=0.3384>=0.0500$

$\mathrm{p}=0.4490>=0.0500$

$\mathrm{p}=0.3087>=0.0500$

$\mathrm{p}=0.2087>=0.0500$

$\mathrm{p}=0.2353>=0.0500$

$\mathrm{p}=0.1888>=0.0500$

$\mathrm{p}=0.2515>=0.0500$

$\mathrm{p}=0.1711>=0.0500$

$\mathrm{p}=0.1100>=0.0500$

$\mathrm{p}=0.0986>=0.0500$

$\mathrm{p}=0.0815>=0.0500$

$\mathrm{p}=0.1015>=0.0500$

$\mathrm{p}=0.0995>=0.0500$

$\mathrm{p}=0.1487>=0.0500$

$\mathrm{p}=0.0863>=0.0500$

$\mathrm{p}=0.1139>=0.0500$

$\mathrm{p}=0.0842>=0.0500$

$\mathrm{p}=0.0790>=0.0500$

$\mathrm{p}=0.0525>=0.0500$

removing Iqualis vi 3

removing Iies_1 aut_5

removing ${ }^{-}$Iies ${ }^{-}{ }^{-}$aut ${ }^{-} 7$

removing Iies_1_aut_6

removing Iies_1_aut_14

removing Iies_1 aut_11

removing ${ }^{-}$Itit ${ }^{-}{ }^{-}$aut ${ }^{-} 4$

removing - Iies_1_aut_16

removing Iies_1_aut_3

removing Iqualis vi ${ }^{-} 8$

removing Irevista $2 \overline{7}$

removing prop mulhèr

removing _Iabordagem_2

removing Irevista 2

removing - Iposicao_2

removing Iies_1_aut_17

removing _Irevista_ $1 \overline{4}$

removing $\bar{n}$ - ${ }_{-}$tit

removing I Iiess_1_aut_9

removing Iies 1 aut 12

removing Irevista_6-

removing Iarea 4

removing

removing Iarea $\overline{5}$

removing $\bar{n}$ pag

removing _Irevista_29

removing $\bar{n} \_\mathrm{p} \_\mathrm{p} \_$chave

removing Iies 1 aut 18

removing Iqualis vi 2

removing Irevistā $2 \overline{6}$

removing - Itit_1_aut_2

removing Iies_1_aut_19

removing Iies_ ${ }^{-}$aut 13

removing _Irevista_1 $\overline{9}$

removing _Iqualis_vi_ 4

removing Iarea $6^{-}$

removing Iies_ $\overline{1}$ aut 15

removing Irevista_ $1 \overline{2}$

removing Iqualis $\overline{\mathrm{V}} \mathrm{i} 7$

removing Irevistā $3 \overline{5}$

removing Iqualis $\overline{v i} 6$

removing Iqualis_vi_5

removing Iies 1 aut ${ }^{-} 2$

removing _Iarea $\overline{3}$

removing Iord_ou_es_2

removing Irevistā_li

removing $\overline{\mathrm{n}}$ autores 


$\begin{array}{llll} & \text { LR chi2 (30) } & = & 442.58 \\ \text { Dispersion } & \text { mean } & \text { Prob > chi2 } & =0.0000 \\ \text { Log likelihood }=-4735.5826 & \text { Pseudo R2 } & = & 0.0446\end{array}$

\begin{tabular}{|c|c|c|c|c|c|c|c|}
\hline citacoes & | & IRR & std. Err. & $\mathrm{z}$ & $\mathrm{P}>|\mathrm{z}|$ & [95\% Conf. & Interval] \\
\hline Irevista 28 & | & 1.820596 & .2064843 & 5.28 & 0.000 & 1.457719 & 2.273805 \\
\hline Irevista 33 & i & .2598179 & .0719415 & -4.87 & 0.000 & .1510005 & .4470539 \\
\hline Irevista-31 & | & .2683102 & .0896023 & -3.94 & 0.000 & .1394371 & .5162931 \\
\hline${ }^{-} \quad n_{-} \overline{r e f}$ & i & 1.008835 & .0020954 & 4.23 & 0.000 & 1.004736 & 1.01295 \\
\hline Irevistā 25 & | & 1.632268 & .2386142 & 3.35 & 0.001 & 1.225626 & 2.173827 \\
\hline - Iareāa_2 & i & .6902962 & .0423185 & -6.05 & 0.000 & .6121428 & .7784276 \\
\hline$-\quad$ ida $\overline{d e}$ & | & .8554689 & .0128495 & -10.39 & 0.000 & .8306515 & .8810278 \\
\hline Iies_1_aut_4 & | & .8128651 & .047107 & -3.58 & 0.000 & .7255875 & .9106409 \\
\hline Irēvista-3 & | & .4424396 & .0928094 & -3.89 & 0.000 & .2932917 & .6674339 \\
\hline -Irevista_4 & | & 2.240912 & .3588209 & 5.04 & 0.000 & 1.6373 & 3.067055 \\
\hline -Irevista_5 & | & 1.932195 & .2857238 & 4.45 & 0.000 & 1.446037 & 2.5818 \\
\hline Iiess_1_aut_īo & i & 1.678057 & .3940943 & 2.20 & 0.028 & 1.059011 & 2.658965 \\
\hline 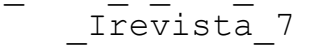 & | & 5.463727 & .9518691 & 9.75 & 0.000 & 3.883256 & 7.687445 \\
\hline -Irevista_8 & i & 29.37296 & 7.892325 & 12.58 & 0.000 & 17.34744 & 49.73477 \\
\hline -Irevista_9 & i & 2.662802 & .4661109 & 5.60 & 0.000 & 1.889471 & 3.752647 \\
\hline - & | & 2.426386 & .605868 & 3.55 & 0.000 & 1.487356 & 3.958264 \\
\hline -Irevista_30 & | & .1006287 & .1084851 & -2.13 & 0.033 & .0121636 & .8324916 \\
\hline -Irevista-34 & | & .3952762 & .1118602 & -3.28 & 0.001 & .2269954 & .6883105 \\
\hline -Irevista_13 & | & 1.384445 & .1827501 & 2.46 & 0.014 & 1.068846 & 1.793232 \\
\hline - Irevista_32 & | & .3626943 & .1121469 & -3.28 & 0.001 & .1978541 & .6648697 \\
\hline Irevista-15 & i & .1622325 & .0712882 & -4.14 & 0.000 & .0685651 & .3838599 \\
\hline -Irevista_16 & | & .1759208 & .069598 & -4.39 & 0.000 & .0810147 & .3820066 \\
\hline - Irevista_17 & | & 2.416331 & .4099161 & 5.20 & 0.000 & 1.732827 & 3.36944 \\
\hline Irevista-18 & i & 3.034524 & .5851878 & 5.76 & 0.000 & 2.079419 & 4.428321 \\
\hline Igen_1_aut_2 & | & 1.124145 & .065178 & 2.02 & 0.044 & 1.00339 & 1.259433 \\
\hline _Irevista_ž 0 & | & 2.342595 & .3395896 & 5.87 & 0.000 & 1.763212 & 3.112361 \\
\hline Irevista-21 & i & 1.697354 & .2545775 & 3.53 & 0.000 & 1.265042 & 2.277402 \\
\hline -Irevista_22 & | & 1.69011 & .2268917 & 3.91 & 0.000 & 1.299104 & 2.198801 \\
\hline -Irevista_23 & | & .5847103 & .1035046 & -3.03 & 0.002 & .413297 & .8272166 \\
\hline - Irevista_24 & i & .2339038 & .1660548 & -2.05 & 0.041 & .0581762 & .9404354 \\
\hline- & | & 4.556833 & .4397898 & 15.71 & 0.000 & 3.77148 & 5.505724 \\
\hline & & & -------- & & & --------- & --------- \\
\hline / Inalpha & | & .1657378 & .0447582 & & & .0780134 & .2534622 \\
\hline alpha & | & 1.180264 & .0528264 & & & 1.081137 & 1.288479 \\
\hline
\end{tabular}

LR test of alpha=0: chibar2(01) $=4335.88$

Prob $>=$ chibar $2=0.000$

.

-

- quietly stepwise, pr(0.05): poisson citacoes n_p_tit n_p_p_chave n_pag n_ref n_autores prop_mulher idade_I*

- prcounts prpoisson, plot

- quietly stepwise, pr(0.05): nbreg citacoes n_p_tit n_p_p_chave n_pag n_ref n_autores prop_mulher idade _ I*

- prcounts proneg, plot

- graph twoway (scatter prbnegobeq prbnegpreq prpoissonpreq prbnegval, connect (1 1 1))

(note: named style 1 not found in class connectstyle, default attributes used) (note: named style 1 not found in class connectstyle, default attributes used) 
(note: named style 1 not found in class connectstyle, default attributes used)

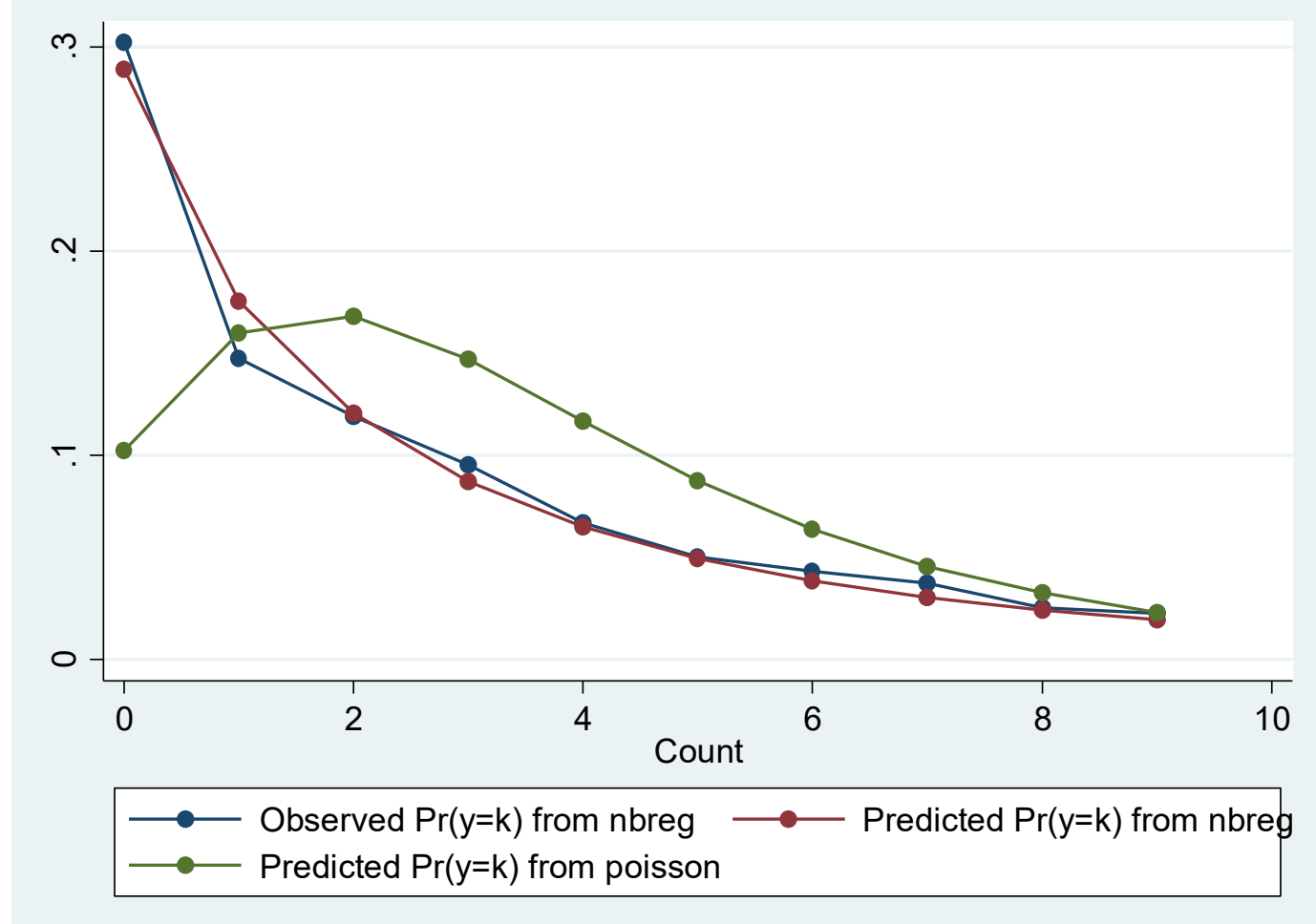

- countfit citacoes n_p_tit n_p_p_chave n_pag n_ref n_autores prop_mulher idade _ I*, prm nograph noestimates nofit

Comparison of Mean Observed and Predicted Count

\begin{tabular}{|c|c|c|c|}
\hline Model & $\begin{array}{c}\text { Maximum } \\
\text { Difference }\end{array}$ & $\begin{array}{c}\text { At } \\
\text { Value }\end{array}$ & $\begin{array}{l}\text { Mean } \\
\mid \text { Diff }\end{array}$ \\
\hline $\mathrm{PRM}$ & 0.199 & 0 & 0.043 \\
\hline
\end{tabular}

PRM: Predicted and actual probabilities

\begin{tabular}{|c|c|c|c|c|}
\hline Count & Actual & Predicted & | Diff| & Pearson \\
\hline \multicolumn{5}{|c|}{ - - - - - - - - - - - - - - - - - - - - - - - - - - - - - - - - - - - - - - } \\
\hline 0 & 0.302 & 0.103 & 0.199 & 804.215 \\
\hline 1 & 0.147 & 0.161 & 0.014 & 2.371 \\
\hline 2 & 0.119 & 0.169 & 0.050 & 30.389 \\
\hline 3 & 0.095 & 0.147 & 0.051 & 37.459 \\
\hline 4 & 0.067 & 0.116 & 0.049 & 43.031 \\
\hline 5 & 0.050 & 0.087 & 0.037 & 32.316 \\
\hline 6 & 0.043 & 0.063 & 0.020 & 12.959 \\
\hline 7 & 0.038 & 0.045 & 0.008 & 2.772 \\
\hline 8 & 0.026 & 0.032 & 0.007 & 2.984 \\
\hline 9 & 0.023 & 0.023 & 0.000 & 0.013 \\
\hline \multicolumn{5}{|c|}{-------------------------------------- ----------} \\
\hline & 0.910 & 0.946 & 0.435 & 968.509 \\
\hline
\end{tabular}

- countfit citacoes n_p_tit n_p_p_chave n_pag n_ref n_autores prop_mulher idade _I*, nbreg nograph noestimates nofit

Comparison of Mean Observed and Predicted Count

$\begin{array}{lccc} & \text { Maximum } & \text { At } & \text { Mean } \\ \text { Model } & \text { Difference } & \text { Value } & \mid \text { Diff } \mid \\ ------------------------------ & \\ \text { NBRM } & -0.030 & 1 & 0.008\end{array}$


NBRM: Predicted and actual probabilities

$\begin{array}{lcccc}\text { Count } & \text { Actual } & \text { Predicted } & \mid \text { Diff| } & \text { Pearson } \\ -----1 & 0.015 & 1.568 \\ 0 & 0.302 & 0.287 & 0.015 \\ 1 & 0.147 & 0.178 & 0.030 & 10.606 \\ 2 & 0.119 & 0.122 & 0.003 & 0.144 \\ 3 & 0.095 & 0.088 & 0.008 & 1.386 \\ 4 & 0.067 & 0.065 & 0.002 & 0.111 \\ 5 & 0.050 & 0.049 & 0.001 & 0.020 \\ 6 & 0.043 & 0.038 & 0.005 & 1.456 \\ 7 & 0.038 & 0.030 & 0.008 & 4.023 \\ 8 & 0.026 & 0.024 & 0.002 & 0.260 \\ 9 & 0.023 & 0.019 & 0.004 & 1.340 \\ ---------------------------------------- \\ \text { Sum } & 0.910 & 0.900 & 0.076 & 20.915\end{array}$

- graph twoway mspline u citacoes || mspline lambda citacoes ||, legend(label(1 "Binomial Negativo") label(2 "Poisson"))

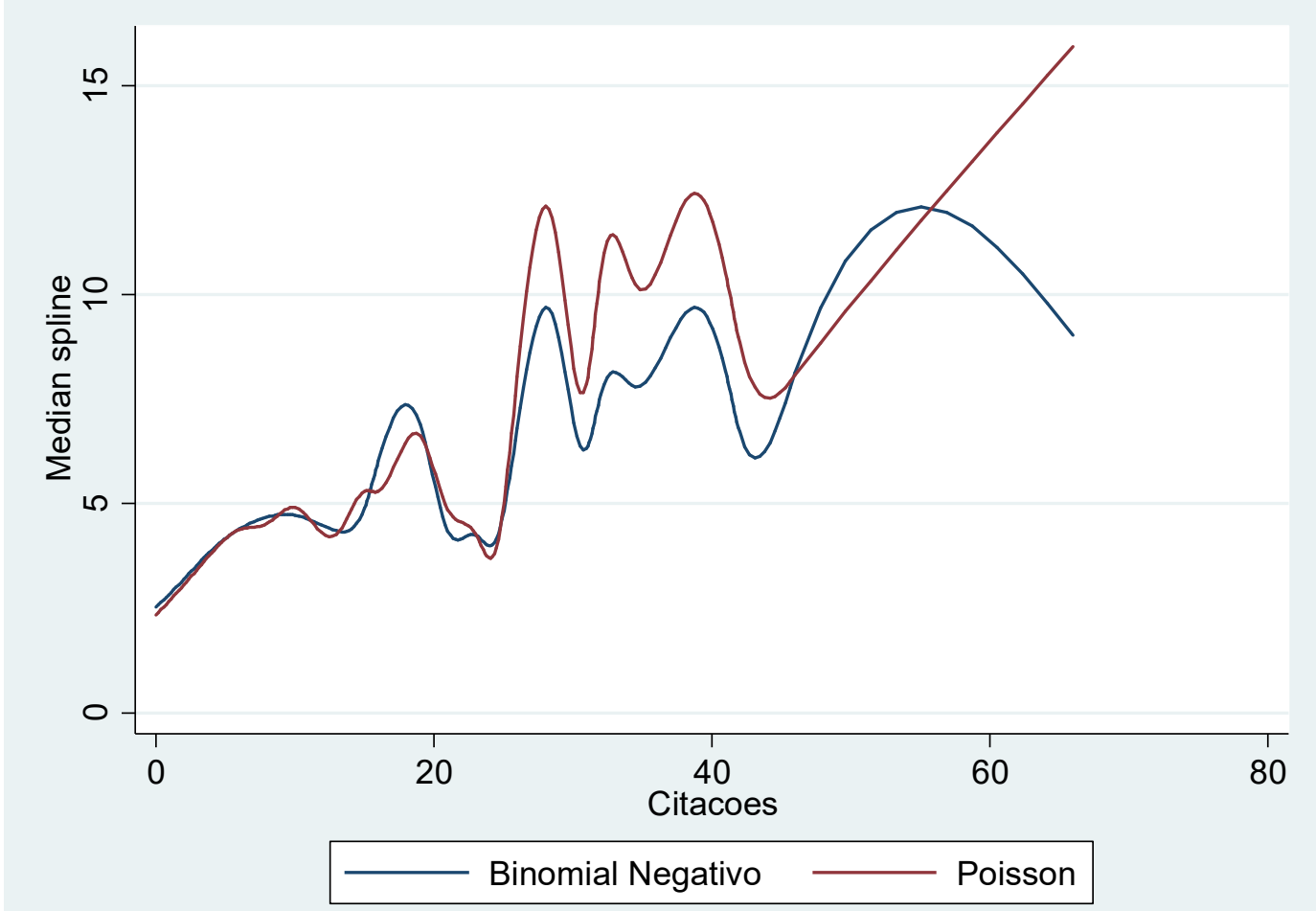

- gen lncitacoes=ln (citacoes)

(627 missing values generated)

- quietly reg lncitacoes n_p_tit n_p_p_chave n_pag n_ref n_autores prop_mulher idade $I^{\text {* }}$

- predict yhat

(option xb assumed; fitted values)

- gen eyhat $=\exp ($ yhat) 
- graph twoway lfit u citacoes || lfit lambda citacoes || lfit eyhat citacoes ||, legend(label(1 "Binomial Negativo") label (2 "Poisso

$>$ n") label (3 "OLS"))

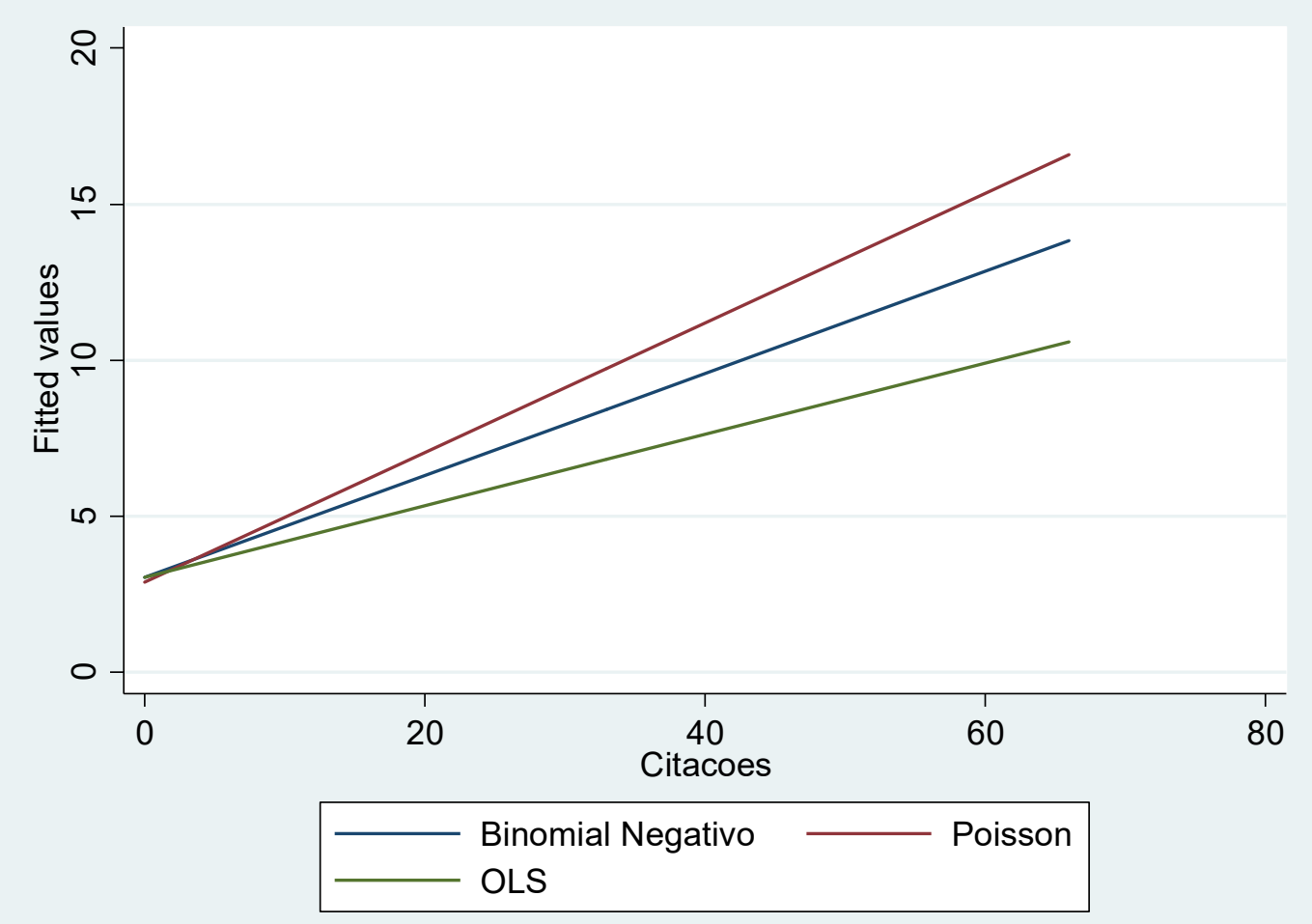

